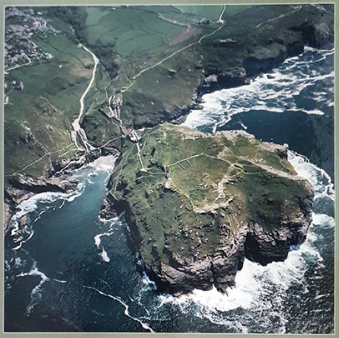

\title{
Excavations at Tintagel Castle, Cornwall, 1990-1999
}


Reports of the Research Committee of the Society of Antiquaries of London, No. 74

\section{Excavations at Tintagel Castle, CORNWALL, 1990-1999}




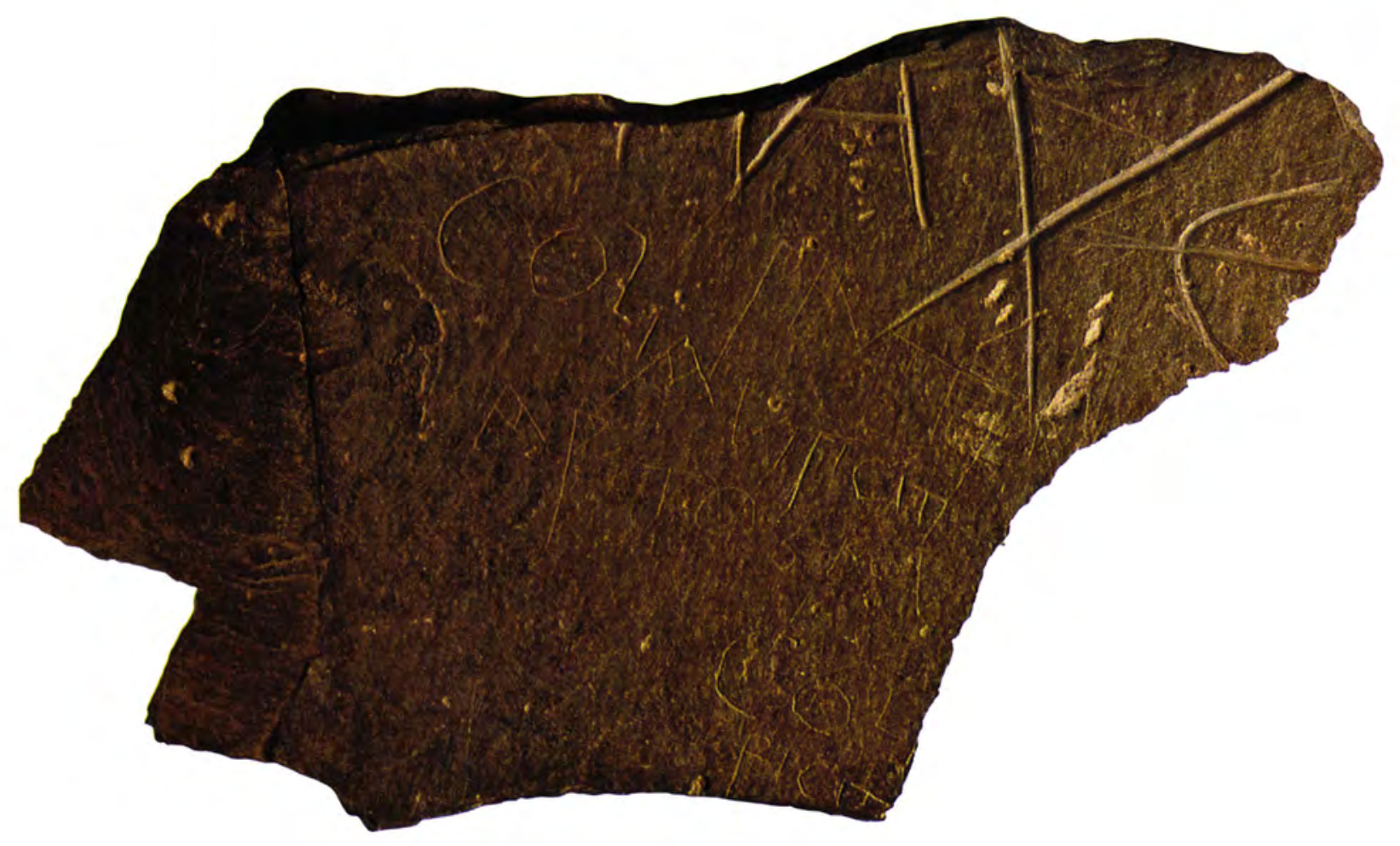

Tintagel Castle: inscribed slate (RF 3486). Photograph: P G Johnson 


\title{
EXCAVATIONS AT \\ Tintagel Castle, Cornwall, \\ 1990-1999
}

\author{
Rachel C Barrowman, Colleen E Batey \\ and Christopher D Morris
}

with contributions from

Kevin J Brady, Paul G Johnson, Vanessa Straker, Carl M Thorpe and Charles Thomas

and

John Arthur, Polydora Baker, Chris Barrowman, Alex Bayliss, Christopher Bronk Ramsey, Ewan N Campbell, Catherine Freeman, Rowena Gale, Jennifer Heathcote,

David Jefferson, Jennifer Jones, Julie Jones, Richard Jones, Francis Kelly, Lorraine McEwan, Timothy Palmer, Effie Photos-Jones, Mark Robinson, Heather Tinsley and Gary Tompsett 


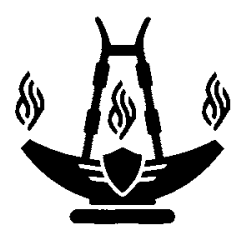

First published 2007

by

The Society of Antiquaries of London

Burlington House

Piccadilly

London W1J 0BE

www.sal.org.uk

(C) The Society of Antiquaries of London 2007; illustrations $\odot$ as credited to individual copyright holders.

The right of Rachel C Barrowman, Colleen E Batey and Christopher D Morris to be identified as the authors of this work has been asserted by them in accordance with the Copyright, Designs and Patents Act 1988.

All rights reserved. Except as permitted under current legislation, no part of this work may be photocopied, stored in a retrieval system, published, performed in public, adapted, broadcast, transmitted, recorded or reproduced in any form or by any means, without the prior permission of the copyright owners.

The Society of Antiquaries gratefully acknowledges the financial support of English Heritage in the publication of this book.

ISBN 978-0-85431-286-3

ISSN 0953-7163

British Library Cataloguing in Publication Data A CIP catalogue record for this book is available from the British Library.

Cover illustration: aerial view of Tintagel Castle, Cornwall (taken 17 May 2004). Photograph: (O) English Heritage, NMR (NMR 23510/22, sX 0489/44)

Original series design by Chuck Goodwin, London W2 5DA

Designed and laid out by 4 word Ltd, Bristol

Printed and bound in Great Britain by The Cromwell Press,

Trowbridge, Wiltshire 


\section{CONTENTS}

List of illustrations viii

List of tables $\quad \mathrm{x}$

Acknowledgements xii

Summary xiv

Résumé Xvi

Zusammenfassung xviii

PART I PREVIOUS WORK 1

1 Background, Archives and Survey Work 3

Background 3

The Wright Archive $\quad 5$

The Radford Archive 16

Location of Radford's trenches: the 1995 survey 26

Archaeological research and interpretation since the 1930s 32

The programme of work by Glasgow University in the 1990s 33

PART II SITE C 37

2 Summary of Excavations on the Lower Terrace, Site C, 1990-4 39

Introduction: synopsis of work undertaken 39

Correlated phasing $\quad 41$

Structures and stratigraphy $\quad 43$

The artefactual assemblage $\quad 47$

The ecofactual assemblage $\quad 50$

Dating $\quad 52$

The Lower Terrace in context 55

3 Trial Excavations 1990-4 on C A Ralegh Radford's Trenches 57 on the Upper Terrace, Site C

Background 57

Fieldwork methodology and synopsis of work undertaken $\quad 57$

Re-excavation of Radford's trenches $\quad 59$

Discussion $\quad 62$

Conclusion 66

4 Excavations 1990-4 on C A Ralegh Radford's Trenches on 67 the Middle Terrace, Site C

Background $\quad 67$

Fieldwork methodology and synopsis of work undertaken $\quad 67$

Re-excavation of Radford's trenches to the north and south $\quad 68$ of Site C

$\begin{array}{ll}\text { Discussion } & 78\end{array}$

$\begin{array}{ll}\text { Conclusion } & 79\end{array}$ 
5 Excavations In and Around the Middle Terrace: Trench C15, 199981

Introduction $\quad 81$

Fieldwork methodology and synopsis of work undertaken $\quad 81$

Summary of stratigraphy and phasing $\quad 81$

Discussion 101

Conclusion 104

6 Excavations In and Around the Middle Terrace: Site C Building, 106

1991-8

Radford's work at Site C 106

Excavation methodology $\quad 107$

Summary of stratigraphy and phasing $\quad 108$

Discussion $\quad 143$

$\begin{array}{ll}\text { Conclusion } & 145\end{array}$

$\begin{array}{lll}\text { PART III SITE T: THE GREAT DITCH AREA } & 147\end{array}$

7 Topographic Survey and Trial Excavations 1999 on C A Ralegh 149

Radford's Trenches In and Around Site T

Introduction $\quad 149$

Survey work in 1999

Excavation methodology and synopsis of work undertaken $\quad 150$

The Trial Trenches: summary of stratigraphy and phasing 155

The Little Ditch: summary of stratigraphy and phasing 156

Discussion $\quad 160$

Conclusion 161

8 Archaeological Assessment in 1999 of C A Ralegh Radford's 162

Trenches in the Great Ditch, Site $\mathrm{T}$

Geological observations on the Great Ditch 162

Fieldwork methodology and synopsis of work undertaken $\quad 163$

The Great Ditch: summary of stratigraphy and phasing $\quad 167$

Discussion $\quad 178$

Conclusion $\quad 179$

9 Archaeological Assessment in 1999 of C A Ralegh Radford's $\quad 180$

Trenches in the Lower Ward, Site T

Fieldwork methodology and synopsis of work undertaken $\quad 180$

Summary of stratigraphy and structures in Trench T01 ext 181

Discussion $\quad 185$

$\begin{array}{ll}\text { Conclusion } & 187\end{array}$

$\begin{array}{llr}\text { Part IV ARTEFacts AND ECOfacts } & 189\end{array}$

10 The Artefactual Assemblages 191

Stone: the inscribed slate from the Site C building 191

Stone 200

Flint $\quad 216$

Architectural stone from the Great Ditch, Site T 216

Mortars 221

Glass $\quad 222$ 
Ceramics: Romano-British 229

Ceramics: post-Roman imported 231

Ceramics: chemical and organic residue analysis of types 247

$\mathrm{Bi}, \mathrm{Bii}$ and $\mathrm{Bv}$ amphorae from Tintagel

Ceramics: medieval and post-medieval 257

$\begin{array}{ll}\text { Iron } & 267\end{array}$

Industrial waste $\quad 268$

11 The Ecofactual Assemblages 280

Methodologies 280

Site C, Middle Terrace: Radford's trenches 281

Site C, Middle Terrace: Trench C15 283

Site C, Middle Terrace: Site C building 286

Site T: Radford's trenches 291

Site T: the Great Ditch, Trench T01 291

Site T: the Lower Ward, Trench T01 ext 298

Discussion $\quad 300$

$\begin{array}{ll}\text { PART V IN CONCLUSION } & 303\end{array}$

12 Overview and Final Discussion 305

Introduction $\quad 305$

Radford and the monastic paradigm 305

Radford's work at Tintagel, 1933-55 306

Overall chronology 308

Prehistory: Period $0 \quad 309$

Romano-British Tintagel: Period I 309

Early medieval Tintagel: Period II 313

Later pre-Conquest and early Norman: Period III 321

Later medieval Tintagel: Period IV 322

From the end of the later medieval period to the present: 326 Period V

The local context $\quad 327$

The wider world $\quad 328$

Conclusion: what was Tintagel? 334

Appendix 1 Chemical Compositions 337

Appendix 2 The Chemical Composition Characteristics of the Reference 339 Material

Appendix $3 \quad$ Modern Material 341

Notes 343

Abbreviations and 351

Bibliography
Index 


\section{ILLUSTRATIONS}

Frontispiece Tintagel Castle: inscribed slate

1 Location of Tintagel

2 General view of Tintagel Castle

3 Plan of Tintagel Island with sites identified by Radford

4 Wright's drawing of 'Tintagel Castle. Island side. April 1933. Sheet 2'

5 Wright's drawing of 'Tintagel. Excavations. July 1934. Sheet 5 '

6 Wright's drawing of 'Trenches on hill between Sites B and C, September 1936'

7 Wright's drawing of 'Tintagel Castle. Plan of cuts on quarry ledges N. of Site C. September 1936

8 Wright's drawing of 'Tintagel. Island Site. Excavations. Survey. September 1938. Site H. Plan of Trenches'

9 Wright's drawing of 'Tintagel. Buildings south of chapel. Excavations. July 1934. Sheet 6'

10 Radford's published plan of Site A from the 1939 guidebook

11 Wright's drawing of Tintagel Castle. Site C. 1938

12 Sites $B$ and $C$ and neighbouring trenches

13 '1938 Tintagel Castle', archive photograph

14 '1938 Tintagel Castle, Site C, Room 2, north end', archive photograph

15 Wright's drawing showing position of 1938 trenches

16 Wright's drawing showing 1938 section no. 1 of Great Ditch

17 Photograph of Radford's cutting across the Great Ditch 1938 from the south

18 Photograph of Radford's cutting across the Great Ditch 1938 from the north

19 Tintagel 1955, Wall Walk sections

20 Wright's drawing of 'Tintagel. Excavations. July 1934 . Sheet 7 '

21 Map of 1995 survey on the 'Island'

22 RCHME survey of Tintagel Island

23 Stake impressions on rock ledge above Site $\mathrm{C}$

24 Location of trenches and survey profiles, Site $\mathrm{C}$

25 Location plan of terraces, Site $\mathrm{C}$

26 Aerial photograph of Site $\mathrm{C}$ and the Lower Terrace

27 Work on the Lower Terrace area excavation in 1991

28 Trench $\mathrm{C} 03$ sections and elevation of wall (25)

29 Area C03/4/8 Phase Q1, box hearth (174)

30 Area C03/4/8 Phase U1, hearth (139) / (140), with stake-holes (152) and (141)

31 Area C03/4/8 Phase U1, stake-holes (149) and (150)

32 Area $\mathrm{C} 03 / 4 / 8$ Phase W structure showing collapsed wall (97), in situ wall (51) and floor layer (105)

33 Firelighting slates and slate discs

34 Whetstone, glass and weight ii 35 Flint and quartz 48

436 Pottery 49

537 Calibration of radiocarbon results 53

38 Mathematical model of radiocarbon dating results, showing inconsistency of 113 at $95 \%$ confidence 54

39 Alternative mathematical model for dating of $113 \quad 54$

40 Alternative mathematical model for dating of all contexts

41 Trench C19. Phase plans and sections 60

42 Trench C19. Radford's cut 62

1143 Trench C18. Phase plans and sections 63

44 Trench C05. Phase plans and sections 69

45 Trench C05. General view with Radford's cut $\quad 72$

46 Trench C15. Phase plans and sections 73

47 Trench C15. View of wall 666

48 Trench C17. Phase plans and sections

49 View of area of trench C15 before deturfing 82

50 Phases $P$ and $Q$ plans

51 Phases $\mathrm{R}$ and $\mathrm{S}$ plans

52 Phases $\mathrm{T}$ and $\mathrm{U}$ plans

53 Phases $V$ and $W$ plans

54 North-facing section of wall 666

55 North- and south-facing sections featuring wall 666

56 Collapsed walls 666,687 and 688

57 South-facing section of 501

58 South-facing section featuring wall 501, and south section of trench

59 Phases $X$ and $Y$ plans

60 Radford's trench 673 49 (1) 4

2

63

69

\section{4} 82

72 Site C building. Plan of Phase V 124

73 Site C building. Wall (556) showing blocked doorway

74 Site C building. Wall (556) showing break in walling 
82 3D terrain model of the Great Ditch, Site $\mathrm{T}$ area

83 Location of trenches T01 to T05 in 1999

84 Trench T03 across path

85 Wright's drawing showing 1938 section no. 2 of trench across road and section no. 3 of trench from low wall to rampart

86 Trench T02 after excavation

87 T03 Phases $\mathrm{W}, \mathrm{X}$, and $\mathrm{Y}$

88 T02 Phase $V$, and Phases $W, X$ and $Y$

89 T02 north-facing sections

90 Geological fault on east side of the valley

91 Geological features related to the Great Ditch

92 Trench T01 after excavation of Radford's trench

93 T01 east- and west-facing sections

94 Excavation of trench T01

95 Photograph of Vertical Technology and planning T01

96 T01 plans

97 T01 north bank sections

98 T01 south bank sections

99 T01 ext Phases $V$ and $W$, and $X$ and $Y$ phase plans

100 T01 ext west-facing section

101 Areas of pits, scratches and markings on inscribed slate, RF 3486

102 Reconstruction drawing (annotated) of inscribed slate, RF 3486

103 The lower smaller letters

104 Provisional completion of the four larger upper letters as $\mathrm{H} \mathrm{A} \mathrm{V} \mathrm{G}$

105 Capital letters of continuing Romano-British type from four Insular memorial stones of the fifth century

106 Capital letters suggesting introduction of new Continental fashions on five Insular stones of the sixth century

107 Imported Bii pottery

108 Worked slate

109 Trench C17. RF 2828 graffiti slate from Phase X

110 Graffiti slate: RF 3731 (659)

111 Stone artefacts

112 Photograph of incomplete spindle whorl RF 3830 (685)

113 Slate amphora discs, flint and spindle whorls

114 Pottery amphora discs
115 Whetstones and a perforated slate

210

153

116 Incised slate: RF 3429 (C16)

211

$154 \quad 117$ Pot lids and whetstone from T01 and T01 ext 213

118 Notched/shaped slates from T01 214

119 Perforated slates from T01 and T01 ext 215

155120 Worked stone from T01: RF 4298

156121 Notched/shaped slates from T01 ext 217

$157 \quad 122$ Architectural stone finds from T01 (1) 218

158123 Architectural stone finds from T01 (2) 219

159124 Glass finds from the Site C building (Vessels 1, 6, 12,14 and 16 and glass beads)

125 Glass finds from Tintagel, other than Site C building (Vessels 2, 3, 4, 5, 7, 8, 9 and 10)

126 Romano-British and imported post-Roman ceramics

127 Imported and Roman native pottery 232

128 Large sherd of pottery: RF 3477

129 Imported post-Roman ceramics 239

130 Imported post-Roman ceramics 240

131 Imported Bi pottery 242

132 Principal components analysis plot of the Tintagel amphorae

$133 \mathrm{MgO}-\mathrm{Cr}$ plots of the Tintagel amphorae and the reference groups

$134 \mathrm{MgO}-\mathrm{CaO}$ plots of the Tintagel amphorae and the reference groups

$195135 \mathrm{MnO}-\mathrm{CaO}$ plots of the Tintagel amphorae and the reference groups

196136 Co-Cr plots of the Tintagel amphorae and the reference groups

137 Medieval pottery

138 SEM sections of two samples of industrial waste

139 SEM-BS images of RF 3956b

140 SEM-BS images of RF 6092

141 SEM-BS images of RFs 6093 and 6019

252

142 SEM-BS images of RF 4293

143 SEM-BS images of RFs 4337/4339

144 Radiocarbon dating: probability distributions of dates from Site $\mathrm{T}$

145 Wright's drawing of 'Tintagel Castle. Site F. Section W-E looking $\mathrm{N}$ across site. September $1936^{\prime}$

146 Aerial photograph of the local context for Tintage Castle 


\section{TABLES}

1 Summary archival information for Radford's excavations

2 Ceramics from the Radford archive

3 All pottery types from the Lower Terrace

4 Summary of plant macrofossils from Area C03/4/8

5 Radiocarbon results

6 Trench C19: contexts and finds

7 Trench C18: contexts and finds

8 Trench C05: contexts and finds

9 Trial trench C15: contexts and finds

10 Trench C17: contexts and finds

11 Trench C15 Phase P: contexts and finds

12 Trench C15 Phase R: contexts and finds

13 Trench C15 Phase S: contexts and finds

14 Trench C15 Phase T: contexts and finds

15 Trench C15 Phase U: contexts and finds

16 Trench C15 Phase V: contexts and finds

17 Trench C15 Phase W: contexts and finds

18 Trench C15 Phase X: contexts and finds

19 Trench C15 Phase Y: contexts and finds

20 Trench C15 Phase Z: contexts and finds

21 Site $\mathrm{C}$ building Phase S: contexts and finds

22 Site $\mathrm{C}$ building Phase $\mathrm{T}$ : contexts and finds

23 Components of the four richest samples from the fill of the fissure, Phase $T$

24 Weeds, by group, from the fill of the fissure, Phase T

25 Site $\mathrm{C}$ building Phase U: contexts and finds

26 Site $\mathrm{C}$ building Phase V: contexts and finds

27 Site $\mathrm{C}$ building Phase $\mathrm{W}$ : contexts and finds

28 Trench C09: waterlogged plant macrofossils from drain-fill context 1022

29 Site $\mathrm{C}$ building Phase $\mathrm{X}$ : contexts and finds

30 Site $C$ building Phase $Y$ : contexts and finds

31 Site $\mathrm{C}$ building Phase $\mathrm{Z}$ : contexts and finds

32 T02 Phase X: contexts and finds

33 T02 Phase Y: contexts and finds

34 T02 Phase Z: contexts and finds

35 T01 Phase U: contexts and finds

36 T01 Phase V1: contexts and finds

37 T01 Phase V2: contexts and finds

38 T01 Phase W: contexts and finds

39 T01 Phase X: contexts and finds

40 T01 Phase Y: contexts and finds

41 T01 Phase Z: contexts and finds

42 T01 ext Phase W: contexts and finds

43 T01 ext Phase X: contexts and finds

44 T01 ext Phase Y: contexts and finds

45 Slate finds from trench $\mathrm{C} 18$

46 Stone finds from $\mathrm{C} 15$ by type and phase

47 Slate discs from the Site $\mathrm{C}$ building

48 Notched slates from the Site $\mathrm{C}$ building
49 Perforated slates from the Site $\mathrm{C}$ building

211

50 Stone finds from Site $\mathrm{T} \quad 212$

17

51 Surface analysis of glass Vessel 6 sherds by EDXRF

52 Romano-British pottery

53 Fabric types of imported pottery, Radford trenches, Upper Terrace

54 Fabric types of imported pottery, Radford trenches, Middle Terrace

55 Imported pottery from trench C15, Middle Terrace, by fabric and context

56 Fabric types of imported pottery by phase, Site C building

57 Imported pottery from trench T01, Great Ditch, Site $\mathrm{T}$ by fabric and context

58 Imported pottery from trench $\mathrm{T} 01$ ext, Lower Ward, Site $T$ by fabric and context

59 The samples analysed chemically

60 Fabric descriptions

61 Reference material

62 Correlation between chemical groups $\mathrm{A}-\mathrm{D}$ and amphora types

63 Results of organic residue analysis

64 Medieval pottery from the Upper Terrace, Radford trenches, by fabric type and context

65 Medieval pottery from the Middle Terrace, Radford trenches, by fabric type and context

66 Medieval pottery from trench C15, Middle Terrace, by fabric type and context

67 Medieval pottery from the Site $\mathrm{C}$ building, by fabric type and context

68 Medieval and post-medieval pottery from Site $\mathrm{T}$, trenches $\mathrm{T} 01$ and $\mathrm{T} 02$, by fabric type and context

69 Total sherds of medieval and post-medieval pottery by fabric type and trench

70 SEM-EDAX analyses of industrial waste from trench $\mathrm{C} 15$

71 SEM-EDAX analyses of fragment of vitrified ceramic ( $\mathrm{RF} 3301$ ) from trench $\mathrm{Cl} 5$

72 Industrial material analysed from trench $\mathrm{C} 15$

73 SEM-EDAX analyses of industrial waste from trench $\mathrm{C} 15$

74 SEM-EDAX analyses of industrial waste from trench T01 ext

75 Plant macrofossils from Radford trenches $\mathrm{C} 05$ and trial trench $\mathrm{C} 15$

76 Charred plant macrofossils from trench $\mathrm{C} 15$

78 Wood charcoal identified from Phases $\mathrm{T}$ to $\mathrm{W}$, trench $\mathrm{C} 15$

79 Distribution of identified and unidentified specimens by phase: hand-collected assemblage from trench $\mathrm{C} 15$ 
80 Identified hand-collected specimens listed by phase, context and RF number, trench C15

81 Plant macrofossils from the Site $\mathrm{C}$ building

82 Percentage presence by context of plant macrofossils other than charcoal, Site $\mathrm{C}$ building

83 Crop macrofossils by phase and context, Site C building

84 Site T: charred plant macrofossils from T01 (Great Ditch), T01 ext and T02
85 T02: pollen assessment

86 Site T: charcoal identification

87 Site T: pollen assessment from T01 (Great Ditch, north bank), and T01 ext

88 Site T: molluscs from T01 (Great Ditch) and T01 ext

89 Identified hand-collected bone fragments from Site T
296

297 


\section{ACKNOWLEDGEMENTS}

The invitation to undertake this programme of work at Tintagel came from English Heritage, initially through the former Chief Inspector, Andrew Saunders, and has since been supported by the Directors for Historic Properties (SW Region): Beric Morley, Brian Davison and Kevin Brown. Geoffrey Wainwright, formerly Chief Archaeologist for English Heritage, took a personal interest in the project in 1998 and masterminded the post-excavation project through the intricacies of AMAC (Ancient Monuments Advisory Committee) scrutiny and approval in 1999. Christopher Morris is grateful to all, but particularly to Brian Davison, initially as the Inspector responsible for the monument, who has provided the financial and logistical support over the years, followed by Francis Kelly and Ian Morrison in 1998 and 1999. Colleen Batey and Rachel Barrowman are indebted to Sarah Jennings, the English Heritage monitor for the latter years of the project, who has been very understanding throughout. Specialist advice on environmental sampling has been given by Vanessa Straker, as the English Heritage Regional Environmentalist based at Bristol University, and she also organized most efficiently the post-excavation environmental programme there as well as participating enthusiastically in the project as a whole. The custodians at the monument, led by Robert Orton and Patrick O'Riordain, have been most courteous to the excavation teams, particularly since we have disrupted the normal routine of a heavily visited monument. Support from English Heritage works staff, and more recently contractors, has been masterminded by Gerald Byrd without whose help the excavations would have been unable to proceed relatively smoothly on a site that is a logistical nightmare!

Charles Thomas has always generously and freely given academic support and advice: his regular visits to the site - especially during the autumn 1993 and spring 1994 seasons when the Project Director was unable to be on site due to a back injury - have been much appreciated. He, too, has shared with the Project Director the frustrations of both genuine and 'fringe' interest from the press and public over the finding of the 'Arthnou Stone' and the other 'A' word. Other academic colleagues who have materially assisted with advice both on site and in discussion more generally are the late Leslie Alcock, Ewan Campbell, Rosemary Cramp, Peter Fowler, Michael Fulford, Robert Higham and Malcolm Todd. Colleagues in the Cornwall Archaeological Unit, especially Steve Hartgroves, Nicholas Johnson, Jacqueline Nowakowski and Adam Sharpe, have been generous with help and assistance and have always been welcoming to the members of the excavation.

Kevin Brady, Norman Emery, Caitlin Evans, Stuart Halliday, Robert James, Paul Johnson and Jo Story all supervised work on site and the authors wish to thank them for this, along with Carl Thorpe for his supervision of the finds recording and Paul Johnson for his supervision of on-site surveying. The contribution of Lorraine McEwan and Carl Thorpe to the illustrative side of the report's publication is considerable and is gladly acknowledged here - as is that of both Caitlin Evans and Gillian McSwan, who made amendments at a late stage. We especially wish to thank all the students from the Department of Archaeology, University of Glasgow, who have volunteered for their field training at the site over the years. Without them, the project could never have been completed so successfully.

Christopher Morris is particularly indebted to Rachel (Harry) Barrowman, co-author and Research Assistant, for her unstinting work on the project both on site and in post-excavation between 1991 and 2000, for 
writing and re-writing the post-excavation project design for English Heritage and for masterminding the post-excavation work towards completion. Colleen Batey, Rachel Barrowman and Paul G Johnson kept the work going on site in autumn 1993 and spring 1994; these three, and Kevin Brady, have at various times also kept faith with the project when official support seemed lost. Following the unexpected find of the inscribed slate in 1998, Kevin Brady in particular demonstrated unsuspected talents for dealing with innumerable requests for information about it, 'King Arthur' and the so-called 'Arthurian period'.

Colleen Batey wishes to thank Carl Thorpe for his assistance with finds-processing on site, Rachel Barrowman and Kevin Brady for assistance with the post-excavation work, and the various specialists who have contributed to this work. Others who have given notable assistance include Jennifer Jones in her capacity as English Heritage Conservator at Durham University, and Anna Tyack from the Royal Cornwall Museum, who facilitated the study of all the glass in Glasgow. In the last stages of this project, the assistance of Jane Marley of the Royal Cornwall Museum in the hunting down of archive records is gratefully acknowledged. Financial support from the Society of Antiquaries through the Headley Trust Fund enabled detailed examination of the surviving archives of Radford's excavations at Tintagel, and this is most gratefully acknowledged.

Vanessa Straker is very grateful to the project staff from Glasgow, especially Aileen Maule, for sterling efforts to implement the sieving programme in difficult circumstances, and to Ben Waldman and Denise Druce for sample processing in Bristol. Since 1991 many people have assisted with sample processing both on site and in the laboratory in Bristol and she is grateful to them all.

Carl Thorpe would like to thank Professor Charles Thomas for his support and encouragement, which greatly enriched the content of the pottery report. Catherine Freeman would like to thank John Allan (now of Exeter Archaeology) who on many occasions since 1976 has helped with identification and information on South-Western pottery, also supplying reference material and draft reports in advance of publication. However, this, as with all previous reports (as C O'Mahoney), represents her own views.

Charles Thomas is indebted to Professor Christopher D Morris, with colleagues and friends at the University of Glasgow, for the opportunity to contribute to this volume and is especially grateful to both Paul Johnson and Carl Thorpe for photography, inspections and drawings of the slate and for sharing their ideas and conclusions with him.

Paul Johnson is grateful to Janet Hooper for her assistance during the 1995 survey to relocate Radford's trenches. Effie Photos-Jones is grateful to Rachel Barrowman and Colleen Batey for useful discussion, and also to Sarah Philips for IT support and Dave Sneddon for technical support. Polydora Baker would like to thank Claire Ingrem for identifying the two fish bones from Trench T01 Ext, and Rachel Barrowman for responding to numerous queries about the site.

Rachel C Barrowman, Colleen E Batey and
Christopher D Morris
Glasgow
November 2006 


\section{SUMMARY}

The site of Tintagel Castle in north Cornwall is one of the best-known medieval sites in Guardianship in Britain, and attracts large numbers of visitors, mainly because of its Arthurian connections. These connections are tenuous at best, and dependent initially upon the reference to Arthur's conception at Tintagel by the twelfth-century writer, Geoffrey of Monmouth, and subsequent romances. Modern scholarship has established that in the post-Roman centuries there is a greater claim for association with the Tristan and Isolde stories, and the shadowy 'King Mark' of Dumnonia. What the visitor sees at the site today, however, are the remains mainly, not of the early medieval period, but of the Castle-building activities of Earl Richard of Cornwall in the thirteenth century.

However, work in the 1930s and 1950s by Dr Ralegh Radford also uncovered remains inter alia of buildings arguably from the fifth to sixth centuries, dated by means of significant numbers of fragments of imported pottery from the Mediterranean, and especially the eastern Byzantine area and North Africa. These he interpreted not as 'Arthurian' but as the buildings of an early Christian monastery, scattered across the site, especially on the plateau and a series of terraces created on the eastern side of the 'Island'. Despite a number of publications about the site, a 'final report' was never published on this work. Thus, one of the motivations on English Heritage's part for renewed work in the $1990 \mathrm{~s}$ was to maximize the information to be retrieved from this work by re-examination of parts of the site Radford had examined. From an academic perspective, following critical assessment of aspects of the earlier work and the outcome of emergency fieldwork following a fire on this promontory site in the 1980 s, there was by then an urgent need to apply modern techniques to a reexamination of the site.
English Heritage commissioned Christopher D Morris to undertake this work, which began in April 1990 , and was continued in a number of short excavation and survey seasons until July 1999. The work focused initially on excavations on the three terraces of 'Site C' on the 'Island', but expanded later to 'Site T' on the mainland side of the Castle, together with survey and archive work both to establish the extent of Radford's work and to provide an up-to-date context for the two areas. Radford died during the latter stages of the work, and so the archive work was further expanded to include reconsideration of relevant papers from his personal archive.

The work described and analysed in the following twelve chapters has provided much detail of structures, major features, occupation surfaces, artefacts and ecofacts from both sites. The work on the terraces of Site C demonstrated a complexity and variability of building forms and associated occupation, but also - more importantly - the wide-ranging connections of Tintagel during the fifth to seventh centuries, as demonstrated through the ceramic and glass assemblages. The late Roman period appears to have seen activity on the site, most notably demonstrated on a stone with, arguably, an Imperial inscription to Honorius, later the object of graffiti from three post-Roman personages, Paternus, Coliavus and Artognou. Despite media speculation, the latter is not 'Arthur', although the stone itself is dramatic testimony to the cultural and literary milieu of highstatus Dumnonian society in the post-Roman period. The work on Site $\mathrm{T}$ demonstrated unequivocally that the 'Great Ditch' dates from the fifth to seventh centuries and thereby encloses the largest promontory or hill-top site of the period. It also established that there was late Roman and post-Roman activity, both domestic and potentially industrial. With the routine examination of soil samples 
from both sites, a new dimension has also been brought to the study of Tintagel with an appreciation of the exploitation of the local environment and the cropprocessing activities that clearly went on in the vicinity.

Although the work on Site C demonstrated that the restored stone foundations initially uncovered by Radford are post-Roman in date rather than later medieval, nevertheless some sidelights have been cast upon the activity in the post-Conquest period, especially through study of the pottery assemblage. Between and after the two 'highlights' of the early medieval occupation and the Castle phase, archaeologically there are periods of apparent stagnation. However, in the end, the interest in Arthurian romances has fuelled both the growth of the village at Tintagel and the modern yearround public interest in the site of Tintagel Castle. While the work described here has in no way 'validated' any Arthurian claims, it has demonstrated the iconic importance of the site from the post-Roman period, not just in Dumnonia, but in the wider world of western and northern Britain and Ireland and the economy of the late Antique and Byzantine world. 


\section{RÉSUMÉ}

Le Château et site de Tintagel, dans les Cornouailles du Nord, est l'un des sites médiévaux protégés les plus connus de la Grande Bretagne et attire un grand nombre de visiteurs par ses liens avec le Roi Arthur. Or, ces liens sont pour le moins ténus, et, sont tout d'abord basés sur une référence de l'écrivain du xilème siècle, Geoffrey de Monmouth, et, ensuite sur divers textes romanesques, établissant le lieu de naissance du Roi Arthur à Tintagel. Une nouvelle école a établi, qu'après le chute de l'Empire Romain d'Occident, une association avec Tristan et Iseult et le sombre Marc'h de Dumnonée serait plus appropriée. Mais, ce que les visiteurs voient aujourd'hui du site ne sont pas les vestiges du début du Moyen-Age, mais ceux du XIIème siècle associés au château et à la cour du Comte Richard de Cornouailles.

Cependant dans les années 30 et 50 , les fouilles du Dr Ralegh Radford ont permis de découvrir entre autres des bâtiments estimés datés du v et vième siècles, dates basées sur un nombre considérable de céramiques provenant de la Méditerranée et particulièrement des régions orientales Bysantines et de l'Afrique du Nord. Selon lui, ces bâtiments ne sont pas d'origine Arthuriennne mais ceux d'un monastère du début de l'ère chrétienne, qui sont disséminés sur tout le site, particulièrement sur le plateau et les versants en terrace à l'est de l'Ile. Malgré de nombreuses publications, les travaux finaux du Dr Radford n'ont jamais été publiés. C'est pourquoi dans les années 90, English Heritage a entrepris de nouvelles recherches afin de maximiser les informations obtenues par les travaux du Dr Radford et de reéxaminer les chantiers qu'il avaient ouvert. D'un point de vue académique, suite à une évaluation critique des premières recherches et suite aux résultats de fouilles de sauvetage après un incendie sur le site principal du château dans les années quatre-vingt, il est devenu urgent d'appliquer des techniques modernes à cette réexamination du site.
English Heritage a chargé Christopher D Morris de l'exécution de ce travail, qui a commencé en avril 1990 avec une série de fouilles de courte durée et de prospections jusqu'en juillet 1999. Ce travail s'est tout d'abord concentré aux fouilles des trois terraces de l'IleChantier C, et, s'est étendu ultérieurement à l'emplacement principal du Château - Chantier T. Ceci s'est conjugué à une prospection et une recherche documentaire afin et, d'établir l'étendue du travail de Radford, et, de fournir une étude récente des deux Chantiers C et T. Dr R Radford est décédé au cours des dernières étapes de ses recherches; c'est pourquoi le travail documentaire nécessitait une reconsidération des archives personnelles du Dr Radford.

Le travail décrit et analysé dans les douze chapitres suivants ont fourni une étude minutieuse des structures, caractéristiques principales, aires d'occupation, artefacti et résultats environnementaux des deux Chantiers. Le travail sur les terraces du Chantier $\mathrm{C}$ a montré la complexité et le changement des bâtiments et leur occupation, mais surtout la diversité des échanges à Tintagel du v au vilème siècles grâce aux assemblages de céramiques et de verreries. Le site a connu une période d'activité à la fin de la période impériale romaine qui s'est tout particulièrement démontré par la présence d'une pierre ayant - ce qui est contestable - une inscription associée à Honorius, et, ayant aussi été l'objet de graffiti de trois personnalités de la période qui suit la chute de l'Empire Romain d'Occident: Paternus, Colavius et Artognou. Ce dernier, et ce malgré les spéculations médiatiques, n'est pas attribué à Arthur. Mais cette inscription reste néanmoins le témoignage spectaculaire du milieu culturel et littéraire de la société Dumnonéenne après la Chute de l'Empire Romain d'Occident. Le travail sur le Chantier $\mathrm{T}$ a démontré sans équivoque que le Grand Fossé datait du v au viı̀me 
siècles et clôture ainsi le plus grand site promontoire ou hilltop de cette période. Ce travail a aussi établi la présence d'activité domestique et potentiellement industrielle durant le période Romaine et post-Romaine. Létude systématique des échantillons environnementaux des deux chantiers a aussi apporté une nouvelle dimension aux travaux sur Tintagel et a permis une évaluation de l'exploitation environnementale locale et des activités agricoles de la région.

Bien que le travail sur le Chantier $\mathrm{C}$ ait démontré que les fondations en pierre, tout d'abord découvertes par Radford, appartiennent à la période post-Romaine et non à la fin du Moyen-Age; l'étude des assemblages de poteries a aussi permis d'envisager la possibilité d'une activité durant la période qui suit 1066 - Post-Conquest.
Au milieu et après les deux highlights de l'occupation du début du Moyen Age et la période de d'occupation du Château, les résultats archéologiques ont démontré des périodes d'apparente stagnation. Cependant, l'intérêt porté aux légendes Arthuriennes ont dynnamisé à la fois la croissance du village de Tintagel et l'intérêt du public pour le Château et le site de Tintagel. Tandis que le travail décrit ici n'a en aucun validé des revendications Arthuriennes, il a démontré l'importance iconographique du site de la période post-Romaine, non seulement en Dumnonée mais aussi dans les plus vastes contrées du Nord et de l'Ouest britanniques et irlandais et l'économie à la fin de l'Antiquité et durant la période Byzantine.

Traduction: Charlotte Francoz 


\section{ZUSAMMENFASSUNG}

Tintagel Castle und Umgebung, im Norden Cornwalls, ist eine der bekanntesten, unter Denkmalschutz stehenden mittelalterlichen Stätten in Großbritannien und zieht hauptsächlich wegen der Verbindungen mit König Arthur viele Besucher an. Diese Verbindungen sind wenig stichhaltig, sie beruhen ursprünglich auf der Erwähnung der Arturlegende im Zusammenhang Tintagel Castle und Umgebung, im Norden Cornwalls, ist eine der bekanntesten, unter Denkmalschutz stehenden mittelalterlichen Stätten in Großbritannien und zieht hauptsächlich wegen der Verbindungen mit König Arthur viele Besucher an. Diese Verbindungen sind wenig stichhaltig, sie beruhen ursprünglich auf der Erwähnung der Arturlegende im Zusammenhang mit Tintagel im Werk von Geoffrey of Monmouth, der im 12. Jahrhundert schrieb und in späteren Ritterromanzen. Die moderne Forschung hat erwiesen, $\mathrm{da} ß$ in den nachrömischen Jahrhunderten eher eine Verbindung mit der Sage von Tristan und Isolde und dem schattenhaften 'King Mark' besteht. Die heute sichtbaren Überreste sind jedoch meist nicht dem Mittelalter zugehörig, sondern stammen aus dem 13. Jahrhundert, mit Earl Richard of Cornwall als Erbauer.

Ausgrabungen in den 30er und 50er Jahren unter Dr Ralegh Radford brachten unter anderem jedoch Gebäudereste zum Vorschein, die aus dem 5.-6. Jahrhundert stammen dürften, datiert mit Hilfe von zahlreichen Tonscherben aus dem Mittelmeergebiet, vor allem aus dem ostbyzantinischen und dem nordafrikanischen Raum. Radford deutete sie nicht als 'Arthurian', sondern als einem frühchristlichen Kloster zugehörig, hauptsächlich auf dem Plateau und den Terrassen auf der Ostseite der 'Insel' verstreut. Trotz einer Reihe von Publikationen über die Anlage wurde ein 'final report' über diese Arbeit nie veröffentlicht.
Daher war einer der Beweggründe in den 90er Jahren von English Heritage für die Wiederaufnahme der Arbeit, Teile von Radfords Ergebnissen zu revaluieren. Kritik an der teilweisen Beurteilung und am Ergebnis der Arbeit im Gelände nach einem Brand in den 80er Jahren machten die Anwendung moderner Grabungsmethoden zu erneuter Untersuchung der Anlage im höchsten Maße notwendig.

English Heritage beauftragte Christopher D Morris mit dieser Arbeit, die im April 1990 begann und in mehreren kürzeren Ausgrabungen und Vermessungen bis Juli 1999 fortgesetzt wurde. Die Grabungen auf den drei Terrassen auf 'Site C' auf der 'Insel' standen anfangs im Blickfeld, wurden aber später auf 'Site T' auf den dem Festland zugekehrten Teil der Burg ausgedehnt. Vermessungen und Archivarbeit sollten den Umfang von Radfords Arbeit demonstrieren. Nach seinem Tod wurde die Archivarbeit weiter ausgedehnt, um relevante Unterlagen aus seiner persönlichen Hinterlassenschaft neu zu erwägen. Die folgenden zwölf Kapitel liefern viele strukturelle Einzelheiten, besondere Merkmale, Wohnflächen, Artefakte und Ekofakte von beiden Stätten. Die Arbeit auf den Terrassen von 'Site C' zeigte vielschichtige und verschiedenartige Bauformen und damit verbundene Okkupationen, aber was noch bedeutender ist, die weitreichenden Handelsverbindungen Tintagels während des 5.-7. Jahrhunderts, sichtbar durch Keramik- und Glasansammlungen. Die spätrömische Anwesenheit scheint vor allem durch einen Stein vertreten zu sein, mit einer wohl imperialistischen Widmung an Honorius, mit späteren Graffiti von drei nachrömischen Persönlichkeiten, Paternus, Coliavus und Artognou. Trotz Spekulationen in den Medien ist der letztere nicht 'Arthur', obwohl der Stein selbst für die hohe Stellung des kulturellen und literarischen Milieus in der 'Dumnonian' Gesellschaft in der nachrömischen Ära Zeugnis ablegt. 
Die Arbeit auf 'Site T' zeigt eindeutig, daß der 'Great Ditch' aus dem 5.-7. Jahrhundert stammt und dam it den größten Berggipfel umschließt. Spätrömische oder nachrömische Aktivität, sowohl häuslich wie auch möglicherweise industriell, wurde offenbar. Routinemäßige Untersuchungen von Bodenproben an beiden Stätten zeigten Tintagel in einer neuen Dimension, nämlich in der ganz offensichtlichen Nutzung der örtlichen Umgebung mit ihrer Landwirtschaft.

Obwohl sich die restaurierten Steinfundamente, ursprünglich von Radford freigelegt, in 'Site C' als nachrömisch und nicht mittelalterlich herausstellten, zeigten sie dennoch eine gewisse Aktivität in der Zeit nach 1066, besonders durch das Studium der Keramikanhäufungen. Zwischen und nach den beiden 'highlights' der frühmittelalterlichen Besiedlung und der Burgphase gibt es anscheinend keine archäologischen Beweise.

Jedoch hat letzten Endes das Interesse an der Arthurlegende das Wachstum des Dorfes bei Tintagel und das Interesse an Tintagel Castle das ganze Jahr hindurch positiv beeinflußt. Während die hier beschriebene Arbeit in keiner Weise irgendwelche Arthur-Ansprüche bestätigt, zeigt sich doch die ikonische Bedeutung der Stätte von der nachrömischen Periode an, nicht nur in Dumnonia, sondern in der weiteren Welt des westlichen und nördlichen Britanniens und Irlands und der Ökonomie der Spätantike wie auch der byzantinischen Welt.

ÜBERSETZUNG: SIGRID MORRISON 


\section{PART I}

\section{PreVIOUS Work}





\title{
CHAPTER 1
}

\section{BACKGROUND, ARCHIVES AND SURVEY WORK}

\author{
with contributions from PAUL G JOHNSON
}

\section{BACKGROUND}

Tintagel is situated on the north coast of Cornwall (sx 04988925; figure 1) and is the name now given to the village whose economic existence is intricately bound up with the tourist industry. It is dominated by the ruins of a castle, probably thirteenth century in date, which has been much depleted by collapse and erosion (figure 2). Traditionally Tintagel is connected with the legendary King Arthur: the source of this tradition, Geoffrey of Monmouth's History of the Kings of Britain (c 1135-8), places Arthur's conception by the union of Uther Pendragon and Igerna, the wife of Gorlois, Duke of Cornwall at Tintagel, Gorlois's safest maritime fortress. ${ }^{1}$ The link with 'King Arthur' is further emphasized by later written sources. As Professor Charles Thomas has said: 'On so slight a foundation, almost every subsequent writer was able to expand the conception of Arthur at Tintagel to his birth there and, by implication, ownership and even residency.' ${ }^{2}$

Up to the 1930s the model presented of Tintagel as an early residence of Arthur and fortress of the rulers of Cornwall was the norm. In 1942 Dr C A Ralegh Radford wrote that, due to the romantic setting at Tintagel, the vogue in the mid-nineteenth century for Arthurian romances, and the lack of historical rivals, 'Arthur therefore reigns supreme in Tintagel and few would wish to displace him.'3 However, by then, the powerful influence of Henry Jenner's re-evaluation of the historical and literary evidence, ${ }^{4}$ and the results of the excavations carried out by Radford himself, ${ }^{5}$ were sufficient to encourage him to propose an alternative interpretation based upon an Early Christian monastic model. Radford's excavations at Tintagel in the 1930s were extensive, and an important component in an interpretative 'shift' away from the 'Arthurian' model towards that of Early Christian 'Celtic' monasticism. ${ }^{6}$ Unfortunately, due to the lack of a full report on his work or archive of his findings, it has been difficult to study the basis of his interpretations.

In 1935 the first (and only) 'Interim Report' of excavation work carried out to that date under Radford's direction at Tintagel Castle was published in the Antiquaries Journal. ${ }^{7}$ However, the work undertaken by Radford was considerably more extensive than that reported in the 'Interim Report', and it is known from a study of the Wright and Radford archives (see below) that excavations took place across both the plateau of the 'Island' and around the margins, especially on the northeast side, outwith Sites A-G depicted on Radford's plan. A guidebook to the site, written by Radford and first issued in 1935, was updated to a second edition in $1939,{ }^{8}$ possibly as a result of Radford's further work on the Island in 1936 and 1938. His paper on 'Tintagel in History and Legend' ${ }^{\prime}$ in 1942 was to follow and in 1956 his seminal paper on the imported ceramics appeared in print following submission in $1954 .{ }^{10}$ In 1955 he returned to Tintagel to conduct smaller excavations on parts of the site, but he was never to finish these and they remained unpublished, with the precise location and scale of the work unknown. However, in the 1960s and 1970s Radford published several papers of synthesis and these help to document the extent of the work. ${ }^{11}$

As a result of this, a definitive Tintagel publication never appeared. ${ }^{12}$ Until shortly before Radford's death in 

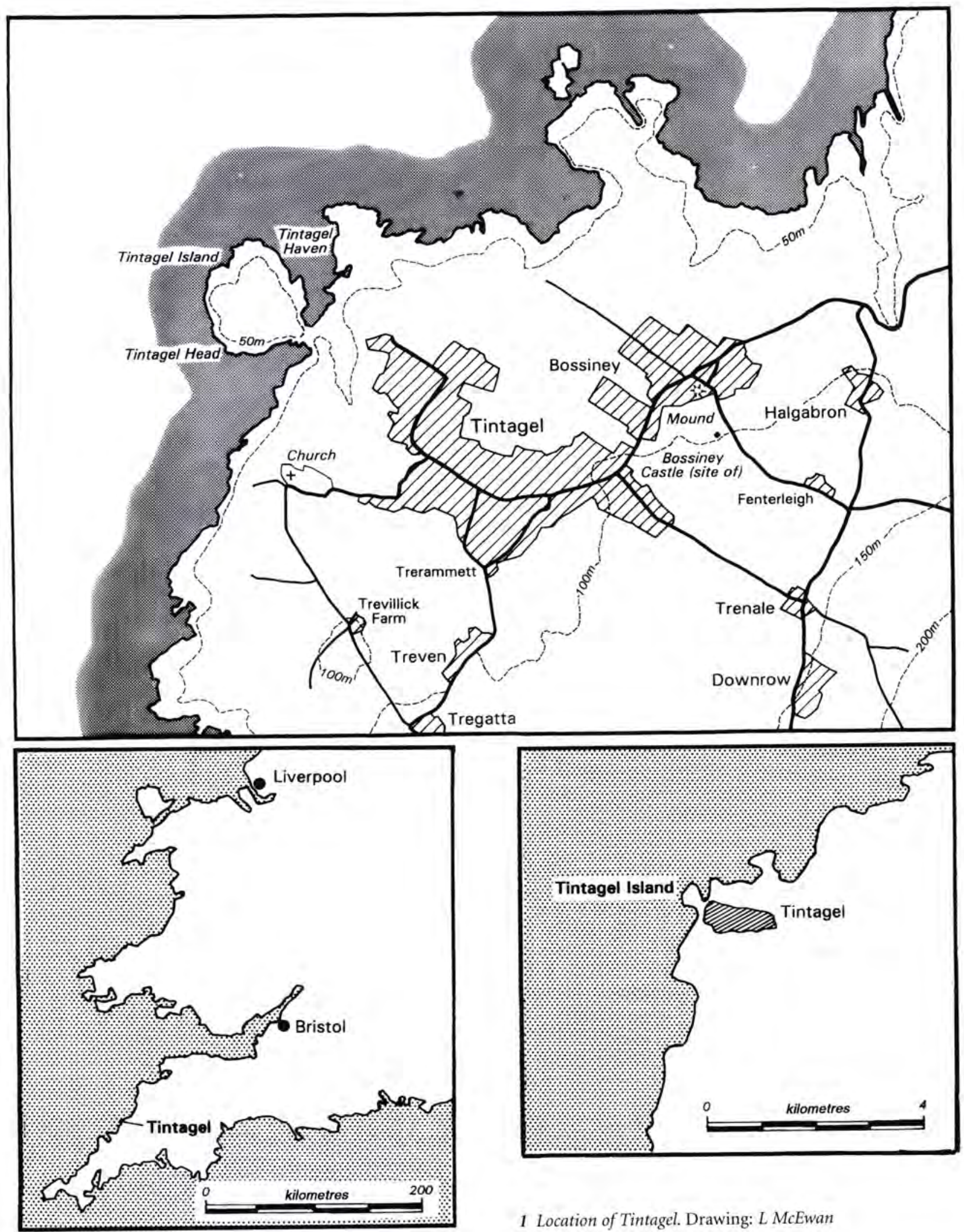

1 Location of Tintagel. Drawing: L McEwan 


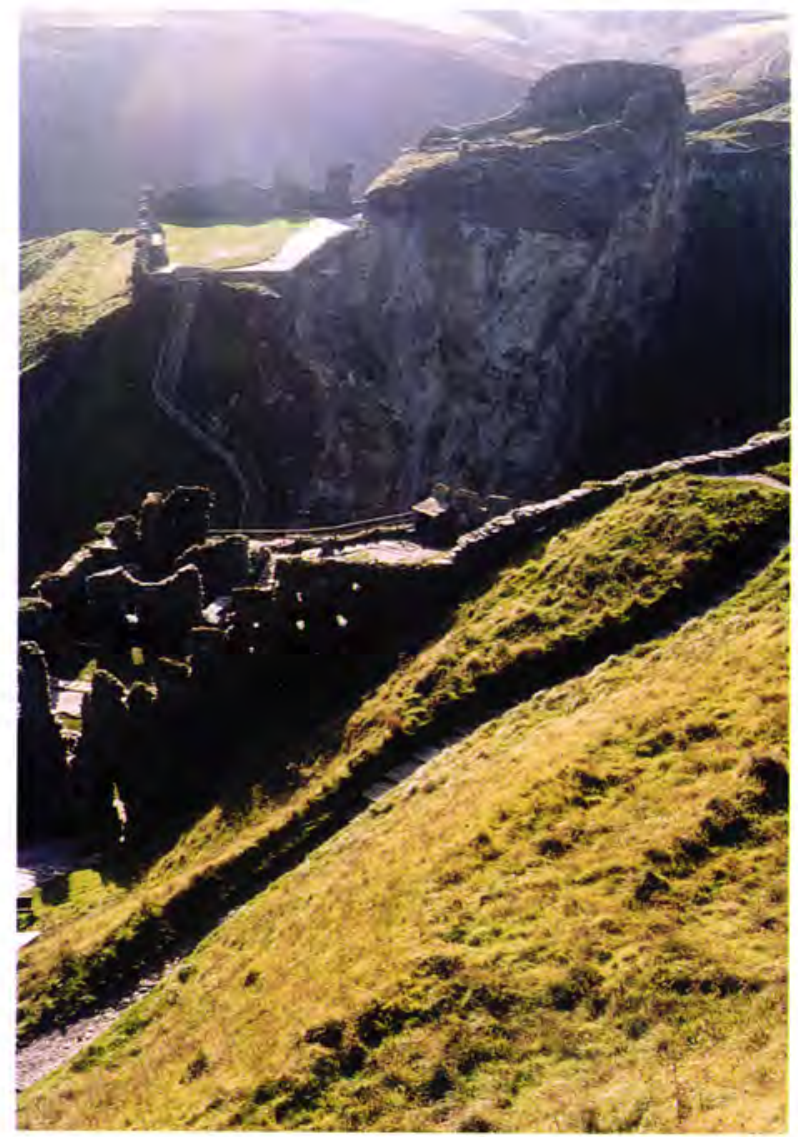

2 General view of Tintagel Castle. Photograph: $R$ Barrowman

December 1998 it was assumed that the only surviving paper record of his work was made by J A Wright, an architectural draughtsman and surveyor from the Office (later Ministry) of Works (MoW). It was Wright's task to visit Radford's excavations, sometimes at the close of the season, and record the extent of the archaeological activities and any discoveries made during that year. A series of paper records of plans and sections by Wright from the 1930s work were accessioned by the National Monuments Record (NMR) at Swindon in 1992 and copies were made available by English Heritage $(\mathrm{EH})$ to the Glasgow University excavation team. This is the only remaining indication of the precise location of Radford's trenches other than what is contained within the excavator's several, and sometimes contradictory, syntheses and the extant reconstructed remains visible on the Island today.

Various additional papers, notebooks and plans received from Radford were catalogued in outline in September 1998 by the National Monuments Record (in fact this was just prior to Radford's death on 27 December 1998) and this cache included material from his work at Tintagel, dating from both before and after the Second World War. Letters within the Radford archive indicate the unfortunate history of the site documents. Radford seems to have kept the majority of his excavation records at his house in Exeter, presumably to continue working on them after the war. Unfortunately, however, Radford's house was damaged in an air raid in 1942 and the written archive apparently destroyed. ${ }^{13}$ In a letter from Radford to Ken Dark dated 2 August 1982 he confirms the fact that not all his 1939-40 records survive ${ }^{14}$ (we presume these to be from the 1939 excavations in the Great Ditch as there are no records for work taking place at Tintagel in 1940, although it may have been work for a draft report).

Thomas has noted that Radford 'played a full but sometimes necessarily secret role' in the war which curtailed his excavations at Tintagel. ${ }^{15}$ Writing on 21 November 1985 to Peter Fowler, Radford notes that he had hoped to dig in early 1939 but the Czech crisis meant he had to quickly return to Rome. ${ }^{16}$ Radford stated that he wrote the 1942 article on his work 'in great haste because the Royal Institute of Cornwall were anxious to have a summary account. I had been advised of a probable posting abroad for secret intelligence purposes. It did not come off till $1943 \ldots .{ }^{17}$ He was in fact sent to Tangier in 1943, where according to his obituary he worked in the intelligence department of the Foreign Office, becoming chief intelligence officer in the department of psychological warfare at Allied HQ with the rank of staff colonel. ${ }^{18} \mathrm{He}$ returned to London in 1945 only to find that all his personal files had perished there.

In a letter to Peter Rose of the Cornwall Archaeology Unit dated 21 July 1993, he confirms losses of the copies of his Tintagel records in the Exeter bombing, as well as further records going astray while working in Rome in 1945. The reorganization of the Ministry of Works in London meant that no records were available. In his view 'the pre-war guide was probably the most reliable for work undertaken 1930-39 ... work which had been undertaken "to make the site intelligible".'19

\section{THE WRIGHT ARCHIVE by Paul G Johnson}

\section{BACKGROUND}

The activities of Ralegh Radford on Tintagel Island between the years of 1933 and 1939 are characterized by 
a general paucity of empirical information. The blame for this cannot be wholly placed on Radford's shoulders; he was operating at a time when there were no definitive procedures for the excavation and recording of archaeological sites and monuments.

Radford's excavation philosophy at Tintagel has already been thoroughly and critically examined by others. ${ }^{20} \mathrm{He}$ appears to have concentrated his activities upon areas containing visible remains (eg the Castle itself, the chapel dedicated to St Juliot on the plateau of the Island, and the area of the so-called 'Herb Garden' also situated on the plateau). Radford examined areas with shallow stratigraphy, which probably gave at least some surface indication of the presence of archaeological remains (eg Site D situated on the plateau adjacent to one of the two Napoleonic-period 'rampiers' on the Island), or else he employed a time-honoured trial-trenching methodology. It was the latter that prevailed in his explorations of the 'terrace' sites, B, $\mathrm{C}, \mathrm{F}$ and $\mathrm{G}$ (figure 3 ), and as a result, the remaining archaeological deposits in these areas are criss-crossed with the backfilled remains of Radford's trenches. The excavations reported in this volume, which centred on Site $\mathrm{C}$, have demonstrated that what Radford considered to be an unpromising trench quite often proved to be of greater interest (see, for example, excavation Trench C15 discussed in Chapter 5).

There remains a significant degree of uncertainty as to exactly what Radford did and where in the 1930s and, indeed, in 1955. As an attempt to assist in future

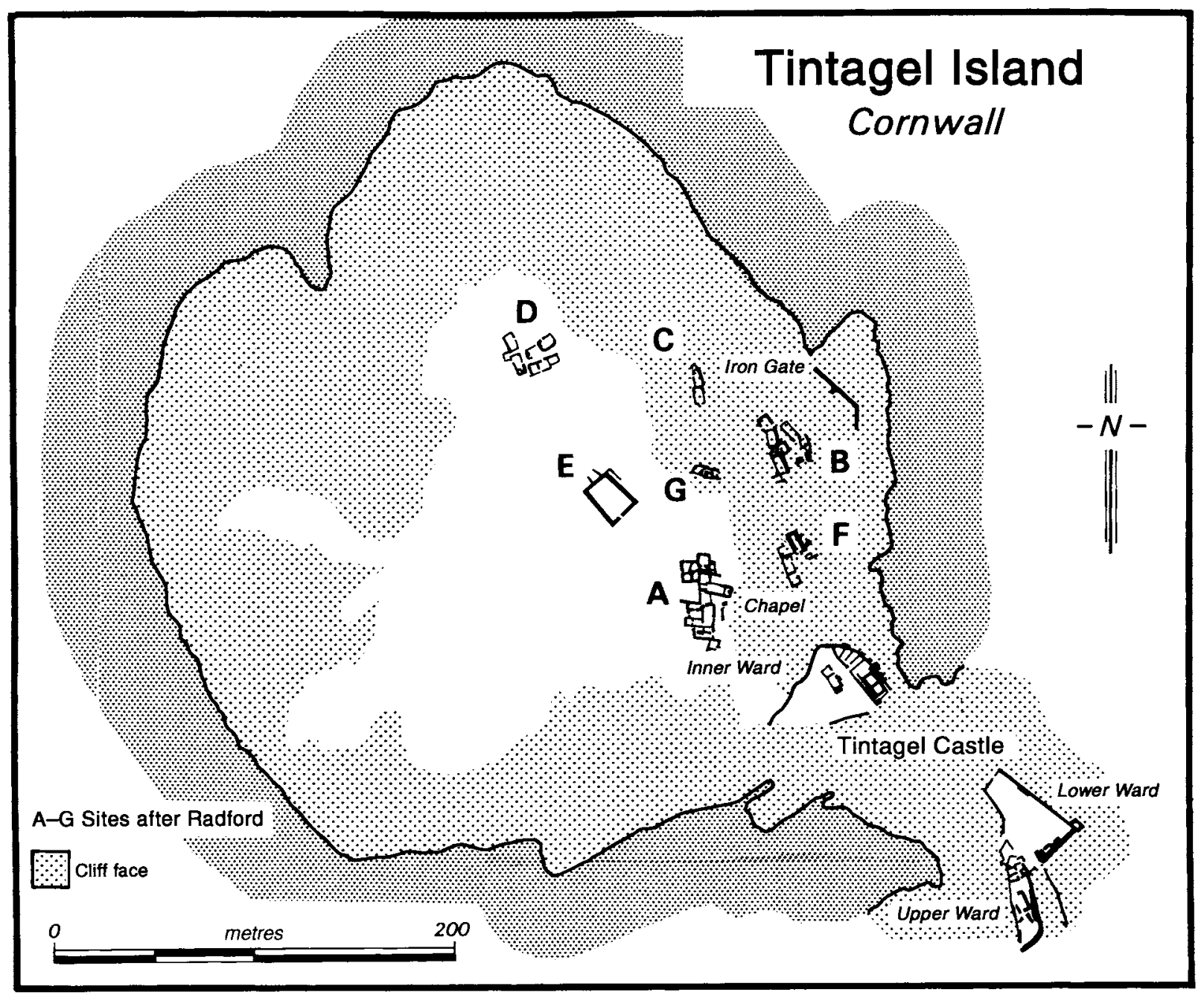

3 Plan of Tintagel Island with sites identified by Radford. Drawing: L McEwan after MoW 
archaeological activity on the Island, a thorough reappraisal of Wright's 1930s material was required (he was not involved in the 1955 campaign), along with an attempt to relocate and map Radford's work.

\section{OVERVIEW OF J A WRIGHT'S DRAWINGS FROM} THE $1930 \mathrm{~s}$

The Wright archive is composed of fifty-eight A3 (approx) sheets of Imperial graph paper, still in good condition, held in the NMR at Swindon. There are none of his notebooks or any other form of written account, Wright apparently preferring to annotate his drawings directly. It is obvious that he must have maintained a notebook since, for example, none of the levels in his drawings are reduced, and therefore he must have had empirical datum values recorded somewhere else. Similarly, information concerning his control system(s) must also have been recorded, otherwise it would have been virtually impossible for Wright to have spatially organized Radford's interventions using the archive as it stands today on its own.

Wright was at Tintagel twice in 1933, in April and June/July. In April his remit seems to have been to record extant structures as they appeared in advance of excavation. By June/July his role had changed and he appears to have been charged with recording the results of Radford's endeavours, which he may have been doing concurrently with the excavations that year. In subsequent years Wright seems to have gone to Tintagel at the close of the excavation season, usually in September, and was charged solely with the recording of the outcomes of that year's digging. The Wright archive contains no material from 1935 or 1937 at all. With the benefit of the 1998 cache of documents (see 'The Radford Archive' below and table 1), it seems that this can be explained by the fact that in both these seasons Radford visited the site to give general clearance instructions to workmen. Radford refers to a visit to Tintagel (in 1935) to assess what the workmen should do next; however, he had failed to meet the foreman of the work and noted that 'nothing had been done since last summer' (ie 1934). ${ }^{21}$ In 1937 letters confirm this same situation: one of 19 August records that the foreman had run out of work and they were mending the Castle walls; 22 one of 23 August notes 'new details had emerged in clearance' and he had met with the foreman this time to discuss alterations to the work programme to accommodate this; ${ }^{23}$ and according to a letter of 8 September, during further clearance 'no supervision was needed.' ${ }^{4}$ It is clear from this information that as no primary excavation was being undertaken the services of Wright were not required in these two years, hence the lack of plans in the archive.

The general quality of Wright's drawings, and the quantity of information contained within them, varies enormously over time. In April 1933 all seven of Wright's numbered drawings are neat and concise and contain much information. They are exclusively concerned with the recording of wards of the Castle, the Iron Gate and the Chapel. Just about every possible triangulation measurement was made and recorded (see, for example, figure 4, which is a record of the Inner Ward of the Castle). The seven numbered sheets from July 1933 are slightly more schematic, but are copiously annotated. Most are plans concerned with the excavations around Site A, the Chapel and Sites B and C, which had been partially excavated at that time. Scaled section-drawings are also provided for the Chapel and Sites A and B. The plans are well constructed and reflect Wright's pedantic attention to detail, but some confusion or absentmindedness is revealed in the section-drawings. Although Wright made a solid attempt at recording the gross stratigraphy in his sections, he either omitted to supply locational information or supplied what was in fact incorrect information.

Wright was back at Tintagel in July 1934, and the ten numbered drawings produced then are less tidily executed in comparison to those from 1933. Plans and sections are provided for Sites A, D and E. In addition, there is a plan of a series of gullies to the west of Site A, a sectiondrawing of a trench in excess of $214 \mathrm{ft}$ [ $65 \mathrm{~m}$ ] long, and a plan of various structures in relation to parts of a sitecontrol framework. Once again, Wright made every effort to record important stratigraphic information in his section-drawings. All of the 1934 drawings have the appearance of being hurried and are largely schematic (for example, figure 5, the $214 \mathrm{ft}$ trench), although generally informative and legible. It is obvious from a number of the 1934 drawings that Wright was not equipped with a compass that year, as his compass-roses were wildly inaccurate, often by over a hundred degrees!

If the record from 1934 can be described as schematic, Wright's drawings from September 1936 are at best sketchy, sometimes scrappy (figure 6). Eight plans and nine sections exist, none of them numbered. The plans are concerned with the recording of the structures on Sites B, C, D and F, the location of a third well and the 
Table 1 Summary archival information for Radford's excavations

\begin{tabular}{|c|c|c|}
\hline Year & Site & Source of archival information \\
\hline 1933 & $\begin{array}{l}\text { Pre-excavation } \\
\text { Castle: standing remains recording } \\
\text { A } \\
\text { Chapel } \\
\text { B } \\
\text { C }\end{array}$ & $\begin{array}{l}\text { Wright: April Sheets 1-7 standing remains } \\
\text { Wright: April Sheets } 1-5 \\
\text { Wright: July Sheet } 1 \text { 'Site West of Chapel' et al } \\
\text { Wright: July Sheet } 6 \text { 'Chapel Section' } \\
\text { Wright: July Sheet } 4 \text { 'Lower Platform (Site B)' et al } \\
\text { Wright: July Sheet } 5 \text { 'Site C' }\end{array}$ \\
\hline 1934 & $\begin{array}{l}\text { A } \\
\text { Gullies W of A } \\
\text { C } \\
\text { D } \\
\text { E }\end{array}$ & $\begin{array}{l}\text { Wright: July Sheet } 3 \text { 'Trenches North of Chapel' et al } \\
\text { Wright: July Sheet } 9 \text { untitled } \\
\text { Radford TINBOX } 46,58 \\
\text { Wright: July Sheet } 8 \text { 'Western Huts' } \\
\text { Wright: July Sheet } 1 \text { 'Herb Garden' and Sheet } 2 \text { 'Garden } \\
\text { Sections' }\end{array}$ \\
\hline 1935 & $\begin{array}{l}\text { B - clearance only } \\
\text { D - clearance only }\end{array}$ & $\begin{array}{l}\text { Radford Notebook TINBOX 46, } 55 \\
\text { Radford Notebook TINBOX 46, } 55\end{array}$ \\
\hline 1936 & $\begin{array}{l}\text { Trenches S of Site C } \\
\text { Valley } \\
\text { D } \\
\text { F } \\
\text { Trenches between B and F } \\
\text { 3rd Well }\end{array}$ & $\begin{array}{l}\text { Wright: September. Re-planning N and S ends } \\
\text { Radford Notebook TINBOX 46, } 55 \\
\text { Wright: September. 'Plan of Upper Platform' } \\
\text { Wright: September. Plan } \\
\text { Radford Notebook TINBOX 46, } 55 \\
\text { Wright: September. Two sections et al } \\
\text { Radford Notebook TINBOX 46, } 55 \\
\text { Wright: September. 'Re-plan to show extension' } \\
\text { Wright: September. Plan et al } \\
\text { Radford Notebook TINBOX } 46,55 \\
\text { Wright: September. Trenches Beta and Alpha. Section } \\
\text { Wright: September. 'Position of 3rd Well' }\end{array}$ \\
\hline 1937 & General clearance only: Sites F and B & Radford TINBOX 46, 58uue, 58uuf, 58uus \\
\hline 1938 & $\begin{array}{l}\text { A } \\
\text { B } \\
\text { C } \\
\text { D } \\
\text { F } \\
\text { G } \\
\text { H } \\
\text { Valley } \\
\text { Tunnel } \\
\text { Great Ditch and Lower Ward }\end{array}$ & $\begin{array}{l}\text { Wright: September. Shallow section } \\
\text { Wright: September. Plan of steps to higher level } \\
\text { Wright: September. Detailed sections Chamber A and B } \\
\text { Wright: September. Sections } \\
\text { Wright: September. Sections A and B } \\
\text { Radford Notebook TINBOX } 46,55 \text {. } \\
\text { Wright: September. Plan and section location et al } \\
\text { Wright: September. Position of trenches et al } \\
\text { Radford Notebook TINBOX } 46,55 \text {. Completion } \\
\text { Wright: September. Section } \\
\text { Wright: September. Section } \\
\text { Wright: September. Section } \\
\text { Radford: Sections labelled } 1938 \text { marked on } 1933 \text { plan } \\
\text { TINSITE } 8,44,1 / 21 \text {. } \\
\text { Radford: Photo of } 1938 \text { of Great Ditch } \\
\text { TINBOX } 46,50 \text { and } 59\end{array}$ \\
\hline
\end{tabular}




\begin{tabular}{lll}
\hline Year & Site & Source of archival information \\
\hline & Small Ditch & Wright: September. Section \\
& Section of road & Wright: September. Section \\
1939 & Great Ditch and Lower Ward & Radford TINBOX 46, 28D; TINBOX 46, 55 \\
$1946-7$ & General consolidation advice & Radford TINBOX 46, 58uus \\
1955 & B & Radford: Site Notebook, measurements for \\
& & consolidation TINBOX 46, 55 \\
& & Radford: Letter TINBOX 46, 28c \\
& Great Ditch & Radford: Letters TINBOX 46, 28 c and d and 58n \\
& Radford: Notes TINBOX 46, 10 \\
& Wall Walk trench & Radford: 1955 sketch section. Sections i, ii and iii and \\
& Wall Walk TINSITE 8, Bundle 44, 2/24 \\
& Radford Notebook TINBOX 46, 55 \\
& Lower Ward & Radford: Site notebook, TINBOX 46, 55
\end{tabular}

Note: full details of all entries of archival material can be found in Barrowman, Batey and Morris archive records deposited with EH/NMR and RCM

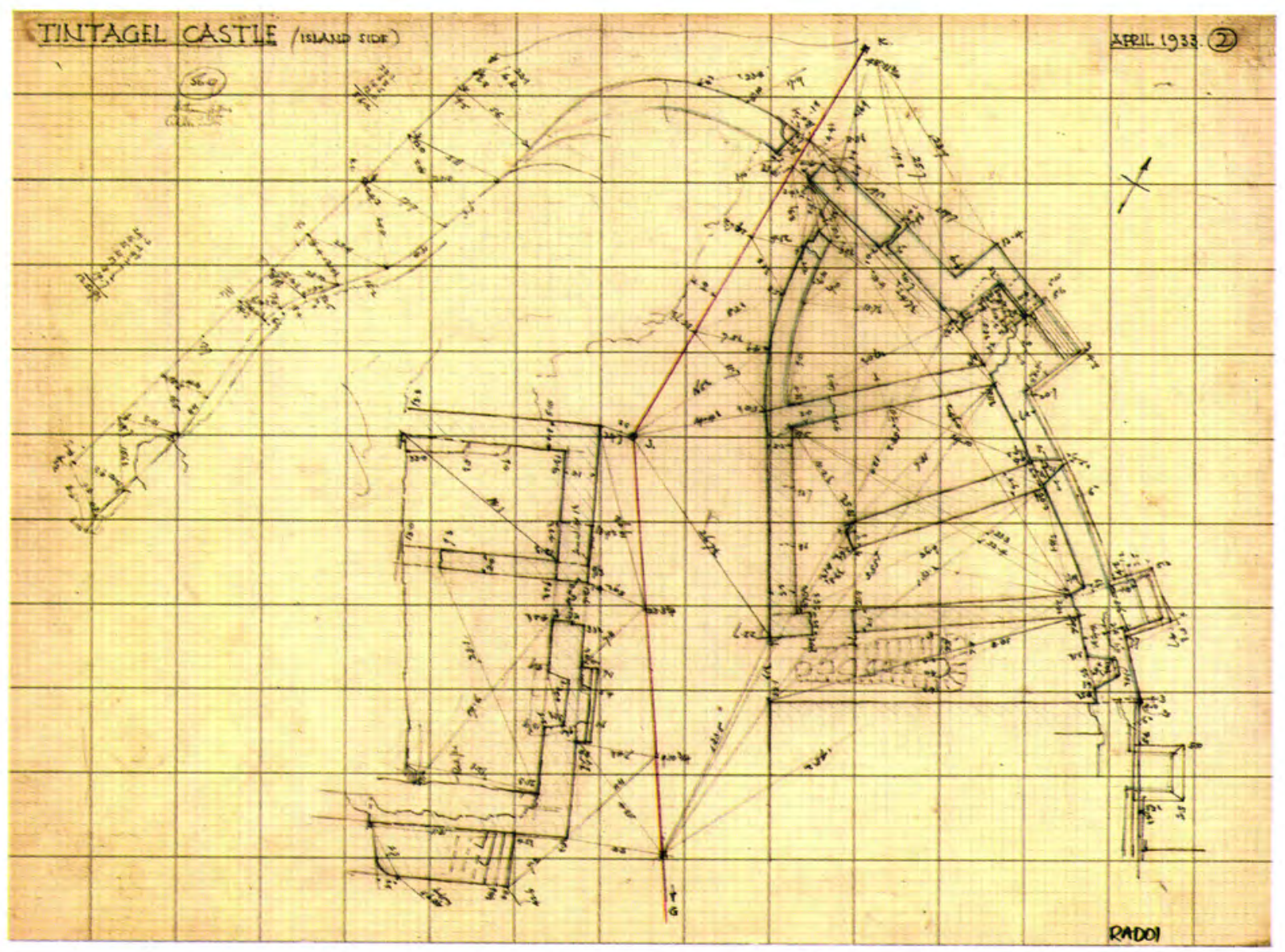

4 Wright's drawing of 'Tintagel Castle. Island side. April 1933. Sheet 2'. Reproduced by permission of English Heritage (NMR) 


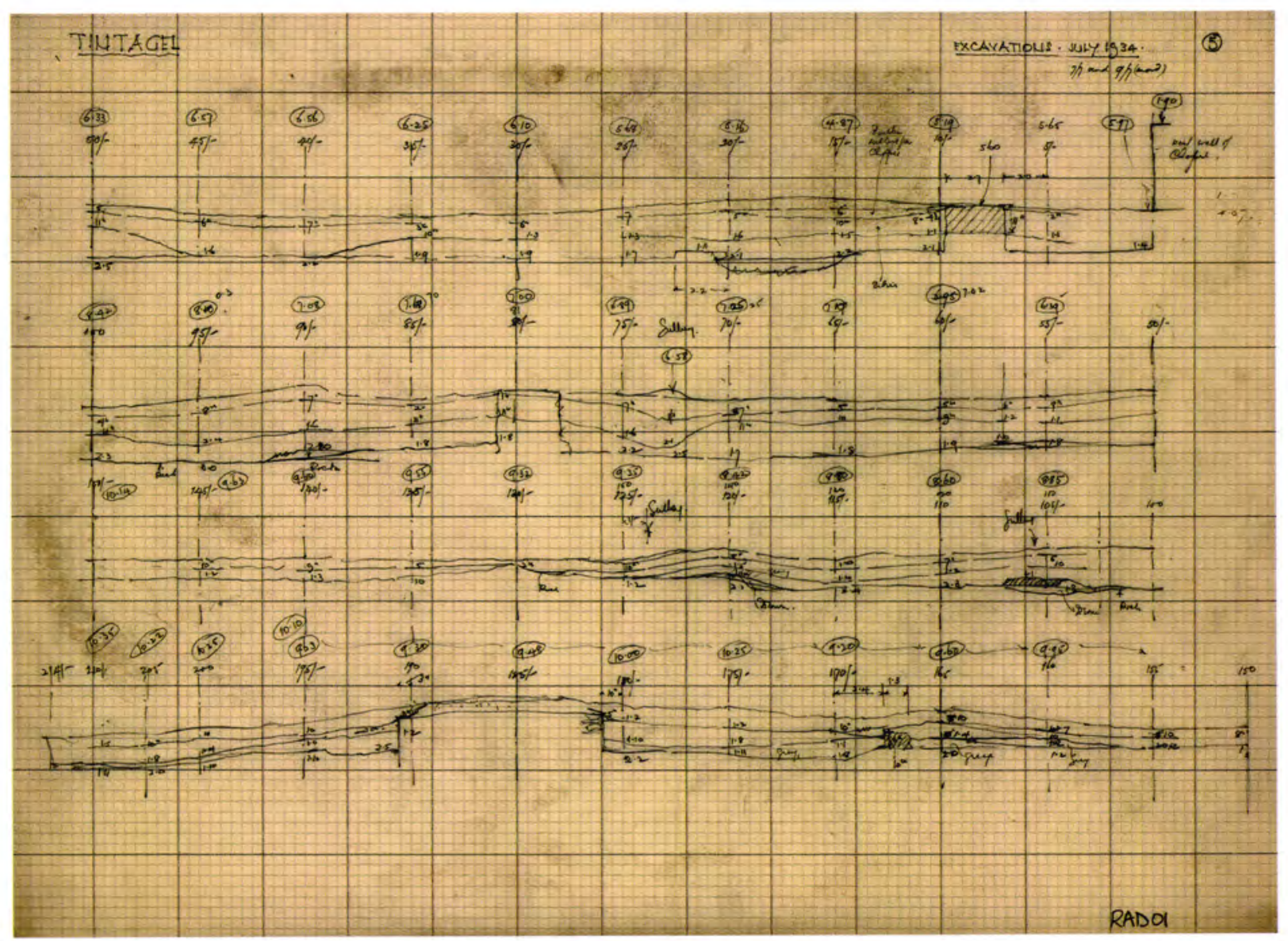

5 Wright's drawing of 'Tintagel. Excavations. July 1934. Sheet 5'. Reproduced by permission of English Heritage (NMR)

positions of a large number of trial trenches scattered around the Island to the north of Site C ('Upper Terrace', see Chapter 3) and between Sites B and C. There are also plans of cuts on the quarry ledge to the north of Site C dated to September 1936 (figure 7). The sectiondrawings are records made on Sites $\mathrm{B}, \mathrm{C}$ and $\mathrm{F}$ and two other trenches, alpha $(\alpha)$ and beta $(\beta)$ located between B and $\mathrm{C}$. The only clue as to the positions of the latter two is contained within a thumbnail sketch on the sectiondrawing for $\beta$.

The stratigraphic information contained within the section-drawings for 1936 is minimal in comparison with previous years, but it is in the trench-location plans that more serious flaws become evident. Prior to 1936, Wright was generally fastidious in his triangulation of structures and trenches, but even in 1934 he displayed a tendency to locate trial trenches in relation to one another. He then fully triangulated a single key trench with a structure in order to reconstruct the positions of the others. This was only attempted in an extremely halfhearted manner for the trenches in and around Sites B and $\mathrm{C}$ as can be seen in Figure 6. Only that trench which was re-excavated as Trench C05 in 1990 and 1991 (see Chapter 4) was fully triangulated with the building on Site $\mathrm{C}$, and all of the others have vital triangulation information missing. This may not have seemed an important point to Wright at the time, as he was, after all, simply recording the positions of supposedly unproductive trenches, but it caused some degree of consternation five and a half decades later!

Sixteen drawings from September 1938 survive: twelve section-drawings, three plans and a sheet containing a plan, a section and an elevation drawing of a rock face, depicting 'beam slots' carved into rock. Although none are numbered, the quality of the 1938 drawings is much improved in comparison to those from 1936, even if they are still largely schematic. The plans depict the rock-cut steps leading down to Site B, a 


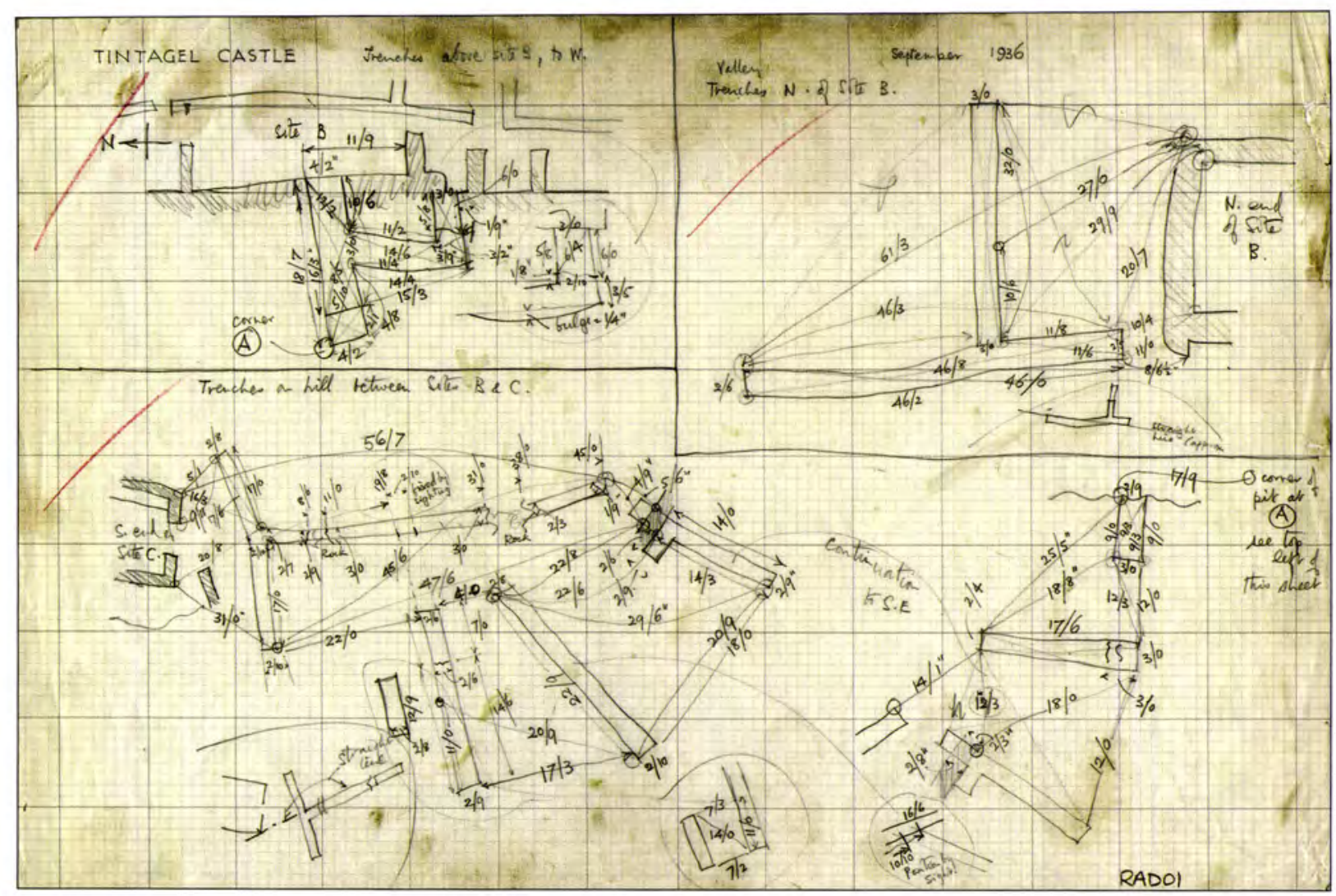

6 Wright's drawing of 'Trenches on hill between Sites B and C, September 1936'. Reproduced by permission of English Heritage (NMR)

plan of several trenches established at Site G and a number of trenches located over the enigmatic Site $\mathrm{H}$. The composite sheet contains a partial plan of one of the structures of Site B, a sketch section of that structure and the rock-face elevation. The section-drawings are concerned with various structures and the stratigraphy of parts of Sites A, C, D, F, G and H. There is also a section-drawing of the 'Tunnel', depicting collapse deposits within it. Three section-drawings from the mainland side of the site are also provided, a section of the 'Great Ditch', another of the smaller ditch running parallel to the road leading to the entrance of the Lower Ward and a section of the road itself. There are no accompanying location-plans for these three mainland cuts. Of all the 1938 drawings those of Site $\mathrm{H}$ are perhaps the most significant (figure 8). Wright indicates at least six trenches on Site $\mathrm{H}$ and hints at the presence of a seventh, but locates them all in relation to one another only. There are also two sheets containing four sectiondrawings of some of those trenches, which clearly depict walling. These drawings have all been labelled 'cancelled'. The implications are that there was another site examined at Tintagel which Radford knew contained structural evidence but which he did not have the resources to deal with. It is extremely unfortunate that Wright elected to record the position of this site so inadequately.

\section{EVALUATION OF THE WRIGHT ARCHIVE}

The full evaluation of the surviving Wright archive was a time-consuming but very necessary task. Although the record-sheets themselves are generally in good condition, the information they contain was drawn and written in pencil, on which time has taken its toll. Additionally, Wright's annotations and aides-mémoires are often written in a minute, spidery hand, which, even when it is not smudged or faint, is often difficult to decipher. This section of the report is merely a précis of the bulk of the information supplied by Wright, the full account being provided in the Research Archive Report. 


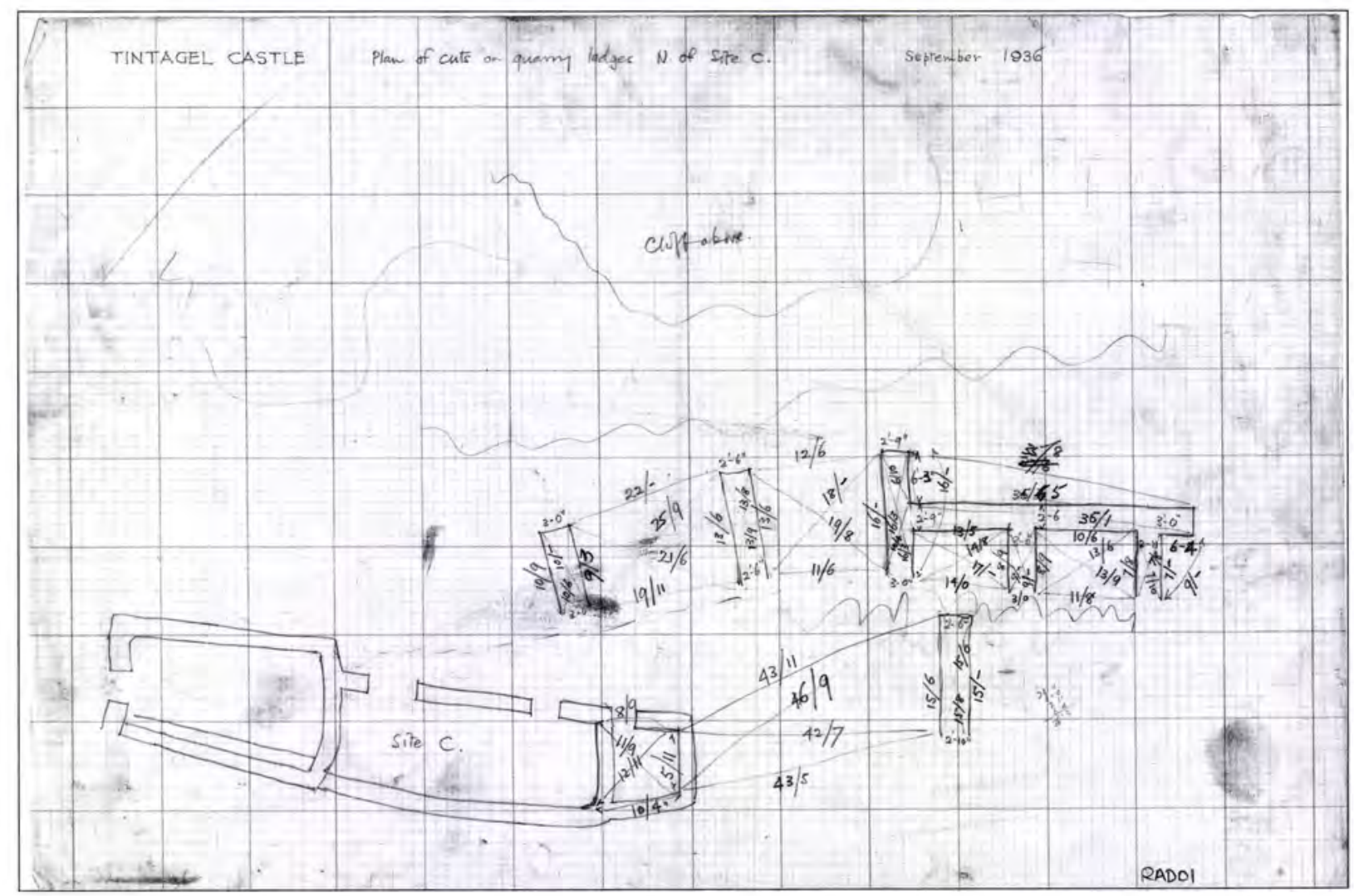

7 Wright's drawing of 'Tintagel Castle. Plan of cuts on quarry ledges N. of Site C. September 1936'. Reproduced by permission of English Heritage (NMR)

One of the leading questions concerning Wright's activities at Tintagel between 1933 and 1938 must be that regarding his role in relation to Radford's excavations. This is most easily answered in connection with the April 1933 visit: the MoW clearly required a record of the extant remains in advance of any intervention by Radford. However, in July 1933 he appears to have been acting as a site planner, recording information as it was dug. This also seems to have happened in 1934, but only during the 6th and 13th of July that year. It must be assumed, therefore, that Wright was required to visit Tintagel after the excavations were well underway that year. Thereafter he appears to have had little to do with the excavations themselves and made visits in September of 1936 and 1938, perhaps after the season was over.

As noted above, the quality of Wright's material varies considerably. His section-drawings are generally executed to scale and usually (but not always) some degree of care was involved in their creation. In contrast, most of his trench-location plans are sketch-plans and not drawn to scale. Some of these have the appearance of a very hurried product, whilst others were constructed with considerable attention to neatness and clarity; presumably they had been re-drawn at some stage. This may indeed be the case, as there are a number of peculiarities that suggest that the Wright archive is not simply a record of what was found and where. There is little doubt that part of Wright's remit was to record his impressions of the archaeological character of the sites he worked on - even though the level of that information might be easily criticized from today's perspective. In addition, Wright was not an archaeologist himself (he was the chief architectural draughtsman for the MoW), yet in spite of this he seems to have been more than familiar with the standard archaeological procedures of the time.

The on-site relationship between Radford and Wright is unclear and it appears that Wright simply interpreted what he saw and recorded that information 


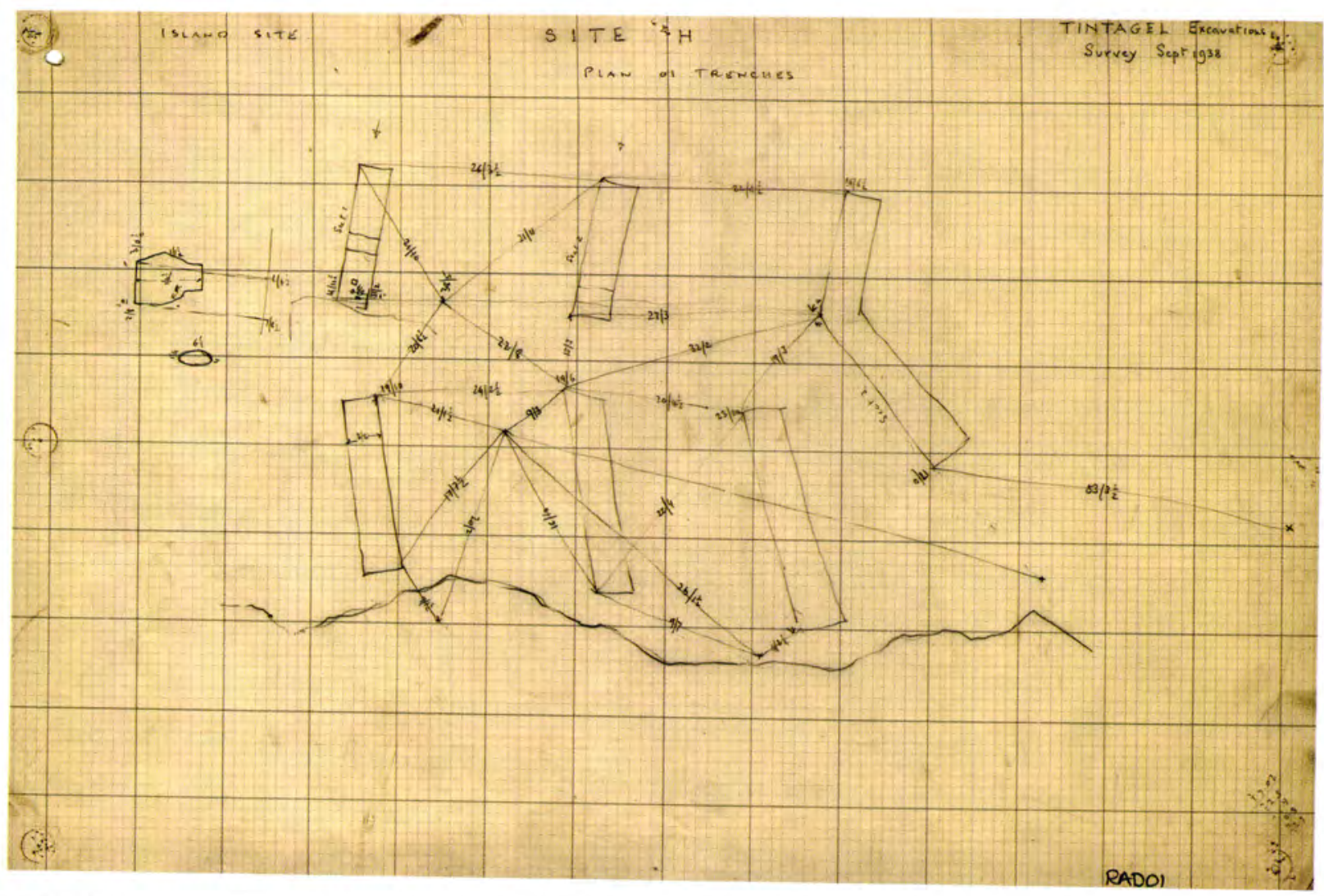

8 Wright's drawing of 'Tintagel. Island Site. Excavations. Survey. September 1938. Site H. Plan of Trenches'. Reproduced by permission of English Heritage (NMR)

using the conventions of the day. How much of that interpretation resulted from discussion with Radford is unknown, and indeed it is quite possible that they did not even coincide on site. However, Wright clearly took pains to distinguish between construction and destruction debris, for example, and he also noted where walls were bonded with clay, rather than mortar. Whatever the intended purpose of Wright's drawings, their real value lies in their record of the archaeological strata depicted in his section-drawings. His plans are of varying use; certainly his trench-location plans often leave much to be desired, but where he was required to record structures he was more thorough.

Some of Wright's structural plans are extremely interesting from a twenty-first-century perspective - if they truly can be assumed to be an accurate record of the archaeology - since they indicate clear discrepancies between what Wright saw, and what can be seen as consolidated remains on the ground today. For example, Sheet 6 (produced in 1934, entitled 'Buildings South of Chapel') depicts some of the structures associated with
Radford's Site A (figure 9). This is essentially a continuation of Wright's recording of the complex that he began in July 1933 (Sheet 2). Not only are there are a number of distinct discrepancies between the 1933 record and that from 1934, but also between it, Radford's published plan (figure 10) and the structures as seen on the Island today. The discrepancies between the 1933 and 1934 plan might arguably result from a misinterpretation of the partially excavated remains by Wright in 1933, but at least one 'inconvenient' wall had been dramatically remodelled between the years. More important are the discrepancies between Wright's record, Radford's plan and the consolidated remains of Site A. There appears to have been a judicious re-siting or removal of door apertures in the published plan, and the insertion of at least two additional walls in a gap between buildings where no walls appear according to Wright. One target for this treatment is Room 8, which according to Wright had a doorway facing north, which does not appear on Radford's plan. Instead, a doorway leading to Room 10, which according to Wright is not a 


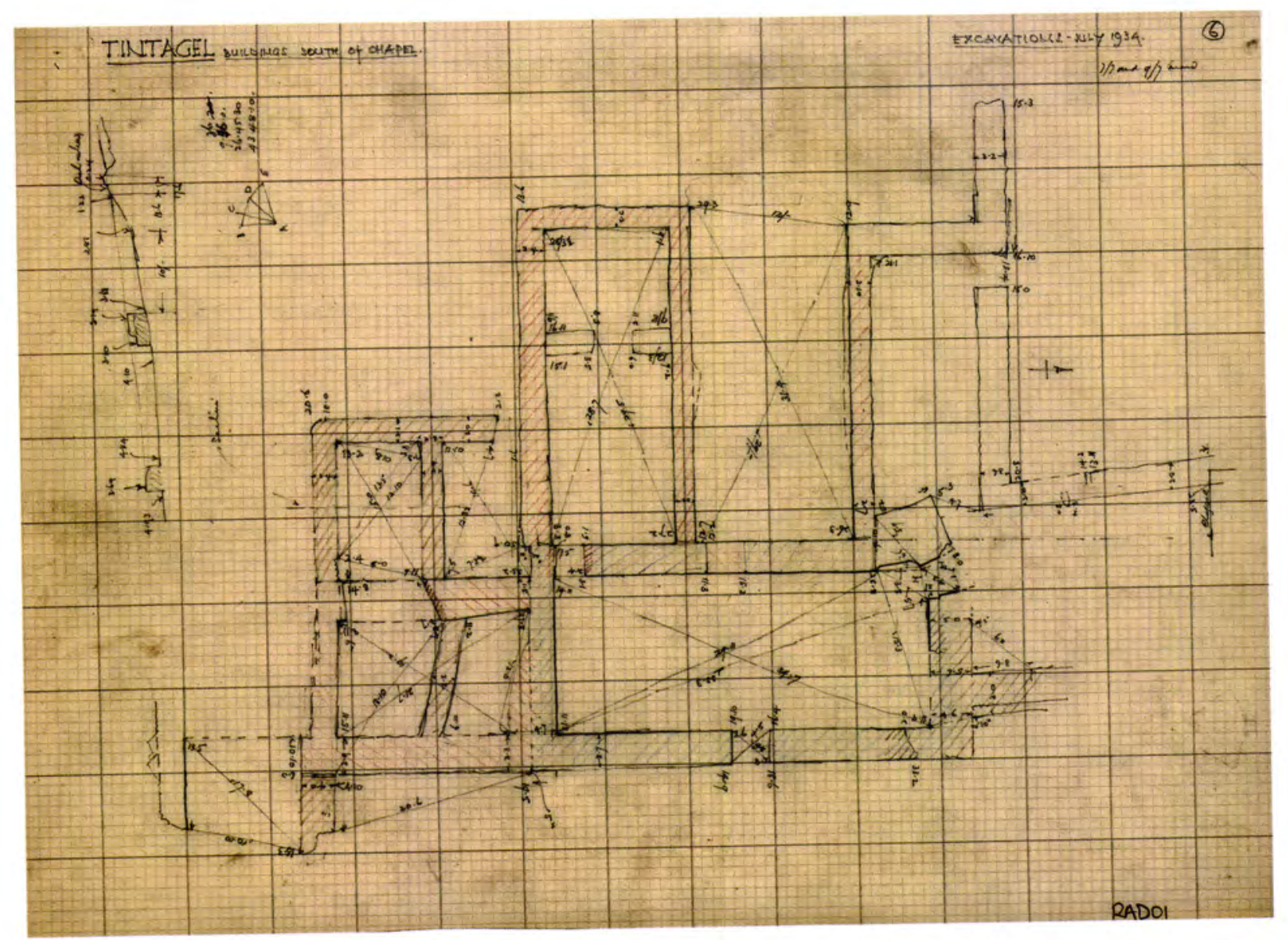

9 Wright's drawing of 'Tintagel. Buildings south of chapel. Excavations. July 1934. Sheet 6'. Reproduced by permission of English Heritage (NMR)

room at all but a gap between Rooms 8 and $11 \mathrm{a} / \mathrm{b}$, perforates the south wall of Room 8. In Radford's plan, two stub walls bridge this gap (period 4), thus creating another room (Room 10), with an entrance aperture facing east. Another example of this kind of tampering is seen in a series of three door apertures at the eastern extremities of Rooms 13a and 13b and the outside of the building complex. Radford's plan depicts three doorways here, none of which appear on Wright's plan; he simply records solid walls at this point. It would seem that there has been a significant level of imaginative interpretation of Wright's record at some stage in the past, which has become fossilized due to the equally imaginative reconsolidation of the structures of the site.

There are indications within the archive that some of Wright's drawings were intended for several purposes. One of those purposes was undoubtedly publication and several of his drawings are annotated with small notes to himself (or some third party) regarding modifications required to certain aspects of what must have been, in these instances, field drawings at the drafting stage. He was also acutely aware of the archival value of his product; all of his plans have numerous triangulation measurements transcribed onto them, the current relevance of which will be discussed below. Perhaps most importantly his drawings must have formed the basis of instruction to other parties involved with the consolidation, preservation and presentation of the buildings uncovered by the excavations. In certain cases, this may have been the prime concern, for example, the mysterious Site H recorded by Wright in 1938 (see figure $8)$. The trench-location plans are inadequate, simply being located in relation to one another but otherwise 'floating' in a wider context. His section-drawings of the trenches are scored out and labelled 'Cancelled', even though they clearly demonstrate the presence of 
10 Radford's published plan of Site A from the 1939 guidebook (Radford 1939)

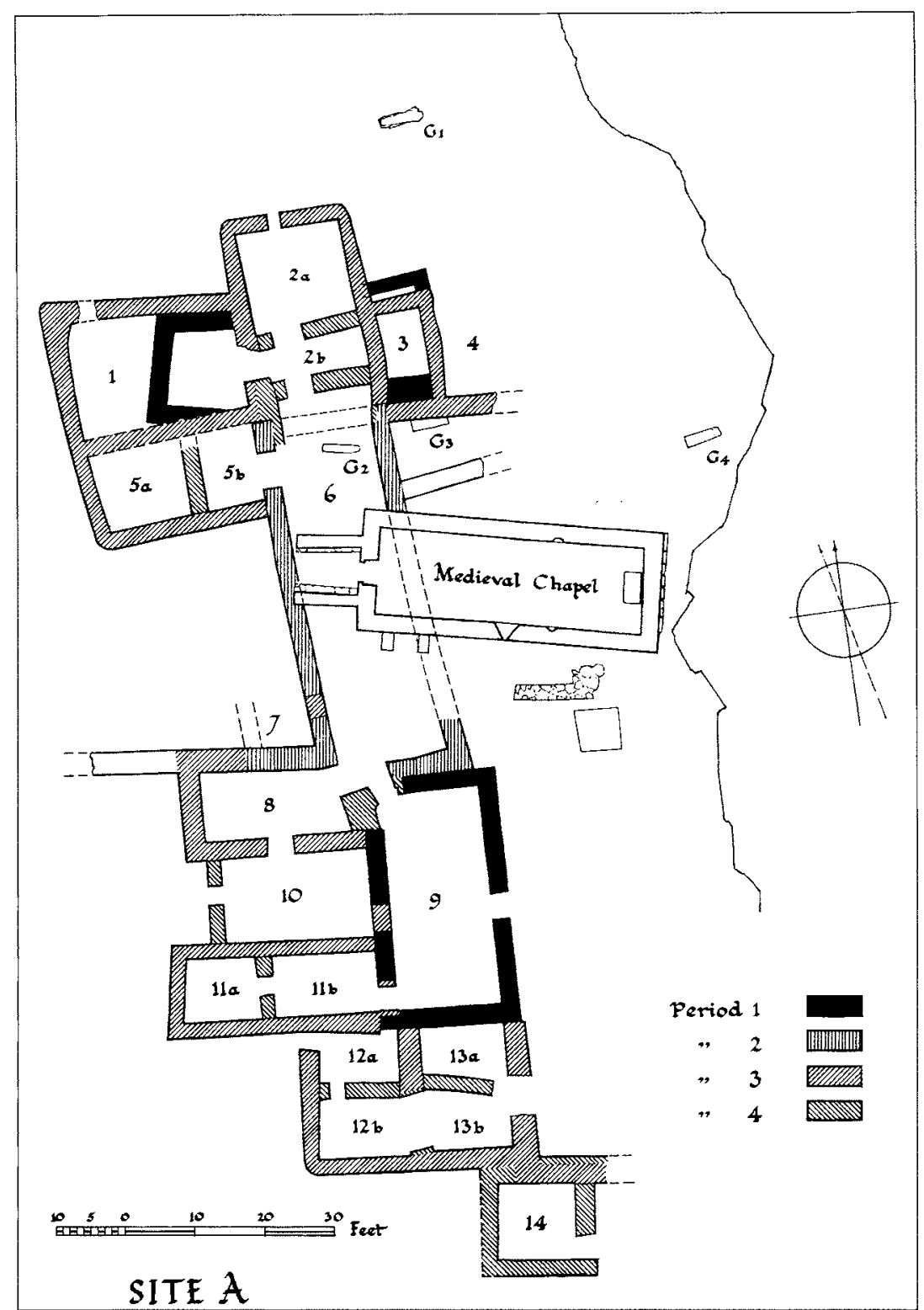

archaeological remains. Why anyone would wish to cancel a drawing that was primarily intended for archive or publication purposes is unclear. The predominant reasons for Wright's work at Tintagel might, therefore, have been one of instruction: to create architect's drawings that would guide future consolidation work. This is confirmed by Radford's view that he was working to enable the coherent layout of the buildings on the site and 'to make the site intelligible.'25 The world events of 1939 would seem to have curtailed any plans for such an activity for the then foreseeable future, and in those circumstances the accurate location of Site $\mathrm{H}$ was not documented.

The possibility of Wright's record being created for the purposes of consolidation rather than archaeological record lends a worrying degree of ambiguity to some of the notes and annotations contained within his drawings. For example, section-drawings across the building situated on Site $\mathrm{C}$ bear the legend 'Make up to floor level (Soil and Debris)' (figure 11) which could arguably represent an instruction rather than an archaeological observation. If Wright's representation of 
Site $\mathrm{C}$ were taken as being primarily an archaeological record, it would mean that the building on Site $C$, a terrace site, was not inundated by overburden before excavation, since Wright's drawings only indicate a few centimetres of material above bedrock.

\section{THE RADFORD ARCHIVE}

\section{GENERAL OVERVIEW}

The new part of the archive which came to light upon Dr Ralegh Radford's death in 1998 became available immediately prior to the completion of excavations on site in 1999, and therefore at a very late stage in the project. An opportunity was afforded for an initial examination of the contents in order to seek any specific information relevant to the publication of Site $C$. During this examination it became clear that the new material had some potential for the understanding of Radford's work at Tintagel.
The initial catalogue by the NMR identified in excess of one hundred items of material, of various forms, which related directly to Radford's work at Tintagel, and this preliminary listing was made available to the authors. The material was initially subdivided into two boxes: TINBOX 39 contained ceramics which were initially identified as being from the Great Ditch excavation of 1955 (table 2), although this was subsequently revised (see below). TINBOX 46 incorporated approximately sixty packages and documents including drafts of publications, excavation photographs, site notebooks and correspondence dated between 1933 and 1982. Two other groups, labelled TINPUB 2, Bundle 25 and TINPUB 12, Bundle 32 comprised rolls of plans and publication drawings of site and finds, in several cases duplicates of Wright's plans. Finally, TINSITE 8, Bundle 44 included two rolls of plans, mainly dyelines, and once again duplicates some of the Wright material. The more significant items

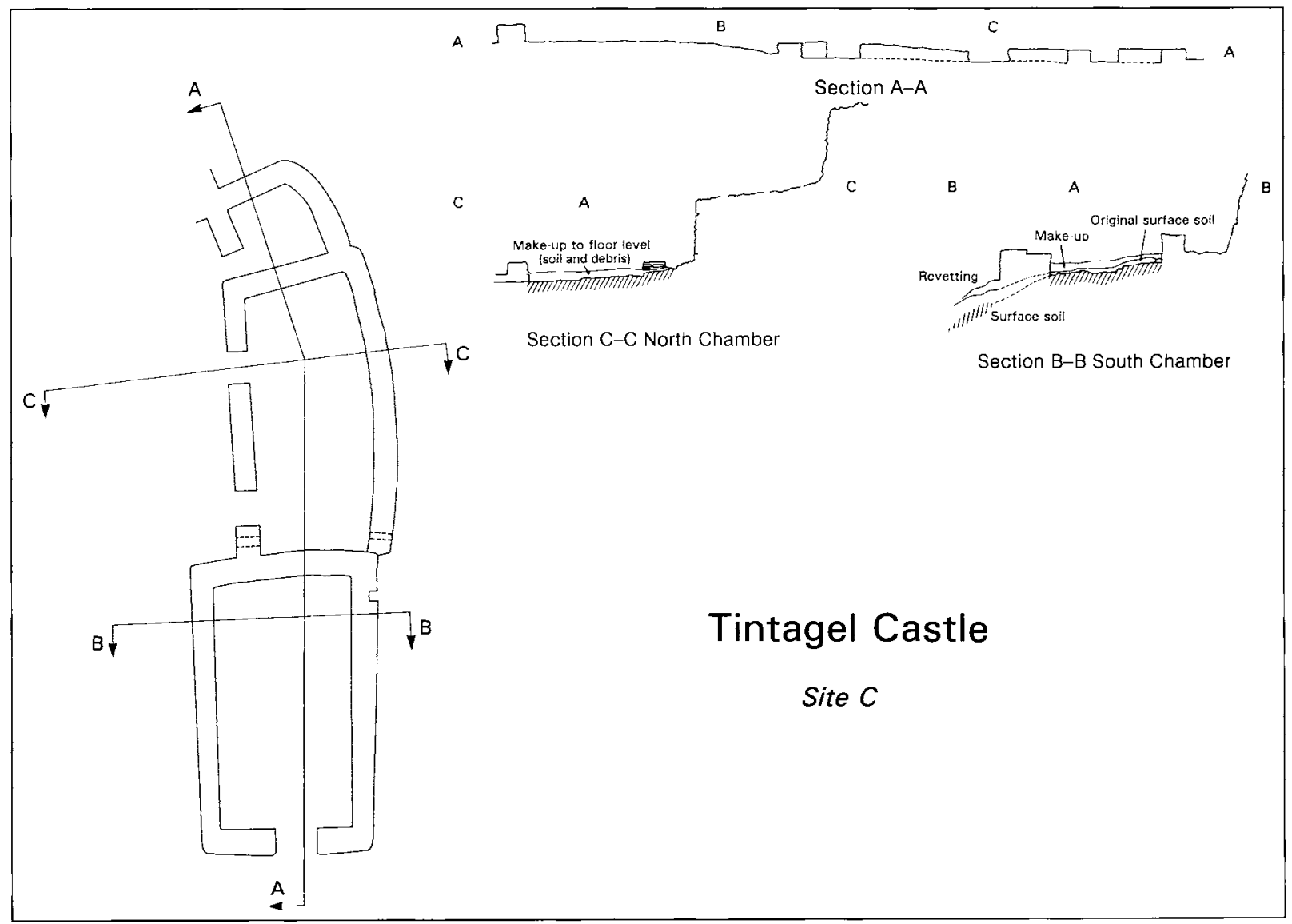

11 Wright's drawing of Tintagel Castle. Site C. 1938. Reproduced by permission of English Heritage (NMR). Redrawn: L McEwan 
Table 2 Ceramics from the Radford archive

\begin{tabular}{|c|c|}
\hline Description from label & No. of sherds and type \\
\hline 'Tintagel 1955 Section $I / 5^{\prime} 6^{\prime \prime} / 4^{\prime} 11^{\prime \prime}$ down in early bank' & Three conjoining sherds Bii \\
\hline 'Tintagel 1955 Section I/ 6'-8'/2" down in bank' & One small sherd Bii; one crumb indeterminate \\
\hline 'Tintagel 1955 Section I/ 6'-10'/ 3" down in bank' & $\begin{array}{l}\text { One small sherd Bii; three conjoining sherds of } \\
\text { worn PRSW }\end{array}$ \\
\hline 'Tintagel 1955 Section I/ 6'-10'/4'6" down in early bank' & Six sherds Bv \\
\hline 'Tintagel 1955 Section $\mathrm{I} / 10^{\prime}-12^{\prime} / 4^{\prime \prime}$ down in bank' & One sherd Bii \\
\hline 'Tintagel 1955 Section I/ $26^{\prime}-30^{\prime} / 3^{\prime} 9$ " down on old turf line' & One worn $\mathrm{Bii}$ sherd with corrugation; one large sherd $\mathrm{Bi}$ \\
\hline 'Tintagel 1955 Section I/ surface and dump' & $\begin{array}{l}\text { Two sherds Bi with grooving; four sherds conjoining } \\
\text { Bii with possible traces of faded dipinti }\end{array}$ \\
\hline 'Tintagel 1955 Section II/ $2^{\prime}-5^{\prime} / 1^{\prime} 6$ " down in bank' & One small sherd Biv; one handle sherd Biv \\
\hline
\end{tabular}

are considered below and information integrated as appropriate elsewhere in this monograph.

Rachel Barrowman made the initial inspection of the material in Swindon and made a more detailed listing for the purposes of the Tintagel excavation project. This has been expanded, through further research by Colleen Batey following the award of a grant from the Headley Trust via the Society of Antiquaries, for inclusion here. It was immediately clear that although there is a mass of material, it is largely undifferentiated and relatively little comprises primary archive material relating to any of the areas examined by Radford. The Radford archive evidence for each area is outlined below (also see table 1 above), but it is clear from this research that the new material sheds little light on areas other than Sites $C$ and T. In each case the summaries below indicate just how limited these new resources are.

\section{SITE A MATERIAL}

A very small quantity of material survives in the archive. There are a number of plans, commonly dyelines including publication plans of the excavations in 1934-5 (TINPUB 2, Bundle 25, Roll 1/3), the section through the Chapel (TINPUB 12, Bundle 32, Roll 4/40) and a copy of the published version of Site A (TINBOX 46, 2). A dyeline copy of a section-drawing which does not appear in the Wright archive is clearly his work (TINPUB 2, Bundle 25, Roll 2/7). A site plan drawn in 1935 by Wright shows Site $A$, the Chapel and the Garden (TINBOX 46, 10c) and a plan of the Chapel with the specific periods distinguished (TINBOX 46, 10d). There are two dyelines of pencil drawings of sections through the Chapel, marked 1933 and 1934 respectively (TINBOX 46, 10a and b) and photos which include Site $A$ in the distance and in the case of one example, a photograph with the caption 'Tintagel Celtic Monastery Room 7 in foreground' (TINBOX 46, 58bb). A selection of handwritten notes with some sheets dated 1933 are part of the preparation for publication and the phasing has been integrated (TINBOX 46, 45). These were clearly mostly prepared for the interim reports published in 1935.26

Thomas is not inclined to give credence to the alleged find spot of a silver penny of the reign of Alfred (871-99) picked up near the Chapel of Site $\mathrm{A}^{27}$ from the 'chambers south of chapel' (TINBOX 46, $16 \mathrm{jj}$ ). However, there are a number of letters in the Radford archive connected with this find. A letter from Gerald Dunning of the Ministry of Works, dated August 1946, concerns the reference on the envelope in which the coin was allegedly placed after discovery. The caption 'Tintagel 4/1/35 64a' indicates a find made outwith the excavations, probably by a visitor to the site, but the find number 64a does seem to fit within the Finds Lists supplied by Radford, whereby Finds 1-14 and then 79-85 (of the 1938 season) have their origins in the 1930 s campaigns. Find number 64 would suggest a pre-1938 discovery, and 4/1/35 indicates 1935 . The coin is of a two-line type (BMC xiv), moneyer Beornmær, issued $c 880-99$, but its circulation outwith Wessex may suggest a deposition $c 880-910 .{ }^{28}$ This does not assist in identifying the find spot but does extend the chronology of the pre-Castle occupation phase at Tintagel beyond the immediately post-Roman period. 
SITE B MATERIAL

This evidence is dominated by a series of dyeline plans and sections, such as TINPUB 2, Bundle 25, Rolls 1/1 and $3 / 17$, dated 1936 , in addition to Roll $1 / 2$ at a slightly larger scale with the structures drawn in outline. A trench near the north of Site B, dated 1936, indicates basic stratigraphy (TINPUB 2, Bundle 25, 3/20). TINSITE 8 , Bundle $44,2 / 30$ is predominantly of Site F but includes Site $B$ and the position of sections drawn. TINPUB 12, Bundle 32, 4/42 indicates sections of both Sites $B$ and $F$ and $4 / 43$ is a plan of the south end of Site B drawn by Wright in 1938. Limited photographic information survives, such as TINBOX $46,58 \mathrm{hh}$, which includes two unlabelled photographs which might be of Site B, but $58 \mathrm{jj}$ can be confirmed as including photographs of walling in Site B which is very similar in form and style to that of the Lower Terrace of Site C. A list of plans and sections by site includes a plan and section of Site $\mathrm{B}$ to be drawn by Harvey (undated) (TINBOX 46, 16 oo). In the black site notebook (TINBOX 46/55) five pages dated 1937 include reference to Site B with a list of jobs and an indeterminate sketch with very little further information.

\section{SiTE C MATERIAL}

A limited amount of data regarding the examination of Site C during Radford's work there is to be found in this archive. TINBOX 46, 58 contains a letter from Radford to Bushe-Fox of 23 July 1935 in which he states 'Nothing done since last summer' in reference to Site C. However, he notes that he did not see the foreman on site, although presumably he expected to do so as it would seem that some unsupervised activity was being undertaken by the workmen. TINBOX 46, 55 is an A5 black notebook with notes from 1935, 1936, 1937, 1938 and 1955. Site C is not referred to in 1935 , but it is clear that this site was examined in 1936 and in 1938, and that Radford was intending to prepare Site $\mathrm{C}$ for publication in 1938.

The first page of Radford's 1936 notes states that 'Site $\mathrm{C}$ was investigated by means of trial trenches which were not carried out below the ground level of the cells', and a sketch on the second page numbers the 'cells' as 1,2 and 3 from the north. A neat sketch on the third page indicates that Radford regarded Room 3 (now shown with a 'bench' on the east side) as being of a different (and implicitly later) phase from the other two rooms; its entrance is shown to the south. Across the southern end of Room 2 a 'drain' is shown running under the north-south walls, and a doorway in the west. The drawing seems to indicate that the wall dividing Room 2 and 3 has a butt-joint (Radford calls it 'bar?') with the eastern long wall of these two rooms. A pencil list of plans and sections is to be found in TINBOX 46, 16 oo, and this indicates that at that stage one plan and three sections existed of Site C. These survive as TINPUB 2, Bundle 25, Roll 2/8 (no scale or date given). The plan (see figure 11) shows the Site $\mathrm{C}$ building as it is today, with a drain through the south of the walls in Room 2 and a niche in the north-east corner (outer face) of Room 3. The plan also shows the location of the sections: Section A through the middle of the building from the southern doorway of Room 3 and then on a different alignment through Room 2 and out beyond Room 1 to the north; Section $B$ across the northern half of Room 3; Section $\mathrm{C}$ through the northern half of Room 2, from the northern doorway.

The fifth page of the 1936 entry has a sketch of ten trenches opened to the south of Site C. It is clear that two of these were opened at right angles to each other immediately to the south of the buildings of Site $C$ (Trenches A and B), and these have been re-examined in the current excavations. Two further trenches ( $C$ and $D$ ), also at right angles to each other, were placed in the area to the north of Site B and south east of Site C. As the sketch shows a 'Dipping Hole' that is still visible as an apparent spring or well towards the southern end of the approach to the 'Lower Terrace', it is evident that these trenches lie across the contours of the slope through which a path now leads up to Site C from Site B. Six further trenches are shown at the southern end of what is described in our excavations as the 'Upper Terrace', three (Trenches G, E and F, from south to north) to the north west of a 'Rock' above Site B, and three (Trenches $\mathrm{H}, \mathrm{I}$ and $\mathrm{K}$ ) further to the north and apparently above the trenches to the south of the Site $\mathrm{C}$ buildings. Trenches E and F were identified in 1994 as part of Trench $\mathrm{C} 18$ (see Chapter 3), and the excavation of Trenches C06, C07 and C19 in 1994 have probably identified Radford's Trenches H, I and K, but in a different position to that annotated on Radford's sketch. There is a pencil (dyeline) drawing of Sites $\mathrm{B}$ and $\mathrm{C}$ on TINPUB 2, Bundle 25/Roll 1/ Drawing 1 (figure 12). This shows Site $C$ as it is now, with trenches above on the Upper Terrace, together with the two (A and B) to the south of Site C. A further plan (TINPUB 2 Bundle 25/Roll 2/Drawing 6, duplicated in TINPUB 8, Bundle 44/Roll 2/Drawing 31) shows both Sites $\mathrm{H}$ and $\mathrm{C}$ on the 
same drawing, but there is no date or scale on it and it adds no new information.

Some photographs of Site $\mathrm{C}$ exist in the archive. One from 1936 (TINBOX 46/58/jj) appears to be of the trench between Sites B and C (Trench B), but little is visible. A further undated photograph in TINBOX $46 / 31 /$ b shows a bank/wall or edge of strip-trench beyond (ie to the south of) Room 3 (re-excavated as C10: see Chapter 6), and there are a further eight photographs in TINBOX 46/58/ $\mathrm{w}$ and $\mathrm{x}$, some of the inside of the rooms of Site $\mathrm{C}$, and one or two outside, plus one possibly of the Upper Terrace. Those that are dated in this group are dated 1938. Two are reproduced here as representative examples (figures 13 and 14). Of particular interest is the fact that Figure 13 shows the existence of a spoil-heap in the corner of C09. As mentioned in Chapter 5, this may well have been a factor in the survival of the deposits beneath the spoil-heap prior to excavation in 1998.

\section{SITE D MATERIAL}

This small amount of material includes dyelines of Site D sections that are not dated (for example TINPUB 2,
Bundle 25, Rolls 2/9 and 2/10), and a plan showing the positions of sections marked in pencil, on which Rooms 1-7 are labelled (TINSITE 8, Bundle 44, Roll 2/28). A single illustration in ink is a publication plan (TINPUB 12, Bundle 32, Roll 3/39). Reference to a large-scale plan of the site in a letter from Wright (TINBOX 46, 10c) and a single photograph of the site dated 1935 (TINBOX 46, $58 \mathrm{nn}$ ) complement the eleven pages of notes and sketches in Radford's black site notebook under 1935 (TINBOX 46, 55). These supply very little additional information to the published record although it is clear that in 1935 work at Site D was only clearance.

\section{Site E MATERIAL: THE GARDEN}

A dyeline of an ink publication plan showing the Garden with Site E marked in blue pencil is dated 1935 (TINPUB 12, Bundle 32, 1/32), and an illustration depicting the Plan and Sections of the Garden, dated March 1935 also for publication, are in TINBOX 46, 8. These may have been among those sent by Wright to Radford in August 1935, showing Site A, the Chapel and the Garden (letter TINBOX 46, 10c). Photographic evidence in the form of a 'Medieval garden with paths

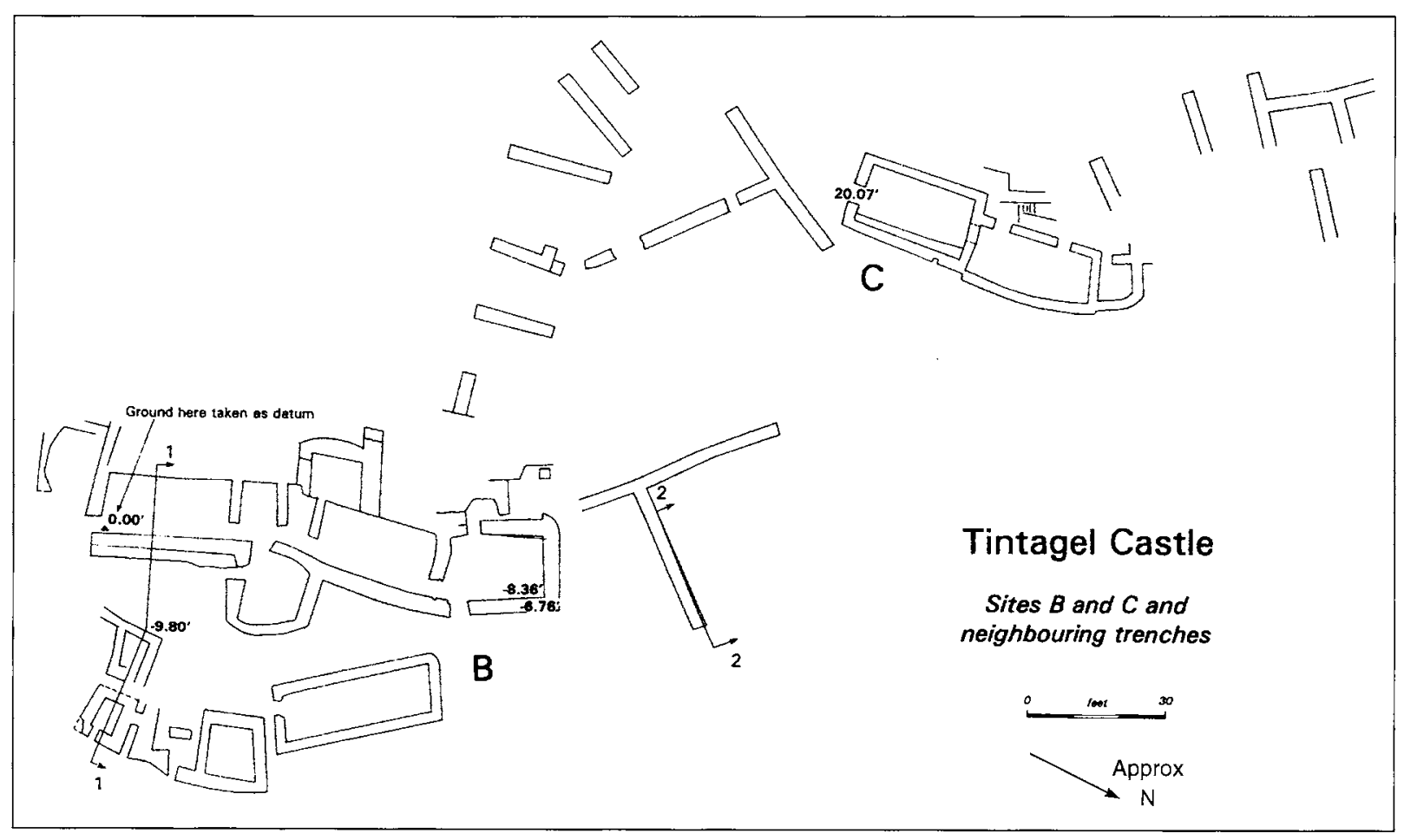

12 Sites $B$ and $C$ and neighbouring trenches. Publication drawing from Radford archive. Drawing: $L M c E w a n$ after MoW 


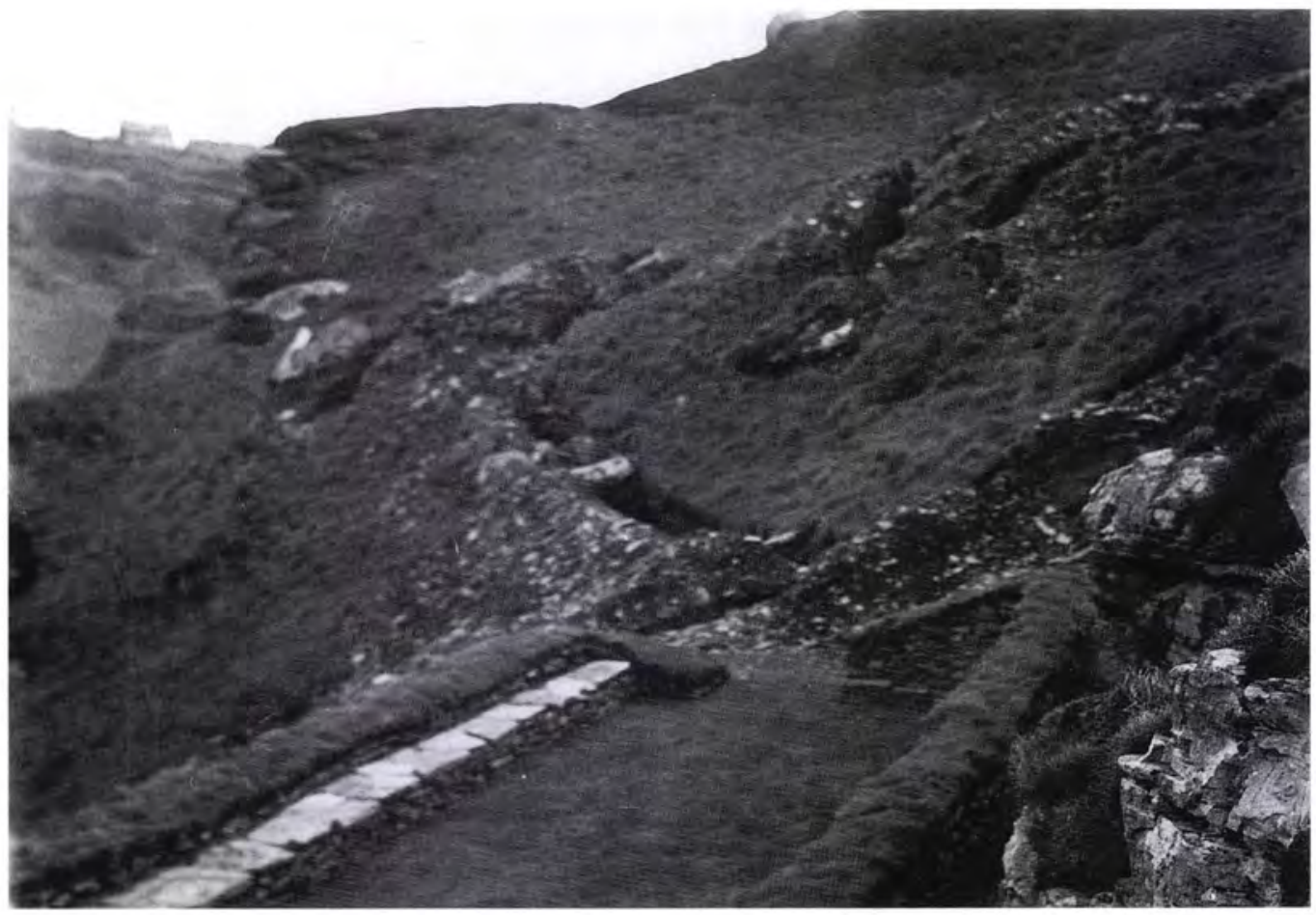

13 '1938 Tintagel

Castle', archive

photograph.

Photograph:

$C$ A R Radford.

Reproduced by

permission of

English Heritage

(NMR)

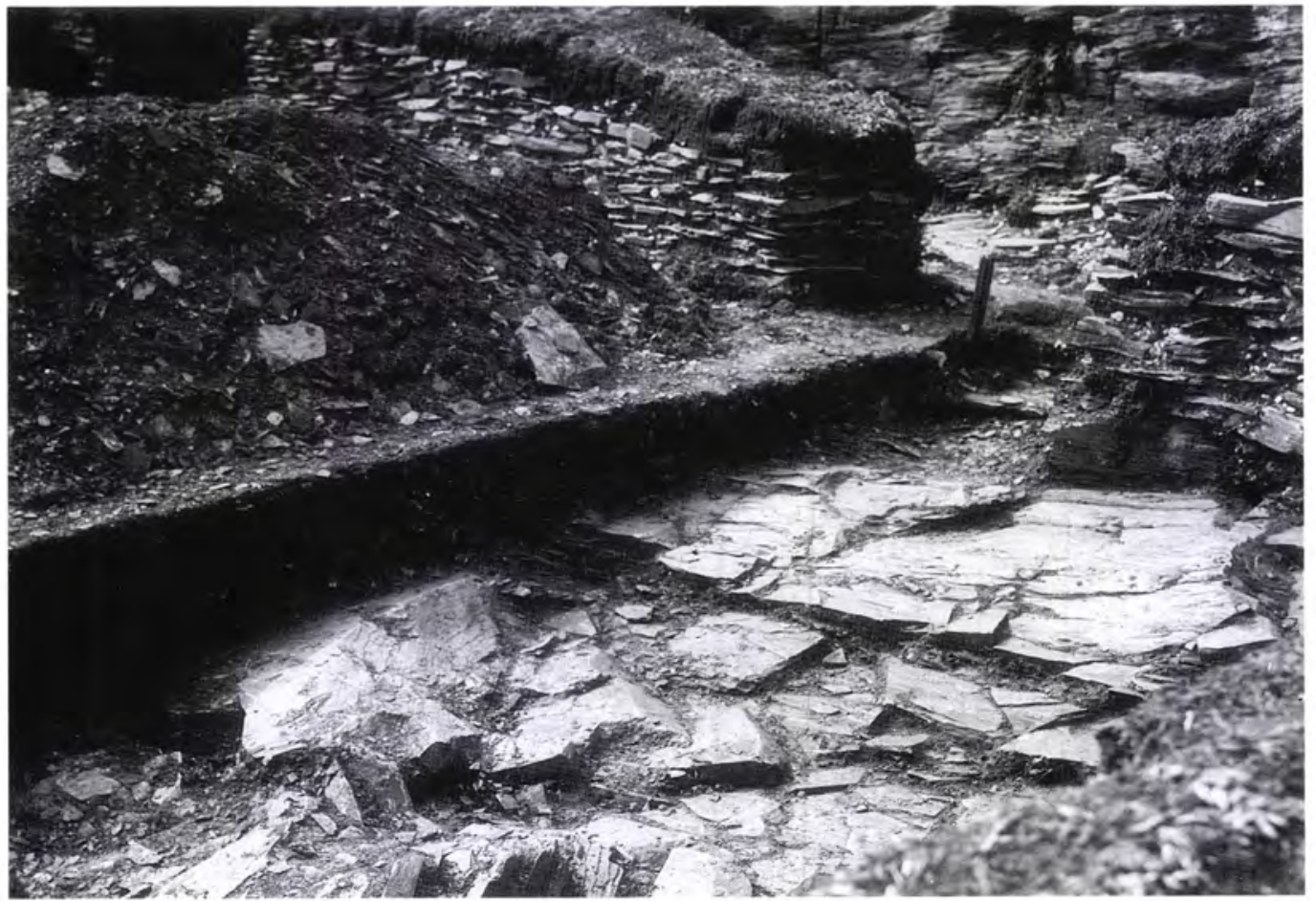

14 '1938 Tintagel

Castle, Site C,

Room 2, north

end', archive

photograph.

Photograph:

C A R Radford.

Reproduced by

permission of

English Heritage

(NMR) 
restored in foreground' is noted (TINBOX 46, 16f) and also in more general shots (TINBOX 46, 51 and 52). A photograph (TINBOX 46, 58i) dated 19 January 1935 shows the interior of the Garden with reconstructed beds. The evidence from the archive indicates that the drawing of the plan and sections dated March 1935 are most likely to reflect a recording of trenches left open at the end of the digging season in 1934, when it is known that Radford excavated Site E.

\section{SiTE F MATERIAL}

A series of plans and sections, predominantly dyeline copies of pencil originals, form the bulk of the Radford archive for this site (eg TINPUB 2, Bundle 25, Rolls $1 / 4$, $2 / 15,2 / 16$ and $3 / 17$ ). The main purpose of these is to indicate the location of sections drawn. Many appear to be undated, but one from TINPUB 12, Bundle 32, Roll 4/41, is dated 1936. This shows the positions of work on sections in this area. Also from 1936, two photographs of Site F show considerable overburden of scree and were taken in December 1936, following excavation but obviously pre-backfilling (TINBOX 46, 58ii). From the 1938 season, photographs of the heating channel survive with a letter from Gerhard Bersu dated
22 September 1938 (TINBOX 46, 5800). Among a mixed group of photographs dated 1938 are four from this area which show: 'general views from the South West', 'Room 3 West wall', 'Room 2 North East angle from the East' and 'Room 2 North West angle' (TINBOX 46, 61). Perhaps of greater interest is a letter sent by Radford to Peter Fowler, dated 21 November 1985, where he refers to a structure underlying the modern hut on the site (between Site F and the Castle Wall; TINBOX 46, 12). This is coincidentally very close to the material recovered in the region of the newly cut Steps and reported on elsewhere. ${ }^{29}$

In Radford's notebook he makes reference to working on Site F in 1936, but with no detail, and again in September 1938, when he worked with ten men on site. He notes of Site $\mathrm{F}$ that it lay on an artificial terrace which had been quarried and levelled and which ran north-south. He notes the structural distinction between periods 1 to 4 with evidence of some rebuilding and includes a sketch plan of the 'drain filled with silt with charcoal and burnt slate' (TINBOX 46,55 ). It is clear that this has very close similarities with the evidence recovered from the Site C area (see Chapter 6). Of a set of undated photographs labelled 'Site F
15 Wright's drawing showing position of 1938 trenches. Reproduced by permission of English Heritage (NMR)

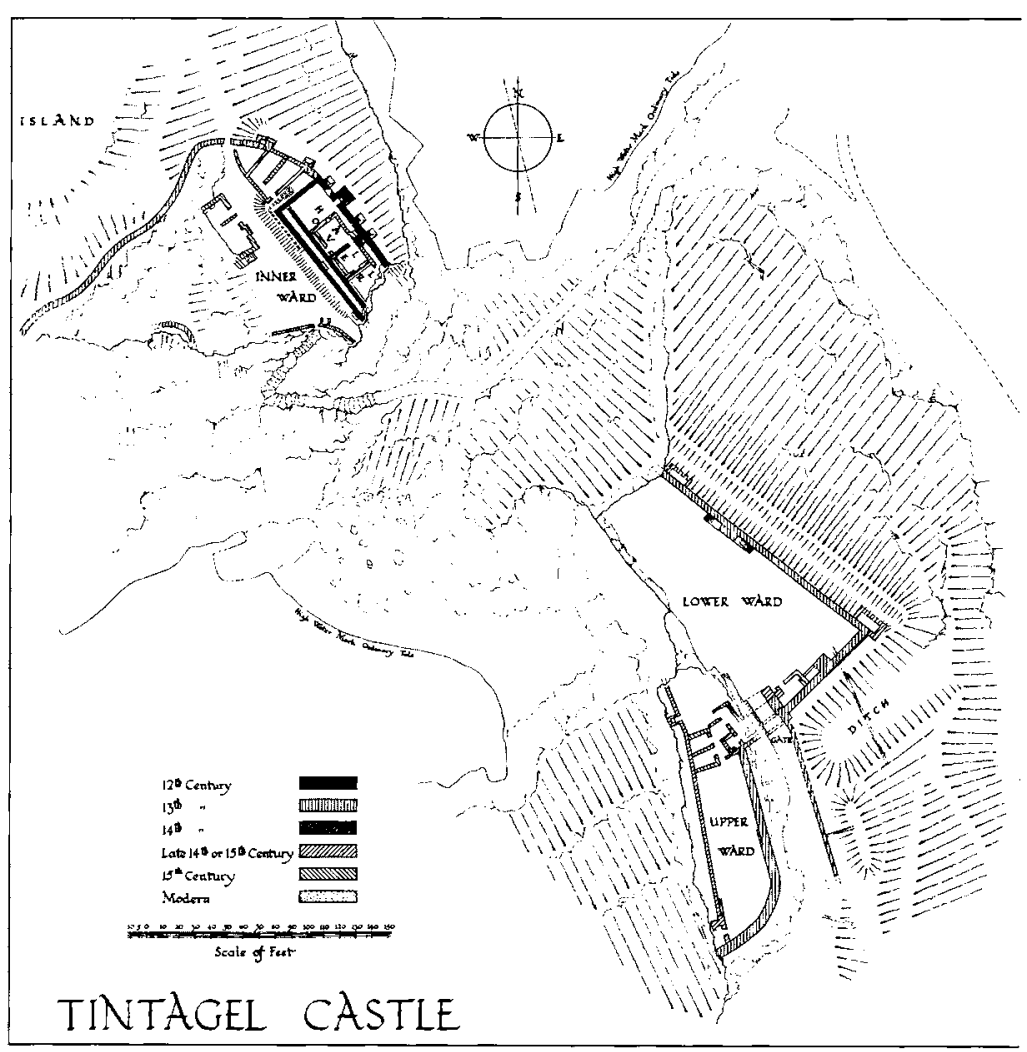




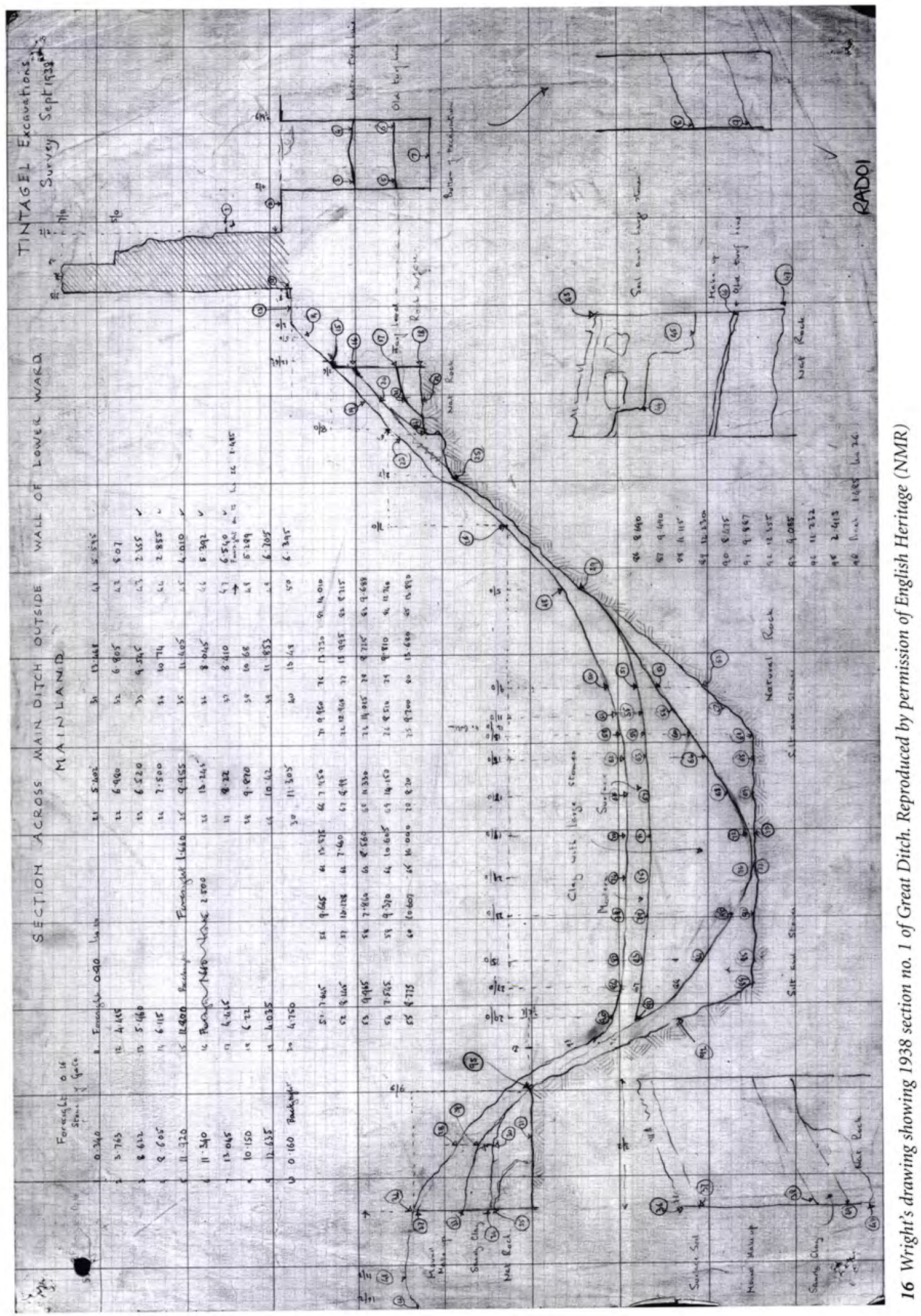




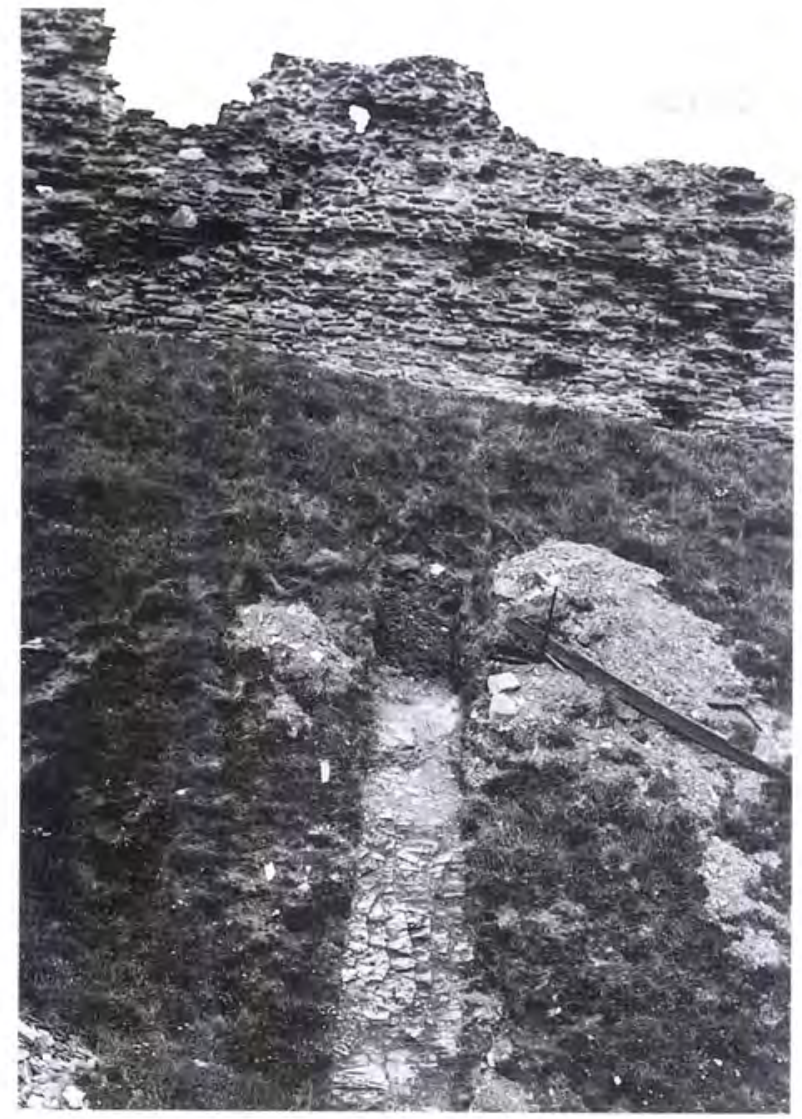

17 Photograph of Radford's cutting across the Great Ditch 1938 from the south. Reproduced by permission of English Heritage (NMR)

scriptorium Upper Room, one shows a doorway with threshold covering a heating channel, one the heating channel passing through the doorway under the floor and another the heating channel beneath the floor, separating into two channels (TINBOX 46, 16g).

\section{SITE G MATERIAL}

Dyeline plans such as TINPUB 2, Bundle 25, Roll 2/5 show an undated plan and section. Reference to needing a plan to be made of the site and supplied to MoW (presumably to aid consolidation) is to be found in list TINBOX 46, 160o. Although this is undated, Site G appears only to have been excavated in 1938 and references to section-drawing and plans of sites F, B/F and $B$ in the same entry seem to support this.

\section{Site H MATERIAL}

The only material from the Radford archive for this area

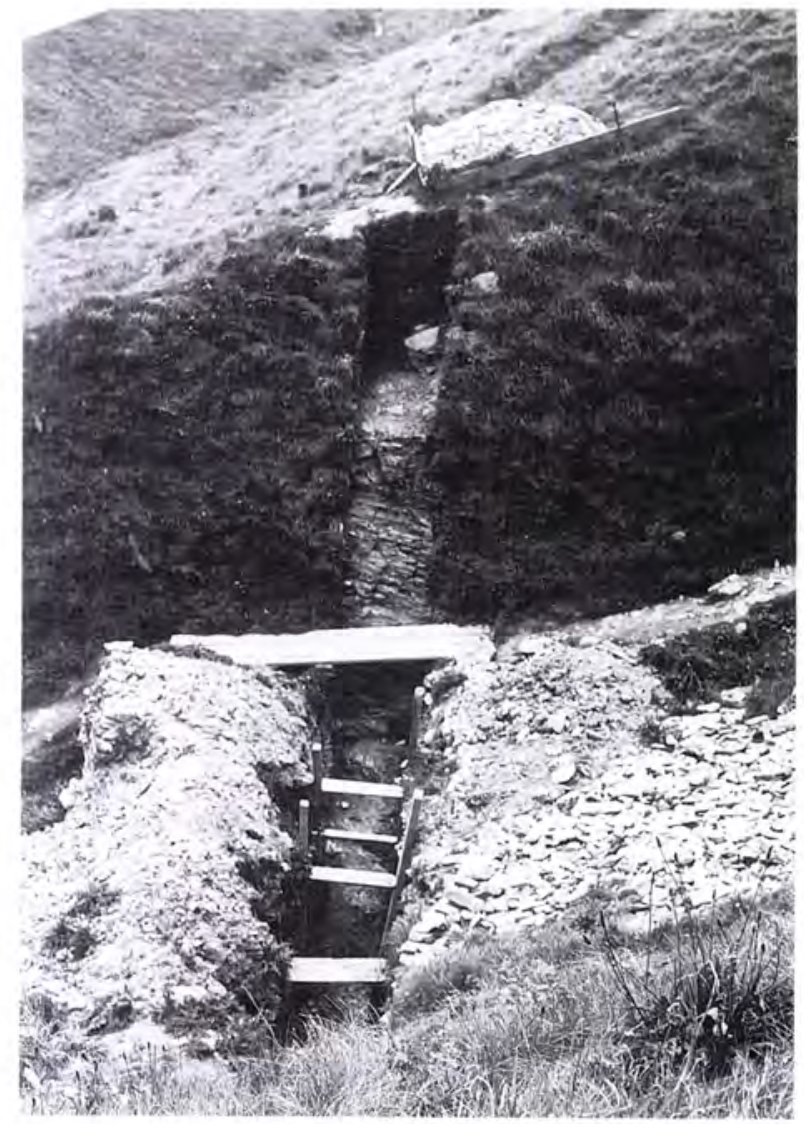

18 Photograph of Radford's cutting across the Great Ditch 1938 from the north. Reproduced by permission of English Heritage (NMR)

is two unidentified section-drawings by Wright copied in TINPUB 2, Bundle 25, Roll $2 / 6$. They probably date from the 1938 season.

\section{Site T MATERial with Paul G Johnson}

Wright recorded on drawings that in 1938 Radford opened three trenches in the area of the Great Ditch (figure 15). His drawings also show that the long 1938 section started inside the Lower Ward, was broken by the south wall of the Ward, and then cut across the Great Ditch (figure 16). This archive evidence is enhanced by photographs from Radford's own archive, which depict the 1938 cutting in the Great Ditch (figures 17 and 18).

It appears that Radford also worked on this part of the site in 1939. The information on Radford's work in 
1939 on this part of the site is limited to just four sources of evidence:

1. In a letter dated February 1955 from Radford to Gilyard Beer, the Chief Inspector of Ancient Monuments, Radford wrote:

You may remember that in August 1939 I tried to cut a section across the bank and ditch of the mainland ward. The ditch was done but the bank proved must [sic] much higher than I had anticipated and we could not get down to the bottom as there was no timbering for the deep trench or fencing for the safeguarding of the public. This is the only thing that really needs doing at Tintagel. We established that the bank and ditch were of two dates, the second fill medieval, probably of the 12th century. The first period is presumably monastic or pre-monastic, but there is a possibility that there are two full medival [sic] periods, as the second was not closely dated. I think that this point should be cleard [sic] up before I complete the report.

The work would entail a section on [sic] between 40 and 50 feet [12.2 and $15.2 \mathrm{~m}$ ] long and reached at the maximum to porbably [sic] 7 or 8 feet [ 2.1 or $2.4 \mathrm{~m}$ ]. You will have the trial sections in the office and be able to judge better than I the depths required to reach natural soil all along. I want to start on the inner lip of the ditch and extend some 10 feet $[3 \mathrm{~m}]$ in from the inner lip of the bank, wherever that is. I want to go down to natural soil all the way only leaving in the centre a sufficient baulk to preserve the safety of the 14th century curtain. I would recall that the bank was formed largely of loosely packed shale and the sides of the trench will not stand. For the same reason it must be fairly wide, say 4 or 5 feet [ 1.2 or $1.5 \mathrm{~m}]$. I cannot do this in July-September this year as I am otherwise engaged... If you would prefer to postpone matters til 1956 I shall not be sorry. I do not propose to undertake any further work at Tintagel once this is done. I will complete the report and if you feel more should be uncovered someone else can take over... (TINBOX 46, 28, d)

2. The notebook referring briefly to work in 1955 also includes an annotation in Trench 1 ' 1939 trench by wall' (TINBOX 46, 55).

3. The illustration of the 'Wall Walk' trench includes reference to 1939 work (figure 19).

4. A letter from Gilyard Beer about the Great Ditch work mentions the datum on the Castle Gate used in 1938 and 1939 (TINBOX 46, 58/n).
Taken together these four indications support work in the Great Ditch area in 1939, as well as in 1938. Given the wartime activities of Radford, it seems highly unlikely that he would have confused the crucial year of 1939 with the preceding one.

We know from letters in the archive (see table 1) that Radford returned to Tintagel in 1955 and excavated a further cutting in the Great Ditch and the area immediately north of the south wall of the Lower Ward. Although no drawings could be found relating to these particular excavations, there is a pencil sketch section, entitled 'Tintagel 1955: Sections I, II and III. Wall Walk', written in what appears to be Radford's handwriting (see figure 19). At first it was thought that these sections pertained to the Great Ditch and that - at last - some record had been found of the 1955 excavations. However, the drawings were subsequently studied by Paul Johnson, the surveyor for the project, and identified as belonging to the path along the shallow bank and ditch at the base of the north-east Lower Ward wall.

The 1955 pencil section was discovered after the project design for new work at Site $\mathrm{T}$ had been submitted and approved, and was not correctly identified until after the 1999 work had been completed. It was therefore impossible, due to the pressures of time and resources, to investigate the Radford cutting in this area through excavation. However, the sections provide a clear picture of the deposits, and the discovery of pottery from this cutting enables tentative dating. Nine small bags of pottery from this work were discovered amongst material in the NMR from Radford's excavations at Glastonbury ${ }^{30}$ and were transferred from the NMR in Swindon to the Royal Cornwall Museum in Truro. This pottery was examined in June 1999 by Carl Thorpe and Charles Thomas, and the listings and identifications are shown in Table 2. The descriptions in quotation marks are from Radford's own labels, which accompanied the material. The identifications support the chronology first put forward by Charles Thomas, who assigns this feature initially to the post-Roman period, with adaptation later when the Castle was built in the thirteenth century. ${ }^{31}$

Thomas discusses the work in the Great Ditch, noting excavation work in 1956, but the records indicate work in $1955 .{ }^{32}$ In this excavation season, Radford's recovery of a small cache of Roman coins in the Ditch is noteworthy, and the subject of a number of exchanges in the archives. Workmen had apparently discovered a 




19 Tintagel 1955, Wall Walk sections. Reproduced by permission of English Heritage (NMR)

small, unidentified hard object wedged amongst rocks and gave it to a local schoolboy believing it to be a fossil. On rehydration, this turned out to be a small leather bag containing Roman coins probably deposited in the second half of the fourth century. ${ }^{33}$ Radford's archive includes several letters between Thomas, Radford and Professor Anne Robertson who identified the coins, as well as confirmation of the cutting of the 1955 Great Ditch trench (eg TINBOX 46, $14 \mathrm{a}-\mathrm{d}, 15 \mathrm{a}-\mathrm{c}$ ).
GENERAL COMMENTS

Radford became Director of the British School at Rome from 1936 to 1939, and so his personal involvement at Tintagel in these years was perhaps somewhat curtailed. It is clear that he continued to visit the site to give instruction and there are records by Wright of an extensive excavation programme across the site in 1938. Work continued into 1939 and subsequently to 1955 with work in the area of the Great Ditch. It is interesting 
to discover that Radford was also acting in an advisory capacity even in 1946-7 during repairs to the exposed structures. ${ }^{34}$ Throughout the later 1940s Radford continued to negotiate between the Royal Institute of Cornwall (now Royal Cornwall Museum (RCM)) and the British Museum regarding the deposition of finds, ensuring a full and useful reference collection was retained in Cornwall. ${ }^{35}$ This is confirmed by RCM records in a letter dated 20 November 1948 between George Penrose, the museum director and Radford (Duchy of Cornwall Accession March 1949, History File).

It is clear from the surviving records that much is missing from the Radford archive and, as noted above, the story of the depletion of the archive is itself a sad tale. However, in combination with data from the Wright archive and detailed on-site excavation and survey, particularly with reference to Sites $\mathrm{C}$ and $\mathrm{T}$, a fuller picture can be gained of Radford's campaign. For instance, a significant number of photographs exist of different parts of the site, only some of which are titled, but most of which are unlabelled. A number of the forty-four extant drawings (TINPUB 2, Bundle 25, TINPUB 12, Bundle 32 and TINSITE 8, Bundle 44), which are mostly dyelines of Wright's drawings, comprise different versions of each other. There are some handwritten notes, but many of these relate to the pottery found on the site, and parallels, and will have been subsumed within Radford's 1956 article. Although there are three notebooks, and some of their contents are specific to particular excavation areas at Tintagel, little is capable of very detailed analysis of the work undertaken in 1933-9 and 1955. Table 1 provides a listing by year of Radford's activities at Tintagel, brought together by combining both surviving archival groups (Wright and Radford). A full listing of both archives is lodged with EH/NMR, Swindon, and the RCM, Truro.

\section{LOCATION OF RADFORD'S TRENCHES: THE 1995 SURVEY by Paul G Johnson}

\section{BACKGROUND}

Following the 1990-4 excavation seasons on Site C, where the Wright drawings were used to good effect, it became clear that the archive of Wright's work could enable us to understand more fully Radford's work elsewhere on the Island. As a result, further work was undertaken in the spring of 1995 to locate Radford's trenches. From the outset of this exercise problems were encountered, the most significant of which were associated with Wright's own recording system. The positions of the 1930s trenches were recreated in the same manner that they were recorded, that is by taped triangulation measurements. However, Wright did not indicate in any of his drawings whether his triangulation measurements were true horizontal measurements or slope-measurements. This was not considered to be so much of a problem on the plateau Sites, A, D and E, where the surface conditions are almost flat, and where Wright had supplied measurements to several extant structures. In contrast, for trenches sited in areas where he had only partially triangulated trench positions at various elevations on the terrace sites it proved to be a significant omission.

In addition, and in stark contrast to the care he took over his recording of extant and excavated structures, Wright was almost cavalier in his locating of trenches that were considered archaeologically sterile, or that were not to be investigated more fully at the time. His triangulation measurements for such trenches are inadequate (see the discussion above). This was especially the case for the trenches established around Site C and between Sites B and C, and had it not been for the excavated information obtained in the 1990s (see below), the positions of the majority of these would remain equivocal.

Wright had established a control-framework of sorts to facilitate the recording of the visible remains of the Upper, Lower and Inner Wards of the Castle, and the Chapel in April 1933. These are simply a series of local frameworks consisting of little more than straight lines equipped with a number of stations of known relationship to one another. The various controlframeworks seemed to have played an important role in the location of structures on various parts of the Island at times, but were ignored completely at others. For example, the line established between the south-east corner of the Chapel and a point between the two wells to the south west of Site $\mathrm{E}$ (A-C line) was used to record the Chapel in April 1933, but not used at all in the recording of the excavated structures of Site A in July 1933. Subsequent years saw the creation of additional rays emanating from a station along the $\mathrm{A}-\mathrm{C}$ line (station $\mathrm{B}$ ), only marked on Sheet 9 for 1934, in order to locate Sites $E$ (B-E line), D (B-F line) and the 'Tunnel' (annotated 'A-D continued', but which is more likely to be $\mathrm{B}-\mathrm{D}$ continued). No plan of Wright's control-framework survives, but it was possible to recreate some of the plateau control- 


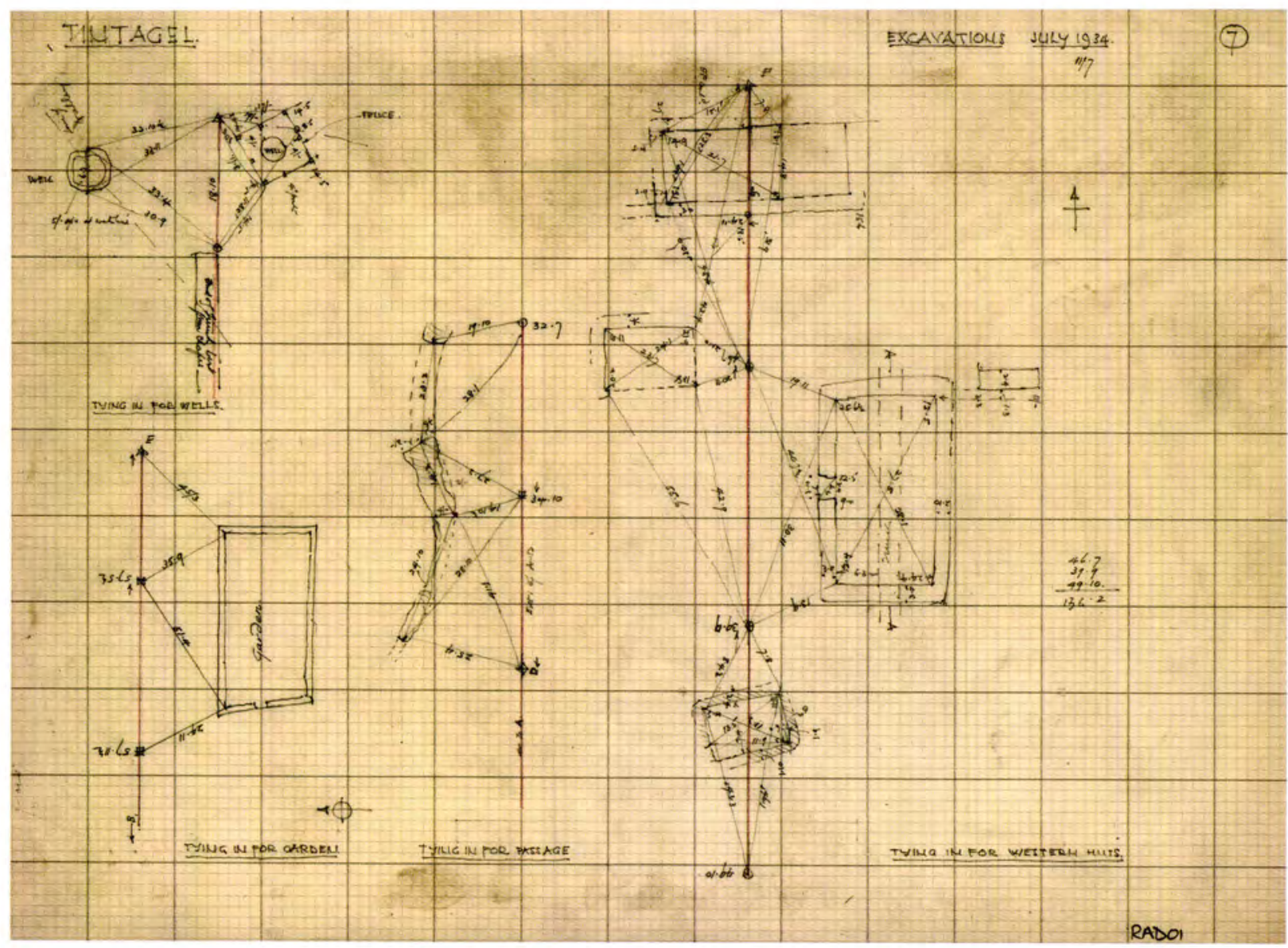

20 Wright's drawing of 'Tintagel. Excavations. July 1934. Sheet 7'. Reproduced by permission of English Heritage (NMR)

system by reference to a number of his plans, most especially Sheet 7 from July 1934 (figure 20). Once achieved, this enabled a more thorough cross-correlation regime to be operated upon the Wright archive.

\section{OVERVIEW OF 1995 SURVEY}

The survey of 1995 undertook to recreate the positions of those trenches recorded by Wright and to establish their positions using Electronic Distance Measurement (EDM) technology in order to superimpose that information onto a base map of the site. From the outset it was acknowledged that some of the trenches recorded by Wright in the early stages of his activities would no longer exist. In particular the early plans of Site A depict trenches that would later have been swallowed up as the clearance of the site took on the form of an open-area excavation. It was also realized towards the end of the fieldwork aspect of the 1995 survey that the Wright archive does not include all Radford's interventions (which may simply be due to a partial survival of the archive). The 1995 survey was greatly facilitated by the ability to see, in certain instances, the line of slight slumping that had occurred in the backfill of the 1930s excavation trenches, once their general positions had been identified using Wright's plans. However, over time, it became possible to recognize a pattern to Radford's excavation methodology and similarly to recognize the remains of excavation trenches, most commonly $2 \mathrm{ft} 6 \mathrm{in}$ to $3 \mathrm{ft}$ [0.75 to $0.9 \mathrm{~m}$ ] wide, in positions where none were recorded, but where they might reasonably have been expected. For example, three unrecorded excavation trenches were identified on the periphery of Site D after the close of the 1995 season. The positions of these were recorded in 1998 and added to the information obtained in 1995, and the suspicion that there might be more trenches than recorded was confirmed.

The ability to see the remains of the 1930 s trenches was invaluable in areas where Wright had located their 
positions inadequately. Wright's drawings provided reasonably accurate measurements between trenches, but the potential for mislocating whole complexes of trenches was high because of poor triangulation. In practice, the 'key' trench, that which provided some measurements to a structure, was always sought first. This was a time-consuming business but the 'key' trench was usually visible, especially on the plateau sites. Thereafter, the reconstruction of other trenches in the complex was straightforward and, once their general location was deduced, these too were usually visible. Once all the trenches in a complex were relocated, every possible measurement supplied by Wright was crosschecked. Not all of the measurements are correct and there are some impossible relationships contained within the archive. However, these are generally the result of hasty transcription, rather than bad workmanship on Wright's part. The terrace site trenches were slightly more complicated to relocate, but it was soon recognized that Wright employed slopemeasurements in his record, although how he intended to relate these to a base 'map' without recording vertical angles remains something of a mystery. The known positions of the excavated Site $\mathrm{C}$ trenches aided matters enormously, but the trenches that proved to be the most difficult to relocate were those with no extant structural remains to which Wright could relate the cuts.

In all, the positions of seven trenches (including the $214 \mathrm{ft}[65 \mathrm{~m}]$ trench across the plateau) were located at Site $A$, two at Site B, three (in addition to those proven by excavation in the 1990s) at Site C (labelled R to avoid confusion with the 1990s excavation trenches), four at

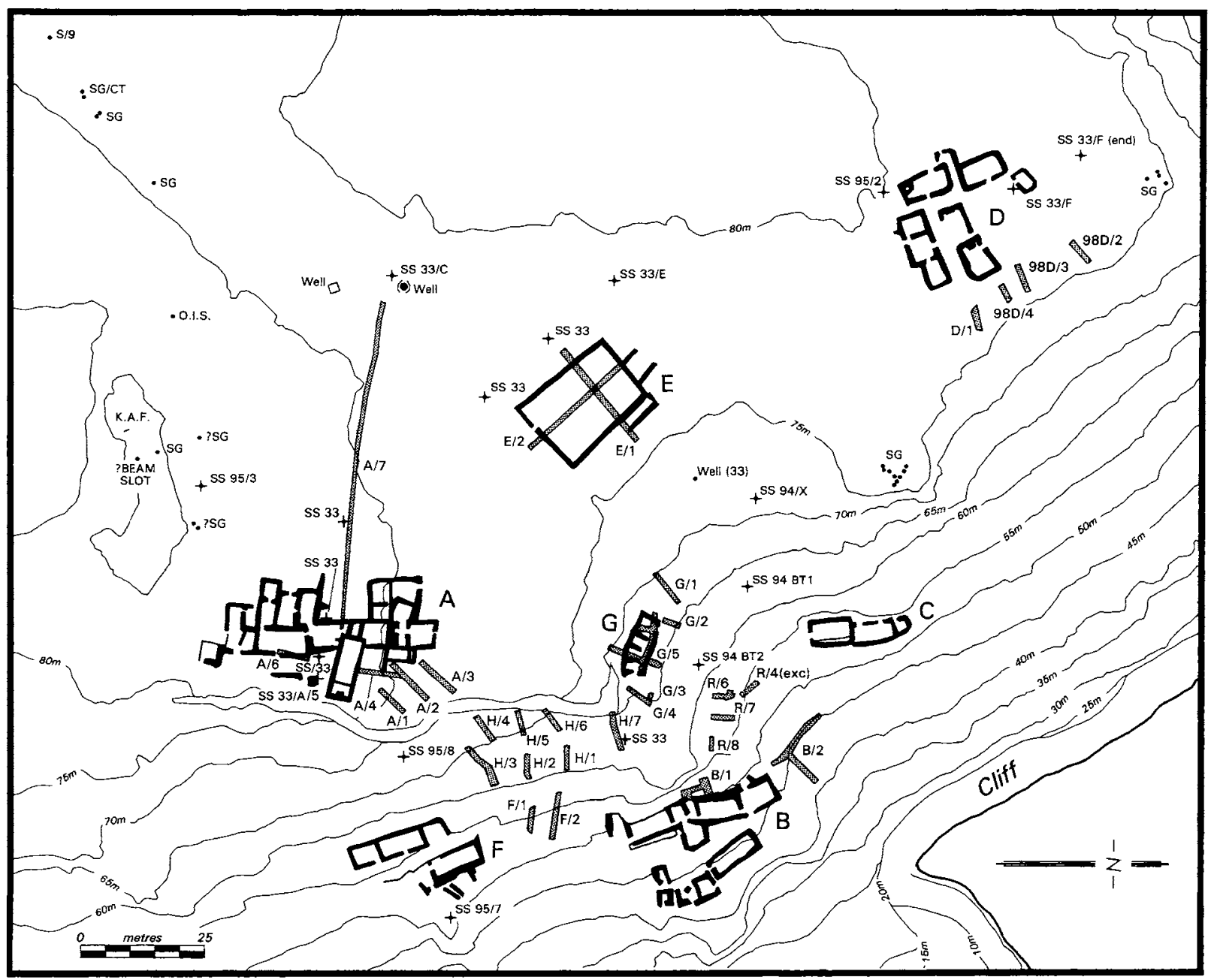

21 Map of 1995 survey on the 'Island'. Drawing: L McEwan 
Site D, two at Site E, two at Site F, five at Site G, and seven at Site $\mathrm{H}$ (figure 21). The whereabouts of Site $\mathrm{H}$ was hitherto unknown and its location was only arrived at by examining the levels Wright recorded on the sections of the trenches established on that site. Wright employed the same temporary bench mark (TBM) at Site $\mathrm{H}$ as he did at Site G. There is only one possible location on the Island of sufficient dimension to accommodate all of the trenches depicted in the archive and still to have utilized a TBM in common with Site $\mathrm{G}$. Site $\mathrm{H}$ is situated on a broad, gently sloping terrace above and to the north west of Site $\mathrm{F}$.

On the mainland side of the site, the positions of a trench across the Great Ditch (Site T), a trench in the smaller ditch running parallel to the road into the Lower Ward, and a trench cut across that road were also identified and recorded (see figure 15). A second cut across the Great Ditch made by Radford during a return visit to the site in the 1950s was also (more tentatively) identified and recorded. The precise location of these trenches and an investigation of the deposits through which they had been cut was a major research objective for excavations in 1999 (see Chapter 8).

Throughout the course of the 1995 survey, a controlsystem based upon that established by the Simmons Survey Partnership in advance of the 1990 excavation season was utilized. This system had been expanded over the years in order to encompass various aspects of the excavation programme, and stations on the plateau had been established in 1994 in order to locate an evaluation trench examined in advance of the building of a pumphouse. ${ }^{36}$ Additional stations were created to the south west of Site A and to the south of Site D. This enabled all of the plateau trenches to be recorded. The trenches around Sites B, C and G made use of existing surveystations at Site $C$ while new stations were required in the proximity of Sites $\mathrm{F}$ and $\mathrm{H}$. New stations were also necessary in the vicinity of the Great Ditch trenches.

The data recovered during the course of the survey were initially processed in the field using 'SDR-Map'. A recent reprocessing of the data was undertaken in 'LisCad' with final graphic plots being generated by 'AutoCad'. These were superimposed, by hand, on a base map of the site generated by a photogrammetric survey, commissioned from AMC Ltd on behalf of EH in March 1988.

\section{DISCUSSION OF SURVEY DATA IN RELATION TO MATERIAL}

FROM THE 1930S TO THE PRESENT DAY

The results of the 1995 survey are depicted in Figure 21. The 1930s excavation trenches were each designated by a number prefixed by its site code letter eg $\mathrm{A} / 1$, as given by Radford, with the exception of those trenches around Site $C$ which were prefixed with the letter ' $R$ '. The trenches recorded by Wright as ' $\alpha$ ' and ' $\beta$ ' were re-designated as $F / 1$ and $F / 2$ as there were survey-stations of identical nomenclature at Site $C$ and trenches $\alpha$ and $\beta$ lie closest to Site $F$. The positions of the 1930 s trenches on Site $C$ proved by excavation are not included on Figure 21 as their positions are more accurately depicted in the excavation plans of the trenches. Two of Radford's Site $\mathrm{C}$ trenches are unaccounted for. The first lies on the Upper Terrace and was not identified in excavation trench $\mathrm{C} 07$, although it must have been in that position. The second was not identified by excavation in trench C18 in 1994. This latter trench lies directly below a short flight of steps leading from the path to the plateau and Site B. As noted above, it is apparent that Radford's excavation strategy involved the targeting of visible structures. The distribution of his trial trenches perhaps reflects an intention to work his way around the terraces of the Island in an anticlockwise direction, starting at the gate of the Inner Ward of the Castle. The Second World War may have frustrated these aims, and after it Radford really only came back to Tintagel to elucidate a few minor points, as demonstrated by his third attempt at cutting a section across Site $\mathrm{T}$, or the Great Ditch, in 1955. As noted above, it was Radford's aim in this work 'to make the site intelligible' (TINBOX 46,21/b) and it is clear that the workmen were instructed only to work to a pre-agreed level to facilitate laying out of the individual exposed structures (TINBOX 46, 55).

The distribution pattern of the known sites and the Radford trial trenches reflect just how little of the site was excavated in the 1930s. Given that we know that there was structural evidence in Site $\mathrm{H}$, that a considerable quantity of artefactual material was recovered in the 'rescue' excavation of the 'Steps' site to the south of Site $F_{3}{ }^{37}$ and that new structures exist on the Lower Terrace of Site C, ${ }^{38}$ this pattern must also reflect how little we still know of the archaeology of Tintagel, rather than how much.

This state of affairs was significantly addressed by the RCHME survey undertaken in 1985 (figure 22), where a substantial number of additional structures were identified on the Island, especially on the plateau where much of the vegetation was destroyed following a disastrous fire in 1983. These are more ephemeral structures, not readily discernible as structural at all to the untrained eye, but Wright nevertheless had already recorded some of them in the 1930 s. 


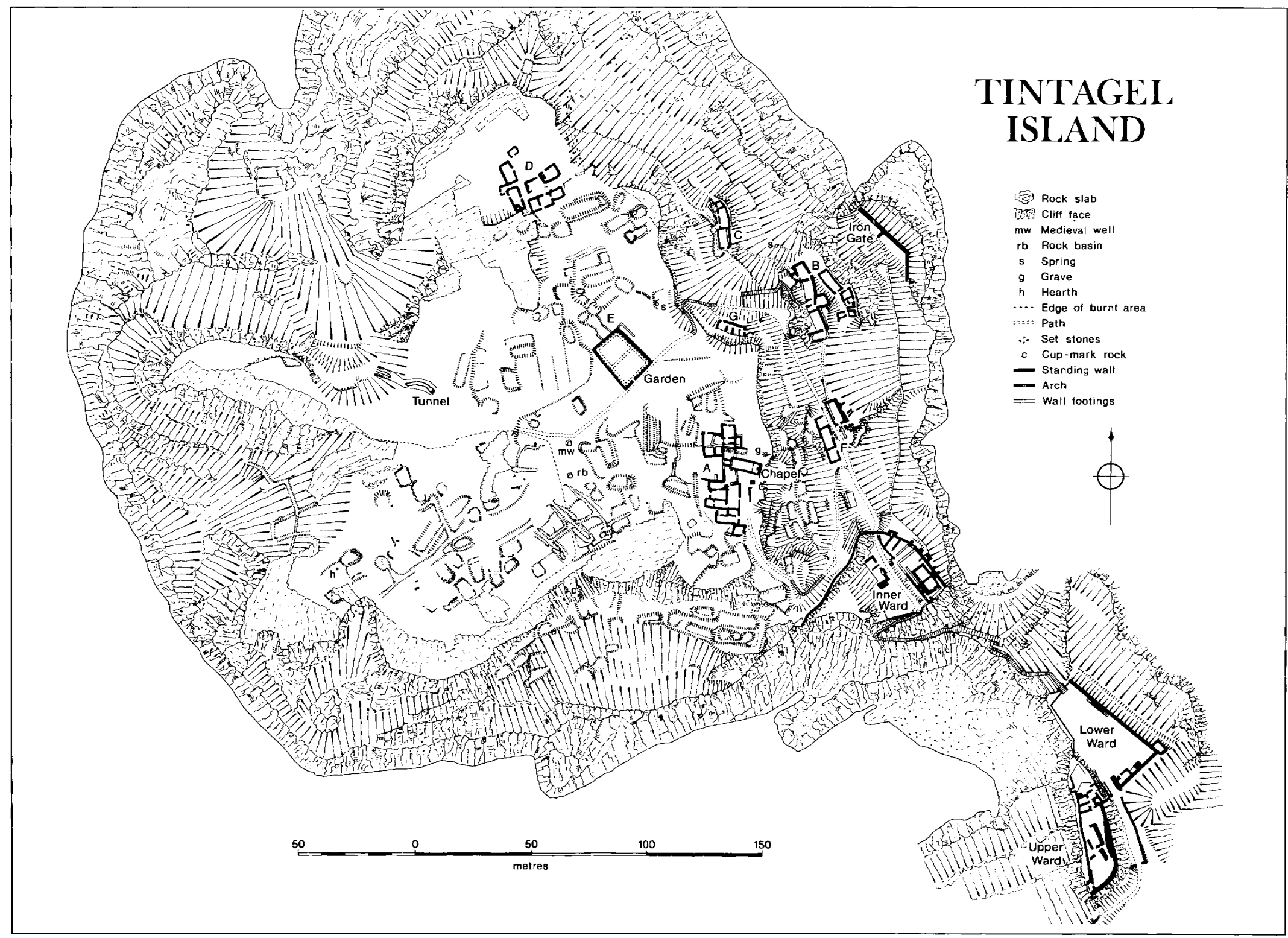

22 RCHME survey of Tintagel Island. Drawing: (C) Crown copyright, NMR 
During the course of the 1995 survey the opportunity was taken to record some of these ephemeral features. Erosion to the naked slate surface of some of the plateau, exposed in the fire of 1983 , was rapidly resulting in the loss of further structural evidence such as that suggested by the stake impressions identified by Thomas. ${ }^{39}$ Although evidence of this nature is extremely difficult to detect, a further five definite and two possible clusters of stake impressions were identified. These were largely concentrated in the 'Burnt Area' of the Island, as with the example noted by Thomas, but other groups were noted adjacent to Site D and on a rock ledge above Site C (figure 23 , and annotated 'SG' on figure 21). While this report is not primarily concerned with the form, function or date of such features, the present distribution of these groups simply reflects areas where the stakes employed were driven sufficiently hard enough to scar bedrock that has subsequently become exposed. Such areas are inevitably towards the edges of the plateau, and the instinctive interpretation of the stake-scar features is that they merely represent the remains of a fence or something of that nature, around the lip of the plateau. However, once exposed, they would not survive long due to erosion exacerbated by visitors, and those recorded by Thomas are increasingly difficult to relocate. The eroded remains of a putative beam-slot were also identified and recorded in 1995 , of particular interest since it is located only $6.5 \mathrm{~m}$ to the east of the feature known as 'King Arthur's Footprint' on the southern extremity of the plateau.

All in all, a study of the Wright archive and, to a lesser extent, the Radford archive has enabled some reconstruction and re-identification of the less welldocumented aspects of Radford's excavations. In addition to the trench positions presented here, Radford also 'cleared' the structural remains of Sites A to F, the Iron Gate, and the Upper, Lower and Inner Wards of the Castle. There are few records of the excavations of the latter four sites in Wright's material, save for the

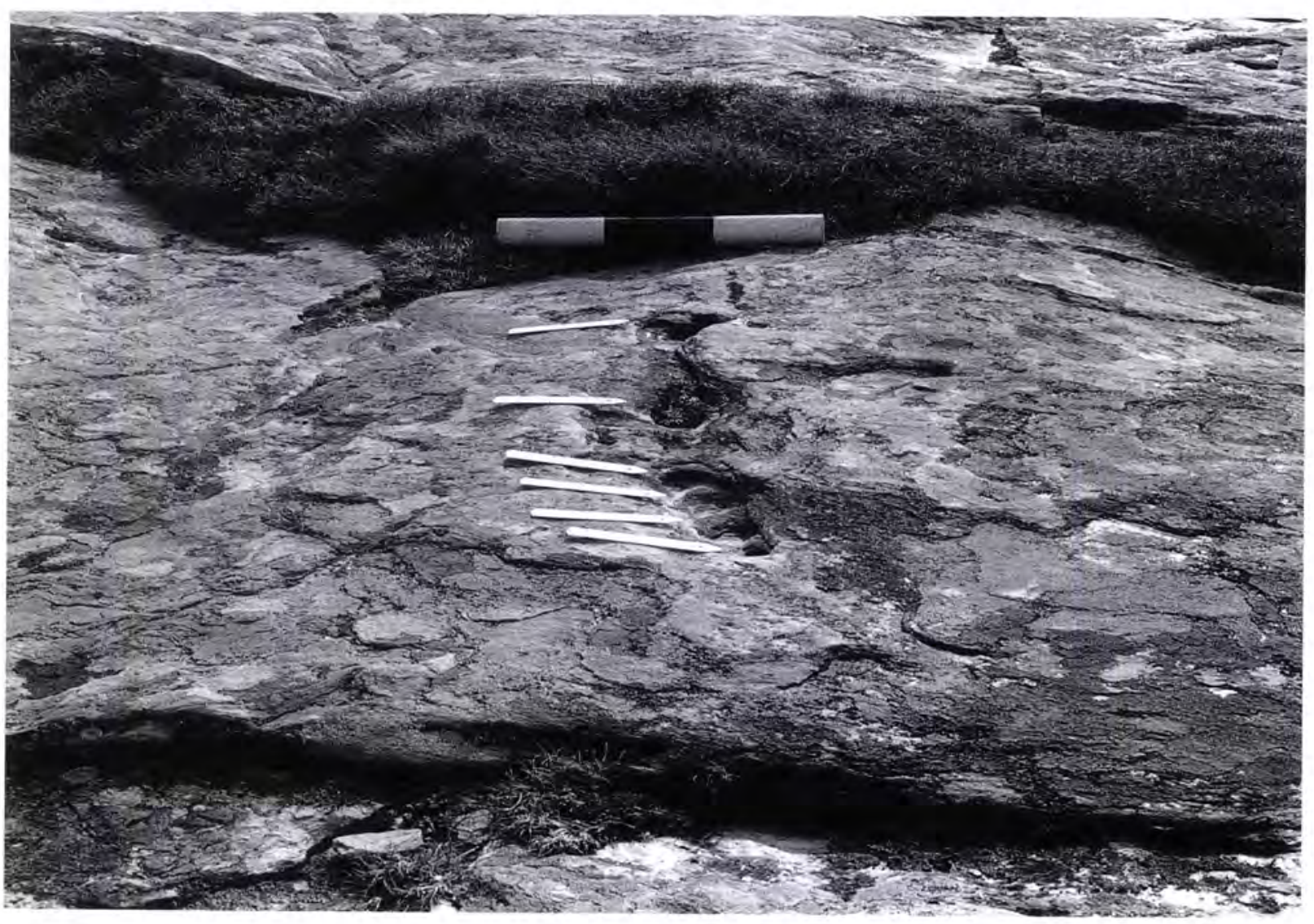

23 Stake impressions on rock ledge above Site C. Photograph: P G Johnson 
presumed pre-excavation drawings made in April 1933 and a section across the Great Ditch which shows part of the Lower Ward. The possibility of other 1930s trenches existing in and around these structures has also been suggested by others. ${ }^{40}$ As discussed above, the Radford documents include sketchy site notes, photographs (many unlabelled and sadly unrecognizable) and sections drawn by his own hand, particularly in the 1955 works on the mainland side of the site. It had been hoped that by correlating both sets of archival material Wright's illustrative material and Radford's written and photographic record - a gross stratigraphic analysis of the overall site would be feasible. This is not possible with the surviving material. It is obvious from Radford's letters that he relied on workmen to 'clear' the sites under the supervision of a foreman, with periodic visits and lists of jobs for the workmen being made during the work (see above) and this led to the survival of very little stratigraphic information.

As can be clearly seen in the dates of work undertaken by Wright at the site in Table 1, his involvement was largely at the end of the excavation season and presumably he worked without the benefit of Radford's input in terms of explanation and checking of the stratigraphy represented in the sections. As an architectural draughtsman, however, he was adept at distinguishing different phases of structural sequences. Continuing consolidation at the site, using Wright's plans as guidance (see Chapter 6) saw further input from Radford through the 1940s, with a note dated 1947 providing, for instance, a job list for the workmen (TINBOX 46, 56 uus). However, Radford's Government activities in the 1930s and early 1940s clearly had an impact on the amount of time he was able to spend at the site, and he must have had a heavy heart when he wrote in 1985 to Peter Fowler that he had 'never seen Tintagel at the best season' (TINBOX 46, 12).

\section{ARCHAEOLOGICAL RESEARCH AND INTERPRETATION SINCE THE 1930S}

There can be no doubt of the international significance of the site of Tintagel. Evidence from the first commissioned archaeological work in the 1930s demonstrated that one of the most important aspects of the site, regardless of the interpretations that were put onto the nature of the occupation there, was the attested link with a wider world. This was first established when Radford recognized that the large numbers of sherds of wheel- made pottery he had found at the site in the 1930s had all been imported from the eastern Mediterranean, Spain or Gaul. ${ }^{41}$

Since this important discovery, archaeological and historical research has continued to produce evidence of the importance of Tintagel to a world outside Britain. Links with Europe, the Eastern Mediterranean and North Africa continue to be demonstrated by finds of imported fifth-/sixth-century (post-Roman) pottery, the study of which has already prompted several important research projects ${ }^{42}$ and which have been included in wide-ranging pottery analyses and research. ${ }^{43}$

For almost fifty years following Radford's work, Tintagel was regarded as an outstanding example of a 'Celtic monastery'. However, during the 1970s and 1980s new perspectives prompted reconsideration of Tintagel's role in the history and archaeology of the immediately post-Roman period. ${ }^{44}$ Renewed study of both site and artefacts led Dr Ian Burrow and Dr Kenneth Dark to challenge the monastic 'model' and for Charles Thomas to recant his previous support for Radford's overall interpretation. ${ }^{45}$ At the same time, Dr Oliver Padel was providing an alternative historical context for the importance of the site at this period, through association with the Tristan and Isolde tradition, and also demonstrated that Tintagel was universally considered a 'royal place' in documents. ${ }^{46}$ Thomas suggested that a better explanation for the presence of so much imported pottery at Tintagel was to see it in the context of an important secular site (see Chapter 12). ${ }^{47}$

As mentioned above, the fire of 1983 that denuded part of the plateau of the Island of much of its vegetation revealed remnants of buildings and occupation areas. These were further at risk from erosion due to nongeneration of the turf cover and the activities of visitors and so were surveyed by the RCHME in 1985 (see figure 22). ${ }^{48}$ It became evident that many more structures, and more varied forms of them, were to be seen than was evident from the overall plan of the 1930s work (see figure 3 ). In fact, the severe erosion on the plateau had revealed the plans of up to 130 more buildings than had been recorded by Radford, and the sheer extent of the site had to be reconsidered..$^{49}$ As pointed out by Charles Thomas and Professor Peter Fowler in a commentary on the survey, further east in England a settlement with a minimum of 170 buildings would be considered a village or even a small town - although it might be added that these should be coeval..$^{50}$ 
Later in the 1980s, under Thomas's direction, a largescale project on the artefactual archive, particularly pottery, from the 1930s excavations and subsequent casual finds was undertaken to catalogue all known material from the site. ${ }^{51}$ A number of other aspects of Tintagel from the material record, including small-scale rescue excavations by the Cornwall Archaeology Unit (CAU) (eg 1988 in the area of the Great Hall), were also published towards the end of that decade, ${ }^{52}$ and the implications to be drawn from them discussed. ${ }^{53}$ Most recently, Charles Thomas has produced a clear, yet comprehensive, account to place both the earlier (1930s) and more recent (1980s and early 1990s) work against a background of both general and academic fascination with the 'mysterious' site of Tintagel Castle which has persisted to the present day. ${ }^{54}$

The rescue strategy begun by CAU in the 1980s continued into 1990 during the re-cutting of new steps adjacent to Site F by workmen. Here, building on the initial CAU investigations on the route of the stepped path, Batey was able to identify both in situ early medieval middens and substantial numbers of imported ceramic sherds. ${ }^{55} \mathrm{~A}$ wider perspective on the archaeology of Tintagel was gained in 1990-1 when Thomas and Jacqueline Nowakowski carried out excavation in the churchyard of St Materiana on the mainland, south of Tintagel Castle. Here the earliest phases were found to date to the sixth to eighth centuries $\mathrm{AD}$ and consequently to overlap with activity on the Island nearby. Imported ceramics and incised stone slabs with simple crosses were found in association with the cist and slate-lined graves in the churchyard, and it would be perverse to suggest that activities here on the mainland which were contemporary with at least some of those on the nearby Island are not in some way related. Indeed Thomas has suggested that the dead of the Island may well have been buried there. ${ }^{56}$

\section{THE PROGRAMME OF WORK BY GLASGOW UNIVERSITY IN THE 1990s}

Following on-site discussions in 1988/9 between the Tintagel Research Committee (founded to promote a coherent programme of research work in and around the site) and representatives of the Historic Buildings and Monuments Commission for England (HBMCE), commonly known as English Heritage $(\mathrm{EH})$, it was decided that a re-examination of the previous work at the site was needed in order to clarify the nature and date of the settlement remains and to present a more coherent story for public and scholar alike. As a result, Christopher D Morris, then of the University of Durham, was invited to set out a programme of work at the site of the Castle, particularly to elucidate further the post-Roman and early medieval period of occupation. This was submitted in August 1989 to Dr Brian K Davison, then Inspector for Ancient Monuments with HBMCE/EH. This document represents the original research design for a series of investigations at different parts of the site to answer specific research objectives. As a consequence, $\mathrm{EH}$ commissioned a small feasibility exercise for Spring 1990 on the three terraces above, to the north of and below Radford's Site $C$ respectively (figure 24, C01-C07). ${ }^{57}$ This work was to follow on from the new survey from the RCHME, which had apparently identified a previously unknown terrace below and to the east of the Site C complex (figures 25 and 26) where Radford had excavated stone buildings in $1934 .^{58}$

As well as the prima facie case for the presence of an additional terrace, the remains of possible walls could also be seen on the ground here. This feasibility exercise aimed to evaluate the nature of the newly identified features, and more specifically the survival of any potential archaeological deposits on what seemed to be a previously undisturbed terrace perhaps with a complex of buildings directly comparable to those of Site $\mathrm{C}$ on the terrace above. Furthermore, it was hoped that these excavations would supplement and illuminate the information recovered by Radford's excavations at Site C. Thus the potential of 'Site C' for further, largerscale work could be assessed, and also an attempt be made to evaluate Radford's work and to assess the potential for future research on 'untouched' areas of the site.

According to Wright's archive (see above), Radford not only excavated the Site $\mathrm{C}$ building, but also opened trenches on both the 'Upper' and 'Middle' Terraces of Site $\mathrm{C}$ (see figure 7 ). Long, $3 \mathrm{ft}-[0.9 \mathrm{~m}-]$ wide trenches were also cut across the whole area (see figure 6). These are shown in Figure 12, which is based upon the Radford archive material. It was necessary to relocate and examine the remains of all of these trenches, in order to be able to evaluate Radford's work and assess the remaining archaeological potential of the site. Following this evaluation $\mathrm{EH}$ decided to extend the work, both to other terraces on Site C, and also more extensively on the 'new' terrace (hereafter described as the 'Lower Terrace'). Hence, the first investigations on the terrace below and to 


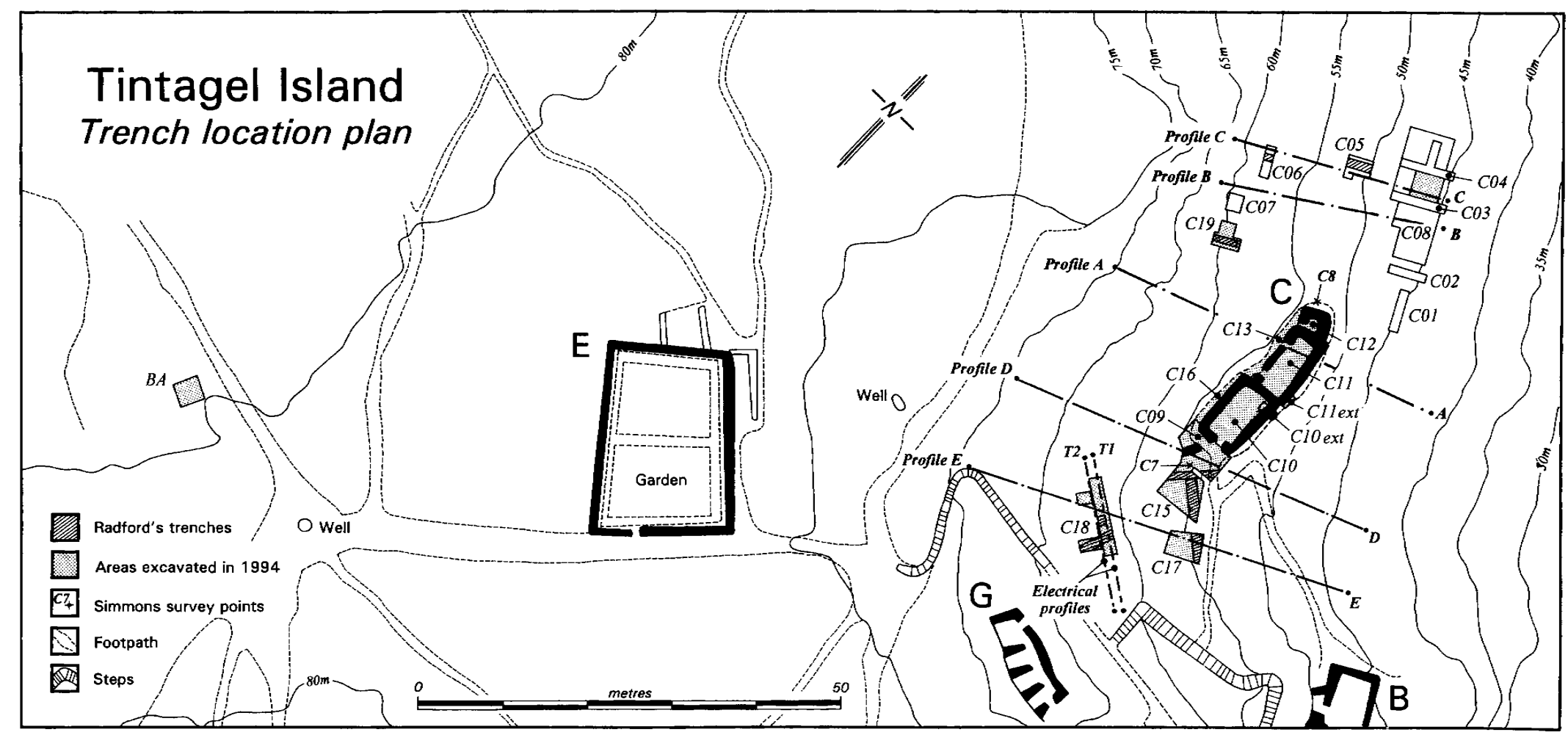

24 Location of trenches and survey profiles, Site C. Drawing: $L$ McEwan 


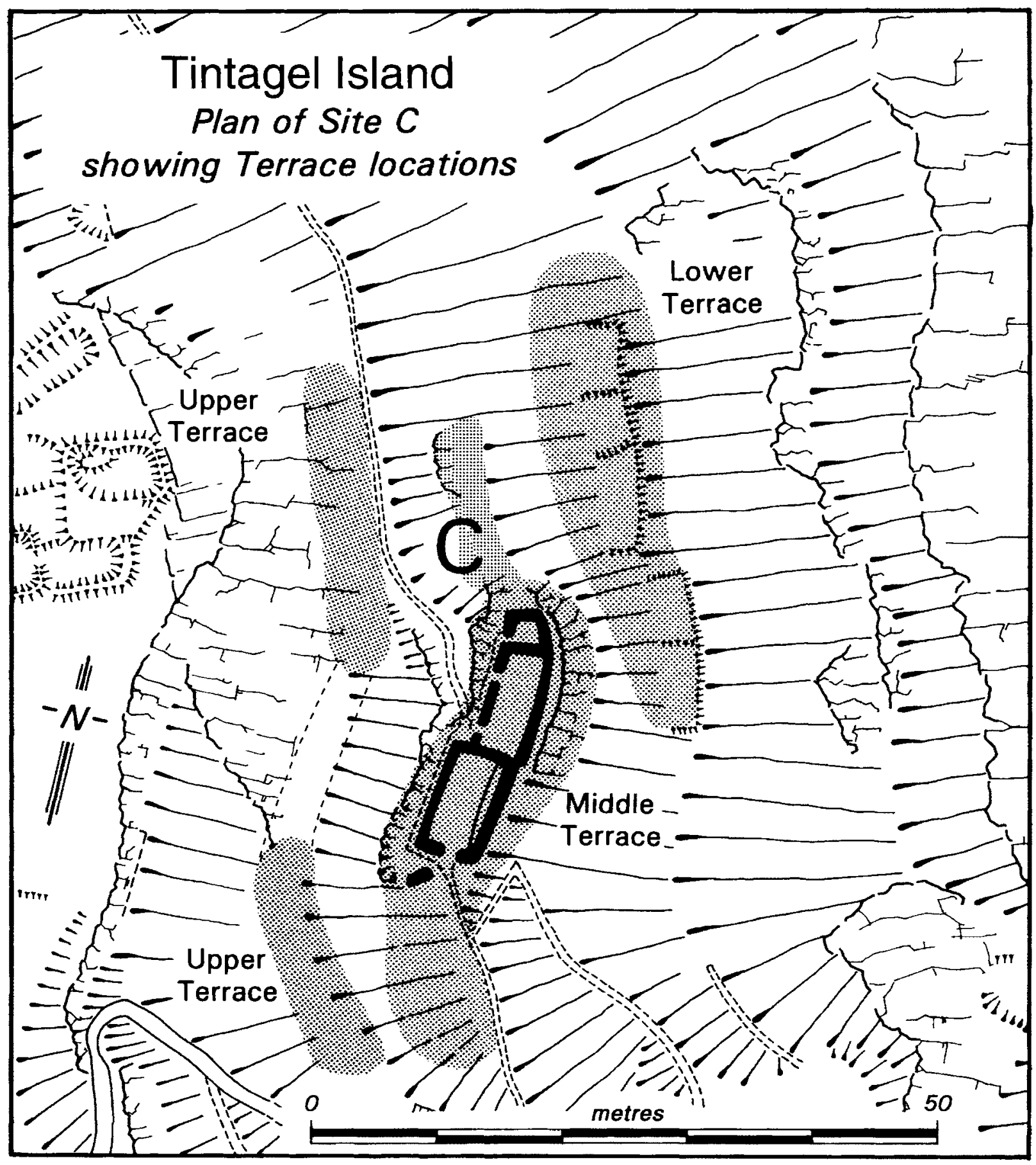

25 Location plan of terraces, Site C. Drawing: L McEwan

the east of Radford's Site C were subsequently developed until the greater part of the terrace was excavated as one area in 1991, 1993 and 1994.

The excavation of the Lower Terrace of Site $C$ served to demonstrate the archaeological potential of a terrace on Tintagel that had not been excavated by Radford. As a comparative exercise, English Heritage supported the excavation of the other terraces of Site $\mathrm{C}$ which had been investigated in the 1930s. Re-examination of Radford's trial trenches on the Site C Upper and Middle Terraces 


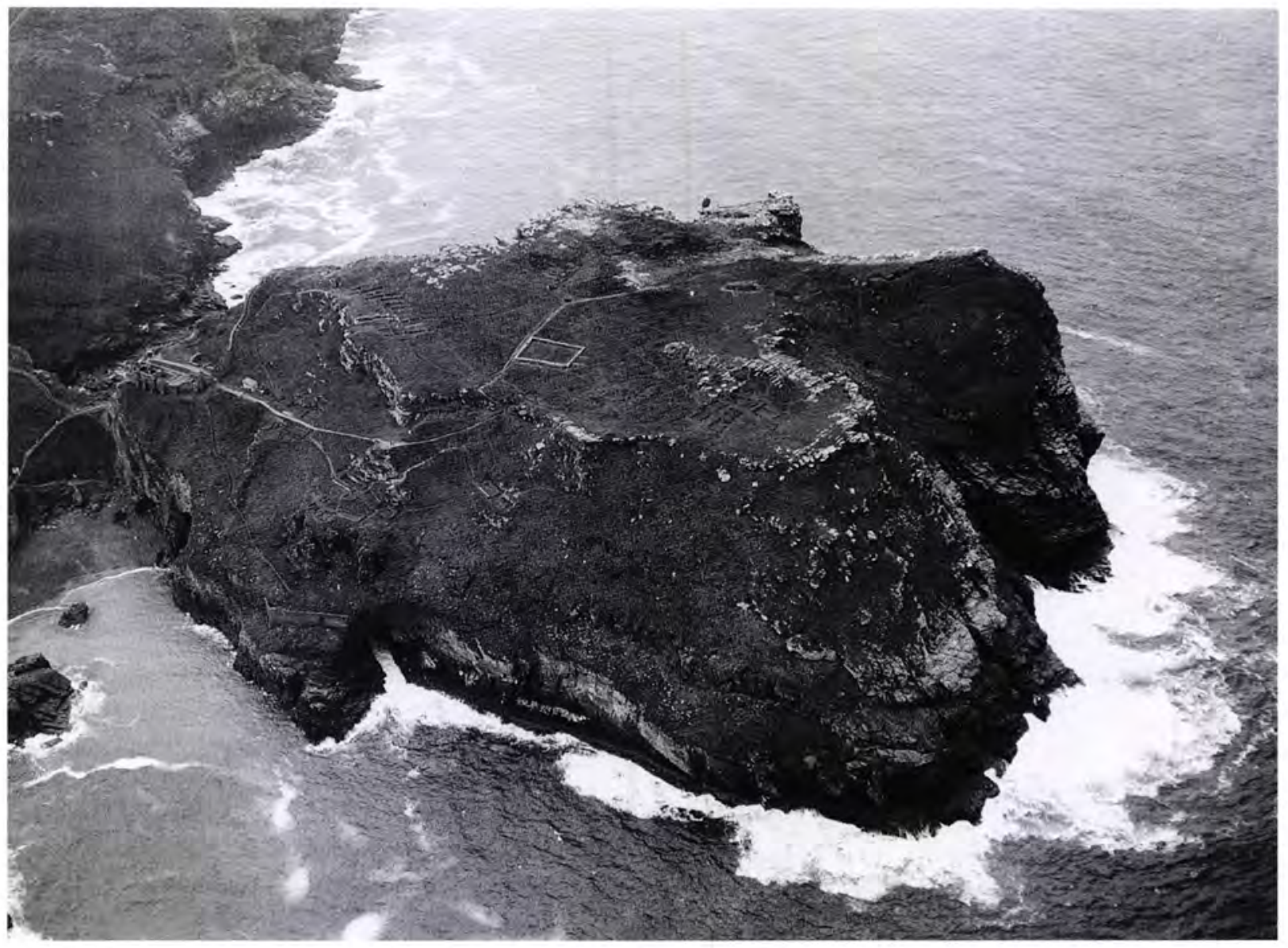

26 Aerial photograph of Site C and the Lower Terrace (Harry and Morris 1997). Copyright: Cornwall County Council

took place at various times between 1990 and 1994 (see Chapters 3 and 4), and the building which had first been examined by Radford on Site C 'Middle Terrace' (see Chapter 6) was excavated in 1993-4 and 1998. Finally, extension to the south of this, into an area trial trenched by Radford, entailed an investigation of another building (Site C15: see Chapter 5) in 1999 as the final phase of work on Site $\mathrm{C}$ by the Glasgow University team. ${ }^{59}$

On the wider front, as detailed above, a survey programme building on the re-examination of the Wright archive took place on the 'Island' area in 1995, while some small-scale investigations other than at Site $\mathrm{C}$ were undertaken at EH's request. ${ }^{60}$ Further, the work of Radford on 'Site T', or the Great Ditch, on the landward side of the site, was re-investigated in 1999 (see
Chapters 7, 8 and 9). Radford's trenches were located and extended to investigate the original, early medieval, date for the cutting of the Great Ditch, and its possible re-use in the later medieval period, together with the contemporary Lower Ward curtain wall and 'Little Ditch'.

All of these investigations are reported here, in a monograph under the aegis of the Society whose Journal published Radford's original 'Interim Report'. A full Research Archive Report has been prepared to accompany this report and will be housed with the National Monuments Record for England, English Heritage, and the Royal Cornwall Museum, to whom the finds are assigned by the owners of the site, the Duchy of Cornwall. 


\section{PART II Site C}





\title{
CHAPTER 2
}

\section{SUMMARY OF EXCAVATIONS ON THE LOWER TERRACE, SiTE C, 1990-4}

\begin{abstract}
This chapter is a summary of the previously published report on excavations undertaken between 1990 and 1994 on the 'Lower Terrace' of Site C.' Several phases of ephemeral stone and turf structures with associated hearths, floor deposits and stake-holes were found. These were separated by periods during which shillet (tiny flakes of slate in sandy clay soil) accumulated or was dumped as levelling material. After the collapse of the last structure the terrace was buried by layers of scree and slate slip from the slope above. Artefact groups of fire-lighting stones, whetstones and worked flint and quartz were recovered, predominantly from the earlier phases, together with Romano-British pottery. Later phases mainly comprised sherds of imported Mediterranean pottery ( 84 per cent of all finds) and slate pot-lid discs. An extensive programme of environmental sampling clarified that a wide range of probably locally growing trees and shrubs was exploited for fuel, as well as for wattles and larger posts and beams. Tiny burnt fragments of animal and some human bone were found scattered through a few deposits, but were probably residual. A programme of radiocarbon dating was possible with the availability of charcoal material from hearths and stake-holes. This programme produced three distinct date ranges of structural activity: cal AD 395-460 for one of the earliest phases of hearths, floors and stake-holes pre-dating the occurrence of imported pottery; cal AD 415-535 for a later structural phase with hearths and first occurrences of imported and Romano-British pottery together and cal $A D$ 560-670 for the latest and best surviving structure, with hearths, stake-holes and a large assemblage of imported pottery.
\end{abstract}

\section{INTRODUCTION: SYNOPSIS OF WORK UNDERTAKEN}

The results of the April 1990 investigations were extremely promising, ${ }^{2}$ demonstrating that the terrace indicated below Site $\mathrm{C}$ on the RCHME plan existed. The surface features also shown on the plan were, however, by no means so obvious. Many 'tussocks' and/or anthills had to be removed before excavation, and so perhaps the cross-walls indicated on the plan were in fact a conjunction of such features. The four small trial trenches all indicated the archaeological potential of the site (see figure 24). Although trench $\mathrm{CO} 1$ was only partially excavated, five distinct phases of activity were identified within this small area. Trench $\mathrm{C} 02$ was fully excavated down to the slate bedrock, and seven phases of activity above natural geology, including a charcoal feature and possible surface, were identified. Trench $\mathrm{C} 03$, despite being only partially excavated, revealed a stub of walling and indications of activity surfaces. In trench C04, further remains of walling and other structural features were uncovered. Although the early medieval site of 'Tintagel appears to have a 'focus' well to the south on the eastern side of the Island (as defined by artefact distribution and density), ${ }^{3}$ this terrace - as the furthest from it - was clearly shown to have intact deposits with some structural remains. The presence of imported pottery sherds and little or no later medieval pottery was encouraging in that it appeared to indicate early medieval occupation of the site.

Subsequent work in March/April 1991, ${ }^{4}$ was facilitated by a shift of emphasis from trial trenches to 
area excavation, and resulted in a broader understanding of the archaeological deposits in the northern part of the terrace (figure 27). The stubs of walling uncovered in the 1990 trial trenches C03 and C04 provided a focus for the 1991 area excavation, although the entire area was fully investigated for further signs of activity to the north and south. It was shown that the walling related to the fugitive remains of a small structure, with associated floor levels and pottery sherds that provided a chronological marker in the fifth to seventh centuries AD.

The objectives in 1993 were twofold: primarily, to complete the excavation of the central part of the trench in order to bring it to the same stage of excavation as the rest of the area; secondly, to further investigate the entire area, bringing a degree of uniformity to the stratigraphic phasing across the site. This enabled sequences of activity to be defined across the whole area. A further structural phase and two further floor surfaces were identified within the small structure, together with an interesting artefactual assemblage, including locally made as well as imported pottery. Slate disc amphorastoppers, whetstones, a spindle whorl and a flint were also recovered. For the first time it was thought that perhaps the ephemeral structures and activity surfaces on the Lower Terrace were associated with successive short, possibly seasonal, activity at the site. ${ }^{5}$

At the beginning of the 1994 season it was felt that only limited stratigraphy remained on the terrace. However, the excavation of further complex deposits during the Easter season demonstrated that this was not the case. Work continued in September and, although most of the small area was excavated to bedrock, the eastern edge of the terrace remained unfinished for safety reasons. The extension of a section at the eastern edge to uncover the extent of the later floor levels revealed ephemeral traces of early walling, which were

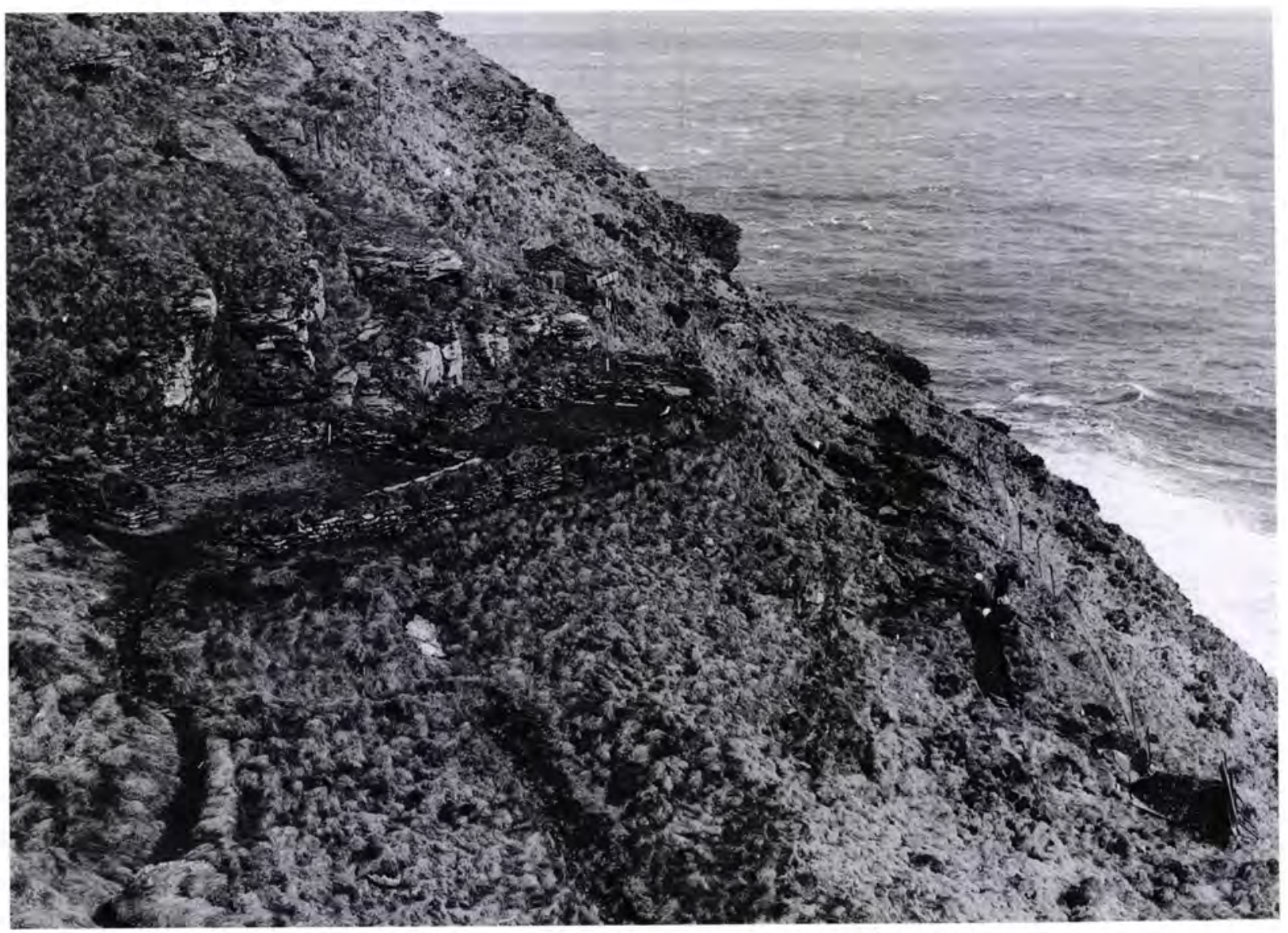

27 Work on the Lower Terrace area excavation in 1991, viewed from the southern end of the terrace. Photograph: C D Morris (Harry and Morris 1997) 
also too close to the edge of the terrace and the cliff-edge to excavate fully. It seemed quite clear that there had been several phases of occupation and activity on this terrace in the period before the fifth-seventh centuries, marked for instance by the presence of hearths and surfaces with stake-holes as well as other forms of pottery. It also seemed that the earlier activity was nearer to the present cliff-edge, so that the inhabitants may have gradually retreated back up the slope from the edge to avoid cliff-side erosion. ${ }^{6}$

\section{CORRELATED PHASING}

Following the removal of baulks in 1993 it was possible during excavation to link stratigraphically all layers excavated in area $\mathrm{C} 03 / 4 / 8$. However, the trial trenches $\mathrm{C} 01$ and $\mathrm{C} 02$ remained physically separated from $\mathrm{C} 03 / 4 / 8$ and each other by baulks of $1 \mathrm{~m}$ and $2 \mathrm{~m}$ respectively. Trench C01 was also not excavated fully down to the bedrock (Phase $S$ in C02; Phase $M$ in $\mathrm{C} 03 / 4 / 8$ ); topsoil is Phase $\mathrm{Z}$ in all areas. A number of layers located in different trenches showed similarities in colour, texture, consistency etc, allowing correlations between phases in $\mathrm{C} 01, \mathrm{C} 02$ and $\mathrm{C} 03 / 4 / 8$ to be proposed as follows:
Twelve major phases of human activity have been recognized, with two subdivided ( $Q$ and $U$ ). Two phases of $\mathrm{C} 02$ ( $\mathrm{W}$ and $\mathrm{X}$ ) appear to relate to one in the main area $\mathrm{C} 03 / 4 / 8(\mathrm{~W})$. In the following summary, the C03/4/8 phase descriptions have been used, and reference made where necessary to $\mathrm{C} 01$ and $\mathrm{C} 02$. Figure 28 shows the sections drawn before the removal of the baulk between areas.

Particularly notable are the three phases with clearly defined - if at times fugitive - structures in Phases N, U2 and $\mathrm{W}$, and those phases which indicate human activity on floors and surfaces and the presence of hearths in Phases Q, R, S, U1 (and W/X of trench C02). The surface and charcoal deposit found on Phases W/X of C02 may indicate another building to the south, contemporary with that in Phase $\mathrm{W}$ in the main area C03/4/8. Apart, possibly, from the building in Phase U2, none of the walls would appear to be from major, well-constructed buildings of a permanent nature. The sequence of hearths and fire-pits in Phases Q1, Q2, U1, U2 and W are also significant, demonstrating the regular use of this area of the site for similar activities over time. Lines of stake-holes in Phases Q1, Q2, R and U1 may have acted as windbreaks for the hearths and fire-pits.

\begin{tabular}{|c|c|c|c|}
\hline $\mathrm{C} 03 / 4 / 8$ & $\mathrm{CO} 1$ & $\mathrm{C} 02$ & \\
\hline $\mathrm{Z}$ & $\mathrm{Z}$ & $\mathrm{Z}$ & Turf and topsoil \\
\hline Y & Y & Y & Scree deposits \\
\hline $\mathrm{X}$ & $\mathrm{X}$ & - & Collapse, disturbance and clay deposit \\
\hline W & W & $\begin{array}{l}\mathrm{X} \\
\mathrm{W}\end{array}$ & $\begin{array}{l}\text { Structure, floor, hearths, possible } \\
\text { surface and charcoal deposit }\end{array}$ \\
\hline $\mathrm{V}$ & $\mathrm{V}$ & $\mathrm{V}$ & Disuse/collapse (clay and slate deposits) \\
\hline $\mathrm{U} 2$ & - & $\mathrm{U}$ & Structure, floors, hearths and possible human activity \\
\hline $\mathrm{U} 1$ & - & - & Hearth and stake-holes \\
\hline $\mathrm{T}$ & - & $\mathrm{T}$ & Shillet levelling and soil development \\
\hline $\mathrm{S}$ & - & - & Clay floors \\
\hline $\mathrm{R}$ & - & - & Stake-holes, burning and floor levelling \\
\hline Q2 & - & - & Burning, fire-pit, stake-holes and concreted floor \\
\hline Q1 & - & - & Hearths, stake-holes and clay surface \\
\hline $\mathrm{P}$ & - & - & Shillet levelling \\
\hline $\mathrm{N}$ & - & - & Remains of walling \\
\hline M & - & S & Natural geology \\
\hline
\end{tabular}




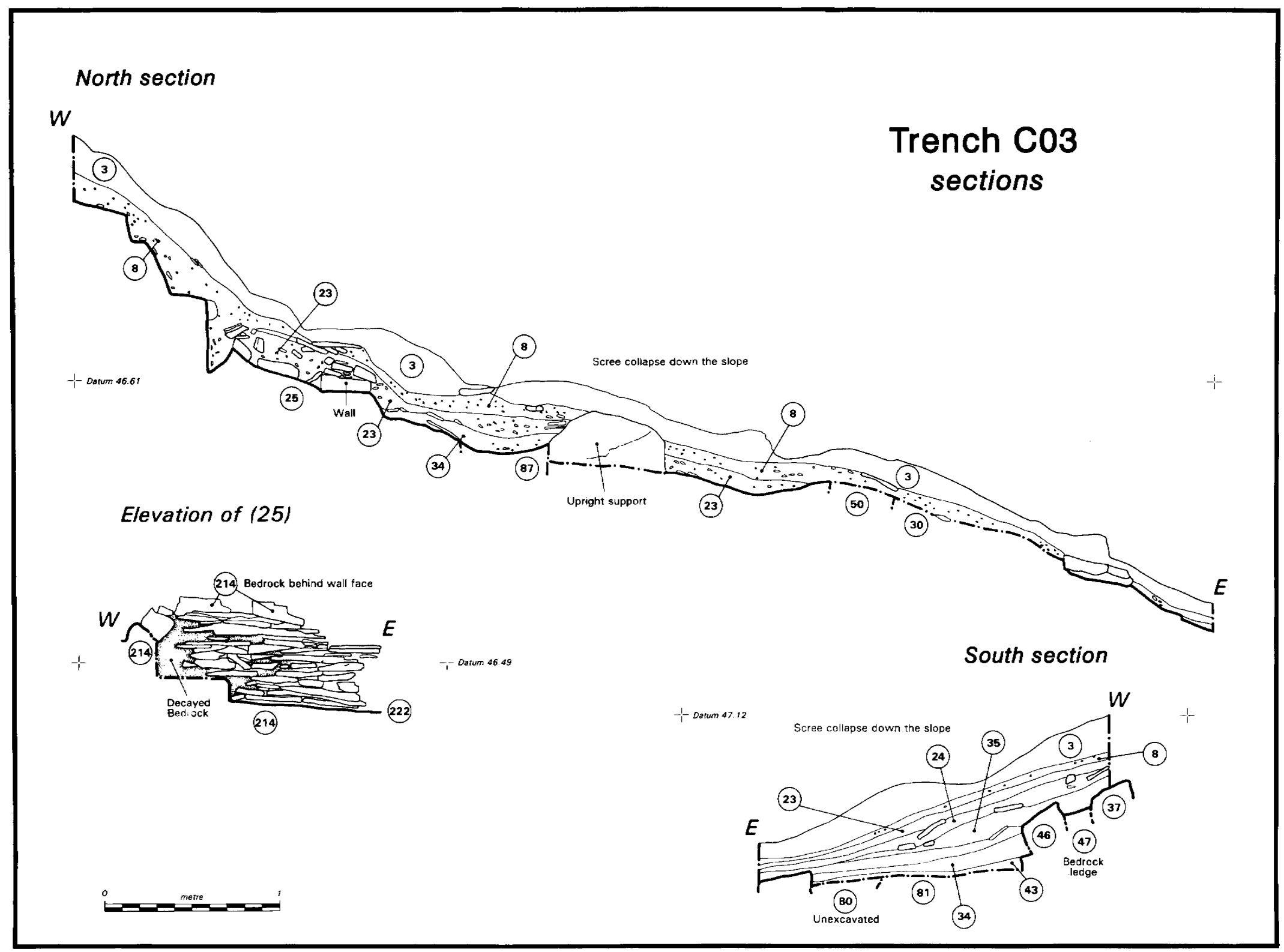

28 Trench C03 sections and elevation of wall (25). Drawing: L McEwan, after N Emery and R Harry (Harry and Morris 1997) 


\section{STRUCTURES AND STRATIGRAPHY}

In both Phase $\mathrm{S}$ of trench $\mathrm{C} 02$ and Phase $\mathrm{M}$ of area $\mathrm{C} 03 / 4 / 8$, the original configuration of the terrace can be appreciated with a prominent, roughly vertical, face at the west, with a stepped or ledged base, and with a curving northern limit to the terrace. In $\mathrm{C} 03 / 4 / 8$, the original flat 'shelf' (albeit with a slope away on the eastern edge towards the cliffs below) provided the base for later construction, and the earliest evidence for this was provided by the walling of Phase $\mathrm{N}$, although in a fragmentary state. Both in this phase and in the bedrock there is evidence for the rock providing the support for timber uprights, as part of such structures. There were remains of two walls, perhaps in a D-shape, in Phase $\mathrm{N}$ at the north east of the terrace, collapsing towards the sea. The occupation represented by these fugitive structures was clearly separated from the activity of Phase Q by a phase of shillet (Phase P) and clay levelling, probably deliberately placed to form a base for floors.

In the earlier part of Phase Q, as well as two possible floors, a notable 'box hearth' consisting of a square setting of flat and upright slabs (figure 29), and three burnt stake-holes, perhaps acting as a windbreak, were established. The charcoal of the hearth was associated with burnt bone, both animal and human. This was clearly the case also in Phase Q2, with the material found in association with an oval fire-pit 171/173 (from which sample UB-3883 was dated to cal AD 410-535) and a group of stake-holes acting again as a windbreak, on a second floor surface. Burning was the main activity (again with both animal and human material) in the succeeding phase (Phase R), where charcoal patches were found on clay floors, along with stake-holes. Further charcoal spreads were to occur in Phase $\mathrm{S}$ on further clay floors. Phase T (of both C03/4/8 and C02) represents an intermediate phase of shillet and scree-tips and soil development with little human activity evident, except through artefactual deposition, occasional carbonized material and a burnt area.

On top of the Phase T levels, in Phase U1, was constructed another hearth, of flat slabs, with associated stake-holes (figures 30 and 31). The second clearly defined structure, with a north-south wall of up to
29 Area C03/4/8 Phase Q1, box hearth (174), from the east.

Photograph: C E Batey (Harry and Morris 1997)

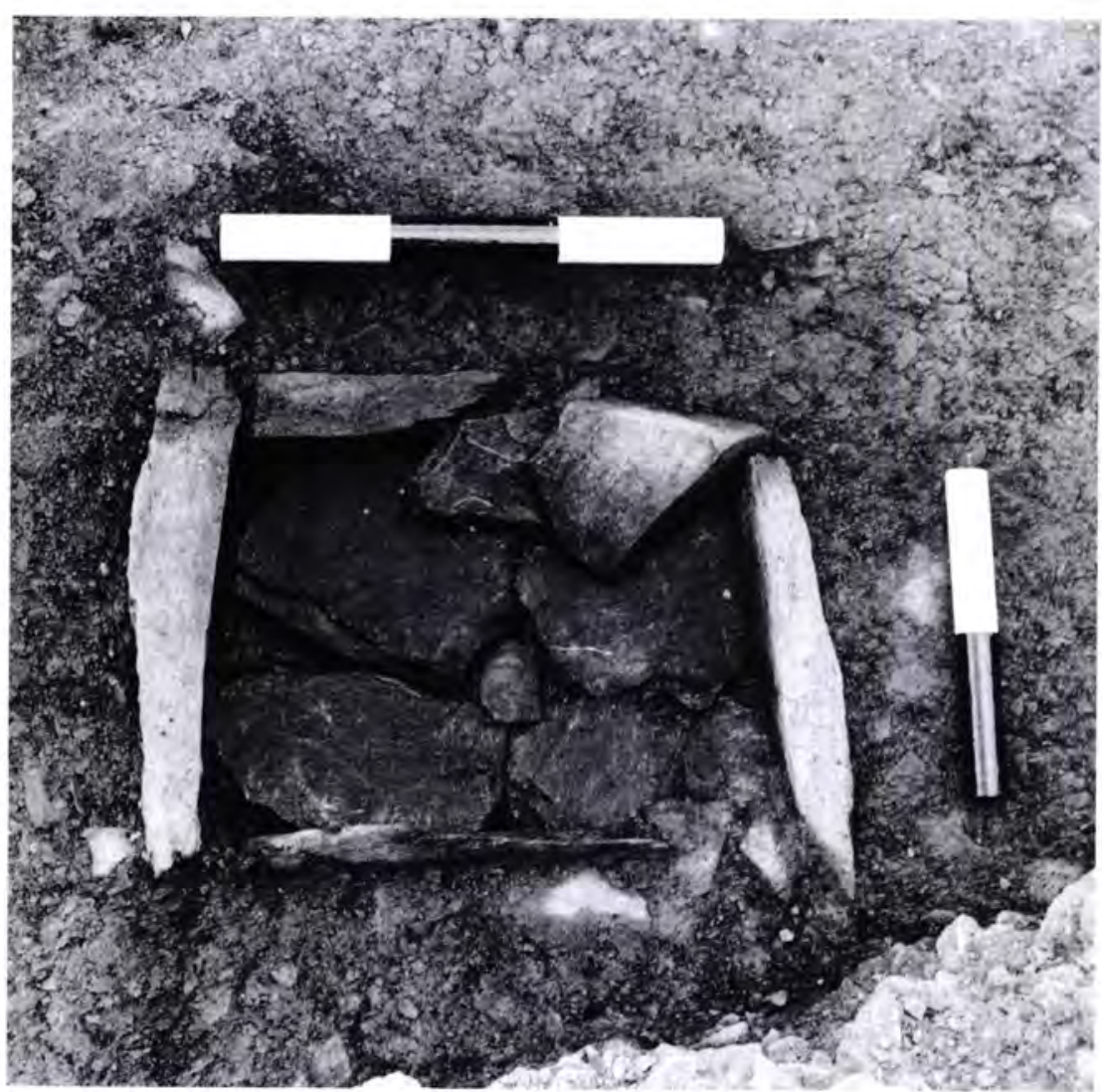




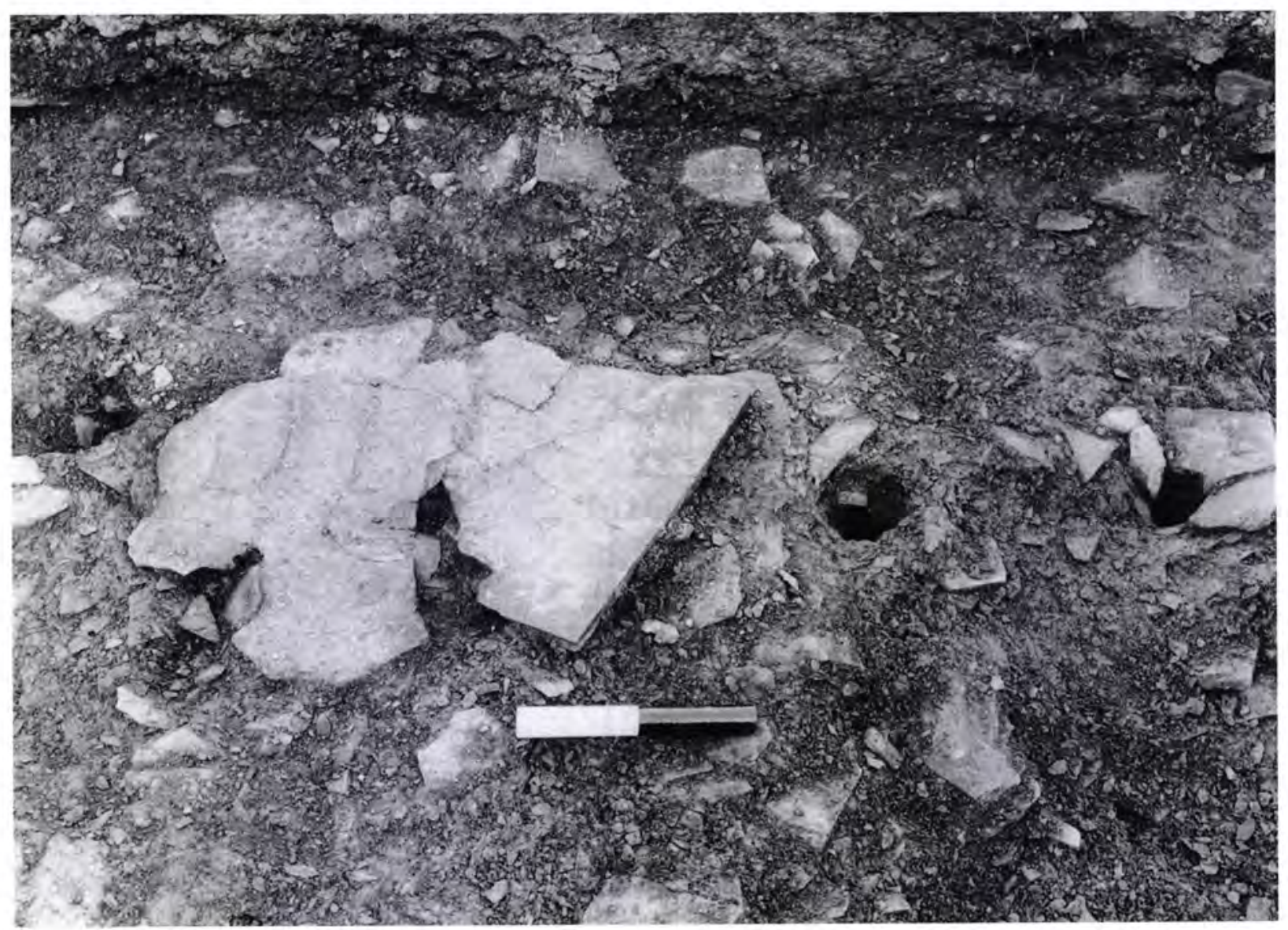

30 Area C03/4/8 Phase U1, hearth (139) / (140), with stake-holes (152) and (141), from the west.

Photograph: $R$ James (Harry and Morris 1997)

fifteen surviving courses and possibly with an earth core, is seen in Phase U2. Associated with this were upright slabs, a slot and a compacted floor surface. On the floor surface were two hearths, one a bowl-shaped depression or fire-pit (samples UB-3795 and UB-3796 dated to cal $\mathrm{AD} 395-445$ and cal $\mathrm{AD} 405-535$ respectively from hearth fill 126), the other a slab-lined sub-rectangular feature (sample UB-3797 dated to cal AD 420-550 from hearth fill 123) like the 'box hearth' of Phase Q1. Ash-dumping from hearths was also a feature of this phase. $\mathrm{C} 02$ also saw human activity in that vicinity with a stone surface and charcoal and burnt bone being present. This structure went out of use, and gradually collapsed - as recorded in Phase V. Clusters of slates, and clay deposits, as well as shillet, have been recognized both in area $\mathrm{C} 03 / 4 / 8$ and trenches $\mathrm{C} 01$ and $\mathrm{C} 02$. The artefactual assemblage includes a single example (RF 1933) of a setting of stones on edge which might have held a squared post in position, and a group of structural slates which would appear to have the function of supporting stake uprights for the various structures. While they were found in phases such as Phases N, R, S, U1 and U2 where actual structures or features implying structures nearby were found, the greatest concentration was in Phase $\mathrm{T}$, an intermediate phase of shillet levelling and soil development; we have to assume that they represent clearance of structures from the previous phase (S). Phases $\mathrm{S}$ and $\mathrm{T}$ have also produced examples of crudely finished possible roofing slates. The implication, then, from both structural evidence and artefactual recovery, is that there were a number of structures originally on this terrace, some perhaps of a relatively flimsy nature and which were replaced with some regularity. The implications of this will be explored further below.

In Phase $\mathrm{W}$ a third structure was erected on the site (figure 32). It appears to have been curvilinear, with 


\section{Area $\mathrm{C} 03 / 4 / 8$}

Phase U1, stake-

holes (149) and

(150), from above.

Photograph:

$R$ James (Harry and

Morris 1997)
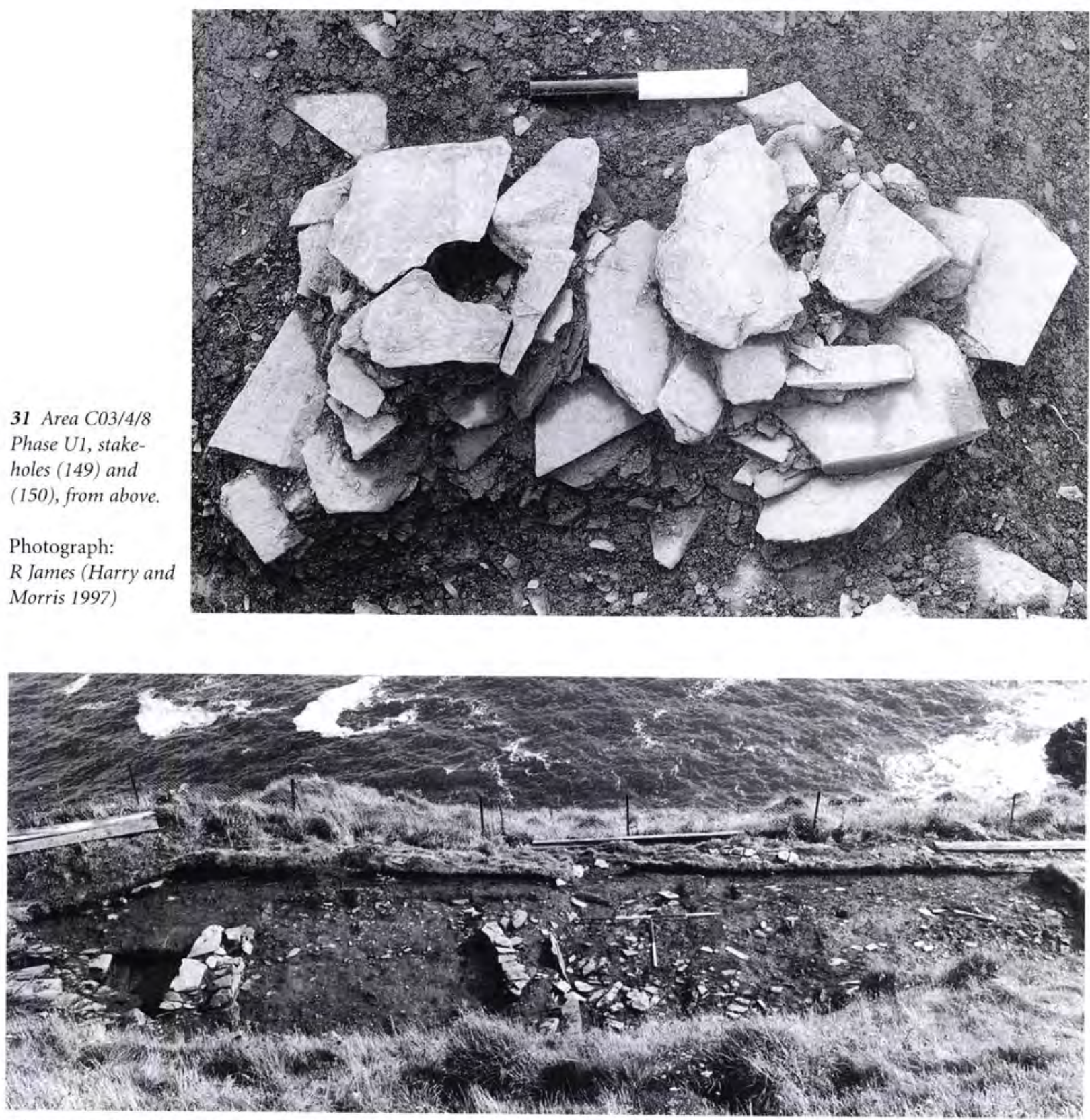

32 Area C03/4/8 Phase W structure from above, showing collapsed wall (97), in situ wall (51) and floor layer (105), from the west, above the terrace. Photograph: P G Johnson (Harry and Morris 1997)

roughly built slate walls (up to ten courses surviving) and a clayey floor deposit, with an associated oval hearth cut into it. A second floor deposit and another bowlhearth (sample UB-3799 dated to cal AD 340-435; and samples OxA-6002-6006, see table 5, from hearth fill 113) represent continued use of the structure. To both north and south, as well as in trenches $\mathrm{CO1}$ and $\mathrm{CO2}$, there were surfaces with activity contemporaneous with a possible surface (Phase $\mathrm{W}$ ) and a charcoal deposit (Phase X) in a hollow in C02, perhaps evidence of a second small structure to the south on this terrace.

The later phases in all trenches and areas represent collapse, disuse and subsequent scree deposition across the terrace. In Phase $\mathrm{X}$ of $\mathrm{C} 03 / 4 / 8$ surfaces were 


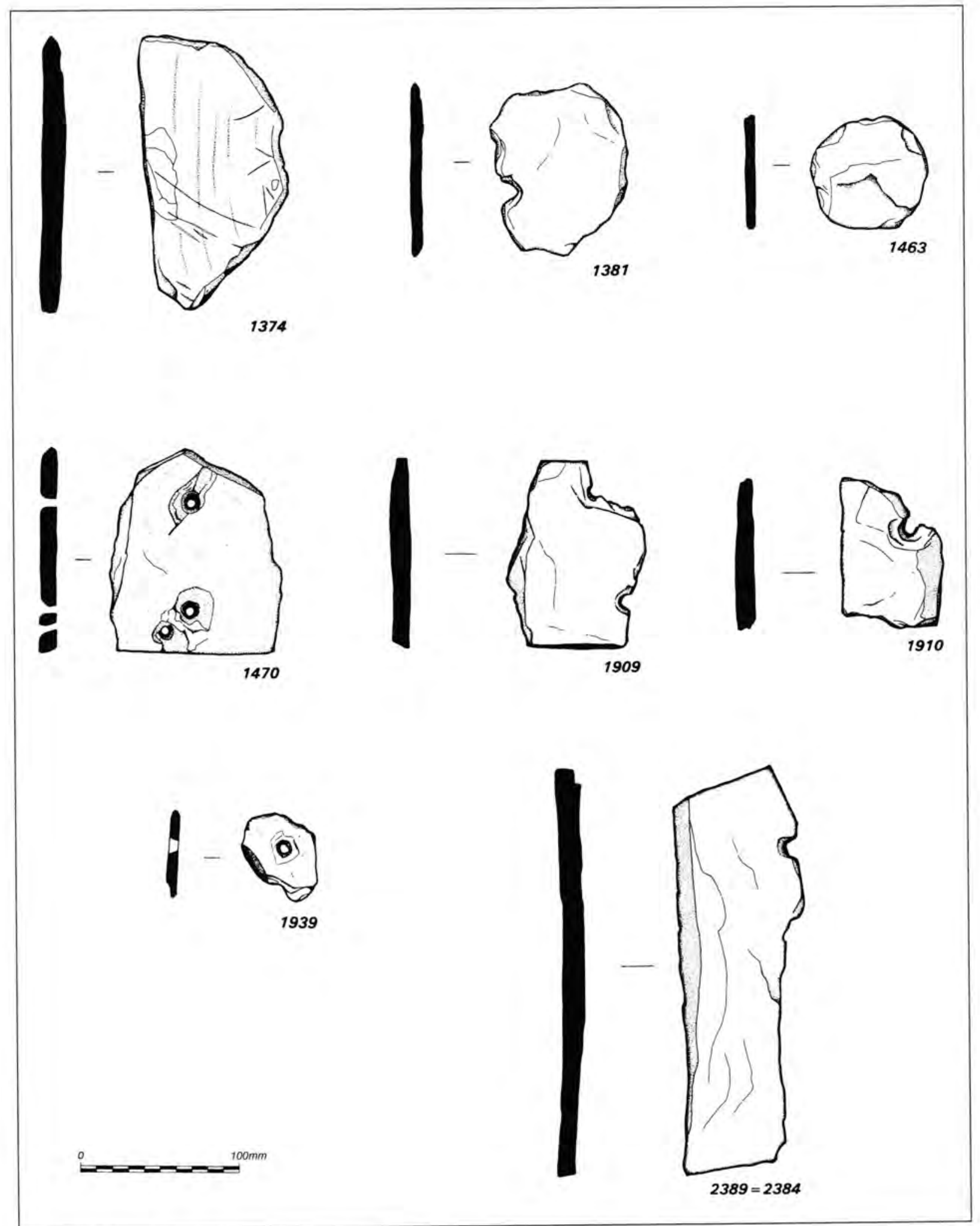

33 Firelighting slates and slate discs. Drawing: CM Thorpe (Harry and Morris 1997) 
recognized onto which stones from the structure had collapsed and on which significant artefactual material was deposited. In $\mathrm{C} 01$ a clay deposit was probably contemporary. Extensive scree deposits covered the whole area over a period of time in Phase $\mathrm{Y}$, to be covered by loamy topsoil and turf in Phase $\mathrm{Z}$.

\section{THE ARTEFACTUAL ASSEMBLAGE}

As well as finds of structural slates in Phases N, R, S, U1 and $\mathrm{U} 2$, and possible roofing slates in $\mathrm{S}$ and $\mathrm{T}$, other artefactual groups include different groups of stone: firelighting stones (thirty-three in all: figure 33), with again a concentration of examples in the possible clearance phase $(\mathrm{T})$ and some actually in situ in the sides of a hearth (Phase U1); a group of whetstones, including one possible touchstone (figure 34); groups of flints and worked quartz (figure 35), which could as well be contemporary as residual from an entirely hypothetical earlier prehistoric phase; worked and notched slates; water-worn pebbles, mostly quartz, for which a variety of purposes and origins may be postulated, with varying degrees of conviction; and twelve slate discs (eg see figure 33), some of which, with central perforations, may have been whorls, but most of which are probably potlids for the pottery vessels whose fragments were found in large numbers.

Non-stone finds (other than ceramics) were limited, but included a significant piece of vessel glass (RF 2376: see below) in Phase Q2 (see figure 34); small amounts of industrial debris, including a fragment of a crucible, which may indicate small-scale industrial working on the terrace in Phase V; a small conical lead weight also from Phase V (figure 34) and a number of carbonized stake-fragments.

Of the pottery found (table 3 and figure 36), the only later medieval sherd (thirteenth to fourteenth century in date) was in a late scree deposit (Phase Y), and so is not

34 Whetstone, glass and weight.

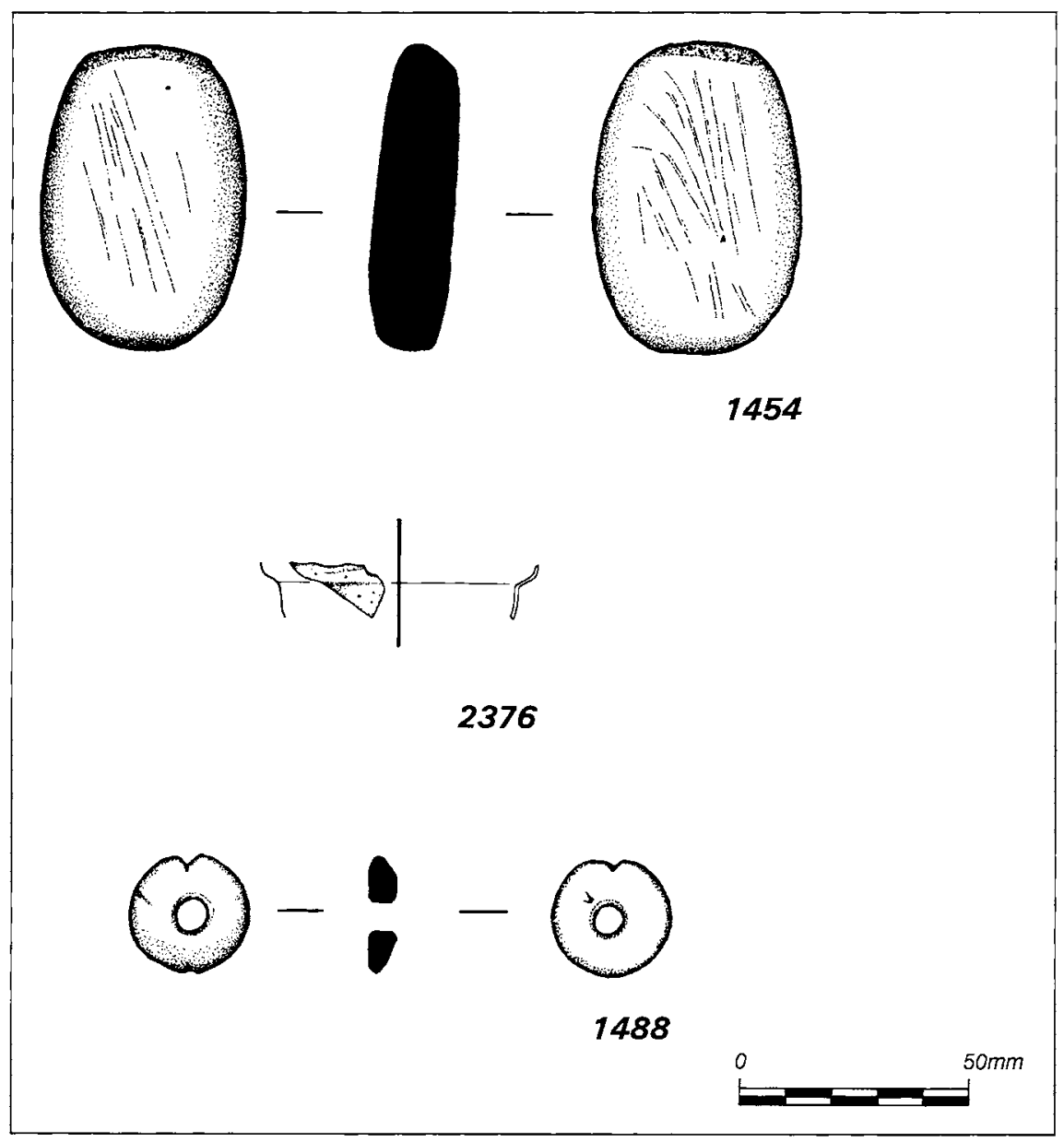

Drawing: CM Thorpe (Harry and Morris 1997) 


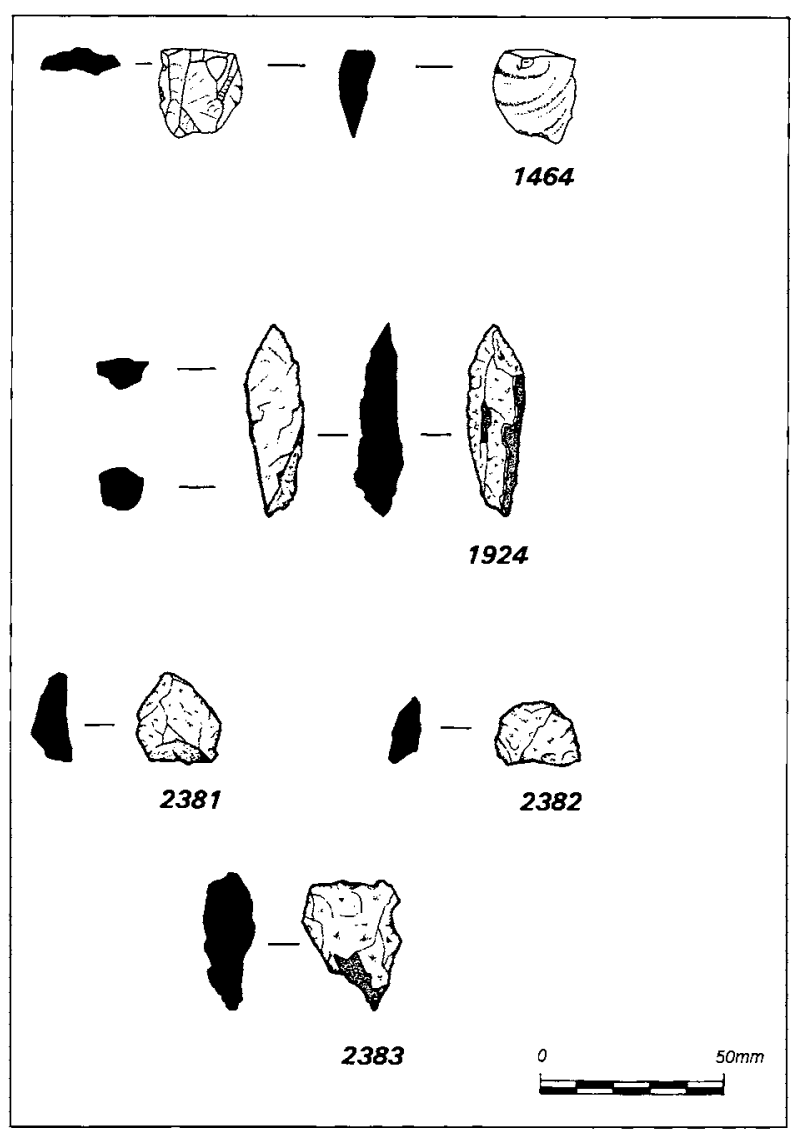

35 Flint and quartz. Drawing: CM Thorpe (Harry and Morris 1997) evidence of occupation on this terrace. On the other hand, with the Romano-British pottery, although seven of the sherds (including two Gabbroic and three Granitic wares) come from similar late deposits (and presumably relate to activity on a higher terrace or even the plateau of the Island), one sherd of Granitic ware in Phase $\mathrm{T}$ and several fragments of Local wares in contexts from Phases U1, V2 and especially U2 (several fragments of the same fourth-/fifth-century jar) are more reasonably seen as from usage on the terrace. However, only the single sherd in Phase U1 is unaccompanied by post-Roman material and Phase $\mathrm{T}$ below also contains one sherd of imported Mediterranean material, so the usage of this group is either late (ie fifth century) or, more probably, the material is mostly residual.

The imported Mediterranean pottery accounts for almost 84 per cent of the total but it is noticeable that very little of the fine table-wares, Phocaean Red slipped ware (PRSW) and African Red slipped ware (ARSW), is found on this site. Rather, over half of the total collection of pottery consists of fragments of storage vessels of wellknown types (Amphorae Bi, Bii, Biv and $\mathrm{Bv}$ ). The absolute numbers of sherds in each case are not enormous $(51,12,2$ and 12 respectively) by Tintagel standards, ${ }^{7}$ and it has been suggested that they may have come from a single vessel of each type. ${ }^{8}$ However, this suggestion would seem unlikely in view of the distribution by phase. In particular, although a large

Table 3 All pottery types from the Lower Terrace, expressed as a percentage of the total assemblage

\begin{tabular}{|c|c|c|c|c|c|c|c|c|c|c|c|c|c|c|c|}
\hline Trench & $B i$ & $B i i$ & Biv & $B v$ & ARSW & $\begin{array}{l}\text { Coarse- } \\
\text { ware } \\
\text { Fabric } \\
1\end{array}$ & $\begin{array}{l}\text { Coarse } \\
\text { ware } \\
\text { Fabric } \\
5\end{array}$ & $\begin{array}{l}\text { Coarse- } \\
\text { ware } \\
\text { Fabric } \\
21\end{array}$ & Uniden & $\begin{array}{l}\text { Roman } \\
\text { Gabbroic }\end{array}$ & $\begin{array}{l}\text { Roman } \\
\text { Granitic }\end{array}$ & $\begin{array}{l}\text { Roman } \\
\text { Local }\end{array}$ & Medi & $l$ Total & $\begin{array}{l}\text { Per } \\
\text { cent }\end{array}$ \\
\hline $\mathrm{C} 01$ & 2 & & & 3 & & 2 & & & & & & & & 7 & 4.6 \\
\hline $\mathrm{C} 02$ & 1 & 2 & & & & & & & 1 & & 1 & & 1 & 6 & 3.9 \\
\hline $\mathrm{C} 03$ & 11 & 2 & 1 & & & 4 & & & 5 & & & 1 & & 24 & 15.7 \\
\hline $\mathrm{C} 03 / 4$ & 18 & 4 & 1 & 6 & $? 2$ & 9 & 1 & & 7 & & 1 & 15 & & 64 & 41.8 \\
\hline $\mathrm{C} 04$ & 3 & 2 & & 2 & & & & & 2 & & & & & 9 & 5.9 \\
\hline $\mathrm{C} 03 / 8$ & & & & & & & & & 2 & & & & & 2 & 1.3 \\
\hline $\mathrm{C} 08$ & 16 & 2 & & 1 & & 1 & & 1 & 14 & 2 & 2 & 2 & & 41 & 26.8 \\
\hline $\begin{array}{l}\text { Total } \\
\text { Per }\end{array}$ & 51 & 12 & 2 & 12 & 2 & 16 & 1 & 1 & 31 & 2 & 4 & 18 & 1 & 153 & 100 \\
\hline cent & 33.3 & 37.8 & 1.3 & 37.8 & 1.3 & 10.4 & 0.7 & 0.7 & 20.3 & 1.3 & 2.6 & 11.8 & 0.7 & 100 & \\
\hline
\end{tabular}


36 Pottery. RF 1000 , Phase $Z, B v$ wall sherd. RF 1018, Phase Y, Bi rim sherd. RF 1090 , Phase Y, Bi wall sherd. RF 1096, Phase Y, RomanoBritish Local ware base sherd. RF 1093, Phase $X$, Bii handle sherd. RF 1370, Phase $X, B v$ handle sherd. RF 1360, Phase W, Bi wall sherd. RF 1078, Phase V, RomanoBritish Local ware rim sherd. RF 1480, Phase V, RomanoBritish Local ware wall sherd. RFs 1479 and 1487, Phases $V$ and $U 2$ respectively, Romano-British Local ware rim sherds. RF 1358, Phase T, RomanoBritish Granitic ware wall sherd.

Drawing: $C M$
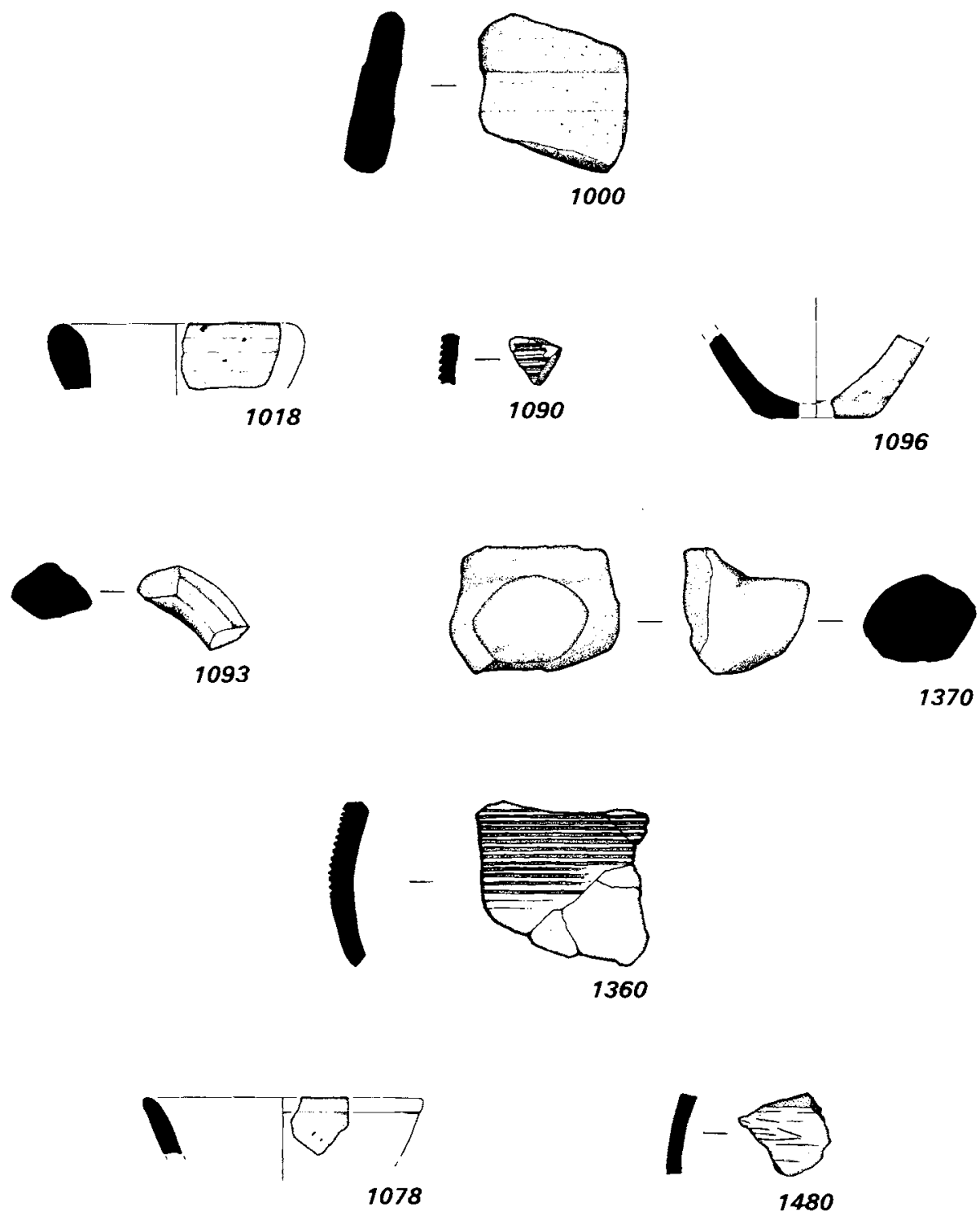

Thorpe (Harry and Morris 1997)
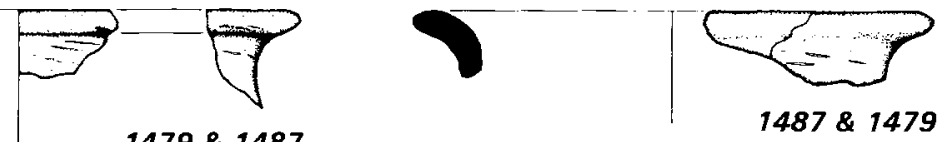

$1479 \& 1487$

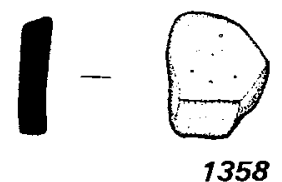

$100 \mathrm{~mm}$ 
number (twenty-six sherds of $\mathrm{Bi}$, Bii and $\mathrm{Bv}$ ) came from the disturbed deposit of Phase $Y$ (together with two other sherds from Phase $Z$ or unstratified), there was also a significant number from the various occupation phases (some forty-nine sherds of $\mathrm{Bi}, \mathrm{Bii}, \mathrm{Biv}$ and $\mathrm{Bv}$ ). Unless one assumes that all these deposits were subject to considerable post-depositional disturbance, effectively destroying the stratigraphy, the collections from the different phases should be treated as representing different deposits and originally different vessels. In addition, there were numbers of other imported coarsewares, mainly East Mediterranean Red Ware (Fabric 1), again spread across several phases. Although the range of imported material reflects a heterogeneous origin in the Mediterranean area, it is notable that the concentrations within the deposits are in those wares which it is suggested came from the eastern Mediterranean (ie Bi and Fabric 1). As with the material previously published from the Steps area watchingbrief," it is the case, as emphasized by Carl Thorpe, that the quantities of sherds (other than from fine tablewares) recovered from this part of the Tintagel site are comparable with the totals from the whole of major excavations at other comparable sites of the period (such as Dinas Powys, Dunadd and Cadbury Castle). ${ }^{10}$

It is of some interest also that the bulk of the slate discs (interpreted as stone pot-lids) relate to contexts from which imported pottery (both B-wares and coarsewares) are found, that is Phases $\mathrm{T}$ to $\mathrm{Y}$. The date range for occupation on this terrace in Phases $\mathrm{T}$ to $\mathrm{W}$ as deduced from the conventional dates of the imported pottery would, therefore, be mid-fifth to mid-sixth century, or possibly later, up to $\mathrm{AD} 600$ (taking the full ranges for $\mathrm{Bi}$ and $\mathrm{Bii}$ ).

The only other material that is datable by conventional means is the glass vessel sherd (RF 2376) from Phase Q2, of a type normally seen as typical of the later fourth century, but viewed as fifth century at some sites. Hilary Cool surmises that indented truncated conical bowls are typical of the second half of the fourth century and into the fifth on Romano-British sites. ${ }^{11}$ On the mainland of Europe, they continue to be used well into the fifth century. They are well represented in fifthcentury contexts at, for example, Bordeaux. ${ }^{12} \mathrm{Cool}$ concludes that on a site such as Tintagel, with its Continental contacts, a fifth-century date for this fragment could be as likely as the late fourth-century date which would be appropriate for most of the other examples in England. ${ }^{13}$

\section{THE ECOFACTUAL ASSEMBLAGE}

While the analysis of the artefacts from the recent work at Tintagel may legitimately be seen in the context of previous material deriving from the long history of investigations at the site, in the case of the ecofacts the situation is altogether different. The recovery of material from small samples taken during the watching brief on the Steps site indicated the potential, ${ }^{14}$ but the Lower Terrace was the first part of the site on which a systematic programme of ecofactual recovery was undertaken. Archaeobotanical material from secure fifth- to seventh-century deposits is rare, and especially so in this part of Britain, so although the assemblage recovered is small (table 4 ), it has an importance nationally as well as regionally.

In the charcoal assemblage it is clear that quite a wide range of trees and shrubs was exploited for fuel, with a preference for oak and hazel for construction: hazel especially for smaller posts or wattles and presumably oak for larger posts and beams. Although little is known from pollen records showing vegetation changes before the medieval period, prehistoric vegetation was clearly dominated by hazel and oak; there is some relict oak woodland further up the coast. It is likely that the species identified could have grown locally. The implication, therefore, is that the timber need not have been imported from very far away, and that basic necessities of heat and shelter could be supplied from local resources.

Likewise, among the plant remains there is nothing that could not have been grown locally; no exotic foodstuffs such as might have been imported are in evidence from the environmental samples. However, the identification of cereals is of considerable interest, even though it cannot be shown that cultivation took place on the Island itself. The implication of this is that there was an inter-relationship between the Island and its hinterland. Barley and particularly oats are represented throughout the deposits (definitely from Phase Q1 and possibly earlier), with wheat only occurring in the later deposits (Phases $\mathrm{X}$ and $\mathrm{Y}$ ) after active usage of the site had ceased. The presence of various weed seeds, especially from Phase Q2, implies the existence of arable fields and suggests that the cereals, while they may have been grown and harvested unripe (and partially cleaned) away from the Island, were cleaned here prior to consumption of the 'prime grain'.

The waste from cleaning may well have been given to animals as fodder, even if the oats and barley themselves 
Table 4 Summary of plant macrofossils from Area CO3/4/8

\begin{tabular}{|c|c|c|c|c|c|c|c|c|c|c|c|c|}
\hline Taxon & Common name & $P$ & Q1 & $Q 2$ & $R$ & $T$ & $U 1$ & $U 2$ & $V$ & $W$ & $X$ & $Y$ \\
\hline \multicolumn{13}{|l|}{ Cereals } \\
\hline Avena sp. & oats & & & 0 & 0 & & & 0 & 0 & 0 & $\square$ & $\square$ \\
\hline Avena / Hordeum sp. & oats / barley & & & & & & & 0 & & & & \\
\hline Hordeum sp. & barley, hulled & & & 0 & 0 & 0 & & $\mathrm{O}$ & 0 & 0 & $\square$ & $O$ \\
\hline Hordeum sp. & barley, naked & & & & & & & 0 & & & & \\
\hline Hordeum sp. & barley & & 0 & 0 & 0 & & & $\bigcirc$ & 0 & 0 & 0 & $\bigcirc$ \\
\hline Triticum sp. & wheat & & & & & & & & & & O & O \\
\hline Cereal sp. & cereal NFI & 0 & 0 & 0 & $\bigcirc$ & & & 0 & 0 & 0 & 0 & 0 \\
\hline \multicolumn{13}{|l|}{ Other taxa } \\
\hline Chenopodium sp. & goosefoot & & & $\square$ & 0 & & & $\square$ & & & & \\
\hline Chenopodium rubrum / glaucum & red / glaucous goosefoot & & & & $\bigcirc$ & & & 0 & & & & \\
\hline Chenopodium album $\mathrm{L}$. & fat hen & 0 & & $\bullet$ & $\square$ & & & $\bigcirc$ & & & & \\
\hline Chenopodium / Atriplex (no testa) & goosefoot / orache & & & $\bullet$ & 9 & & & $\bullet$ & & & & \\
\hline Atriplex sp. & orache & & & 2 & - & & & 0 & & & & \\
\hline Cerastium sp. & mouse-ear & & & O & & & & $\bigcirc$ & 0 & & & \\
\hline Stellaria media L. & common chickweed & & & & 0 & & & $\bullet$ & O & 0 & $\bigcirc$ & \\
\hline Polygonum persicaria L. & redshank & & & O & & & & $\bigcirc$ & & & & \\
\hline Polygonum aviculare $\mathrm{L}$. & knotgrass & & & $\square$ & $\square$ & & & $\bullet$ & & & & 0 \\
\hline Malva sp. & mallow & & & & & & & & & 0 & & \\
\hline Brassicaceae NFI & cabbage family & & & & & & & 0 & & 0 & & \\
\hline cf. Empetrum nigrum L. & crowberry & & & & & & & & & & 0 & \\
\hline Rubus sect. Glandulosus & blackberry & & & $\square$ & 0 & & & & & & & \\
\hline cf. Filipendula ulmaria (L.) Maxim. & cf. meadowsweet & & & & & & & 0 & & & & \\
\hline Lathyrus / Pisum & vetch / pea & & & 0 & 0 & & & & & & & \\
\hline Medicago / Trifolium sp. & medick / clover & & & & 0 & 0 & & 0 & 0 & 0 & & $\square$ \\
\hline Trifolium spp. & clovers & & & & & & & & & & $\square$ & $\mathrm{O}$ \\
\hline Trifolium cf. dubium Sibth. & cf. lesser trefoil & & & & & & & & & & $\square$ & 0 \\
\hline Apiaceae NFI & carrot family & & & & & & & & 0 & & & \\
\hline Apium graveolens $\mathrm{L}$. & wild celery & & & & 0 & & & & & & & \\
\hline Veronica sp. & speedwell & & & $\bigcirc$ & & & & & & & & \\
\hline Galium sp. & bedstraw & & & 0 & & & & & & & & \\
\hline Asteraceae NFI & daisy family & & & $\bigcirc$ & & & & & & & & \\
\hline cf. Cyperaceae NFI & sedge $(s)$ & & & & & & 0 & 0 & & & & \\
\hline Carex $\mathrm{sp}(\mathrm{p})$ & sedge family & & & & & & & 0 & & & & \\
\hline Eleocharis palustris / uniglumis & spike-rush & & & & & & & & & & 0 & \\
\hline Juncus sp. & rush & & & & $\square$ & & & & & $\bullet$ & & \\
\hline Luzula sp. & woodrush & & & & $\square$ & & & & & & & \\
\hline Poaceae & grasses & & & 0 & $\square$ & & & & & & $\bigcirc$ & \\
\hline Poaceae (length $1 \mathrm{~mm}$ and $<$ ) & grasses & & & & & & $\square$ & 0 & & & & \\
\hline Poacaeae (length $1.5-2 \mathrm{~mm}$ ) & grasses & & & & & & 0 & $\mathrm{O}$ & & 0 & & \\
\hline cf. Phleum sp. & cf. cat's tail & & & & & & & & & 0 & & \\
\hline Bromus hordaceus / secalinus & soft / rye brome & & & & & & & & & & 0 & 0 \\
\hline Total & & 0 & O & $\diamond^{*}$ & $\bullet$ & 0 & $\square$ & $\iota^{*}$ & $\square$ & $\bullet$ & $\bullet$ & - \\
\hline Items / L & & .11 & 63.6 & 18.7 & 10.6 & .1 & 72 & 9.4 & .2 & 3.2 & .5 & .2 \\
\hline
\end{tabular}

Total nos: 0-10: O; 11-50: $\square$; 51-100: O; >100: ; >500: *

cf. Avena sp. and Avena sp. combined 
were not. Even some of the grassland weeds can be explained as weeds of arable plants as easily as by more obvious explanations such as having been brought in with turfs for fuel and with animal fodder. Blackberry, crowberry, wild celery and vetch or pea, although found in tiny numbers, nevertheless point to a variation in diet on the site at different periods. Some remains are equivocal: sedge and spike-rush may have been arable weeds or alternatively from roofing or flooring material, the latter is also implied by the charred rush and woodrush seeds. Some of the charcoal may also imply the availability nearby of other edible resources: bramble, apple and pear all make their appearance in these deposits.

The biggest disappointment from the point of view of interpretation of diet is the absence, due to the acidity of the soil, of uncarbonized bone from this site. From very late contexts some fragments of animal teeth have been recovered, but otherwise the only bone material to be recovered is burnt. Even so, the presence of burnt animal bone would not have been surprising, given the presence of domestic hearths and the convenience of waste disposal by that means.

What was quite unexpected was the identification of carbonized human bone, not merely from one particular deposit (although it comprised about half of the identified material), but from three (Phase Q1 box hearth fill 175, Phase Q2 stake-hole fill 178 and Phase R burnt patch 157) of the five contexts in which identification of the carbonized bone was possible. Moreover, the burning of the bone had probably not occurred either in cooking or by accidental burning in campfires etc. Accidental burning would be expected to result in a range of colours, reflecting temperature range, and cooking would result in charring rather than burning. It would seem therefore that these bone fragments represent either cremations or material deliberately burnt as rubbish. ${ }^{15}$ The suggestion of human cremation on the site in Phases Q1, Q2 and R is quite dramatic and adds an entirely new dimension to the understanding of the nature of the site. Although there can be no doubt that burning took place in situ within the box hearth (175), it seems unlikely, from the nature of the hearth fill, that a constant high temperature was maintained, and certainly not the constant temperature required to produce the uniform colour of the burnt bone. The remaining fragments of burnt bone were recovered scattered through a patch of charcoal (157) and a stake-hole fill (178). There is therefore nothing to suggest that the bone fragments were burnt within the areas excavated on the Lower Terrace; they could have been from pyres elsewhere on the Island.

Although inhumation was the dominant burial rite in Britain by the fourth century, occasional examples of cremation are known. By the late fourth/early fifth century, cremation is rare and unusual anywhere in the British Isles except in an Anglo-Saxon context where there is a preponderance of evidence in the fifth to sixth centuries $\mathrm{AD}$, with some falling later. Lucy's major study of Anglo-Saxon burial traditions naturally focuses on Eastern England and it is clear that in Cornwall there was no native tradition of cremation. ${ }^{16}$

\section{DATING}

The carbonized material was potentially capable of dating by radiocarbon and had come from deposits underlying those with imported pottery conventionally dated to the fifth to seventh centuries AD. Some of the little-understood, poorly dated Romano-British pottery was also associated with the carbonized material. In particular, large quantities of charcoal from hearths in Phases Q2, U2 and W provided the opportunity for Bayliss and Harry ${ }^{17}$ to apply independent, absolute forms of dating to the deposits upon this terrace. Six samples were analysed in 1994-5 at the Queen's University, Belfast, Radiocarbon Laboratory, and a further five measured by the Oxford Radiocarbon Accelerator Unit in 1995. Both laboratories maintain continual programmes of quality assurance procedures, in addition to participation in international intercomparison studies. ${ }^{18}$ These tests indicate no laboratory offsets and demonstrate the validity of the precision quoted. Samples were processed in Belfast according to methods outlined in McCormac et al. ${ }^{19}$ Samples processed by Oxford were prepared using the methods outlined in Hedges et al. ${ }^{20}$ The results are given in Table 5 , quoted in accordance with the international standard known as the Trondheim convention; ${ }^{21}$ they are conventional radiocarbon ages. ${ }^{22}$

The calibrations of these results, which relate the dating evidence directly to the calendrical time scale, are given in Table 5 and Figure 37. All have been calculated using the dataset published by Stuiver and Pearson and the computer program OxCal (v2.17). ${ }^{23}$ The calibrated date ranges cited in the text are those for 95 per cent confidence. They are quoted in the form recommended 
Table 5 Radiocarbon results

\begin{tabular}{llllll}
\hline $\begin{array}{l}\text { Laboratory } \\
\text { number }\end{array}$ & Context & Phase & $\begin{array}{l}\text { Radiocarbon } \\
\text { age }(B P)\end{array}$ & $\delta^{13} \mathrm{C}(\%)$ & $\begin{array}{l}\text { Calibrated date } \\
\text { range (95 per cent confidence) }\end{array}$ \\
\hline UB-3795 & 123 & U2 & $1617 \pm 18$ & $-26.4 \pm 0.2$ & cal AD 395-445 \\
UB-3796 & 123 & U2 & $1605 \pm 20$ & $-26.3 \pm 0.2$ & cal AD 405-535 \\
UB-3797 & 126 & U2 & $1569 \pm 18$ & $-26.6 \pm 0.2$ & cal AD 420-550 \\
UB-3798 & 126 & U2 & $1607 \pm 20$ & $-25.4 \pm 0.2$ & cal AD 400-530 \\
UB-3883 & $171 / 173$ & Q2 & $1595 \pm 18$ & $-25.8 \pm 0.2$ & cal AD 410-535 \\
UB-3799 & 113 & W & $1645 \pm 22$ & $-26.0 \pm 0.2$ & cal AD 340-435 \\
OxA-6002 & 113 & W & $1490 \pm 50$ & -26.2 & cal AD 430-660 \\
OxA-6003 & 113 & W & $1550 \pm 45$ & -25.0 & cal AD 410-610 \\
OxA-6004 & 113 & W & $1430 \pm 45$ & -26.1 & cal AD 540-670 \\
OxA-6005 & 113 & W & $1705 \pm 50$ & -25.5 & cal AD 220-430 \\
OxA-6006 & 113 & W & $1565 \pm 45$ & -26.2 & cal AD 400-600 \\
\hline
\end{tabular}

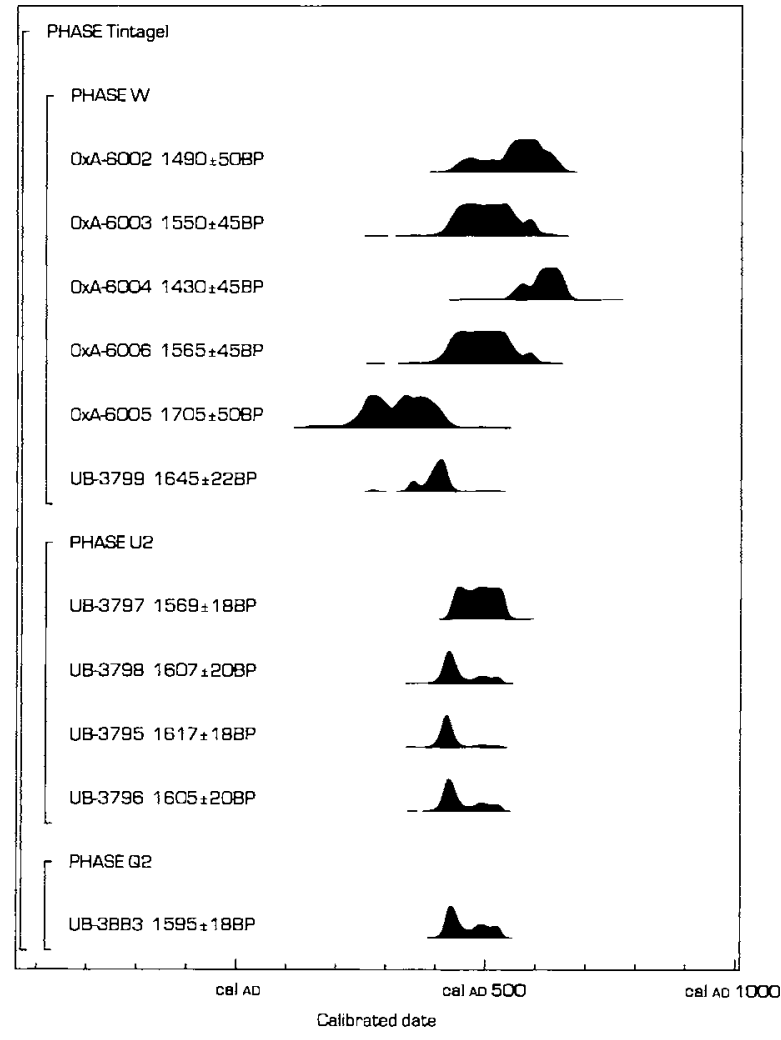

37 Calibration of radiocarbon results (Harry and Morris 1997)

by Mook, with the end points rounded outwards to 5 years where the error term is \pm 25 years or less, and to 10 years for error terms larger than this. ${ }^{24}$ The ranges in Table 5 have been calculated according to the maximum intercept method, ${ }^{25}$ all other ranges are derived from the probability method. ${ }^{26}$ Ranges given in italic type are derived from mathematical modelling of archaeological problems (see below).

Although the calibrated dates shown in Table 5 and Figure 37 are accurate representations of the dates of the samples, a better estimate of the date of the features is provided by the mathematical model, which includes the relative order provided by the stratigraphy along with the radiocarbon results.

When the initial series of six results from Belfast were analysed, however, this model proved statistically inconsistent at 95 per cent confidence (figure 38). The index of agreement values for UB-3799 (6.8 per cent) and overall (29.5 per cent) suggested that radiocarbon evidence strongly contradicted the stratigraphic position of (113), Phase $\mathrm{W}$, in the sequence. ${ }^{27}$ The stratigraphic position of (113) was checked and found to be reliable. This suggested that either the radiocarbon measurement (UB-3799) was inaccurate or the interpretation of the taphonomy of the charcoal within (113) was faulty. In fact UB-3799 had caused problems in analysis because of a slight quench, ${ }^{28}$ although re-measurement produced almost identical results and so was believed to be accurate. However, further examination of (113) in the light of earlier hearths excavated on the Lower Terrace ((123) and (126), Phase U2), suggested that the burnt material within (113) could have been redeposited and not burnt in situ as first thought. Crucially, there was no evidence of a burnt surface below the fill once excavated, despite the fill itself containing burnt flakes of scree and burnt soil, suggesting that burning had indeed not taken place at that location. 


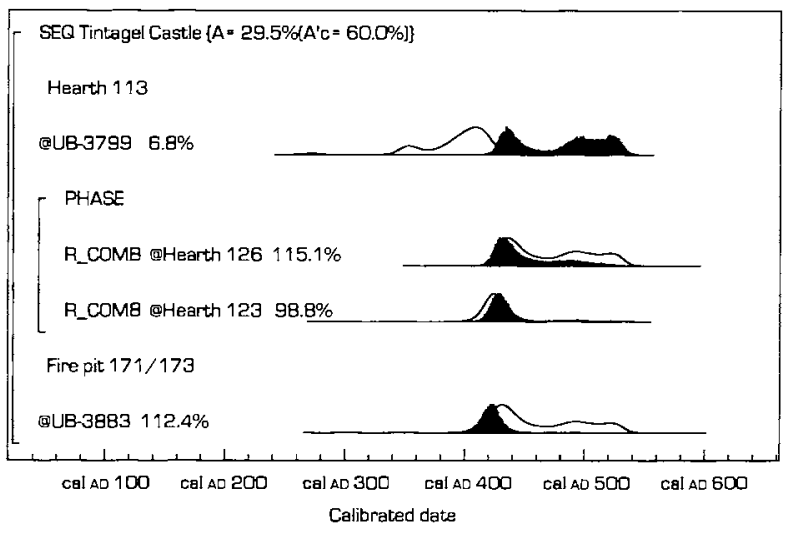

38 Mathematical model of radiocarbon dating results, showing inconsistency of 113 at 95 per cent confidence. @ indicates mathematically modelled date (Harry and Morris 1997)

In order to check whether this reinterpretation of the taphonomy of (113) was reasonable, five further samples from the deposit were submitted for Accelerator Mass Spectrometry (AMS) dating (table 5; figure 37). These five results were statistically significantly different at 95 per cent confidence, ${ }^{29}$ although if an (invalid!) weighted mean was taken of them this was not significantly different from UB-3799. This suggested that the original determination was accurate, but demonstrates that (113) did contain material of different ages. In fact this was likely to be residual material, as the oldest of the AMS dates (OxA-6005) was from a piece of Ulex sp./Cytisus sp. charcoal. This species burns particularly efficiently and so is often collected as fuel; it also rarely reaches a size larger than twigs and so is extremely unlikely to have been collected as driftwood.

For this reason an alternative model for the dating of this area of Tintagel was suggested (figures 39 and 40). This suggested that the best estimate for the deposition of (113) was the last dated event represented by the determinations, on the principle that a context must date to the latest material within it. It is only the estimated date for this event which must be later than Phase U2, since the lack of a functional relationship between the material within the context and the context itself allows residual items of any age to be contained within (113).

This model produced an estimated range for the last dated event in context 113 of cal AD 560-670 (95 per cent confidence). This range is also a terminus post quem for the building in Phase $\mathrm{W}$, and was perhaps rather later than might be expected for the associated ceramics.

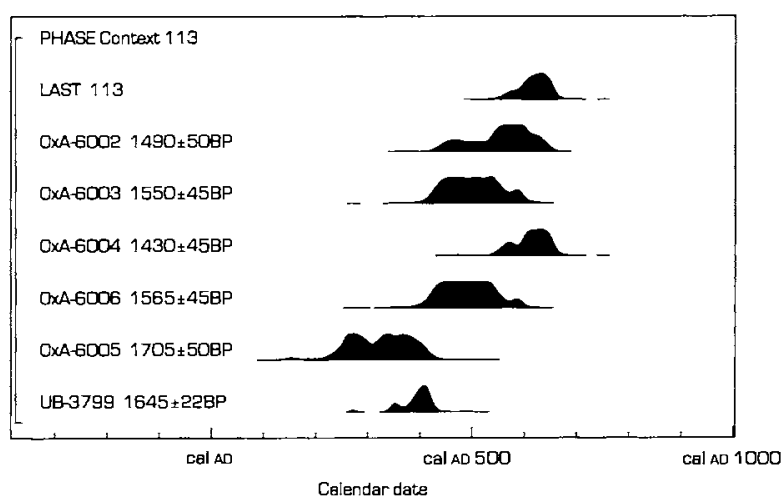

39 Alternative mathematical model for dating of 113 (Harry and Morris 1997)

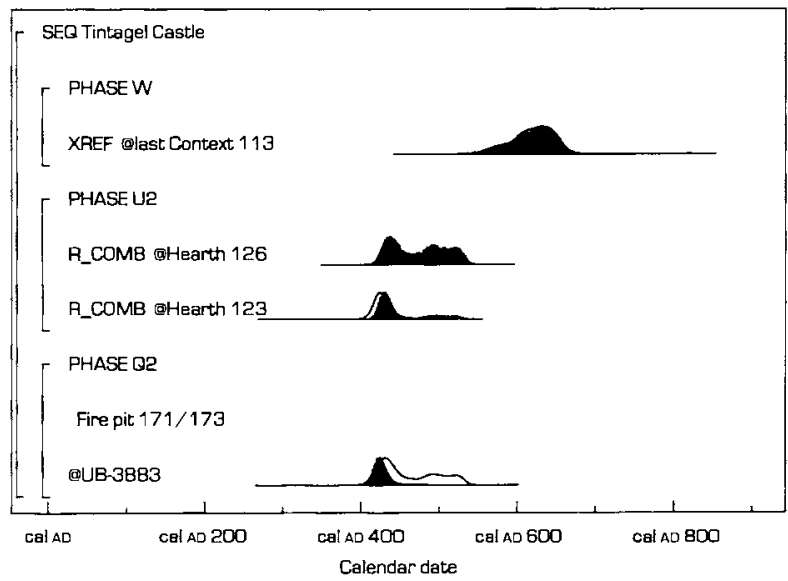

40 Alternative mathematical model for dating of all contexts. @ indicates mathematically modelled date (Harry and Morris 1997)

However, the pottery was in a severely abraded state and while this certainly may be attributed in part to the acidity of the soil on the site it may also be an indication that the pottery was in use for a longer period than was first anticipated.

The estimated date ranges for hearth 123 were $\mathrm{Cal} A \mathrm{D}$ 415-460 (74 per cent confidence) or cal AD 480-530 (21 per cent confidence) and for hearth 126, cal AD 425-535 ( 95 per cent confidence). Thus the hard fabric burnished Romano-British sherds are in a context dated to the fifth or very early sixth century. The relative date of the two hearths in Phase U2 was difficult to estimate, although it was thought quite likely by Bayliss that hearth 123 was earlier (77 per cent confidence). The estimated date range for the remaining fire-pit $171 / 173$ was cal $\mathrm{AD}$ 395-460 (95 per cent confidence). 
Despite some difficulties, the radiocarbon dating programme resulted in some significant conclusions: the fire-pit (171/173) dated in Phase Q2 was found to be early to mid-fifth century in date, suggesting that the sherd of glass (RF 2376) found within that phase was already of some antiquity when deposited at the site. The two hearths (123) and (126) dated in Phase U2 were shown to date to the fifth to early sixth century, and the problematic deposit (113) in Phase $W$ was estimated to be rather later than expected, cal AD 560-670 (95 per cent confidence). This may suggest that the ceramics in Phase $\mathrm{W}$ were used for rather longer than originally anticipated. The secure stratification of the pottery sherds from Phase W, especially those from floor layer (105), could also support either a longer period of use for the imported pottery than first anticipated, or the importation of soil from elsewhere on the site in the building of the Phase $\mathrm{W}$ structure and levelling for the floor.

The mathematical modelling of the radiocarbon results also suggested that it was very likely that Phases Q2 and U2 took place within a relative short space of time as the gap between the two phases was estimated as very likely to be less than fifty years ( 93 per cent confidence). However, there was also a slight hiatus between Phases $\mathrm{U} 2$ and $\mathrm{W}$, since the gap between them was estimated as likely to be more than fifty years ( 95 per cent confidence). This could support a repeated shortlived, possibly seasonal, occupation on the terrace. This hiatus is also borne out by the layers of considerable structural collapse (Phase $\mathrm{V}$ ) excavated from between Phases U2 and W.

The implications for stratigraphical and structural interpretation are not insignificant. In the first place, the results from, and subsequent re-examination of, the material from Phase $\mathrm{W}$ demonstrated that deposit (113) was composed of material redeposited from elsewhere and not burnt in situ. Perhaps of more significance was the fact that it gave a terminus post quem (95 per cent confidence level) for the building in Phase W. This building, the third on the site, is potentially considerably later than the mid-sixth century. The activities of the succeeding phase, representing the collapse of the building, obviously post-date this, and include imported pottery, although this is presumably not in situ.

Before Phase $\mathrm{W}$, the period of disuse and collapse represented by Phase $V$ would appear to have lasted at least fifty years, as suggested by the terminus post quem provided by the estimated date ranges for the hearth-fills
(123 and 126) from Phase U2. In addition, the various activities of Phases $\mathrm{U} 1$ to $\mathrm{R}$, between dated phases Q2 and $U 2$, appear to have happened in less than fifty years and suggest successive short-lived, possibly seasonal activity at the site.

The fire-pit of Phase Q2 (171/173) is important not only in itself, but because it is contemporary with the middle group of human bone distinguished as possibly deriving from cremation activities. It also gave an estimated date range to these activities of the late fourth to fifth centuries, and a terminus ante quem of cal $\mathrm{AD}$ 395-460 for the preceding structure, the first recovered from the site, of Phase N. Although there were no datable artefacts recovered which could be associated directly with this structure, it is perhaps not unreasonable to suggest that it is late Roman in date. The absence of imported pottery, and the presence from Phase $\mathrm{T}$ onwards of apparently late Roman pottery types, ${ }^{30}$ some of which could be residual, would appear to indicate an earlier date for this structure.

\section{THE LOWER TERRACE IN CONTEXT}

The previous sections have focused upon the direct evidence from the excavations themselves. Perhaps it is worth emphasizing that the structural remains of Phases $\mathrm{N}, \mathrm{U} 2$ and $\mathrm{W}$ were far from substantial, and not strictly comparable with the buildings which were excavated elsewhere at the site during the 1930s and laid out (if not actually reconstructed) for the benefit of the visitor to the site, which Thomas now suggests are Period IV (ie later medieval). Of more immediate relevance, perhaps, are the groups of structures uncovered during the fire in 1983 and subsequently surveyed. A distinction could be made at that time between fairly substantial, rectangular buildings and those which tended to a more 'square plan, with walls consisting of 'lines of shillet ie thin, flat pieces of local "slate", often no more than 20-30m [sic, recte cm] across, on top of and in a matrix of soil, small stone and myriad fragments of shillet ... the impression is that the "walls" are but a few courses high and little more than footings, perhaps for turf walls and/or timber-framed structures .... 31 Thomas has more recently observed that, at one point on the burnt area, it was possible to observe a series of small holes in the bedrock, representing the points where stakes were hammered through the low turf walls to keep them in place. ${ }^{32} \mathrm{He}$ interprets these as 'bivouacs' with temporary roofs, a 'Period II camp-site'. Further, it was observed that '... structures proper to the 
5th-7th centuries $\mathrm{AD}$ ought to be with low walling of curvilinear or miscellaneously-shaped ground plans, and with evidence of post-holes as principal structural elements ...; $; 3$ and one example from Site B is illustrated as an example and as a parallel to the structure(s) on the Lower Terrace of Site C. ${ }^{34}$

This would suggest, then, that the evidence from the Lower Terrace contains both of these elements. The archaeological evidence from Phase $\mathrm{N}$ both of postsupports set into the bedrock and of fragmentary wall remains in that phase would perhaps incline one to see modest, but reasonably well-built buildings at an early stage of the structural history of the site. The evidence discussed for structural slates from Phase $\mathrm{N}$ onwards would perhaps support the notion of fairly regular replacement, while the presence of a series of hearths and floor surfaces between Phases Q and U1, often with lines of stake-holes (interpreted as acting as windbreaks, but conceivably also having a more obviously structural function in relation to putative turf walls), here also indicates more intermittent occupation of this terrace or platform. The concentration of structural slates from Phase $\mathrm{T}$ (argued to be from Phase $S$ originally), together with possible roofing slates from Phases $S$ and $T$, also indicate regular rebuilding here. 'Summer quarters', 'bivouacs', 'simple structures of turf and stone' are the descriptions used by Thomas ${ }^{35}$ to describe the structures from the plateau and there is nothing from the material from the Lower Terrace which need contradict this.

It is only with the low, rather irregularly shaped, but neatly stone-walled structure of Phase U2 (subsequently rebuilt in Phase $\mathrm{W}$ ) that we have structural remains which would then go with the description of the 'structures proper to the 5th-7th centuries AD'. These buildings are known from elsewhere in Cornwall, although they are altogether slighter in construction than the buildings associated with the 'Rounds'. Trethurgy Round, for instance, has five substantial oval houses which have been excavated and in later stages of the site's development (contemporary with Tintagel) when imported pottery was arriving on the site, despite the episodes of rebuilding, the site is quite clearly of a different character to Tintagel. ${ }^{36}$ Quite similar to the Lower Terrace structure(s) are a number of subrectangular buildings on Bodmin Moor, interpreted as transhumance huts, for instance at Brown Willy and Brockabarrow, and considered to come from 'a broadly similar post-prehistoric context, ${ }^{37}$ if not perhaps early medieval. Perhaps even closer are the huts from Gwithian, dated to the fifth/sixth to eighth centuries by the presence of imported pottery and so-called 'souterrain ware', arguably subsidiary to larger as yet unlocated buildings and associated with middens and agrarian activity close by. ${ }^{38}$

The structures of Phases $\mathrm{U} 2$ and $\mathrm{W}$, then, would appear to represent a more substantial occupation that would tie in well with Thomas's suggestions for Period II occupation represented by extant buildings on both Site $\mathrm{B}$ and on the plateau at the centre of the Island. ${ }^{39}$ They are certainly not the buildings occupied by the upper echelons of society, but would fit with the concept of structures occupied by a retinue at specific periods of the year, or of a 'caretaking' group. Further, it may be worth reiterating the implications from the work at Longbury Bank, Dyfed, ${ }^{40}$ in relation to the amphora material, where the possible identification of Structure A as a storage room for the containers of wine and olive oil etc was suggested. The Lower Terrace structures could possibly have performed that function, even though there is no close structural similarity with the contemporary Welsh site. 


\title{
CHAPTER 3
}

\section{TRIAL EXCAVATIONS 1990-4 ON C A RALEgH RaDFORD's TRENCHES ON THE UPPER Terrace, Site C}

\author{
with contributions from PAUL G JOHNSON
}

\begin{abstract}
This chapter is concerned with trial excavations undertaken between 1990 and 1994 on Dr C A Ralegh Radford's exploratory trenches opened in the 1930s on the Upper Terrace of 'Site C'. Although the aims of this re-examination were limited, and no extensive excavation of new deposits was attempted, a better understanding of the stratigraphical sequences has emerged. It has become clear that in some areas (notably at the southern end of the terrace) significant undisturbed deposits remain. Artefacts recovered include several sherds of imported fifth- to seventh-century (Mediterranean) pottery, but more particularly a significant collection of medieval (south-western British) pottery. The presence of the latter indicates that there may be undisturbed deposits on the Upper Terrace relating to the Castle period of the site's history.
\end{abstract}

\section{BACKGROUND}

The work undertaken by the University of Glasgow on Radford's trenches on the Upper Terrace of Site C took place between 1990 and 1994. Following the initial season in 1990, between 1991 and 1993 the main emphasis was upon the Lower Terrace, ${ }^{1}$ only small-scale work being undertaken elsewhere on Radford's original trenches. Larger-scale excavations took place on the Upper Terrace in 1994 in order to complete the reexcavation of Radford's trenches. Figure 24, Chapter 1, indicates the position of the trenches. It also locates electrical resistivity and topographic profiles which were taken across the site. The latter proved particularly useful in giving an indication of both the topography before the 1990s excavations, and the relationships of the building and the excavations to the topography of the site.

\section{FIELDWORK METHODOLOGY AND SYNOPSIS OF WORK UNDERTAKEN}

The 'Upper Terrace' is a fairly narrow, sinuous ledge located directly below a substantial crag at the eastern edge of the plateau of Tintagel Island. Wright recorded the presence of a number of trenches cut under Radford's supervision in September 1936 on this terrace (see Chapter 1, figure 7). Three trenches (C06, C07 and C19) were opened in 1990 and 1994 to locate three of Radford's trenches at the north end ( $\mathrm{H}, \mathrm{I}$ and $\mathrm{K}$ - see Chapter 1). Trench C18, by contrast, was opened at the south end in 1994 to locate the position of a further three of Radford's trenches - of which two were indeed located (see Chapter 1 and figures 12 and 24). Only in C18 and C19 was any excavation of original deposits undertaken, and then only with the intention of shedding light on the deposits that Radford had encountered. To undertake a more extensive excavation would have been to stray beyond the brief for this particular aspect of the work.

GEOPHYSICAL SURVEY 1990

Before excavation on the Upper Terrace in 1990, a smallscale geophysical survey was undertaken in an attempt to locate the three 1930s excavation trenches situated there. Wright's trench location plans simply recorded the position of Radford's excavation trenches in relation to one another, but not to anything else fixed or tangible 
(see Chapter 1, figure 7). Relocating them on the basis of Wright's record alone was so problematic that it was decided to attempt to find them by alternative means.

A restricted geophysical survey grid was established on the Upper Terrace centred upon control stations C9 and $\mathrm{C} 10$ provided by the Simmons Survey Partnership in 1990. The available area was surveyed by electrical resistivity at a uniform sampling density of $0.5 \mathrm{~m}$, selected as the preferred method because it was considered that the bedrock conditions of the Island might compromise geomagnetic survey techniques. The results of the survey were inconclusive both at the time and following recent reprocessing in more sophisticated graphics packages. They are therefore included in the Research Archive Report only.

Trial trenChes C06 ANd C07 1990

The inadequacies of Wright's plans and the failure of the geophysical survey to locate Radford's trenches resulted in a more intuitive approach being adopted to find them. Consequently, trial trenches $\mathrm{C} 06$ and $\mathrm{C} 07$ were opened in 1990. C06 was positioned to examine part of a complex of 1930s cuts at the northern extremity of the terrace, and $\mathrm{C} 07$ was located over the projected position of the central trench of a group of three depicted by Wright, about $3 \mathrm{~m}$ to the south of C06. It was hoped that if those 1930s trenches could be found, others indicated on Wright's plans could then be located.

As with $\mathrm{C} 05$ on the Middle Terrace (see Chapter 4), the excavation strategy was to establish a search-trench at right angles to the projected line of the 1936 trench depicted by Wright, but the vagaries of his record necessitated C06 measuring $4 \mathrm{~m}$ by $1 \mathrm{~m}$ to identify the single cut recorded in 1936 as being a mere $3 \mathrm{ft}$ [0.9m] wide. Once that had been located, nothing other than straightforward recording was undertaken. Unlike trench $\mathrm{C} 06$, which was located towards the edge of the terrace, $\mathrm{C} 07$ was located at the back of the terrace exposing the slate crag there which delimited its western extremities; it measured only $1 \mathrm{~m}$ by $1.5 \mathrm{~m}$ as it was designed to locate a cut recorded in 1936 as being only $2 \mathrm{ft}$ 6ins $[0.75 \mathrm{~m}]$ wide.

\section{TRIAL TRENCH C19 1994}

C19 was a T-shaped trench located over the projected position of the third of three Radford cuts on the Upper Terrace. Once located, in September 1994, C19 was excavated more fully in order to investigate the deposits Radford had encountered.

\section{GEOPHYSICAL SURVEY 1994}

In September 1994 a further small-scale geophysical survey was undertaken in an attempt to confirm the location of three more of Radford's 1930s trenches (see Chapter 1, figure 6). Wright had recorded their positions simply by partial triangulation with other trenches on the Middle Terrace (which, in turn, were subsequently incompletely triangulated with the building on Site C).

The area available for geophysical survey was again restricted and, as a consequence, it was decided to use a different method. This was an attempt to create geophysical 'sections' (more correctly 'pseudo-sections') of the terrace, with the line of these sections being designed to cut the projected positions of Radford's trenches more or less at right angles. Two vertical electrical profile surveys were carried out on the terrace, the first between points $\mathrm{T} 1$ and $\mathrm{T} 2$, the second parallel and $1 \mathrm{~m}$ further to the east (see Chapter 1, figure 24). A Wenner probe configuration was used with the Geoscan RM15 electrical resistivity meter in this survey, employing a sequential expansion of the inter-electrode separation values over a single point of survey, rather than the more conventional Offset Wenner Sounding (OWS). This was employed because of the relatively shallow deposits expected before the 1930s cuts would be encountered, and also to avoid the tapered data set obtained by the OWS system. Three readings were obtained at every survey point, which were separated by $0.5 \mathrm{~m}$ along both profiles, and the current supplied by the survey device was biased to approximately $0.5,1$ and $1.5 \mathrm{~m}$ respectively, thus rendering the survey device at its most sensitive at approximately these depths.

The results of the survey, presented as simple line graphs in the Research Archive Report, are not particularly instructive. The reasons for this once more have much to do with the physical nature of the targets and the topography of the site. At Tintagel, the cuts were backfilled with the same material that was removed from them as a single act, and therefore little electrical contrast was apparent. In addition, later excavation of the 1930s trenches revealed that they seem to have been acting as drains across the terrace resulting in the phenomenon that the upper fills were actually dryer than might normally be expected, and the deeper deposits considerably wetter. There are a number of peaks and troughs that might have equated with the positions of Radford's cuts, but none were convincing enough to act as the sole guide to the positioning of an excavation trench. 


\section{TRIAL TRENCH $\mathrm{C} 18$}

In September $1994 \mathrm{C} 18$ was opened also in order to locate and re-examine these 1930 s excavation trenches. This was established over the projected position of three further Radford cuts above (west) and to the south of the Site $\mathrm{C}$ building, on a gently sloping terrace to the south of and below (east of) trenches C06, C07 and C19 (see Chapter 1, figure 24). It comprised a strip-trench running north to south, orientated at right angles to the projected positions of Radford's trenches, with two extensions to the west. Two of the three 1930s cuts were immediately apparent once the turf and topsoil had been removed, but the third cut remained elusive during the course of the 1994 excavation. It was subsequently inferred that the third 1930s trench lay to the south of C18, immediately below a flight of steps leading to Sites $\mathrm{C}$ and $\mathrm{B}$, when a part of a Radford trench was located in $\mathrm{C} 15$ and $\mathrm{C} 17$ on the Middle Terrace (see Chapter 4) and Wright's measurements were rechecked (see table 1: 1938 B and Chapter 1, figure 12).

\section{RE-EXCAVATION OF RADFORD'S TRENCHES}

\section{TRIAL TRENCH C06: STRATIGRAPHICAL SEQUENCE}

Phase X: Stony deposit. The lowest layer excavated was 405 , a spread of shillet and soil. No further excavation was undertaken below this deposit.

Phase Y: Radford's trench and backfill. Context 405 had been cut by a trench, presumably that from the 1930s, approximately $0.9 \mathrm{~m}$ (originally $3 \mathrm{ft}$ ) wide which was subsequently backfilled with loose brown earth containing a random scatter of stones (404).

Phase Z: Turf and topsoil. The fills of the excavation trench (Phase $Y$ ), and the spread of slate and shillet (Phase $\mathrm{X}$ ), were both sealed by a layer of turf and topsoil.

Artefacts, ecofacts and dating. No material was recovered from any phases.

\section{TRIAL TRENCH C07: STRATIGRAPHICAL SEQUENCE}

Phase Y: Scree layer. The earliest deposit encountered was 403, a substantial spread of soil containing shillet fragments. There were no visible indications of a cut or a fill in this deposit, and it was not possible to carry out any further work in this trench. It was acknowledged at the time that the cut from the 1930s trench probably existed in deeper strata and the deposits were left intact for future examination given that the effort required to examine them at this stage was disproportionate to the resources available.

Phase Z: Turf and topsoil. A layer of turf and topsoil (402) sealed the shillet deposit of Phase Y.

Phase Z: Artefacts, ecofacts and dating. The sole find was of a modern plastic comb.

\section{TRIAL TRENCH C19: STRATIGRAPHICAL SEQUENCE}

$$
\text { (figure 41) }
$$

Phase W: Natural geology. Natural slate bedrock (415) covered the entire area of the trench, angling slightly eastwards in relation to the slope of the terrace.

Phase X: Layers cut by Radford. A number of layers were visible in section only and, therefore, had been cut by Radford's work. The earliest of these layers, also visible underlying Radford's trample, were scree deposits 416 and 417 , overlain by slates 418 . Above 418 lay shillet deposit 411 . No evidence of cultivation, as referred to by Radford in the old site guidebook, ${ }^{2}$ was visible. Given the nature of the deposits (essentially scree-tips, slates and shillet) encountered during excavations in 1994, it would not seem in any case that cultivation was really feasible.

Phase X: Artefacts, ecofacts and dating (table 6). One sherd of fifth- to seventh-century imported Bi-ware amphora was recovered from shillet 411 .

Phase Y: Radford trenches and backfill (figure 42). Overlying the scree deposit 416 was 414,1930 s trample at the bottom of Radford's trench (413). This was defined by the fill of the cut (412). It was clear that the original trench was $3 \mathrm{ft}[0.9 \mathrm{~m}]$ wide.

Phase Y: Artefacts, ecofacts and dating (table 6). This phase produced sherds of fifth-to seventh-century imported pottery including $\mathrm{Bi}$ amphorae, and an abraded sherd from a thirteenth-/fourteenth-century Chert-tempered (SO) fabric medieval pot. A notched slate and a perforated, probably pick-marked, slate, three slate discs, probable vessel lids, and a water-worn pebble were also found. A single piece of metallic slag was subsequently identified as possibly related to ironmaking activity (see below). 


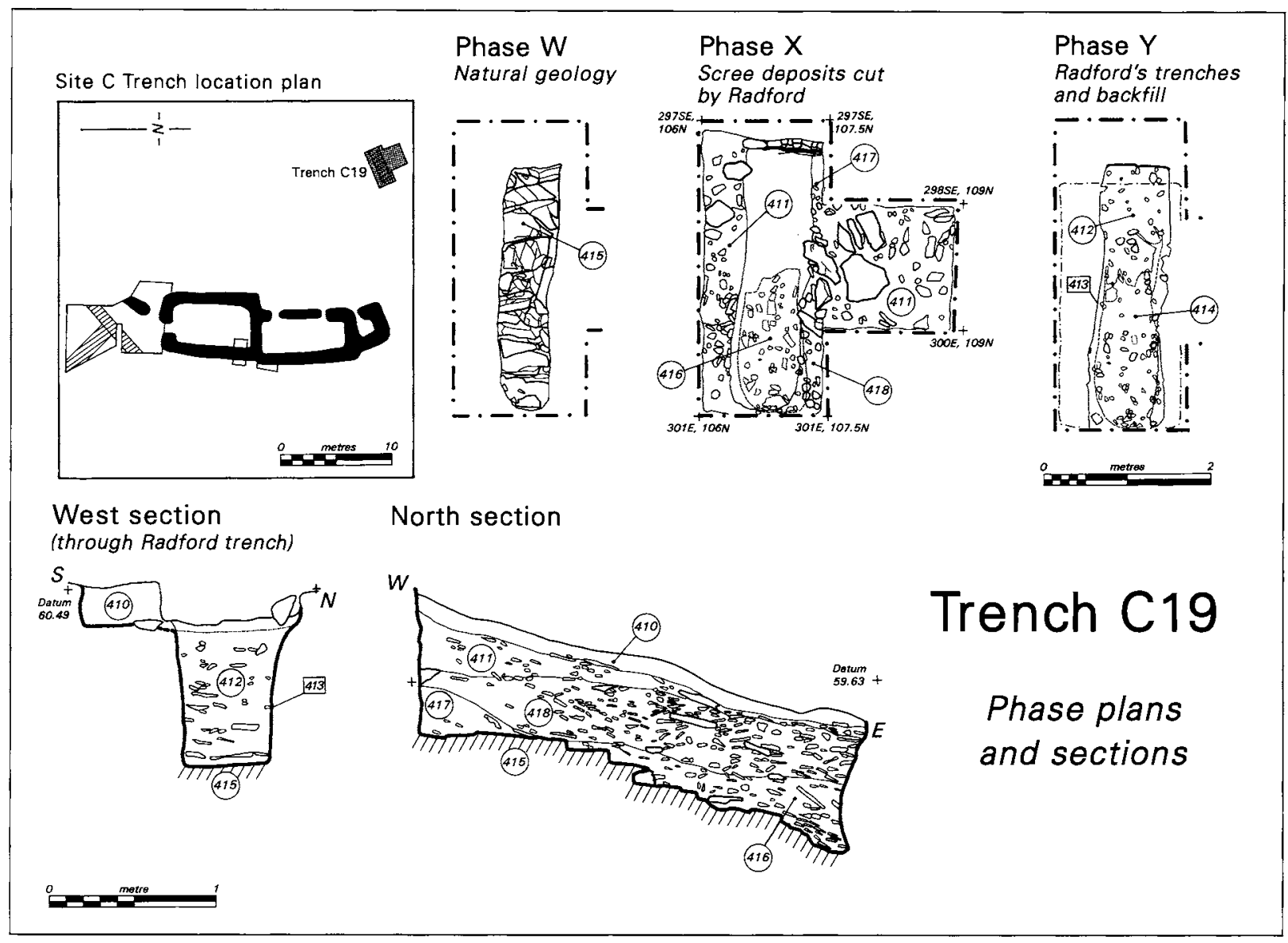

41 Trench C19. Phase plans and sections. Drawing: L McEwan

Phase Z: Turf and topsoil. The whole area was covered by loamy topsoil and turf (410).

Phase Z: Artefacts, ecofacts and dating (table 6). Eight sherds of fifth- to seventh-century imported pottery were found, including $\mathrm{Bi}$ amphorae and Phocaean Red slipped ware (PRSW). Two slate discs (eg RF 1229: Chapter 10, figure 107), a fragment of charcoal and a water-worn quartz pebble were also recovered.

TRIAL TRENCH C18: STRATIGRAPHICAL SEQUENCE (figure 43)

Phase U: Unexcavated layers below Radford disturbance. The earliest layers identified were soil and shillet deposits 809 and 810 .

Phase V: Scree deposits cut by Radford. Directly overlying 810 was 812 , a soil and shillet deposit visible in section only.
Phase W: Disturbed feature. A cut (806) containing a fill of charcoal (807), which had in turn been cut by Radford's trench, was also excavated. This may be evidence of a single event, but since it was cut by the trench and visible in section only, little can be said concerning its importance.

Phase W: Artefacts, ecofacts and dating (table 7). A single sherd of a fifth- to seventh-century Bi imported amphora came from this phase.

Phase X: Disturbed scree deposits. The truncated feature of Phase $\mathrm{W}$ was overlain by mixed slate and shillet layers 811 and 801 , also cut by Radford's trench.

Phase X: Artefacts, ecofacts and dating (table 7). Modern finds, such as an iron nail-head and plastic sheeting, were recovered from this phase, as well as finds of 103 abraded sherds of medieval pottery, including Stuffle- 
Table 6 Trench C19: contexts and finds

\begin{tabular}{|c|c|c|c|}
\hline Phase & Context & Context description & Finds \\
\hline $\begin{array}{l}\text { Phase W: } \\
\text { natural geology }\end{array}$ & 415 & $\begin{array}{l}\text { Natural slate bedrock, sloping slightly } \\
\text { eastwards }\end{array}$ & \\
\hline \multirow[t]{4}{*}{$\begin{array}{l}\text { Phase X: layers } \\
\text { cut by Radford }\end{array}$} & 411 & $\begin{array}{l}\text { Moderately compact loamy shillet with } \\
\text { large slate inclusions }\end{array}$ & One imported Bi amphora sherd (RF 1255) \\
\hline & 416 & Loose brown scree deposit & \\
\hline & 417 & Scree-tip contemporary with 416 & \\
\hline & 418 & Band of large slates & \\
\hline \multirow[t]{3}{*}{$\begin{array}{l}\text { Phase Y: } \\
\text { Radford's } \\
\text { trenches and } \\
\text { backfill }\end{array}$} & 412 & $\begin{array}{l}\text { Broad band of fairly loose shillet and } \\
\text { loam with tipping slates }\end{array}$ & $\begin{array}{l}\text { One sherd of a 13th-/14th-century } \\
\text { Chert-tempered fabric medieval pot } \\
\text { (SO: RF 1245), seven Bi amphora (eg RFs } \\
1243 \text { and 1246) and two imported } \\
\text { unknown fabric (RF 1248), one pebble (RF } \\
\text { 1237), one lump of slag (RF 1242), three } \\
\text { slate discs (RFs 1238-1240) and two } \\
\text { notched/perforated slates (RFs } 1250 \\
\text { and 1254) }\end{array}$ \\
\hline & 413 & Radford's trench cut & \\
\hline & 414 & $\begin{array}{l}\text { Compact clay-like shillet layer with } \\
\text { occasional larger slates }\end{array}$ & $\begin{array}{l}\text { Two sherds of imported unknown ware } \\
\text { (RF 1256) }\end{array}$ \\
\hline $\begin{array}{l}\text { Phase Z: } \\
\text { turf and topsoil }\end{array}$ & 410 & Loamy topsoil and turf & $\begin{array}{l}\text { Six sherds of Bi amphora (eg RFs } 1232 \text { and } \\
\text { 1234), one PRSW (RF 1228) and one } \\
\text { imported unknown fabric (RF 1226), pebble } \\
\text { (RF 1227), two slate discs (RFs } 1229 \text { and } \\
\text { 1230) and charcoal (RF 1233) }\end{array}$ \\
\hline
\end{tabular}

type ware (SA), North Devon Medieval Coarseware (OK) and Lostwithiel ware (LO).

Forty-seven sherds of fifth- to seventh-century imported pottery were recovered, including $\mathrm{Bi}$, Bii amphorae and Coarseware Fabric 1. Worked stone from this phase includes two possible slate vessel lids and two notched slates; one possibly a strike-a-light, the other structural. A possible piece of furnace-lining has also been identified from this deposit. The assemblage of mixed date from the uppermost scree layer testifies to the disturbance caused by Radford's excavations and to the natural scree slip.

Phase Y: Radford's trenches and backfill. Two of Radford's trench-cuts were visible: 802 and 804 . Both were clearly originally $2 \mathrm{ft}$ 6ins $[0.75 \mathrm{~m}]$ wide. 804 only appeared as a short cutting, and the third Radford cut was clearly outwith the confines of $\mathrm{C} 18$ to the south.
Cut 802 was defined by lines of tipping slates and was filled by 808 , later identified as trample at the bottom of Radford's trench, and was overlain by soil, shillet and slates 803 . Cut 804 was similar to 802 and was defined by lines of tipping slates. The cut was filled by soil and slates 805.

Phase Y: Artefacts, ecofacts and dating (table 7). Two sherds of medieval pottery were recovered from the Radford backfill, identified as OK and SA, and twentyfour sherds of fifth- to seventh-century imported wares, including Bi, Bii, Bv amphorae, African Red slipped ware (ARSW) and Coarseware Fabric 1.

Seven slate discs identified as possible vessel lids/amphora-stoppers and five water-worn pebbles were found from this phase. Once again, notched slates, probably damaged by pick-axes, were recovered. Three have very large and pronounced notches and are likely to 


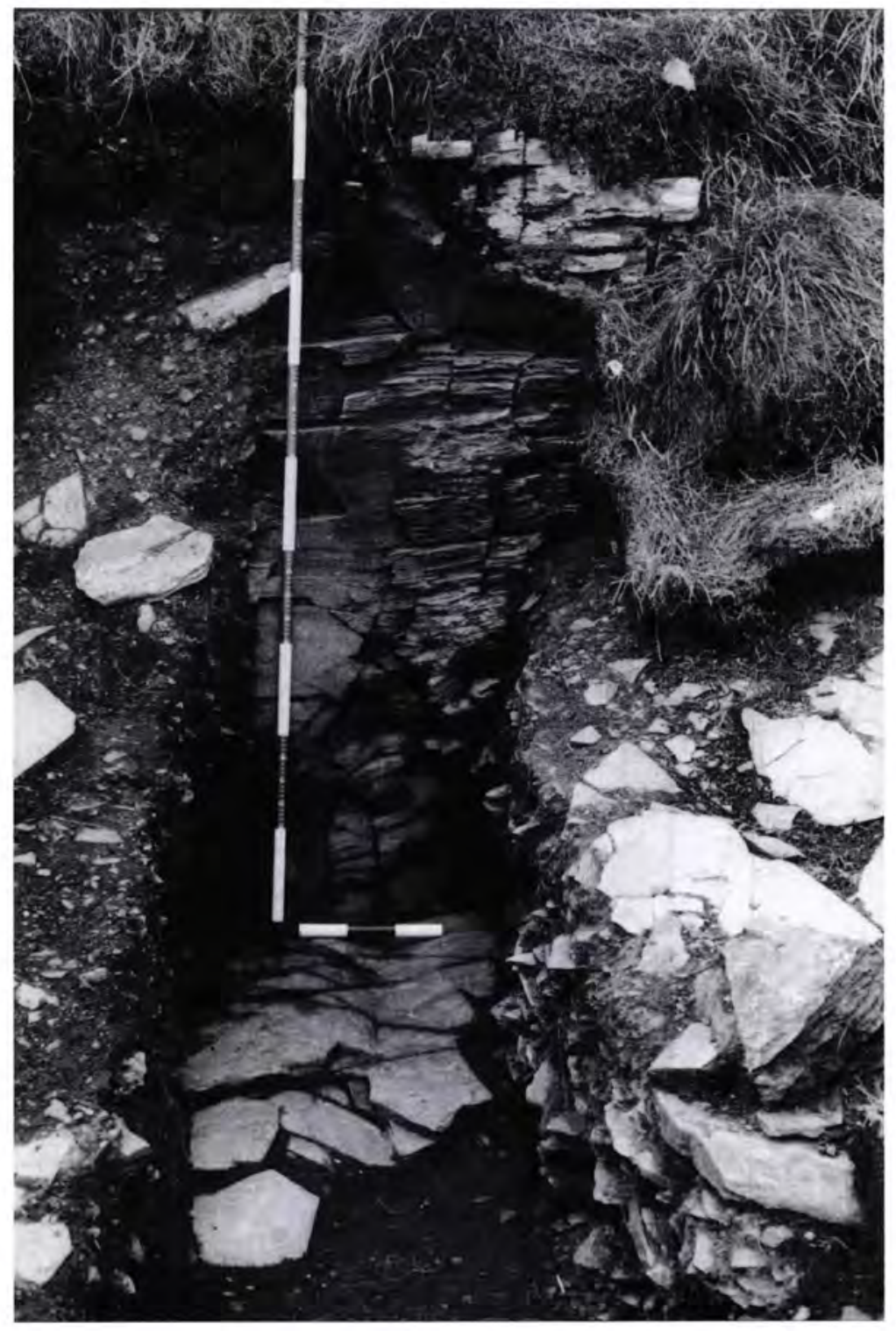

42 Trench C19. Radford's cut.

Photograph: C D Morris be structural pieces, the remaining six have smaller notches, presumed to be from use as strike-a-lights. A perforated slate was probably a roofing slate.

Phase Z: Turf and topsoil. The whole area was overlain by loamy topsoil and turf (800).

Phase Z: Artefacts, ecofacts and dating (table 7). Finds included modern material. Fifteen water-worn pebbles, three slate discs and one notched slate, an iron fragment and a piece of iron slag, possibly relating to smithing or smelting activity, were also found.
Sixty-eight sherds of fifth- to seventh-century imported pottery were found, including $\mathrm{Bi}$, Bii amphorae, ARSW, PRSW and Coarseware Fabric 1. Twenty-five sherds of medieval wares were recovered, including SO, SA, OK and LO.

\section{DISCUSSION}

Work on the Upper Terrace aimed to locate six of Radford's trenches, although in the event only five were found due to deficiencies in Wright's primary record. Of the four trenches examined on the Upper Terrace, C06 
Chapter 3 Trial Excavations 1990-4, Radford's Trenches, Upper Terrace, Site C

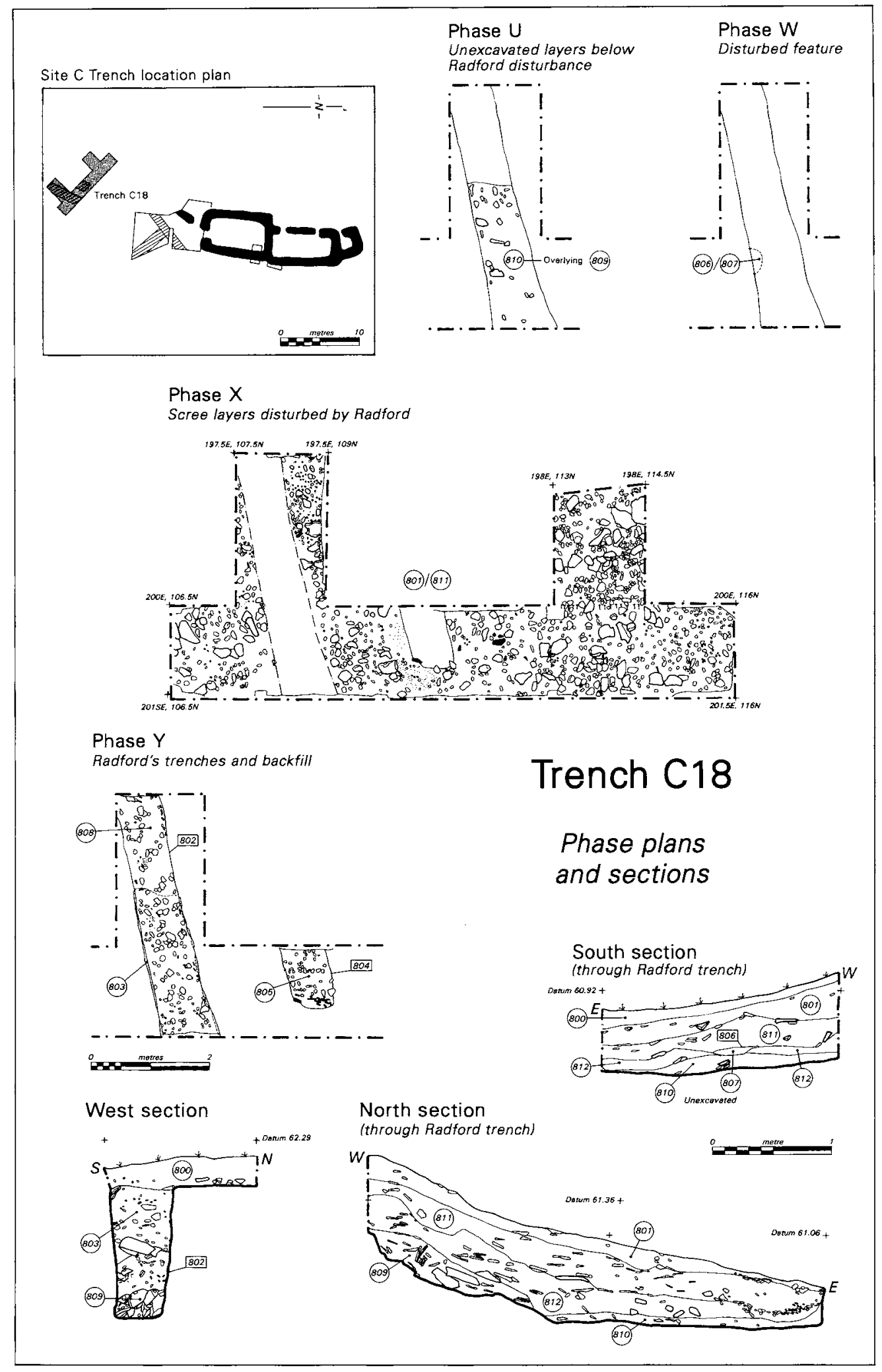

43 Trench C18. Phase plans and sections. Drawing: L McEwan 
Table 7 Trench C18: contexts and finds

\begin{tabular}{|c|c|c|}
\hline Phase & Context & Context description \\
\hline $\begin{array}{l}\text { Phase U: } \\
\text { unexcavated }\end{array}$ & 809 & Very loose reddish-brown shillet \\
\hline $\begin{array}{l}\text { layers below } \\
\text { Radford's } \\
\text { disturbance }\end{array}$ & 810 & $\begin{array}{l}\text { Compact mid-brown loam with } \\
\text { occasional large slates }\end{array}$ \\
\hline $\begin{array}{l}\text { Phase V: scree } \\
\text { deposits cut } \\
\text { by Radford }\end{array}$ & 812 & $\begin{array}{l}\text { Dark brown compact loam with shillet } \\
\text { and slates }\end{array}$ \\
\hline \multirow{2}{*}{$\begin{array}{l}\text { Phase W: } \\
\text { disturbed } \\
\text { feature }\end{array}$} & 806 & $\begin{array}{l}\text { Cut feature apparent in Radford's } \\
\text { trench section }\end{array}$ \\
\hline & 807 & Charcoal fill of 806 \\
\hline \multirow[t]{2}{*}{$\begin{array}{l}\text { Phase X: } \\
\text { disturbed scree } \\
\text { deposits }\end{array}$} & 811 & $\begin{array}{l}\text { Mid-brown band of mixed slate and } \\
\text { shillet in a loam matrix. Scree-tip cut } \\
\text { by Radford's trench }\end{array}$ \\
\hline & 801 & $\begin{array}{l}\text { Compact layer with shillet and slate. } \\
\text { Scree-tip cut by Radford's trench }\end{array}$ \\
\hline
\end{tabular}

Finds

One Bi amphora sherd (RF 2593)

Iron nail (RF 2508), plastic sheeting (RF 2478), 103 sherds of medieval fabrics (eg RF 2495: two sherds of an OK1 jug, RF 2443: two sherds of SA, RF 2559: 14 sherds of vessel SA3, and RF 1541: 24 sherds of vessel SA4; jar fragments RF 2496, LOC1), 47 sherds of imported pottery, including 15 of Bi amphora (eg RF 2509), nine of Bii (eg RF 2485), eight of Coarseware Fabric 1 (eg RF 2312) and 15 of unknown fabric (eg RF 2477), a piece of furnace-lining (RF 2514), two possible slate amphorastoppers (RFs 2467 and 2484) and two notched slates (RFs 2516 and 2561)

$\begin{array}{lcl}\begin{array}{l}\text { Phase Y: } \\ \text { Radford's } \\ \text { trenches and }\end{array} & 802 & \text { Radford's trench cut } \\ \text { backfill } & 803 & \begin{array}{l}\text { Very dark greyish-brown loam with } \\ \text { shillet and tipping slates. Fill of } \\ \text { Radford's trench } 802\end{array}\end{array}$

Two sherds of medieval pottery (RFs 2570 and 2574): one OK and one SA, six sherds of $\mathrm{Bi}$ amphora (eg RFs 2573 and 2576), 14 of Bii (eg RFs 2571 and 2578), two of $\mathrm{Bv}$ (RFs 2569 and 2589), one of ARSW (RF 2579) and one of Coarseware Fabric 1 (RF 2562). Also seven slate disc amphorastoppers (eg RFs 2566 and 2588), nine notched/perforated slates (eg RFs 2583 and 2587) and five pebbles (eg RFs 2564 and 2565) 


\begin{tabular}{|c|c|c|c|}
\hline Phase & Context & Context description & Finds \\
\hline & $\begin{array}{l}804 \\
805 \\
808\end{array}$ & $\begin{array}{l}\text { Radford's trench cut } \\
\text { Loose, very dark greyish-brown loam with } \\
\text { tipping slates. Fill of Radford's cut } 804 \\
\text { Dense clay-like layer with few inclusions. } \\
\text { Trample in the bottom of Radford's } \\
\text { trench cut } 802\end{array}$ & \\
\hline $\begin{array}{l}\text { Phase } \mathrm{Z} \text { : } \\
\text { turf and } \\
\text { topsoil }\end{array}$ & 800 & Loamy topsoil and turf & $\begin{array}{l}\text { Modern material, including plastic ear-ring } \\
\text { (RF 2418) and glass (eg RF 2537, Shippam's } \\
\text { paste jar), } 15 \text { pebbles (eg RFs } 2520 \text { and } \\
\text { 2525), three slate discs (eg RF 2523) and one } \\
\text { notched slate (RF 2400), and also iron } \\
\text { fragment (RF 2422) and iron slag (RF 2447). } \\
\text { Pottery finds include } 31 \text { sherds of Bi } \\
\text { amphora (eg RFs } 2469 \text { and 2532), } 17 \text { of } \\
\text { Bii (eg RFs } 2457 \text { and } 2458 \text { ), one ARSW } \\
\text { (RF 2454), two PRSW (RFs } 2414 \text { and } 2444 \text { ), } \\
\text { eight Coarseware Fabric } 1 \text { (eg RFs } 2437 \\
\text { and 2439) and nine of unknown fabric } \\
\text { (eg RFs } 2535 \text { and 2555). Also } 25 \text { sherds of } \\
\text { medieval pottery (eg RF } 2443 \text { and } 2408 \text { ): } \\
\text { one SO, one SA (SA3), three OK (OK5 and } \\
\text { OK6), one LOC (LOC1) and one unglazed } \\
\text { body sherd }\end{array}$ \\
\hline
\end{tabular}

and $\mathrm{C} 07$ were designed solely to locate the original trenches from the 1930s and they did just that, enabling more accurate predictions to be made of the placing of the other trenches. It should also be noted that excavation was extremely limited in these trenches and so the finds record is minimal. Immediately south of $\mathrm{C} 07, \mathrm{C} 19$ confirmed the position of the third of Radford's trenches in the area, and also - as with C05 on the Middle Terrace below - gave some indication of the nature of the deposits in this area, which had been cut through in the 1930s.

In part, re-examination was prompted by Radford's claim that this was 'a smaller terrace [which] disclosed no sign of buildings, but produced evidence of intensive cultivation. ${ }^{3}$ C06 and C07, when re-opened, gave little indication of deposits compatible with such an interpretation, and C19 contained only the scree-tips, slates and shillet that Radford's workmen had cut through. Although there was no positive evidence for buildings (albeit the trenches were small in dimension), evidence for fifth- to seventh-century occupation was provided by imported ceramics found in both undisturbed and disturbed contexts, as well as in Radford's backfill. The imported sherds in Phase $Z$ (even including one sherd of PRSW), however, cannot tell us much about this particular part of the site, as they may have been introduced from elsewhere or have fallen onto the site from the cliffs above, as could the single later medieval SO pottery sherd and the single piece of metallic slag.

It was hoped that $\mathrm{C} 18$ would locate three of Radford's trenches. In fact, his trenches were farther to the south than expected and so only two such trenches were encountered within the area opened up in 1994. It then became clear that the third of these trenches had lain immediately below what is now a flight of steps to the south. The central one of these trenches contained, in Radford's backfill, two sherds of later medieval pottery, twenty-four sherds of imported wares, seven vessel lids and nine notched/perforated slates - which indicates that the deposits in this area are potentially rich in occupation debris, certainly from the fifth to seventh centuries, if not also the phase associated with the Castle. This trench had cut through scree deposits, of which the uppermost appears to have been partially 
disturbed by Radford's workers. A significant number of abraded later medieval and imported sherds of pottery came from these scree deposits, confirming the contents of Radford's backfill.

Again, there was no direct evidence of buildings, but a charcoal feature cut through by Radford's men might indicate the original presence of the sort of hearths uncovered on the Lower Terrace, ${ }^{4}$ suggesting that this was an area of occupation. In contrast to C19, in this trench Radford's workers did not dig to bedrock; so there may be undisturbed deposits below the level at which they stopped. The contours of the southern end of this Upper Terrace are now partially masked by the later collapse of material from above, and landslip to the east, but the indications are that below them there may be occupation deposits, presumably to be associated with buildings on this terrace.

The greater concentration of finds both in variety of types and in numbers recovered from $\mathrm{C} 18$ would suggest that in that area there was much more activity than elsewhere on the Upper Terrace. Indeed, it is arguable that it has more affinity with the Middle Terrace than with the rest of the Upper Terrace. Even though much of the material comes from disturbed contexts, the range of pottery is of some significance. Occupation from the fifth to seventh centuries was again attested by the presence of imported pottery: the 139 sherds of imported wares of the fifth to seventh centuries from C18 are mainly of different forms of B-ware amphorae (several of newly identified or unknown types), although there are examples of the fine wares ARSW and PRSW. More particularly, a significant collection of medieval pottery attests to later occupation, presumably associated with the Castle period. The latter came from both Radford's backfill and scree deposits cut through by his workmen. The medieval wares, dating to the thirteenth-fifteenth centuries, include Cornish and North Devon types, as well as examples from further afield. They are predominantly from cooking-pots, with some jugs and a few jars. The presence of medieval pottery on this terrace is particularly notable in that it was absent from the Lower Terrace. ${ }^{5}$

\section{CONCLUSION}

Some of Radford's excavation trenches were undoubtedly purely exploratory, often without apparent regard for the topography of the site. Others, however, did relate to the remains of foundations of buildings, which were then extended into larger-scale clearance of the deposits with the aim of laying out coherent structures for public display.

As a result of the work in relocating and partially excavating the Radford trenches on the Upper Terrace, it has become clear that, especially at the southern end (ie around $\mathrm{C18}$ ), this area is artefactually rich from both the early medieval and later medieval periods of the Island's history. The collapse and landslip, which brought further evidence of later medieval occupation from higher level terraces above, has served to mask the original contours of the terrace, and it is also clear that Radford's interest in the area in the 1930s was confined to characterization of the deposits rather than extensive excavation. Any future examination of this southern part of the Upper Terrace would, therefore, undoubtedly encounter evidence of occupation from both the early and later medieval periods.

There has been no programme of radiocarbon dating initiated on the material from the Upper Terrace as, given the extent of earlier interference with the site, it would be difficult to demonstrate unequivocally that any features with charcoal were uncontaminated. It is thus clear that the most period-diagnostic elements of this assemblage are the ceramics. They underline the international context for our current understanding of the site of Tintagel in the early medieval period, and the local context is rather more clearly represented in the ceramics of the later medieval phases on the site. Early medieval imported wares, albeit from topsoil and disturbed contexts, were ubiquitous. Trench C19, at the north end of the Upper Terrace, had imported wares in all contexts excavated, but most significantly in an undisturbed context. C18, to the south, had both imported and later medieval wares. Although there were abraded examples of these from the scree levels (presumably relating to occupation at a higher level above), Radford's backfill had both groups in unabraded condition, indicating that his men had cut through contexts containing them in situ.

The main demonstrable activity, based on imported pottery, was in the early medieval period. The volume of medieval pottery, while not in context, clearly indicates that activity in the thirteenth-fifteenth centuries took place on the Island outside the confines of the Castle. For much of its history, then, these trenches and areas represent periods of stagnation on the site, between bursts of high-status activity in the early and later medieval periods. 


\title{
CHAPTER 4
}

\section{EXCAVATIONS 1990-4 ON C A RALEGH RADFORD'S Trenches on the Middle Terrace, Site C}

\author{
with contributions from PAUL G JOHNSON
}

\begin{abstract}
This chapter is concerned with trial excavations undertaken between 1990 and 1994 on the Middle Terrace of 'Site C'. As in the previous chapter, the aim was to get a better understanding of the stratigraphical sequences in Dr C A Ralegh Radford's 1930 s exploratory trenches. Further significant undisturbed deposits were uncovered at the southern end of the terrace. In particular, the work on Radford's trenches to the south of the Site $C$ building demonstrated the possible existence of a largely undisturbed structure. Artefacts recovered include several sherds of imported fifth- to seventh-century Mediterranean pottery and also a significant collection of medieval (south-western British) pottery originating from the Upper Terrace.
\end{abstract}

\section{BACKGROUND}

As with the Upper Terrace, the work undertaken by the University of Glasgow on Radford's trenches on the Middle Terrace of Site C took place between 1990 and 1994. Following the initial season in 1990, only smallscale work took place in 1991, but larger-scale excavations were undertaken in 1994. Figure 24, Chapter 1 , indicates the position of the trenches.

\section{FIELDWORK METHODOLOGY AND SYNOPSIS OF WORK UNDERTAKEN}

The 'Middle Terrace' appears to have been created by quarrying back the landward slope and is a significantly broader ledge of land than the Upper Terrace. Wright's drawing of the Middle and the Upper Terrace, dated September 1936, describes both as 'quarry ledges' (see Chapter 1, figure 7). Three trial trenches (C05, C15 and C17) were opened at either end of the Middle Terrace, flanking to north and south the upstanding structure of Radford's Site C (see Chapter 6). These trenches were opened in order to locate and re-examine three of Radford's trial trenches from 1936 (see Chapter 1, figures 6, 7 and 12). C05 lay to the north of the building, east of and topographically below $\mathrm{C} 06$ and $\mathrm{C} 07$ and west of and above C03 and C04 of the Lower Terrace. C15 and C17, which were adjacent to each other, lay to the south of the Site $\mathrm{C}$ structure, east of and below C18. As with the equivalent trenches on the Upper Terrace, these were essentially prospective in nature and the main purpose was achieved when Radford's trenches had been discovered and recorded. However, in the case of $\mathrm{C} 05$, a limited examination took place of the deposits to either side of Radford's trench, and through which his workmen had cut.

TRIAL TRENCH C05 1990-1

C05 was established at the northern extent of the Middle Terrace, $15 \mathrm{~m}$ north of the Site $\mathrm{C}$ building. The purpose of the trench was to locate and re-examine a trench recorded on the Wright drawing from September 1936, which depicts the positions of a number of 'cuts on quarry ledges $N$. of Site C' (see Chapter 1, figure 7). The excavation of $\mathrm{C} 05$ was undertaken in two phases. In 1990 , a search-trench was initially placed in a position at right angles to the projected position of the 1936 cut, about halfway down the terrace. Once the fill of Radford's trench had been identified, the whole of its surface was exposed across the entire terrace. The easternmost half of Radford's cut was emptied and the 
sections and floor of the trench examined. It was immediately obvious that the 1930s excavation had not been undertaken stratigraphically, and that the bottom of the trench was nearly horizontal, with a number of contexts exposed. The decision was then made to excavate an undisturbed area, $0.5 \mathrm{~m}$ wide, to the south of the earlier cut, in order to establish and record the site stratigraphy cut by the Radford excavation. When the southern part of C05 was excavated in 1990, it was evident that in the section to the north a number of contexts could be identified in the edge of the earlier trench that did not directly correspond with those excavated to the south. It was therefore decided in 1991 also to excavate the $0.5 \mathrm{~m}$-wide strip along the northern part of the trench to investigate these contexts, particularly a sunken burnt feature which had been cut and partially destroyed by the 1936 excavation.

\section{TRIAL TRENCH C15 1994}

C15 was opened in April 1994 with the primary aim of locating the long strip-trenches opened by Radford across and to the south of Site C, as recorded by Wright in September 1936 (see Chapter 1, table 1). C15 was located on a slope of 45 degrees and consequently excavation was hampered at times by water running through the trench from the slope above. A section of Radford's east-west trench was successfully located and in September 1994 a section of his north-south trench was discovered. In 1999 trial trench $\mathrm{C} 15$ was extended to a larger area trench to encompass the remains of a building uncovered in Radford's trench. During this larger excavation more of Radford's strip-trench was identified and re-excavated; it is reported in Chapter 5.

TRIAL TRENCH C17 1994

It was decided in September 1994 to open C17 as a small area to the south of $\mathrm{C} 15$, in order to investigate whether Radford's second (north-south) trench, at right angles to the first, extended as far as the steep rise up to the path to the south of Site C. Once Radford's trench was located and the backfill removed, it was recorded and then re-backfilled.

\section{RE-EXCAVATION OF RADFORD'S TRENCHES TO THE NORTH AND SOUTH OF SITE C}

\section{TRENCH C05: STRATIGRAPHICAL SEQUENCE (figure 44)}

Phase V: Soil and scree layers. The earliest excavated remains comprised soil layers 313/314, and soil 312 .
Layer 312 appeared to be slightly discoloured in places, as were the later scree and soil layers 311 and 310, the latter being burnt towards the west during the deposition of the charcoal-rich layers above it.

Phase V: Artefacts, ecofacts and dating (table 8). 310 yielded a slate disc; this may well have served as a vessel lid, as discussed elsewhere. ${ }^{1}$ A sample was taken from 310 , which produced golden dock and sorrel and some unidentified fruits and seeds.

Phase W: Features. Above or cut into the soil and scree layers, several contexts of charcoal and burnt soil were encountered, some of which had been observed in section. These included two contexts containing burnt material which had been deposited behind a group of stones (319 and 320) and a cut feature 317. These features were all covered by context 315 .

Phase W: Artefacts, ecofacts and dating (table 8). A sherd of imported Bii amphora pottery was recovered from this phase. Ecofactual material other than charcoal was recovered from three contexts: knotgrass, bramble, rose, red glaucous goosefoot, orache and sedge. Significant amounts of charcoal were recovered from both 315 and 320 , and a lesser amount from 319 .

Phase X: Scree-tip sequence. The sunken feature 317 of Phase $\mathrm{W}$ was sealed by 318 and 316 . A series of later dumps of scree then built up on the site, and at first these were recorded individually as 303, 308 and 309, although subsequently they were removed as one general context. In the southernmost area, scree layer (307) partially overlay 308 at the eastern end of the trench. This layer and the portion of 308 not covered were both overlain by 303 . Finally, sealing these deposits were the eroded remains of shillet (301).

Phase X: Artefacts, ecofacts and dating (table 8). The small assemblage of stone artefacts from this phase comprises four water-worn quartz pebbles. These were clearly not in situ and originally may have been brought to the area above this trench, and then washed down the slope. A piece of possible roofing slate was also found.

Numerically, this phase was the most significant in this trench for imported Mediterranean ceramics, producing eleven amphora sherds. These are discussed more fully in relation to the larger groups from the Middle Terrace building (see Chapter 6). 


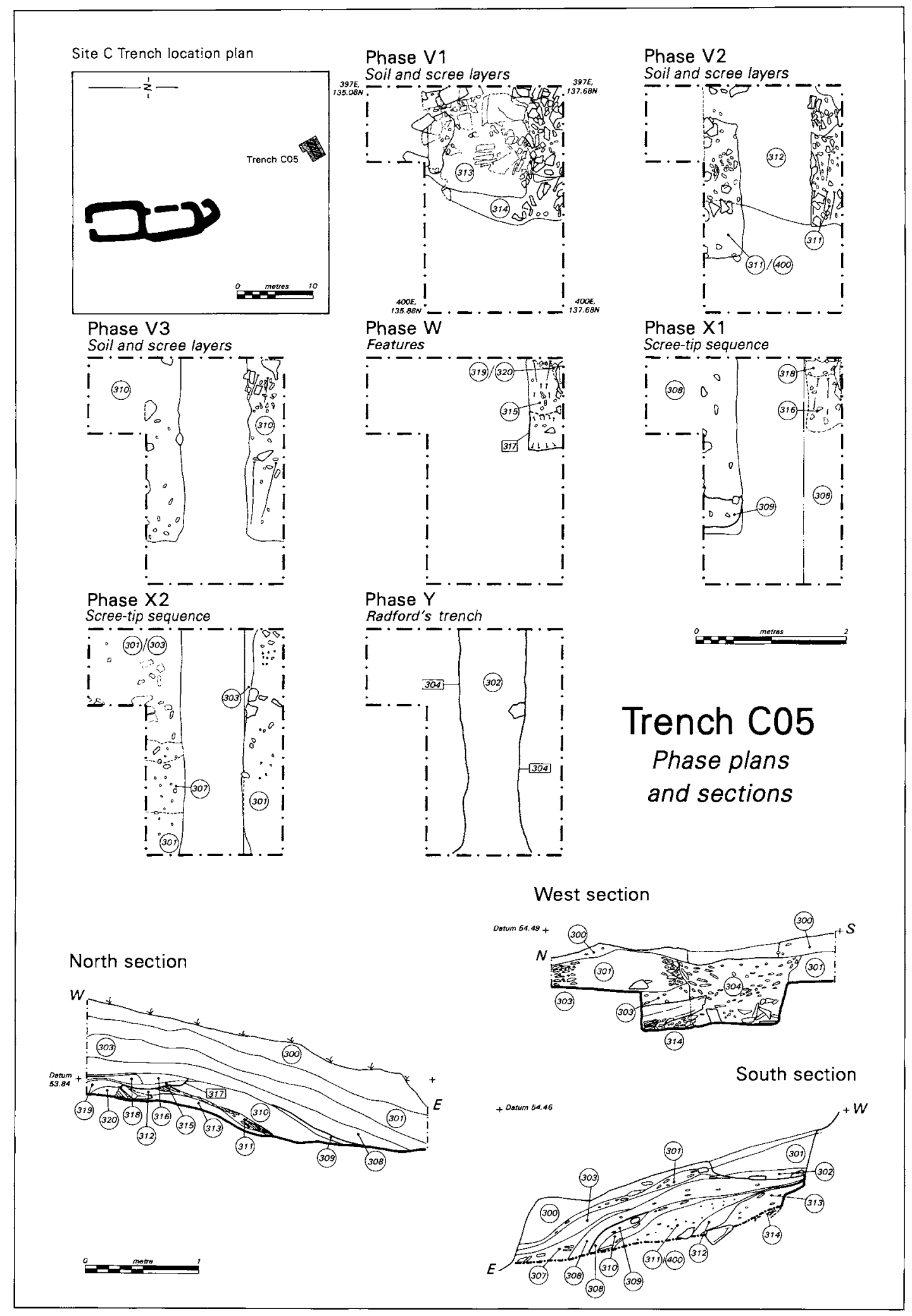

44 Trench C05. Phase plans and sections. Drawing: L McEwan 
Table 8 Trench C05: contexts and finds

\begin{tabular}{|c|c|c|}
\hline Phase & Context & Context description \\
\hline \multirow[t]{5}{*}{$\begin{array}{l}\text { Phase V: soil } \\
\text { and scree layers }\end{array}$} & 310 & $\begin{array}{l}\text { Dense dark reddish-brown clayey loam } \\
\text { with slate fragments, overlying } 311\end{array}$ \\
\hline & 311 & $\begin{array}{l}\text { Brown friable sandy clay with many } \\
\text { slate chips. Overlain by } 310 \text {, overlying } \\
312\end{array}$ \\
\hline & 312 & $\begin{array}{l}\text { Reddish-brown clayey soil overlying } \\
313 \text { and } 314 \text {. Contains small slate } \\
\text { fragments and larger stones }\end{array}$ \\
\hline & 313 & $\begin{array}{l}\text { Loose dark brown soil with fine slate } \\
\text { flakes and some larger stones }\end{array}$ \\
\hline & 314 & $\begin{array}{l}\text { Loose dark brown soil with fine slate } \\
\text { flakes and some larger stones }\end{array}$ \\
\hline \multirow[t]{4}{*}{$\begin{array}{l}\text { Phase W: } \\
\text { features }\end{array}$} & 315 & $\begin{array}{l}\text { Large, } 1.04 \mathrm{~m} \times 0.5 \mathrm{~m} \text {, patch of dark } \\
\text { reddish-brown loam with frequent } \\
\text { large pieces of structural charcoal and } \\
\text { occasional pieces of slate. Overlying } 319\end{array}$ \\
\hline & 317 & Feature cut into scree 310 , filled by 315 \\
\hline & 319 & $\begin{array}{l}\text { Thin patch of dark brown burnt clay, } \\
\text { over } 320\end{array}$ \\
\hline & 320 & Patch of orange clay and charcoal \\
\hline
\end{tabular}

Phase X:

scree-tip

sequence
Scree material contained within a dark brown soil, overlying 308 Dark reddish-brown soil with slatescree material, partially overlying 308, below 303 Scree dump

Dark reddish-brown loamy soil within 308
Finds

Slate disc (RF 1225). Charcoal+; one golden dock (Rumex cf. maritimus) and one sorrel (Rumex sp.) achene

Charcoalt+

Charcoal+

One Bii amphora sherd (RF 1224).

Charcoal++++; one knotgrass (Polygonum aviculare) achene, one bramble (Rubus sect.

Glandulosus) pip, one rose (Rosaceae) spine

Charcoal+; one red/glaucous goosefoot

(Chenopodium rubrum/glaucum) seed

Charcoal++++; one goosefoot

(Chenopodum sp.) seed, one orache

(Atriplex sp.) seed, two sedge (Carex sp.) nuts

Three pebbles (RFs 1201, 1202 and 1213), notched roofing slate (RF 1205) and two Bv amphora sherds (RF 1200). Charcoalt; one indeterminate cereal grain and one grass caryopsis (Poaceae), one unidentifiable large mammal long bone fragment

One Bi amphora sherd (RF 1216) and pebble (RF 1215). Charcoal+ Charcoal+

One Bi amphora sherd (RF 1220), five Bii (eg RFs 1214 and 1221) and one Bv (RF 1222). Charcoal ++++; 12 oat grains (Avena sp.), two hulled barley grains (Hordeum sp.), one black bindweed achene (Fallopia convolvulus), one bramble pip (Rubus sect. glandulosus)

\section{Charcoalt}




\begin{tabular}{|c|c|c|c|}
\hline Phase & Context & Context description & Finds \\
\hline & 316 & $\begin{array}{l}\text { Dark reddish-brown clayey layer with } \\
\text { medium-sized slate flakes and smaller } \\
\text { scree }\end{array}$ & $\begin{array}{l}\text { One Bi amphora sherd (RF 1223). } \\
\text { Charcoal +++; two oat (Avena sp.) grains, } \\
\text { one sorrel (Rumex sp.) achene. Sample from } \\
315 / 316 \text { contained charcoal }+++\end{array}$ \\
\hline & 318 & $\begin{array}{l}\text { Dark brown compact soil with small } \\
\text { slate fragments }\end{array}$ & $\begin{array}{l}\text { Charcoal++; one cf. oats (cf Avena sp.) } \\
\text { grain, one hazel (Corylus avellana) nut shell } \\
\text { fragment }\end{array}$ \\
\hline \multirow[t]{2}{*}{$\begin{array}{l}\text { Phase Y: } \\
\text { Radford's trench }\end{array}$} & 302 & $\begin{array}{l}\text { Fill of Radford trench - loose brown } \\
\text { soil with slate rubble }\end{array}$ & $\begin{array}{l}\text { Three perforated slates (RFs } 1203,1204 \text { and } \\
\text { 1207), possible strike-a-light/structural } \\
\text { piece (RF 1211), three Bi amphora sherds } \\
\text { (RFs } 1206,1209 \text { and } 1212 \text { ), three Bii (RF } \\
1210 \text { ) and one Coarseware Fabric } 1 \text { (RF } \\
1208 \text { ) }\end{array}$ \\
\hline & 304 & $\begin{array}{l}\text { Cut of Radford's trench, } 0.8 \mathrm{~m} \text { wide, } \\
\text { aligned west to east }\end{array}$ & \\
\hline $\begin{array}{l}\text { Phase } \mathrm{Z} \text { : } \\
\text { topsoil } \\
\text { development }\end{array}$ & $300 / 305$ & $\begin{array}{l}\text { Dark reddish-brown loamy topsoil } \\
\text { covering the area }\end{array}$ & \\
\hline
\end{tabular}

Charcoal fragments $>2 \mathrm{~mm}:+1-10 ;++11-50 ;+++51-100 ;++++>100$

The ecofactual remains identified from this phase include cereal (oats and barley) plus grass, black bindweed, bramble, sorrel and hazel. A large mammal long bone fragment was recovered from 301, but was unidentifiable to species.

Phase Y: Radford's trench. The Radford trench cut through the scree layers of Phase $\mathrm{X}$ and the feature in Phase W (figure 45). The cut (304) was approximately $0.8 \mathrm{~m}$ wide (possibly originally $0.73 \mathrm{~m}$, equating with the width of the trench as recorded by Wright, $2 \mathrm{ft} 6 \mathrm{ins}$ ) and traversed the terrace from west to east. The bottom of the cut was nearly horizontal since no attempt had been made to follow the naturally sloping stratigraphy of the site. The cut was subsequently filled with 302 .

Phase Y: Artefacts, ecofacts and dating (table 8). Within Radford's backfill 302 four perforated slates were recovered. One has a small, very even perforation, which could suggest it had been used as a strike-a-light (RF 1211). The other pieces are more likely to have had a structural function: a possible roofing slate fragment and two stones which have very large perforations more indicative of a postsupporting function, as noted on the Lower Terrace where such examples were identified in situ. ${ }^{2}$ There are seven sherds of imported Mediterranean ceramic from this phase including Bi and Bii amphorae and Coarseware Fabric 1.

Phase Z: Topsoil development. Four stone pieces were recovered as unstratified finds from the surface of $\mathrm{C05}$ (although none were recorded as Recorded Finds): two notched fragments, a perforated slate and a single large stone with a substantial broken perforation at one edge.

\section{TRENCH C15: STRATIGRAPHICAL SEQUENCE}

(figure 46)

Phase T: Natural geology. Slate bedrock 502 formed a sharp drop at the west edge of the trench sloping down to a level at the bottom (east). It could not be determined during this small excavation whether the bedrock had been cut to form the terrace.

Phase U: Possible old land surfaces. Directly overlying bedrock within the area of Radford's north-south trench (673) were small patches of compact clay with shillet 680 and 679 . It was suggested that 679 may be an old land surface, and that 680 may be an earlier archaeological layer. At the bottom of the Radford 


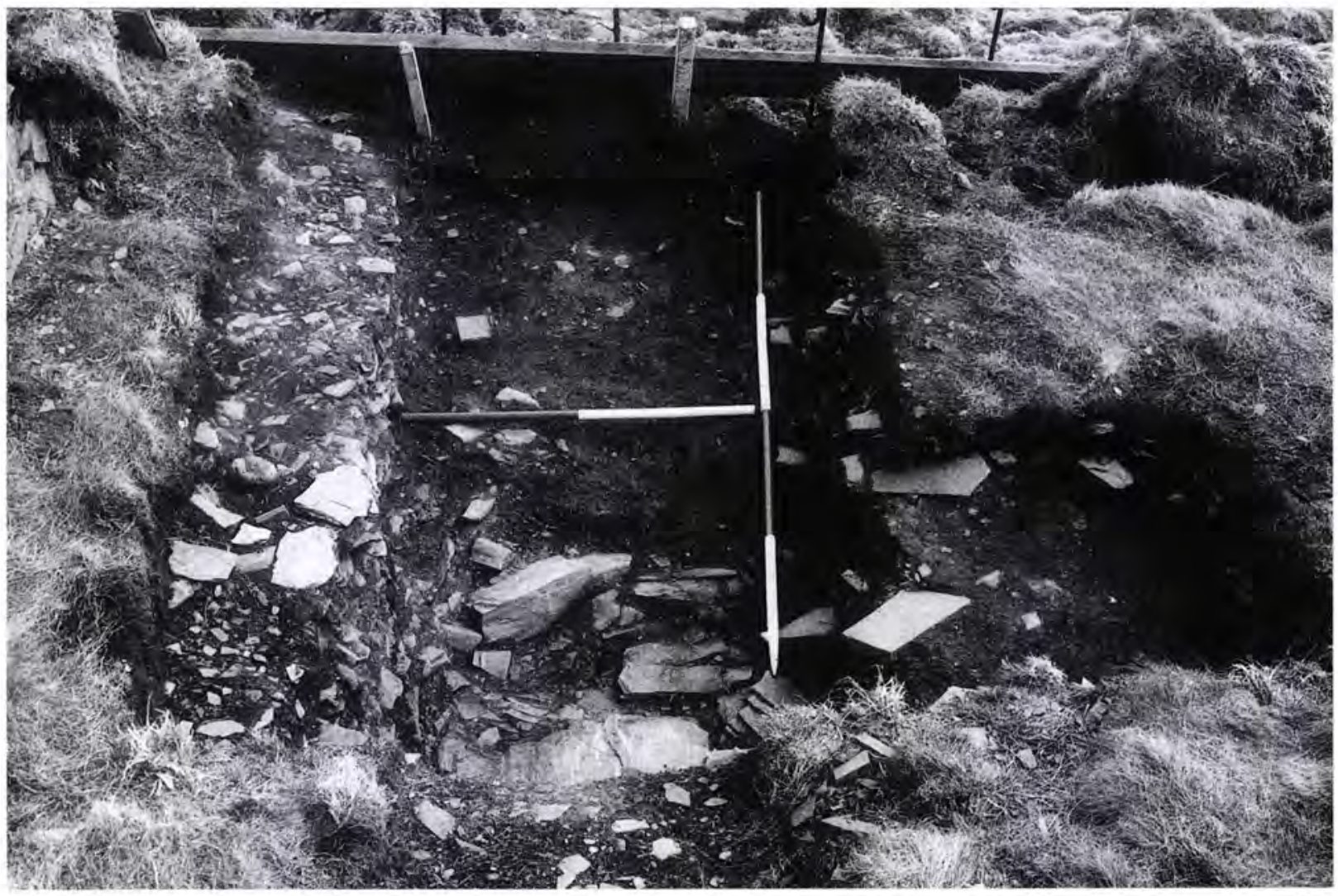

45 Trench C05. General view with Radford's cut. Photograph: C D Morris

trench 663, again over bedrock, a thin compact sand layer 670 was uncovered. It is suggested that this may also be an old land surface. It was overlain by tipping slates 671 embedded in a concreted layer 668.

Phase V: Walling. Truncated by Radford's trench 673 of Phase X, the end of a wall (666) was found below later deposits (figure 47). Due to damage from the cutting of the 1930s trench, there were only three to four courses surviving, but these appeared to be in situ.

Phase W: Collapse. Truncated by Radford's trench 673, flat slates 681 were found at the east end of wall 666 . These may be in situ rubble walling, but appeared more likely to be collapse from the wall. Since this feature was not excavated, it is not possible to interpret it further.

Phase X: Radford's trenches and backfill. Two Radford trenches were recorded in September 1936, cut roughly west-east down-slope from above Site $\mathrm{C}$ across the terrace, and north to south along the edge of Site $\mathrm{C}$ and up the slope to the south (see Chapter 1, figures 6 and 12). The junction of these two trenches to the south of the Site $\mathrm{C}$ building was located and opened in $\mathrm{C} 15$. The Radford cutting 663, aligned roughly east-west, cut through early archaeological deposits and had mainly been excavated down to bedrock in the 1930s. This trench was subsequently backfilled with loam and shillet 662. At right angles to this, aligned north-south, trench 673 was backfilled with three dumps of mixed deposits of material: 672,664 and 660/661.

Phase X: Artefacts, ecofacts and dating (table 9). One slate disc came from this phase. It could quite reasonably be interpreted as a replacement bung for an opened amphora or other vessel. Five notched slates, distinguished from structural slates by the smallness of the notches, and three perforated slates come from Phase X. One is a roofing slab (RF 2700). A piece of industrial ceramic material (RF 3301) was also recovered. Presumably these finds from Radford's 


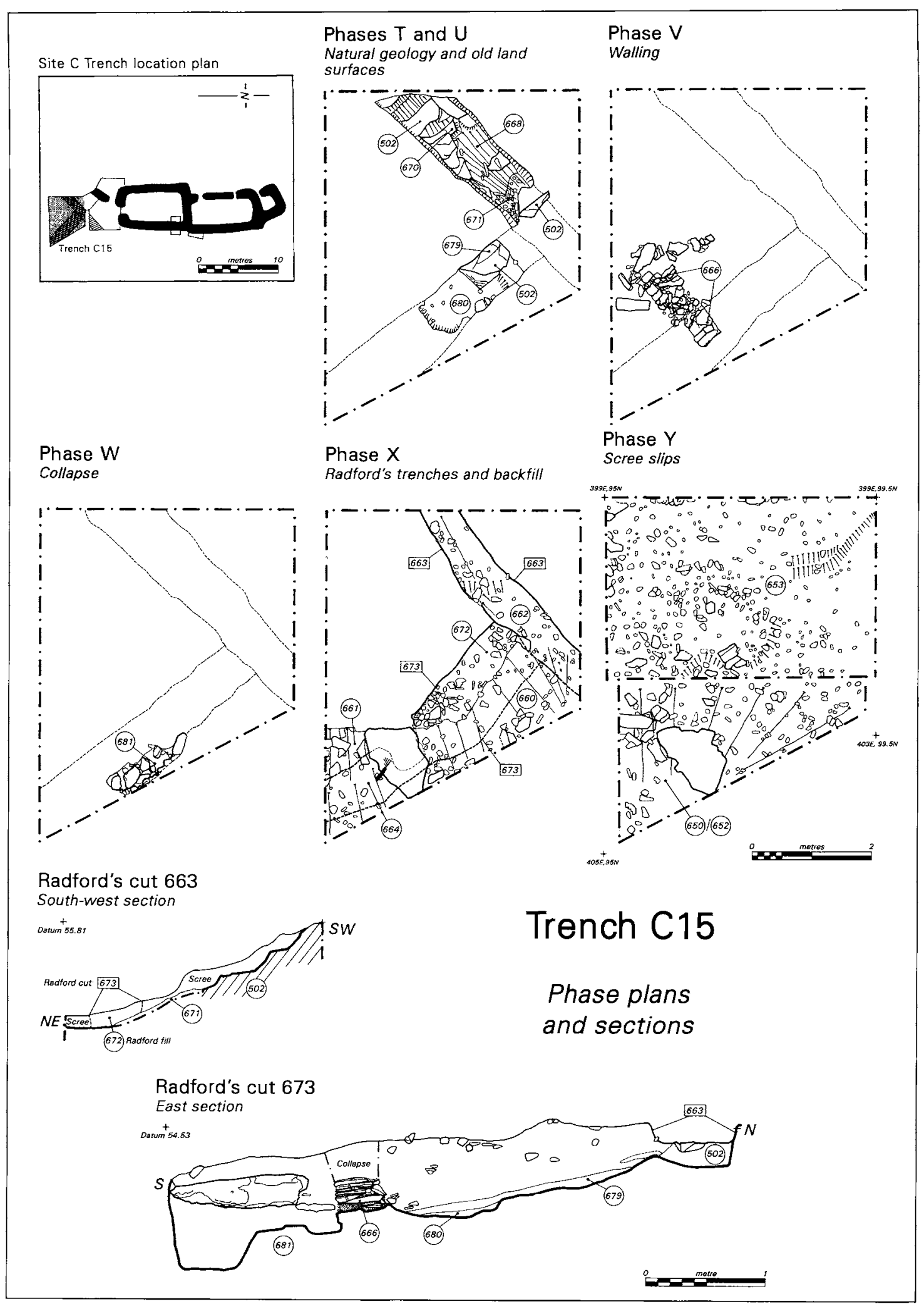

46 Trench C15. Phase plans and sections. Drawing: L McEwan 


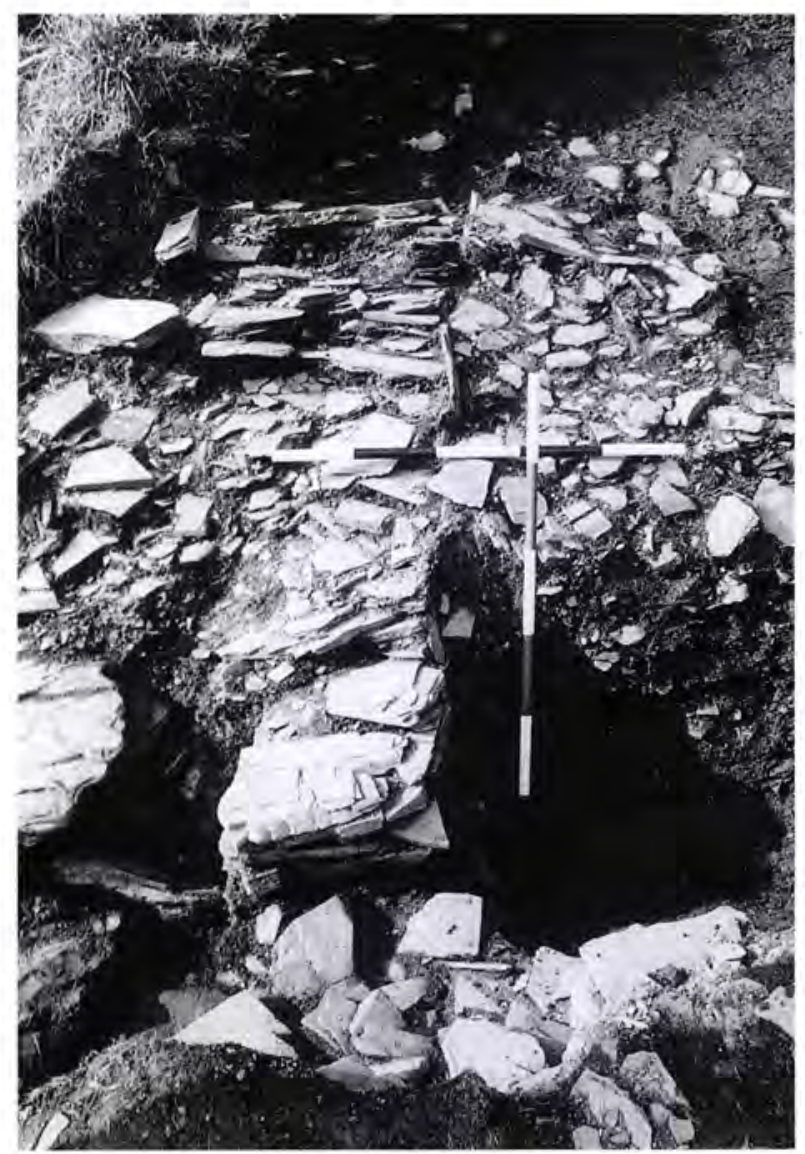

47 Trench C15. View of wall 666 from the east. Photograph: C D Morris

backfill came originally from movement from elsewhere up the slope.

Finds of fifth- to seventh-century imported wares included $\mathrm{Bi}, \mathrm{Bii}, \mathrm{Biv}$ and $\mathrm{Bv}$ amphorae and Phocaean Red slipped ware (PRSW). Finds of medieval pottery include Stuffle ware (SA) and North Devon Medieval Coarseware (OK).

Ecofactual material from a sample of context 660 comprised a single specimen of oats. Two fragmentary pieces of animal bone and tooth came from 672 and 664 respectively.

Phase Y: Scree slips. Blanket layers of scree 653 overlain by $650 / 652$ covered the entire area of $\mathrm{C} 15$, sealing Radford's trenches with up to $0.2 \mathrm{~m}$ depth of soil, slate and shillet. The artefacts found in these contexts had slipped from further up the slope to the west of $\mathrm{C} 15$, probably from the Upper Terrace, together with the scree material, and may suggest the presence of later, medieval layers elsewhere in this area of the site.

Phase Y: Artefacts, ecofacts and dating (table 9). Five quartzite and slate pebbles were recovered from this phase, and were clearly not in their original location, having probably slipped from the terrace above. This relative concentration may be because of the footpath above this part of the site. Four slate discs came from Phase Y. Where they survive completely enough to be assessed, they have a size range of between $50 \mathrm{~mm}$ and $115 \mathrm{~mm}$ diameter and (as elsewhere) they could be interpreted as replacement bungs for opened amphorae. Twenty notched slates come from this phase including three post-supports and a single roofing slab.

From 650 a large fragment (about a third of the total) of an incised slate was recovered, roughly half of a small gaming board (RF 2172) with simple scratched intersecting lines for the game of Nine Men's Morris or Merrells. The incisions comprise a small rectangle at the centre surrounded by three deeper incised lines and a possible earlier attempt near the centre, where the grid is misaligned (see Chapter 10, figure 108). It is very crudely made and parallels another example from the Island found in Radford's 1933-8 work. ${ }^{3}$ The date range for these simple carvings is quite broad, with examples in Cornwall noted from the eleventh century onwards, and this one had clearly been displaced from higher up the slope. ${ }^{4}$

Two finds from Phase $\mathrm{Y}$ that had been identified as being industrial in character were examined using stereo microscopic and SEM-EDAX methods (see Chapter 10, figure 138). Although RF 1758 is of a similar type to RF 3301 of Phase X (ie a highly fired, ceramic type fabric of uncertain process), it does seem to have been involved in a metallurgical process, possibly iron-related. RF 1718 was material comprising fine pebbles mixed with ferruginous black material, partially reduced, and had been subjected to low-temperature heating.

Of particular interest are two sherds of RomanoBritish Gabbroic fabric (see Chapter 10) recovered from Phase $Y$. The forms recognized at Tintagel date from the third and fourth centuries.

There were 156 sherds of fifth- to seventh-century imported wares from this phase including $\mathrm{Bi}, \mathrm{Bii}, \mathrm{Biv}$ and Bv amphorae, PRSW and Coarseware Fabrics 1 and 2. Two pieces of B-ware amphora had also been clipped into disc-forms, to be used as amphora bungs (RFs 1543 (Bii) and 1709 (Bi) from Phase Y: see Chapter 10, figure 107). ${ }^{5}$ 
Table 9 Trial trench C15: contexts and finds

\begin{tabular}{lll}
\hline Phase & Context & Context description \\
\hline $\begin{array}{l}\text { Phase T: } \\
\text { natural geology }\end{array}$ & 502 & $\begin{array}{l}\text { Slate bedrock uncovered at south-west } \\
\text { corner of trench and in the bottom of } \\
\text { the two Radford trenches }\end{array}$ \\
$\begin{array}{l}\text { Phase U: } \\
\text { possible old } \\
\text { land surfaces }\end{array}$ & 668 & $\begin{array}{l}\text { Dark red-brown concreted layer at south } \\
\text { side of Radford trench } 663\end{array}$ \\
& 670 & $\begin{array}{l}\text { Thin layer of brownish-yellow compact } \\
\text { sand in the bottom of Radford trench } \\
\text { 663 over bedrock } \\
\text { Southward-tipping slates embedded in }\end{array}$ \\
& 671 & $\begin{array}{l}668, \text { overlying 671 } \\
\text { Loose spread of dark yellowish-brown } \\
\text { scree overlying 680 } \\
\text { Small patches of dark reddish-brown } \\
\text { compact spread of clay with shillet over } \\
\text { bedrock in Radford trench } 673\end{array}$ \\
& 680 &
\end{tabular}

Phase V: walling 666 The end of a wall, truncated by Radford trench 673, protruding eastwards from west-facing section. Only three to four courses surviving

Phase W: $\quad 681 \quad$ Dump of flat slates at east end of wall collapse 666, possible collapse

Phase X:

660 Soil and shillet, upper layer of backfill

Radford's into Radford's trench 673

Finds

trenches and backfill

Soil and shillet, upper layer of backfill into Radford's trench 673

662 Dark reddish-brown loose clayey loam and shillet backfill of Radford trench 663

663 Radford trench aligned roughly east to west

664 Dark red-brown loamy clay, backfill in the south east of Radford trench 673

672 Dark yellowish-brown loose loamy clay with sand infilling Radford cut 673
One Bi amphora sherd (RF 2260), three Bii (RFs 2224, 2225 and 2299) and one medieval SA (RF 2298). Charcoal+; one oat (Avena sp.) grain

Eleven Bi amphora sherds (eg RFs 2707 and 2712), six Bii (eg RFs 2288 and 2291), three of unidentified fabric (RFs 2226 and 2297), ten medieval SA (eg RFs 2702 and 2706) and three notched slates (eg RF 2700) Six Bi amphora sherds (RFs 2257 and 2316), three Bv (RF 2315), two PRSW (RF 2256) and one medieval SA (RF 2314)

One Bi amphora sherd (RF 2284), nine Bii (eg RFs 2278 and 2280), four medieval OK (eg RFs 2285 and 2281), one tooth (RF 2277 ) and two notched slates (RFs 2282 and 2709)

Nine Bi amphora sherds (RFs 2323 and 2330), two Bii (RFs 2330 and 2933), one Biv ( $R F$ 2324), one $\mathrm{Bv}$ ( $R F$ 2325), 11 medieval SA (eg RF 2721), a slate disc (RF 2329), industrial ceramic material (RF 3301), three perforated slates (RF 3303) and animal bone (RF 3304) 


\begin{tabular}{|c|c|c|c|}
\hline Phase & Context & Context description & Finds \\
\hline & 673 & $\begin{array}{l}\text { Radford trench, aligned roughly north- } \\
\text { south }\end{array}$ & \\
\hline
\end{tabular}

Phase Y: $\quad 650 \quad$ Dark reddish-brown silty clay loam scree slips

652 Dark reddish-brown silty clay loam with shillet

653 Earliest scree layer - orangey-brown spread of clayey scree

Phase Z: $\quad 651 \quad$ Dark reddish-brown loam topsoil turf and topsoil
Forty-seven Bi amphora sherds (eg RFs 1539 and 1591), 49 Bii (eg RFs 1568 and 1738), one Biv (RF 1580), three Bv (eg RFs 1570 and 1706) and four PRSW (eg RFs 2176 and 1557). Also four Coarseware Fabric 1 sherds (eg RFs 2181 and 1749), two Coarseware Fabric 5 (RFs 1715 and 1741), two Romano-British Gabbroic (RF 1745 ) and 21 of unidentified fabrics (eg RFs 1708 and 1731). Sixty-two medieval sherds: six HG (eg RF 1595), 18 SA (eg RF 1545), 22 OK (eg RF 1593), nine RE (eg RF 1572) and seven LO (eg RF 1589). Also 17 notched slates (eg RFs 1744 and 2195), a large fragment of an incised Nine Men's Morris board (RF 2172), four pebbles (eg RF 1558), four slate discs (eg RF 1750), magnetic fines (RF 1718) and highly fired ceramic (RF 1758). Charcoal+; one campion (Silene sp.) seed

One Bi amphora sherd (RF 1535), one Bii (RF 1536) and one medieval SA (RF 1534) Twenty-one sherds of imported pottery: ten Bi (eg RF 2199), six Bii (eg RF 2168), one Coarseware Fabric 1 (RF 2208) and four unidentified (eg RF 2204). Five medieval SA sherds (eg RF 2196), three notched slates (eg RF 2198), one chipped quartz pebble (RF 2217) and one fragment of burnt bone (RF 2216)

One Bii amphora sherd (RF 1550), two PRSW (RFs 1546 and 1549) and one unidentified (RF 1547), two medieval SA (eg RF 1553) and four medieval OK (eg RF 1548), a notched slate (RF 1523) and a slate disc (RF 1525). Charcoal++

Two Bi amphora sherds (RFs 2150 and 2163), three Bii (RFs 2151 and 2159), five $\mathrm{Bv}$ (RFs 2161 and 2162), four medieval SA (eg RF 2155) and three medieval OK (eg RF 2152)

Charcoal fragments $>2 \mathrm{~mm}:+1-10 ;++11-50$ 
Sixty-eight sherds of various thirteenth-century wares were identified including SA, OK, Ham Green ware (HG), Bristol Redcliffe wares (RE) and LO wares.

From a sample of 650 a single specimen of campion was recovered, and one fragment of burnt bone came from 653 .

Phase Z: Turf and topsoil. The whole area was covered by topsoil 651 and turf 500 .

Phase Z: Artefacts, ecofacts and dating (table 9). A notched slate and a slate disc or vessel lid came from this phase. Fifth- to seventh-century imported wares included Bi, Bii and Bv amphorae and PRSW. Medieval wares included $\mathrm{SA}$ and $\mathrm{OK}$.

One slate disc and sixteen sherds of SA including one large strap handle from a vessel (RF 2302: see Chapter 10 , figure 137) were unstratified.
TRENCH C17: STRATIGRAPHICAL SEQUENCE (figure 48)

Phase X: Radford's trench and backfill. The cut of Radford's trench, first identified as 673 in C15, continued on the same alignment to the south where it was excavated as 902 . It was backfilled with loose soil, shillet and slates 901 .

Phase X: Artefacts, ecofacts and dating (table 10). One find of a graffiti- and pick-marked slate was recorded from the backfill. The stone has a square notch at one corner and on the surviving flat surface is a series of incised lines. These lines have no obvious form, barely intersecting at two points (see Chapter 10, figure 109).

Mixed finds of very abraded early and later medieval pottery were also recorded from this layer as unstratified finds. Imported Mediterranean ceramics include Bi, Bii and $\mathrm{Bv}$ amphorae. Medieval wares include $\mathrm{SA}$ and $\mathrm{OK}$.

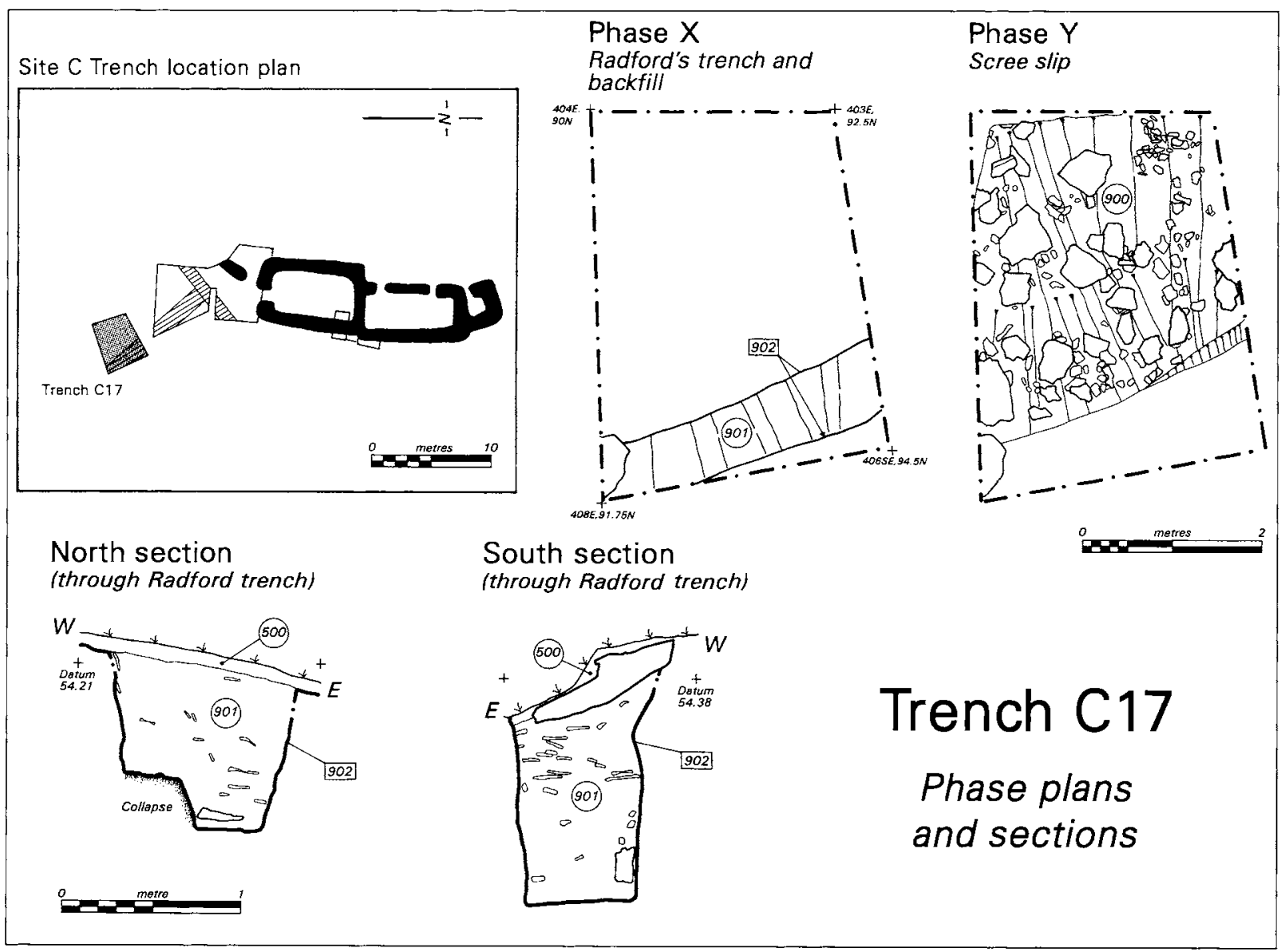

48 Trench C17. Phase plans and sections. Drawing: L McEwan 
Excavations at Tintagel Castle, Cornwall, 1990-9

Table 10 Trench C17: contexts and finds

\begin{tabular}{lll}
\hline Phase & Context & Context description \\
\hline $\begin{array}{l}\text { Phase X: } \\
\text { Radford's } \\
\text { trenches and } \\
\text { backfill }\end{array}$ & 901 & $\begin{array}{l}\text { Dark-brown, loose silty clay loam } \\
\text { with shillet, backfill of Radford } \\
\text { trench } 902\end{array}$ \\
& & \\
902 & $\begin{array}{l}\text { Radford's trench cut, extension of } 673 \\
\text { in C15, extending southwards along } \\
\text { the terrace on same alignment }\end{array}$
\end{tabular}

Phase Y: $\quad 900 \quad$ Dark brown friable clayey loam with scree slip shillet and large slates

Finds

Graffiti- and pick-marked slate (RF 2828)

with mixed pottery finds, unstratified from

fill, including five sherds of medieval pottery (eg RF 2804: one sherd of SA, and RF 2807: one sherd of OK) and 18 of imported pottery: $15 \mathrm{Bi}$ amphora (eg RF 3302), one Bii (RF 2805) and two Bv (eg RF 2802)

Eight Bi amphora sherds (RFs 2810 and 2822), two Coarseware Fabric 1 (RFs 2813 and 2815), two unidentified (RF 2812), two medieval OK (RFs 2814 and 2818), two medieval RE sherds (RFs 2809 and 2820) and three medieval SA (RFs 2821 and 2824). One crucible fragment (RF 2816) and one pebble (RF 2819)

Phase Z: $\quad 500 \quad$ Loamy turf and topsoil Two pebbles (RFs 2805 and 2806) and a turf and piece of highly fired ceramic-type industrial topsoil material (RF 2321)

Phase Y: Scree slip. Consistent with C15, Radford's trench was overlain by a scree slip 900 .

Phase Y: Artefacts, ecofacts and dating (table 10). One water-worn pebble was recovered from Phase Y. In addition, a piece of industrial waste was studied (RF 2816). It was a very small piece, likely to be a fragment of crucible rather than a metallic piece.

Abraded sherds of fifth- to seventh-century imported Mediterranean pottery from this phase include $\mathrm{Bi}$ amphora and Coarseware Fabric 1. Thirteenth-century sherds include $\mathrm{SA}, \mathrm{OK}$ and $\mathrm{RE}$ (Vessel RE2).

Phase Z: Turf and topsoil. The whole area was overlain by topsoil and turf 500 .

Phase Z: Artefacts, ecofacts and dating (table 10). Two water-worn pebbles were recovered from Phase Z. Also, a piece of industrial waste ( $R F$ 2321) identified as a mixture of natural (iron pan) and man-made, highly fired ceramic type fabric of uncertain origin. A single perforated slate (RF 2322) was found unstratified in the turf horizon.

\section{DISCUSSION}

The three trenches under consideration here were intended to locate trenches opened by Ralegh Radford in the 1930s, and only limited excavation of undisturbed deposits took place. It became clear that his trench in C05 had not disturbed any buildings or structural features, as the main deposits cut through were soils and layers of scree tipped down the slope. However, there was evidence for human activity in this area of the site: Phase $\mathrm{W}$ consisted of features that included burnt material such as charcoal, for instance. No medieval material was recovered from any phase in C05, even Radford's backfill, suggesting that any activity on this part of the site took place within an earlier phase of the site's history. A sherd of imported Bii amphora was associated with the Phase $\mathrm{W}$ feature, and similar 
material was recovered from the scree deposits above. However, the Recorded finds assemblage from this trench was recovered predominantly from Phase $\mathrm{X}$ (scree-tips) and Phase Y (Radford's trench), from which eighteen B-ware amphora sherds were noted. The finds assemblage also included many stone artefacts, of which some were identified as having possibly served a structural function. This cannot be related to a structure on this part of the site, as they were clearly not in situ. The layers sampled in this trench contain little evidence of domestic waste in a primary context but, as with the work on the Lower Terrace, ${ }^{6}$ they provide glimpses into the range of plants that were available to the inhabitants of Tintagel Island in the fifth to seventh centuries. Foremost amongst these are a few cereal remains, together with some weeds (which may have come along with crops to the Island from the hinterland) and hints of the collection of fruit and nuts.

Trial trench C15 was located immediately south of the structure (Site C) on the Middle Terrace to reexamine a Radford trench from the 1930s. This demonstrated clearly that in this part of the terrace there had been a structure, represented both by a wall of slates cut through by the 1930 s work and a probable collapse from the wall. There were also indications of possible earlier land surfaces. However, the limited nature of the trial-trenching exercise precluded full examination of either the walling or the putative land surfaces until the area excavation of C15 in 1999 (see Chapter 5). However, the presence of both imported and medieval pottery in both the backfill of the Radford trench and in scree slips above the infilled trench would again suggest that there is likely to have been fifth- to seventhcentury occupation here. Certainly this trench was the richest in material terms of the re-examined Radford trenches in this programme of work. Several stone finds including a gaming board (RF 2172); industrial and iron pieces and 225 imported ware sherds, in addition to two Romano-British sherds and 124 medieval, indicate very clearly that this area was not only subject to considerable overburden which had moved down-slope, but also that the occupation area of the Middle Terrace clearly extended this far south. Palaeobotanical evidence was also recovered, although not in sufficient quantities to be able to draw any meaningful conclusions at this stage (discussed more fully in Chapter 11). It was clear from the re-evaluation of Radford's trenches in $\mathrm{C} 15$ that this area was of high archaeological potential. Investigation of undisturbed deposits outside Radford's work was not the remit of the work reported upon here. However, an area excavation of C15 was finally undertaken and completed in 1999 and the promising results are reported in the following chapter (Chapter 5).

In trench $\mathrm{C} 17$ no deposits outside the confines of the Radford trench were investigated. It is clear that both the backfill of the trench and the scree slip above it contained medieval and earlier material. C17 may be directly related in its artefactual material to trench $\mathrm{C} 18$ which lies up-slope from it to the west. The artefactual assemblage of $\mathrm{C} 17$ is considerably poorer in quantity, at least in terms of the ceramic assemblage, than both $\mathrm{C} 18$ and, more particularly, C15. No environmental material was recovered, as only disturbed deposits were excavated.

\section{CONCLUSION}

Re-examination of a Radford trench in C05 gave a similar picture to that obtained from the trial trenching on the Upper Terrace above (see Chapter 3). This Radford trench is included on Wright's plan of 'Quarry ledges' (see Chapter 1, figure 7). As with the Upper Terrace trenches, there is a lack of any later medieval material. However, the presence of B-ware amphora fragments in Radford's backfill and the existence of a number of features in the sides of the trench, clearly truncated by Radford's workmen, indicate some degree of usage of this part of the site. Although the palaeobotanical evidence is not of the nature of domestic waste, it does include the gathering of food, including cereal remains, associated common plants of waste or arable ground and fruit and nuts. All of this evidence indicates activity on the fringe of a settlement area, as indeed would be suggested by the topographic situation, of a narrow ledge or terrace to the north of the Site $\mathrm{C}$ building.

To the south of the building, re-examination of Radford's trenches ( $\mathrm{C} 15$ and $\mathrm{C} 17$ ) gave a very different picture. This area revealed that Radford's men had encountered, but possibly not recognized, a wall of slates in C15 and its probable collapse. It is clear that, unless Radford (or his workmen) had encountered the substantial remains of walling in the trenches, they tended simply to cut through the deposits regardless of their nature. Similarly, they do not appear to have been too concerned to collect artefacts in those trenches which were not expanded into larger excavations, and consequently the backfill has yielded valuable material 
from both the early (fifth-seventh centuries) and the later (thirteenth-fifteenth centuries) medieval periods. So the area demonstrated that it had much yet to offer, both from the finds recovered from Radford's trenches (C15 and C17), and also from the fact that he did not extend the trenches into a more extensive excavation of the area of a putative building.

Artefacts relating to in situ occupation and arriving from slippage down-slope from the Upper Terrace were also recovered. Although some of the material is abraded (due to downward movement in scree slip), much has clean breaks. One can only assume a lack of familiarity by Radford's workmen in the 1930s with, for instance, imported wares from the Mediterranean, although twenty years later Radford published examples of them from this site. ${ }^{7}$ As with trench $\mathrm{C} 18$, there was a significant later medieval pottery collection, in addition to the fifth- to seventh-century imported wares. Perhaps the medieval pottery and the stone artefacts were deemed as being of little archaeological interest at the time. Other artefactual material, and indicative palaeobotanical evidence from the deposits, demonstrated that this area must have been a continuation of the Middle Terrace to the north, despite the subsequent radical change made to the topography by landslip from the Upper Terrace above. In this case, re-examination of Radford's trenches indicated that the lack of recognition of the potential of the site in the 1930s has in fact preserved much of the area for more systematic examination at a later date - and, indeed, an area excavation took place here in 1999 (see Chapter 5).

Of particular note is the small number of industrial material samples that can be attributed with any certainty to metallurgical practices such as hearth/ furnace-wall and crucible fragments (see Chapter 10). The presence of these materials would seem to suggest the possibility of some industrial activities on this part of the Island, and combined with the recovery of a sprue for copper alloy working from the 'Steps area' examined in $1990,{ }^{8}$ and industrial waste recovered in excavation work in 1999 from 'Site $T$ ' in the Lower Ward (see Chapter 9), it is clear that there is much more to learn about this aspect of the economic life at Tintagel.

As with the Upper Terrace, there has been no programme of radiocarbon dating initiated on the material from the assessment of Radford's trenches on the Middle Terrace as all deposits excavated had been disturbed by later work. Dating of the deposits excavated must rely on the ceramic assemblage. As with the Upper Terrace, this provides us with both the international and local contexts, with the important addition of third-fourth-century Romano-British Gabbroic pottery. Just as C19 at the north end of the Upper Terrace had virtually no later medieval material, so trench $\mathrm{C} 05$ from the north end of the Middle Terrace also had none. Imported Bii pottery was found in the feature of Phase $\mathrm{W}$ of $\mathrm{C} 05$, as well as in later deposits, including Radford's backfill. At the south end of the Middle Terrace, as with $\mathrm{C} 18$ at the south end of the Upper Terrace, trenches $\mathrm{C} 15$ and $\mathrm{C} 17$ had some medieval material, in fact 124 sherds were recovered from C15. These indicate that, while much may well have slipped down the slope from the later medieval occupation of the Upper Terrace, some may originally have been in situ on the Middle Terrace. 


\section{CHAPTER 5}

\section{EXCAVATIONS IN AND AROUND THE MidDlE TERRACE: TRENCH C15, 1999}

In trench C15 in 1999 a newly discovered structure to the south of the upstanding building on Site C was excavated. The results may support interpretations first suggested by work on the 'Lower Terrace' that these buildings were occupied during specific periods of the year, ${ }^{1}$ maybe in association with seasonal trading. ${ }^{2}$ The structure is much less substantial than those excavated by Radford and reconstructed elsewhere on the Island (see Chapter 6). The structure and deposits suggest phases of short-lived activity and an artefactual assemblage dominated by finds of imported fifth- to seventh-century pottery. Small assemblages of industrial material and fragmentary animal bone are also a new development in the range of evidence recovered from the Middle Terrace.

\section{INTRODUCTION}

The aims and objectives were to investigate a building comparable to the Site $\mathrm{C}$ building excavated by Radford (see Chapter 6), establishing a secure stratigraphic sequence, to collect and analyse evidence for the economy and environment through environmental sampling, and through the study of the artefacts recovered, to gain a fuller understanding of the role of trench $\mathrm{C} 15$ in a wider context.

\section{FIELDWORK METHODOLOGY AND SYNOPSIS OF WORK UNDERTAKEN: SPECIFIC ISSUES RELATING TO SITE C15}

Comparable methodologies were employed at $\mathrm{C} 15$ to the rest of the excavation programme at Tintagel. Specific issues relating to the extreme angles at C15 necessitated surveying modifications, however, and these are recorded in the archive.

The area of C15 excavated in 1994 during the evaluation of Radford's trenches (see Chapter 4) was expanded in 1999 to cover an area of $4.6 \mathrm{~m}$ by $9 \mathrm{~m}$ (figures 24, Chapter 1; 46, Chapter 4 , and figure 49). ${ }^{3}$
The alignment of the trench was altered to tie in with the position of Radford's excavated strip-trenches and of the sections of walling uncovered just below the turf.

Once a depth of $1 \mathrm{~m}$ had been excavated from the west side of the trench, the section was stepped outwards to the east by $1 \mathrm{~m}$, and a new section established. Two further sections were also established perpendicular to the stepped section, one corresponding to the south elevation of the collapsed wall 666 , and one to the north. This not only provided useful stratigraphic information but also prevented the collapse of the wall, which was becoming a health and safety hazard.

\section{SUMMARY OF STRATIGRAPHY AND PHASING}

Phase P: Natural (figure 50)

At the base of the trench, the shape of the rock-cut terrace was revealed. A near-vertical rock face defined the western limit of the terrace. This curved around slightly to the south, where the slate naturally formed 'steps' downwards at a less acute angle. David Jefferson suggests that the terrace had been shaped by the deliberate excavation of stone from the bedrock, using natural jointing to break out the stone. ${ }^{4}$ When bedrock 


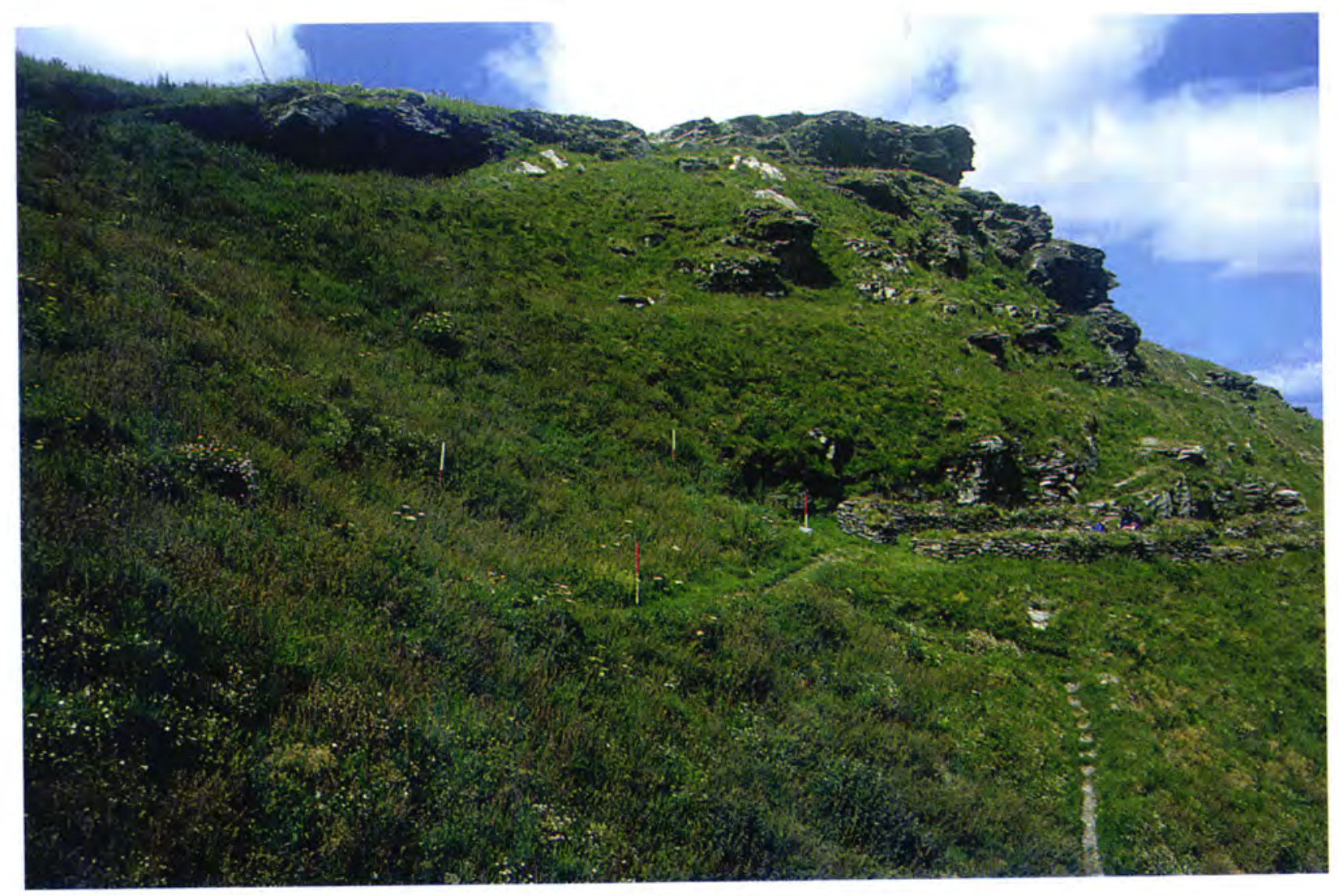

49 View of area of trench $C 15$ before deturfing, from the south east. Photograph: $R$ Barrowman

had been reached it became clear from the southern part of the trench that the terrace was larger than had appeared, and extended up to $6 \mathrm{~m}$ or $7 \mathrm{~m}$ further south below thick layers of turf and tumble. As a result, only a small northern proportion of the ephemeral building remains in this area were excavated in C15.

The bedrock 502 in the majority of the trench consisted of steps and angular lumps of slipped slate. Two areas of level surface were uncovered, at the north and south ends of the trench. The natural steps in the vertical face of the bedrock had been utilized as 'shelves' upon which to place stonework 688 and wall 666 of Phase V, both of which had subsequently slipped $0.5 \mathrm{~m}$ down the slope with the soil creep.

On the flat slate bedrock surface at the north end of the trench slate flakes 686 and silt $676 / 507$ had banked against upright slates 677 . These were situated roughly perpendicular to wall 501 of Phase $\mathrm{V}$ and it was suggested at first that here was a threshold-type feature. This had previously been seen on the Lower Terrace where lines of small upright slates appear to have been used, possibly to hold wattle screens in place. ${ }^{5}$ However, investigation within a small sondage adjacent to wall 501 demonstrated that these layers had all accumulated during a natural process and were earlier than the wall. A large slip of bedrock $686 / 689$, pre-dating all archaeological remains on the terrace, had collapsed down the slope due to water seepage weakening the rock. Subsequent to this, the bedrock lumps, shillet, slate flakes and sandy scree became concreted and leached by water action. The sloping bedrock surface at the east edge, towards the back of the terrace, had resulted in the collection of running water in the crack in the rock. Any waterborne silt was deposited at the edge of the crack, where small slates at the edge of the bedrock had collapsed and lodged upright in the rock. This process was the cause of the upright slate feature and the bank of silt.

Four further layers of natural were investigated. Concreted deposits 668 and 670 were uncovered in the bottom of Radford's trenches in trial trench C15 in 1994 and were thought to be possible old land surfaces (see 


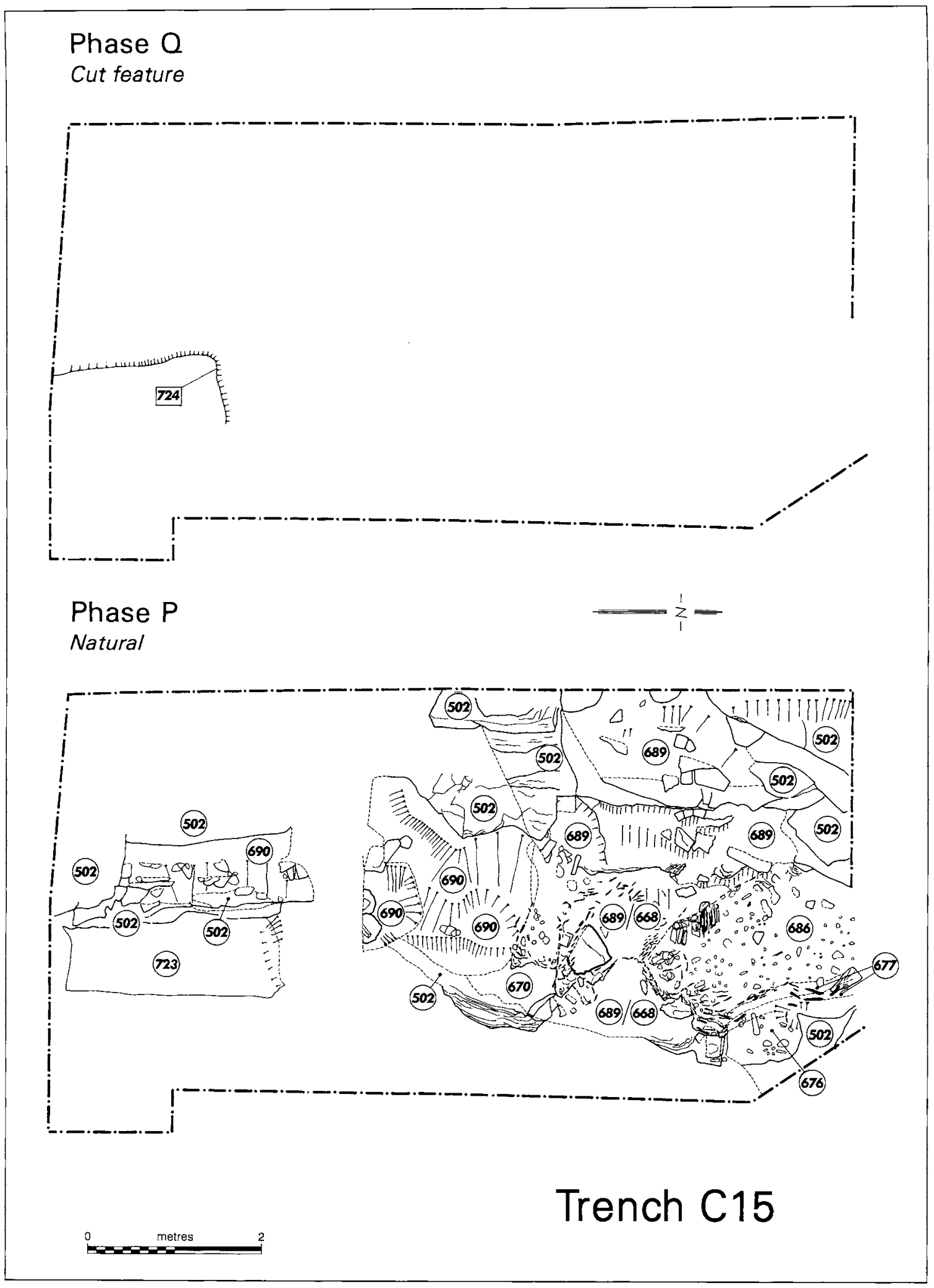

50 Phases $P$ and Q plans. Drawing: L McEwan 
Chapter 4). However, on excavation in 1999 they were seen to be natural that had become trampled during the 1930s work. Elsewhere, decayed bedrock layer 690 and silt 723 were excavated from pockets within the bedrock.

\section{PHASE P: ARTEFACTS, ECOFACTS AND DATING}

(table 11)

One small, abraded fragment of fifth- to seventhcentury imported Mediterranean Bi amphora came from this phase. It had presumably washed in with silt from above the site.

Only a small amount of charcoal was recovered from this phase, which, like the pottery fragment, had presumably washed in to the site.

Phase Q: CUT Feature (figure 50)

A linear feature $724,2.1 \mathrm{~m}$ north to south, curving around at a right angle to $0.9 \mathrm{~m}$ to the east, had been cut $0.35 \mathrm{~m}$ wide into the decayed bedrock. It was situated parallel to the bedrock at the west of the trench and then turned perpendicular towards the east edge of the terrace and the sea. It may have served as a drain to draw water away from the bedrock face. No finds or samples were recovered from this phase.
PHASE R: DUMP OF MATERIAL OR POSSIBLE SURFACE

(figure 51)

This phase of clayey silt 721,722 and 725 also contained charcoal flecks and lumps of carbonized material. It covered and filled the Phase $\mathrm{Q}$ feature below and was sealed by paving slabs 699 of Phase $S$ above. It is possible that it is part of a floor surface of a larger building, although only a small area was excavated. The lack of plant macrofossils or charcoal identified from a sample of the layer (see below) indicates that it is unlikely that this was an occupation surface used for any length of time. The finds of well-preserved pottery sherds, however, suggest that perhaps this area was used for storage of amphora (see Thorpe in Chapter 10).

\section{PHASE R: ARTEFACTS, ECOFACTS AND DATING}

(table 12)

Five sherds of $\mathrm{Bi}$ amphora and two large (RF 6072: see Chapter 10, figure 130) and twelve conjoining sherds of $\mathrm{Bv}$ were excavated from this phase. Two hundred and thirty-two indeterminate large mammal bone fragments in very poor condition and an indeterminate lump of iron were also recovered. Flotation of a sample from 725 produced little charcoal, and no plant macrofossils.

Table 11 Trench C15 Phase P: contexts and finds

\begin{tabular}{|c|c|c|c|}
\hline Phase & Context & Context description & Finds \\
\hline \multirow{9}{*}{$\begin{array}{l}\text { Phase P: } \\
\text { natural }\end{array}$} & 502 & Slate bedrock & \multirow{9}{*}{$\begin{array}{l}\text { Charcoalt. One Bi amphora fragment } \\
\text { (RF 3872) } \\
\text { Charcoalt }\end{array}$} \\
\hline & $676 / 507$ & Yellowish sandy silt banked against 677 & \\
\hline & 668 & $\begin{array}{l}\text { Same as } 689 \text { but trampled in the bottom } \\
\text { of Radford's cut } 663\end{array}$ & \\
\hline & 670 & $\begin{array}{l}\text { Same as } 689 \text { but trampled in the bottom } \\
\text { of Radford's cut } 673\end{array}$ & \\
\hline & 677 & $\begin{array}{l}\text { Upright angular slates roughly } \\
\text { perpendicular to wall } 501\end{array}$ & \\
\hline & 686 & $\begin{array}{l}\text { A large slip of loose chunks of eroded } \\
\text { bedrock and slate flakes }\end{array}$ & \\
\hline & 689 & $\begin{array}{l}\text { Same as } 686 \text {, but situated north of } \\
\text { wall } 666\end{array}$ & \\
\hline & 690 & $\begin{array}{l}\text { Yellowish sandy silt, bedrock and scree } \\
\text { excavated from pockets within the } \\
\text { bedrock }\end{array}$ & \\
\hline & 723 & $\begin{array}{l}\text { Concreted yellowish-brown sandy silt } \\
\text { layer with slate flakes excavated in the } \\
\text { south of the trench overlying bedrock. } \\
\text { Only } 0.02 \mathrm{~m} \text { thick }\end{array}$ & \\
\hline
\end{tabular}

Charcoal fragments $>2 \mathrm{~mm}:+1-10$ 


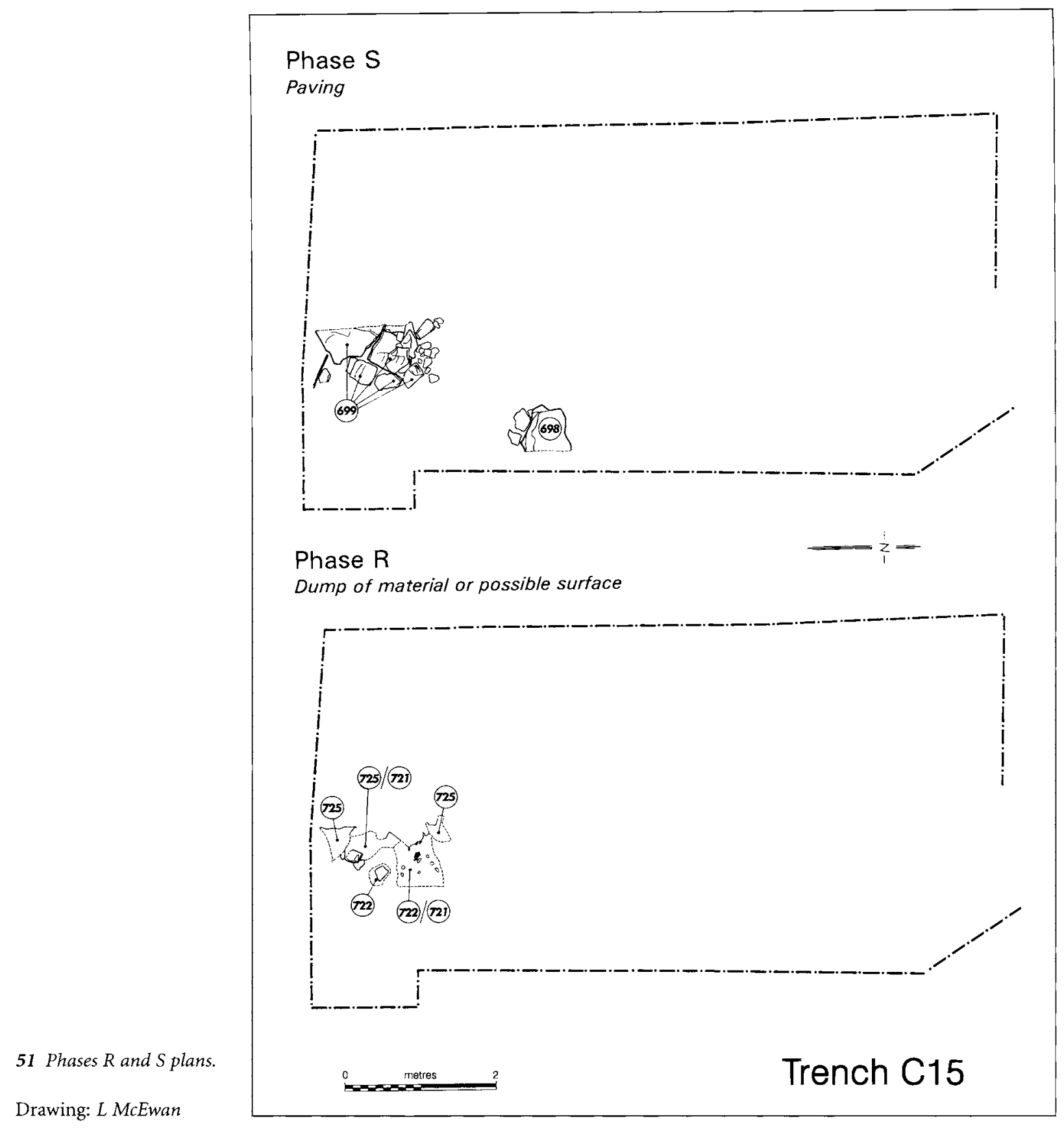

Phase S: PAVING (figure 51)

It is clear from this phase that an earlier structural phase of activity existed prior to the building of the structure suggested by the fugitive remains of walling in Phase V.

Two small areas of paving were excavated, both sealing Phase $\mathrm{R}$. The smaller of the two, 698, may have covered a larger area, as further large, flat stones could be seen in the east section of the trench, falling away to the sea. The Radford excavations seem to have stopped at the paving stones, and the edge of the large stone had been chipped by pick-axes.

The second area of paving excavated, 699, was also truncated by Radford's trench (Phase X). To the west, the paving was built against the bedrock face, and continued under the trench-section to the south. The paving lay on top of the dumps of material (a possible surface) of Phase $R$. 
Table 12 Trench C15 Phase R: contexts and finds

\begin{tabular}{|c|c|c|c|}
\hline Phase & Context & Context description & Finds \\
\hline $\begin{array}{l}\text { Phase R: } \\
\text { dump of } \\
\text { material or } \\
\text { possible surface }\end{array}$ & $\begin{array}{l}721 / 722 / \\
725\end{array}$ & $\begin{array}{l}\text { A waterlogged and manganese-stained } \\
\text { clayey silt with shillet, sand, occasional } \\
\text { flat slates and charcoal flecks and lumps } \\
\text { of carbonized material. Possibly a } \\
\text { surface }\end{array}$ & $\begin{array}{l}\text { One large Bi amphora sherd (RF 6080), and } \\
\text { an iron object (RF 6082) from 721. Three } \\
\text { large Bi sherds (RFs 6071 and 6073), two } \\
\text { large conjoining Bv (RF 6072), one } \\
\text { smaller Bi (RF 6081), } 12 \text { conjoining Bv } \\
\text { (RF 6079) and unidentifiable large } \\
\text { mammal bone fragments (RF 6070) from } \\
722 \text {. B-ware (RF 6074) from } 725 \text {. } \\
\text { Charcoal+ }\end{array}$ \\
\hline
\end{tabular}

Charcoal fragments $>2 \mathrm{~mm}:+1-10$

\section{PHASE S: ARTEFACTS, ECOFACTS AND DATING} (table 13)

One large sherd of $\mathrm{Bi}$ amphora was excavated from this phase, located on paving 699.

Phase T: DUmp of Material (figure 52) This phase is characterized by probable midden dumps at the south end of the trench. 696 and 695 were truncated by the trench edge and covered by a silty clay layer, 697, which may possibly have been a surface. It was truncated to the east by the Radford cutting 673 and to the south by the trench edge. It was clear that the terrace was larger than first thought and extended further south below turf and tumble.

\section{Phase T: ARTEFACTS, ECOFACTS AND DATING}

(table 14)

Layer 695 contained a fragmentary pig molar, Bi amphora sherds showing clean breaks and no abrasion and the sample taken from this layer contained charcoal and indeterminate large/medium mammal and bird bone fragments.

Imported pottery (amphora) sherds, again with clean breaks, were recovered from 697 and included Bi (including handle/neck and rim sherds eg RF 6051: see Chapter 10, figure 129), Bii and Bv. Two slate amphorastoppers and one sherd of Romano-British Local ware (RF 6022: see Chapter 10, figure 126) were also identified from this layer.

Two unusual stone finds from this phase include a flint flake and a perforated, probable roofing slate. The thick flint flake is snapped at the proximal and distal ends and has no visible retouch. The roofing slate may be suggestive of building collapse.

The three finds of industrial material from 697 have been identified as vitrified fuel ash (VFA) slag, suggestive of burning in a domestic hearth.

Finds of rotten mammal bone and teeth, identified to cattle, sheep/goat and pig, and lumps of birch and hazel charcoal were recovered from 697, and the samples

Table 13 Trench C15 Phase S: contexts and finds

\begin{tabular}{|c|c|c|c|}
\hline Phase & Context & Context description & Finds \\
\hline \multirow[t]{2}{*}{$\begin{array}{l}\text { Phase S: } \\
\text { paving }\end{array}$} & 698 & $\begin{array}{l}\text { Small area of paving, consisting of one } \\
\text { large flat slab, surrounded by smaller } \\
\text { slabs, situated at the east end of wall } \\
\text { (666). Truncated on three sides by } \\
\text { Radford's work }\end{array}$ & \\
\hline & 699 & $\begin{array}{l}\text { The larger area of paving, situated in } \\
\text { the south of the trench. Truncated to } \\
\text { the east by Radford's trench }\end{array}$ & One large Bi amphora sherd (RF 6049) \\
\hline
\end{tabular}




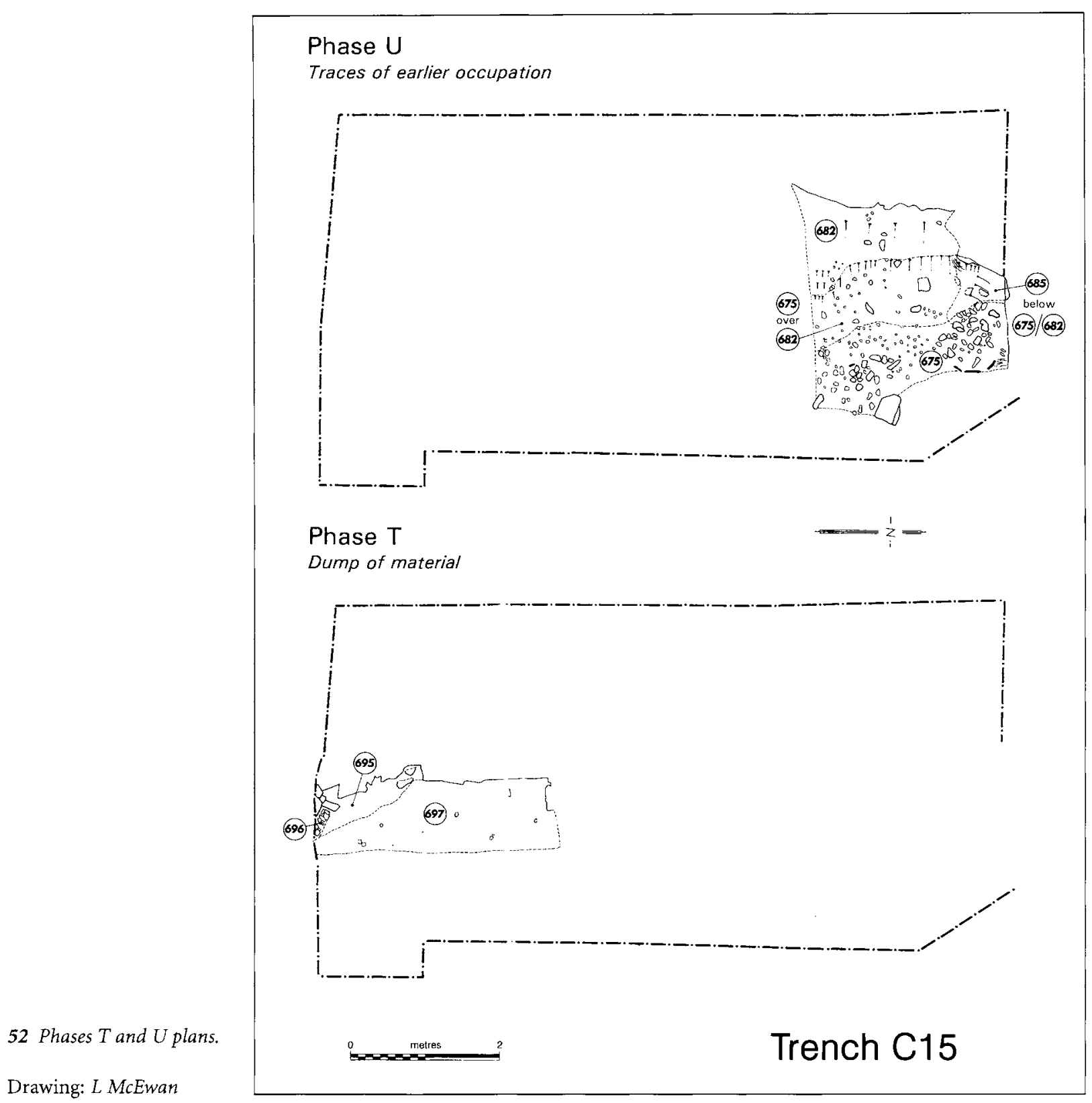

from this layer contained charcoal fragments and indeterminate mammal bone and burnt bone fragments but, surprisingly, no plant macrofossils.

\section{PHASE U: TRACES OF EARLIER OCCUPATION}

(figure 52)

Traces of early occupation in the form of slipped soil deposits were excavated from below Phase V. The slips 682 and 685 were localized to this part of the trench, and had slipped from the bedrock at the back (west) of the trench, rather than from the slopes above the excavation area. Clayey soil 675 had slipped onto 682 from the bedrock.

\section{PHASE U: ARTEFACTS, ECOFACTS AND DATING}

(table 15)

Layer 685 contained an incomplete spindle whorl of Bii amphora (see Chapter 10, figure 112: RF 3830) and 
Table 14 Trench C15 Phase T: contexts and finds

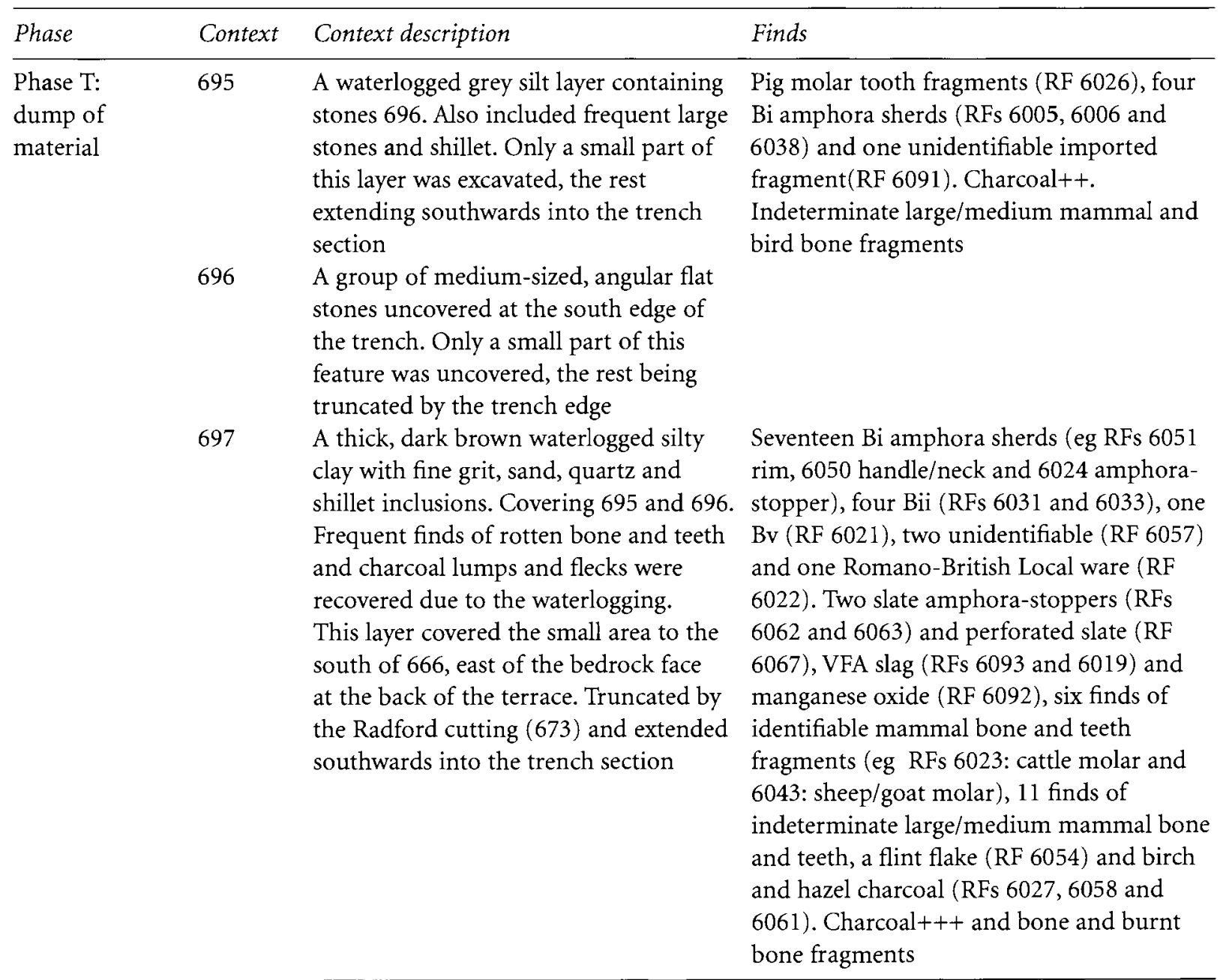

Charcoal fragments $>2 \mathrm{~mm}:+1-10 ;++11-50 ;+++51-100$

charcoal. The sample taken from this layer contained one indeterminate carbonized grain and two campion seeds. Layer 682 contained many imported amphora sherds, including $\mathrm{Bi}, \mathrm{Bii}, \mathrm{Biv}$ and $\mathrm{Bv}$. Finds of fragmentary mammal bone and tooth enamel were also recovered from this layer and the environmental sample contained surprisingly very little charcoal and no plant macrofossils. Layer 675 contained hazel charcoal, a fragment of burnt large mammal long bone, a pebble fragment, a notched stone and frequent imported pottery, including $\mathrm{Bi}, \mathrm{Bii}$ and the first find of a Bv handle at Tintagel (RF 3723: see Chapter 10, figure 130). This may enable work to begin on identifying and provenancing this form, together with rim sherds also recovered from $\mathrm{C} 15$ (see Phase $\mathrm{W}$ below). One
Coarseware Fabric 1 and one $\mathrm{D}$-ware sherd from a flanged bowl (eg RF 3748: see Chapter 10, figure 126) were also recovered from 675 . The environmental sample from this layer contained charcoal and three barley grains.

Phase V: COLlapsed STRucture (figure 53)

A structure had first been indicated in this area by the uncovering of part of a truncated wall, 666, during the 1994 assessment of Radford's Site C cuttings (see trial trench C15, Chapter 4). During excavations of the Site C building (see Chapter 6 ), the end of a second wall was seen protruding from below the turf at the back (east) of the terrace immediately to the south of the building. ${ }^{6}$ These two small sections of walling taken together 
Table 15 Trench C15 Phase U: contexts and finds

\begin{tabular}{|c|c|c|c|}
\hline Phase & Context & Context description & Finds \\
\hline \multirow[t]{3}{*}{$\begin{array}{l}\text { Phase U: } \\
\text { traces of earlier } \\
\text { occupation }\end{array}$} & 675 & Clayey soil with stones & $\begin{array}{l}\text { Hazel charcoal (RF 3764), burnt large } \\
\text { mammal long bone fragments (RF 3675), } \\
\text { sandstone pebble fragment (RF } 3615 \text { ), } \\
\text { notched stone (RF 3693a). Thirty Bi } \\
\text { amphora sherds (eg RFs } 3696 \text { amphora- } \\
\text { stopper and } 3749 \text { rim), six of Bii (eg RFs } \\
3693,3758 \text { and } 3765 \text { ), three of Bv (RFs } \\
3694,3752 \text { and } 3723 \text { handle), five } \\
\text { unidentifiable (RF 6102), one Coarseware } \\
\text { Fabric } 1 \text { (RF 6103) and one D-ware from a } \\
\text { flanged bowl (RF 3748). Charcoal++; three } \\
\text { barley (Hordeum sp.) grains }\end{array}$ \\
\hline & 682 & $\begin{array}{l}\text { Adjacent to } 685 \text {, a slip of silty clay } \\
\text { and shillet lying immediately over } \\
\text { bedrock at the west edge of the trench. } \\
\text { Had slipped from the bedrock at the } \\
\text { back (west) of the trench, rather from } \\
\text { the slopes above the excavation area }\end{array}$ & $\begin{array}{l}\text { Twenty-five Bi amphora sherds (eg RFs } \\
3888 \text { and } 3698 \text { ), three Bii (RFs } 3719,3722 \\
\text { and } 089 \text { ), one Biv (RF } 6100 \text { ), two Bv (RFs } \\
3715 \text { and } 3720 \text { ) and one unidentifiable } \\
\text { (RF } 6100 \text { ), and five finds of indeterminate } \\
\text { large mammal bone and tooth enamel } \\
\text { fragments (eg RFs } 3699 \text { and } 3859 \text { ). } \\
\text { Charcoal+ }\end{array}$ \\
\hline & 685 & $\begin{array}{l}\text { At the north end of the trench, patches } \\
\text { of dark brown clay with charcoal flecks }\end{array}$ & $\begin{array}{l}\text { Three Bii amphora sherds (RFs } 3814 \text { and } \\
\text { 3815), an incomplete spindle whorl (RF } \\
\text { 3830) and charcoal (RF 3831). Charcoal++; } \\
\text { one indeterminate carbonized grain and } \\
\text { two campion (Silene sp.) seeds }\end{array}$ \\
\hline
\end{tabular}

Charcoal fragments $>2 \mathrm{~mm}:+1-10 ;++11-50$

implied the presence of a further building on the terrace, to the south of that already excavated by Radford (see Chapter 6). In 1999, however, investigation in C15 showed that the two walls differed markedly in their construction, and no evidence of a contemporary floor layer or other indication of a building between the two walls was identified.

Wall 666 (figure 54) had been built from large to medium angular flat stones bonded with clayey soil. The same construction technique was noted in the buildings excavated on the Lower Terrace of Site C. ${ }^{7}$ It had been built into a small wall trench 692 , which had been cut into the hillside to the north of 666 and infilled with 691, redeposited decayed bedrock (figure 55). The damage to the section of wall 666 by Radford's excavations (see Phase X below) was more extensive than first thought. Not only had his excavations truncated the east end, but his workmen had also pick-axed around and over it.
This was evidenced by pick-marks to the stones on the upper surface of the wall, as well as to the southern face.

In addition, the wall together with a contemporary perpendicular wall 688 (see below), had slipped and then collapsed eastwards down the slope from its original position against the bedrock prior to Radford's excavations. Following the backfilling of the Radford cutting along the east edge of the terrace, the east half of the wall then sunk further downwards and eastwards into the softer soil of the 1930s backfill.

As mentioned above, the remains of a wall, 688, were also excavated, running at right angles to 666 . The stones of 688 had once been set onto the bedrock shelf at the back (west) of the trench and comprised very large to medium flat stones in two rows aligned north to south, resembling an inner and outer wall face (figure 56). The collapsed remains of this wall were excavated as 687 . Finds from this layer (see below) suggest that the slip of 


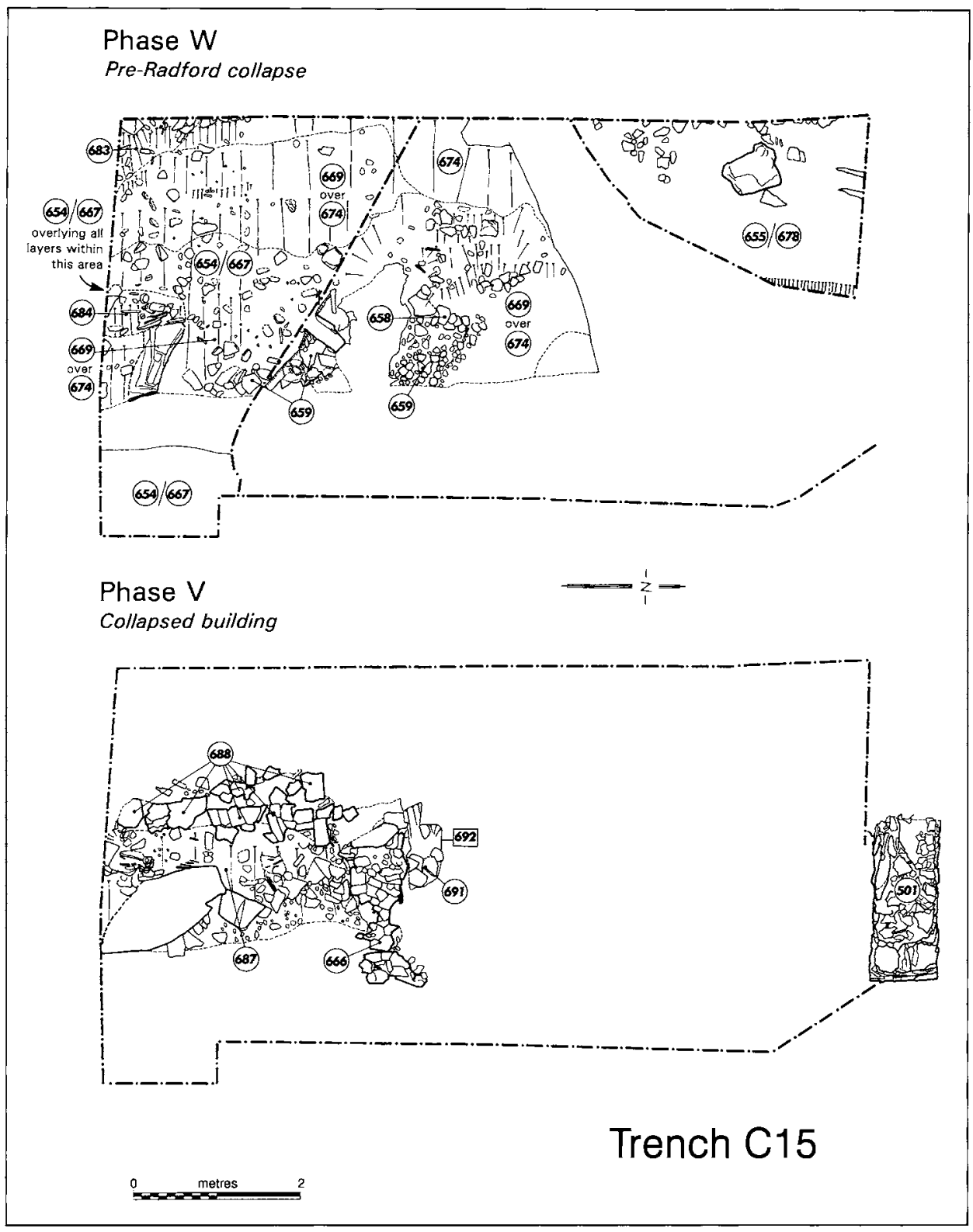

53 Phases $V$ and $W$ plans.

Drawing: $L$ McEwan

the structure represented by 666 and 688 down the slope destroyed the floor layer of the building also.

At the opposite end of the trench, the stub of wall 501 was built onto a natural layer 686 of Phase P (see above). As mentioned above, it was thought initially that this stub wall was the remains of the north wall of a building immediately adjacent to the Site $\mathrm{C}$ building (with truncated wall 666 perhaps forming the south wall). However, excavations in 1999 provided no evidence of this. Excavation adjacent to 501 in $\mathrm{C} 09$ in 1998 revealed it to be built onto layers associated with drainage of the site, immediately below the Site $\mathrm{C}$ building phase (see Chapter 6 ). It is unusual that the wall is built over bedrock on one side (figure 57), but over a considerable depth (up to $0.15 \mathrm{~m}$ ) of soil on the other (figure 58). It is possible from the stratigraphy of the layers above and below it chronologically, therefore, that wall 501 may be contemporary with the Site $\mathrm{C}$ building. It may even have been built as a revetment to keep soil slip out of the area of the building at the time of its use. It is certainly unconnected with contexts 666 and 688 to the south. 


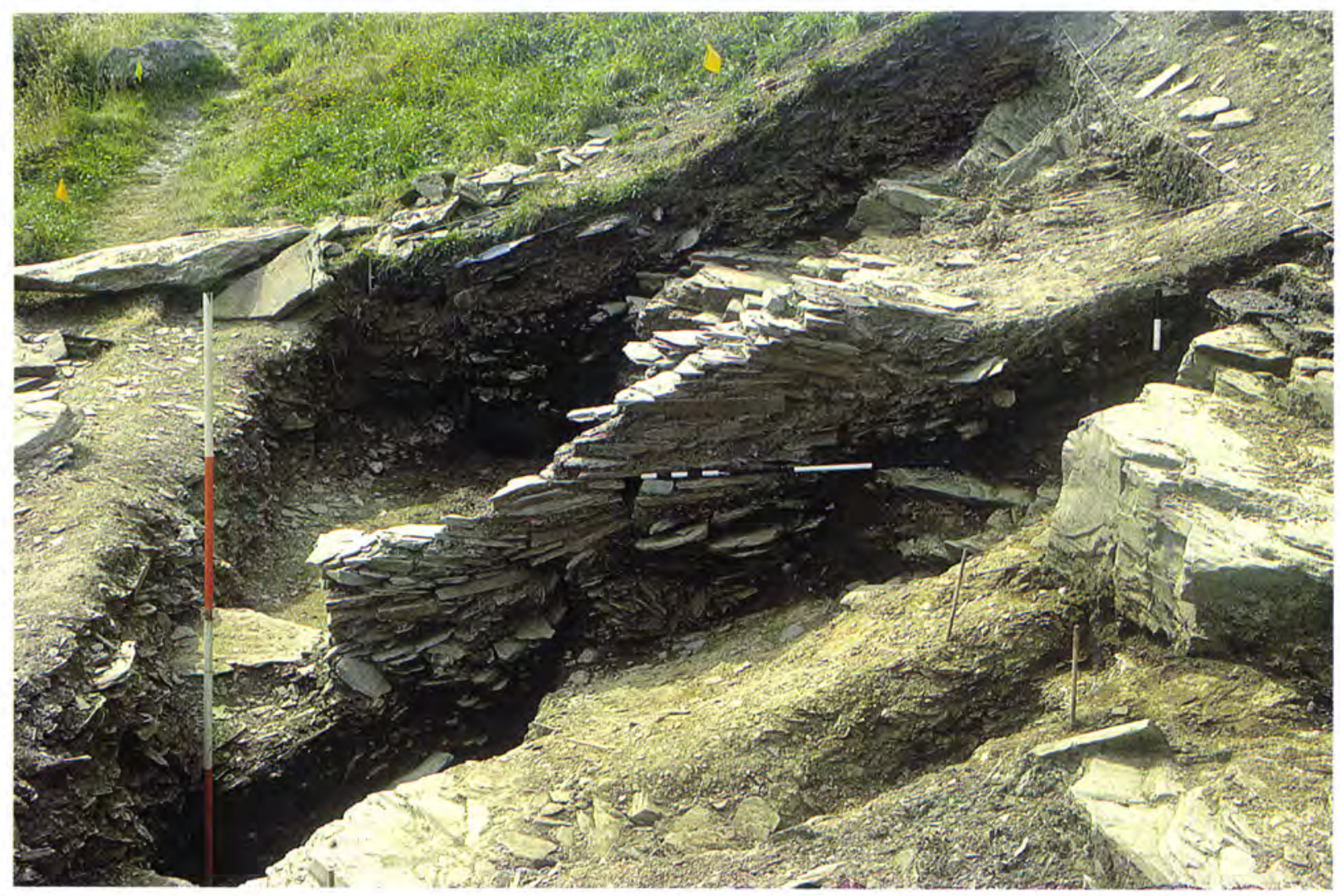

54 North-facing section of wall 666 from the north. Photograph: R Barrowman

The fabric and method of construction of wall 501 is altogether different from that of wall 666. It is more comparable to that of the reconstructed upper courses of the Site C building (as built in the 1930s, and seen in the background of figure 57). Also wall 501 had not slipped at all from the bedrock face at the west edge of the terrace, unlike all other archaeological deposits excavated in the area, and no features or layers associated with the use of a building associated with 501 were uncovered. What is clear from archive photographs is that Radford's spoil-heap for the excavations was situated adjacent to 501, in the south-west corner of Site C (see Chapter 6), and that 501 could have been a revetment wall to contain it. The construction techniques used are those of reconstructed walls elsewhere, but two of Wright's plans clearly depict wall 501 adjacent to the Site $\mathrm{C}$ building. ${ }^{8}$ As Wright and not the excavators made these plans after the excavation had been completed, it is possible that no one told him that he was recording one of Radford's spoil-heap revetment walls (see Chapter 1).
All of the above points taken into consideration, it may still be possible that wall 501 is contemporary with wall 666 of Phase V. However, with a lack of stratigraphic evidence to link the two, there is no archaeological evidence that they were connected structurally. It is also still possible that wall 501 is in fact connected with the Site $\mathrm{C}$ building to the north, and of unknown purpose.

\section{PHASE V: ARTEFACTS, ECOFACTS AND DATING}

(table 16)

Finds from within wall 666 include $\mathrm{Bi}$ and $\mathrm{Bii}$ amphorae sherds, one spindle whorl (RF 3909: see Chapter 10, figure 111) and one quartz pebble. Collapsed wall 688 contained one slate disc only.

Layer 687 contained frequent inclusions of imported pottery sherds including $\mathrm{Bi}, \mathrm{Bii}, \mathrm{Bv}$ and one basal and foot-ring sherd of African Red slipped ware (ARSW). Five lumps of iron, including two nails, and three finds of industrial material identified as vitrified fuel ash slag and bloomery slag were excavated from this layer. Finds also excavated from this layer included fragmentary mammal 


\section{Trench C15}

North-facing section featuring wall 666

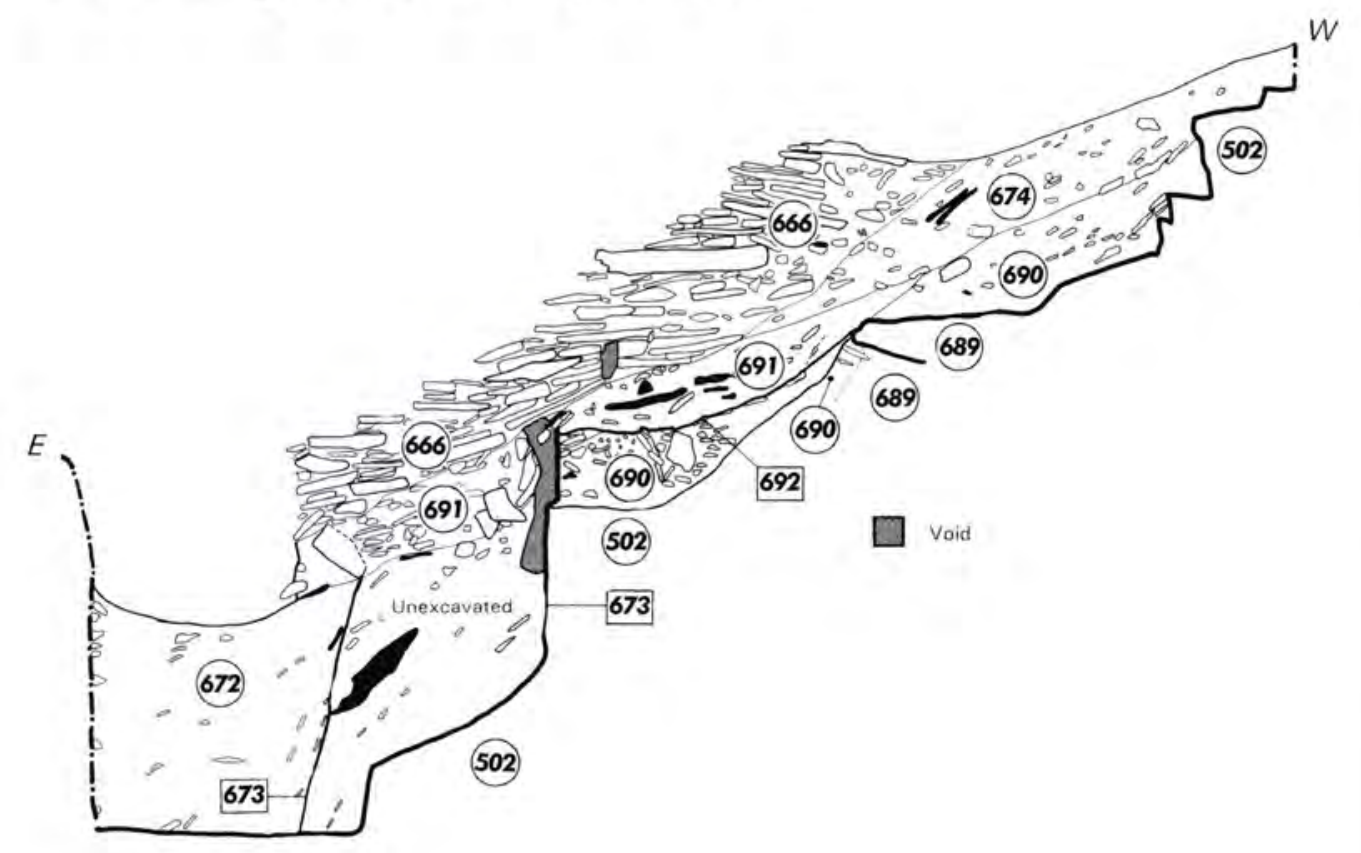

\section{Trench C15}

South-facing section featuring wall 666

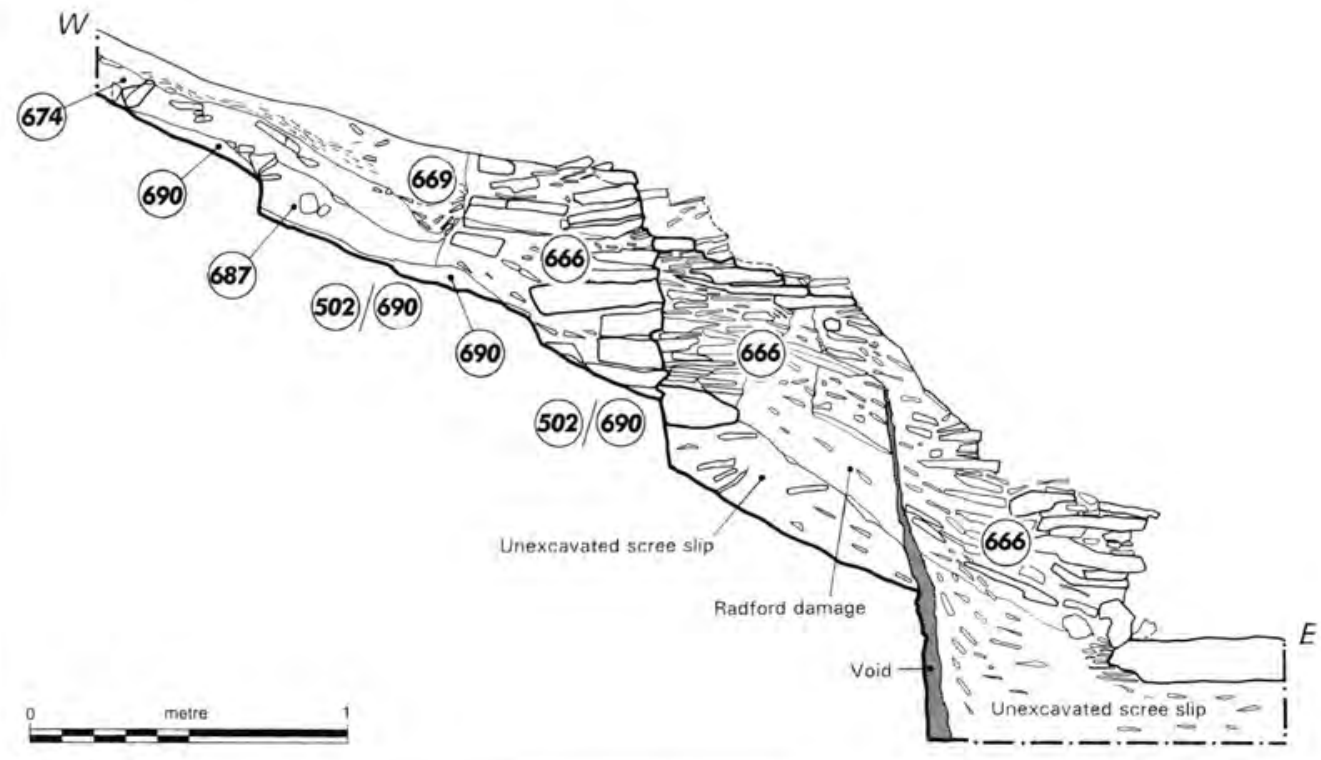

55 North-and south-facing sections featuring wall 666. Drawing: L McEwan 


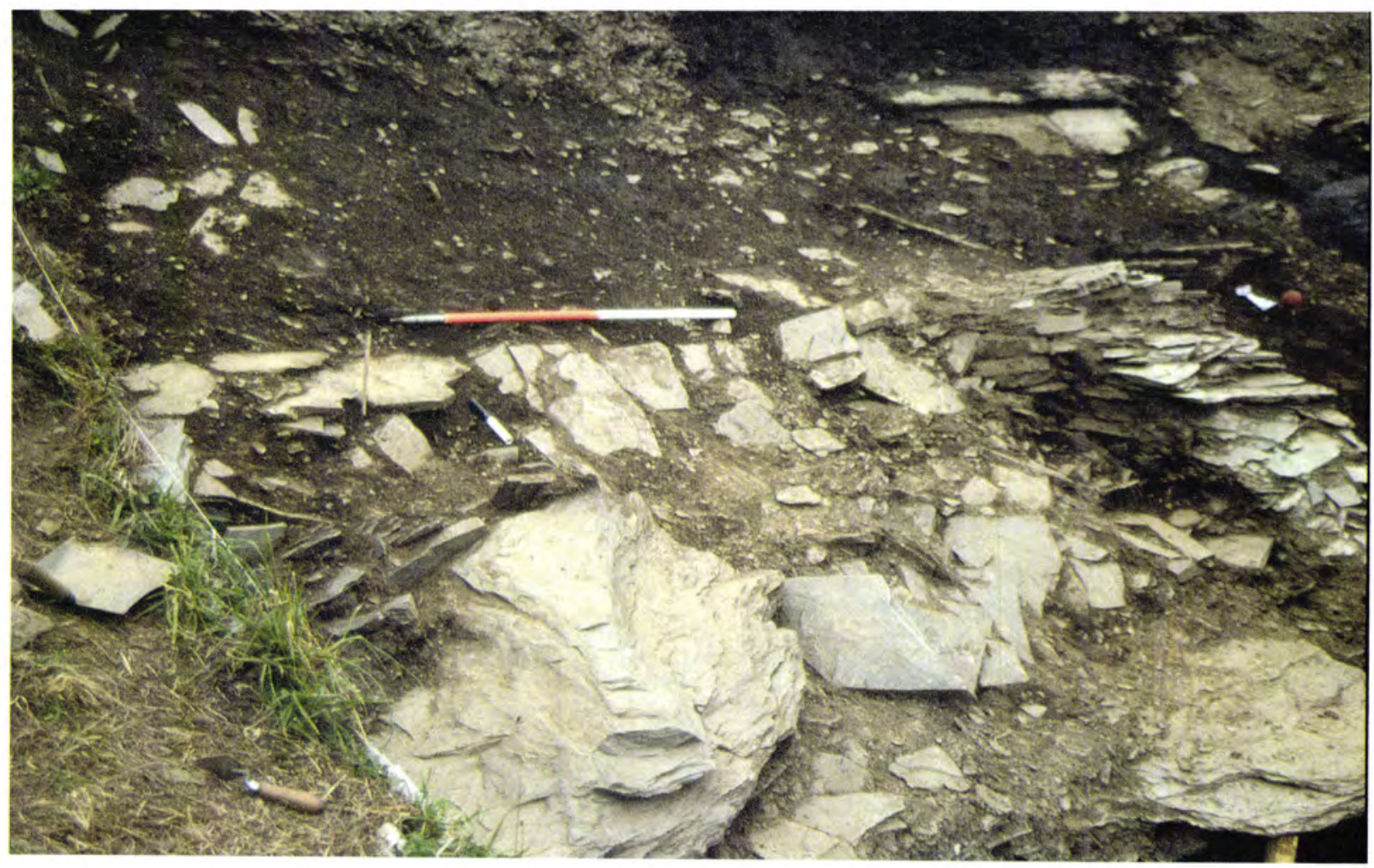

56 Collapsed walls 666, 687 and 688, from the south east. Photograph: R Barrowman

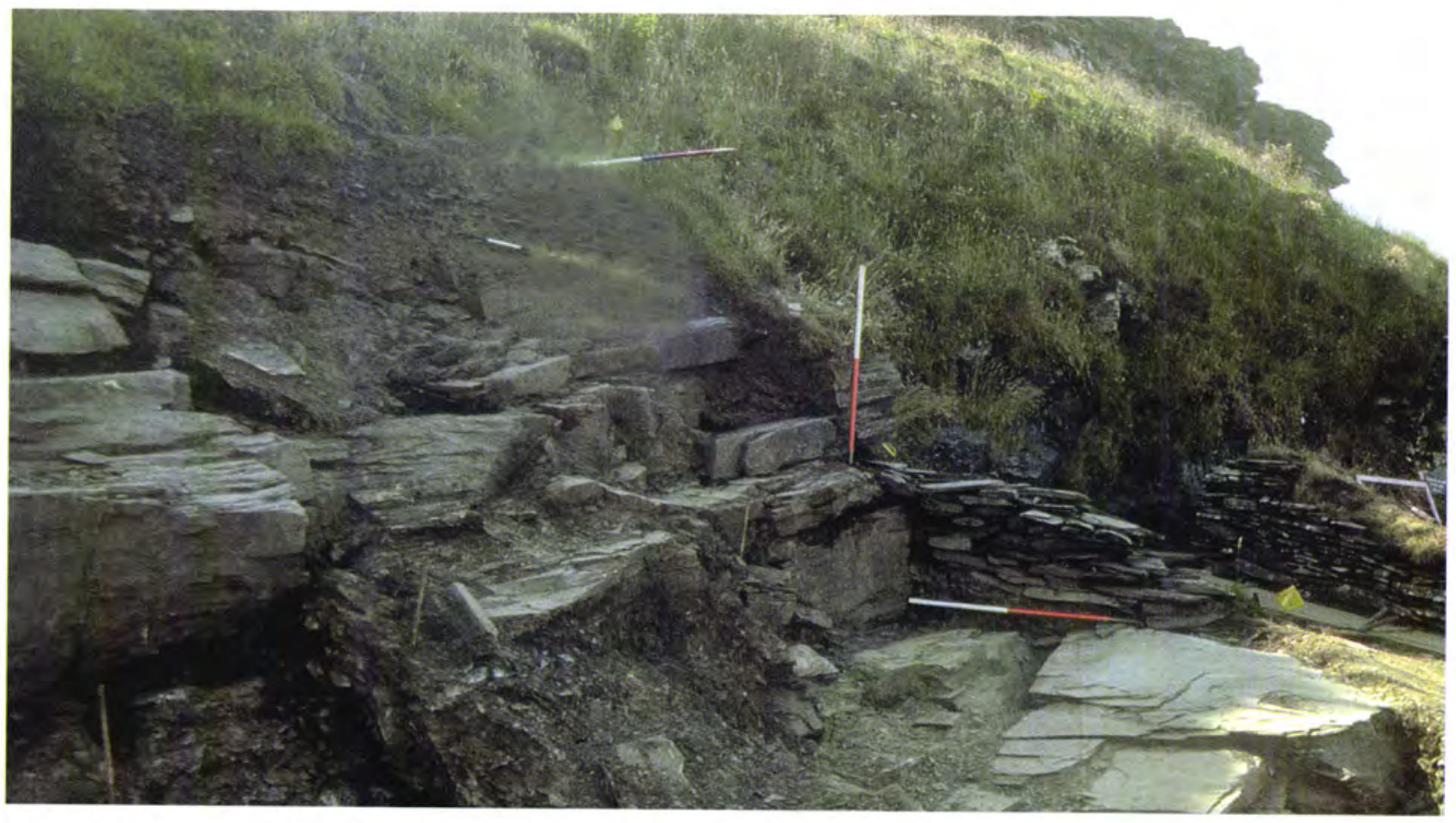

57 South-facing section of 501, from the south. Photograph: R Barrowman 


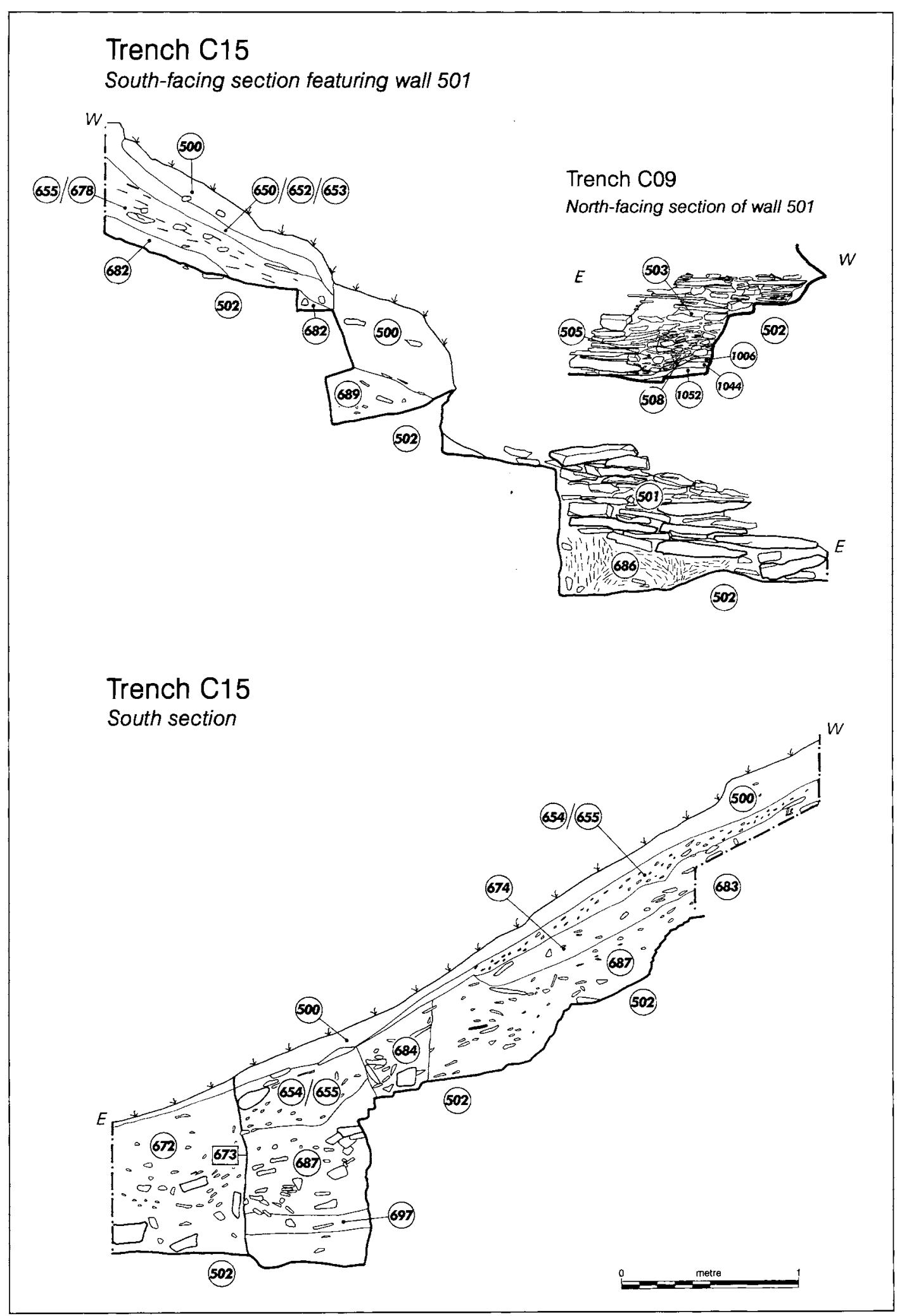

58 South-facing section featuring wall 501, and south section of trench. Drawing: $L M c E w a n$ 
Table 16 Trench C15 Phase V: contexts and finds

\begin{tabular}{|c|c|c|c|}
\hline Phase & Context & Context description & Finds \\
\hline \multirow{6}{*}{$\begin{array}{l}\text { Phase V: } \\
\text { collapsed } \\
\text { structure }\end{array}$} & 501 & $\begin{array}{l}\text { Stub of wall perpendicular to bedrock } \\
\text { face at north end of trench }\end{array}$ & \\
\hline & 666 & $\begin{array}{l}\text { Built from angular flat stones in clayey } \\
\text { soil. Truncated at the east end by } \\
\text { Radford's excavations. The wall had } \\
\text { slipped and then collapsed a con- } \\
\text { siderable distance from its original } \\
\text { position against the bedrock }\end{array}$ & $\begin{array}{l}\text { Two Bi amphora sherds (RFs } 3944 \text { and } \\
6065 \text { ), two of Bii (RFs } 3829 \text { and } 3842 \text { ), one } \\
\text { unidentifiable (RF } 3922 \text { ), one spindle } \\
\text { whorl (RF 3909) and one quartz pebble } \\
\text { (RF 6078) }\end{array}$ \\
\hline & 687 & $\begin{array}{l}\text { Layer of large flat angular stones in a } \\
\text { silty loam and shillet. The completely } \\
\text { collapsed remains of the remainder of } \\
\text { the wall } 688\end{array}$ & $\begin{array}{l}\text { Fifty-seven Bi amphora sherds (eg RFs } \\
6008 \text { and } 3894 \text { neck), } 13 \text { of Bii (eg RFs } 3967 \\
\text { and 3943), one of Bv (RF 6083), } 12 \\
\text { unidentifiable (eg RFs } 6014 \text { and } 3980 \text { ) and } \\
\text { one basal and foot-ring of ARSW (RF } \\
\text { 3900). Five lumps of iron, including nails } \\
\text { (eg RFs } 3936 \text { and } 3941 \text { ), } 13 \text { finds of } \\
\text { medium/large mammal bone and teeth } \\
\text { fragments, one only identifiable to species } \\
\text { (RF 3940; pig molar), two lumps of } \\
\text { charcoal, including Prunoideae (RFs } 3926 \\
\text { and } 3958 \text { ), one bloomery slag (RF } 3956 \text { b) } \\
\text { and two VFA slag (RFs } 3968 \text { and } 3981 \text { ), } \\
\text { three slate discs (RFs } 3903,3948 \text { and 6088), } \\
\text { one snapped flint blade (RF } 3965 \text { ), and } \\
\text { seven stone pebbles (eg RFs } 3893 \text { and } \\
6085 \text { ). Charcoal+; two carbonized oat } \\
\text { grains }\end{array}$ \\
\hline & 688 & $\begin{array}{l}\text { Fugitive remains of a wall that had } \\
\text { once been set onto the bedrock shelf } \\
\text { at the back (west) of the trench lying } \\
\text { perpendicular to } 666\end{array}$ & One slate disc (RF 3881) \\
\hline & 691 & Fill of 690 . Silty sand and slate flakes & \\
\hline & 692 & $\begin{array}{l}\text { A linear cut into the slope of decayed } \\
\text { bedrock to the north of } 666 \text { into which } \\
\text { wall (666) had been set, together with } \\
\text { infill } 691\end{array}$ & \\
\hline
\end{tabular}

Charcoal fragments $>2 \mathrm{~mm}:+1-10$

bone and teeth, only one identifiable to species (a pig molar), Prunoideae charcoal, three slate discs (eg RF 3903: see Chapter 10, figure 111), and stone pebbles were also recovered. An unusual find was that of the proximal end of a snapped flint blade, very abraded and showing irregular and steep retouch down the right-hand side (RF 3965). The sample taken from this layer contained a little charcoal and two carbonized oat grains.
PhaSe W: PRE-RADFORD COLLAPSE (figure 53) Stony rubble and clayey soils, 659 and 669 , first uncovered in 1994 (see Chapter 4) in the centre of the trench in a north-south aligned band adjacent to 658, were fully excavated in 1999. It became clear that this was all material which had collapsed from the remains of wall 666 as a result of natural scree slip movement. Two enormous stones that had crashed down the slope were 
removed. They had dragged a considerable dump of soil, scree and archaeology with them from the slope above, including a group of medieval pottery sherds.

Patches of clay within 669 may have been the remains of a surface associated with the Phase $\mathrm{V}$ structure or, more likely the remains of turf used in the construction of the building, as seen on the Lower Terrace (see Chapter 2).

Context 674, a layer of slip over the stepped bedrock, contained frequent inclusions of occupation material, possibly originally associated with the collapsed Phase $\mathrm{V}$ structure (see above) truncated by Radford's trench. In addition, a patch of burnt material, containing charcoal and burnt bone was excavated from within the layer. This was clearly a slip of material from elsewhere on the site as there was no evidence, such as burnt soil around the feature, to indicate that it resulted from in situ burning.

Loam 683 overlay 674, and a tip of upright slates (684) was found to be lodged behind a very large stone situated in the tip layers in the south part of the trench. This tip was a later collapse from wall 688 of Phase V.

The uppermost of the collapse layers were 654/667 and $655 / 678$ to the north. As noted in 1994, layers $654 / 667$ overlay a 'shelf' of clay and stones aligned north to south along the terrace. The stones of this shelf had no specific form or shape within the layer - they may be collapse associated with the ephemeral wall 666.

\section{PHASE W: ARTEFACTS, ECOFACTS AND DATING}

(table 17)

A large number and range of sherds of post-Roman imported wares were excavated from this phase. These include Bi, Bii (eg RF 3650 and RF 3863: see Chapter 10, figure 129) and $\mathrm{Bv}$ amphorae, Coarseware Fabric 1, Phocaean Red slipped ware (PRSW) and ARSW. The Bv sherds recovered included a rim/handle sherd (eg RF 3595: see Chapter 10, figure 130), which taken with the handle sherd from Phase $\mathrm{U}$ (above) may go some way to identifying the profile of this large amphora form. Two Romano-British Local ware sherds (cf Phase $\mathrm{T}$ above) were also recovered from this phase, including a rim sherd of a flanged vessel (RF 3609: see Chapter 10, figure 126), and a Romano-British Gabbroic ware sherd was found in layer 655/678. Medieval pottery recovered includes Bristol Redcliffe ware (RE) and North Devon Medieval Coarseware (OK).

Stone finds from this phase include notched and perforated slates, slate discs, pebbles, an unworked piece of greenstone, a broken spindle whorl, a gritstone disc and an incised graffiti slate (RF 3731: see Chapter 10, figure 110). Metalwork and industrial material from this phase includes iron nail shanks and a lump of bloomery smelting slag.

The sample from 658 produced one oat grain and one twisted hulled barley grain, and the sample from 659 produced a little charcoal. However, from two samples from 669 , one specifically from the area of clay patches, charcoal and nineteen plant macrofossils, including seventeen oat grains, one barley grain and one unidentified fruit/seed were recovered. Finds from 669 also include fragmentary mammal bone and teeth, two of which are identifiable to species - cattle molars - and two lumps of oak charcoal. The burnt material patch from within 674 was separately sampled and contained charcoal fragments but no plant macrofossils. Mammal bone and teeth fragments were recovered from all remaining layers; and although most are identifiable to large/medium mammal only, five fragments could be identified to cattle. The sample from 667 produced only a little charcoal, and from 678 , a little charcoal and two oat grains, one barley grain and one wheat grain.

Phase X: Radford's EXCAVATIONS (figure 59) A part of Radford's strip-trenches (cut numbers 663 and 673 respectively) across Site $C$ were re-opened, emptied and recorded in 1994 (see trial trench 15, Chapter 4, figure 46) and expanded in 1999.

At the end of the 1994 season, tipping slates 671 were uncovered in the bottom of Radford's cut 663 and interpreted as a possible old land surface. However, in 1999 these were shown to be part of Radford's backfill. Apart from this layer, the majority of cut 663 had been emptied and fully studied in 1994, although a small area of the cut fill 662 was removed at the east edge of the trench.

A larger part of 673 was revealed and emptied at the south end of the terrace in 1999 (figure 60). A small area of flat slates, 681, was uncovered at the east end of wall 666 . It was suggested that these had collapsed from the wall in antiquity, or were even the remains of a return wall forming the corner of a building at the east edge of the terrace. However, excavation revealed that they had collapsed from wall 666 due to damage by Radford's excavations.

Stony soil deposits 664 and 665, uncovered in 1994, were also identified as backfill and collapse from Radford's excavation and the same event as 672 . 
Table 17 Trench C15 Phase W: contexts and finds

\begin{tabular}{lll}
\hline Phase & Context & Context description \\
\hline Phase W: & $654 / 667$ & $\begin{array}{l}\text { Uppermost of a series of } \\
\text { layers of collapse with scree } \\
\text { pre-Radford } \\
\text { collapse }\end{array}$ \\
& $\begin{array}{l}\text { and soil slip, to the south of } \\
\text { Radford's east-west } \\
\text { trench } 663\end{array}$
\end{tabular}

Finds

Pottery from 654 includes $19 \mathrm{Bi}$ amphora sherds (eg RFs 3570 and 2262), nine Bii (eg RFs 2252 and 3602), one Biv (RF 2261), two Bv (RFs 2220 and 2236), 12 unidentifiable fragments (eg RFs 2263 and 3573), four PRSW (RFs 2218, 2243 and 2266), one ARSW (RF 2234), two medieval OK (RFs 3568 and 3601) and 13 medieval SA (eg RFs 3569 and 3578). From 667, $42 \mathrm{Bi}$ sherds (eg RFs 3655 amphora-stopper, 3656 footspike, 3634 rim and 3632 sherd with graffiti), four Bii (RFs 3642, 3652 and 3663), eight Bv (eg RFs 3637 and 3680), one unidentifiable fragment (RF 3681), one

Coarseware Fabric 1 (RF 2716) and six medieval OK (RFs 3628, 3631 and 3633). Also three sherds of Romano-British Local ware including a rim of a flanged vessel (RFs 3641, 3653 and 3609 rim). Stone finds include, from 654, one notched slate (RF 2934) one pebble (RF 3571) and one perforated slate (RF $3569 a$ ). From 667 one notched slate (RF 3644) and one pebble (RF 3654). Burnt indeterminate mammal bone fragments (RFs 2230 and 2264) and unburnt mammal tooth fragments (RF 2267) from 654, three finds of mammal teeth fragments from 667 (RFs 3664, a cattle molar, 3677 and 3668). Also bloomery slag (RF 3682). Charcoal +

655/678 Scree and soil slip to the north of Radford's trench 663

Pottery from 655 includes three Bi amphora sherds (RFs 2904, 2906 and 2913), four Bii (RFs 2907 and 2909), one Coarseware Fabric 1 (RF 2911), one PRSW (RF 2908) and five unidentifiable fragments (RFs 2905, 2910 and 2912). Pottery from 678 includes eight $\mathrm{Bi}$ sherds (eg RFs 3611 and 3661), one Bii (RF 3614), three Bv (RFs 3660 and 2931) and one unidentifiable (RF 3610). Pottery from 655/678 includes $26 \mathrm{Bi}$ sherds (eg RFs 3621 and 3647), two Bii (RFs 3588 amphorastopper and $3650 \mathrm{rim}$ ), seven Bv (eg RFs 3590 and 3595 rim/handle), one PRSW (RF 3618), one medieval OK rim (RF 3598) and one Romano-British Gabbroic ware (RF 3624). From 678 one pebble (RF 2932) and from $655 / 678$ three pebbles (RFs 3597, 3622a and 3623c), an unworked piece of greenstone (RF 3649) and a broken spindle whorl ( $R F$ 3623b). Indeterminate large mammal bone and teeth fragments from 655 (RF 2916), and 678 (RFs 2926 and 2927) and one from 655/678 (RF 3648). From 678, charcoal+; two oat grains (Avena sp.), one barley grain (Hordeum sp.) and one wheat grain (Triticum sp.) 


\begin{tabular}{|c|c|c|c|}
\hline Phase & Context & Context description & Finds \\
\hline & $\begin{array}{l}659 / 669 / \\
658\end{array}$ & $\begin{array}{l}\text { Stony rubble and clayey } \\
\text { soils situated in the centre } \\
\text { of the trench in a north- } \\
\text { south aligned band. } \\
\text { Situated to the north of } 666\end{array}$ & $\begin{array}{l}\text { Finds from } 659 / 669 \text { include medieval RE jug sherds } \\
\text { (RFs } 3912,3915 \text { and } 3918 \text { ), seven Bi (eg RFs } 3913 \\
\text { and } 3916 \text { ) and one Bii amphora (RF } 3917 \text { ). Finds from } \\
658 \text { include six Bi sherds (eg RFs } 2286 \text { and } 2921 \text { ), two } \\
\text { Bii (RFs } 2919 \text { and 2922), one Bv (RF 2923), two } \\
\text { unidentifiable fragments (RFs } 2271 \text { and 2920), one } \\
\text { Coarseware Fabric } 1 \text { (RF 2917) and three medieval SA } \\
\text { (RFs 2258, 2275 and 2276). Finds from } 659 \text { include } 15 \\
\text { Bi sherds (eg RFs } 3737 \text { and } 3826 \text { ), one Coarseware } \\
\text { Fabric } 1 \text { (RF } 3741 \text { ), two unidentifiable fragments (RFs } \\
3823 \text { and } 6090 \text { ) and two medieval SA (RFs } 3738 \text { and } \\
3784 \text { ). A gritstone disc (RF } 3716 \text { ), an incised graffiti } \\
\text { slate (RF } 3731 \text { ), a notched slate (RF } 3739 \text { ), a quartz } \\
\text { pebble (RF } 3824 \text { ) and a lump of charcoal (RF } 3822 \text { ) } \\
\text { also from } 659 . \text { Finds from } 669 \text { include } 34 \text { Bi sherds (eg } \\
\text { RFs } 3867 \text { and } 3770 \text { ), 16 Bii (eg RFs } 3863 \text { rim and } \\
3768 \text { ), two Bv (RF } 3811 \text { ), 18 unidentifiable (eg RFs } \\
3792 \text { and } 3874 \text { ), two Romano-British Local ware (RFs } \\
3688 \text { and } 3705 \text { basal), eight finds of large mammal } \\
\text { bone/teeth fragments, two identified to species (cattle } \\
\text { molars RFs } 3849 \text { and } 3873 \text { ), two lumps of oak charcoal } \\
\text { (RFs } 3818 \text { and } 3844 \text { ), two iron nail shanks and two } \\
\text { indeterminate fragments (RF } 3795 \text { ) and a granitic } \\
\text { stone (RF } 3820 \text { ). 658 produced one oat grain (Avena } \\
\text { sp.) and one twisted hulled barley grain (Hordeum sp.). } \\
659 \text { charcoal+. } 669 \text { two samples, charcoal+++ and } \\
\text { charcoal+; } 19 \text { plant macrofossils, including } 17 \text { oat } \\
\text { grains (Avena sp.), one barley grain (Hordeum sp.) and } \\
\text { one unidentified fruit/seed }\end{array}$ \\
\hline & 674 & $\begin{array}{l}\text { A compact shillet dipping } \\
\text { down behind the collapse } \\
\text { layers of stony rubble (659) } \\
\text { and (669) from the top } \\
\text { (west) of the trench to the } \\
\text { bottom (east). Frequent } \\
\text { inclusions of occupation } \\
\text { material including a patch } \\
\text { of burnt bone and charcoal } \\
\text { slipped from Phase V } \\
\text { structure }\end{array}$ & $\begin{array}{l}\text { Thirty-three Bi sherds (eg RFs } 3740 \text { handle, } 3877 \\
\text { handle, } 3735 \text { amphora-stopper and } 3905 \text { neck), ten } \\
\text { Bii (eg RFs } 3744 \text { and 2726), two Bv (RFs } 3875 \text { and } \\
3876 \text { ) and seven unidentifiable fragments (eg RFs } 3726 \\
\text { and } 3890 \text { ). Two slate discs (RFs } 3717 \text { and } 3753 \text { ), one } \\
\text { pebble (RF } 3718 \text { ), three notched slates (RFs } 3728,3777 \\
\text { and } 3836 \text { ), one lump of charcoal (RF } 3834 \text { ) and eight } \\
\text { finds of indeterminate large mammal bone/teeth } \\
\text { fragments (eg RFs } 3734 \text { and } 3780 \text { ). The burnt patch } \\
\text { contained charcoal+++ fragments }>2 \text { mm but no plant } \\
\text { macrofossils, whereas the general environmental } \\
\text { sample of layer } 674 \text { contained no charcoal or plant } \\
\text { macrofossils }\end{array}$ \\
\hline & 683 & $\begin{array}{l}\text { A clayey loam with stones, } \\
\text { tipping north east from the } \\
\text { south-west corner of the } \\
\text { trench }\end{array}$ & \\
\hline & 684 & $\begin{array}{l}\text { A collapse from } 688 \text { of up- } \\
\text { right slates lodged behind a } \\
\text { very large stone situated in } \\
\text { the tip layers in the south } \\
\text { part of the trench }\end{array}$ & \\
\hline
\end{tabular}

Charcoal fragments $>2 \mathrm{~mm}:+1-10 ;++11-50 ;+++51-100$ 


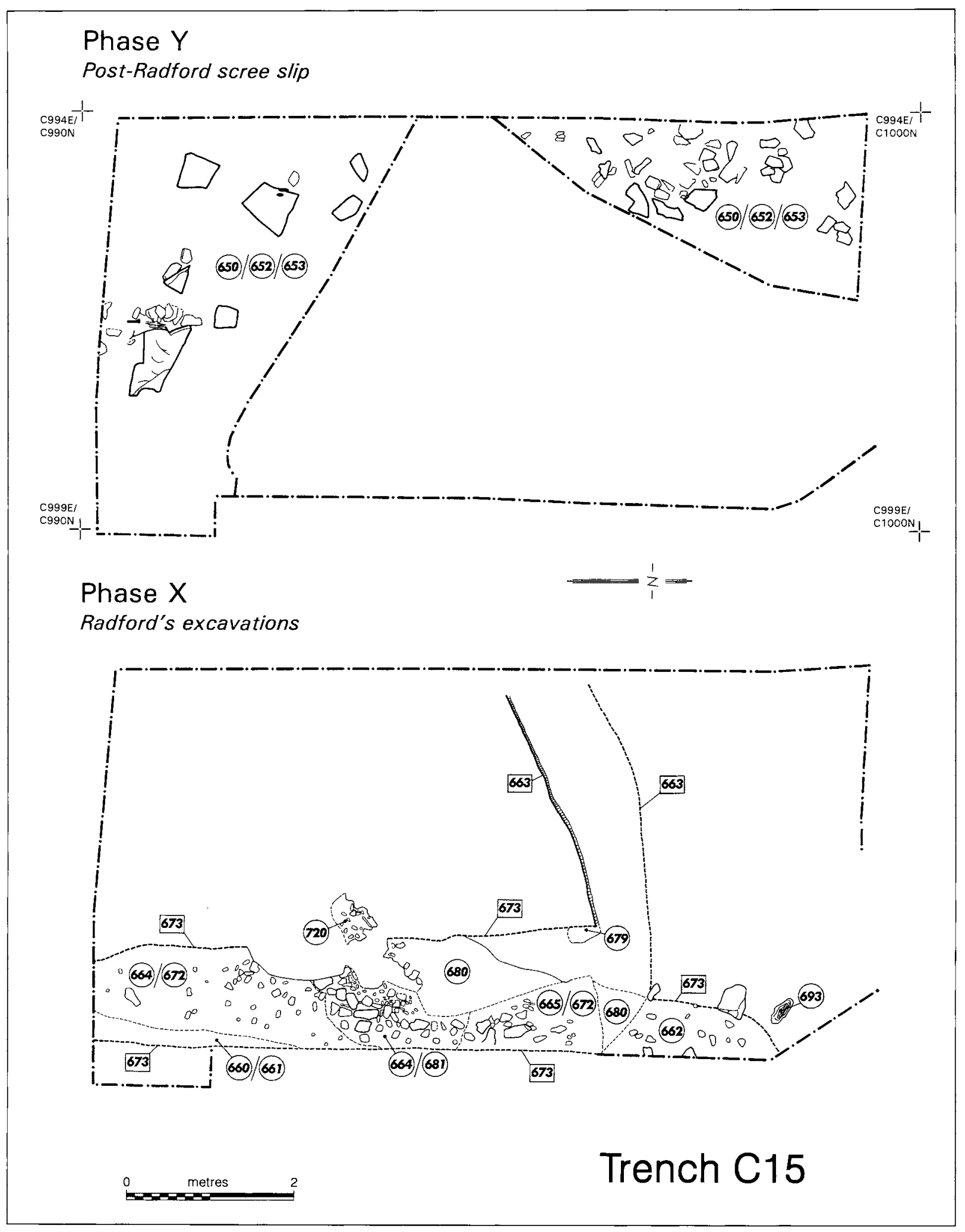

59 Phases $X$ and $Y$ plans. Drawing: L McEwan 


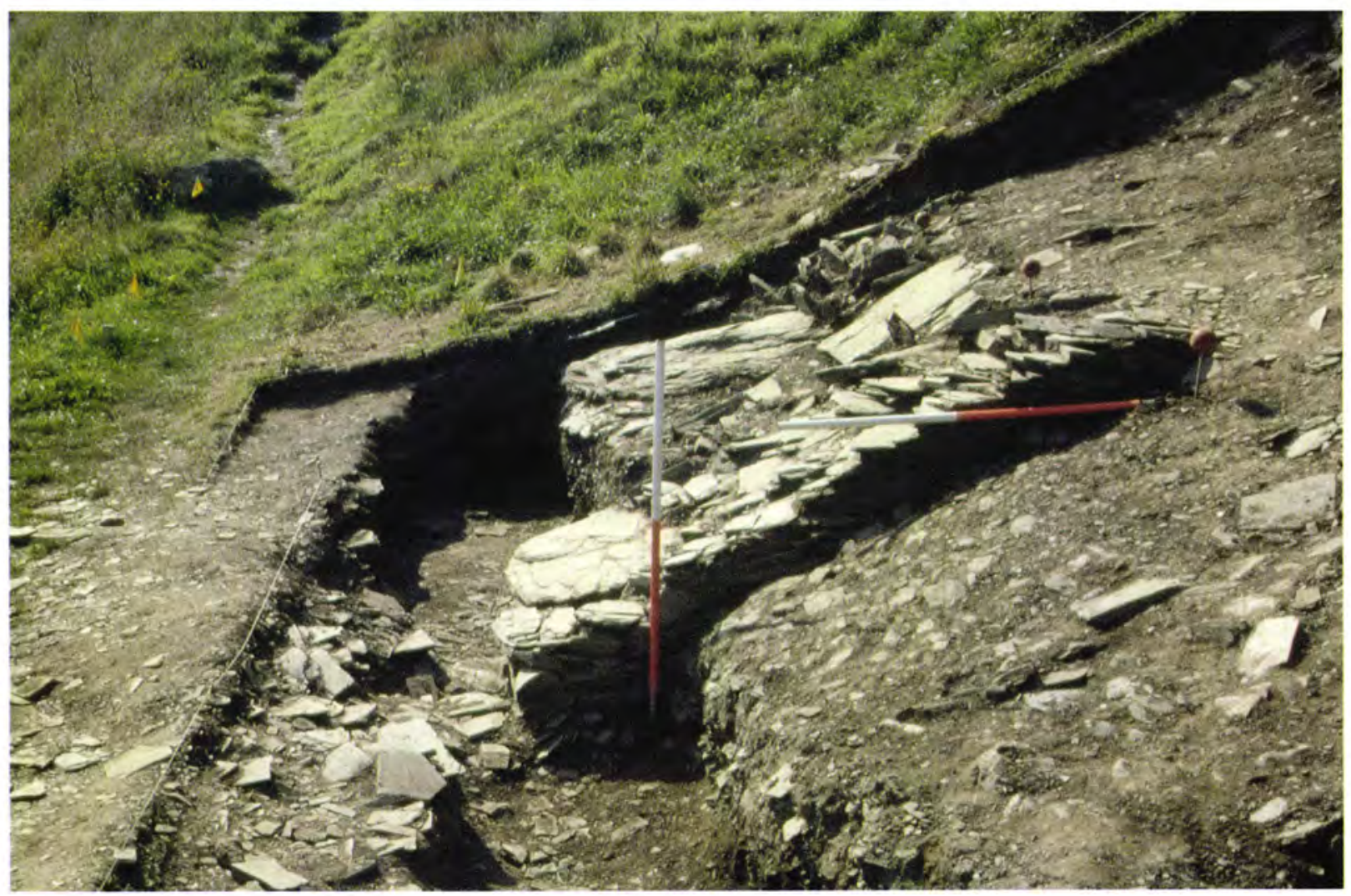

60 Radford's trench 673, from the north east. Photograph: $R$ Barrowman

At the end of the 1994 season a possible old land surface, 679, was uncovered in the bottom of Radford's cut 673. Excavation in 1999 showed it to be trample left at the bottom of the 1930 s trench. This revealed that 680 below it was a spread of trample within the cut 673 , below fill layer 672 , which had been excavated to a greater depth than first thought towards the east edge of the terrace (see below). Below the trample, layer 694 was excavated, and below this the Radford trench had cut the natural decayed bedrock deposits.

With excavation of a larger area in 1999, the extent of the north-south Radford cutting 673 became clearer. The trench had obviously been cut along the edge of the terrace, and Radford's workmen had followed the edge of the bedrock at the east edge down presumably until they hit the natural rock. It was not possible to reexcavate the trench to this same depth in 1999 due to health and safety regulations, although backfill layers of redeposited decayed bedrock were reached.

A mixture of shillet and Radford backfill, 720, was identified along the south edge of wall 666. It had seemed unusual at first that the south elevation of the wall was so ragged. Excavation demonstrated that the south face had been damaged during the cutting of Radford trench 673 . The workmen seem to have pickaxed around the east end and south side of the wall in an attempt to 'chase' the wall. The resulting damage removed all stratigraphy of the south elevation of the wall and therefore the stratigraphical relationships between the wall and the earlier Phase $\mathrm{S}$ and $\mathrm{T}$ deposits to the south.

A foot-shaped hollow, 693, was uncovered immediately below turf and topsoil at the east side of the trench, cut into the bedrock to the south of wall 501. It was thought at first that this was a rock-cut socket, possibly for an upright timber. However, closer inspection of the socket revealed a definite pick-axe-shaped profile to the bottom of the cut, and a shattering of the rock around it. The hollow is also situated at the northern end of Radford's north-south cutting (673), and was probably made when the end of the cutting was extended along the edge of the bedrock. 
PhASE X: ARTEFACTS, ECOFACTS AND DATING

(table 18)

Finds recovered from this phase include $\mathrm{Bi}$, a Bii rim sherd (RF 3856: see Chapter 10, figure 129), Bv amphorastopper (RF 3805: see Chapter 10, figure 126) and medieval Stuffle ware (SA) and conjoining rim and shoulder sherds (RF 3616b) from a single cooking-pot of OK. Water-worn pebbles, a perforated slate, an unworked irregular flint chunk, a lump of bloomery slag (either smelting or smithing) and corroded iron nail fragments were also recovered.

A sample taken from layer 665 was unexpectedly rich, containing charcoal fragments and plant macrofossils, including oat grains, barley grains, wheat grains and one corn marigold achene. The sample from 694 contained a little charcoal and an indeterminate bone fragment, that from 679 charcoal and barley grains and from 720 charcoal and oat grains. Indeterminate Bovidae and other large mammal bone and tooth fragments were also recovered from this phase.

Phase Y: POST-RAdFord SCRee SLIPS (figure 59) A depth of up to $0.3 \mathrm{~m}$ of scree and soil had accumulated over the area, above the backfill of Radford's 1930s excavations. The depth of deposits that had accumulated in just over sixty years was quite staggering, demonstrating clearly the impact of soil movement over time to the archaeology of the site in general. All scree layers in Phase $Y$ had accumulated down a 45-degree slope over the terrace from the slopes and terraces above (eg the Upper Terrace of Site C, see Chapter 3). In 1994 scree slips were excavated as separate events. However, in 1999 time was more pressing, and the nature of the scree deposits and their provenance had been amply demonstrated in 1994. Therefore all scree layers were removed as one deposit, 650/652/653.

\section{PHASE Y: ARTEFACTS, ECOFACTS AND DATING}

(table 19)

The condition of the finds recovered from these layers was affected by the nature of the deposits. Large numbers of abraded pottery sherds of both imported fifth- to seventh-century and later medieval wares were recovered. This includes Bi (eg RF 3566: see Chapter 10, figure 126), Bii, Biv and Bv amphorae, and medieval SA and $\mathrm{RE}$ ware. A perforated slate was also recovered (RF 3550: see Chapter 10, figure 111). One unexpected find was that of a flint knife/end scraper (RF 3562) from the west edge of the trench. The scraper had irregular invasive knapping techniques applied to it and was retouched at the distal end with more retouch visible along the sides.

\section{PHASE Z: TURF AND TOPSOIL}

The whole area was covered in well-established turf and topsoil, 500. Although only four and a half years had elapsed since the 1994 excavations, a considerable depth of topsoil and tussocks deriving from anthills had built up. Patches of clayey loam 656 and 657 proved on excavation to be anthills made up of material from deep below the topsoil.

Phase Z: ARTEFACTS, ECOFACTS AND DATING

(table 20)

The environmental sample from anthill 656 produced a little charcoal, including three pieces of mature oak, and seven oat grains, one barley grain and one wheat grain, presumably from layers below dug up by the ants. Pottery finds from the topsoil include sherds of $\mathrm{Bi}, \mathrm{Bii}$ and Bv amphorae, and medieval SA and OK (RF 3533, OK8). Also recovered were a notched slate (RF 3530: see Chapter 10, figure 111) and a pick-marked stone, slate discs and pebbles.

\section{DISCUSSION}

Following the removal of the backfill from the 1994 excavation, and the Phase $\mathrm{Z}$ turf and topsoil, the Phase $\mathrm{Y}$ series of tip layers of shillet and scree that had slipped down from the slopes above the site were excavated. This gradual slip of material is a feature of the soils at Tintagel, which appears to be slowly but inexorably falling into the sea. These layers typically contained artefacts of mixed provenance and date, ranging from Romano-British and post-Roman imported fifth- to seventh-century pottery to later medieval pottery. A flint blade was also recovered from these layers. Clearly this material had slipped from a terrace above the Middle Terrace.

Below the layers of scree slip, it also became clear that there had once been a building on this part of the site, but it was not as expected. Layers of stone collapse (Phase W), often in a silty soil, began to emerge across the southern part of the trench, to the south of the truncated Phase V wall 666 showing in Radford's cutting (Phase X). Also, once the scree layers had been removed from around the 'stub' of walling 501 at the north end of the trench, no evidence of collapse or any further structure was found. It soon became clear that within 
Table 18 Trench C15 Phase X: contexts and finds

\begin{tabular}{lll}
\hline Phase & Context & Context description \\
\hline $\begin{array}{l}\text { Phase X: } \\
\text { Radford's } \\
\text { excavations }\end{array}$ & 662 & $\begin{array}{l}\text { Fill of } 663 \text { - the majority had been } \\
\text { emptied and fully studied in 1994, } \\
\text { although a small area was removed at } \\
\text { the east edge of the trench when it was } \\
\text { expanded in 1999 } \\
\text { Radford's east-west cutting across } \\
\text { the site } \\
\text { Stony soil backfill of Radford's trench } \\
673\end{array}$ \\
663 & $\begin{array}{l}\text { Stony soil backfill of Radford's trench } \\
673\end{array}$
\end{tabular}

One Bi amphora sherd (RF 2719), three Bii (RFs 3801, 3802 and 3854), one Bv handle scar (RF 3858), three unidentifiable (RFs 2718 and 3855), three Romano-British Local ware (RF 2915), a chunk of flint (RF 3853), a lump of slag (RF 3852) and a lump of charcoal (RF 3883). Charcoal $+++; 14$ plant macrofossils, including seven oat grains (Avena sp.), two barley grains (Hordeum sp.), four wheat grains (Triticum sp.) and one corn marigold achene (Chrysanthemum segetum)

671 Southward-tipping slates uncovered in the bottom of 663, part of Radford's backfill

672 Part of fill of 673 excavated in 1999 with the expansion of the trench southwards

Forty-two Bi amphora sherds (eg RFs 3813 and 6068b), eight Bii (RFs 3810, 3954 and 3971c), four unidentifiable (RF 6069), two medieval $O K$ and 22 medieval SA (both RF 3616b), seven pebbles (RFs 3616c, 3971a and 6066), a perforated slate (RF 3971b), cattle molar (RF 3971d) and indeterminate mammal bone fragments (RF 6068a)

673 Radford's north-south cutting across the site, a larger part of which was revealed at the south end of the terrace in 1999, with the expansion of the trench Trample in the bottom of 673

Charcoal ++ ; two barley grains (Hordeum sp.)

680 Trample below 679 in the bottom of 673

681 A small area of flat slates collapsed from wall 666 due to damage by Radford's excavations

Two Bi amphora sherds (RFs 3806 and 3809), one Bii rim (RF 3856), one Bv amphora-stopper (RF 3805), 10 medieval SA (RF 3808), a perforated slate (RF 3845), a lump of slag (RF 3804), a quartz pebble (RF 3807) and indeterminate large mammal tooth fragments (RF 3857) 


\begin{tabular}{|c|c|c|c|}
\hline Phase & Context & Context description & Finds \\
\hline & 693 & $\begin{array}{l}\text { Foot-shaped rock-cut hollow resulting. } \\
\text { Pick-axe damage from Radford's } \\
\text { excavations }\end{array}$ & \\
\hline & 694 & $\begin{array}{l}\text { Loose silty loam with slate fragments } \\
\text { in the bottom of } 673\end{array}$ & $\begin{array}{l}\text { Two Bi amphora sherds (RFs } 3972 \text { and } \\
\text { 3988), corroded iron nail fragments (RF } \\
\text { 3974), a quartz pebble (RF 3987), } \\
\text { indeterminate mammal teeth and bone } \\
\text { fragments (RFs } 3973,3998,3999 \text { and } 6001 \text { ). } \\
\text { Charcoal+; a bone fragment }\end{array}$ \\
\hline & 720 & $\begin{array}{l}\text { A mixture of slipped shillet and } \\
\text { Radford backfill, consisting of sandy } \\
\text { silt, shillet and small, flat angular slates } \\
\text { along the south edge of wall } 666\end{array}$ & $\begin{array}{l}\text { Charcoal+++; seven oat grains (Avena sp.) } \\
\text { and one unidentifiable item }\end{array}$ \\
\hline
\end{tabular}

Charcoal fragments $>2 \mathrm{~mm}:+1-10 ;++11-50 ;+++51-100$

Table 19 Trench C15 Phase Y: contexts and finds

\begin{tabular}{llll}
\hline Phase & Context & Context description & Finds \\
\hline Phase Y: post- & $650 / 652 /$ & Scree slip down the slope & Forty-three Bi amphora sherds (eg RFs \\
Radford scree & 653 & & 3543 amphora-stopper, and 3557), 18 Bii \\
slips & & (eg RFs 3560 rim and 3585), four Biv (RF \\
& & $3586)$, four Bv (RFs 3549 and 3558), one \\
& & unidentifiable (RF 3537) four medieval SA \\
& (eg RFs 3542 and 3543) and two medieval \\
& RE (RF 3584). Also a perforated slate (RF \\
& 3550) and a flint knife/end scraper (RF \\
& 3562 ) \\
\hline
\end{tabular}

Table 20 Trench C15 Phase Z: contexts and finds

\begin{tabular}{|c|c|c|c|}
\hline Phase & Context & Context description & Finds \\
\hline \multirow[t]{2}{*}{$\begin{array}{l}\text { Phase Z: turf } \\
\text { and topsoil }\end{array}$} & 500 & Turf and topsoil & $\begin{array}{l}\text { Nineteen Bi amphora sherds (eg RFs } 3510 \text { and 3527), five Bii } \\
\text { (eg RFs } 3515 \text { rim and 3525), one Bv (RF } 3523 \text { ), eight } \\
\text { unidentifiable (RF 3526), two medieval SA (RFs } 3509 \text { and } \\
\text { 3522) and one medieval OK (RF 3533). Also a pick-marked } \\
\text { slate (RF 3508) and a notched slate (RF } 3530 \text { ), two slate discs } \\
\text { (3517 and 3534) and five pebbles (RFs } 3518 \text { and 3531) }\end{array}$ \\
\hline & 656 & Anthill & $\begin{array}{l}\text { One Bi amphora sherd (RF 2269), one Bii (RF 2268) and one } \\
\text { unknown (RF 2270). Charcoal+ including three pieces of } \\
\text { mature oak; seven oat grains (Avena sp.), one barley grain } \\
\text { (Hordeum sp.) and one wheat grain (Triticum sp.) }\end{array}$ \\
\hline
\end{tabular}

Charcoal fragments $>2 \mathrm{~mm}:+1-10$ 
the trench two quite separate areas of archaeology were represented in Phase V (the collapsed structure). In the northern half were thick layers of slipped decayed bedrock, overlying large chunks of slipped bedrock (Phase $\mathrm{P}$ natural), and occasional early slipped soils (Phase $U$ traces of earlier occupation). In the south, there were thick layers of collapsed structural slates and pieces of abraded imported pottery and flecks of charcoal (Phase W pre-Radford collapse). In the north there appeared to be no surface or features associated with the stub of wall 501 that had so baffled us, and the wall itself was built straight onto the layer of compact but sterile silty scree. This same sequence was seen at the south-west corner of the adjacent Site $\mathrm{C}$ building (see Phase V, trench C09, Chapter 6).

As the layers of collapsed stones and soil from around the truncated wall at the south end of the trench were removed, a return wall was uncovered, keyed very neatly into the wall 666 first evidenced in Radford's trench. However, this return wall could only be seen extending up to $0.2 \mathrm{~m}$ to the south. Beyond this the entire wall, which had originally been built from flat, angular slates upon a shelf of bedrock at the back (west) of the terrace, had collapsed down the slope to the east, taking the floor layer of the building with it. Consequently, very little of this building remained. First, the trench now covered only half of a building, as it had wrongly been anticipated that the return from the truncated wall would be northwards, not southwards. Second, due to the truncation of the building by two huge stones ploughing over the area in Phase W, most of the evidence for this building was found redeposited in these later layers of collapse. Patches of reddish silty soil with charcoal flecks were found among the collapsed stones indicating possible use of turf as walling, together with many sherds of imported post-Roman pottery. Unfortunately, no structural elements or floor deposits had remained in situ, other than the wall truncated by Radford's trench. The wall itself had also sunk considerably, as the end had collapsed, dragged with the subsidence of the softer soil of Radford's backfilled trench to the east. Evidence could be seen of pick-marks down the wall, where it appears that Radford's workmen had pick-axed their way across and down the wall.

All intact features were now concentrated in an area to the south of the truncated wall. The section of wall was left in situ, leaving a small area, $3 \mathrm{~m} \times 1 \mathrm{~m}$, in which deposits pre-dating the building could be investigated; the area to the east of this was completely removed down to bedrock by Radford's trench. In this small area, two layers of wet, grey gritty silt were excavated (Phase $\mathrm{T}$ dump of material), which contained sherds of amphorae, lumps of slag, rotten bone and carbonized material. Below these, a layer of flat slates, arranged as a paved surface extending into the south section, was uncovered (Phase $S$ paving). On this surface a large sherd of amphora was recovered. Usually the imported pottery found on Site $C$ has been abraded and worn from the soil movement. However, the sherds recovered from Phases $\mathrm{S}$ and $\mathrm{T}$ were in good condition, with clean breaks, and were of a larger size than has ever been recovered from the site. Pieces of animal bone were also found in these phases, in fragmentary condition but surviving due to the wet soil. This is very unusual for the site, as the acidic nature of the soil usually militates against the preservation of any bone unless burnt.

Below the slabs, a layer of waterlogged gritty silt and clay was excavated (Phase $\mathrm{R}$ dump of material or possible surface), again containing large sherds of amphorae and pieces of bone in fragmentary condition. Below this layer, a drain or possibly wall-foundation was excavated (Phase $Q$ cut feature), cut into the bedrock (Phase $\mathrm{P}$ natural). This feature ran parallel to the bedrock at the west of the trench (ie north to south), out from the south section, turning at a right angle to the east for $1.2 \mathrm{~m}$ until it was truncated by Radford's trench. Its function is unclear, as such a small area was excavated, but a drain seems a likely explanation.

\section{CONCLUSION}

The excavation of trench $\mathrm{C} 15$ has revealed part of a fragmentary structure, the majority of which has collapsed down-slope towards the sea. However, despite the ephemeral nature of these remains, they have produced important new evidence that adds to our understanding of Tintagel. Below the collapsed structure, glimpses of earlier phases of use were recovered in Phases $R, S, T$ and $U$. In Phase $V$ what was thought at first to be the remains of another building comparable with that on Site $\mathrm{C}$ to the north (see Chapter 6), was revealed during excavation to be of a different form altogether. A 'stub' of walling seen immediately adjacent to the Site $\mathrm{C}$ building appears to stand in isolation, whereas a parallel wall to the south, cut through by Radford's workmen, is the north wall of a separate, collapsed structure to the south. Only the northern half of this structure has been excavated in 
trench C15. The construction of the walls of this building is more in keeping with that of the successive, temporary buildings excavated on the Lower Terrace below (see Chapter 2), being composed of thin slates and earth cores, and utilizing the 'steps' formed in the slate bedrock at the back of the terrace.

The surviving evidence relating to the function of this building is scant, but affords a glimpse into activities so far only hinted at on the site. Such a small part of the internal area of the building was revealed that it is not surprising that no hearths were located. However, indications of floor layers and burning have been recovered from the layers of collapse resulting from the structure's slide into the sea (Phase W). Small indications of industrial activity were recovered in the form of smithing or smelting slags, from deposits contemporary with as well as post-dating the use of the building, and occasional finds of iron nails. The large collection of imported post-Roman sherds from trench C15 is probably due for the most part to the fact that Radford's workmen did not clear the structure. It hints at the huge amounts of pottery that can be expected from areas of the site undisturbed by Radford's excavations.

The pottery recovered from the undisturbed lower phases exhibits clean breaks and little abrasion. Pottery finds from later layers of collapse include, most unusually, examples of $\mathrm{Bv}$ amphora handle and rim sherds. The sheer number of sherds alone is an indication of the scale of the activities being undertaken at Tintagel. The excavations in trench $\mathrm{C} 15$ would appear to support suggestions first made following on the Lower Terrace excavations, that some of the structures at the site can be identified as temporary, seasonal buildings, perhaps associated with the trade in olive oil and wine from the Mediterranean (see R Jones, Chapter 10). Finds of later medieval pottery from the scree layers adds to the picture of possible later medieval occupation further up the slope on the Upper Terrace.

In addition to the structures and artefacts excavated, the ecofactual material recovered is of importance. The fifth to seventh centuries $\mathrm{AD}$ are a period for which archaeobotanical evidence is extremely scarce in Britain and, despite the small size of assemblage recovered so far from renewed excavations at Tintagel, it is of importance nationally as well as for the better understanding of the environment and economy of Tintagel itself. ${ }^{9}$ A large number of environmental samples were recovered during the $\mathrm{C} 15$ excavations and later analysed (see Chapter 11). The results contributed to a larger sample data set from which to study this important, yet neglected, aspect of post-Roman archaeology in Britain.

The remains of cereals and weeds were scarce in C15, and originate largely from the collapse of the building and the later excavations by Radford. Taxa identified from the Phase $U$ and $W$ contexts were comparable to those recovered from the Lower Terrace buildings, but the $\mathrm{C} 15$ assemblages were too small to draw comparisons. Charcoal was also recovered, but it is thought that it originates from the scattering of ash from domestic fires.

The undisturbed and waterlogged contexts at Site C15 produced over fifty small bags of animal bone and/or teeth. Unfortunately, as with the small number of bones recovered from excavations on the Lower Terrace in previous years, due to the acidity of the soils at the site all the bone recovered was in a highly fragmentary state. However, cattle, caprine and pig teeth were identified, and some indications of age of death of the animals can be shown (see Chapter 11). 


\title{
CHAPTER 6
}

\section{EXCAVATIONS IN AND AROUND THE MidDle TERRACE: Site C BuILDING, 1991-8}

\author{
with contributions from KEVIN J BRADY and PAUL G JOHNSON
}

\begin{abstract}
In this chapter the examination of Dr Ralegh Radford's clearance in the 1930s of a tri-compartmental building on the Middle Terrace of 'Site $C$ ' and adjacent areas around it is described. The results confirm a fifth- to seventh-century $A D$ date for a building previously suggested as later medieval. Nearby, in a previously unexcavated part of the site, a remarkable inscribed slate, with two periods of lettering (late Roman and post-Roman), and a cache of unique contemporary glass, possibly Spanish, were recovered. These are discussed in Chapter 10. Other artefacts include a major collection of imported fifth- to seventhcentury Mediterranean pottery and a smaller collection of later medieval (south-western British) pottery. There is also clearly an earlier post-Roman timber structural phase. Ecofactual material includes rich carbonized (predominantly grain) deposits below the building, interpreted as both animal fodder and human food refuse.
\end{abstract}

This chapter covers the part of the project concerned with the re-excavation of the building on the Middle Terrace of Site $\mathrm{C}$ and immediately adjacent areas. The intention from the outset was to excavate undisturbed deposits as well as re-excavating areas examined by Radford in the 1930s (see Chapter 1, figure 3). A trial trench (C09) was opened in 1991 outside the south west of the building, followed by two across the area of the main building in 1993 (C10 and C11). These were extended to an area excavation in 1994, and finally completed in 1998 .

\section{RADFORD'S WORK AT SITE C with Paul G Johnson}

A drawing in the Wright Archive (discussed in Chapter 1) from Radford's work, entitled 'July 1933: Excavations (Site C)' is a careful survey-plan of the central and southern 'rooms' of the building, with detailed measurements, together with a schematized longitudinal section. It gives no archaeological detail beyond the locations of walls of the building. A further survey-plan in September 1936 (presumably after the excavation season) is another plan of the walls, also taking in the northern 'room' of the building (see Chapter 1, figure 7). Again, beyond the position of the walls, no archaeological detail is given. Somewhat in contrast, a drawing from September 1938 contains two sectiondrawings across the northern and southern 'chambers' and depicts stratigraphy at a gross level (see Chapter 1, figure 11 and table 1). If Wright's representation of Site C is taken as being primarily an archaeological record, it would mean that the building on Site $\mathrm{C}$, a terrace site, was not inundated by overburden before excavation, since Wright's drawings indicate only a few centimetres of material above bedrock. However, the possibility of Wright's record being created as a guide for consolidation of the building, rather than archaeological record, lends a worrying degree of ambiguity to some of the notes and annotations in his drawings (see Chapter 1).

Among the new archive material discussed in Chapter 1 was fresh material which can be used to supplement Wright's drawings, including a wholly unexpected collection of photographs. One of these (see 
Chapter 1, figure 13) shows the position of a spoil-heap over the area subsequently excavated in 1998 as trench C09; because of the spoil-heap, a part of Site $\mathrm{C}$ appears to have 'escaped' the attentions of those working under Radford's direction in the 1930s. Unfortunately, the entries on Site $\mathrm{C}$ in the three notebooks which have survived in this archive are of limited use.

At Site C Radford clearly recognized the presence of wall-foundations for a building and obviously instructed the workmen to clear out the area within the walls, and to some extent outside (see Chapter 1, figure 3). Radford also recognized (and Wright recorded in his 1938 section) that at the seaward edge of the terrace the land had been made up to provide a roughly level surface for building. The recent excavations also found evidence for revetting at the edge, and confirm Radford's and Wright's observations.

\section{EXCAVATION METHODOLOGY}

(TRENCHES C09-13 AND C16)

with Kevin J Brady and Paul G Johnson

Following the preliminary excavations in 1990 on all three terraces of Site C (see Chapter 1, figure 25), more extensive work in and around the Site $\mathrm{C}$ building (figure 61) began in 1991 when trench $\mathrm{C} 09,3 \mathrm{~m}$ by $4 \mathrm{~m}$, was opened adjacent to wall 501 and the south end of the Site C building. Building on this, in September 1993 two trial trenches, $\mathrm{C} 10$ ( $1 \mathrm{~m}$ east-west) and C11 $(0.75 \mathrm{~m}$ wide, at right angles to $\mathrm{C} 10$ ) were opened in the larger two rooms of the Site $\mathrm{C}$ building. It was clear from the work in $\mathrm{C} 09$ that some undisturbed contexts were present to the south west of the building and the trial trenches C10 and $\mathrm{C} 11$ indicated that there were deposits present which were sufficiently promising to be worthy of further investigation. Therefore an excavation in and around the Site $\mathrm{C}$ building was planned, taking in both the outside and the inside of the building. In 1994 two seasons (in April and September) of excavations were undertaken and in view of the degree of previous disturbance it was decided that excavation should be total and down to bedrock. The one significant exception was the building itself, the walls of which were left intact apart from a limited examination in trenches C10 ext and C11 ext (see below), with arrangements for subsequent reinstatement in order to maintain the site for display to the public. This effectively divided up the area to be excavated into smaller sub-areas. Radford's

\section{Site C Trench location plan}
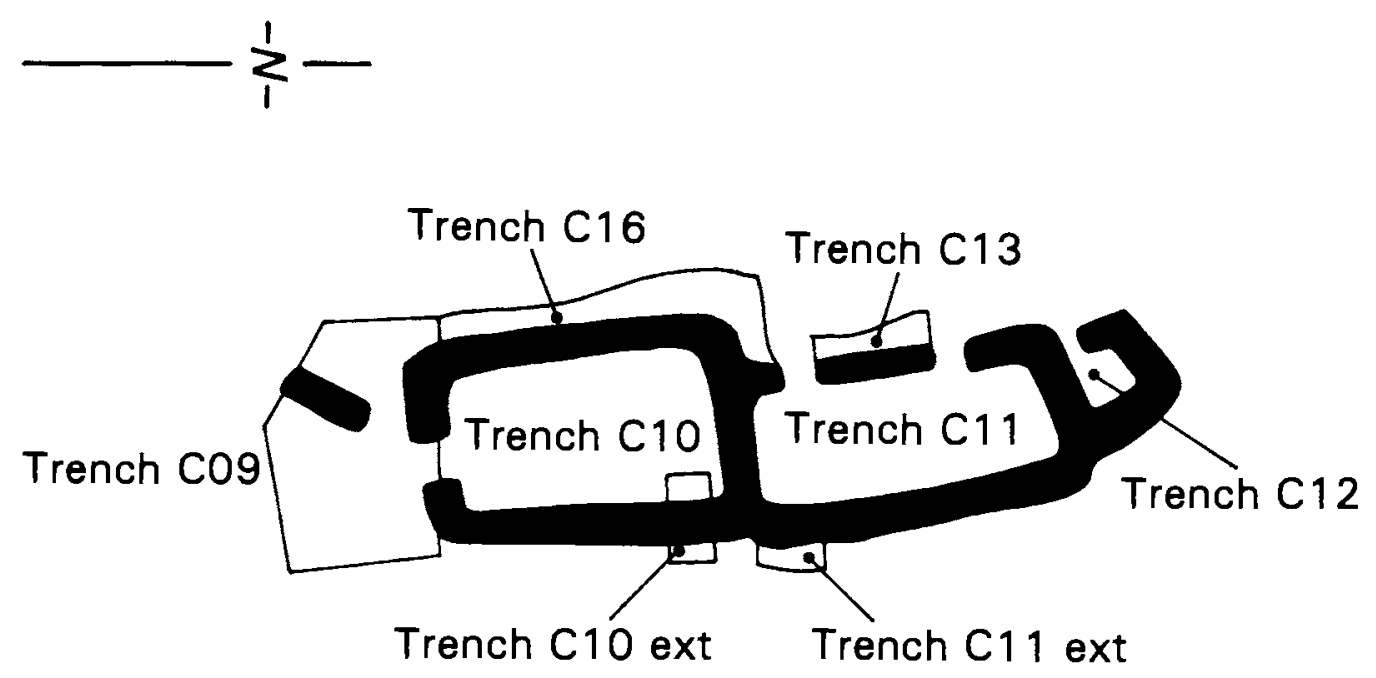

61 Site $C$ building: trench location plan. Drawing: $L M c E w a n$ and $C$ Evans 
excavations were found to be quite extensive, both horizontally and vertically, so that the undisturbed areas were small relative to the overall area examined. However, the presence of the 1930s spoil-heap in the south-west corner of the site meant that underlying deposits here appear to have been completely untouched (see Chapter 1, figure 13).

As a result of the above methodology the postexcavation analysis and creation of the stratigraphical sequence was an extremely complex matter. It has been necessary to create individual sequences for the subareas or trenches, which were then correlated across the site as a whole. By no means all the phases represented in the sequence were recognized in each sub-area and in some cases only appear in one area. The details are in the Research Archive Report.

In April 1994 it was decided to excavate the middle room in its entirety, extending trench $\mathrm{C} 11$ to an area excavation (see Chapter 1, figure 24). In the later season a small trench (C11 extension) at the south-east corner of $\mathrm{C} 11$ was opened. This was undertaken with the aim of investigating the antiquity of a drain through the wall and the relationship of the reconstructed east and south walls to any original structure and to Radford's excavations within the building. The results of this small excavation proved invaluable in establishing the chronology of the middle room of the Site $\mathrm{C}$ building, and solved many questions that had arisen from the C11 area excavation of April 1994.

New excavations were also begun in April 1994 within the northernmost room of the building (trench C12) and the northern half of the footpath to the west of the building (trench C13: see Chapter 1, figure 24).

In September 1994 it was decided to open the whole area of the southern room of the Site $\mathrm{C}$ building as an extended trench C10 (see Chapter 1, figure 24). The interior of the room itself was excavated, together with part of the east bench and east wall. The latter excavation (C10 extension) was situated adjacent to an enigmatic recess in the east face of the east wall. The southern half of the footpath to the west of the building (trench C16) was also excavated at this time.

Following the exploratory excavation of 1991, C09 was extended and opened in 1994 as three distinct trenches. The first trench was the original area and two new trenches were opened to the east and west of the original. Additionally, the eastern half of the southern wall of the southern room was dismantled and examined in September 1994, as part of C09. To the west of the original trench, a second extension was opened up to the quarry/cliff face at the extreme west. A natural spring-line, running from the top of the Island, followed a course along the bedrock that brought it streaming down the quarry/cliff face into the south-west corner of C09, causing serious flooding problems. By the end of the September season of 1994, C09 was excavated as one area (see Chapter 1, figure 24), but work remained unfinished largely because of this flooding. After a break of four years a small team returned to C09 in June 1998 and completed the excavation of C09 down to bedrock under much drier conditions.

\section{SUMMARY OF STRATIGRAPHY AND PHASING with Kevin J Brady}

In structural and stratigraphic terms, we can see three main usages of the area: first, preparation of the terrace and quarrying of rock face (Phase S), and rock-cut features and levelling deposits (Phase T); second, drainage works (Phase $\mathrm{U}$ ) and third, Building $\mathrm{C}$ and its associated features (Phase V). After the use of the building, Phase $\mathrm{W}$ covers a long period of its collapse and disuse, together with the overlying scree-tips, which accumulated up to the twentieth century. The work of Radford in the 1930s is Phase X, followed by the postRadford accumulations (Phase $\mathrm{Y}$ ) and Phase $\mathrm{Z}$ as turf and topsoil cover.

\section{PHASE S: NATURAL GEOlOGY (figure 62)}

Excavation revealed the natural slate bedrock (502) in all trenches. The shape of the rock-cut terrace on which Site $C$ is situated is defined to the west by a vertical, quarried rock face. The bedrock at the western edge lies beneath a thin covering of turf and topsoil. Here it forms a level terrace about $4 \mathrm{~m}$ wide east-west. The rock slopes sharply downwards at the east and north-east edges of the terrace, around $1 \mathrm{~m}$ west of the east walls in trenches $\mathrm{C} 10$ and $\mathrm{C} 11$ and forms a step (figures 63a and b) on the east side of the north end of the building.

On the west side of the terrace, where the deposits above were most shallow, there was evidence of pickmarks on the bedrock. Further to the east, the bedrock in C10 was more decayed (704 and 705/708), and a slip of fractured rock (711) lay along the east edge of the terrace. The bedrock fell away sharply, forming a vertical edge, in the central room (C11). This edge had been followed by Radford's team (see Phase X below) and the bedrock at the base of the wall dividing $\mathrm{C} 10$ and $\mathrm{C} 11$ had been cut 


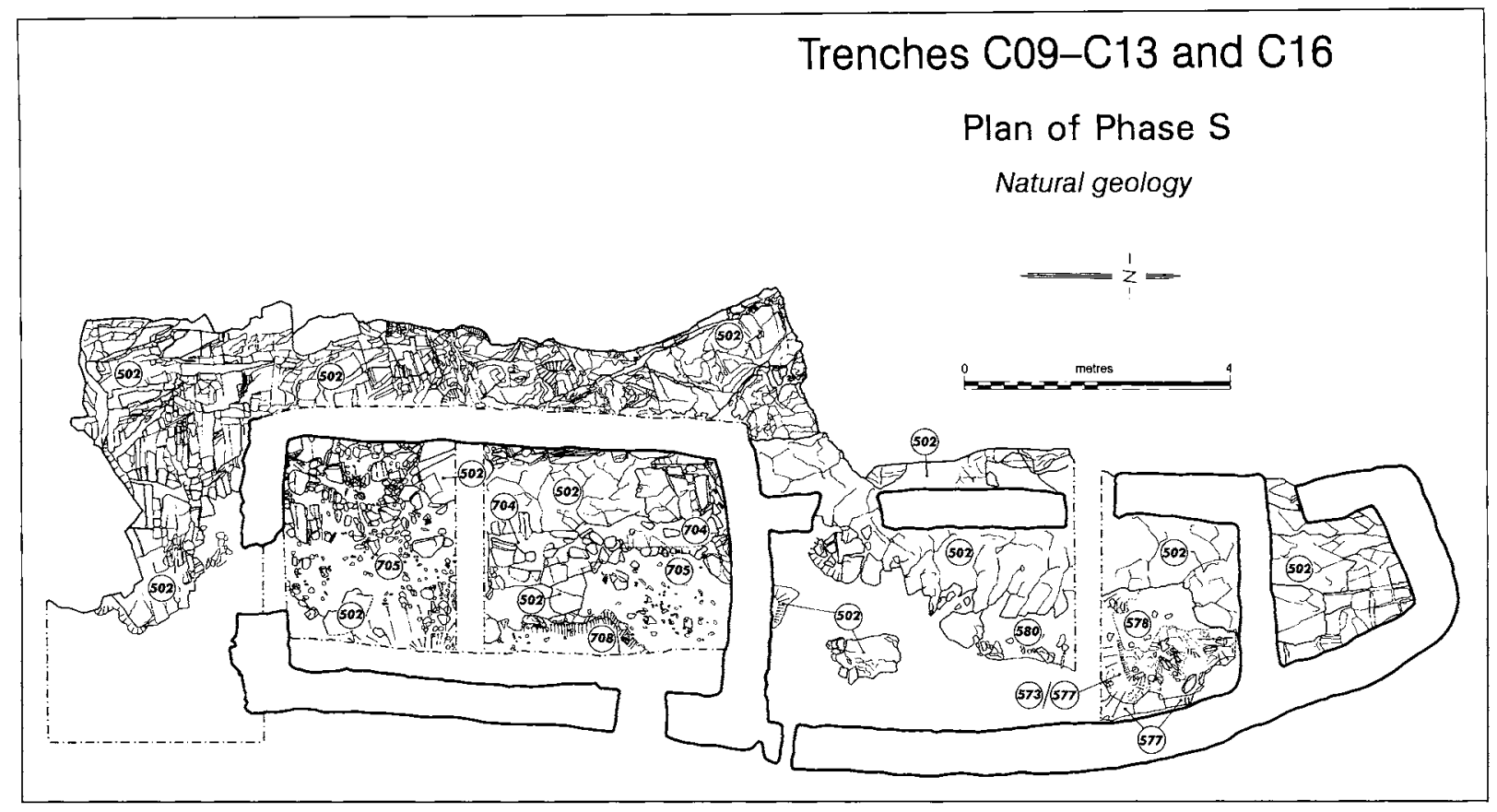

62 Site C building. Plan of Phase S. Drawing: L McEwan

and broken during the 1930 s excavations, due to its fragmentary, rotted state. Below Radford's excavations at the north-east corner of trench $\mathrm{C} 11$, scree and rotted slate (577) lay against the bedrock edge and within hollows in the natural bedrock (578/580). In C12 the bedrock formed a level surface over the trench except at the east edge area where it stepped downwards. The lower parts of the west walls of $\mathrm{C} 10, \mathrm{C} 11$ and $\mathrm{C} 12$ were built directly onto the bedrock and at the south-west entrance to $\mathrm{C} 11$ it appeared to have been cut to form steps.

\section{PHASE S: ARTEFACTS, ECOFACTS AND DATING}

(table 21)

These layers of decayed bedrock were artefactually sterile, apart from the occasional pick-marked slate that had resulted from damage to the bedrock by Radford's excavations above and a single notched slate (RF 1827). Some small amounts of charcoal were recovered.

\section{Phase T: EARLY MAKe-UP AND ROCK-CUT Features} (figures 64 and 65)

This phase of activity pre-dates the construction of the Site $\mathrm{C}$ building. It is probable that several separate building episodes are represented, but it is not possible to separate them chronologically due to a lack of surviving stratigraphic information. The surface of the terrace was not particularly even, and there is clear evidence in this phase of the levelling and make-up activities, particularly at the eastern edge, to create a better building surface.

A group of features which may represent the remains of a fully or partially timber-built structure based upon a set of vertical timbers set into the natural rock on the west side of the terrace was excavated. These include possible post-settings 544 and 545 in C16 (figures 66 and 67); a conical-shaped cut and possible beam-slot (1037 and 1038) and rectangular-shaped socket 706 in $\mathrm{C} 10$. To the north were two further post-slots (C11, 567 and 566), with an outlier to the east (C10, post-hole type of cut 702). However, it should be noted that it is possible that some of these features (eg 706, 566 and 567) are sockets for door-fittings of the Phase $V$ building. It is consequently not possible to reconstruct a building from such fragmentary evidence. With hindsight it might have been valuable to clean down and examine the vertical rock face behind the building to the west to see if any convincing slots were visible which might have related, for instance, to a lean-to roof for such a building.

In trench $\mathrm{C} 13$ in the north west of the site, three conjoining flat slates (563) may be the remains of paving or flooring to the north of the putative building, and, 
Trench C09 north section

Bench 513 and Wall 1013 after removal of reconstruction walling

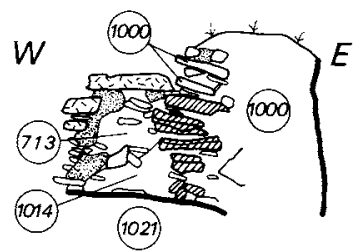

$\square$ Mortar
Vi: 1013
$072 \quad(513)$

Trench $\mathrm{C} 10$ baulk north section

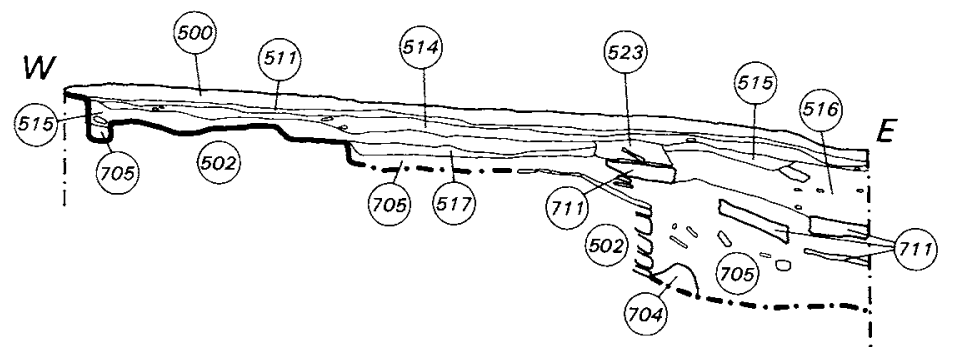

Trench $\mathrm{C} 12$ section below east wall

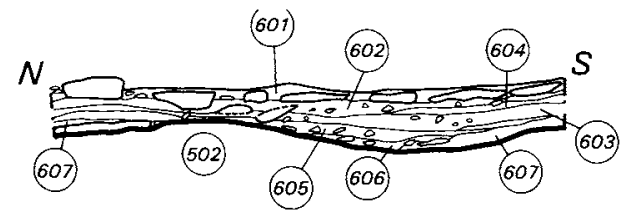

Trench C16 baulk north section

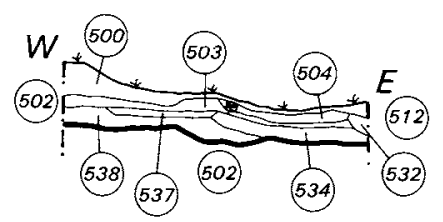

\section{Trench C09}

Profile of Radford's trench

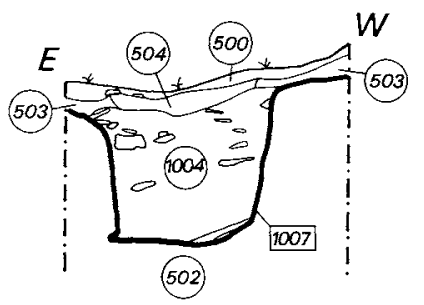

\section{Trenches C09, C10, C12 and C16}

0 metres 2 
Trench $\mathrm{C} 11$ and $\mathrm{C} 13$ baulk north section
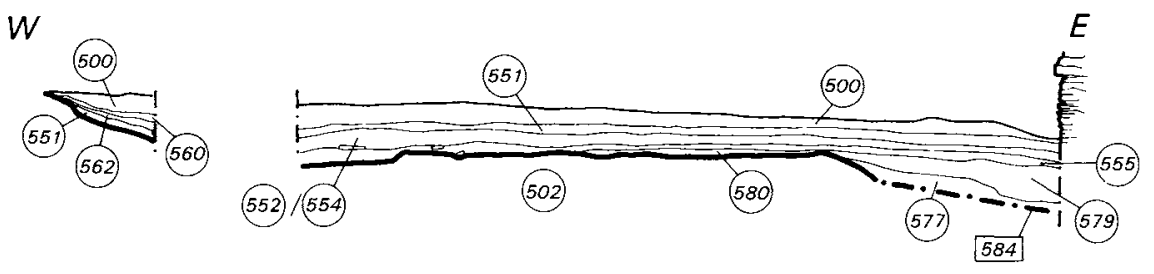

Trench C11 baulk south section

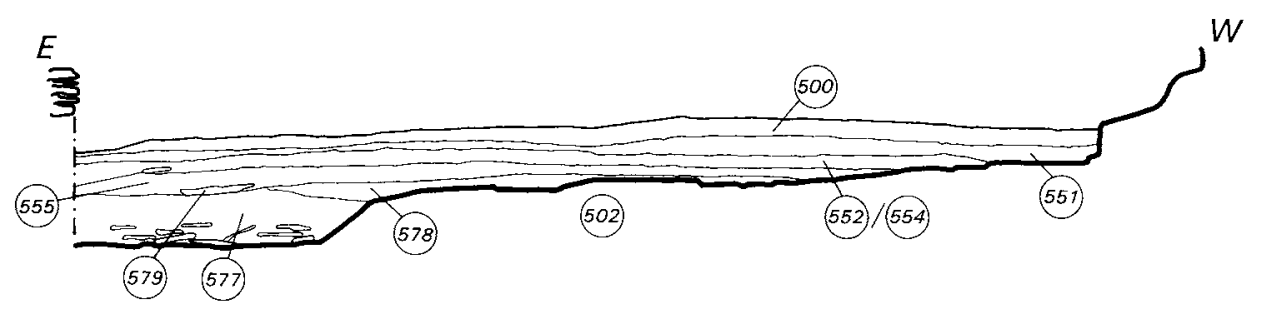

Trench C11 south wall section below 556

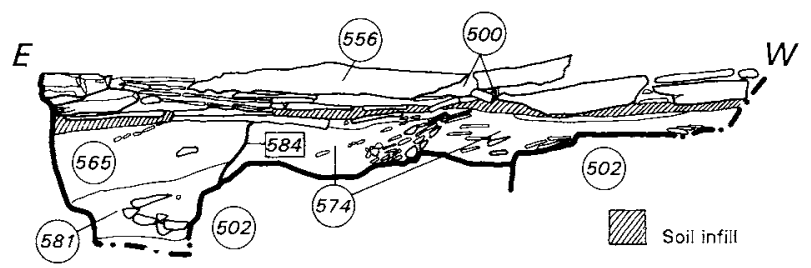

Trench $\mathrm{C} 11$ ext west section

\section{TRENCHES C 11 and $\mathrm{C} 13$}

0 metres

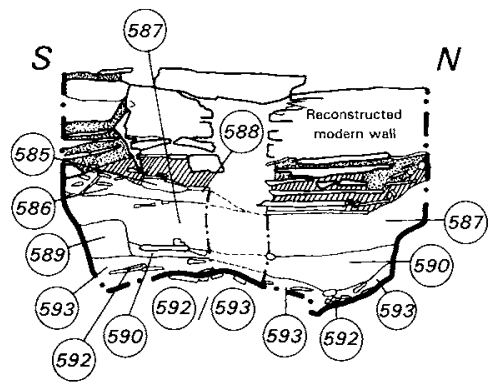

Modern Concrete

Soil inf:[l] 
Table 21 Site C building Phase S: contexts and finds

\begin{tabular}{|c|c|c|c|c|}
\hline Phase & Trench & Context & Context description & Finds \\
\hline \multirow{5}{*}{$\begin{array}{l}\text { Phase S: } \\
\text { natural } \\
\text { geology }\end{array}$} & \multicolumn{2}{|c|}{$\begin{array}{l}\mathrm{C} 10-\mathrm{C} 13,502 \\
\mathrm{C} 16\end{array}$} & \multicolumn{2}{|l|}{ Natural slate bedrock } \\
\hline & $\mathrm{C} 10$ & $704,705 / 708$ & Iron pan decayed bedrock & \multirow[t]{2}{*}{ Charcoalt } \\
\hline & $\mathrm{C} 10$ & 711 & Slip of fractured rock & \\
\hline & $\mathrm{C} 11$ & 577 & Scree and rotted slate against the bedrock edge & Charcoal+ \\
\hline & $\mathrm{C} 11$ & $578 / 580$ & Scree and rotted slate in hollows in bedrock & $\begin{array}{l}\text { Notched slate } \\
\text { (RF 1827). Charcoalt }\end{array}$ \\
\hline
\end{tabular}

Charcoal fragments $>2 \mathrm{~mm}:+1-10$

similarly, a small charcoal-filled patch $(\mathrm{C} 13,564)$ in a hollow in the bedrock may represent the fugitive remains of activity. Two features in C10 pre-date the building of Phase V: a group of stones possibly from an earlier structure (710), and a circular hollow in the bedrock (528), but again they are too fragmentary to utilize for reconstruction.

In general, there is clear evidence here for the infilling with silty clay, stones and scree material of natural features and fissures in the bedrock on the west side (eg
C16, 1011, 548, 547, 546, 543, 542 all infilling fissure 1012: figure $68 ; C 09,1020,1034)$. There also appears to be a build-up of deposits and infilling of hollows to the south and east over the sloping bedrock (eg C09, 1028, 1051, $1052,1005,1010,1025$; C10, 709, 716, 718; C11, 574, 582, 571). There was in addition a revetment to the east (eg C09, 1047; C10, 719/516, 707, 523, 713; C11, 592/593, 589, 587/590: see figure 63b, 582 and 583), and similar activity in the north $(\mathrm{C} 12,607,606,605,603)$, as preparation for the Phase $\mathrm{V}$ building. There was also a hint in the

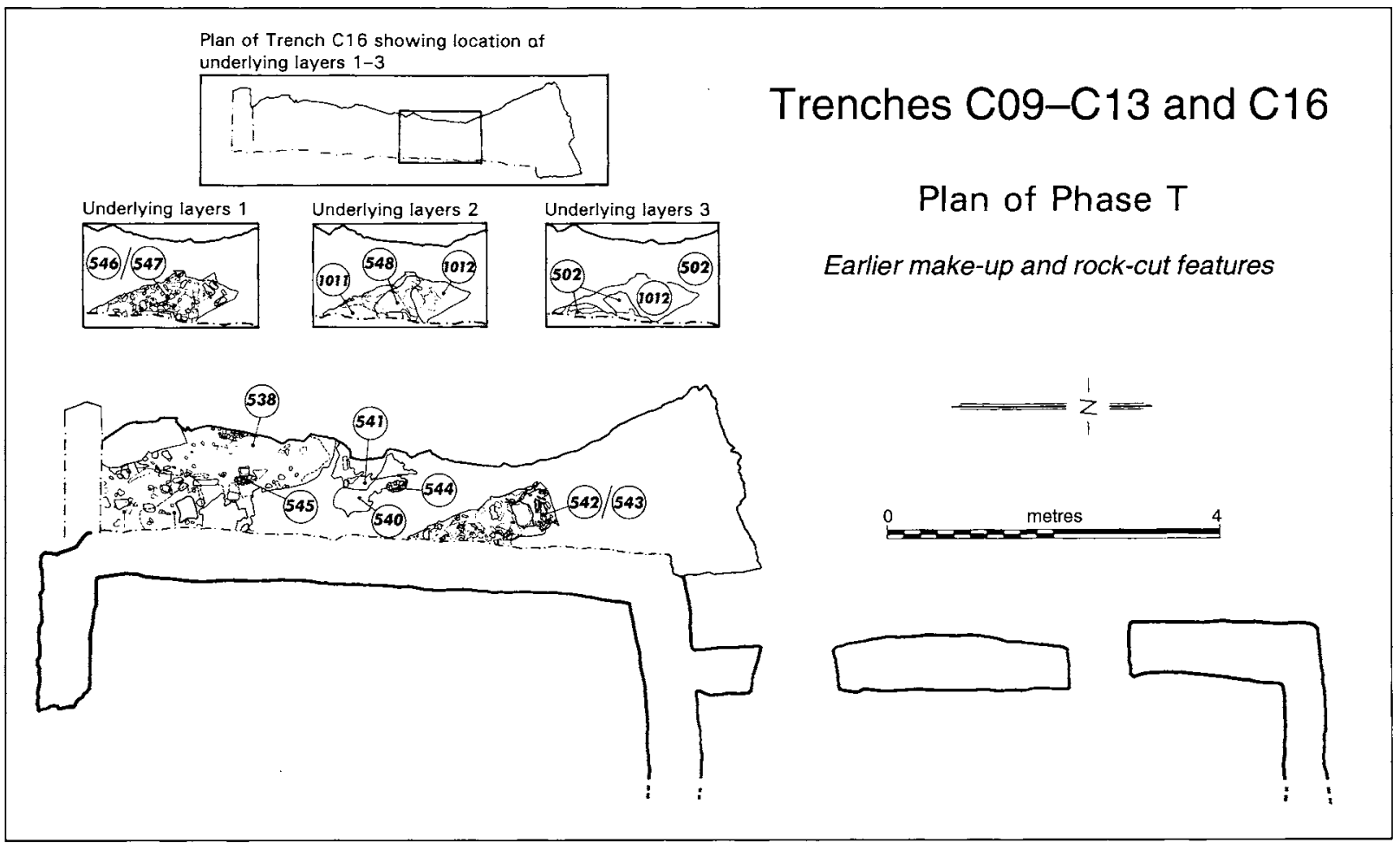

64 Site $C$ building. Plan of Phase $T$ (1). Drawing: $L M c E w a n$ and $C$ Evans 


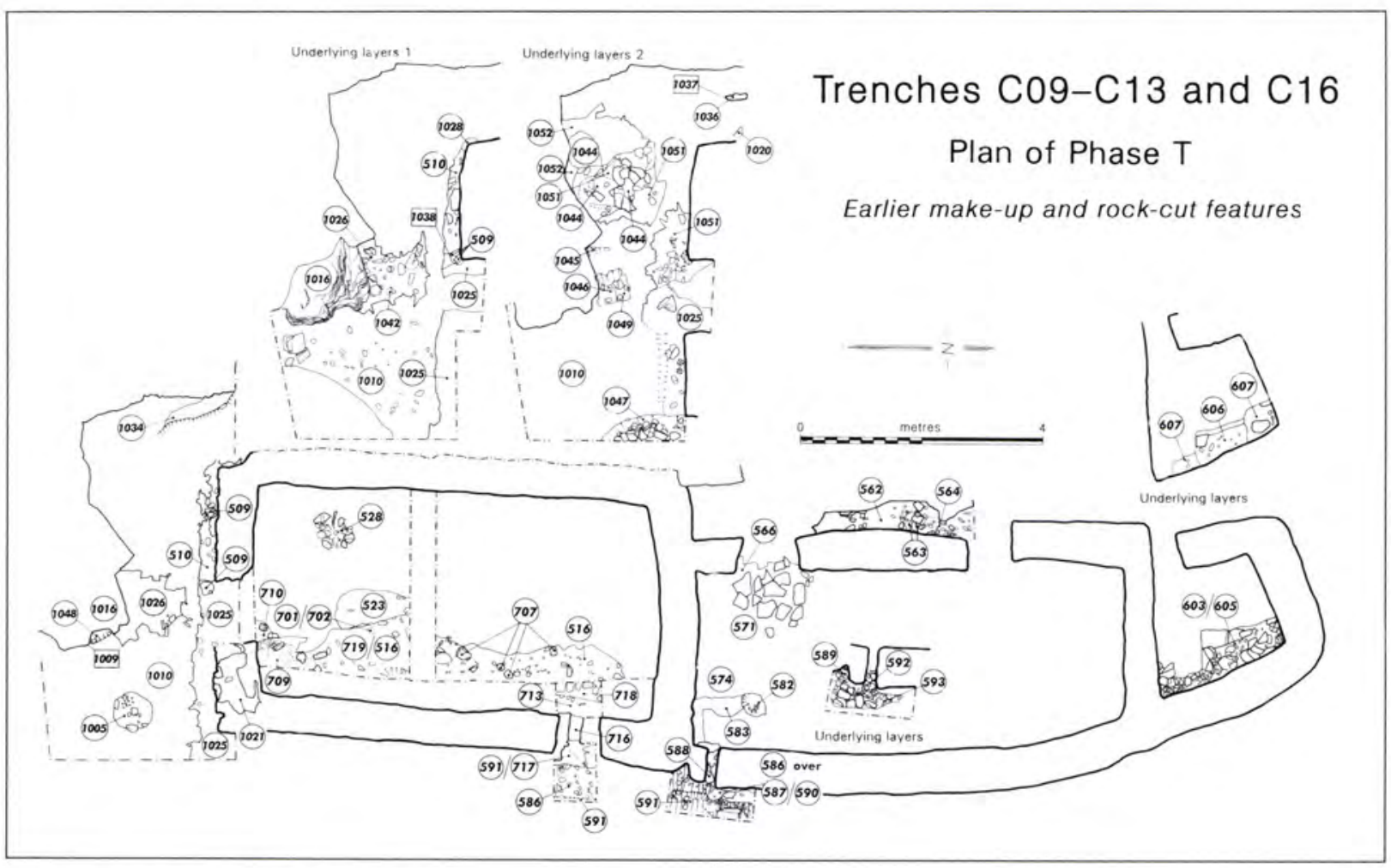

65 Site C building. Plan of Phase T (2). Drawing: L McEwan and C Evans

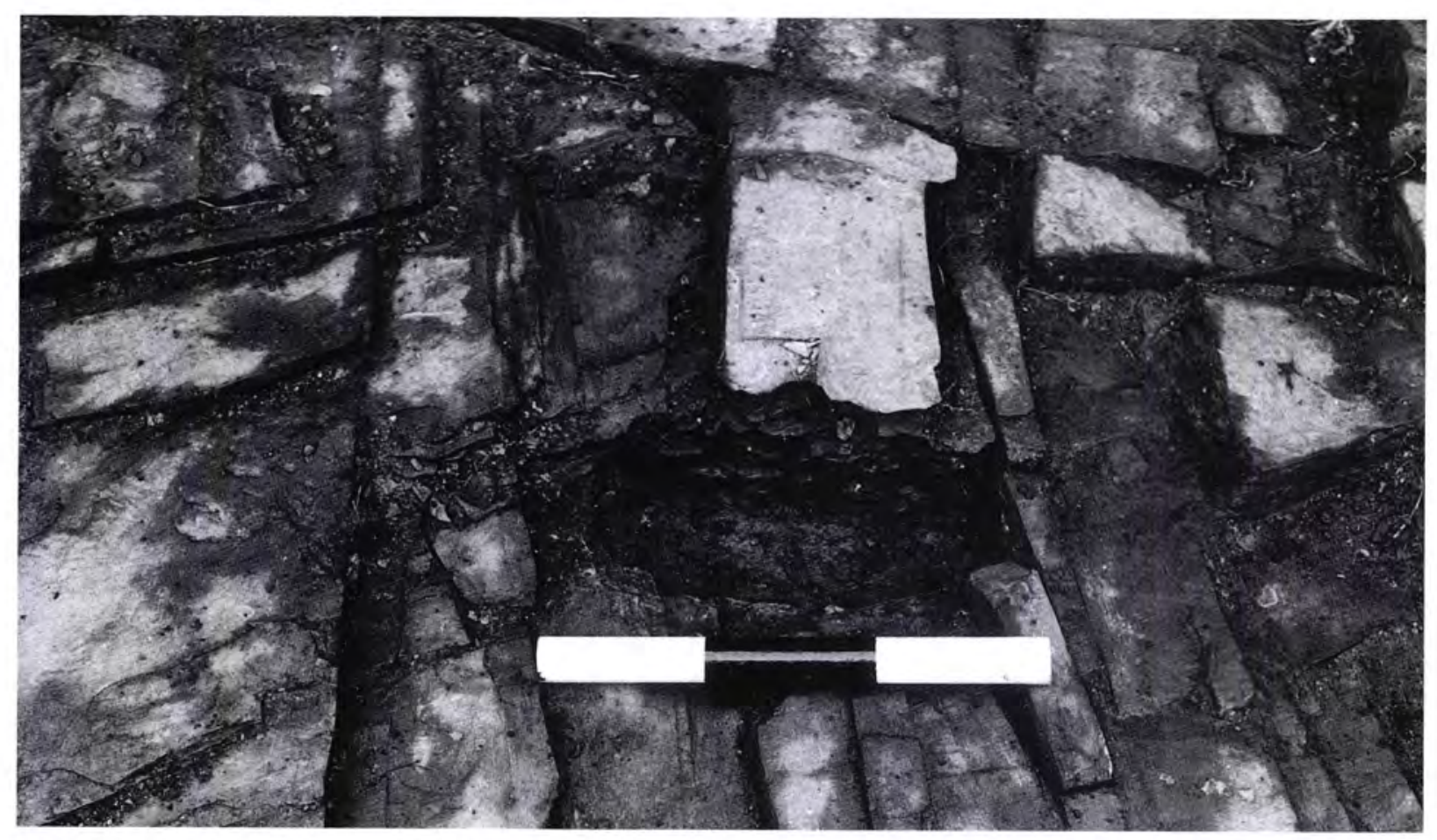

66 Trench C16. Rock-cut post-slot (544). Photograph: C D Morris 


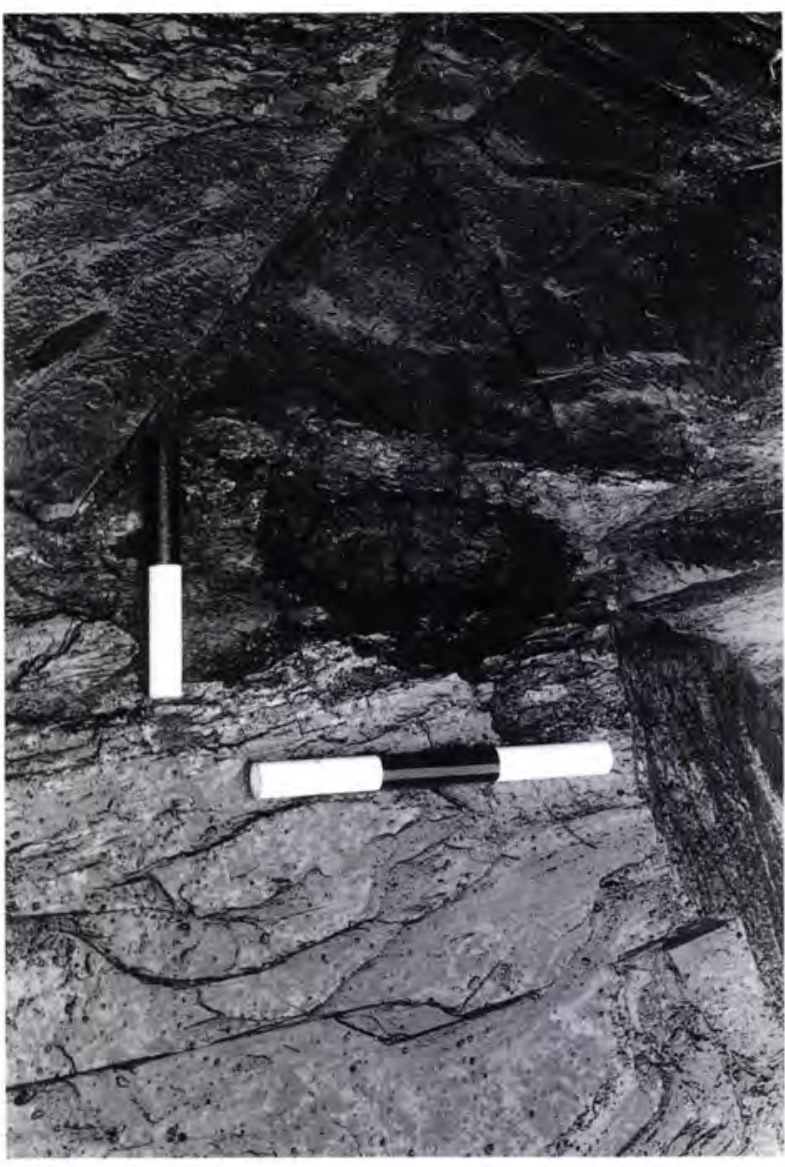

67 Trench C16. Rock-cut post-slot (545). Photograph: CD Morris

excavations of the possible existence of the ground surface upon which the later building was placed (C09, 510, although this could not be explored without dismantling the wall, and 1044; 1021 is also a possible ground surface), and one place where - importantly - this putative ground surface overlay one of the post-settings cut into bedrock $(\mathrm{C} 16,538,537)$. Both the infill of this post-setting and the infill of a large fissure approximately halfway along the west wall and underlying it (see figure 68), can securely be identified as early deposits uncontaminated by later activity. An area of burning (540) overlay the other postsetting, burning (509) infilled the conical-shaped cut 1038 in C09, and gravel (1036) infilled the possible beamslot 1037 in C09.

A number of further layers and features occurred to the south of the building in C09 from this phase, including a large socket or post-hole (1009/1048) cut through a large slate slab (1016), and also a number of apparently early deposits (1026, 1042, 1046, 1049, 1045).

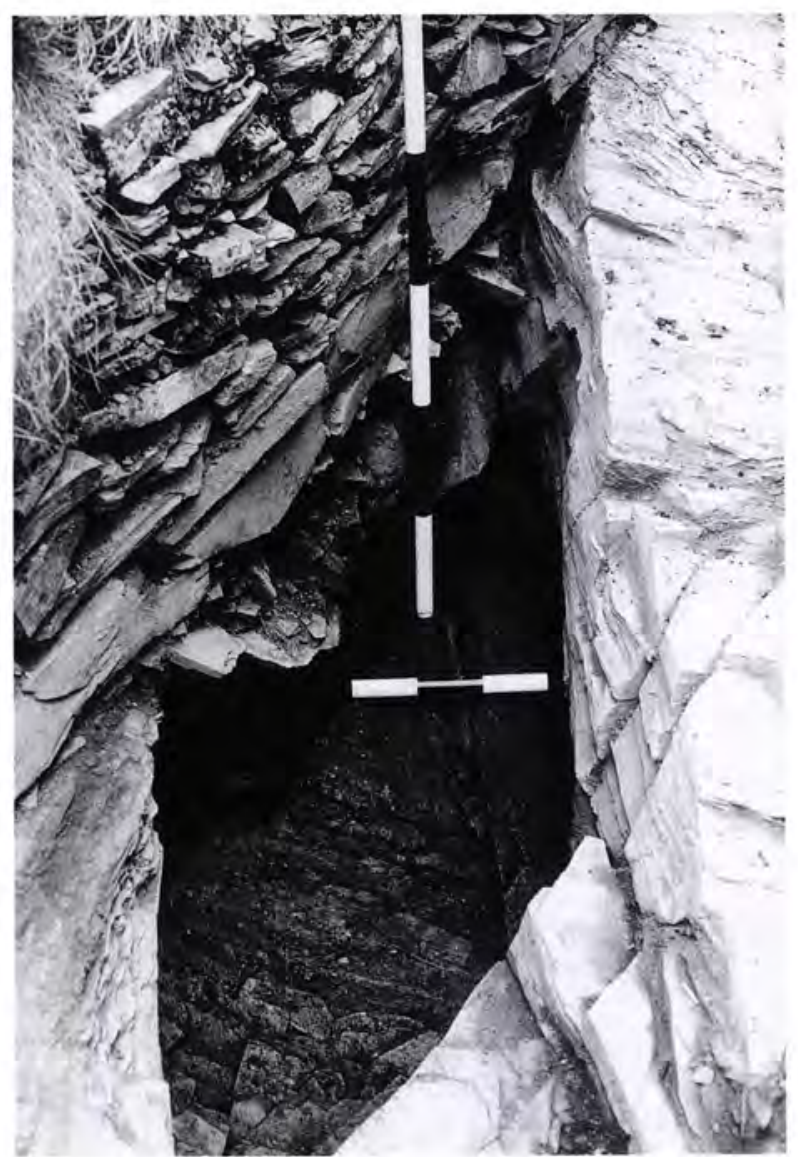

68 Trench C16. Fissure in bedrock from the north. Photograph: CD Morris

PHASE T: ARTEFACTS, ECOFACTS AND DATING

(table 22)

There are exciting palaeobotanical contents here, particularly from the layers that filled a natural fissure in the bedrock in the north of $\mathrm{C} 16$, and are thought to have been build-up to allow construction of wall 512 (C16, successively 1012, 1011, 548, 547, 546, 543 and 542). These are some of the largest assemblages recovered to date from either the Lower or Middle Terrace at Tintagel. Vanessa Straker and Julie Jones have examined these (see Chapter 11). All contained significant amounts of charcoal, and a few burnt bone fragments came from 1012. Table 23 gives details of the main components of the four richest samples and their analysis follows.

The samples from the fill of the fissure are dominated by grain, ranging from $70-92$ per cent, with only $1-2$ per cent chaff and 7-28 per cent weed seeds. In the upper three layers oat grain predominates, but in the lowest barley is more common. However, in this sample 
Table 22 Site $\mathrm{C}$ building Phase $\mathrm{T}$ : contexts and finds

\begin{tabular}{|c|c|c|c|c|}
\hline Phase & Trench & Context & Context description & Finds \\
\hline \multirow{21}{*}{$\begin{array}{l}\text { Phase T: } \\
\text { early make- } \\
\text { up and } \\
\text { rock-cut } \\
\text { features }\end{array}$} & $\mathrm{C} 09$ & 509 & Black peaty burnt material, fill of 1038 & \\
\hline & $\mathrm{C} 09$ & 510 & Thin layer of compact scree and clay & Two small sherds of Coarseware \\
\hline & $\mathrm{C09}$ & 1005 & $\begin{array}{l}\text { Light brown loam of moderate } \\
\text { compaction with small stones and slates, } \\
\text { part of } 1010\end{array}$ & One PRSW sherd (RF 3352) \\
\hline & $\mathrm{C} 09$ & 1009 & Socket carved into the east edge of 1016 & \\
\hline & $\mathrm{C} 09$ & 1010 & $\begin{array}{l}\text { Dark brown compact clayey loam } \\
\text { layer of build-up/levelling material }\end{array}$ & $\begin{array}{l}\text { One Bii amphora sherd (RF 3504) } \\
\text { and one unknown (RF 3503). } \\
\text { Charcoal++ }\end{array}$ \\
\hline & $\mathrm{C} 09$ & 1016 & $\begin{array}{l}\text { Massive slab of slate disassociated from } \\
\text { the natural geology }\end{array}$ & \\
\hline & $\mathrm{C} 09$ & 1020 & $\begin{array}{l}\text { Small patch of black, silty charcoal in a } \\
\text { niche in the bedrock }\end{array}$ & \\
\hline & $\mathrm{C} 09$ & 1021 & $\begin{array}{l}\text { Moderately compact, yellow clay with } \\
\text { small stones, possible old ground surface }\end{array}$ & \\
\hline & $\mathrm{C} 09$ & 1025 & $\begin{array}{l}\text { Medium brown clay with small stones } \\
\text { cut by Phase V drain }\end{array}$ & $\begin{array}{l}\text { Two Bi amphora sherds (RFs } 3445 \\
\text { and } 3489 \text { ) and notched slate (RF } \\
3444 \text { ) }\end{array}$ \\
\hline & $\mathrm{C} 09$ & 1026 & $\begin{array}{l}\text { Dump of earth and stones underlying } \\
1016\end{array}$ & $\begin{array}{l}\text { Three notched slates (RFs } 3488,3433 \\
\text { and 3435) and one sherd of PRSW } \\
\text { (RF 3434). Charcoal++ }\end{array}$ \\
\hline & $\mathrm{CO9}$ & 1028 & $\begin{array}{l}\text { Shillety yellowish-brown silty clay } \\
\text { under wall } 549 \mathrm{~A}\end{array}$ & Indeterminate plant \\
\hline & $\mathrm{CO9}$ & 1034 & $\begin{array}{l}\text { Deposit under upright stones of } 506 \\
\text { of drain below } 1031\end{array}$ & Charcoal+; Cereal sp. \\
\hline & $\mathrm{C} 09$ & 1036 & $\begin{array}{l}\text { Moderately compact shillety gravel fill } \\
\text { of } 1037\end{array}$ & $\begin{array}{l}\text { One Bii amphora sherd (RF 3478). } \\
\text { Charcoal+ }\end{array}$ \\
\hline & $\mathrm{C09}$ & 1037 & Rock-cut, possible beam-slot & \\
\hline & $\mathrm{C} 09$ & 1038 & Conical-shaped cut under wall 549A & \\
\hline & $\mathrm{C} 09$ & 1042 & $\begin{array}{l}\text { Patch of loose silty loam filling hollow } \\
\text { in } 1026\end{array}$ & Charcoal+++ (oak) \\
\hline & $\mathrm{C} 09$ & 1044 & $\begin{array}{l}\text { Sealed silty clay with shillet, possible } \\
\text { old ground surface }\end{array}$ & $\begin{array}{l}\text { Two Bi amphora sherds, } 13 \text { Bii, one } \\
\text { Bv and one Coarseware Fabric } 1 \\
\text { (RFs } 3494-3496,3502 \text { and } 3505- \\
3506 \text { ) and several sherds of a glass } \\
\text { vessel (RFs } 3426,3500 \text { and } 3501 \text {, } \\
\text { Vessel 6). Charcoal++ (oak and elm) }\end{array}$ \\
\hline & $\mathrm{C} 09$ & 1045 & $\begin{array}{l}\text { Compact yellowish-brown sandy clay } \\
\text { primary deposit }\end{array}$ & \\
\hline & $\mathrm{C} 09$ & 1046 & $\begin{array}{l}\text { Sandy clay with stones and shillet } \\
\text { below } 1026\end{array}$ & $\begin{array}{l}\text { One Bii amphora sherd (RF } 3497 \text { ). } \\
\text { Charcoal++ (oak and other); oats; } \\
\text { barley }\end{array}$ \\
\hline & C09 & 1047 & $\begin{array}{l}\text { Slumped tumble of large slates in a } \\
\text { loose loam revetment overlying } 1010\end{array}$ & \\
\hline & $\mathrm{C09}$ & 1048 & Loose shillet filling void below 1009 & One Bv amphora sherd (RF 3498) \\
\hline
\end{tabular}




\begin{tabular}{|c|c|c|c|c|}
\hline Phase & Trench & Context & Context description & Finds \\
\hline & $\mathrm{C} 09$ & 1049 & Compact silty clay below 1046 & $\begin{array}{l}\text { Perforated slate (RF 3499). } \\
\text { Charcoal++ }\end{array}$ \\
\hline & $\mathrm{C} 09$ & 1051 & $\begin{array}{l}\text { Very compact silty clay with scree, } \\
\text { decayed bedrock and occasional } \\
\text { charcoal flecks infilling hollows in } \\
\text { bedrock }\end{array}$ & \\
\hline & $\mathrm{C} 09$ & 1052 & $\begin{array}{l}\text { Moderately loose, dark greyish-brown, } \\
\text { clayey silt with slate flakes above } 1051 \\
\text { but underlying all phases of drain. }\end{array}$ & Charcoal ++ \\
\hline & $\mathrm{C} 10$ & $719 / 516$ & Light brown/yellow soft sandy layer & $\begin{array}{l}\text { One Bi amphora sherd (RF 2097) } \\
\text { and one unknown imported (RF } \\
6095 \text { ). Charcoal+ }\end{array}$ \\
\hline & $\mathrm{C} 10$ & 523 & Dry yellow loam & Charcoal++ \\
\hline & $\mathrm{C} 10$ & 528 & Circular hollow in the bedrock & Slate whetstone (RF 2073) \\
\hline & $\mathrm{C} 10$ & 701 & Silty clay soil fill of 702 & \\
\hline & $\mathrm{C} 10$ & 702 & Post-hole type cut & \\
\hline & $\mathrm{C} 10$ & 706 & $\begin{array}{l}\text { Small, rectangular-shaped rock-cut } \\
\text { socket at south doorway }\end{array}$ & \\
\hline & $\mathrm{C} 10$ & 707 & $\begin{array}{l}\text { A group of stones pitching down } \\
\text { eastwards }\end{array}$ & \\
\hline & $\mathrm{C} 10$ & 709 & $\begin{array}{l}\text { Small clay patch with occasional } \\
\text { charcoal flecks above } 710\end{array}$ & Charcoal ++ \\
\hline & $\mathrm{C} 10$ & 710 & $\begin{array}{l}\text { Group of stones possibly slipped from } \\
\text { an earlier structure }\end{array}$ & \\
\hline & C10 ext & 713 & $\begin{array}{l}\text { Loose clayey loam with shillet similar } \\
\text { to } 719 \text { - part of a revetment }\end{array}$ & $\begin{array}{l}\text { One Bii amphora sherd (RF 2087). } \\
\text { Charcoal++; oats; barley }\end{array}$ \\
\hline & C10 ext & 716 & $\begin{array}{l}\text { Dark yellowish-brown layer with shillet } \\
\text { and occasional charcoal }\end{array}$ & Charcoal++ \\
\hline & C10 ext & 717 & $\begin{array}{l}\text { Over } 716 \text { and contemporary with } 718- \\
\text { loose dark brown clayey loam }\end{array}$ & $\begin{array}{l}\text { One PRSW sherd (RF 2088), one } \\
\text { Bii amphora (RF 2090), lump of } \\
\text { charcoal (RF 2089) }\end{array}$ \\
\hline & C10 ext & 718 & $\begin{array}{l}\text { Make-up layer overlying revetment - } \\
\text { dark brown clayey loam }\end{array}$ & \\
\hline & $\mathrm{C} 11$ & 566 & Rock-cut post-slot at south doorway & \\
\hline & $\mathrm{C} 11$ & 567 & Rock-cut post-slot at north doorway & \\
\hline & $\mathrm{C} 11$ & 571 & $\begin{array}{l}\text { Dump of closely packed, large angular } \\
\text { lumps of slate infilling hollows in the } \\
\text { bedrock at the south doorway of the } \\
\text { room }\end{array}$ & \\
\hline & $\mathrm{C} 11$ & 574 & $\begin{array}{l}\text { Levelling dump of scree and slates } \\
\text { overlying fractured bedrock }\end{array}$ & \\
\hline & $\mathrm{C} 11$ & 582 & An area of burnt material and soil & Charcoal +++ \\
\hline & $\mathrm{C} 11$ & 583 & $\begin{array}{l}\text { Layer of dark brown clayey silt, scree } \\
\text { and flat stone revetment }\end{array}$ & $\begin{array}{l}\text { Eight ARSW sherds (RFs } 1849 \text { and } \\
\text { 1850). Charcoal++ }\end{array}$ \\
\hline
\end{tabular}




\begin{tabular}{|c|c|c|c|c|}
\hline Phase & Trench & Context & Context description & Finds \\
\hline & C11 ext & $\begin{array}{l}592 / 593 \\
589 \\
587 / 590\end{array}$ & $\begin{array}{l}\text { Cutting through the east wall of } \mathrm{C} 11 \\
\text { possibly fulfilling a revetting function } \\
\text { at the eastern edge of the terrace. } \\
\text { Closely packed flat stones in dark } \\
\text { reddish-brown to dark brown silty } \\
\text { clays with charcoal flecks }\end{array}$ & $\begin{array}{l}\text { One Romano-British Gabbroic } \\
\text { sherd (RF 2091), one Bi amphora } \\
\text { (RF 2851) and a piece of bone (RF } \\
\text { 2852). Charcoal+++ (frequent small } \\
\text { twigs); wheat; barley }\end{array}$ \\
\hline & C11 ext & $591 / 586$ & $\begin{array}{l}\text { Loose deposits shillet in dark brown } \\
\text { loam sealing revetment layers }\end{array}$ & \\
\hline & C11 ext & 587 & Layer of stones within drain feature & One Bii amphora sherd (RF 2850) \\
\hline & C11 ext & 588 & Over 587 - patch of charcoal & Charcoal +++ (frequent small twigs) \\
\hline & C11 ext & 590 & $\begin{array}{l}\text { Dark brown clayey loam east of wall } \\
715 \text { in C10 extension }\end{array}$ & \\
\hline & $\mathrm{C} 12$ & 603 & $\begin{array}{l}\text { Overlying } 605-\text { spread of large flat } \\
\text { slates in a clayey loam matrix }\end{array}$ & $\begin{array}{l}\text { Two Bii amphora sherds (RFs } 1692 \\
\text { and 1801), water-worn pebble (RF } \\
\text { 1693) and notched slate (RF 1802). } \\
\text { Charcoal++; oats; stinking chamomile }\end{array}$ \\
\hline & $\mathrm{C} 12$ & 605 & $\begin{array}{l}\text { Overlying } 606 \text { - spread of large flat } \\
\text { slates in a clayey loam matrix }\end{array}$ & Slate disc (RF 1821) \\
\hline & $\mathrm{C} 12$ & 606 & $\begin{array}{l}\text { Overlying } 607 \text { - a dark reddish-grey } \\
\text { spread of shillet in clayey loam }\end{array}$ & Oats \\
\hline & $\mathrm{Cl} 2$ & 607 & $\begin{array}{l}\text { Earliest fill of step at east edge - a hard } \\
\text { patch of reddish-brown clayey loam } \\
\text { with shillet }\end{array}$ & \\
\hline & $\mathrm{Cl3}$ & 562 & $\begin{array}{l}\text { Levelling of dark reddish-brown spread } \\
\text { of scree and stones overlying } 563\end{array}$ & $\begin{array}{l}\text { Notched slate (RF 1667), burnt clay } \\
\text { lump (RF 1666), one Bii sherd } \\
\text { (RF 1623) }\end{array}$ \\
\hline & $\mathrm{C} 13$ & 563 & Three conjoining flat slates set onto 564 & \\
\hline & $\mathrm{C} 13$ & 564 & $\begin{array}{l}\text { Small patch of compact dark brown } \\
\text { loamy clay filling a hollow in the bedrock }\end{array}$ & \\
\hline & $\mathrm{C} 16$ & 537 & $\begin{array}{l}\text { Dark grey clayey loam with frequent } \\
\text { inclusions of charcoal, overlying } 538\end{array}$ & $\begin{array}{l}\text { Seven Bii amphora sherds (RF } \\
\text { 2623), two Bi (RFs 2624 and 2625) } \\
\text { and one Bv (RF 2616). Charcoal+; } \\
\text { oats; barley }\end{array}$ \\
\hline & C16 & 538 & $\begin{array}{l}\text { Light reddish-brown clayey loam, } \\
\text { possible old land surface, fill of } 545\end{array}$ & Barley \\
\hline & C16 & 540 & $\begin{array}{l}\text { Thin strip of clayey loam with frequent } \\
\text { inclusions of charcoal, fill of } 544\end{array}$ & $\begin{array}{l}\text { Glass bead (RF 2620), two Biv } \\
\text { amphora sherds and one Bii (RF } \\
6098 \text { ). Charcoal++; oats; barley; } \\
\text { wheat; sorrel; a few burnt bone frags }\end{array}$ \\
\hline & $\mathrm{C} 16$ & 541 & $\begin{array}{l}\text { Light yellow clay sitting directly over } \\
\text { bedrock }\end{array}$ & \\
\hline & C16 & 542 & $\begin{array}{l}\text { Dark brown silty loam with stones and } \\
\text { charcoal above } 543\end{array}$ & $\begin{array}{l}\text { Industrial material (RF 2621) and } \\
\text { natural Fe (RF 2622). Plant } \\
\text { macrofossils (Table 3); charcoal+++ }\end{array}$ \\
\hline & $\mathrm{C} 16$ & 543 & $\begin{array}{l}\text { Medium brown clayey silt with small } \\
\text { and large angular stones above } 546\end{array}$ & Charcoal++; plant macrofossils \\
\hline
\end{tabular}




\begin{tabular}{|c|c|c|c|c|}
\hline Phase & Trench & Context & Context description & Finds \\
\hline & $\mathrm{C} 16$ & 544 & $\begin{array}{l}\text { Footstep-shaped post-slot cut into } \\
\text { bedrock }\end{array}$ & \\
\hline & $\mathrm{C} 16$ & 545 & $\begin{array}{l}\text { Footstep-shaped post-slot cut into } \\
\text { bedrock }\end{array}$ & \\
\hline & $\mathrm{C} 16$ & 546 & $\begin{array}{l}\text { Dark brown clayey loam with } \\
\text { substantial charcoal above } 547\end{array}$ & $\begin{array}{l}\text { Rich in plant macrofossils (table } 81 \text { ); } \\
\text { charcoal }+++\end{array}$ \\
\hline & $\mathrm{C} 16$ & 547 & $\begin{array}{l}\text { Medium brown clayey silt with large } \\
\text { and small angular stones above } 548\end{array}$ & $\begin{array}{l}\text { Plant macrofossils (table } 81 \text { ); } \\
\text { charcoal }+++\end{array}$ \\
\hline & $\mathrm{C} 16$ & 548 & Hard localized purplish-brown layer & $\begin{array}{l}\text { Plant macrofossils (table } 81 \text { ); } \\
\text { charcoal }+++\end{array}$ \\
\hline & $\mathrm{Cl} 16$ & 1011 & $\begin{array}{l}\text { Medium brown clayey silt with large, } \\
\text { angular stones and charcoal overlying } \\
1012\end{array}$ & $\begin{array}{l}\text { One Romano-British Gabbroic ware } \\
\text { sherd (RF3400) and two Bii amphora } \\
\text { (RF 3401). Very rich in plant } \\
\text { macrofossils (table 81); charcoal+++ }\end{array}$ \\
\hline & $\mathrm{C} 16$ & 1012 & $\begin{array}{l}\text { Earliest fill layer within a fissure in the } \\
\text { bedrock. Very dark brown clayey silt } \\
\text { with stones }\end{array}$ & $\begin{array}{l}\text { Four Bii fragments (RFs } 3402 \text { and } \\
6096 \text { ) and vessel glass (RF } 6097 \text {, } \\
\text { Vessel 16). Plant macrofossils (table } \\
81 \text { ); charcoal++; a few burnt bone } \\
\text { fragments }\end{array}$ \\
\hline
\end{tabular}

Charcoal fragments $>2 \mathrm{~mm}:+1-10 ;++11-50 ;+++51-100$

Table 23 Components of the four richest samples from the fill of the fissure, Phase $T$

\begin{tabular}{|c|c|c|c|c|c|c|c|c|c|c|c|c|c|c|c|}
\hline $\begin{array}{l}\text { Con- } \\
\text { text }\end{array}$ & $\begin{array}{l}\text { Oat } \\
\text { No. }\end{array}$ & $\begin{array}{l}\text { grain } \\
\text { Per } \\
\text { cent }^{*}\end{array}$ & $\begin{array}{l}\text { Barl } \\
\text { No. }\end{array}$ & $\begin{array}{l}\text { ey grain } \\
\text { Per } \\
\text { cent }\end{array}$ & $\begin{array}{l}\text { Whe } \\
\text { No. }\end{array}$ & $\begin{array}{l}\text { at grain } \\
\text { Per } \\
\text { cent }\end{array}$ & $\begin{array}{l}\text { No. oat } \\
\text { chaff }\end{array}$ & $\begin{array}{l}\text { No. barley } \\
\text { chaff }\end{array}$ & $\begin{array}{l}\text { No. wheat } \\
\text { chaff }\end{array}$ & $\begin{array}{l}\text { Total } \\
\text { grain }\end{array}$ & $\begin{array}{l}\text { Total } \\
\text { chaff }\end{array}$ & $\begin{array}{l}\text { Weeds } \\
\text { No. }\end{array}$ & $\begin{array}{l}\text { Per } \\
\text { cent } \\
\text { grain }\end{array}$ & $\begin{array}{l}\text { Per } \\
\text { cent } \\
\text { chaff }\end{array}$ & $\begin{array}{l}\text { Per } \\
\text { cent } \\
\text { weeds }\end{array}$ \\
\hline 546 & 248 & 80 & 56 & 18 & 6 & 2 & 1 & 3 & 2 & 310 & 6 & 136 & 69 & 1 & 30 \\
\hline 547 & 70 & 86 & 10 & 12 & 1 & 1 & 0 & 1 & 0 & 81 & 1 & 21 & 79 & 1 & 20 \\
\hline 548 & 57 & 90 & 5 & 8 & 1 & 2 & 1 & 0 & 0 & 63 & 1 & 6 & 91 & 1 & 8 \\
\hline 1011 & 136 & 22 & 478 & 77 & 8 & 1 & 3 & 1 & 0 & 622 & 4 & 49 & 92 & 1 & 7 \\
\hline
\end{tabular}

* per cent total identified grain

(context 1011) two floret bases characteristic of domesticated oats (Avena sativa or strigosa, bristle oat), were present suggesting that the barley was mixed with at least some domesticated rather than wild oats. In the upper three layers, no oat chaff is preserved and in theory the oats could be wild and therefore crop weeds or domesticated and a crop. On balance, the composition of the assemblages suggests that it was spoiled human or grain-dominated animal feed rather than crop-processing waste that was among the refuse used to fill up the fissure. At least twenty weed taxa accompanied the crop remains. These fall broadly into three categories, as suggested in table 24. Most of the weeds could have been harvested with the crops, to be removed during the later stages of crop processing or fed to animals with oats and barley. The revetment layers were also rich in palaeobotanical material: charcoal, including frequent small twigs, oats, barley and wheat were recovered from the samples from these contexts.

Similarly the artefacts from this primary phase of usage of the terrace are of some importance. The lowest context of the fissure (1012) contained Bii amphorae 
Table 24 Weeds, by group, from the fill of the fissure, Phase T

\begin{tabular}{|c|c|c|}
\hline Plants of arable and disturbed ground & $\begin{array}{l}\text { Grassland / rough ground } \\
\text { plants }\end{array}$ & $\begin{array}{l}\text { Various habitats or plants not } \\
\text { identified to species }\end{array}$ \\
\hline $\begin{array}{l}\text { Urtica dioica (stinging nettle) } \\
\text { Chenopodium album (fat hen) }\end{array}$ & $\begin{array}{l}\text { Medicago / Trifolium sp. } \\
\text { (medick/clover) }\end{array}$ & $\begin{array}{l}\text { Atriplex sp. (orache, often } \\
\text { coastal) Chenopodium sp. } \\
\text { (goosefoot) }\end{array}$ \\
\hline Stellaria media (chickweed) & Silene sp. (campions) & Polygonum sp. (knotgrass) \\
\hline Fallopia convolvulus (black bindweed) & $\begin{array}{l}\text { Leucanthemum vulgare } \\
\text { (ox-eye daisy) }\end{array}$ & $\begin{array}{l}\text { Rumex maritimus } \\
\text { (golden dock, often damp) }\end{array}$ \\
\hline Raphanus raphanistrum (wild / sea radish) & $\begin{array}{l}\text { Vicia sp. (vetch, also } \\
\text { disturbed / arable) }\end{array}$ & $\begin{array}{l}\text { Rumex sp. (sorrel) } \\
\text { Ulex sp. (gorse, heathland, scrub) }\end{array}$ \\
\hline Lathyrus / Pisum sp. (vetch / pea, also grassland) & $\begin{array}{l}\text { Lathyrus / Pisum sp. (vetch / } \\
\text { pea, also disturbed / arable) }\end{array}$ & $\begin{array}{l}\text { Juncus sp. (rush) } \\
\text { Poaceae (grasses) }\end{array}$ \\
\hline \multicolumn{3}{|l|}{ Vicia sp. (vetch, also grassland) } \\
\hline \multicolumn{3}{|l|}{ Anthemis cotula (stinking chamomile) } \\
\hline \multicolumn{3}{|l|}{ Chrysanthemum segetum (corn marigold) } \\
\hline \multicolumn{3}{|l|}{ Tripleurospermum inodorum (scentless mayweed) } \\
\hline \multicolumn{3}{|l|}{ Avena / Bromus sp. (oats / brome) } \\
\hline Bromus hordaceus / secalinus (soft / rye brome) & & \\
\hline
\end{tabular}

and a fragment of early vessel glass from the Bordeaux area (Vessel 16: see Chapter 10). This was overlain by 1011, which contained one sherd of Romano-British Gabbroic ware pottery (RF 3400: see Chapter 10, figure 127) and two sherds of Bii. This collection of pottery from these deposits suggests that a late Roman date cannot be sustained for the infilling of the fissure. This is reinforced by the small collection of imported ceramics ( $\mathrm{Bi}, \mathrm{Bii}$ and $\mathrm{Bv}$ ) in a deposit overlying one of the postholes which may also be part of an old ground surface (C16, 537). Similarly, a small cylindrical glass bead, perhaps from the fifth to seventh centuries, and sherds of Bii and Biv imported amphorae in post-setting 540 (C16) and beam-slot 1037 filled with 1036 support a post-Roman date.

Some make-up for the building (eg C11, 583; C09, $1010,1025)$ produced African Red slipped ware (ARSW) sherds, in addition to $\mathrm{Bi}$ and $\mathrm{Bii}$ and a notched slate. Other such deposits (C09, 1005; C10 ext, 717) produced Phocaean Red slipped ware (PRSW), including a rim, and a Bii sherd. Make-up in C12 included Bii, a notched slate, a pebble and a slate disc.

Another PRSW rim with rouletted decoration came from context 1026 (C09). Elsewhere in this trench $\mathrm{Bi}$, Bii, Bv and Fabric 1 imported Coarseware were noted. In addition to these, the unique glass flagon fragments interpreted as potentially originating from Spain (Vessel 6: see Chapter 10, figure 124), came from a possible old ground surface to the south west of the building ( $\mathrm{C} 09$, 1044). B-ware sherds were also recovered from the revetment layers, 719/516 in C10, 713 in C10 ext, and those in $\mathrm{Cll}$ ext. A single sherd of Romano-British Gabbroic ware and a piece of bone were also found in these layers. The total absence of later medieval pottery in this phase is a critical element in defining the date of these features as early medieval.

Other individual finds of note include a whetstone made from a simple cobble which has been used as sharpening stone (C10, 528: RF 2073; see Chapter 10, figure 115), and industrial waste from domestic hearth activity (RF 2621 from 542 of C16).

\section{Phase U: U1 DRAINAGE, U2 DRAINAGE REPAIR (figure 69)}

The second major activity on the terrace before the construction of the stone-walled building was the construction of a drain in the south-west corner (trench C09). Originally (Phase U1), this drain (figure 70) served to channel water, which flowed through a hole in the bedrock away from the area. The channel capped with flagstones (1008A) was cut directly through bedrock and appeared to follow a natural fault which 


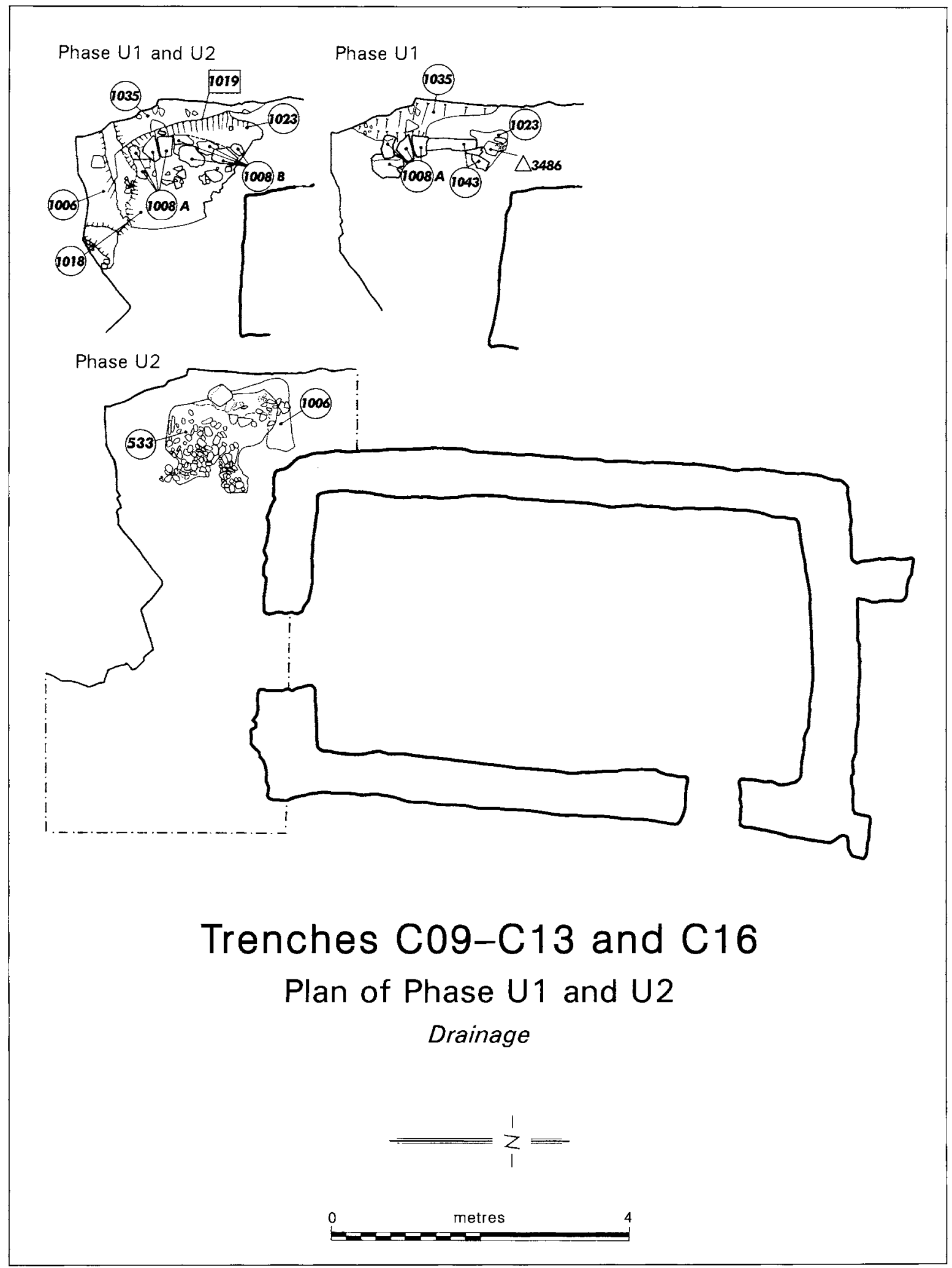

69 Site C building. Plans of Phases UI and U2. Drawing: L McEwan 


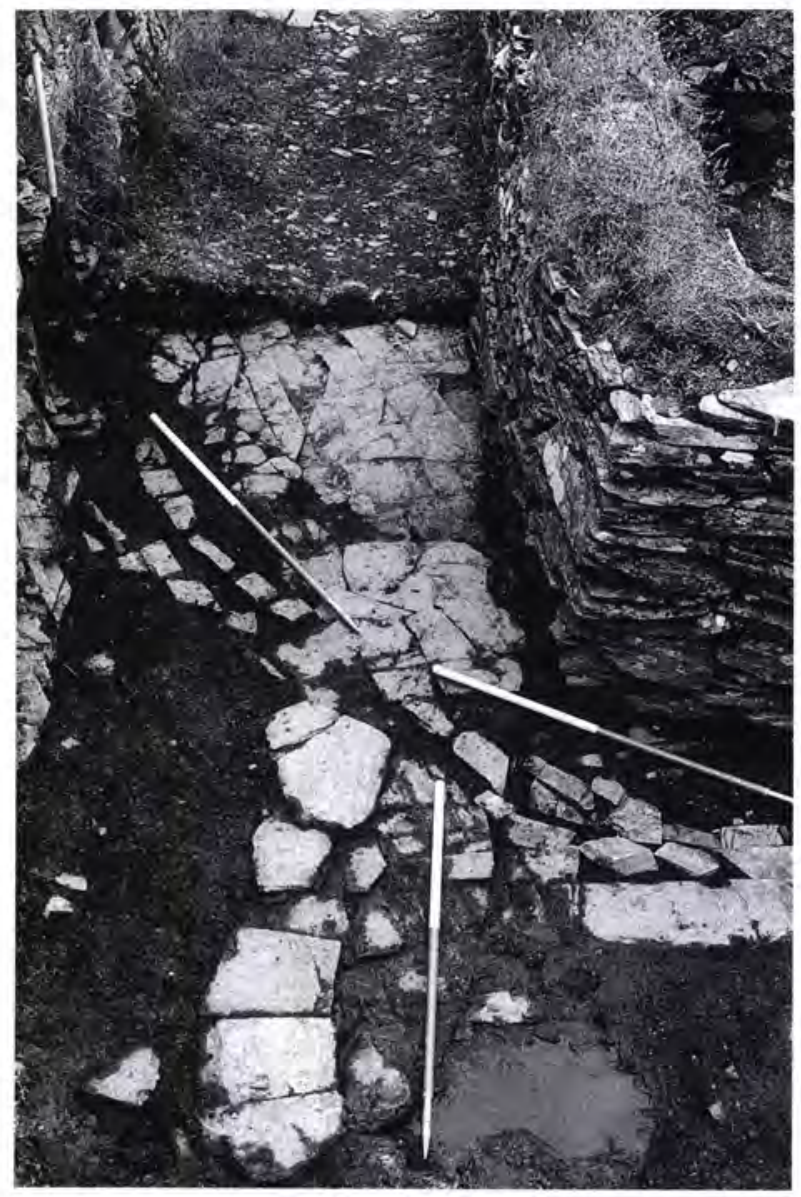

70 Trench C09. Drain flags (1008A) from the south.

Photograph: C D Morris

had been manually adapted for this purpose. The natural slope of the bedrock carried excess water from the spring to the north and towards the south-west corner of trench $\mathrm{C} 10$. The capstones of this drain were levelled either directly onto the bedrock or onto small, sub-rectangular bluish slates (1043), which served the dual purpose of creating sides for the channel and wedges to level the caps where the lie of the bedrock was too uneven.

Overlying the capstones in this area was shillet (1035). This context did not continue over to the north end of the drain, but it did overlie a layer of silty clay (1023) which was present in the north area. It is the relationship of these two contexts to the capstones $(1008 \mathrm{~A} / 1008 \mathrm{~B})$ and uprights (1043) of the drain across the entire length of the feature that is crucial in separating the events of Phases Uland U2.
The second episode (U2) in this phase relates to the repair of the north end of this drain, where the capstones (1008B) overlay context 1023, but 1023 overlay the uprights (1043) of the drain. Furthermore, context 1035 clearly overlay 1023 around the south half of the drain. It would appear that 1035 represents a phase of partial destruction of this drain. An inscribed slate (RF 3486) was found at the bottom of 1023, within the channel of the drain and underneath a complete flagstone of the 1008B set (figure 71). It is suggested that the north capstones had been re-set after the event that led to the inscribed slate, which had served as a capstone, being dislodged and broken down into the channel of the drain that it had covered. This event was the accumulation of the silty clays (1023/1035).

A possible cut (1019) was noted which went through both 1023 and 1035. The flooding of this area led to continual silting and it was unclear if these contexts simply stopped along this line or whether there was indeed a cut. If this was a cut, 1019 could have been part of the same episode that saw the repair of the north half of the drain, as the slumped materials of 1023 and 1035 were partially removed to expose the line of the drain and replace the broken capstones. The area to the east of the cut 1019 was filled by two deposits very rich in artefacts ( 1006 and 533 respectively). These two contexts were limited to the area above the flags (1008A and B). To the east of 1008A and 1008B, light brown clay (1018) was identified in 1994, which sat directly over bedrock but remained unexcavated. It may have been the result of silting following water saturation. No evidence of this phase of activity was excavated in trenches $\mathrm{C} 10-\mathrm{C} 13$ and C16.

\section{Phase U: ARTEFACTS, ECOFACTS AND DATING}

(table 25)

The silty clay 1023 of Phase U1 contained both imported pottery - $\mathrm{Bi}$ and $\mathrm{Bv}$ - and one sherd of Romano-British Local pottery, as well as one piece of unidentified burnt mammal bone and some charcoal, in addition to the inscribed stone (RF 3486: see Chapter 10, figure 102) discussed fully in Chapter 10. It is possible to see successive silting deposits above, which contain a comprehensive range of imported pottery sherds all dating from the post-Roman period. For instance, finds recovered from 533 of Phase $\mathrm{U} 2$ included $\mathrm{Bi}$, Bii and $\mathrm{Bv}$ amphorae and one Romano-British Granitic ware, a water-worn pebble, a slate disc and two pieces of unidentifiable large mammal bone and teeth. Further, 


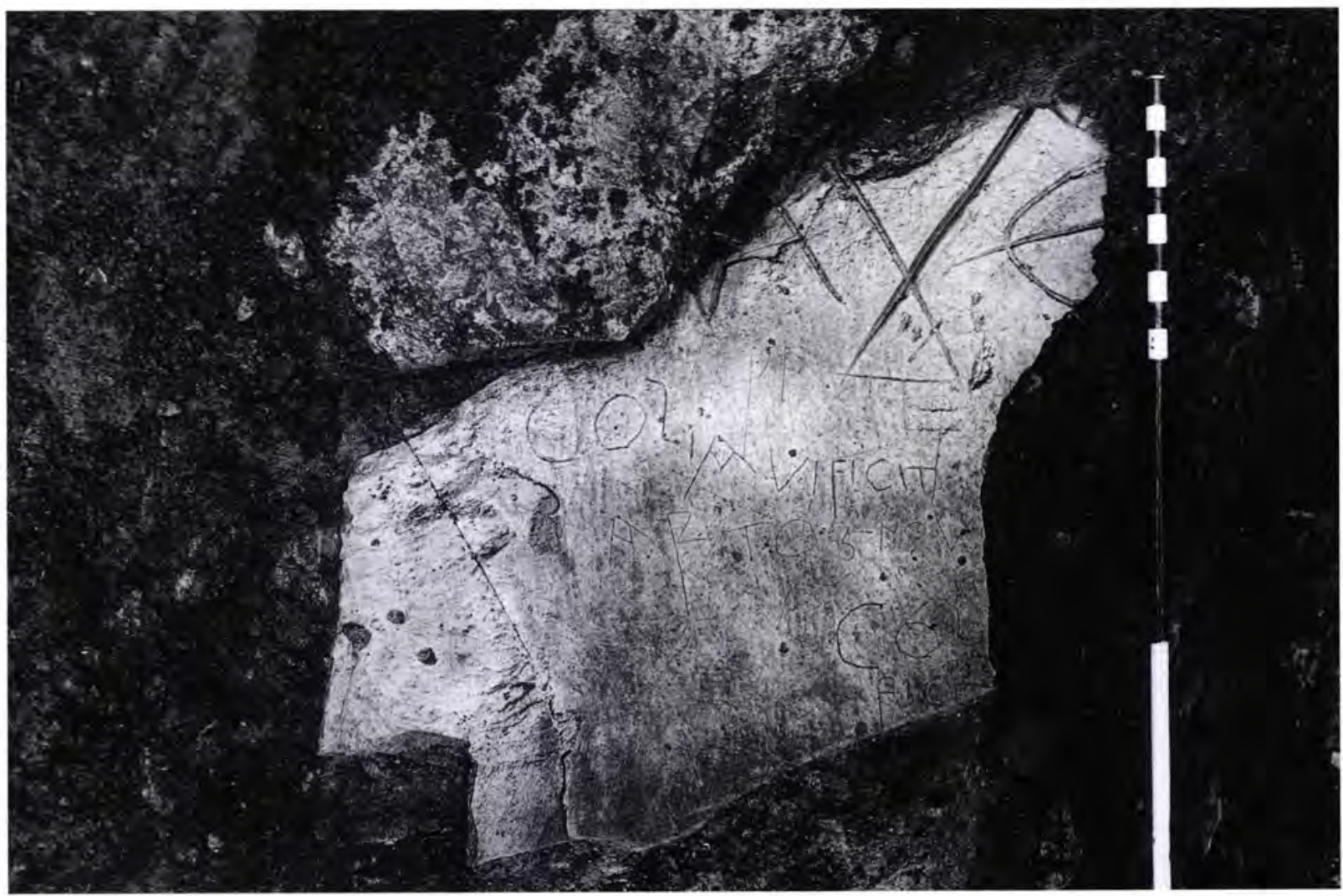

71 Inscribed slate, RF 3486, in situ. Photograph: K J Brady

within 1006 (also of Phase U2) were found two PRSW sherds, Bi, Bii, a Biv foot-spike (RF 3361: see Chapter 10, figure 127), Bv and Fabric 1 imported Coarseware. These were all in good condition with little abrasion. Six pieces of bone and tooth, a flint, a slate disc, and a piece of charcoal were also recovered. Unfortunately, of the six finds of mammal bone and tooth fragments recovered, only one was identifiable to species (a cattle upper molar: RF 3465).

One of the apparently unknown fabric sherds is the unusual RF 3477 (C09, 1006: see Chapter 10, figure 128). Although this large sherd of a thick-walled vessel was originally suggested to be of stone, it now seems possible that it is in fact a ceramic type not previously identified at the site or locality. At the time of writing there is no suggestion for its origin, but it is possible that it may be part of a very substantial imported vessel of amphoratype. Two slate discs and a piece of worked flint were also recovered.

Clearly, the inscribed slate (RF 3486) re-used as a drain cover (see figure 71) is the most notable find from this phase (see Chapter 10). This piece, with incised lettering from the immediately post-Roman (and even late Roman) centuries on one face, is of native Cornish slate, probably from the bedded slate forming the natural rock at the summit of the Island at Tintagel. It is of irregular shape, measuring at a maximum $297 \mathrm{~mm}$ by $192 \mathrm{~mm}$, with diagonal dimensions $348 \mathrm{~mm}$ top right to bottom left by $228 \mathrm{~mm}$ top left to bottom right. It has sheered along the bedding plane of the rock face and subsequent damaging lamination has resulted in a varying thickness of up to $20 \mathrm{~mm}$. The lower face is somewhat rougher than the surface selected for a writing surface in both stages of its use. The working face has not been dressed, but it is naturally relatively smooth with minor irregularities. One part of the slate has been trimmed into a rough curve, presumably damaged at the time of the cutting of the west-east drain of Phase V. A detailed conservation assessment of the stone has been undertaken by Jennifer Jones who has confirmed that several of the apparent 'drilled holes' on the worked surface are in fact the result of natural mineralization 
Table 25 Site $\mathrm{C}$ building Phases $\mathrm{U} 1$ and U2: contexts and finds

\begin{tabular}{|c|c|c|c|c|}
\hline Phase & Trench & Context & Context description & Finds \\
\hline \multirow[t]{4}{*}{$\begin{array}{l}\text { Phase U1: } \\
\text { drainage }\end{array}$} & $\mathrm{C} 09$ & $1008 \mathrm{~A}$ & $\begin{array}{l}\text { Flags capping southern half of the } \\
\text { south-north running drain, utilizing } \\
\text { natural fault in bedrock manually } \\
\text { adapted for drain }\end{array}$ & \\
\hline & $\mathrm{C} 09$ & 1023 & Layer of silty clay & $\begin{array}{l}\text { Four Bi amphora sherds (RFs 3482, } \\
3483 \text { and 3485), one Bv (RF 3484) } \\
\text { and one Romano-British Local (RF } \\
\text { 3492). Inscribed slate (RF 3486). } \\
\text { One piece of unidentifiable burnt } \\
\text { mammal bone (RF 3473). Charcoal+ }\end{array}$ \\
\hline & $\mathrm{C} 09$ & 1035 & $\begin{array}{l}\text { Shillet in a silty clay matrix overlying } \\
\text { capstones } 1008 \mathrm{~A}\end{array}$ & Charcoal ++ \\
\hline & $\mathrm{C} 09$ & 1043 & $\begin{array}{l}\text { Small, rectangular bluish slates creating } \\
\text { sides for channel and wedges to level } \\
\text { caps } 1008 \mathrm{~A} \text { where bedrock surface } \\
\text { is uneven }\end{array}$ & \\
\hline \multirow[t]{5}{*}{$\begin{array}{l}\text { Phase U2: } \\
\text { drainage } \\
\text { repair }\end{array}$} & $\mathrm{C} 09$ & 533 & Artefactually rich deposit & $\begin{array}{l}\text { Twelve Bi amphora sherds (eg } \\
\text { RFs } 2332 \text { and 2643), five Bii (eg } \\
\text { RFs } 2658 \text { and 2660), one Bv (RF } \\
\text { 2654), and one Romano-British } \\
\text { Granitic (RF 2645). A water-worn } \\
\text { pebble (RF 2639), a slate disc (RF } \\
\text { 2661), unidentifiable large mammal } \\
\text { bone and tooth fragments (RFs } 2655 \\
\text { and 3425). Charcoal+ }\end{array}$ \\
\hline & $\mathrm{CO9}$ & 1006 & Artefactually rich deposit & $\begin{array}{l}\text { Two PRSW sherds (RFs } 3362 \text { and } \\
\text { 3365), } 15 \text { Bi amphora (eg RFs } 2698 \\
\text { and 3369), seven Bii (eg RFs } 2693 \\
\text { and 3351), one Biv foot-spike (RF } \\
\text { 3361), four Bv (eg RFs } 2689 \text { and } \\
3472 \text { ), two Coarseware Fabric } 1 \text { (RFs } \\
2690 \text { and 3383) and three unknown } \\
\text { (eg RF 3477). Also, five finds of } \\
\text { unidentifiable mammal bone and } \\
\text { tooth fragments (eg RFs } 3368 \text { and } \\
\text { 2694), a cattle upper molar (RF } \\
\text { 3465), a flint (RF 2699), a slate disc } \\
\text { (RF 3364) and a piece of charcoal } \\
\text { (RF 3382) }\end{array}$ \\
\hline & $\mathrm{CO9}$ & $1008 \mathrm{~B}$ & $\begin{array}{l}\text { Flags capping northern half of the } \\
\text { south-north running drain, later than } \\
1008 \mathrm{~A} \text { and representing repair of the } \\
\text { drain }\end{array}$ & One Bi sherd (RF 3428) \\
\hline & $\mathrm{C} 09$ & 1018 & Light brown clay east of drain & One Bi amphora sherd (RF 3404) \\
\hline & $\mathrm{C} 09$ & 1019 & $\begin{array}{l}\text { Cut made whilst repairing drain flag } \\
\text { stones }\end{array}$ & \\
\hline
\end{tabular}

Charcoal fragments $>2 \mathrm{~mm}:+1-10 ;++11-50$ 


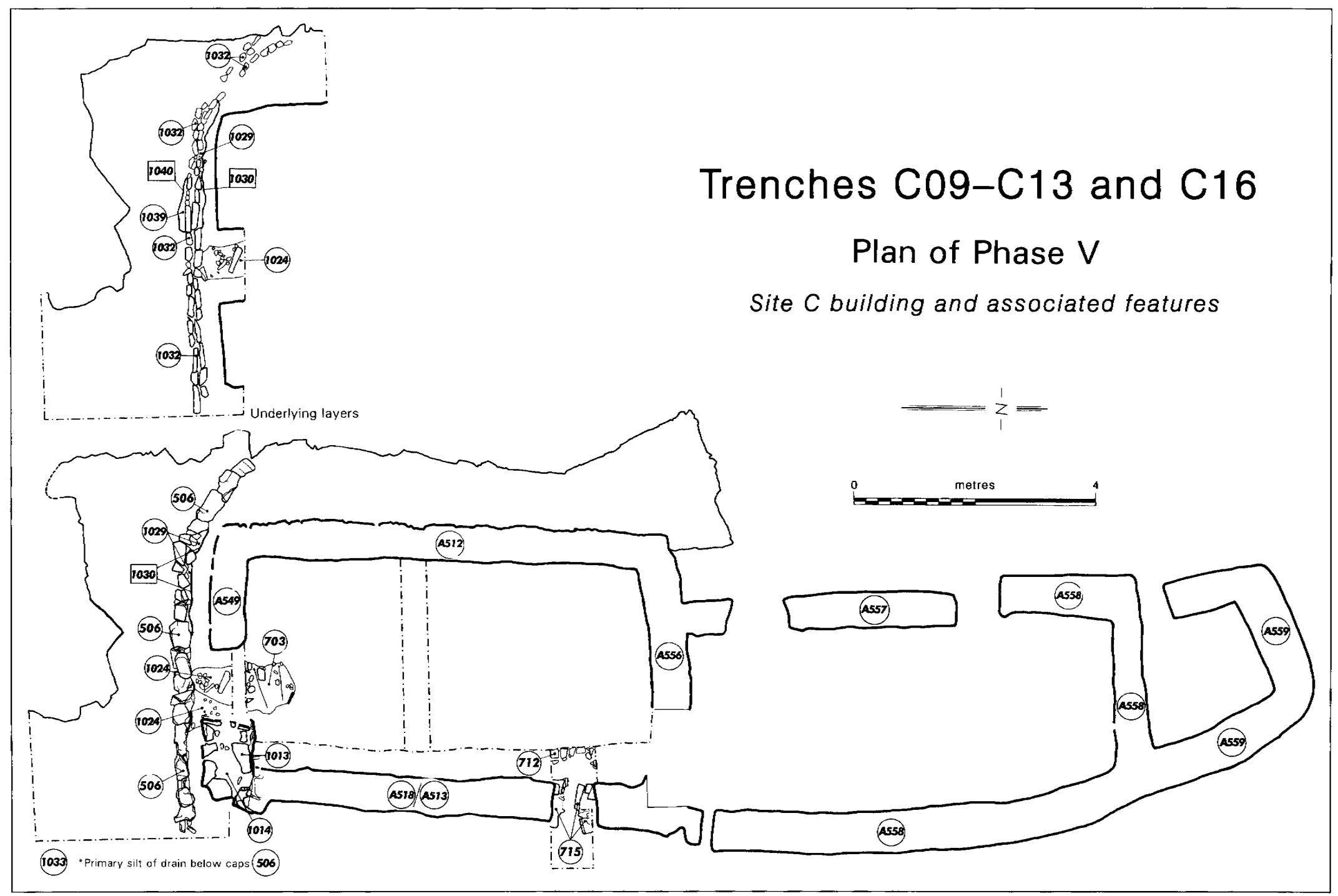

72 Site $C$ building. Plan of Phase V. Drawing: $L$ McEwan 
rather than being man-made. The inscribed face of the slate is darker in colour than the reverse, which she has suggested could be the result of exposure to the elements during use. This spectacular find is discussed separately in Chapter 10 by David Jefferson and Charles Thomas. However, in summary, it is argued that there are two separate inscriptions, with the earlier dating from the turn of the fourth-fifth century $\mathrm{AD}$, and possibly originally reading $\mathrm{H}$ [onorius] AVG[ustus], that is, referring to the Emperor Honorius (AD 393-423). The later inscription appears to be of a series of names, in the form of '[The mark of, or name] of -'. The names in question are Paternus or Paterninus, Coliauus and Artognou, and are likely to date from the sixth century. While the first inscription may be placed in a late Roman context, possibly as a label fixed to the front of a building, the second is a remarkable recovery of evidence for post-Roman literacy.

Overall, the finds from this phase suggest that the above layers can definitely be dated to an early, rather than later, medieval occupation.

\section{Phase V: Site C building ANd associated features} (figure 72)

The second structural phase in this part of the site, and the third major phase of activity, relates to the construction of Building $\mathrm{C}$ and its associated features (figures 73-75). This was almost certainly not a unitary structure, and had had more than one phase, but the 1930s excavations removed all the crucial evidence. The plan itself suggests, a priori, that the southern room excavated in trench $\mathrm{C} 10$ and the northern two rooms (excavated in trenches $\mathrm{C} 11$ and C12: see figure 61) are likely to be of different phases, and this was borne out in excavation by the evidence that the wall A558 of C11 abuts the wall $\mathrm{A} 518$ of $\mathrm{C} 10$, indicating that it was later.

Most of the walls as now visible had been reconstructed from the 1930s onwards, but it was possible in the excavations of the 1990s to determine that the bottom two or three courses were generally original (defined in the context record as ' $\mathrm{A}$ '), as they remained of dry-stone, unmortared construction, in contrast to higher courses which had mortar and cement bonding (defined in the context record as 'B'), seen from Palmer's analyses to be modern (see Phase $Y$ below). Excavation of trench $\mathrm{C} 10$ ext (see figure 61) illustrated that the lower two to three courses (712) of the east bench and east wall (715) were unmortared and therefore probably original, forming the base for the reconstruction from the $1930 \mathrm{~s}$ onwards. 712 was up to three courses deep while 715 was up to two courses deep. Excavation in trench $\mathrm{Cl} 1 \mathrm{ext}$ (see figure 61) uncovered undisturbed deposits associated with the basal courses of the east wall of the building, suggesting that the unmortared basal courses here are also probably original. The lower two to three courses of the south west (A549), the west (A512) and the remainder of the east (A518) walls of $\mathrm{C} 10$ (also C16) may be original as they are unmortared. The south-east wall was dismantled during excavations in trench C09 to the south and demonstrated that a course of stones from the original structure survived under the rebuilds of the 1930s and later. These stones (1013) sat on the old ground surface (1021) of Phase $\mathrm{T}$ and had a shilletty fill (1014). Investigation of the walls delineating C11 revealed that the bottom two or three courses of each stretch of wall were also unmortared, and constructed from more substantial elements than the upper, mortared courses. Wall 557, at the west side of trench C11, was built directly over the bedrock, and the lower courses appear to be dry-stone with no mortar, suggesting that the lower courses at least belong to A557. However, there were also some places where even the bottom courses were disturbed and re-set in the 1930s and in the south-west corner of $\mathrm{Cll}$ a drain feature (probably modern in date) had been built into the wall above the original courses (A556). There was practically nothing within the building that could be considered as original occupation deposits. A layer of angular stones in a clayey loam matrix (1024) was recorded at the entrance to the south end of building $C$ and may represent a levelling deposit for that entrance.

By far the best surviving feature excavated in this phase was a stone-capped drain (see figure 75) in C09 which skirted the south wall of $\mathrm{C} 10$. It was clearly associated with the building. It was cut into the bedrock and through an earlier drain $(1008 \mathrm{~A} / 1008 \mathrm{~B})$ and, incidentally, through the inscribed stone at its western end. Three flagstones (506), originally identified in 1991, were augmented by the uncovering of more than a dozen additional flags in subsequent seasons. These ran east-west, past the south wall of $\mathrm{C} 10$, joining with earlier flags 1008A/B (see Phase U1/U2). Later flags 536 (see Phase $\mathrm{Y}$ in $\mathrm{C16}$ ) were subsequently added. The drain had filled with silt 1033. This drain had been constructed in two ways. The west end had been channelled through the bedrock; a particularly clear stretch was where the bedrock had been chiselled away to form a bend at the south of wall (A549) to create a link with the pre-existing 


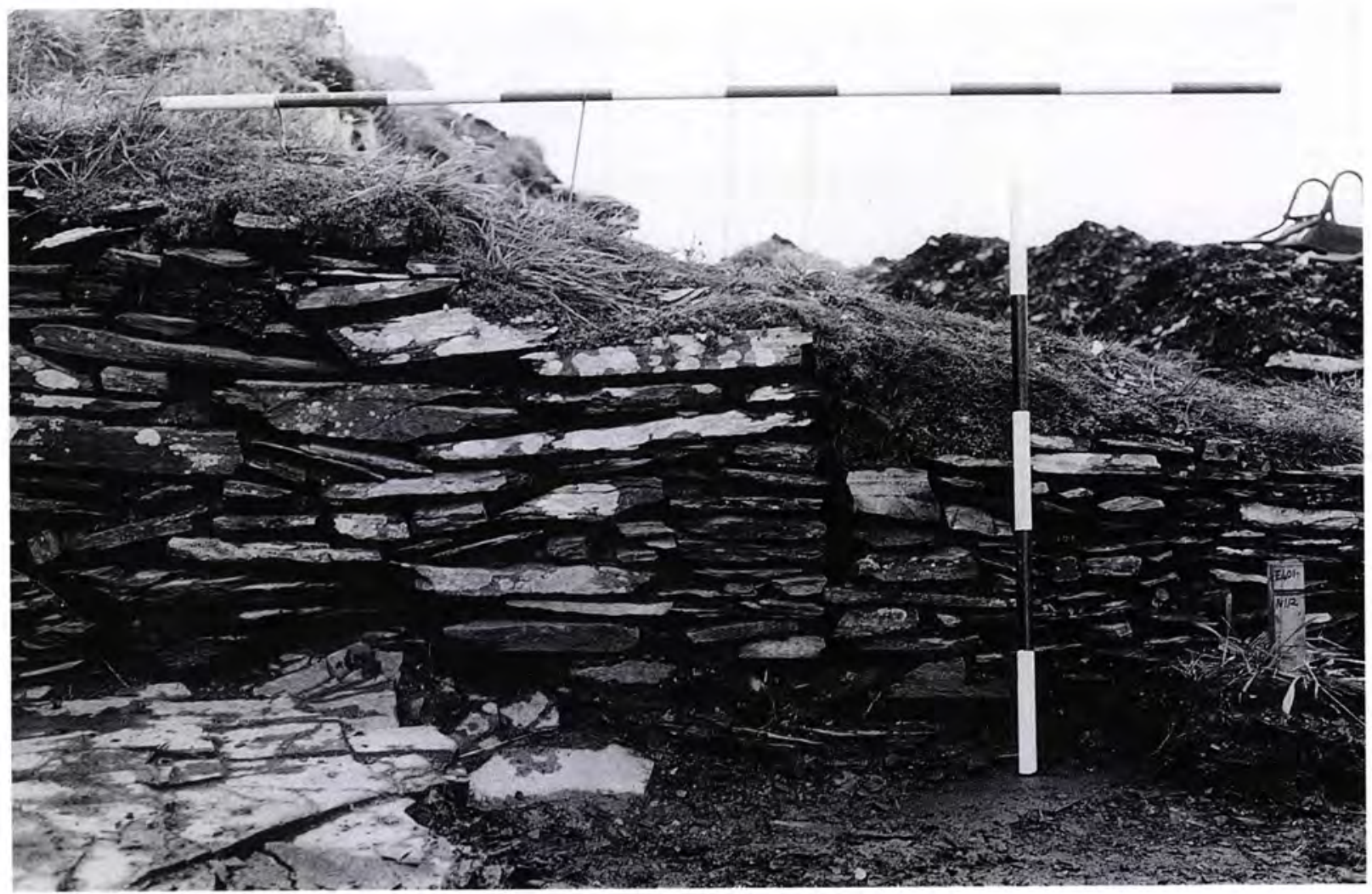

73 Site C building. Wall (556) from the south, showing blocked doorway. Photograph: P G Johnson

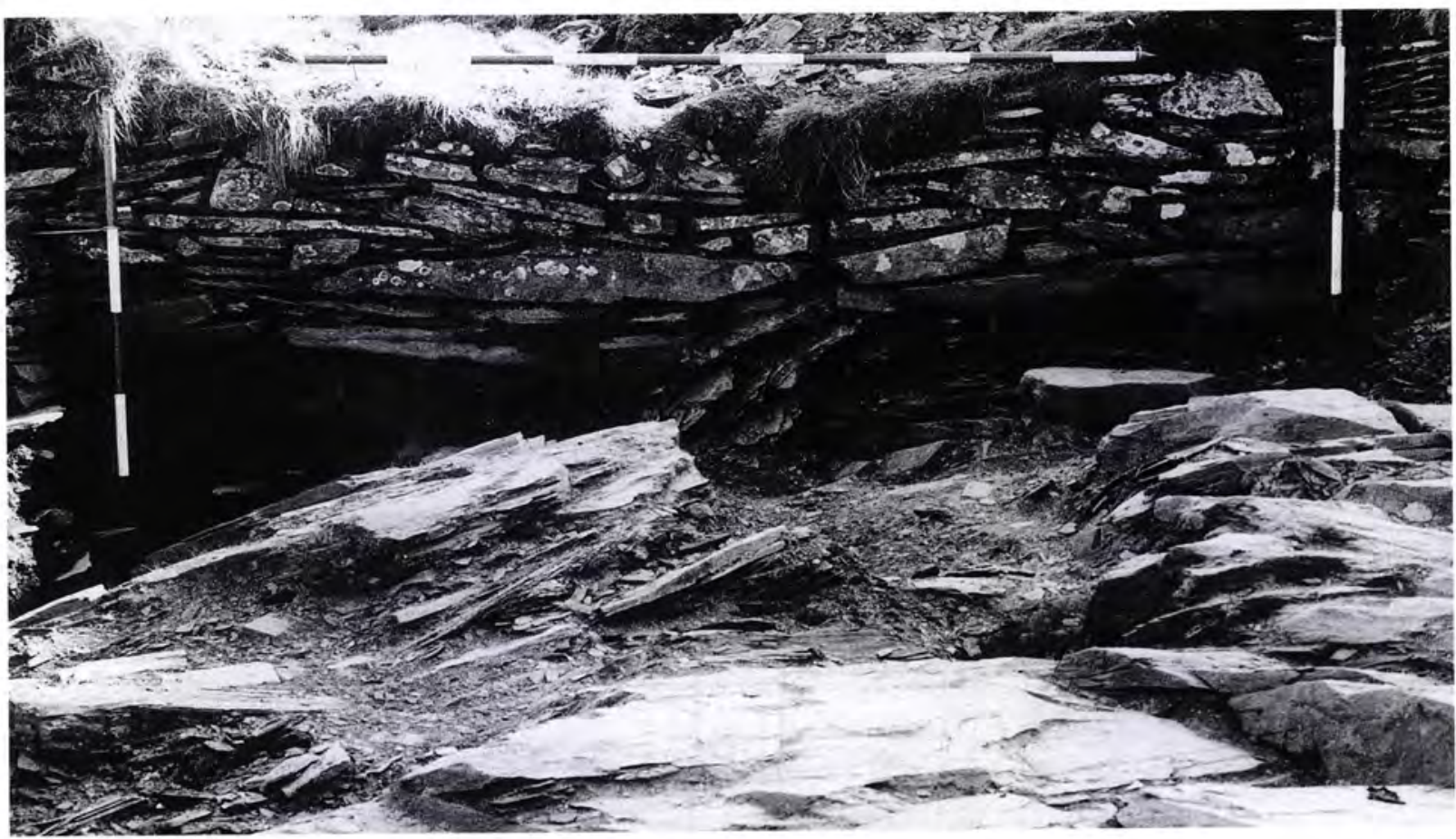

74 Site $C$ building. Wall (556) from the north, showing break in walling. Photograph: R Barrowman 
75 Trench C09. Drain (506).

Photograph: CD Morris

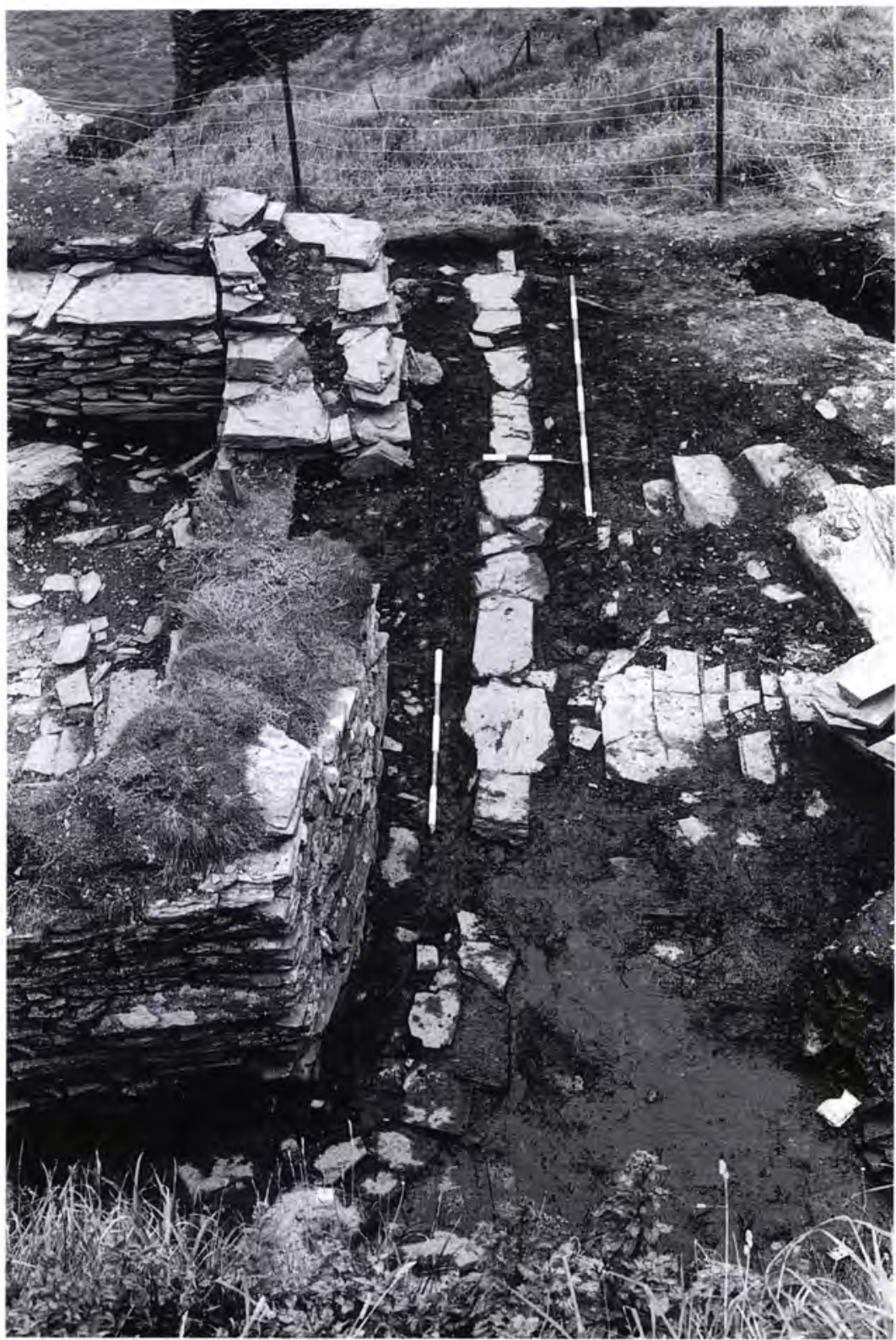

north-south running drain which was capped by 1008A/1008B. The inscribed slate (RF3486) had probably been damaged along its north side (as it lay in the ground) as a result of this event. The capstones (506) of this west end rested directly on either the bedrock or on subrectangular slate uprights (1032) at the south and on 1032 solely at the north. The cut for the drain at the north was 1030 and at the south 1040. Within these cuts for the drain was a clayey loam (1029 at the north and 1039 at the south) packing around uprights 1032. As the drain ran east, the method of construction changed as the bedrock gave way to the shillet build-up that made up the rest of the terrace. In this area a channel had been dug through the underlying deposits and slate blocks placed within to support the sides and to level up the capstones.

\section{Phase V: ARTEFACTS, ECOFACTS AND DATING}

(table 26)

Finds from the building itself were few. 1024 and 703 at the entrance of the building contained a small group of 
Table 26 Site $\mathrm{C}$ building Phase V: contexts and finds

\begin{tabular}{|c|c|c|c|c|}
\hline Phase & Trench & Context & Context description & Finds \\
\hline \multirow[t]{18}{*}{$\begin{array}{l}\text { Phase V: } \\
\text { Site C } \\
\text { building and } \\
\text { associated } \\
\text { features }\end{array}$} & $\mathrm{C} 09$ & 506 & $\begin{array}{l}\text { Over a dozen flags aligned east to west. } \\
\text { West end resting directly on bedrock at } \\
\text { the south and over uprights } 1032 \text { at the } \\
\text { north edge }\end{array}$ & One graffiti slab ( $\mathrm{RF} 3448$ ) \\
\hline & $\mathrm{C} 09$ & 1013 & $\begin{array}{l}\text { Lower two to three courses of dismantled } \\
\text { south-east wall unmortared and } \\
\text { therefore presumed original }\end{array}$ & \\
\hline & $\mathrm{C} 09$ & 1014 & Shillety fill of 1013 & $\begin{array}{l}\text { Large mammal tooth fragments } \\
\text { (RF 3424); charcoal++; occasional } \\
\text { snail shell frags }\end{array}$ \\
\hline & $\mathrm{CO9}$ & 1024 & $\begin{array}{l}\text { Levelling dump of medium-sized } \\
\text { angular stones in a clayey loam matrix } \\
\text { at entrance to } \mathrm{C} 10\end{array}$ & $\begin{array}{l}\text { Two notched slates (RFs } 3475 \text { and } \\
3476 \text { ) and an iron nail head } \\
\text { (RF 3443) }\end{array}$ \\
\hline & $\mathrm{C} 09$ & 1029 & $\begin{array}{l}\text { Loose clayey loam with stones infilling } \\
1030 \text { and abutting } 1032\end{array}$ & $\begin{array}{l}\text { Four conjoining Bi amphora sherds } \\
\text { (RF 3432) and a stone hone (RF } \\
3431 \text { ) }\end{array}$ \\
\hline & $\mathrm{C} 09$ & 1030 & Cut to north of drain 506 , at the east end & \\
\hline & $\mathrm{C} 09$ & 1032 & $\begin{array}{l}\text { Sub-rectangular slate uprights on the } \\
\text { north side of drain capped by } 506 \text {. Fill } \\
\text { of } 1030\end{array}$ & Notched slate (RF 3474) \\
\hline & $\mathrm{C} 09$ & 1033 & Silt fill of drain below 506 & $\begin{array}{l}\text { One Bi amphora sherd (RF 3471). } \\
\text { Charcoal++; oats }\end{array}$ \\
\hline & $\mathrm{COS}$ & 1039 & Loose clayey loam with stones & Charcoal + \\
\hline & $\mathrm{C} 09$ & 1040 & $\begin{array}{l}\text { Cut for uprights } 1032 \text { at south of drain, } \\
\text { cutting bedrock and 1051, and filled } \\
\text { by } 1039\end{array}$ & \\
\hline & $\mathrm{C} 10$ & A512 & $\begin{array}{l}\text { Lower two to three courses of west wall } \\
\text { unmortared and therefore presumed origi }\end{array}$ & \\
\hline & $\mathrm{C} 10$ & A518 & $\begin{array}{l}\text { Lower two to three courses of east walls } \\
\text { unmortared and therefore presumed origi }\end{array}$ & inal \\
\hline & $\mathrm{C} 10 / \mathrm{C} 09$ & A549 & $\begin{array}{l}\text { Lower two to three courses of south-west } \\
\text { wall unmortared and therefore presumed } \\
\text { original }\end{array}$ & \\
\hline & $\mathrm{C} 10$ & 703 & $\begin{array}{l}\text { Dark yellow-brown loamy clay, same } \\
\text { as } 1024\end{array}$ & $\begin{array}{l}\text { Red glass bead (RF 2079). } \\
\text { Charcoal+; barley }\end{array}$ \\
\hline & C10 ext & 712 & $\begin{array}{l}\text { Lower two to three courses of east bench } \\
\text { unmortared and therefore presumed } \\
\text { original }\end{array}$ & \\
\hline & C10 ext & 715 & $\begin{array}{l}\text { Lower two courses of east wall } \\
\text { unmortared and therefore presumed } \\
\text { original }\end{array}$ & \\
\hline & C10/ C11 & A556 & $\begin{array}{l}\text { West half of wall between } \mathrm{C} 10 \text { and } \mathrm{C} 11 \text {, } \\
\text { unmortared and built directly over bedroc }\end{array}$ & \\
\hline & C11 & A557 & $\begin{array}{l}\text { West wall lower courses unmortared and } \\
\text { built directly over bedrock }\end{array}$ & \\
\hline
\end{tabular}




\begin{tabular}{|c|c|c|c|c|}
\hline Phase & Trench & Context & Context description & Finds \\
\hline & $\mathrm{C} 11$ & A558 & \multicolumn{2}{|l|}{$\begin{array}{l}\text { North and east walls unmortared and } \\
\text { directly over bedrock on north side, } \\
\text { abutting the end of east wall of C10 (A518) } \\
\text { thus showing that C11 post-dates C10 }\end{array}$} \\
\hline & $\mathrm{C} 12$ & A559 & $\begin{array}{l}\text { Lower courses of wall unmortared and } \\
\text { built directly over bedrock }\end{array}$ & \\
\hline & $\mathrm{C} 16$ & 506 & $\begin{array}{l}\text { Over a dozen flags aligned east to west. } \\
\text { West end resting directly on bedrock } \\
\text { at the south and over uprights } 1032 \\
\text { at the north edge in C09 }\end{array}$ & $\begin{array}{l}\text { Three sherds of unknown imported } \\
\text { pottery (RF 2352) }\end{array}$ \\
\hline
\end{tabular}

Charcoal fragments $>2 \mathrm{~mm}:+1-10 ;++11-50$

finds: two notched slates, an iron nail-head and a fifth-seventh-century glass bead (RF 2079: see Chapter 10, figure 124). A notched slate was associated with the uprights of the drain (1032); a Bi amphora sherd and a hone or whetstone (RF 3431: see Chapter 10, figure 115) were found in the drain packing (1029). A sherd of $\mathrm{Bi}$ amphora was found within the ecofactually rich primary silt fill of the drain (1033). The fill contained charcoal and oats. Otherwise, charcoal was found (together with bariey) in 703 in another clayey loam, 1039, and, along with unidentifiable large mammal tooth fragments, in the fill (1014) of the lowest two to three courses of the dismantled south-east wall.

One of the more interesting finds from this phase is the piece of stone that exhibits graffiti-marks, RF 3448 (from C09, 506). This is a large, slightly shaped but irregular slab of slate. It has rough surfaces and a number of natural flaws. There are, however, traces of a few disparate linear marks, quite deep in places, which may have been incised deliberately. They have no obvious form and, although there are a small number of lighter incisions on the same face, it seems most likely that these were accidental rather than intentional.

\section{PHASE W: SCREE-TIPS AND COLLAPSE OF BUILDING}

\section{(figure 76)}

This phase, comprising scree-tips and the collapse of the building, represents a period only visible archaeologically to the west and south, outside the building, as the deposits inside the building were removed in the 1930s. After the construction of the drain for the building in Phase V, clayey deposits accumulated in that area and all around the building. A considerable depth accumulated with finds that often have the appearance of having been redeposited, for instance, 534, present along the length of $\mathrm{C} 16$ and abutted by 535, a similar layer. Above these layers were shillet and soil layers 505 and 503 . These layers also covered almost the entire area of $\mathrm{C} 09$ and to the west had built up to a considerable depth as deposits had slipped from the Upper Terrace. Below 505 was a clayey loam 508. On excavation in 1998 this layer was noted over most of the area to the south of wall 549, and overlay 1006 of Phase U2 in the area over the capstones 1008B and also the uprights 1032 for the capstones 506 of Phase $\mathrm{V}$ (see figure 72). A compact clayey earth with charcoal (1031) had also accumulated against the uprights (1032) of Phase $\mathrm{V}$ during this phase.

Although it is possible that some material from the fill of the drain may have come in later than its use, either from 'wash-through' or through the drain being open at some period, the excavators were careful to take samples from the lower rather than upper deposits within the drain fill. However, a distinction has been made between the primary silt fill 1033 below 506 in C09, Phase V, and 1022, the fill of the north-south drain below 1008 of Phase U. The latter has been placed in Phase $\mathrm{W}$ because of the possibility of later contamination as water was still passing through the drain at the time of excavation.

PHASE W: ARTEFACTS, ECOFACTS AND DATING (table 27)

The finds from this phase include many pieces of imported pottery (Bi, Bii and $\mathrm{Bv}$ amphorae and Coarsewares) but there is no medieval pottery, which suggests both that there was little activity on this part of 


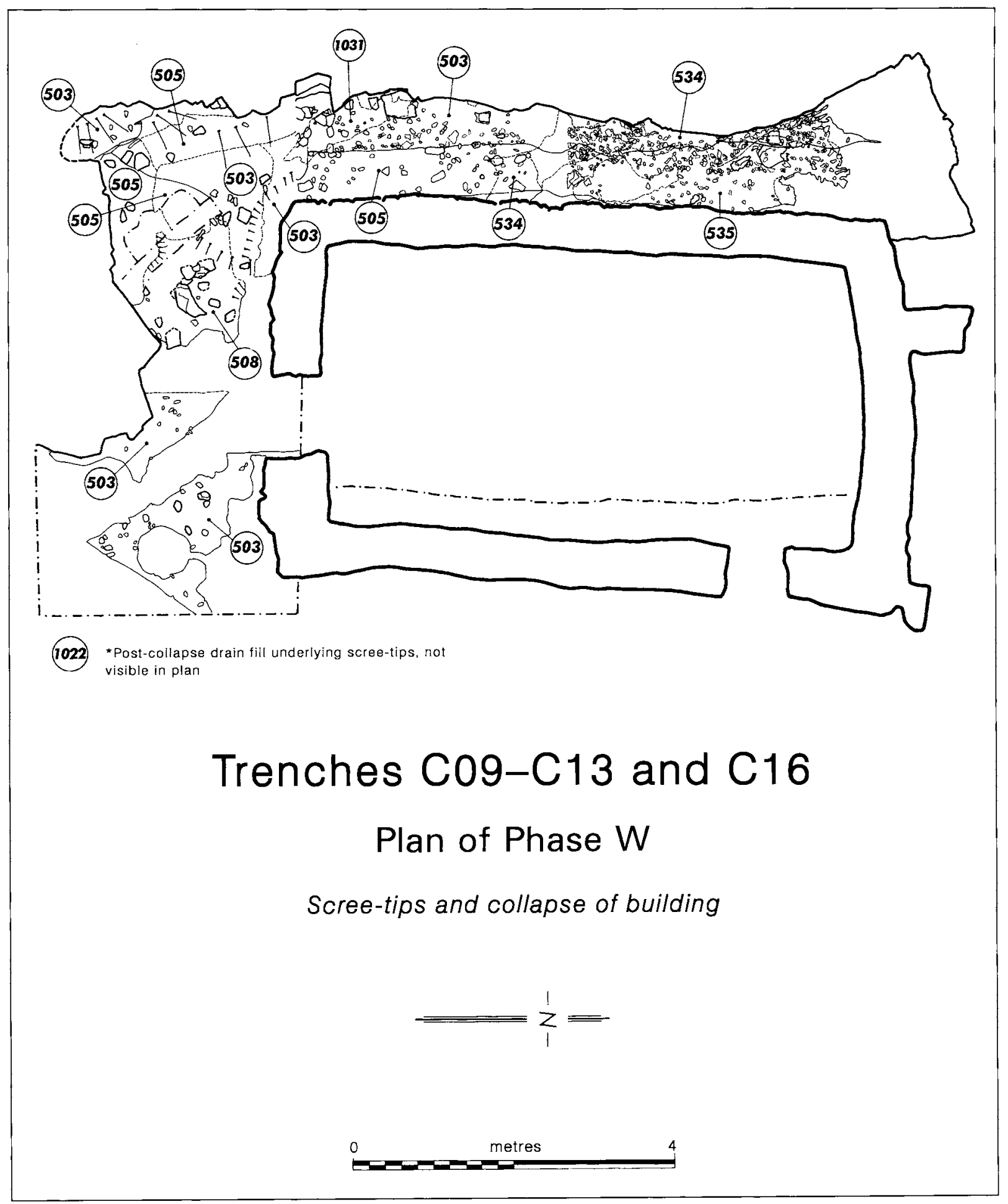

76 Site C building. Plan of Phase W. Drawing: L McEwan 
Table 27 Site $\mathrm{C}$ building Phase W: contexts and finds

\begin{tabular}{llll}
\hline Phase & Trench & Context & Context description \\
\hline $\begin{array}{l}\text { Phase W: C09 } \\
\text { scree-tips and }\end{array}$ & 503 & $\begin{array}{l}\text { Medium brown loam with shillet } \\
\text { slipped from terrace above }\end{array}$ \\
$\begin{array}{l}\text { collapse of } \\
\text { building }\end{array}$ & &
\end{tabular}

Finds

138 sherds of imported pottery, including $65 \mathrm{Bi}$ amphora sherds (eg RF 2130, Bi amphora handle), 20 Bii (eg RF 1116), 26 Bv (eg RFs 1124 and $2666, \mathrm{Bv}$ amphora-stopper), one ARSW (RF 2131), one Coarseware Fabric 1 (RF 2132), two Coarseware Fabric 5 (eg RF 2347) and 23 unknown imported (eg RF 2650). Also three water-worn pebbles (RFs 1123,2114 and 2124), two perforated slates (eg RF 1127), two notched slates (eg RF 1130), two slate discs (eg RF 2123), metallurgical slag (RF 1121) and a fragment of medium mammal phalanx (RF 2695). Charcoalt; unidentifiable plant seed C09 $505 \quad$ Medium brown loam and shillet Eighty-three sherds of abraded imported pottery, including $46 \mathrm{Bi}$ amphora sherds (eg RF $2670-\mathrm{Bi}$ rim), 12 Bii (eg RF 3436), six Bv (eg RF 3414), 18 unknown (eg RF 1138) and one PRSW (RF 2679). Eleven finds of unidentifiable large and medium mammal bone and tooth fragments (eg RF 3419), two pebbles (RFs 1129 and 1137) and a slate disc (RF 3405). Charcoal++; oats

C09 $508 \quad$ Brown clayey loam with stones under Seven Bi amphora sherds (RFs 2100, 2101, 3381, 3386, 3387 and 3427)

C09 $1022 \quad$ Silt fill of drain below 1008A and 1008B

Charcoal++++; rich in plant macrofossils (table 28)

C09 1031 Greasy, compact clayey earth with Charcoal+; barley

C16 $503 \quad$ Medium brown loam and shillet

A cache of 19 flat pebbles, possibly gaming pieces (RF 2311), a piece of unidentifiable mammal bone (RF 2364) and a spindle whorl (RF 2365)

C16 505 Medium to dark brown clayey loam A water-worn pebble (RF 2605). with angular shillet overlying 534 and 535

Charcoal+ 


\begin{tabular}{lllll}
\hline Phase & Trench & Context & Context description & Finds \\
\hline C16 & 534 & $\begin{array}{l}\text { Medium to dark brown clayey loam } \\
\text { with stones and charcoal }\end{array}$ & $\begin{array}{l}\text { Four Bi amphora sherds (RF 2607) } \\
\text { and one Bv (RF 2618), one } \\
\text { unknown (RF 2608) and a piece of } \\
\text { worked flint (RF 2609) } \\
\text { Three Bv amphora sherds (RFs 2610 } \\
\text { and 2611), three unknown (RFs }\end{array}$ \\
& 535 & $\begin{array}{l}\text { Medium to dark brown clayey loam } \\
\text { with stones }\end{array}$ & $\begin{array}{l}\text { 2613 and 2615) and a piece of glass } \\
\text { (Vessel 17, RF 2619). Oats; medick/ } \\
\text { clover }\end{array}$ \\
\end{tabular}

Charcoal fragments $>2 \mathrm{~mm}:+1-10 ;++11-50 ;+++51-100 ;++++>100$

the site at this time and that this was also true of the terrace above, from which it would have slipped. Finds from C16 also include a piece of worked flint (RF 2609: see Chapter 10, figure 113) and a piece of glass identified as mid-Saxon in origin (Vessel 17: see Chapter 10).

Finds recovered from 503 in Trench $\mathrm{C} 09$ included imported fifth- to seventh-century pottery, including a sherd of ARSW, Bi (eg handle sherd RF 2130: see Chapter 10 , figure 131), Bii, $\mathrm{Bv}$, including a $\mathrm{Bv}$ amphorastopper (RF 2666: see Chapter 10, figure 114) and Fabric 1 and Fabric 5 Coarsewares. Also found were waterworn pebbles, perforated slates, slate discs (eg RF 2123: see Chapter 10, figure 113), notched slates, metallurgical slag and a piece of mammal phalanx bone. Finds from the same layer in Trench C16 included a cache of flat pebbles, possibly gaming pieces, a piece of unidentifiable mammal bone and a spindle whorl (RF 2365: see Chapter 10, figure 113).

Layer 505 in $\mathrm{C} 09$ and $\mathrm{C} 16$ contained a mix of redeposited finds, including abraded imported pottery PRSW, Bi (such as rim RF 2670: see Chapter 10, figure 131), Bii and Bv amphorae, and unidentifiable mammal bone and tooth fragments, pebbles and a slate disc. Layer 508 yielded sherds of Bi pottery.

Context 1022 (the fill of the primary north-south drain in C09) is the only one from Tintagel to preserve 'waterlogged' plant macrofossils; all the others survived because they are charred. The species identified from the drain are listed in table 28. However, the waterlogged preservation is patchy; plant remains did not survive in all the samples taken from this context. It was hoped that the drain fill would preserve food remains but, as table 28 shows, the plants derive from a range of open habitats, particularly rough ground or grassland in coastal locations. It was not easy to distinguish archaeological from modern material. The seeds of Silene sp. (probably including S. uniflora, sea campion, and S. vulgaris, bladder campion, which grow on the Island today) are common modern contaminants of the charred macrofossil assemblages. Some scurvy grass (Cochlearia sp.), wild carrot (Daucus carota) and rush (Juncus sp.) seeds were also omitted from the list of macrofossils because partial survival of the starchy seed contents suggested that they were probably modern.

Ox-eye daisy (Leucanthemum vulgare), scurvy grass, mouse ear (Cerastium fontanum), prickly sow-thistle (Sonchus asper), pearlwort (Sagina sp.) orache (Atriplex sp.) wild carrot and grasses could all have grown on the Island as they are all typical of grassland or open habitats, including coastal locations. The plant that has a specifically coastal preference is sea aster (Aster tripolium), which grows on coastal cliffs (as at Tintagel) and salt marshes. A possible damp ground or marsh habitat is also hinted at by the presence of Hemp agrimony (Eupatorium cannabinum) which is usually found in damp soils, but will also tolerate grassland and rough ground. Rushes (Juncus sp.) tolerate a range of generally damp conditions. Two caryopses of sweet grass (Glyceria sp.) were also tentatively identified. This species of grass grows in standing water or marsh. Both rushes and sweet grass could have grown around the springs on the Island.

The plant macrofossils in the fill of the drain seem, therefore, to have accumulated from a range of habitats (open habitats, damp or freshwater marsh habitats and sea coastal habitats), all of which could have been found at Tintagel. How they got into the drain is not certain. If it was uncapped at any time they could have blown in or, 
Table 28 Trench C09: waterlogged plant macrofossils from drain-fill context 1022

\begin{tabular}{|c|c|c|c|c|}
\hline Taxon & $\begin{array}{l}\text { Common } \\
\text { name }\end{array}$ & $\begin{array}{l}\text { Trench C09 } \\
\text { Phase W } \\
\text { Context } 1022 \\
\text { Item }\end{array}$ & No. of items & Habitat \\
\hline Atriplexsp. & orache & seed & 3 & $\begin{array}{l}\text { various, but especially open disturbed } \\
\text { ground and coastal habitats }\end{array}$ \\
\hline Cerastium fontanum & mouse ear & seed & 1 & grasslands, open and cultivated ground \\
\hline Sagina sp. & pearlwort & seed & 8 & $\begin{array}{l}\text { various, often open habitats with bare } \\
\text { ground }\end{array}$ \\
\hline Silene sp. & campion & seed & 69 & $\begin{array}{l}\text { various, S. maritima on cliffs and coastal } \\
\text { habitats }\end{array}$ \\
\hline Viola sp. & violet, pansy & seed & 1 & various \\
\hline Cochlearia sp. & scurvy grass & seed & 7 & various, but $C$. officinalis on cliffs by the sea \\
\hline Rumex sp. & sorrel & achene & 1 & various \\
\hline Daucus carota & wild carrot & mericarp & 26 & $\begin{array}{l}\text { grassy and rough ground, often near the } \\
\text { sea }\end{array}$ \\
\hline Sonchus asper & $\begin{array}{l}\text { prickly sow- } \\
\text { thistle }\end{array}$ & achene & 1 & waste and cultivated ground and grassland \\
\hline Aster tripolium & sea aster & achene & 6 & salt marshes, coastal cliffs \\
\hline Leucanthemum vulgare & ox-eye daisy & achene & 3 & grassy places \\
\hline $\begin{array}{l}\text { Eupatorium } \\
\text { cannabinum }\end{array}$ & hemp agrimony & achene & 2 & $\begin{array}{l}\text { damp places, occasionally dry grassland } \\
\text { and rough ground }\end{array}$ \\
\hline Juncus sp. (p). & rush & seed & 23 & various \\
\hline cf. Glyceria sp. & sweet grass & caryopsis & 2 & aquatic, marsh \\
\hline Poaceae & grass family & caryopsis & 13 & various \\
\hline \multicolumn{2}{|l|}{ Unidentified fruits / seeds } & & 10 & \\
\hline \multicolumn{2}{|l|}{ Total (excl fragments) } & & 176 & \\
\hline \multicolumn{2}{|l|}{ Items per litre soil } & & 16.9 & \\
\hline
\end{tabular}

if it was always sealed, washed through with the water and silt.

Otherwise, ecofactual material in C09 included a number of pieces of animal bone; a significant amount of charcoal from both 503 and 505; charcoal and barley from a clayey earth (1031) abutting the uprights of the Phase $\mathrm{V}$ drain; oats and medick/clover from 535 and some oats from 505.

\section{Phase X: RADFORd's TRENCHeS AND BACKFILL (figure 77)}

Radford made a few short notes in a small notebook on his excavations at Tintagel. For Site $C$ he wrote: 'Tintagel 1936. Site C was investigated by means of trial trenches which were not carried below the ground level of the cells.'1 The assessment of Radford's work in and around the Site $C$ building suggests that he emptied the interior of the building completely, and removed all archaeology down to the bedrock at the west side. His work seems to have stopped at the southern extremity leaving the south-west corner of the terrace (the south sector of C16 and the west part of C09) untouched. To the south east a dump of slates (1017) in soil (1027), and slates (1015), apparently left on the top edge of Radford's trench 1007 in $\mathrm{C} 09$ by the workmen, indicates material rejected by them at the time. The Radford trench 1007 was backfilled in one event 1004. 


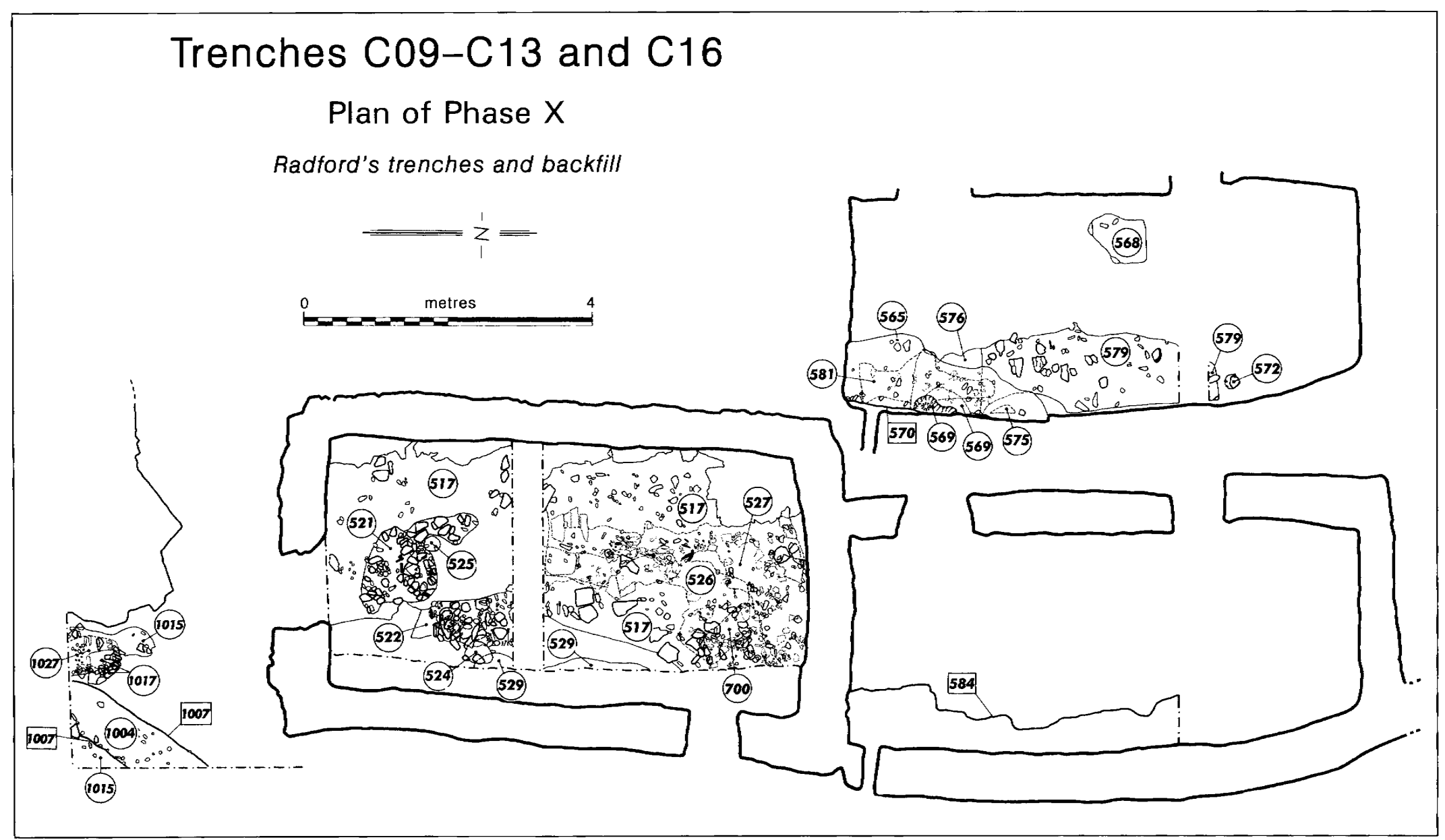

77 Site C building. Plan of Phase X. Drawing: L McEwan 
Within trench C11, a narrow trench had been cut during Radford's work, along the east wall of the room. This (584) had been cut into the Phase $T$ deposits and overlay the burnt feature 582 and soil make-up 583 below it. The cut followed the natural where it fell away sharply at the eastern edge of the terrace, and was much wider at the south end, where it was clearly seen in section, $1.2 \mathrm{~m}$ wide, below the south wall of $\mathrm{C} 11$ (see figures 64 and 65). At the northern extent, the cut curved towards the east wall, falling short of the north-east corner of the room. The excavation of C11 extension demonstrated that Radford's excavators had also followed the inner face of wall 558 of Phase $\mathrm{V}$ downwards. It was initially thought that this cut was the natural edge of the terrace which had been infilled to enlarge the terrace prior to the construction of the Site $C$ building.

However, excavation of the fills of 584 suggested a more recent deposition. The earliest of these (579) and 572 infilled the northern half of the cut. Lying in the bottom of the cut, at the southern end were silty clays 581 and 576, sealed by 565 and 575, a burnt clay patch within 565. The flecks and lumps of charcoal and burnt clay recovered from the fill layers of 584 , and the fact that the trench overlies an earlier hearth, may suggest that deposits associated with the burnt feature from Phase $\mathrm{T}$ (582) had been redeposited as backfill. Cut 570 with fill 569 was found to be a modern feature associated with backfilling. Immediately to the east of the west wall of $\mathrm{C} 11$ directly overlying the bedrock, an isolated, compact patch of dark brown clayey loam, charcoal and scree (568) containing forty-one sherds of medieval pottery had been redeposited during Radford's excavations.

No direct evidence of Radford's excavations was noted in trenches $\mathrm{C} 12, \mathrm{C} 13$ or $\mathrm{C} 16$, and no sign of a cut resulting from Radford's excavations was noted in C10, despite excavation of the majority of the trench down to bedrock. However, groups of pick-marked stones (521 and 522: RFs 2075 and 2045 respectively) obviously indicated 1930s activity, as did two spreads of shillet ( 526 and 527), which covered the bedrock in the north of the area and contained two pick-marked slates (RFs 2071 and 2072). Apart from a group of flat slates (700) which abutted the east bench, the majority of the trench was covered by soil and stones (517). Lying within it were further pick-marked stones (521), a patch of charcoal and burnt soil (524), a dump of ash (525) and a patch of redeposited clay (529) lying against the east bench.

\section{PHASE X: ARTEFACTS, ECOFACTS AND DATING}

(table 29)

Medieval Chert-tempered ware (SO) (RFs 1842 and 1847: SO2, see Chapter 10, figure 137) and some charcoal were found within one of the fills (579) of the cut 584 in C11. Decayed lumps of large mammal bone and teeth were recovered from another fill 581, together with Bi imported pottery, charcoal and a piece of metal foil, probably modern in date. Two notched, probably pickmarked, slates were recovered from 576, together with a quartz pebble, lumps of charcoal and oats. Lumps of redeposited charcoal; an iron nail; a sherd of Bi imported pottery; notched slates and a perforated slate (RF 1835: see Chapter 10, figure 115) were recovered within 565, and attest to the disturbed nature of this deposit. 569 produced charcoal, oats and wheat. The medieval pottery in patch 568 was identified as forty-one sherds from a thirteenth-century ceramic vessel of $\mathrm{SO}$ (SO2: figure 137), five sherds of another (SO3: RF 1822) and eighteen sherds of Stuffle-type ware (SA: RF 6094).

In $\mathrm{C} 10$ a mix of finds was recorded from 517, including imported Bi, Bii, Biv (rim-sherd RF 2070: figure 127), and Bv pottery, together with two Fabric 1 Coarsewares. Worked slates, probably pick-marked and a piece of modern metal foil were also found. In addition, there were two sixth-/seventh-century glass vessel fragments (Vessels 12 and 14: see Chapter 10).

Imported pottery sherds were also recovered from Radford's backfill 1004 and 1017/1027 in C09.

In summary, this phase has a mix of pottery ranging from imported amphora sherds to a significant amount of medieval pottery. This represents material from the Radford excavation that was not collected. Its original context on excavation is of course unknown. We can only speculate that it does not come from the building or its immediate collapse, since these contexts have been sampled outside the building and have produced no medieval pottery in a stratified context.

\section{Phase Y: Ministry of Works LeVelling/ RECONSTRUCTION OF SITE C BUILDING (figure 78)}

This phase provided evidence of reconstruction and continued maintenance work by the MoW between the 1930s and 1950s. There was clear evidence of significant reconstruction, rebuilding and adding of stone courses to the walls of the building, as well as re-laying and/or addition to some of the stones of the drain.

The reconstructed upper courses of the walls of C10 comprise B512 to the west, $\mathrm{B} 518$ to the east and B549 to 
Table 29 Site C building Phase X: contexts and finds

\begin{tabular}{|c|c|c|c|c|}
\hline Phase & Trench & Context & Context description & Finds \\
\hline \multirow[t]{17}{*}{$\begin{array}{l}\text { Phase X: } \\
\text { Radford's } \\
\text { trenches and } \\
\text { backfill }\end{array}$} & $\mathrm{C} 09$ & 1004 & Backfill in Radford's trench 1007 & $\begin{array}{l}\text { Eight redeposited imported sherds: } \\
\text { one ARSW (RF 3355), three Bi } \\
\text { amphora (eg RF 3358), three Bii (eg } \\
\text { RF 3390) and one Bv (RF 3392) }\end{array}$ \\
\hline & $\mathrm{C} 09$ & 1007 & Radford's trench cut & \\
\hline & $\mathrm{C} 09$ & 1015 & $\begin{array}{l}\text { Thin slate fragments in a loose loam } \\
\text { matrix overlying } 1017 \text { and } 1027\end{array}$ & \\
\hline & $\mathrm{CO9}$ & 1017 & Large angular slates in 1027 & \\
\hline & $\mathrm{C} 09$ & 1027 & Moderately compact clayey loam & $\begin{array}{l}\text { Perforated slate (RF 3490) and one } \\
\text { Bii amphora sherd (RF 3491). } \\
\text { Charcoal+++ }\end{array}$ \\
\hline & $\mathrm{C} 10$ & 517 & $\begin{array}{l}\text { Soil and stones with mixed finds } \\
\text { containing pick-marked stones } 521 \text {, } \\
\text { patch of charcoal } 524 \text { and dump of } \\
\text { ash } 525\end{array}$ & $\begin{array}{l}\text { Twenty imported sherds: eight Bi } \\
\text { amphora (eg RF 1439), five Bii (eg } \\
\text { RF 2063), one Biv rim-sherd (RF } \\
\text { 2070), one Bv (RF 2067), two } \\
\text { Coarseware Fabric 1 (eg RF 1438) and } \\
\text { three unknown. Six worked slates (eg } \\
\text { RFs } 2053 \text { and 2054), a piece of tin-foil } \\
\text { (RF 2078), two glass vessel fragments } \\
\text { (Vessel 12, RF 2058, and Vessel 14, RF } \\
\text { 2076) and a stone cobble (RF 2065) }\end{array}$ \\
\hline & $\mathrm{C} 10$ & 521 & Group of pick-marked slates & RF 2075 \\
\hline & $\mathrm{C} 10$ & 522 & Group of pick-marked slates & RF 2045 \\
\hline & $\mathrm{C} 10$ & 524 & Patch of charcoal and burnt soil & Charcoal+; oats; barley (1 x hulled) \\
\hline & $\mathrm{C} 10$ & 525 & Dump of ash & $\begin{array}{l}\text { Charcoal+++; oats; barley; hazelnut } \\
\text { shell frag }\end{array}$ \\
\hline & $\mathrm{C} 10$ & 526 & Spread of shillet & $\begin{array}{l}\text { Two notched slates (RFs } 2071 \text { and } \\
\text { 2072). Charcoal+; oats }\end{array}$ \\
\hline & $\mathrm{C} 10$ & 527 & Spread of shillet & Charcoal ++ \\
\hline & $\mathrm{C} 10$ & 529 & $\begin{array}{l}\text { Patch of redeposited dark brown clay } \\
\text { lying against east bench }\end{array}$ & \\
\hline & $\mathrm{C} 10$ & 700 & Group of flat slates & \\
\hline & $\mathrm{Cl1}$ & 565 & $\begin{array}{l}\text { Thick layer of dark reddish-brown firm } \\
\text { clay with occasional charcoal flecks } \\
\text { sealing } 576\end{array}$ & $\begin{array}{l}\text { One Bi amphora sherd (RF 1828), } \\
\text { two notched slates (RFs } 1824 \text { and } \\
\text { 1825), one iron nail (RF 6093), two } \\
\text { pebbles (RFs } 1823 \text { and 1826) and a } \\
\text { perforated slate (RF 1835). Charcoal } \\
\text { (RFs } 1816 \text { and 1836), } \\
\text { charcoal+++(+), barley (hulled), } \\
\text { and bell heather leaf }\end{array}$ \\
\hline & $\mathrm{C} 11$ & 568 & $\begin{array}{l}\text { Compact patch of dark brown clayey } \\
\text { loam, charcoal and scree adjacent to } \\
\text { west wall }\end{array}$ & $\begin{array}{l}\text { Forty-one sherds of a 13th-century } \\
\text { pot (SO2: RFs 1811, 1817-1820), } \\
\text { five sherds of another (SO3: RF } \\
\text { 1822) and } 18 \text { sherds of medieval } \\
\text { pottery SA (RF 6094). Charcoal+++ }\end{array}$ \\
\hline & $\mathrm{C} 11$ & 569 & Fill of 570 & $\begin{array}{l}\text { Charcoal++; oats; wheat; } \\
\text { indeterminate cereal }\end{array}$ \\
\hline
\end{tabular}




\begin{tabular}{|c|c|c|c|c|}
\hline Phase & Trench & Context & Context description & Finds \\
\hline & $\mathrm{Cll}$ & 570 & $\begin{array}{l}\text { Modern cut, probably associated with } \\
\text { the consolidation or backfilling work } \\
\text { of the } 1930 \mathrm{~s}\end{array}$ & \\
\hline & $\mathrm{C} 11$ & 572 & Group of stones within 579 & Charcoalt \\
\hline & $\mathrm{C} 11$ & 575 & Burnt clay within 565 & Charcoal +++ ; goosefoot family \\
\hline & $\mathrm{C} 11$ & 576 & $\begin{array}{l}\text { Dark brown silty clay with shillet } \\
\text { overlying } 581\end{array}$ & $\begin{array}{l}\text { Two notched slates (RFs } 1831 \text { and } \\
\text { 1832), a quartz pebble (RF 1837) and } \\
\text { two lumps of charcoal (RFs } 1833 \text { and } \\
\text { 1838). Charcoal++; oats }\end{array}$ \\
\hline & $\mathrm{C} 11$ & 579 & $\begin{array}{l}\text { Shillet and stones in a dark brown } \\
\text { clayey loam, earliest fill layer in cut } 584\end{array}$ & $\begin{array}{l}\text { Two medieval SO2 sherds (RFs } 1842 \\
\text { and 1847). Charcoal+ }\end{array}$ \\
\hline & $\mathrm{C} 11$ & 581 & Strong brown plastic silty clay & $\begin{array}{l}\text { One Bi amphora sherd (RF 1846) } \\
\text { and a piece of metal foil (RF 1829). } \\
\text { Three very decayed finds of } \\
\text { unidentifiable mammal bone and } \\
\text { teeth fragments (RFs } 1844,1845 \text { and } \\
\text { 1848). Charcoal+ }\end{array}$ \\
\hline & $\mathrm{C} 11$ & 584 & $\begin{array}{l}\text { Narrow trench cut along east wall of } \\
\text { room, following natural at edge of } \\
\text { terrace and cutting Phase } T \text { deposits above }\end{array}$ & \\
\hline
\end{tabular}

Charcoal fragments $>2 \mathrm{~mm}:+1-10 ;++11-50 ;+++51-100 ;++++>100$

the south west; those of $\mathrm{C} 11$ are B556, B557 and B558; and the walls of $\mathrm{C} 12$ were $\mathrm{B} 559$. All the reconstructed walling is built from thin slates, bonded with mortar and concrete (see, for instance, figures 73 and 74). The eastern half of wall B556 in the south-east corner of C11 appears to have been completely rebuilt from scratch. The remains of the south-east wall of $\mathrm{ClO}$ was considerably augmented with several courses of stone added to the original stones 1013. These later stones 1000 were set in mortar 1002, and had a shillety fill 1001 . Occasional features were added (such as a recess, 714, in the east wall), some parts of the walls were totally rebuilt, and other parts were bonded with mortar and concrete, perhaps at two separate periods. The east bench (513), for instance, was clearly reconstructed in the 1950s (as evidenced by the presence of a 1951 shilling), and the east wall 518, like this bench, contained concrete and mortar. Also, two pebble-and-concrete bases (1003 and 1041) for the erection of sign-boards were put in, as well as a path of fragments of blue slate (504) to the entrance and around the back (west) of the building.

Blanket layers of levelling (511, 514 and 515) were spread over the interior of $\mathrm{C} 10$. These layers were used in the consolidation of the interior of the building, as substantiated by the recovery of a mixture of abraded medieval and fifth- to seventh-century imported wares. A damper context (519) running alongside the west wall produced an interesting ecofactual assemblage, as discussed below. The interior of C11 was infilled with a succession of layers of scree and loam backfill (555, $552 / 554$ and 551). The interior of $\mathrm{C} 12$ was first covered by clayey loams 602 and 604 . A general blanket layer of shillet and scree (601) was then spread over the room. A patch of clayey loam 561 infilling the bedrockcut steps was excavated in Trench C13, contemporary with 560 , a very compact layer that resembled an old turf surface. Within C16, contemporary with the path is an area of disturbance 532, between the path and the west wall of the building. Two large rectangular flagstones (536) adjacent to the modern path in C16 were clearly re-set during maintenance work. Probably contemporary with the re-setting of this part of the drain was silt 539 . This was probably bonding for the flags either to prevent seepage from the drain or to help set the flags in position. 


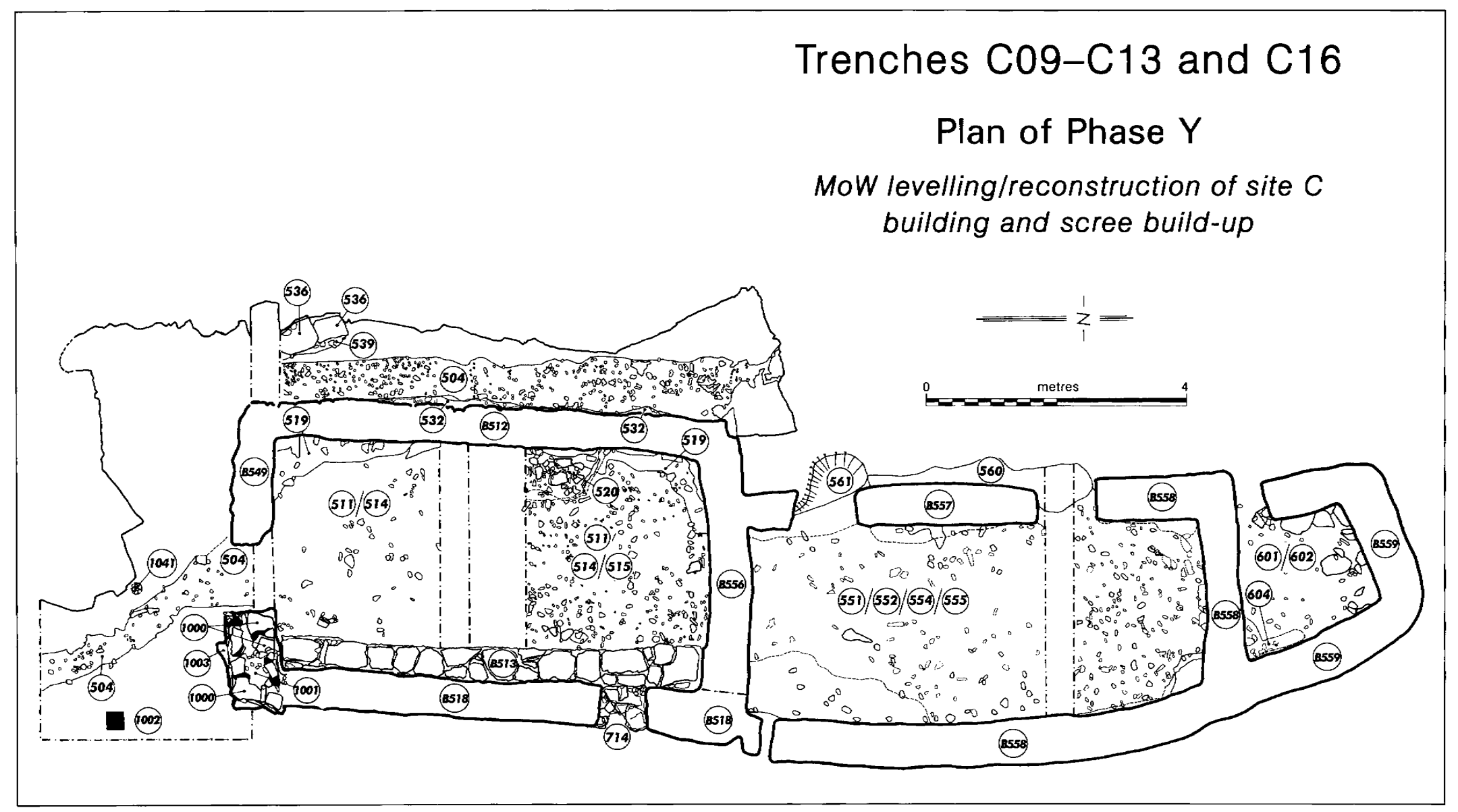

78 Site C building. Plan of Phase Y. Drawing: L McEwan 
Table 30 Site $\mathrm{C}$ building Phase $\mathrm{Y}$ : contexts and finds

\begin{tabular}{|c|c|c|c|c|}
\hline Phase & Trench & Context & Context description & Finds \\
\hline \multirow[t]{6}{*}{$\begin{array}{l}\text { Phase Y: } \\
\text { MoW } \\
\text { levelling/ } \\
\text { reconstructic } \\
\text { of Site C } \\
\text { building, } \\
\text { and scree } \\
\text { build-up }\end{array}$} & $\mathrm{C} 09$ & 504 & $\begin{array}{l}\text { Firmly compacted path of blue slate } \\
\text { fragments }\end{array}$ & $\begin{array}{l}\text { Twenty abraded imported sherds: } \\
\text { seven Bi amphora (eg RF 2106), five } \\
\text { Bii (eg RF 2107), one Bv (RF 2651) } \\
\text { and one PRSW (RF 2357), five } \\
\text { Coarseware Fabric 1 (eg RF 2119) } \\
\text { and one unknown (RF 2358). Also a } \\
\text { pebble (RF 1115) }\end{array}$ \\
\hline & $\mathrm{CO9}$ & 1003 & $\begin{array}{l}\text { Concrete plug, remains of a base for an } \\
\text { interpretation board }\end{array}$ & \\
\hline & $\mathrm{CO9}$ & 1041 & $\begin{array}{l}\text { Discrete dump of pebbles set in concrete, } \\
\text { associated with consolidation work }\end{array}$ & \\
\hline & $\mathrm{C} 10$ & 511 & $\begin{array}{l}\text { Blanket layer of levelling scree make-up } \\
\text { spread over entire trench containing an } \\
\text { abraded mixture of pottery }\end{array}$ & $\begin{array}{l}\text { Fifty sherds of imported pottery, } \\
\text { including one PRSW (RF 1409), five } \\
\text { Bi amphora (eg RF 1972), nine Bii } \\
\text { (eg RF 1441), one Biv (RF 1444), } \\
\text { three Bv (RF 1411), eight Coarseware } \\
\text { Fabric 1 (eg RF 1406), and 23 } \\
\text { unknown fabric (eg RF 1989). Three } \\
\text { sherds of medieval pottery (SO1: RFs } \\
\text { 1966, } 1968 \text { and 1978), four notched } \\
\text { slates (RFs 1942, 1961, } 1981 \text { and } \\
\text { 1987), a piece of iron (RF 1944), a } \\
\text { piece of modern glass (RF 1980), a } \\
\text { fragment of modern Galliformes } \\
\text { (chicken?) humerus (RF 1449), } \\
\text { concrete (RFs 1957 and 1963) and } \\
\text { five pebbles (eg RF 1960). Charcoal+ }\end{array}$ \\
\hline & $\mathrm{C} 10$ & B512 & $\begin{array}{l}\text { Reconstructed upper courses of west } \\
\text { wall of thin slates, mortar and concrete }\end{array}$ & \\
\hline & $\mathrm{C} 10$ & 514 & $\begin{array}{l}\text { Blanket layer of levelling scree con- } \\
\text { taining an abraded mixture of pottery }\end{array}$ & $\begin{array}{l}\text { Twenty-three imported sherds, } \\
\text { including eight Bi amphora (eg RF } \\
\text { 1996), three Bii (eg RF 1993), one } \\
\text { Biv (RF 2015), one Bv (RF 2004, } \\
\text { amphora disc), one Coarseware } \\
\text { Fabric } 1 \text { (RF 2019) and nine } \\
\text { unknown fabric (eg RF 2021). Also a } \\
\text { glass bead (RF 1999), a spindle whorl } \\
\text { (RF 2005), two notched slates (RFs } \\
2013 \text { and 2022), a piece of } \\
\text { unidentifiable mammal bone (RF } \\
\text { 2093) and four pebbles (eg RF 2008). } \\
\text { Charcoal++ }\end{array}$ \\
\hline
\end{tabular}




\begin{tabular}{llll}
\hline Phase & Trench & Context & Context description \\
\hline C10 & 515 & $\begin{array}{l}\text { Blanket layer of levelling scree con- } \\
\text { taining an abraded mixture of pottery }\end{array}$
\end{tabular}

Finds

Twelve imported sherds, including four Bi amphora (eg RF 2035), one Bii (RF 1435), two PRSW (eg RF 2095), three Coarseware Fabric 1 (eg RF 2034) and two unknown (eg RF 2041). Also medieval Stuffle ware (SA) sherd (RF 2037) a piece of modern pot (RF 2040), tin-foil (RF 2029), five worked slates (including discs, eg RF 2039), six pebbles (eg RF 2313) and possible industrial material (RF 1434).

Charcoal++; oats; wheat

C10 B518 Reconstructed upper courses of east wall of thin slates, mortar and concrete

C10 $519 \quad$ Damper patch of blanket scree

C10 $520 \quad$ Dump of stones

C10/ C09 B549 Reconstructed upper courses of southwest wall of thin slates, mortar and concrete

C10/ C09 1000 Reconstructed wall over original courses 1013

$\mathrm{C} 10 / \mathrm{C} 091001$

$\mathrm{C} 10 / \mathrm{C} 091002$

C10 ext 513

C10 ext 518

C10 ext 714

C11 551
Shillet fill used in reconstruction

Mortar used in reconstruction

Reconstructed east bench containing mortar and concrete

Reconstructed east wall containing mortar and concrete

Recess in east wall, part of reconstruction Redeposited blanket layers of levelling scree with abraded pottery of mixed date
Three pick-marked slates (RFs 1995, 2007 disc and 2010) and one Bii amphora sherd (RF 2000).

Charcoal++; rich in plant macrofossils (table 83)

Three $\mathrm{Bi}$ amphora sherds (RFs 1998, 2023 and 2024)

George vi shilling dated to 1951 (RF 1962)

One sherd of Bii pottery (RF 2086)

Two Bi amphora sherds (eg RF 1514), two Bii (eg RF 1516), three unknown (eg RF 1511), nine medieval SO2 (eg RF 1517), four medieval LOC 2 (eg RF 1617), 29 pebbles (RF 1495), seven notched slates (eg RF 1613) and four slate discs (eg RF 1502), one cattle lower molar (RF 1513), one lump of mortar (RF 1496), modern enamel brooch (RF 1503) and charcoal (RF 1518) 


\begin{tabular}{llll}
\hline Phase & Trench & Context & Context description \\
\hline C11 & $552 / 554$ & $\begin{array}{l}\text { Redeposited blanket layers of levelling } \\
\text { scree with abraded pottery of mixed } \\
\text { date }\end{array}$ \\
& & \\
& & \\
& & \\
C11 & 555 & Redeposited blanket layers of levelling \\
& & scree with abraded pottery of mixed \\
& &
\end{tabular}

Finds

Romano-British Local ware sherds (RF 1665), one PRSW (RF 1418), four Bi amphora (eg RF 1424), one Bii (RF 1839), four unknown imported (eg RF 1425), two medieval SO2 (RFs 1430 and 1658), 19 pebbles (eg RFs 1431 and 1664), charcoal (RF 1660), nine notched slates (eg RF 1663) and possible coprolite (RF 1670)

One Romano-British Local ware sherd (RF 1697), two Bi amphora (eg RF 1687), one Bii (RF 1808), one unknown imported (RF 1685), five medieval SO2 (eg RF 1807), three pebbles (eg RF 1699), two slate discs and three notched slates (eg RF 1804), clay lump (RF 1806) and charcoal (RF 1672). Also metal horseshoe fragment (RF 1673). Charcoalt

\begin{tabular}{|c|c|c|}
\hline C11 & B556 & $\begin{array}{l}\text { Reconstructed upper courses of wall } \\
\text { between } \mathrm{C} 10 \text { and } \mathrm{C} 11 \text {, of thin slates, } \\
\text { mortar and concrete }\end{array}$ \\
\hline C11 & B557 & $\begin{array}{l}\text { Reconstructed upper courses of west } \\
\text { wall of thin slates, mortar and concrete }\end{array}$ \\
\hline C11 & B558 & $\begin{array}{l}\text { Reconstructed upper courses of east } \\
\text { wall of thin slates, mortar and concrete }\end{array}$ \\
\hline C12 & B559 & $\begin{array}{l}\text { Reconstructed upper courses of walls } \\
\text { of } \mathrm{C} 12 \text {, of thin slates, mortar and concrete }\end{array}$ \\
\hline $\mathrm{Cl}$ & 601 & $\begin{array}{l}\text { Blanket layer of scree levelling over } \\
\text { whole trench, dark brown loose clayey } \\
\text { loam with shillet and scree }\end{array}$ \\
\hline
\end{tabular}

One Romano-British Local ware sherd (RF 1651), one Bi amphora (RF 1500) and one unknown imported ware (RF 1694), four pebbles (eg RF 1649), two iron objects (RFs 1644 and 1647), one notched slate and one slate disc (RFs 1645 and 1646)

C12 $602 \quad$ Dark reddish-brown friable clayey One notched slate (RF 1684), three loam, earliest levelling scree layer slate discs (eg RF 1683) and one pebble (RF 1680)

C12 $604 \quad$ Yellowish-red friable clayey loam over 602

C13 $560 \quad$ Contemporary with 561, a very compact clayey layer resembling an old turf surface

C13 $561 \quad$ Dark greyish-brown clayey loam infilling bedrock-cut steps

Modern mortar (RF 1510) and two pebbles (RFs 1508 and 1509) 


\begin{tabular}{lllll}
\hline Phase & Trench & Context & Context description & Finds \\
\hline C16 & 504 & $\begin{array}{l}\text { Path, also in C09 } \\
\text { Area of disturbance }\end{array}$ & 532 & $\begin{array}{l}\text { Piece of glass Vessel 1 (RF 2355). } \\
\text { Charcoal+; oats; meadow/timothy } \\
\text { grass }\end{array}$ \\
C16 & 536 & $\begin{array}{l}\text { Two large rectangular flagstones aligned } \\
\text { north-south reset as result of } \\
\text { Guardianship work } \\
\text { Dark grey clayey silt contemporary } \\
\text { with or later than re-setting of 536 }\end{array}$ & $\begin{array}{l}\text { notch on the other (RF 3430) } \\
\text { C16 }\end{array}$ \\
\hline
\end{tabular}

Charcoal fragments $>2 \mathrm{~mm}:+1-10 ;++11-50$

PhASE Y: ARTEFACTS, ECOFACTS AND DATING

(table 30)

Abraded imported pottery $\mathrm{Bi}, \mathrm{Bii}, \mathrm{Bv}$, Coarseware Fabric 1 and PRSW and Romano-British first-/secondcentury glass were recovered from path 504 and adjacent 532.

The mixture of finds from inside the building attests to disturbance during Radford's work in the 1930s and the works of consolidation later. Layers of levelling used in the consolidation of the interior of the building contained a mixture of abraded medieval and fifth- to seventh-century imported wares, including PRSW, Bi, Bii, Biv and Bv amphorae and Coarseware Fabric 1, as well as unknown fabric (eg RF 1989: see Chapter 10, figure 127) and medieval sherds including SO (eg RFs 1966, 1968: SO1). Other finds from this layer were of modern material. A similar range of finds was recovered from the layers of scree and loam backfill infilling, eg five sherds of SO (SO2: see Chapter 10, figure 137), and worked slates (eg RF 1804: see Chapter 10, figure 113).

There are a number of other early finds of interest from this phase, although out of their original context. A spindle whorl recovered from C10, 514 (RF 2005: see Chapter 10, figure 113) is of circular flat form with a central drilled perforation, similar to those discovered on the 'Steps' area of the Island. ${ }^{2}$ A Bv sherd has been used as an amphora disc (RF 2004: see Chapter 10, figure 114), and a squat cylindrical glass bead of opaque terracotta metal with blackish streaks (RF 1999) also came from 514 (see Chapter 10). RF 1434 from C10, 515 was identified as ceramic-type material, possibly debris from a domestic hearth or small-scale industrial activity.

Of the two capstones of 536, one was notched (RF 3430), but the other (RF 3429: see Chapter 10, figure 116) has a large amount of lightly incised graffiti on the smooth upper surface. The slab itself is substantial. There are a number of elements within the graffiti, including a cross within a circle, a series of four (or, in places, five) crudely executed concentric circles, and a deeply scored but obscure element near one edge: a possible 'figure' set within an arcade formed of four lines. It bears a passing resemblance to a seal (see Chapter 10).

The modern finds range from metal foil (RF 2029 from 515) to a small enamel brooch in the form of a dog from C11 (RF 1503 from 551). These are presumably accidental losses. However, the George VI shilling of 1951 (RF 1962) found in the reconstructed east bench (513) in $\mathrm{C} 10$, is presumed to have been a deliberate deposition by the workmen. Four samples of mortar have also been examined and may well represent repair work since the main building work of the 1930s.

It is reported in Chapter 11 that, in contrast to the other samples from the site, the layer running alongside the west wall (519) contained, for Tintagel, a relatively large assemblage of plant macrofossils, presumably because it was slightly waterlogged. The layer is cereal grain-dominated, with oats more common than barley and wheat present just as a trace (oats 74 per cent; barley 23.5 per cent; wheat 2.5 per cent). No chaff was recovered. The wild species, which only comprise 7 per cent of the assemblage, include sorrel, corn marigold (Chrysanthemum segetum) and grasses. There is also a single fragmentary cotyledon of vetch or pea (Lathyrus / Pisum). Although the lack of chaff means that the oats cannot be assumed to be domesticated rather than wild, the relative lack of other weed species suggests that food or fodder rather than crop-processing waste is represented. 
PHASE Z: TURF AND TOPSOIL

The tops of the walls, the interior of the building and footpaths to the west were covered in loamy topsoil and turf (500); there was an accumulation of humic material (585) inside the drain through the south-east corner of C11, and topsoil (531) over the flags (506) in the east extension. There was also a localized patch of decayed turf (530) under 500 that may have come about from turfstripping at the time of the laying of path 504. A final subdivision of the topsoil was created by an anthill (1050).

\section{PHASE Z: ARTEFACTS, ECOFACTS AND DATING}

(table 31)

There are significant numbers of imported pottery sherds (Bi, Bii, Fabric 1 Coarseware), along with worked slates and pebbles from the various layers, and an imported Coarseware amphora-stopper (RF 3380: see Chapter 10, figure 114) from the topsoil (531) over the flags (506) of the drain in C09/C16. Significant amounts of charcoal (twigs) were found in 585 and 1050, together with bone, oats and barley. However, in terms of dating, this clearly relates to modern activity, though the range of finds does not reflect that. Unstratified finds include imported sherds of Bi and Bii, slate discs, a notched slate, a pebble and metal foil.

\section{DISCUSSION}

The major structural evidence from the Middle Terrace comprises the tri-compartmental building cleared by Radford's men. The very limited comments in Radford's publications are typified by the description of Site $\mathrm{C}$ in the official guidebook:

Site $\mathrm{C}$, now reached by a modern path, consists of three rooms set on a narrow terrace constructed in the manner already described. The oldest building is that first seen. Originally this was a long room with a door in the centre of each of the short walls, and an internal bench along the outer wall. Later two rooms with entrances in the rear walls were added at the far end, and the door in the original end wall was blocked. ${ }^{3}$

As regards the relationship of the building to the recovered artefactual material Radford states: 'In every case the pottery found in and under the floor levels and among the fallen debris was of the same type. ${ }^{3}$ In the 'Interim Report' he stated that 'most of the pottery was found lying outside the buildings in unsealed layers. ${ }^{5}$ Unfortunately, most of these statements cannot now be confirmed.

Table 31 Site $\mathrm{C}$ building Phase Z: contexts and finds

\begin{tabular}{|c|c|c|c|c|}
\hline Phase & Trench & Context & Context description & Finds \\
\hline \multirow[t]{5}{*}{$\begin{array}{l}\text { Phase } Z \text { : } \\
\text { turf and } \\
\text { topsoil }\end{array}$} & \multicolumn{2}{|c|}{$\begin{array}{l}\mathrm{C} 09-\mathrm{C} 13,500 \\
\mathrm{C} 16\end{array}$} & $\begin{array}{l}\text { Loamy topsoil and turf covering tops } \\
\text { of the walls, interior of building and } \\
\text { footpaths }\end{array}$ & $\begin{array}{l}\text { Thirteen Bi amphora sherds (eg RFs } \\
2308 \text { and } 1400 \text { ), five Bii (eg RF } \\
1110 \text { ), three Coarseware Fabric } 1 \text { (eg } \\
\text { RF 1109), one Coarseware Fabric } 5 \\
\text { (RF 1101) and four unknown } \\
\text { imported (eg RF 1103), } 38 \text { pebbles } \\
\text { (eg RF 2310) and two slate discs } \\
\text { (RFs } 1106 \text { and 1112) }\end{array}$ \\
\hline & $\mathrm{C} 09$ & 530 & Decayed turf from repairing path & One Bi amphora sherd (RF 2118) \\
\hline & $\mathrm{C} 09$ & 1050 & Anthill & Charcoal ++ ; bone fragment \\
\hline & $\mathrm{CO9}$ & 531 & Topsoil over flags (506), same as 500 & $\begin{array}{l}\text { Three Bi amphora sherds (eg RF } \\
\text { 3399), two Bii (RF 3376), one } \\
\text { imported Coarseware Fabric } 1 \\
\text { amphora-stopper (RF 3380) and } \\
\text { one unknown imported (RF 3379) }\end{array}$ \\
\hline & C11 & 585 & $\begin{array}{l}\text { Accumulation of humic material inside } \\
\text { drain through south-east corner of } \\
\text { trench }\end{array}$ & Charcoal+++ (twigs); oats; barley \\
\hline
\end{tabular}

Charcoal fragments $>2 \mathrm{~mm}:+1-10 ;++11-50 ;+++51-100$ 
As indicated above, the rooms to the north (C11 and $\mathrm{C} 12$ ) had abutted the larger room to the south (C10) but how much time elapsed before this happened cannot be determined. The recent excavations showed that the lowest two or three courses of the walls were generally original, whereas those above them had been heavily restored and/or rebuilt in the 1930s, with maintenance into the 1950s and beyond. Some walls, notably on the eastern edge, and the eastern bench of $\mathrm{C} 10$, appear to have been completely reconstructed, but it is uncertain whether this was rebuilding of dilapidated masonry or more substantial work, perhaps involving some raising of the height of the foundations by using the easily available slates to present more immediately impressive and intelligible walls for visitors. Paul Johnson's caveat in Chapter 1 regarding Wright's drawings should be borne in mind here: section-drawings exist with the annotation 'Make up to floor level (Soil and Debris)' (see Chapter 1, figure 11). This apparent instruction could support the notion that a levelling-up process inside the building was accompanied by some similar activities with the walls and outside the building.

Certainly, the eastern part of the west-east drain associated with the building appeared to have been reset, and the drain around the west and south walls of the building had replaced or linked up with an earlier south-north drainage system in the south-west part of C09. Construction methods for both were simple. In the case of the earlier drain, it simply consisted of a capping for a channel cut through the natural bedrock. For the later, it began in a similar fashion, but with small support stones to the sides of and under the capstones as the drain continued eastward. Some indications of the original post-settings for the doors, however, appear to remain, although other features, such as a drain in C11, may not be original. The eastern 'bench' in C10 appears to have been rebuilt post-1951 - on the basis of the Phase Y 1951 shilling (see above) - but is also a feature essentially without parallel in the post-Roman period.

Given the paucity of primary information about the building it is not profitable to speculate very far about prototypes or parallels for the building complex as a whole. For many years the buildings at Tintagel on sites such as this one and 'Site B' became type-fossils for other so-called 'monastic sites' in Britain and Ireland (see Chapter 1$).{ }^{6}$ In the context of a 'secular' interpretation, however, it provides us with an example of a building or buildings from a 'high-status site. The substantial remains of the buildings on Site C certainly provide a contrast with the fragmentary remains of buildings uncovered on the Lower Terrace, and even the later buildings from Phases U2 and W on that terrace appear less substantial. However, the buildings on both terraces would appear to be broadly contemporary, and perhaps it is the case that these are variants upon a common theme. The types of building, quasi-rectangular, are obviously in a tradition that leads to buildings such as those of a later period from Mawgan Porth, for instance, further down the coast in north Cornwall. ${ }^{7}$ However, in the absence of associated deposits and more reliable dating evidence further discussion would simply be speculative. ${ }^{8}$

In contrast to the Lower Terrace excavations, there has not been a programme of radiocarbon dating on the material from the Middle Terrace. This was for very understandable reasons: given the extent of earlier interference with the site, it would be difficult to demonstrate unequivocally that many of the features with charcoal were uncontaminated. In fact, although this would be true of a number of features, for instance the later drain, there is good reason to think that there are some clearly sealed deposits which could be utilized for dating. The prime candidate would be the successive deposits within the fissure below the west wall of the main Site $C$ building. These would at least give a terminus post quem to the construction of the building. However, a dating programme of sequences of deposits with evidence of in situ burning, as initiated on the Lower Terrace, was not undertaken on the advice of Alex Bayliss, Ancient Monuments Laboratory, English Heritage.

Otherwise, the dating of the site examined in this report has been arrived at by conventional artefactual dating, particularly although not exclusively the fifth- to seventh-century imported pottery. The Site $\mathrm{C}$ building area has some of the late Roman Gabbroic pottery, although clearly found together with Bii amphora fragments in the fissure, suggesting it is residual. However, it is not inconceivable that both kinds of pottery may have co-existed at the very end of the late Roman occupation here. The fill of the fissure produced six sherds of Bii pottery, a sherd of Gabbroic pottery and a glass vessel sherd, possibly of the fourth-fifth centuries in date. Good sealed dating for primary features other than the fissure is to be found: $\mathrm{Bi}, \mathrm{Bii}$ and $\mathrm{Bv}$ in a deposit over a post-hole, Bii in a beam-slot and Bii, Biv and a fifth-/sixth-century glass bead from a post-setting. The old ground surface produced $\mathrm{Bi}, \mathrm{Bii}$ and $\mathrm{Bv}$ as well as Fabric 1 and PRSW, in addition to the unique glass, possibly from Spain, which is of the same fifth-/sixth- 
century bracket. PRSW also comes from primary levelling and ARSW, Bi and Bii from the make-up for the building. The drain that appears to pre-date the building has $\mathrm{Bi}, \mathrm{Bv}$ and local Romano-British pottery from the clay associated with its repair, and the silting of the drain has produced PRSW, Bi, Bii, Biv and Fabric 1. All of this is entirely consistent with a possible levelling deposit at the entrance to the building (the only intact deposit inside it) which had the possible local glass bead of fifthto seventh-century date. The secondary drain, arguably associated with the building, had PRSW associated with its construction and Bi with its fill.

Although there continue to be imported wares associated with the collapse of the building and the scree deposits over it, the same clayey deposits which produced these have turned up part of an eighth-/ninthcentury mid-Saxon glass cup. The sense here is of a fugitive glimpse into a period hardly represented on the site as a whole, but before the Castle occupation (as there is no medieval pottery in this phase). Only later, in Phase $\mathrm{X}$, is there a significant amount of medieval pottery, and this had clearly come from deposits cut through by Radford's workmen. These had produced a sixth/seventh-century (or earlier) glass fragment, but also modern material such as metal foil. The latest 'activity' period here (Phase $Y$, twentieth century) produced both Romano-British pottery and some first-/second-century Roman glass as well as the 1951 shilling which itself dates a reconstruction of the eastern bench.

Overall, the dating here does not seem to indicate the in situ presence of activity in the Romano-British period, but it does suggest that it had occurred in the vicinity. Even the late Roman inscription on the slate was no longer in context, as the stone had been re-used in the post-Roman period. The mid-Saxon glass, similarly, is not supported by the presence of anything else from the eighth-ninth centuries. The main demonstrable activity, based on imported pottery and glass - as well as the secondary inscription - was in the fifth-sixth centuries (probably extending into the seventh). The volume of medieval pottery, while not in context, clearly indicates that activity took place on the Island outside the confines of the Castle in the thirteenth to fifteenth centuries.

\section{CONCLUSION}

In summary, we apparently have a picture of domestic occupation, suggested by the palaeobotanical evidence and the structural evidence of buildings, the later phase of which is quite substantial, in contrast with the buildings on the Lower Terrace. However, the lack of occupation deposits surviving from the 1930s excavations within the building is a problem for interpretation. There is a complete contrast in terms of the nature of the imported pottery assemblage, for example, as the majority of the material recovered is from storage vessels as opposed to fine wares associated with food consumption. Although there is evidence of fine glassware almost certainly from Spain, and a second group provisionally from the Bordeaux region, attesting to high-status presence here, there is a distinct absence of evidence for activities conventionally associated with high-status sites of this period (eg Dunadd in Argyll), such as fine metal-working and glass importation. ${ }^{9}$ However, the inscriptions on the stone from the drain attest to high status, very late Roman associations and also to Latinate literacy in the post-Roman period, which would befit a high-status site.

The seemingly contradictory nature of the evidence from this part of the site can be seen within the ecofactual material. Overall, apart from the intriguing evidence of bone from the site, the botanical evidence indicates that at the earliest period (Phase $\mathrm{T}$ ), there was significant consumption of grain, rather than cropprocessing activity nearby. These data could potentially have offered a dating sequence to compare with that from the Lower Terrace if the burnt grain were discovered in its primary context. Some material from Phase $Y$, if disturbed from its original context, indicates that a similar grain-dominated deposit may originally have been associated with Building $\mathrm{C}$. Equally, the material from the drain fill, presumably related to the usage of the adjacent building, is nevertheless interesting in terms of the wide range of habitats represented. However, the palaeobotanical collection from this part of the site shows no exotics, and very little collection of wild fruit and nuts or exploitation of the heathland plants is to be seen. Alongside the exotic artefactual material, there is more mundane, locally derived material (as seen by the stone artefacts) and, presumably, locally produced grain and meat (as indicated by the fragmentary bone recovered), with an absence of evidence for exotic food imports.

Clearly, one cannot know what has been lost in terms of stratigraphic and artefactual material from the 1930s work, but at least the partial picture from the Site C building can be compared with material from the 
adjacent part of the site which was much less disturbed during the 1930s (see Chapter 5).

As can be seen from these excavations on the Middle Terrace Site $\mathrm{C}$ building, the clearance of the site by Radford's men was comprehensive, and a considerable amount of interesting material was found in the backfill. The stark contrast with the area left unexcavated (C09), apparently by the chance existence of a spoil-heap, is telling. Certainly, the artefactual assemblage from this small area, including as it does the inscribed stone and the unique glass, is presumably indicative of the nature of some of the deposits excavated in the 1930s, for which we no longer have a full record either in archive or print. 


\section{PART III}

Site T: The Great Ditch Area 



\title{
CHAPTER 7
}

\section{TOPOGRAPHIC SURVEY AND TRIAL EXCAVATIONS 1999 ON C A RALEGH RADFORD'S TRENCHES IN AND AROUND SITE T}

\author{
with contributions from PAUL G JOHNSON, JOHN ARTHUR and GARY TOMPSETT
}

\begin{abstract}
There are scant records of excavations by Dr Ralegh Radford in the area surrounding the Great Ditch (Site T) at Tintagel Castle in 1938, 1939 and later in 1955 (see Chapter 1). In 1999, the area was re-examined, initially through topographic survey and then trial excavations. This chapter summarizes the outcomes of a trial-trench assessment of Radford's smaller trenches excavated in the Great Ditch, Little Ditch and a path adjacent to the Little Ditch.
\end{abstract}

\section{INTRODUCTION}

The background to and context of the excavations in 1999 was the earlier programme of archaeological work carried out in the same area by Radford over sixty years previously (figure 79). In 1938 he opened three trenches in the vicinity of the Great Ditch (he termed this 'Site T') as part of his extensive research excavations on the headland of Tintagel. ${ }^{1}$ Confusion has surrounded the exact location and nature of these trenches (see Chapter 1), though through recent survey combined with archival research many of these backfilled trenches have been relocated.

Before the excavations in 1999, the evidence from the landward side of the site for post-Roman occupation was sketchy. Following his excavations there, Radford described the bank and ditch defence (figures 80 and 91) as a "vallum monasterii' notionally cutting off the site from the rest of the world. ${ }^{2}$ A section drawn by J A Wright in 1938, recording Radford's excavations in the Great Ditch, was utilized by Professor Charles Thomas in his 1993 reassessment. ${ }^{3}$ This shows the long section and two other trenches in the area of the Great Ditch (see Chapter 1, figure 15), one further to the south west across the Little Ditch and one adjacent to this to the south, apparently across the route into the site.

\section{SURVEY WORK IN 1999}

with John Arthur, Paul Johnson and Gary Tompsett

In 1999 the opportunity was taken to record the profile of both sides of the steeply inclined valley (the 'Vale') leading to Tintagel Haven, including the geological fault at the east of the Great Ditch. This began from a point behind the curtain wall of the Upper Ward, and terminated at the crest of the slope west of King Arthur's Castle Hotel (figure 81 ). The line of the profile was deliberately engineered to run along the length of the bottom of the Great Ditch.

Although an excellent base map for Tintagel Castle exists as the result of the photogrammetric survey undertaken by AMC Ltd, no two-dimensional image of the area of the Great Ditch and its surrounding area of 'Site T' can begin to provide an adequate impression of that feature's imposing grandeur and proportions. In an attempt to address this after the completion of a small topographic survey in the area of the Great Ditch, it was hoped that a digitally generated surface model of the monument could be created. It would thus be possible to examine such a model from any angle above or around it - something that is impossible to achieve on the ground since views of the ditch are severely restricted by the dominance of the Castle walls. Although the 


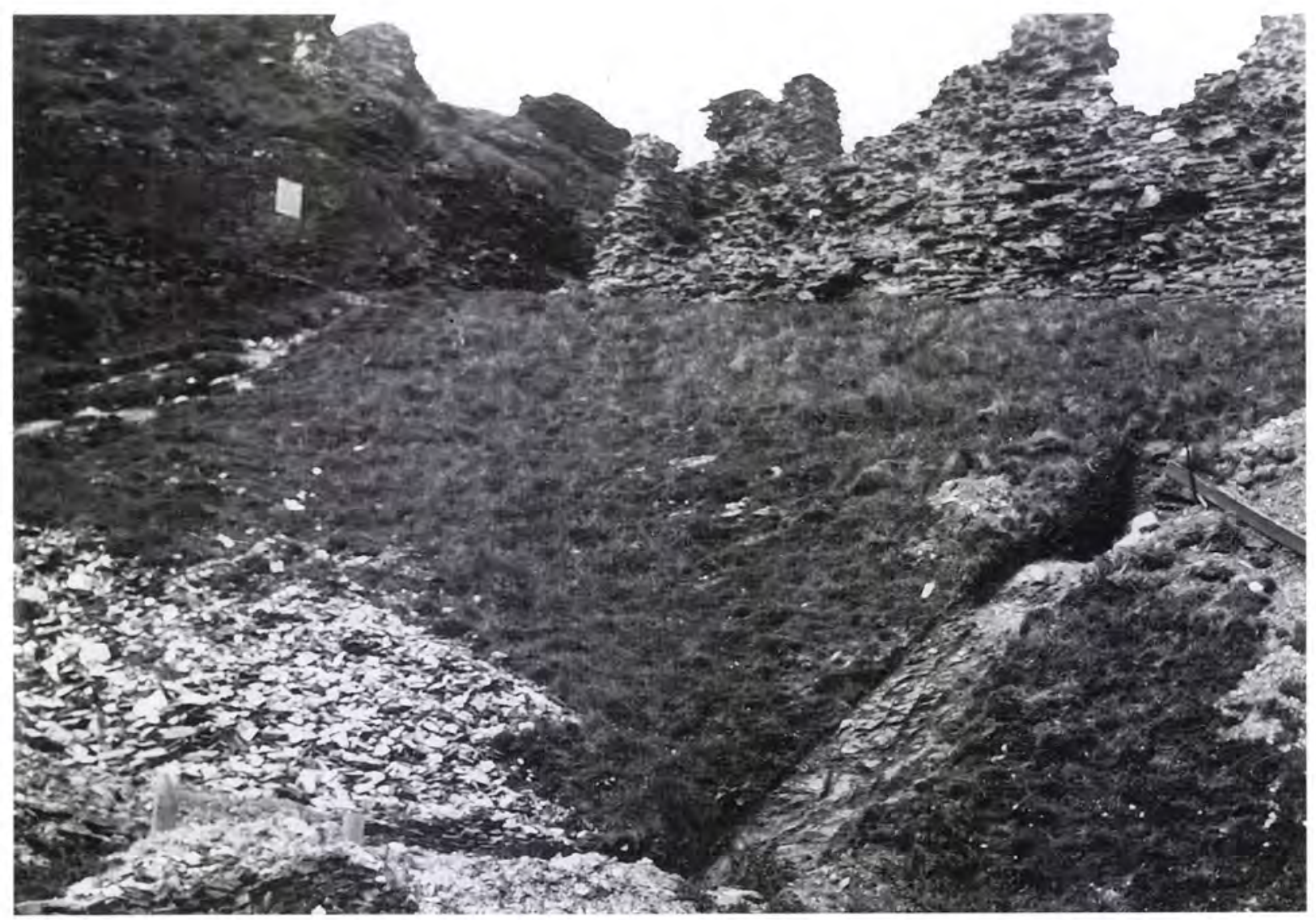

79 Photograph of 1938 Great Ditch section. Reproduced by permission of English Heritage (NMR)

topographic survey was not undertaken with a final 3D model in mind - if it had been, more detail would have been taken to obtain a smoother model - given the limited scope of the survey, it succeeds in demonstrating the massive scale of the Great Ditch (figure 82).

\section{EVALUATION OF SURVEY DATA IN RELATION TO}

MATERIAL FROM THE 1930S TO THE PRESENT DAY

AND LOCATION OF RADFORD'S TRENCHES

Documentary research and on-site survey has pinpointed the four cuttings made in and around Site $\mathrm{T}$ in 1938 and 1939, and later work in 1955 (see Chapter 1). The three trenches opened in 1938: the long cutting, broadly north-south across the Great Ditch itself, the cutting to the south west across the Little Ditch and the third to the south, were all located on the ground and verified by the excavations of trenches T01, T02 and T03. The section inside the curtain wall was located using measurements from Wright's drawings (see Chapter 1, figure 15) and was verified by the excavation of trench T01 ext. The position of a smaller trench excavated across the Ditch in 1955 was located during optical survey, which suggested that it ran from the south bank to the middle of the central depression. This was verified in the excavation of trench T04 and is viewed as a particular success in the absence of any documentary material to suggest its location. A further trench (T05) was opened to test an anomaly brought to light by the survey work (figure 83 ). Thus five trenches (including T01 ext) were opened in the areas suggested to the excavators by the survey work, with positive results in all cases.

\section{EXCAVATION METHODOLOGY AND SYNOPSIS OF WORK UNDERTAKEN}

Following on from the detailed optical survey and archival work, the precise relocating of Radford's Site T trenches was undertaken by removing the turf and backfill to enable study of the stratigraphy. The aims of 


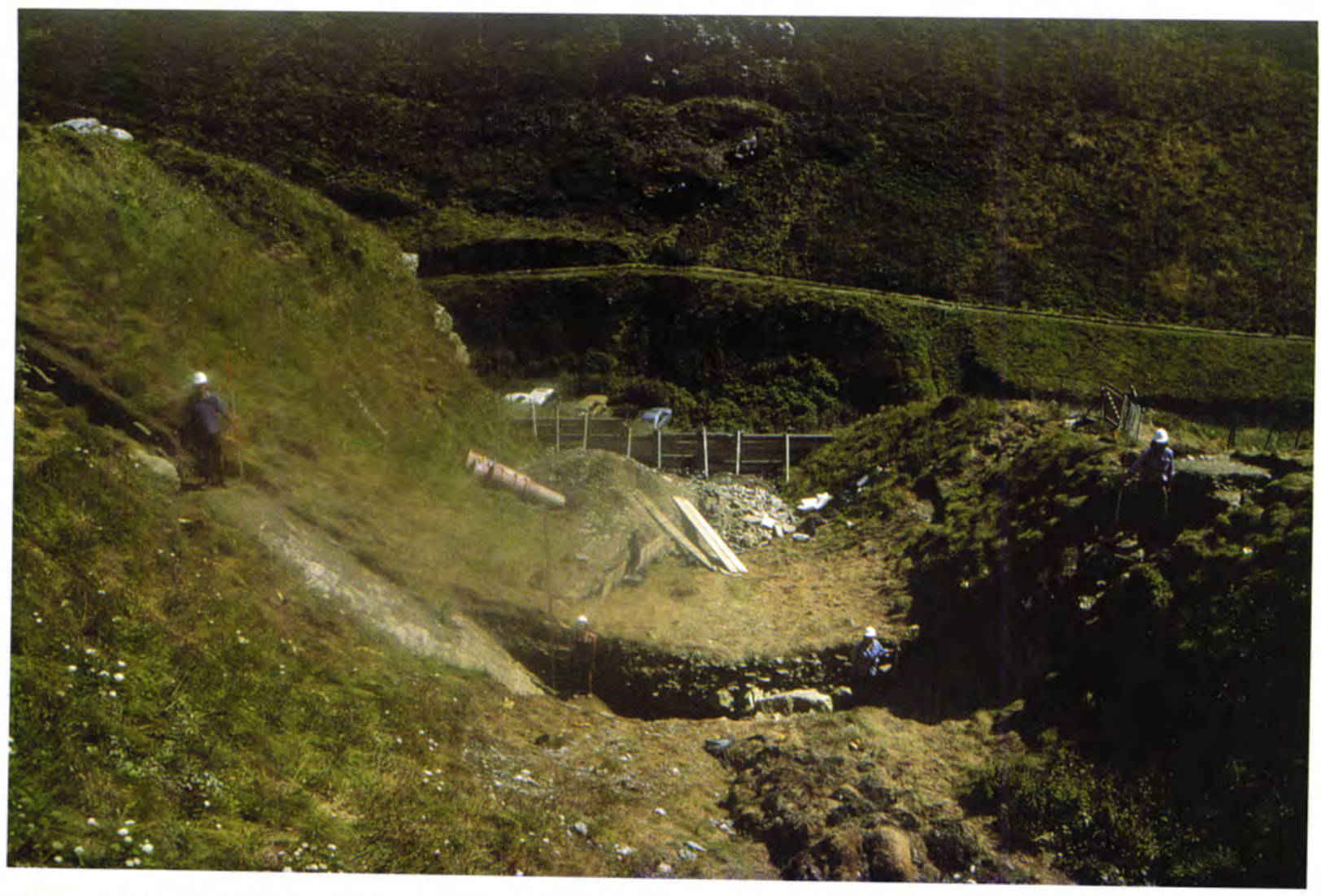

80 View of the Great Ditch from the west. Photograph: C D Morris

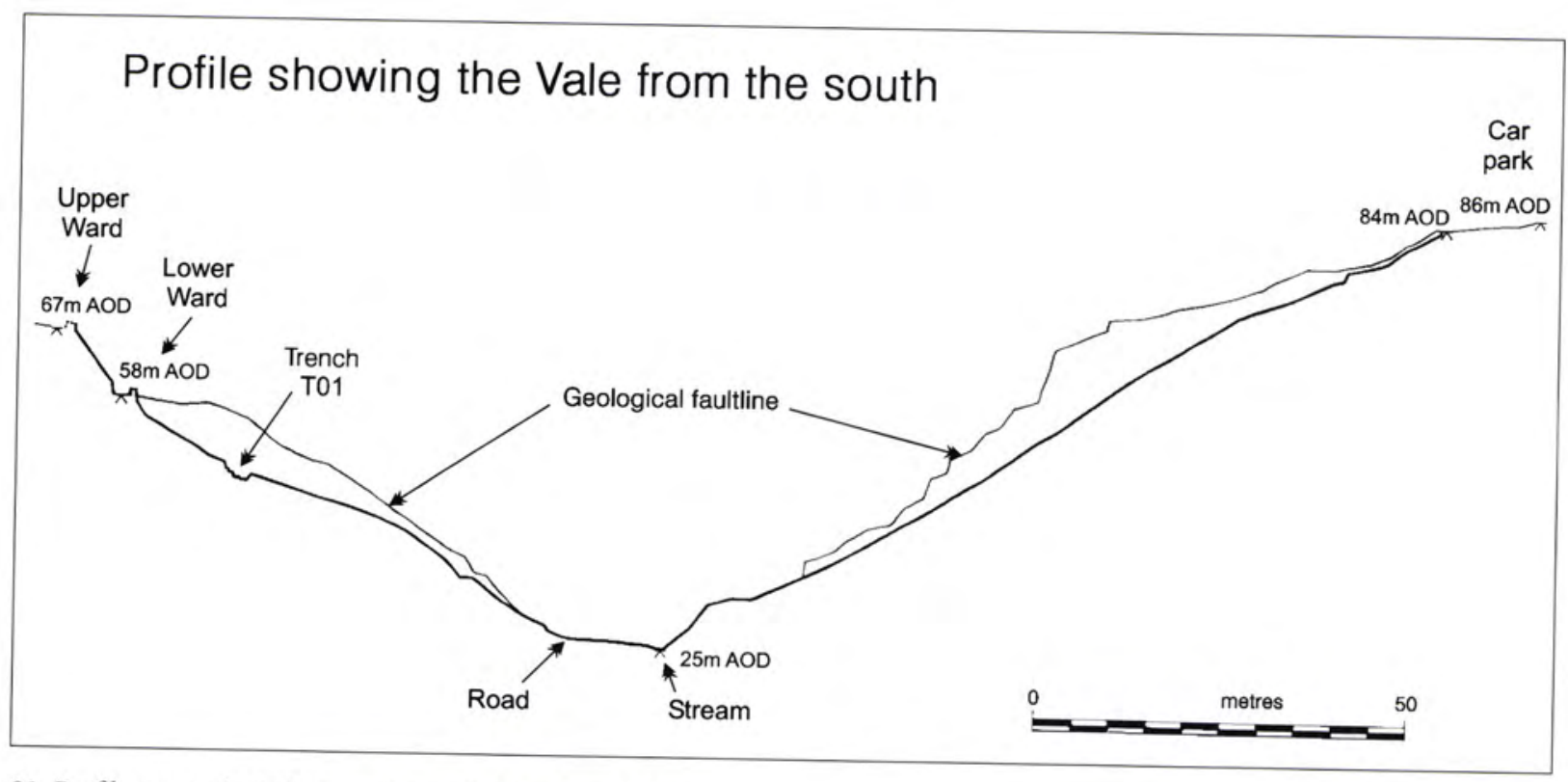

81 Profile across the Vale from the south. Drawing: C Evans 

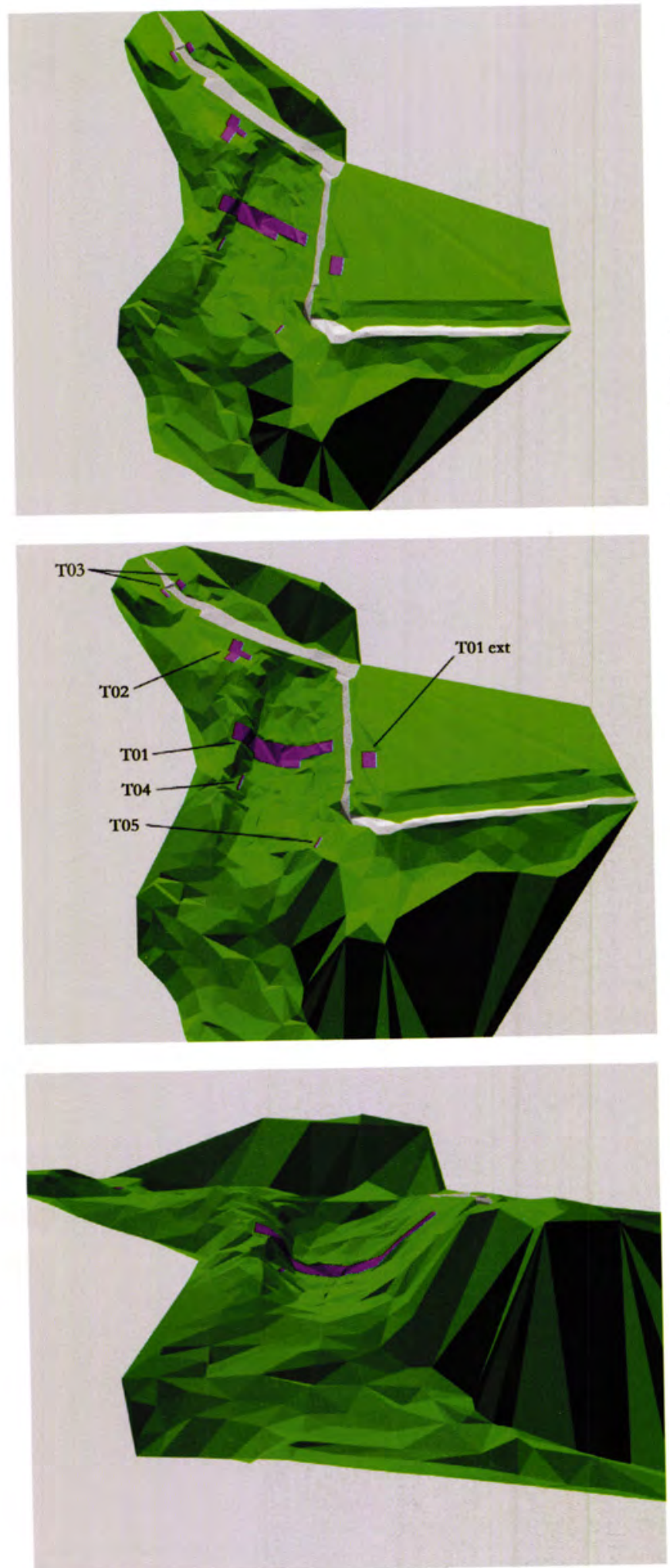

View looking down from above the Great Ditch

Excavation trenches are highlighted in purple
View from the north east, showing trench labels

View from the east. showing ditch profile

$823 D$ terrain model of the Great Ditch, Site T area. Origination: J Arthur and G Tompsett 


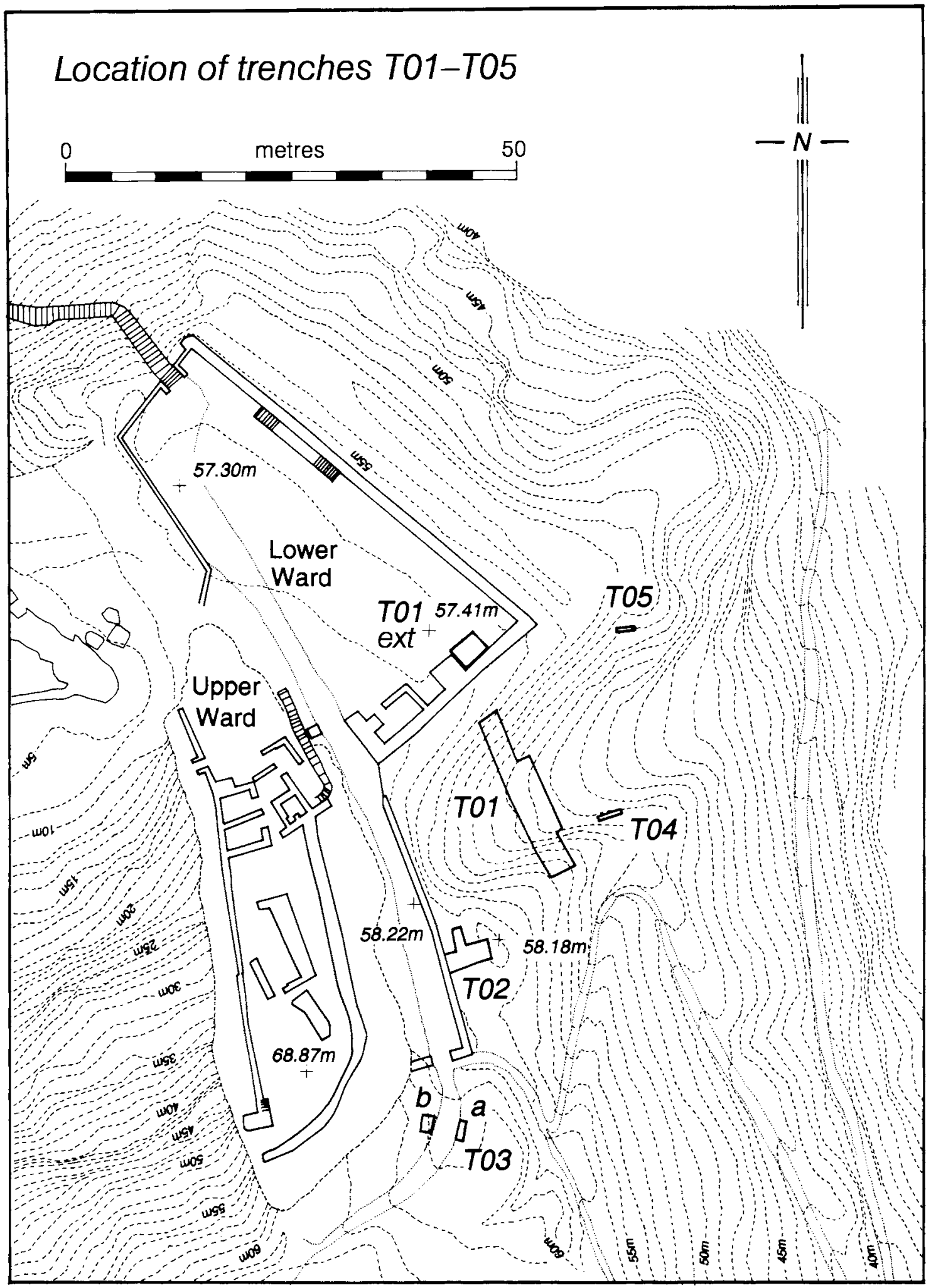

83 Location of trenches TOI to T05 in 1999. Drawing: C Evans and L McEwan 
the renewed excavations and succeeding post-excavation analyses included the following: to establish and interpret a secure sequence of phases of activity in and around Site T; to investigate a possible phase of re-use of the Great Ditch in the later medieval period, as a complement to the Lower Ward curtain wall and the use of the Little Ditch and to analyse the geology, architectural stone and mortar fragments to identify details of the original appearance of the later medieval Castle and its construction; and to study the evidence for the economy and environment of the occupants of Tintagel in the late Roman, early medieval and later medieval periods through the recovery and analysis of ecofactual and artefactual evidence. As with every season and area of the excavations at Tintagel, a comprehensive sampling strategy was employed in 1999.

A brief synopsis of the work carried out and the results recorded from each of these trenches is presented below, beginning with the trial trenches, proceeding to the work on the Little Ditch and, finally, to the major work on the Great Ditch and Lower Ward (see Chapters 8 and 9).
THE TRIAL TRENCHES: T03A AND B, T04 AND T05 T03 was the label assigned to two trenches, T03a and T03b, at either side of the current pathway forming the coastal approach to the site (figure 84). They were opened to test the results of survey and desk-top research by Paul Johnson which had identified a small Radford cutting across the southern access route from the coast to the Lower Ward. The turf was removed from both and the cut and fill of the Radford trench successfully identified; the phasing is described below. No excavation was carried out in either trench beyond deturfing and cleaning the exposed deposit, as the presence of the backfilled Radford trench was quickly established. No artefacts or environmental samples were recovered as the backfill of the trench was not removed.

Trench T04 was located within the bowl of the Great Ditch, further down the slope on the south bank and to the east of T01 (see figure 83). It was established to confirm the suspicion that Radford had probably excavated a Great Ditch trench in 1955 in a different location to that of the $1938 / 9$ trench. A cutting across the

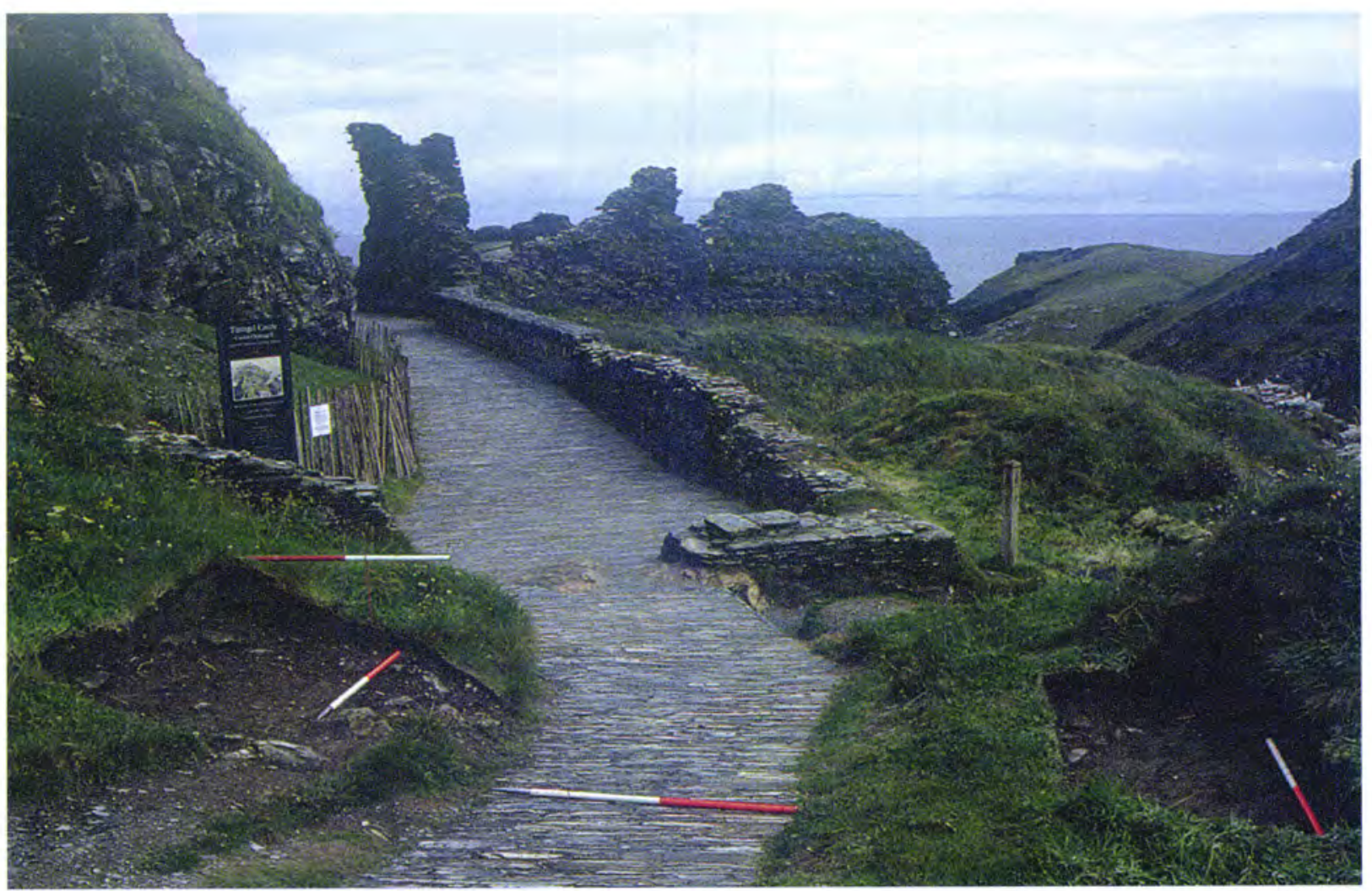

84 Trench T03 across path, from the south. Photograph: P G Johnson 
ditch was located, planned and photographed, but no further work was undertaken here, so no artefacts or environmental samples were recovered.

Trench T05 was located at the east end of the north bank of the Great Ditch, approximately two-thirds of the way up the slope (see figure 83). It was opened to test a deep depression which ran down the slope, noted during preliminary survey work in 1999. It was suggested that this might represent a continuous feature running from the area of T04 right across the Great Ditch, thus making Radford's cutting of 1955 of a similar scale to that opened in 1938 (see trench T01, Chapter 8). On removal of the turf and topsoil, the trial trench demonstrated that this feature was the result of geomorphological processes and probably represents a dried out floodwater channel. No stratigraphic sequence, artefacts or environmental samples were derived from the examination of the area.

\section{THE LiTtLe DITCH: TRENCH T02}

Trench T02 was established in a narrow ditch (the Little Ditch) to the south south east of the Lower Ward of Tintagel Castle. The ditch runs parallel to the road leading to the entrance of the Lower Ward, and its northernmost extremity opens into the top of the Great Ditch. It was positioned by reference to a drawing made by Wright which also depicts the position of the 'trench across road' identified in trench T03 (figure 85), and by the 1995 survey. It successfully identified the 1938 cutting across the Little Ditch, possibly a later medieval feature.

As with the other 1990s excavations, a search-trench was initially established in a position perpendicular to the anticipated position of the 1938 cut, at the lowest point of the ditch. Once the fill of Radford's trench had been identified in the 'search' excavation the whole of its surface was exposed across the entire profile of the ditch. It was immediately obvious that the 1930 s excavation had not been undertaken stratigraphically, and that the bottom of the trench was near horizontal with a number of contexts exposed in section. The decision was made to excavate an undisturbed area, $0.3 \mathrm{~m}$ wide, to the south of the earlier cut in order to establish and record the site stratigraphy cut by Radford's excavation trench (figure 86). The north-facing section thus exposed could then be directly compared with the south-facing section of the same trench recorded by Wright (see figure 85). A strip of undisturbed deposits was excavated to the side of Radford's trench. At the bottom of the ditch, two sherds of post-medieval pottery were discovered in situ in the primary deposit.

\section{THE TRIAL TRENCHES: SUMMARY OF STRATIGRAPHY AND PHASING}

\section{TRENCH T03: STRATIGRAPHIC SEQUENCE (figure 87)}

Phase W: pre-Radford deposits. This phase was one uniform layer across both of the trenches (T03a and T03b). Below 1073 of Phase Z, a compact brown clayey loam with shillet and large angular stones, 1076, was revealed. This was the amorphous layer of soil build-up and debris from the Upper Ward walls above, identical in both trenches, through which Radford's trench was cut. No finds were recovered.

Phase X: Radford trench. The earliest event in this phase was the cut, 1074, for the Radford trench through Phase

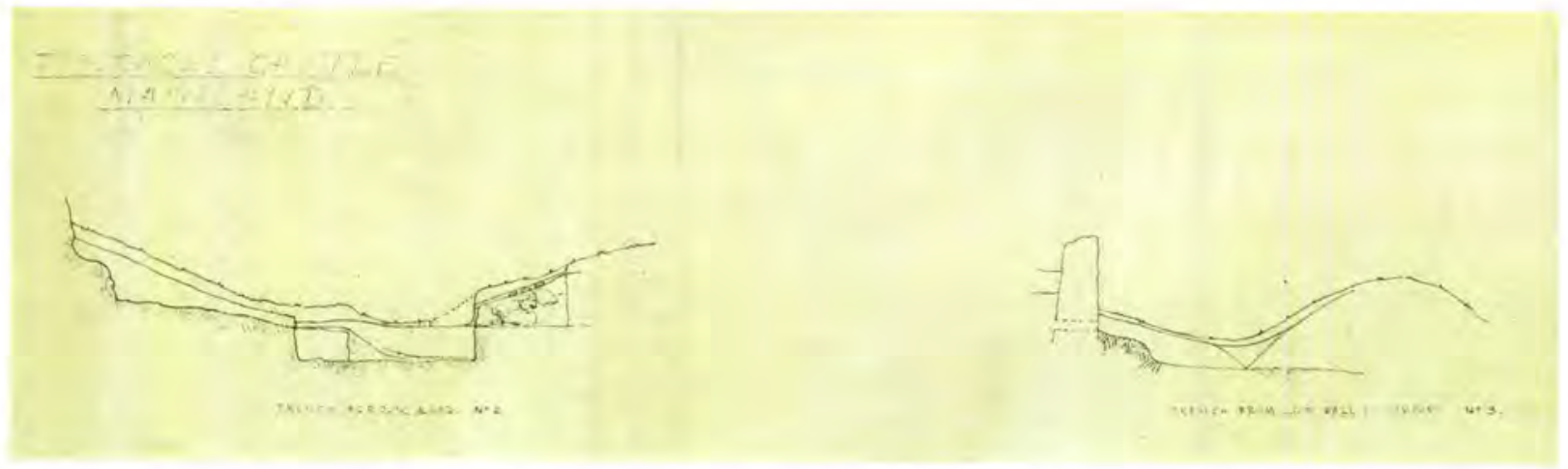

85 Wright's drawing showing 1938 section no. 2 of trench across road and section no. 3 of trench from low wall to rampart. Reproduced by permission of English Heritage (NMR) 


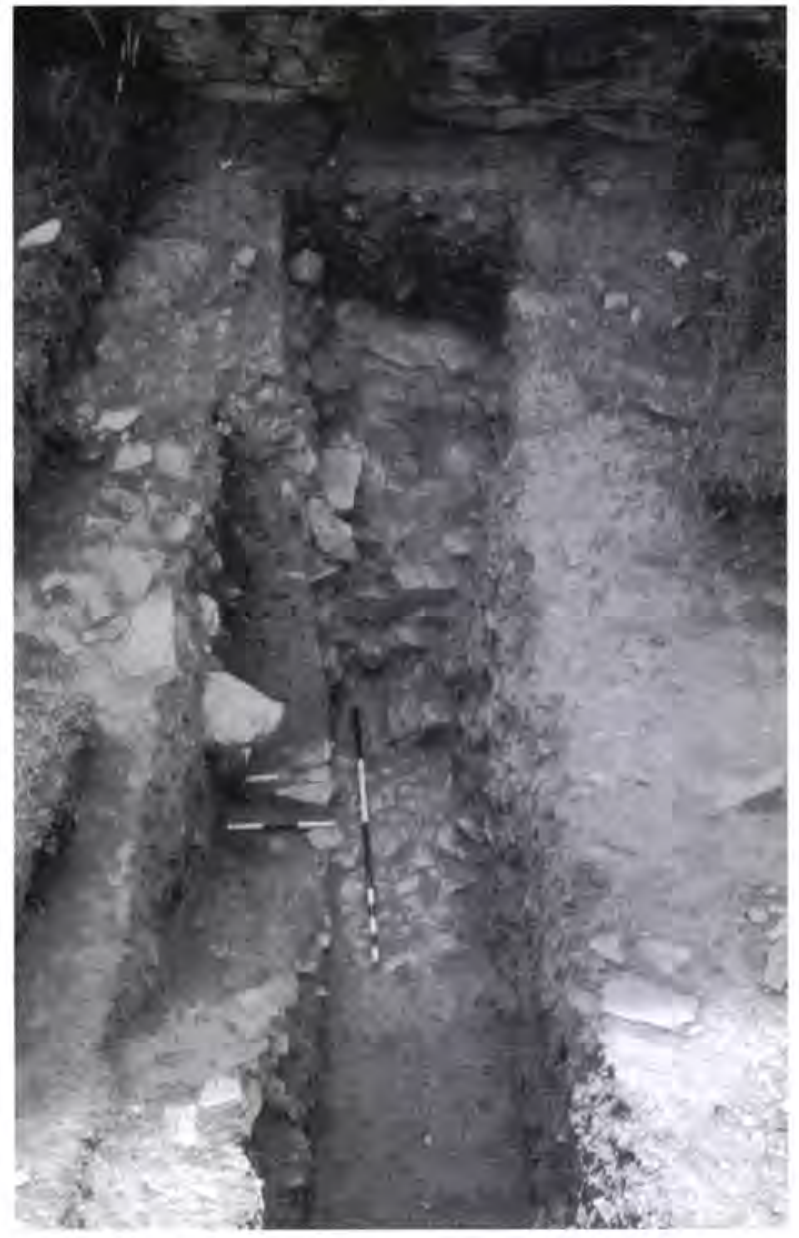

86 Trench T02 after excavation. Photograph: P G Johnson

$\mathrm{W}$ deposits. The trench was aligned east to west and may have cut across the area of the current access path. The fill of the trench was 1075 , a compact, mid-greyish brown clayey loam with shillet and occasional large angular stones which was identical in T03a and b. No finds were recovered.

Phase Y: revetment. This phase was characterized by 1077 , a line of large angular stones which ran north to south along the west side of the coastal path (or the east side of T03b). These stones may be tumble from the Upper Ward walls that have been placed along the west edge of the path to revet the sloping ground at the west. They may have been placed to stabilize 1075 of Phase X, which they clearly overlie. No finds were recovered.

Phase Z: turf and topsoil. 1073 covered the entire area.

\section{TRENCH T04: STRATIGRAPHIC SEQUENCE}

Phase X: pre-Radford deposits. The earliest deposit identified in 1999 was 1223, a layer of red gritty soil containing a substantial quantity of slate fragments tipping in the general direction of the slope. This deposit comprised the bank material located to the south east of the Great Ditch.

Phase Y: Radford's trench. The Phase X bank material was cut by 1221 , a trench containing backfilled material 1222. Once the position of the trench was confirmed, no further excavation was undertaken.

Phase Z: turf and topsoil. All of the deposits of Phases X and $\mathrm{Y}$ were sealed by 1220, a layer of turf and topsoil.

\section{THE LITTLE DITCH: SUMMARY OF STRATIGRAPHY AND PHASING}

\section{TRENCH T02: STRATIGRAPHICAL SEQUENCE}

Phase V: natural deposits (figure 88). Slate bedrock 1205 was apparent at the westernmost limits of the excavation in the form of a low ledge or shelf. This was sealed by 1207 , a deposit of light yellowish brown silty clay containing a large quantity of substantial slate bedrock and shattered slate fragments 1209. A deposit of clean, dense, light yellowish brown silty clay 1206 , containing a few slate fragments, sealed 1209 and partially overlay 1207.

All of the above contexts, with the exception of bedrock and 1209, were cut by the Little Ditch of Phase W.

Phase V: artefacts, ecofacts and dating. Pollen samples were taken through context 1209 . Pollen preservation was very poor in this phase and restricted to dandelion and related Asteraceae pollen (see Chapter 11).

Phase W: the Little Ditch (figure 88). The Little Ditch (1208) is a broad, shallow cut with a flattened U-shaped profile, which runs east of, and parallel with, a low wall constructed alongside the road leading to the Lower Ward. The ditch terminates just to the north of a modern footpath and leads into the Great Ditch at the north end. The western edge of the ditch utilizes a possibly natural ledge in the slate bedrock upon which the road was constructed. The ledge was disturbed by 


\section{Trench T03 $a$ and $b$}

\section{Phases $W, X$ and $Y$}
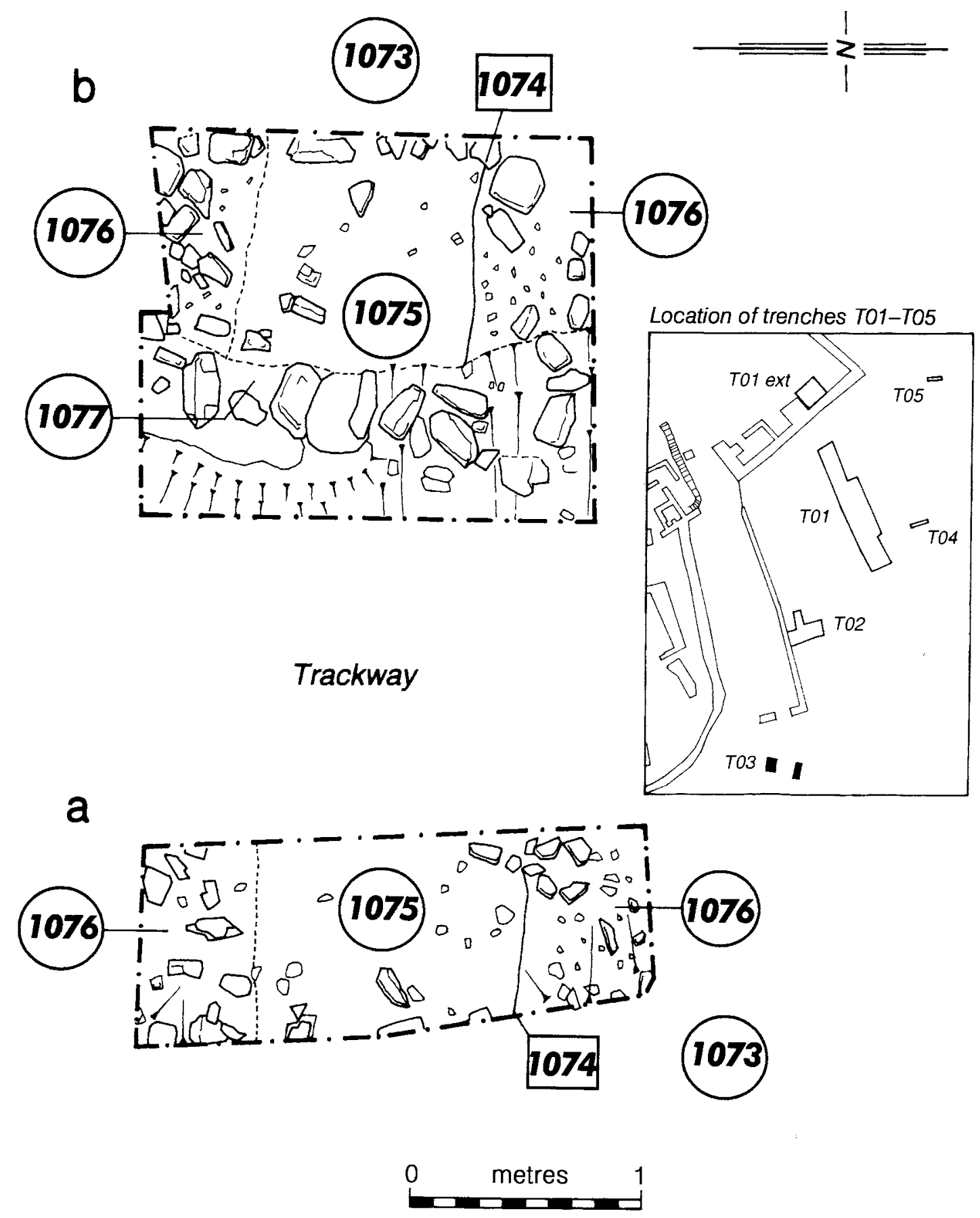

87 T03 Phases $W, X$, and $Y$. Drawing: C Evans 


\section{Trench T02 Phase V}

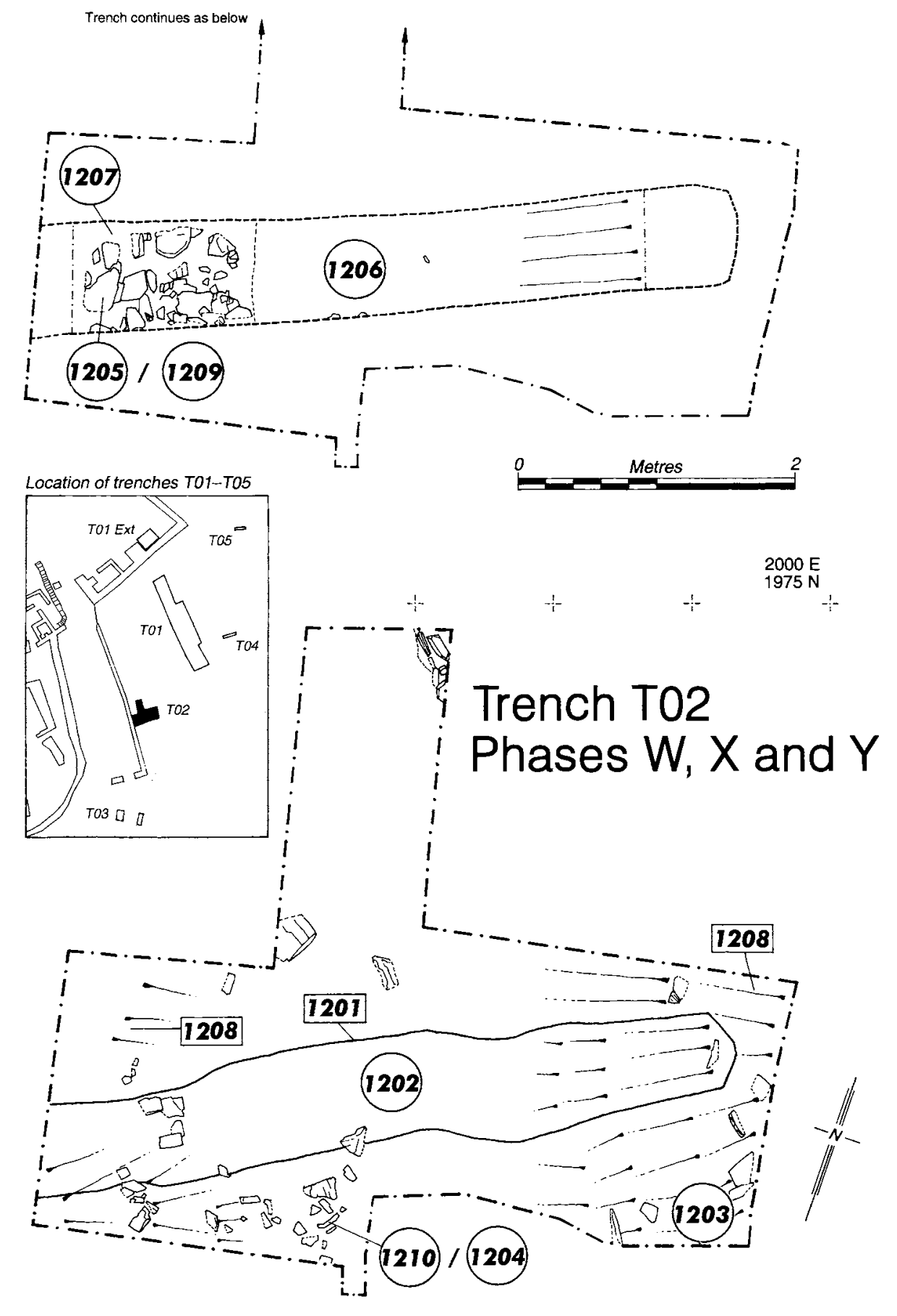

88 T02 Phase $V$, and Phases $W, X$ and $Y$. Drawing: C Evans 


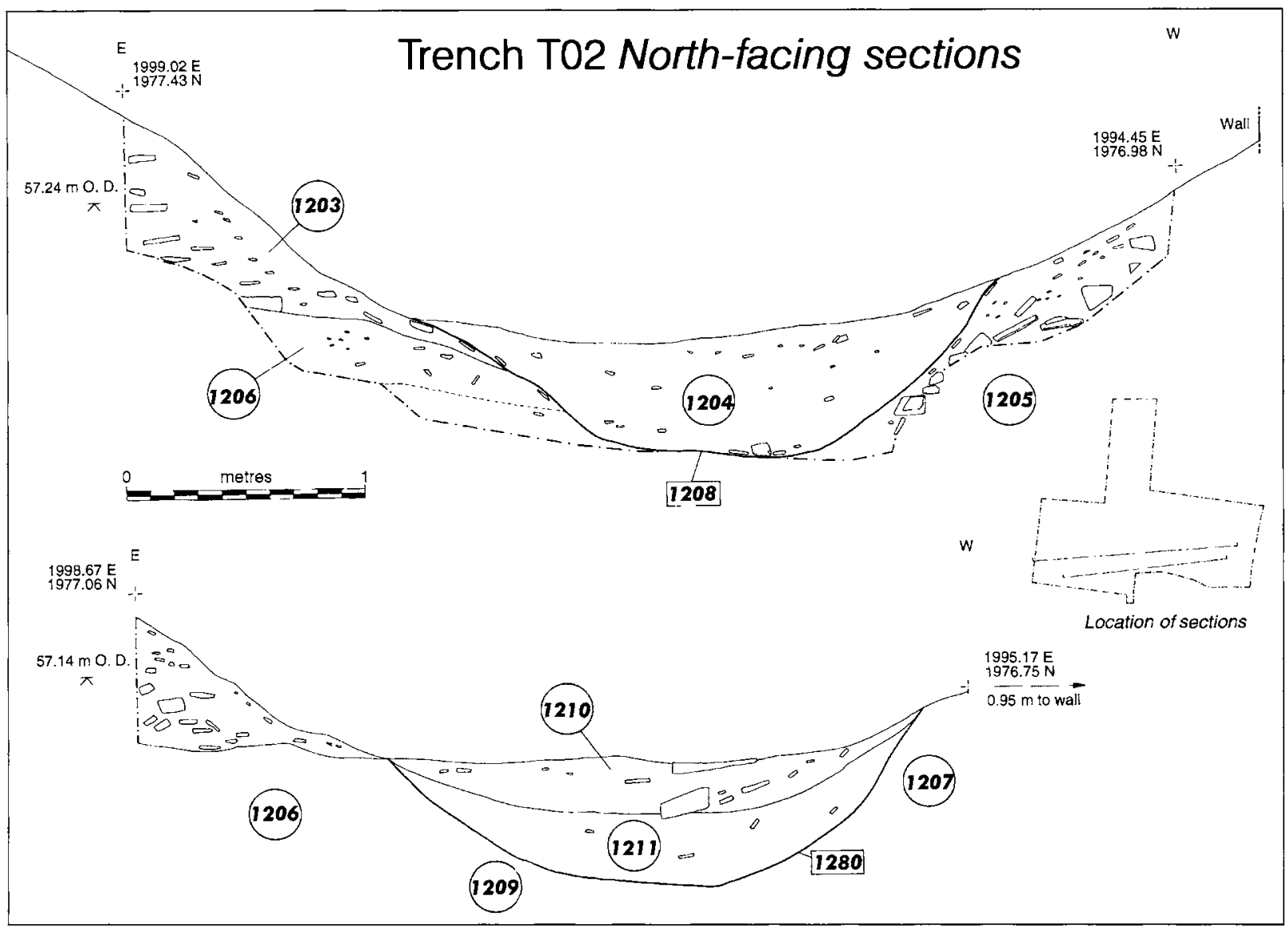

89 T02 north-facing sections. Drawing: C Evans

the digging of the ditch since 1206 and 1207 , natural erosion deposits sealing the bedrock in Phase V, were themselves cut by the Little Ditch. The profile of the ditch may originally have been more defined.

Material removed from the ditch appears to have been deposited to the east of the cut to form a low bank composed of 1203, a dump of slate fragments contained within a loose light reddish brown soil. No attempt was made to stabilize or revet the bank and some of this deposit had slumped back over the edge of the ditch in antiquity (figure 89 ).

Phase X: disuse and ruination of deposits (see figure 89). Upon disuse, a primary deposit of silt, 1211, accumulated within the ditch. This deposit contained a few small slate fragments tipping quite steeply towards the centre of the ditch. This was subsequently sealed by gritty clay 1210 . All of the slate fragments tipped at a shallow angle towards the centre of the ditch. This latter deposit is probably associated with the ruination of the wall running alongside the road to the west of the ditch.

The above deposits were only identified during the course of the excavation of an undisturbed spit of the ditch located to the south of Radford's trench. Up to that point it was assumed that the ditch contained a single, heterogeneous clay and slate fill 1204. The distinction between 1211 and 1210 was not clear in the exposed north-facing section of Radford's trench. In retrospect, deposit 1204 was the equivalent of 1210 but with orientation of its slate inclusions disturbed in the 1930s.

Phase X: artefacts, ecofacts and dating (table 32). Two sherds of post-medieval North Devon Calcareous ware (NC) green-glazed pottery were recovered from 1204 . These jar or jug sherds suggest a sixteenth- to early seventeenth-century date for these deposits accumulated within the ditch. 
Table 32 T02 Phase X: contexts and finds

\begin{tabular}{lll}
\hline Context & Context description & Finds \\
\hline 1204 & Light brownish-grey, gritty clay with slate & $\begin{array}{l}\text { One post-medieval NC sherd (RF 5027). Seven } \\
\text { indeterminate cereal fragments }\end{array}$ \\
1210 & $\begin{array}{l}\text { Light brownish-grey, gritty clay with slate } \\
1211\end{array}$ & Light olive brown, clayey silt with slate
\end{tabular}

Pollen samples were taken from contexts 1210 and 1211 above 1209 (see Chapter 11, table 85). The pollen samples from these layers are dominated by dandelion and related Asteraceae pollen, but also contain sedges, grasses and grains of ribwort plantain. Seven indeterminate cereal fragments were also recovered from this phase.

Phase Y: Radford's trench (see figure 88). This 1938 trench was observed cutting the silts and destruction deposits of Phase $\mathbf{X}$, and the ditch and bank of Phase W. The cut 1201 was approximately $0.75 \mathrm{~m}$ wide (equating with the standard width of most of Radford's trenches at Tintagel, $2 \mathrm{ft} 6 \mathrm{in}$ ) and traversed the ditch from west to east. The cut commenced at the boundary wall of the road leading to the Lower Ward and terminated approximately halfway through the bank delimiting the ditch to the east. The bottom of the cut was near horizontal and no attempt had been made to follow the naturally sloping stratigraphy of the site, contrary to the impression given in the south-facing section recorded by Wright (see figure 85). The cut was subsequently backfilled with 1202 , loose brown soil containing slate rubble lying at various angles. This deposit was only partially removed from Radford's trench 1201 in order to comply with Health and Safety policy.

Since the limit of excavation of the 1930s trench did not correspond with the bottom of the ditch, Radford's cut was over-excavated in order to ascertain the true profile of the ditch. This too was then over-excavated, within the confines of the 1930s trench only, in order to examine the deposits cut by the ditch.
Phase Y: artefacts, ecofacts and dating (table 33). Finds from this phase are very mixed: modern bottle glass, terracotta drainpipe, glazed pottery and a land snail shell (Helix aspera). Also among the clearly modern debris were two notched slates from context 1202 , which could have been displaced from earlier contexts, or even accidentally chipped in more recent years.

Phase Z: turf and topsoil. 1200 sealed all of the above deposits.

Phase Z: artefacts, ecofacts and dating (table 34). Finds included fragments of modern window/bottle glass, terracotta drainpipe fragments, modern pottery, a piece of mortar/cement, a single pebble and a slate disc. A medieval Stuffle ware handle sherd, and two large mammal caudal vertebrae were also recovered.

\section{DISCUSSION}

\section{THE TRIAL TRENCHES}

Although the three trial trenches were essentially 'reconaissance activity', in two cases (T03 and T04), they successfully located trenches opened by Ralegh Radford in the general area of Site T in 1938 and 1955. No excavation took place beyond the uncovering of the trenches and the geological feature identified in trench T05.

\section{THE LITTLE DitCh (TRENCH T02)}

Trench T02 was also designed to locate the original Radford cutting made in 1938 . Once located the cutting

Table 33 T02 Phase Y: contexts and finds

\begin{tabular}{lll}
\hline Context & Context description & Finds \\
\hline 1201 & Cut of Radford's 1938 trench & \\
1202 & Fill of Radford's 1938 trench & $\begin{array}{l}\text { Modern bottle glass (RF 5020), 197 fragments of modern terracotta } \\
\text { drainpipe (eg RFs 5018 and 5026), modern pottery (RF 5024), snail }\end{array}$ \\
& & shell (Helix aspera) (RF 5017), two notched slates (RF 5021) \\
\hline
\end{tabular}


Table 34 T02 Phase Z: contexts and finds

\begin{tabular}{lll}
\hline Context & Context description & Finds \\
\hline 1200 & Dark reddish-brown loamy topsoil & Twenty-two fragments of modern window/bottle glass (RFs 5000, \\
& $5004,5009), 105$ modern terracotta drainpipe fragments (RFs \\
& $5001,5002,5007,5010,5011,5012,5013$ ), modern pottery (RF \\
& $5003)$, pebble (RF 5006), one medieval SA handle sherd (RF \\
& $5008)$, slate disc (RF 5014), two indeterminate large mammal \\
& caudal vertebrae (RFs 5015 and 5016), mortar/cement (RF 5005) \\
\hline
\end{tabular}

was extended into undisturbed deposits. The stratigraphy thus exposed was primarily that of the $U$ shaped trench profile and a low bank to the east (Phase $W$ ), followed by the disuse and partial infilling of the ditch in Phase X. The primary silting phase contained sixteenth- to seventeenth-century pottery, which gives a terminus ante quem for usage of the Little Ditch. Unusually for Tintagel, there were no post-Roman imported pottery sherds, even in Radford's backfill (Phase $\mathrm{Y}$ ), which suggests that the dating of the feature should, indeed, be related to the construction and then extension of the medieval Castle.

\section{CONCLUSION}

The trial trench over the Little Ditch (T02) has enabled a later medieval date to be assigned to this feature, and an association with the building/occupation of the Castle. Other ditches known to belong to the Castle phase (such as the ditch adjacent to the Lower Ward walls excavated by Cornwall Archaeological Unit in $1986)^{4}$ are shallow and narrow and the walls themselves are not monumental in terms of thickness; the evidence from the re-examination of the Little Ditch is consistent with this. 


\title{
CHAPTER 8
}

\section{ARCHAEOLOGICAL ASSESSMENT IN 1999 of C A RALEgH RadFORD'S TRENCHES IN THE GREAT DITCH, SiTE T}

\author{
with contributions from KeVIN J BRADY, DAVID JeFFERSON and PAUL G JOHNSON
}

\begin{abstract}
In 1999, the Great Ditch (Site T) was re-examined and the results of these recent excavations demonstrate that it was in use in the immediate post-Roman centuries. Consequently, it is clear that this defended the largest post-Roman citadel so far discovered in Britain. Furthermore, geological assessment suggests that the Great Ditch was manually quarried in places to enhance a naturally defensive feature. These findings highlight the significance and sheer scale of the site in the early medieval period.
\end{abstract}

\section{GEOLOGICAL OBSERVATIONS ON THE GREAT DITCH \\ by David Jefferson}

The Great Ditch is clearly orientated parallel to a geological fault and fold axes. The linear cliff-like feature on the east side of the valley appears to be a geological fault, and has been mapped as such by the Geological Survey. However, the geological map then shows the fault passing along the south side of the Great Ditch, joining a second fault, which apparently forms the north side of the Ditch, before passing under the Upper Ward. Field observations and a study of aerial photographs suggest that this is a misinterpretation of the geology, possibly due to the fact that the Survey geologists did not appreciate the engineered nature of the Great Ditch. The concept that the 'fault' may have been used as the north side of the Ditch may also have resulted from a misunderstanding of the nature of the faults in the immediate area. The wall-like feature on the east side of the valley (figure 90) does not represent the fault plane. The fault is almost horizontal and occurs at the base of the cliff. The 'thrust' faults and the rock between them act rather like a pack of cards lying on a slightly inclined surface, where the cards will slide sideways over each other. The cliff-like features are merely the weathered edges of a portion of one of the layers, represented by the playing cards in the analogy. As these harder portions of the strata appear to be intermittent, the clifflike features will not be continuous. It is considered that the cliff upon which the southern wall of the Upper Ward is built is the extension of the feature on the east side of the valley, and that the outcrop of the fault plane passes a little to the south of the Great Ditch (figure 91).

Based upon the outcrops of stone at the eastern end of the north side of the Ditch, it is considered that the original landform consisted of a small but steep southfacing drop, with scattered steep and possibly overhanging outcrops. South of this, the land may have risen again slightly. This would have the appearance of a shallow valley trending in an easterly direction down the hillside. It is suggested that this natural ditch-like feature was modified by deepening it, using the excavated waste to build up the southern side, and then smoothing off both sides. The height of the northern side was increased further by the material used to build up the platform beneath the Lower Ward. It is believed that the floor of the Ditch is flat. This will probably follow one of the natural cleavage surfaces in the stone and may even be on or close to the fault plane. 


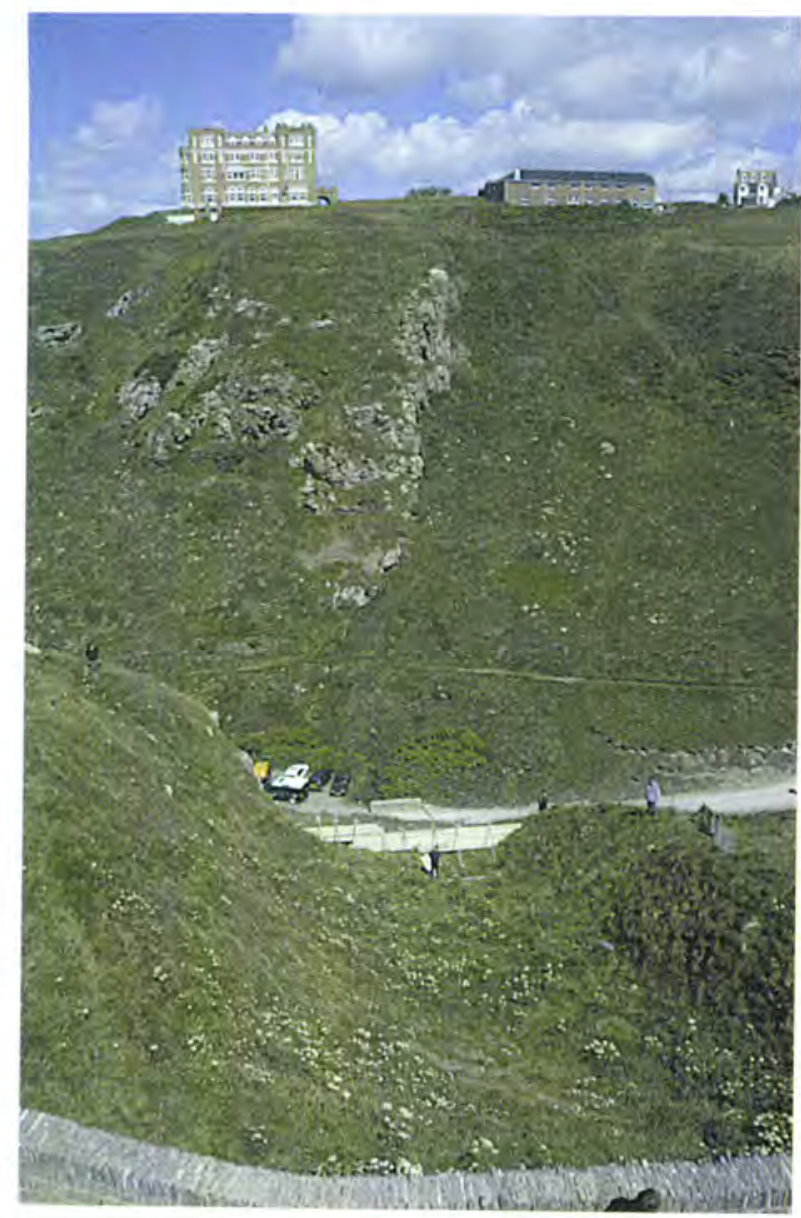

90 Geological fault on the east side of the valley, from the west.

Photograph: K J Brady

\section{FIELDWORK METHODOLOGY AND SYNOPSIS OF WORK UNDERTAKEN}

The background to and context of the excavations in 1999 have been described in the previous chapter.

TRENCH T01, THE LOCAL GRID

by Paul G Johnson

Two separate attempts at creating a site grid that would facilitate the excavation and recording of trench T01 were made. The first, a site grid which was designed to control the excavation of all Site $\mathrm{T}$ trenches, was based upon a base line constructed at the top of the northernmost lip of the Great Ditch, just south of the curtain wall of the Lower Ward. This proved to be unworkable for the excavation team due to the severity of the slopes involved in both horizontal axes. The fact that Radford's trench was neither perpendicular to this grid nor to the Great Ditch itself complicated matters further. An alternative means of controlling the excavation and recording was devised once the full extent of Radford's trench was known, and comprised a 'ladder grid' composed of two parallel rows of survey points established at either side of Radford's trench. The exact position of each point within the ladder was established in three dimensions by EDM, and the ladder grid and excavation trench were both subsequently recorded in relation to the Simmons site control framework by using a Total Station Theodolite.

\section{TRENCH T01, THE EXCAVATION}

This was the main thrust of the 1999 season. A trial trench was cut west to east across the pronounced north to south slump that bisects the Great Ditch and which had long been supposed to mark the line of Radford's 1938-9 trench (see Chapter 7, figure 83). This trial trench was located at the base of the ditch. It was quickly apparent that there was a quantity of overburden and slippage from the west down-slope to the east, which had slumped following the 1938-9 work. Much of this overburden was undoubtedly caused by the movement of Radford's own spoil-heaps and of the dry-stone walls which were built to retain those spoil-heaps and which are visible in the 1938 photographs (see Chapter 1, figure 18). It is probable that other episodes of spoil clearance into the Great Ditch occurred after the 1938 season (although it is also possible that the trench remained open until the following year when the section was certainly drawn or at least checked (see Chapter 1), with smashed clay pipe and slate thrown into this area from the Upper and Lower Wards. In 1999 all of this debris masked the cut of the Radford trench until much of it had been removed. When the line of that trench had been confidently identified, in a trench $3.9 \mathrm{~m}$ east-west and $1.3 \mathrm{~m}$ north-south, an area was deturfed across the base of the ditch large enough to reveal the full extent of the Radford cut. The removal of the turf and postRadford slippage revealed that the edges of the Radford trench were very ragged and of unequal width. Indeed, the west edge of the trench had probably collapsed prior to it being backfilled in the 1930s and was never confidently identified in 1999. The topography of the site effectively split the excavations within the Great Ditch into three distinct areas as described below. The strategy employed differed across the three areas, largely dictated by Health and Safety considerations. 

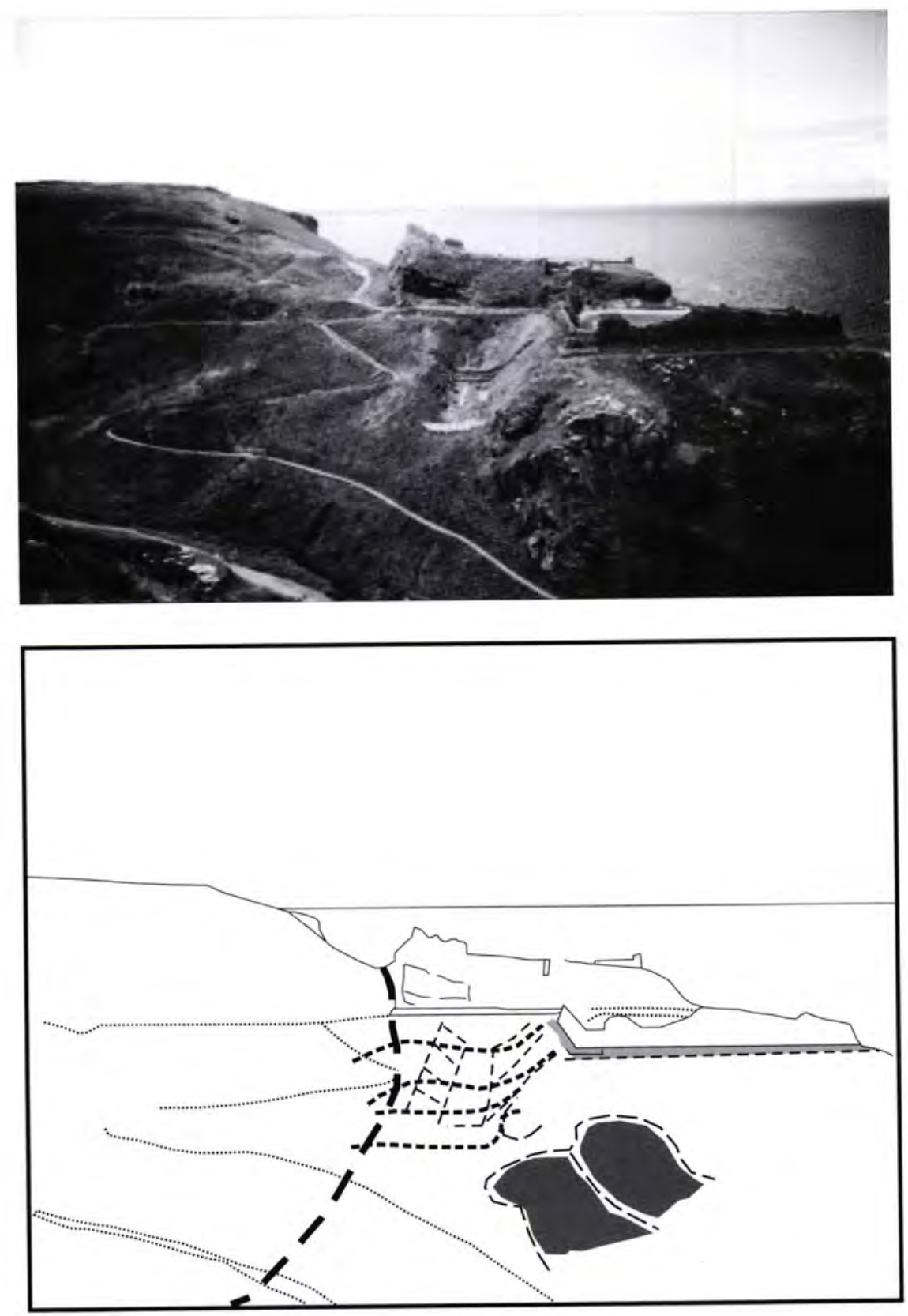

Geological fault forming a feature upon which the south wall of the Upper Ward is built. It continues as a linear cliff on the east side of the valley

Massive strata within the fault complex which gives rise to a steep cliff-like feature on its south side

Form lines on the possible original ground surface

Earth platform used to level the original irregular surface, and which also adds to the height of the northern side of the ditch

91 Geological features related to the Great Ditch.

Illustration: $D$ Jefferson 


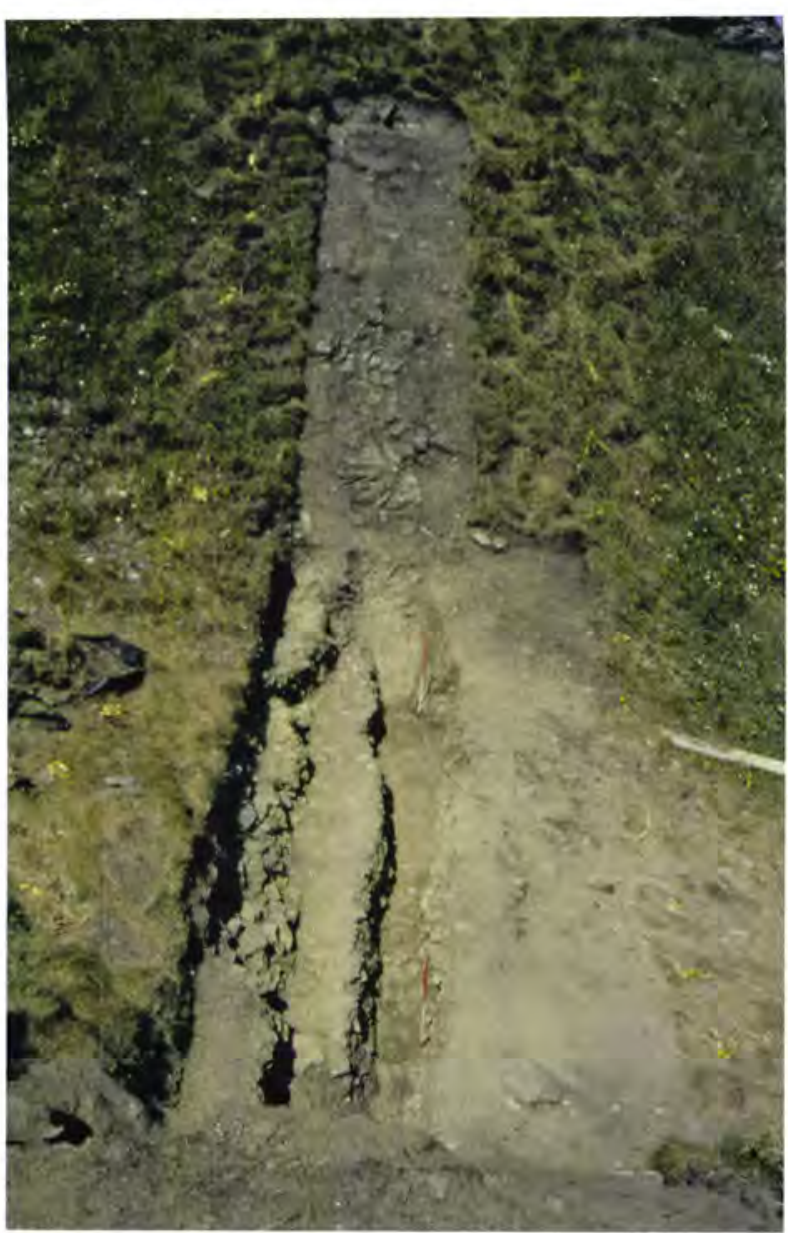

92 Trench T01 after excavation of Radford's trench.

Photograph: K J Brady

Radford's trench was identified and deturfed, with the aid of ropes and harnesses, on both the north and south banks of the Great Ditch. On the slopes of both of these banks there was little to be removed as the turf gave way almost immediately to bedrock. Where the bedrock shelved out on to a plateau on both the north and south banks about $1.2 \mathrm{~m}$ of the backfill of Radford's trench was removed at either side. At the base of the trench, Radford's backfill was emptied from his trench to a depth of $1.2 \mathrm{~m}$, the maximum permitted by Health and Safety requirements. Although the original research design had been to empty fully the Radford trench (see Chapter 1, figure 16) before examining undisturbed deposits at the side, the logistics of this were unfavourable. To open up the 1938 trench (potentially over $2 \mathrm{~m}$ deep) would have involved opening a massive area, through undisturbed deposits at either side, to step down to the bottom of that trench and thus meet Health and Safety regulations. This would have been beyond the means and time available to the team and an alternative approach was adopted after consultation with English Heritage. This approach allowed for the excavators to step the trench to the east of, and away from, Radford's backfill, after having removed $1.2 \mathrm{~m}$ of that backfill (figure 92). This had the twin benefits of opening up a smaller area and of allowing the team to examine undisturbed deposits at an earlier stage than might have been possible otherwise. It also allowed the excavators to cut their own section at the west: a section which was more stable than that left in the 1930s.

This approach allowed a strategy whereby approximately half of the depth excavated was Radford backfill, giving a chance to sieve his backfill and record the west-facing section that he had exposed. The other half of the depth excavated was through undisturbed deposits, giving a chance to examine in situ archaeology and record a freshly excavated section (figure 93). The area left to work within was sometimes as little as $0.5 \mathrm{~m}$ wide at the base. Water running down the slope west to east had clearly scoured through the ditch over the centuries, removing silts during flooding. However, primary silts that had accumulated after the last time the ditch lay open down to bedrock were recorded at the north end. Almost the entire north-south trench was excavated down to bedrock and proved that there had been some manual adaptation of the bedrock to form this ditch. This was subsequently confirmed by Dr David Jefferson (see above).

On the north and south banks it was possible to follow the original design and empty Radford's backfill across the entire trench before excavating undisturbed deposits at the east side (figure 94). On the north bank leading up towards the south wall of the Lower Ward, an area of just over $6 \mathrm{~m}$ north-south by $2 \mathrm{~m}$ east-west was deturfed with the aid of specialist rope-workers, 'Vertical Technology', who secured the excavators in harnesses and ropes fixed to anchor points at the summit of the bank (figure 95). A similar safety strategy was employed for deturfing the south bank, where an area $2.6 \mathrm{~m}$ north-south by $3 \mathrm{~m}$ east-west was opened. The rock face that makes up the south bank incline was near vertical and merely required for the overgrowth to be cleared to expose it.

As with every season and area of the excavations at Tintagel, a comprehensive sampling strategy was employed in 1999. 


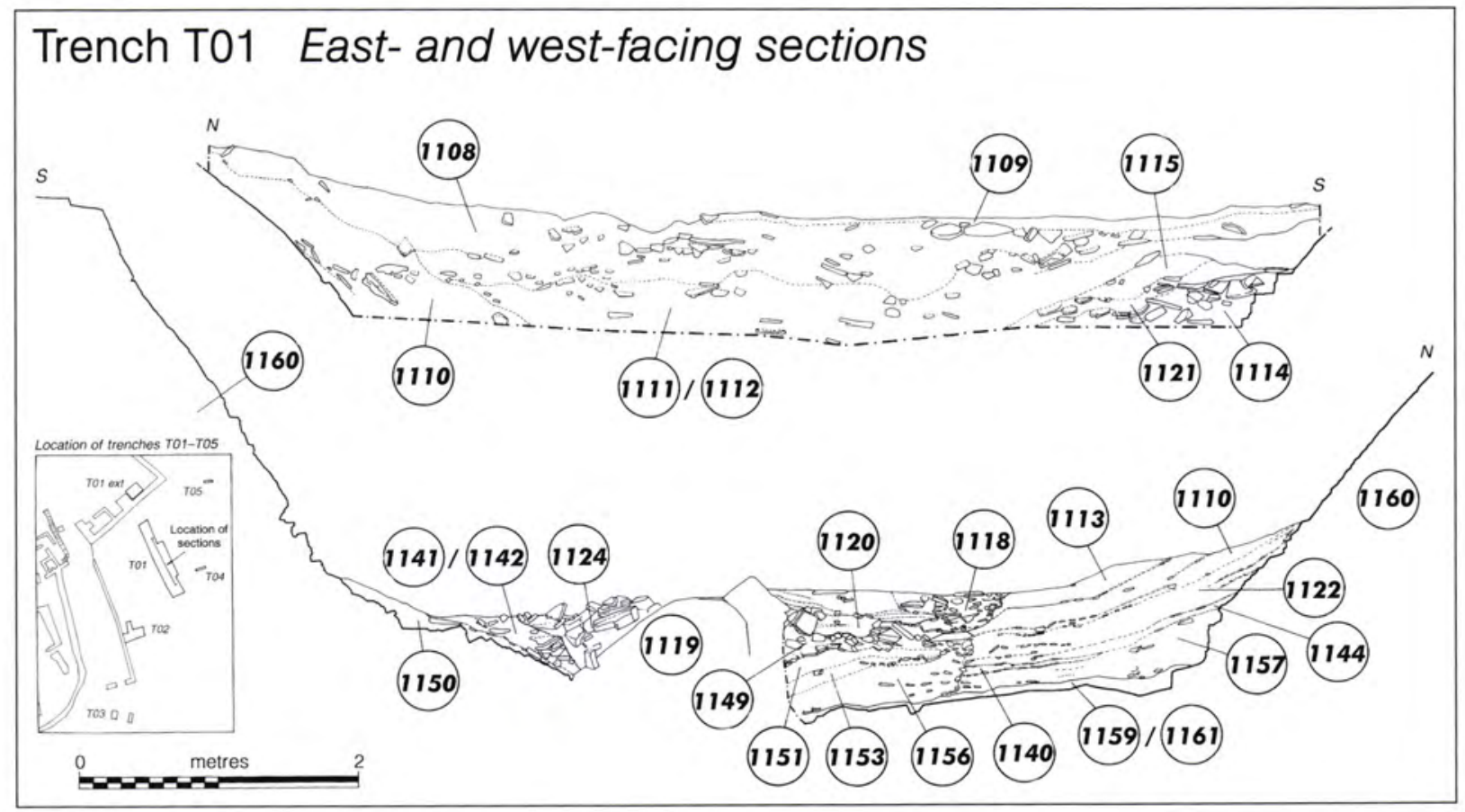

93 T01 east- and west-facing sections. Drawing: C Evans

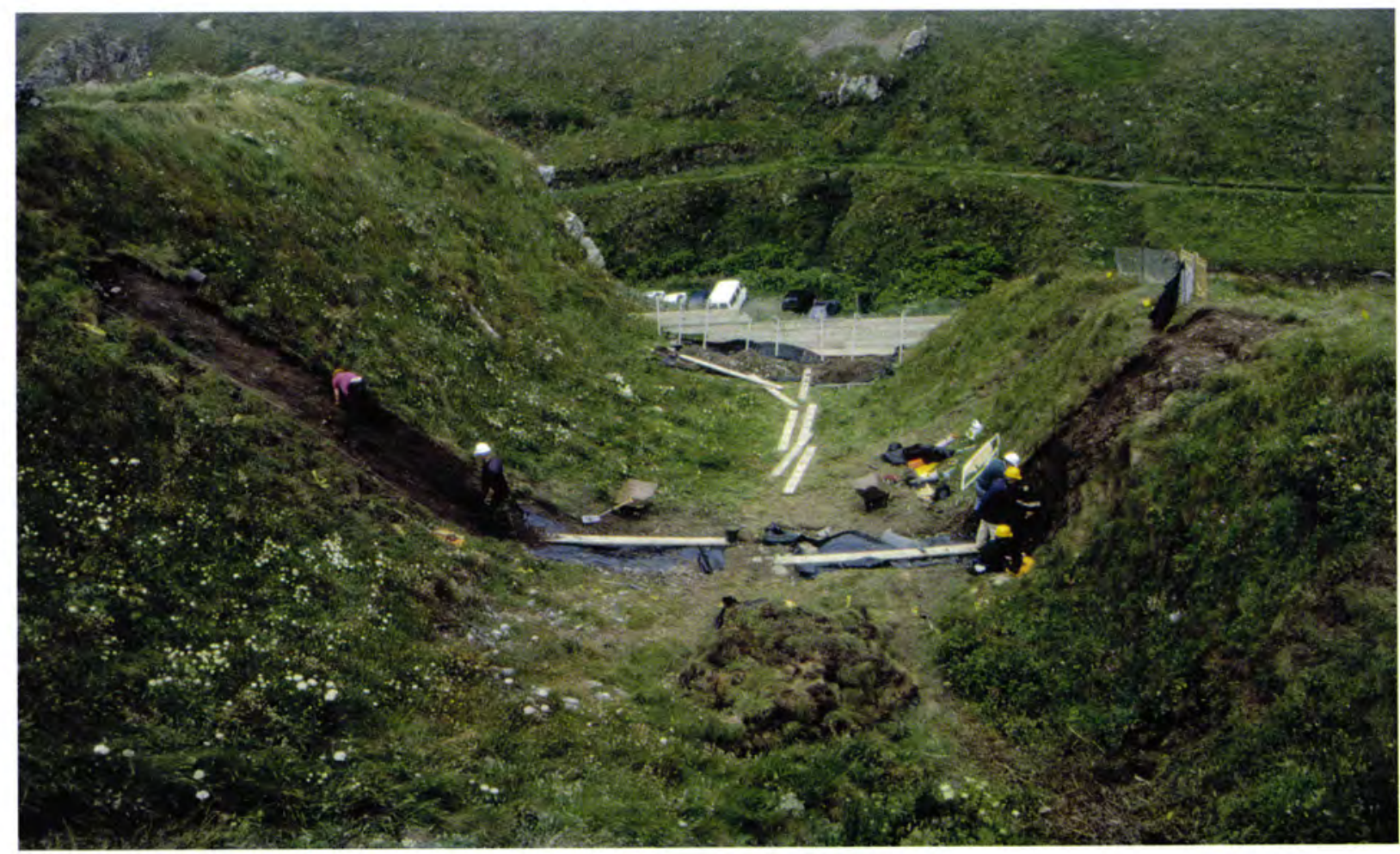

94 Excavation of trench T01. Photograph: K J Brady 


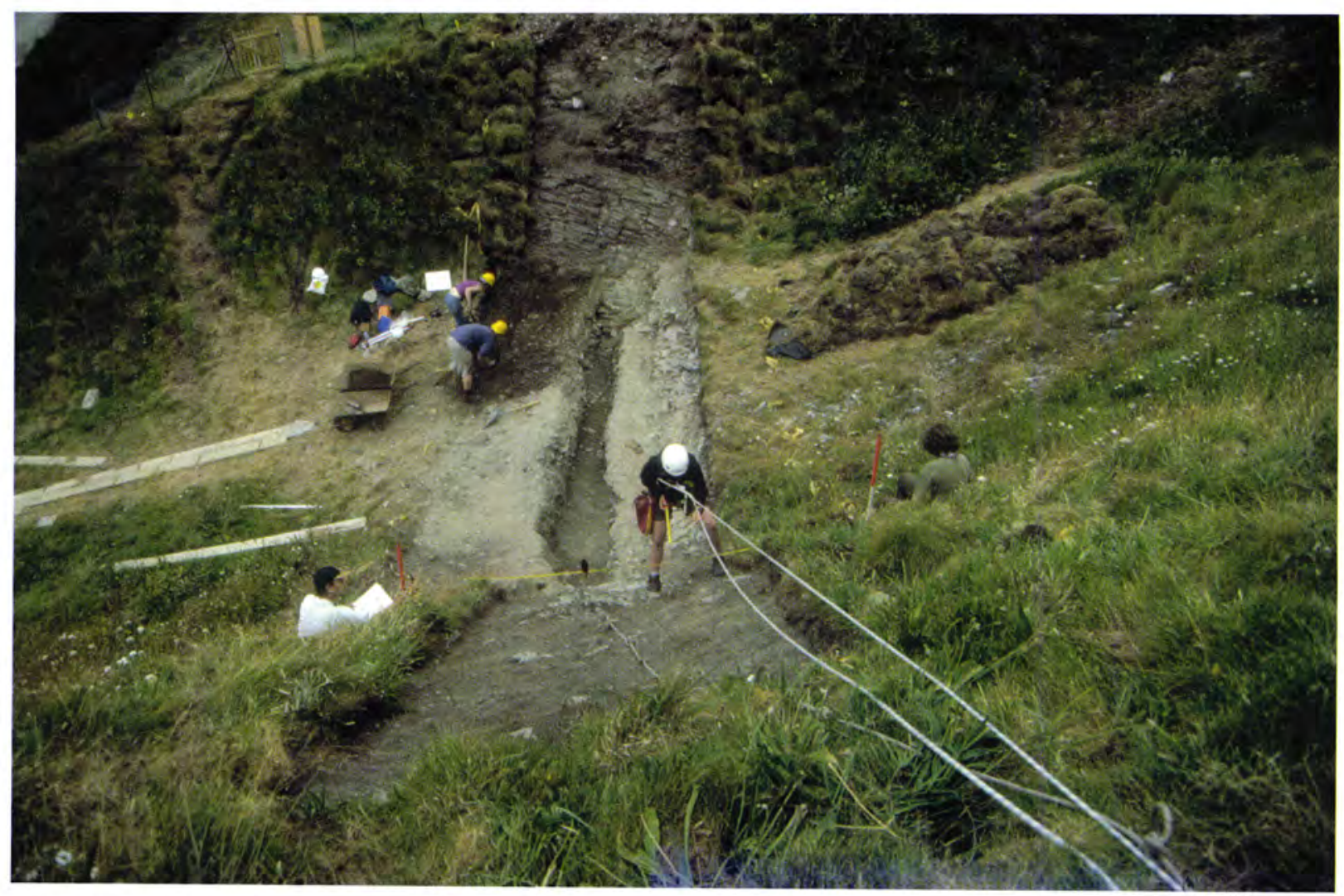

95 Photograph of Vertical Technology and planning T01. Photograph: K J Brady

\section{THE GREAT DITCH: SUMMARY OF STRATIGRAPHY AND PHASING}

Phase T: Natural deposits (figures 96 and 97)

The bedrock, 1160, underlay stony, orangey deposit 1158 below 1155, a thin band of very silty grey clay capped with a lens of iron pan. Layer 1155 is important as it probably coincides with a layer identified by Wright in his composite sketch of the section exposed by Radford (see Chapter 1, figure 16). It was marked then as an 'old turf line' that corresponded with a layer noted within the Lower Ward. The 1999 excavation established that this almost certainly was not the case. 1154, another sterile layer of grey earth, stones and shillet, overlay 1155 and was similarly identified as probably a natural deposit. Also identified in both sections was a natural layer of discontinuous blue/grey clay, 1167, that overlay 1154 and was similar to 1155 . At the south end of the trench, solid grey clay, 1171, was encountered immediately above the bedrock and a thin gravel interface between the two. This sterile deposit was viewed as naturally deposited, and was only recorded in a small area in the north-facing section.

\section{PHASE T: ARTEFACTS, ECOFACTS AND DATING}

The pollen sample from 1155, exposed in the north bank section, is dominated by pollen from the daisy family (which includes dandelion and other species), but also includes ribwort plantain, grasses, the campion family and sedge, as well as examples of elm and birch, fern, bracken and bogmoss. Oat grains, one unidentified fruit/seed and seven charcoal fragments were recovered from samples taken from this phase (see Chapter 11).

\section{Phase U: CUTTING OF DITCH AND MOdifiCATION OF BANKS (figures 96, 97 and 98)}

The exposed bedrock across the 1999 trench established that some modification of the geological feature had occurred. Outcrops of the rock face elsewhere in the valley showed the natural profile of that rock to be jagged and fairly irregular. The south bank bedrock formed almost a sheer drop and showed some signs of 


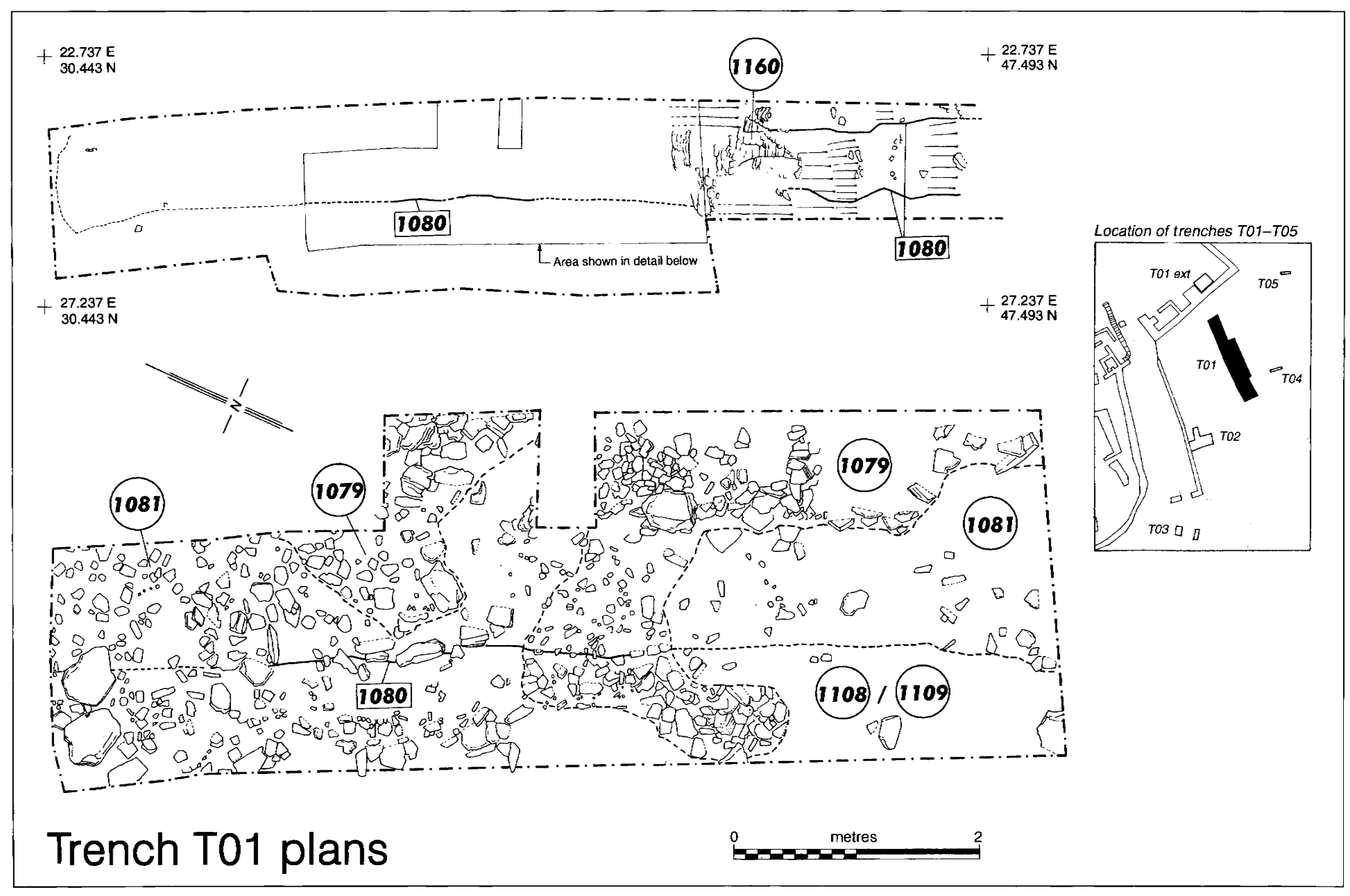

96 T01 plans. Drawing: C Evans 


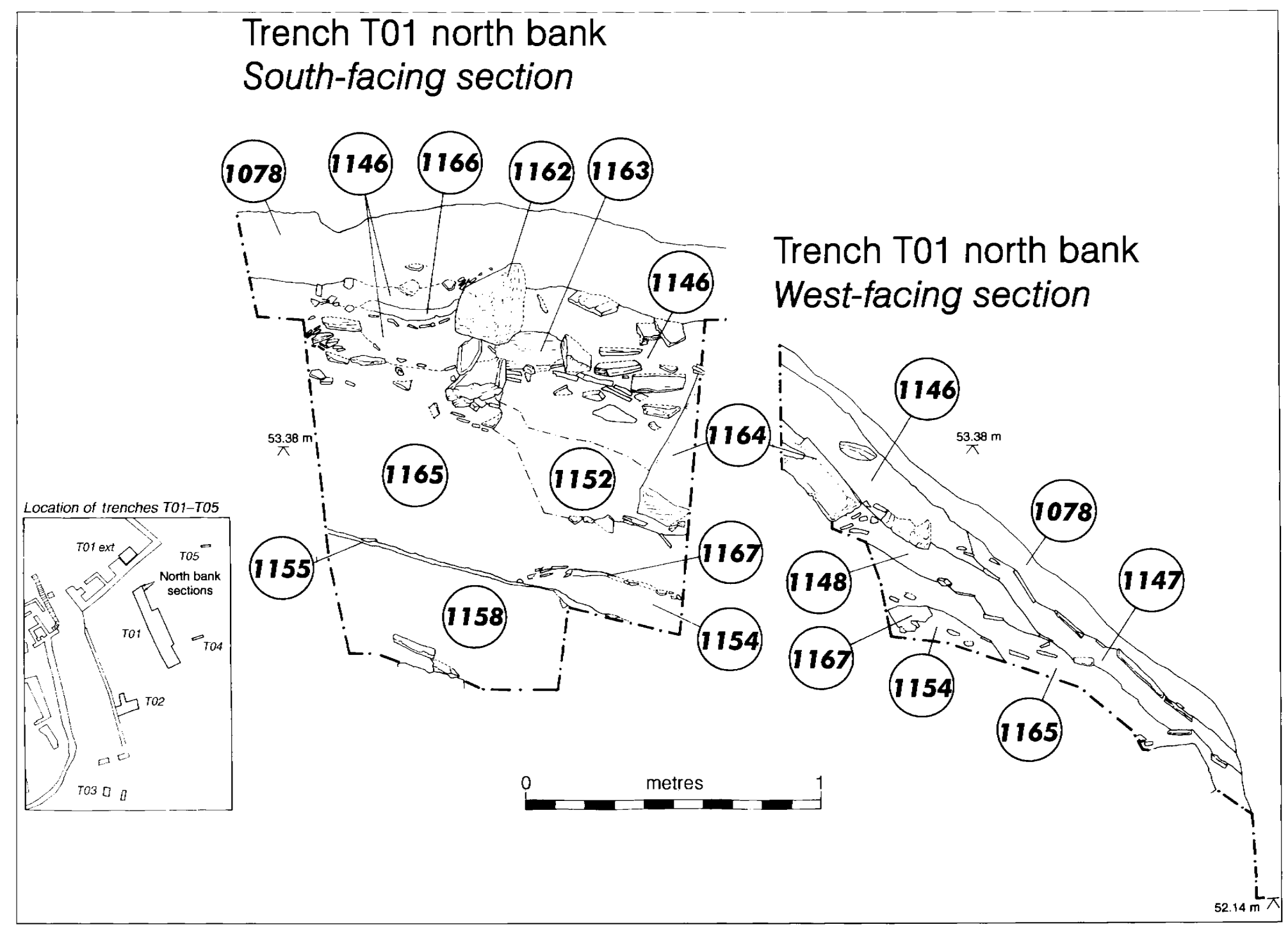

97 T0I north bank sections. Drawing: C Evans 


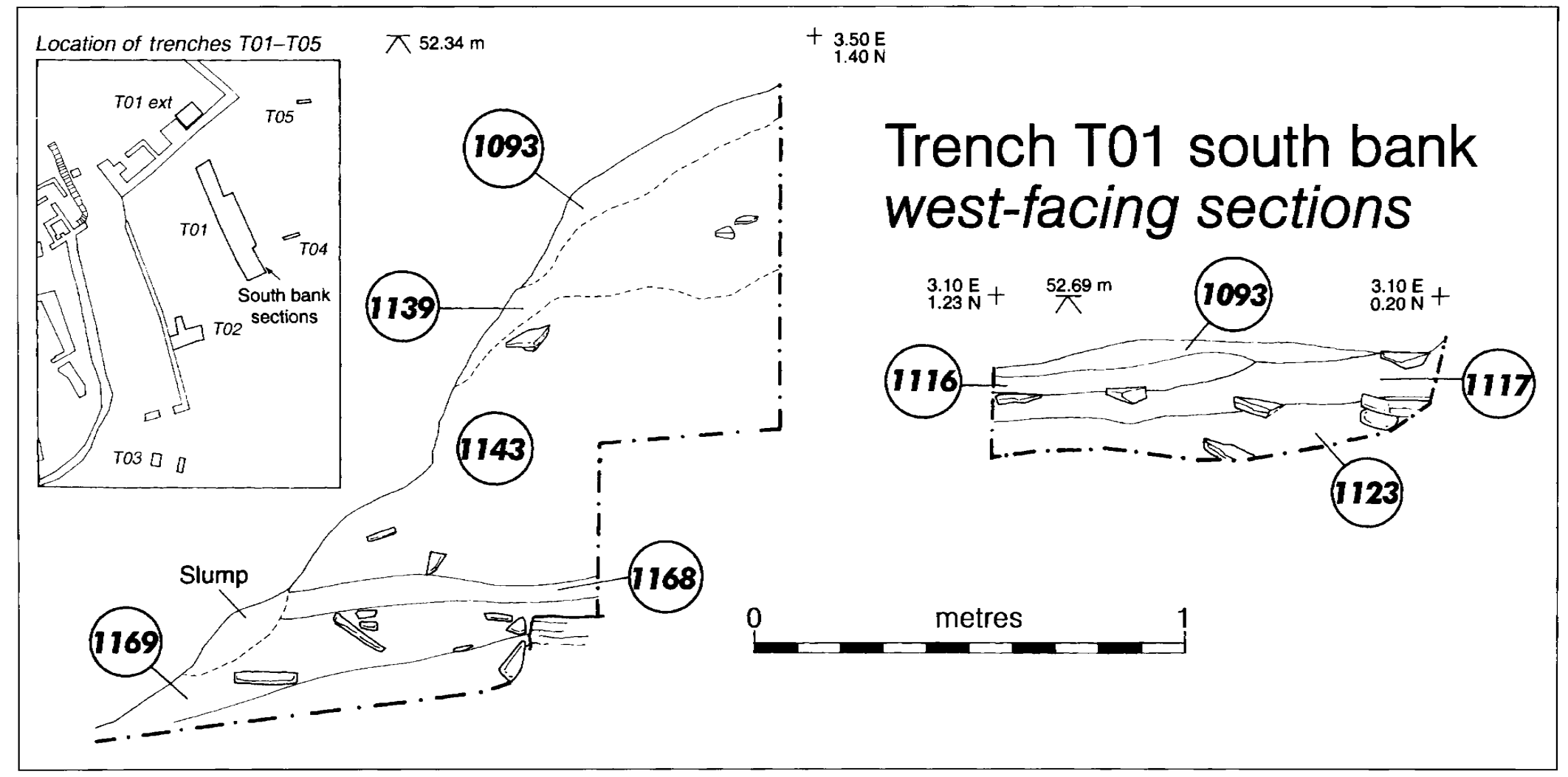

98 T01 south bank sections. Drawing: C Evans 
having been quarried to gain that effect (see Jefferson above). The exposed rock face on the north bank appeared to have been deliberately smoothed to remove the overhangs noted elsewhere. Within the confines of the trench the base of the ditch also appeared to have been fashioned or quarried to provide a flat bottom and angular returns where the north and south slopes rise above the central area. The narrowness of the excavation trench may well have produced a very selective view of the nature of the bedrock surface. However, the evidence for human modification of the bedrock surface is secure within the limited area examined.

On the north bank, there are two contexts that seem to sit between those described as 'natural' in Phase T and those clearly belonging to Phase $W$ (see below). The picture is complicated by the fact that one of these contexts was only identified in section. Located below 1152 of Phase $W$ and above 1154 of Phase T was stony clay layer 1165 . Above 1165 was stony clay 1148 , which underlay 1146 of Phase W. It is argued that these contexts, although slipped down the north bank, may originally have been deposited on the bank to heighten it, or were actually the original ground surface. These contexts had no associated finds but the layers above have collapse and waste from the medieval Castle and the layers below are sterile and geologically derived.

On the south bank, below the 1930s disturbance noted in Phase $\mathrm{X}$ below, were a succession of layers which have been identified as deposits placed on top of the bedrock at the point where it shelves horizontally away to the south. Above 1171 of Phase T, and only evident in the north-facing section, were clays 1168 , 1169 and 1170 . Overlying 1168 , clay 1143 had been partially disturbed by animal burrowing. Located above these contexts, but further up the bank at the summit to the south of Radford's cut, was context 1127. This was not excavated as it was outside the area of examination, but it is presumed to be a further make-up deposit of the bank. Overlying 1127 was clayey loam 1123 and stony clay 1117.

\section{Phase U: ARTefacts, ECOFACTS AND DATING} (table 35)

A small group of stone finds was recovered from this early phase, comprising notched slates, a perforated slate and a worn pebble.

Four small but significant finds of abraded sherds of fifth- to seventh-century imported pottery were also made. Among these, one sherd is identified as Bi amphora, but the remainder are too abraded to identify beyond a general $\mathrm{B}$-ware designation, due to exposure of deposits in the section and disturbance from animal burrowing.

Ecofactual material recovered includes a grass family caryopsis fragment, a barley grain, an oat grain and several charcoal fragments, including a fragment of hazel charcoal.

Table 35 T01 Phase U: contexts and finds

\begin{tabular}{|c|c|c|}
\hline Context & Context description & Finds \\
\hline 1117 & $\begin{array}{l}\text { Moderate to firmly compact, mid-yellow- } \\
\text { brown clay }\end{array}$ & $\begin{array}{l}\text { Three unidentifiable B-ware amphora sherds (RF } \\
4220 \text { ), two notched slates (RF 4221) }\end{array}$ \\
\hline 1123 & Moderately firm, yellow-brown clayey loam & $\begin{array}{l}\text { A grass family (Poaceae) caryopsis fragment, } \\
\text { charcoal }+\end{array}$ \\
\hline 1127 & Make-up deposit of south bank. Not excavated & \\
\hline 1143 & Very firm, brownish-yellow, silty clay with shillet & One Bi amphora sherd (RF 4255) \\
\hline 1148 & Grey clayey earth with angular stones and shillet & \\
\hline 1165 & Grey clayey earth with angular stones & \\
\hline 1168 & Crumbly, brownish earth on north bank & Perforated slate (RF 4314) \\
\hline 1169 & Lumps of yellow clay on north bank & $\begin{array}{l}\text { Notched slate (RF 4315). One barley (Hordeum sp.) } \\
\text { grain, one unidentifiable fragment, hazel (Corylus } \\
\text { avellana) charcoal + }\end{array}$ \\
\hline 1170 & Clay, greyer than 1169 and with fewer stones & $\begin{array}{l}\text { Worn pebble (RF 4316). One oat grain (Avena sp.), } \\
\text { charcoal + }\end{array}$ \\
\hline
\end{tabular}

Charcoal fragments $>2 \mathrm{~mm}:+1-10$ 


\section{PHASE V1: PRIMARY FILL OF DITCH (see figure 93)}

The area with the least disturbed silting deposits was located at the far north end of the trench. The main drainage direction from up-slope west (Upper Ward) to east meant that the ditch had acted as a funnel for all the rainwater from the slopes of the north and south banks and the area of the Upper Ward. This would have led to a greater volume of water pouring down the lowest part of the central depression of the ditch than would be evident at the foot of either bank. This process was reflected in angles of the redeposited shillet and stone inclusions of many of the contexts. The contexts against the north bank rock face clearly accumulated from material silting down that bank. The drainage pattern of the area adjacent to the south bank was affected by the presence of a large slab (see 1119 in Phase $\mathrm{W}$ below).

The deposits encountered next to bedrock in the area north of the slab 1119 of Phase W were silts and decayed bedrock $1159 / 1161$. This context is presumably the result of the weathering of the exposed bedrock after the ditch was manually adapted. Over 1159/1161, and clearly silted in from the area of the north bank, was fine silt 1157 , then shillet 1140 and silt 1144 . Overlying 1144 was silt and shillet 1122 .

\section{PHASE V1: ARTEFACTS, ECOFACTS AND DATING} (table 36)

Two sherds of Bi amphora, two unidentifiable B-ware sherds and one sherd of African Red slipped ware (ARSW) (RF 4266) were excavated from this phase. No further finds were recovered. Charcoal fragments from primary silt 1161 of this phase were submitted for radiocarbon dating and produced dates spanning a considerable period (see Chapter 11), with a terminus post quem of up to the second half of the seventh century $\mathrm{AD}$ (see discussion in Chapter 12). Earlier dates from this phase may suggest activity in the Romano-British period, although this is not indicated in this very small ceramic assemblage.

Context 1161 was relatively rich in ecofactual material, producing several charcoal fragments, the larger ones including hazel or alder, oak, birch and rose family.

\section{PHASE V2: PRIMARY FILL OF DITCH \\ (see figure 93)}

Directly overlying $1159 / 1161$ of Phase V1 was silty clay and stones 1156, then silt and stones 1153 and silt and shillet 1151 . These three contexts may represent primary fills of the ditch. However, as the axis of the stones recorded is different, it was felt safer to place $1151 / 1153 / 1156$ as a separate event to the layers in Phase V1. The drainage pattern seems to suggest that periodical torrents have pushed deposits from the west down to the east, and effectively truncated those fills at the north bank recorded in Phase V1.

\section{PhaSe V2: ARTEFACTS, ECOFACTS AND DATING}

(table 37)

The artefactual assemblage recovered from this phase consists entirely of imported post-Roman Mediterranean ceramics, including ten $\mathrm{Bi}$ (one a possible amphora disc), two $\mathrm{Bv}$, and three unidentifiable amphora sherds and one sherd from an imported Coarseware, Fabric 1.

Table 36 T01 Phase V1: contexts and finds

\begin{tabular}{|c|c|c|}
\hline Context & Context description & Finds \\
\hline 1122 & Light yellow-brown silt with shillet inclusions & \\
\hline 1140 & Well-sorted shillet & $\begin{array}{l}\text { One unidentifiable B-ware amphora sherd (RF } \\
4250 \text { ) }\end{array}$ \\
\hline 1144 & Light yellow-brown fine silt & $\begin{array}{l}\text { One ARSW sherd (RF 4266), two Bi amphora } \\
\text { (RFs } 4269 \text { and 4271) and one unidentifiable B-ware } \\
\text { (RF 4270) }\end{array}$ \\
\hline 1157 & Compact, light yellow-brown, fine silt small stones & \\
\hline 1159 & Clayey silt, shillet, iron pan and decayed bedrock & \\
\hline 1161 & $\begin{array}{l}\text { Loose, brown-grey silt with } 80 \text { per cent small } \\
\text { stones }\end{array}$ & $\begin{array}{l}\text { Six hazel or alder (Corylus avellana or Alnus } \\
\text { glutinosa) and one oak (Quercus sp.) charcoal } \\
\text { fragment, one birch (Betula sp.) fragment, one rose } \\
\text { family (cf. Rosaceae) fragment and one } \\
\text { unidentified bark fragment }\end{array}$ \\
\hline
\end{tabular}


Table 37 T01 Phase V2: contexts and finds

\begin{tabular}{lll}
\hline Context & Context description & Finds \\
\hline 1151 & $\begin{array}{l}\text { Light yellowish-brown, silty gravel, slates } \\
\text { and shillet }\end{array}$ & $\begin{array}{l}\text { Six Bi amphora sherds (RFs 4277 and 4278: } \\
\text { possible amphora disc) and unidentified B-ware } \\
\text { (RF 4276) }\end{array}$ \\
1153 & Light brown silt with frequent angular stone/slate & $\begin{array}{l}\text { One Bi amphora sherd (RF 4319), two Bv (RFs } \\
4282 \text { and 4284) and two unidentified B-ware (RFs } \\
\end{array}$ \\
& Firm, grey-green, silty clay with stones & $\begin{array}{l}4281 \text { and 4283). Charcoal + } \\
\text { Three Bi amphora sherds (RFs 4286 and 4317) and } \\
\text { one Coarseware Fabric } 1 \text { (RF 4318). Three } \\
\text { unidentified charred fragments }\end{array}$ \\
& &
\end{tabular}

Charcoal fragments $>2 \mathrm{~mm}:+1-10$

Six unidentified charcoal fragments and three unidentified charred plant macrofossil fragments were also recovered from this phase.

Phase W: POST-CASTle Fill OF DITCH AND COLl.ApSE EVIDENT ON NORTH BANK (see figures 93, 96 and 97) The contexts that make up the later fill of the ditch were recorded mainly in the exposed west-facing section of Radford's trench. Many of the contexts described below were limited to small areas of the trench, and intercontext difference was often merely a different angle of tilt of stone inclusions.

It should be noted at this point that the area within the central depression of the Great Ditch has various slopes leading into it. The entire feature slopes down from the west to the east, and the north and south banks of the ditch slope into the central area. This is important as it gives three areas from which fill is likely to enter the Great Ditch before it drains eastwards down to the stream at the base of the valley. This had a scouring effect on the fills within the ditch, as noted in Phase $\mathrm{V}$ above.

A massive slab of bedrock, 1119, was encountered towards the south end of the trench overlying bedrock. This created considerable logistical problems for the excavators, as it effectively cut off the southern 2 to $2.5 \mathrm{~m}$ of the trench from the northern area and it could not be removed. The channel created between the south bank bedrock and this slab altered the flow pattern, which resulted in the removal of primary deposits. It is not known whether this slab arrived here from either the north or south bank or from the up-slope at the west, or in which phase. It is placed in this phase due to the effect that it has had on the deposits to the south, which are markedly different to those at the north.
South of the boulder 1119 , silt with small stones, 1150 , overlay bedrock of Phase $\mathrm{T}$ and was the earliest deposit encountered in the south area of the ditch. Overlying 1150 was silt with stones, 1141 , very similar to 1142 , which was further to the north and closer to the boulder. These stones may have arrived here as part of the same process that brought the huge boulder into the ditch.

Stone tumble 1124 partially overlay the boulder and silt 1126 was excavated to the south.

Overlying 1151 of Phase V2 was silt and stones 1149, which may have acted as a filter for deposits washing from the west, as attested by silt 1120 . Silt 1120 was concentrated over the area of 1149. This context was clearly deposited in a succession of washes down the slope and does not relate to either bank. The lens of shillet and gravel within 1120 perhaps represent heavier rainfalls where larger material has been moved downslope. The mixed nature of the finds from this layer (see below) confirms that this is wash of various deposits from further up the slope at the west.

Above 1120 was 1118 , a tumble of silt and slates overlaid by silt and stones 1113 , which covered most of the central area of the trench. Overlying 1126 (see above) was silt, slate and stones 1114 , and over this, at the south end of the trench, was silt and shillet 1121, and silty clay 1115 . There were no finds from any of the above contexts.

Overlying 1113 was silt, stones and shillet 1112 . No finds were recovered from this layer. To the north was silt, clay and shillet 1111 , possibly the same as 1112 , but with a concentration of collapsed stones. At the north edge of the trench, adjacent to 1111 , was silty clay and stones 1110 which had tumbled from the north bank and rested against the bedrock in this area. 
Evident across much of the central area of the ditch was tumbled clayey loam and stones 1108 , and to the south of the trench was silty clay 1109 that had slumped from the south bank above.

These upper contexts encountered in the excavation of the north bank had clearly derived from either construction debris as the medieval Castle was built or, more likely, have been deposited as that structure collapsed. Above 1165 of Phase $U$ was silty clay and stones 1152 . 1146 was differentiated only by the presence of large stones. Three large slabs from the Castle walls $(1162,1163$ and 1164) were recorded protruding from the south- and west-facing sections of 1146 and were not removed as this would have collapsed the section. A band of silty clay, 1166, was also recorded within 1146 in the south-facing section. Overlying 1146 on the westfacing section only was loam and gravel 1147, a further layer of slump from the direction of the Lower Ward into the area of the Ditch.

\section{PHASE W: ARTEFACTS, ECOFACTS AND DATING}

(table 38)

A mixed artefactual assemblage was found in this phase, and it is the earliest phase from which medieval ceramics were identified, including Stuffle-type ware (SA) (eg SA8; RF 4217), North Devon Medieval Coarseware $(\mathrm{OK})$, Lostwithiel ware and eight sherds of unclassified unsourced wares (UU). The unsourced wares included three types of jugs, all from context 1120 . Later postmedieval Sandy Redware (SR) was also recovered.

Residual post-Roman imported Mediterranean ceramics were also recovered from this phase, including some unidentifiable beyond an attribution to B-ware, due to their abraded state, and two sherds identified as $\mathrm{Bi}$, one of which had been shaped into an amphora disc stopper (RF 4207), one sherd of Bii and one sherd of Bv amphora.

The non-ceramic finds from this phase are mixed and comprise mortar pieces, the largest of which have been examined by Dr Timothy Palmer (Chapter 10), modern pipe, a perforated stone disc ( $R F$ 4186: see Chapter 10, figure 119), a grooved slate, terracotta drainpipe and modern glass. A notched architectural structural slate (RF 4245) has been identified by Dr Francis Kelly as a simple walling stone.

The only other noteworthy find from this phase is a corroded iron object of sub-triangular form, probably modern in origin.

Twelve find units of animal bone/teeth and three lumps of charcoal were also recovered. The identifiable animal bone included a fragment of sheep/goat femur, sheep/ goat upper and lower molars and a pig canine. Plant macrofossils and charcoal identified included one cf. barley grain, two oak charcoal fragments, two grass family caryopsis and three oat grains. Eighteen land snail shell fragments were also found.

PhASE X: 1938 TRENCH (see figures 96 and 98) This phase represents the works carried out by Ralegh Radford in the 1938 and possibly 1939 seasons, ie the cutting and backfilling of his trench across the Great Ditch. The fill of the trench, 1081, was excavated within the area of the central depression (see above). The bottom of 1081 was not reached in this central area, although the entire fill was excavated on the north and south inclines at either side. The fill was not evident on the near-vertical face of the south bank, but evident in places on the less steeply inclined north bank. However, a substantial quantity of fill was removed towards the top of both banks where the bedrock plateau levelled off.

The fill of the trench was almost completely slate and stone with little soil on the south bank (1094 and 1139), presumably packed in to retain the integrity of the bank at this point, and on the north bank was 1145 .

The cut of Radford's trench (1080) was very irregular and almost impossible to trace at the up-slope side within the area of the central depression of the ditch. In places, the trench appears to be in excess of $6 \mathrm{ft}[1.8 \mathrm{~m}]$ wide. However, this is at odds both with the surviving 1938 photographs of the excavation and with what is known of the dimensions of most other Radford trenches at Tintagel (see Chapter 1), which are almost invariably just wide enough for one man to swing a shovel. Surviving photographs from 1938 show that this was also the case within the Great Ditch (see Chapter 7, figure 79). Furthermore, the photographs show that the spoil from the trench was cast up-slope and revetted with low dry-stone slate walls, presumably constructed from material being removed from the ditch. These spoil-heaps are very close to the west edge of the trench. It is known that the trenches dug by Radford at Tintagel could remain open for several months before a work team was detailed to backfill them ${ }^{1}$ and it is possible in this case that the trench remained open into 1939 (see Chapter 1). ${ }^{2}$ This combination of overburden at the west, and the possibility that the trench remained open through all conditions, suggests that the difficulty in identifying the west edge of the 1938 cut was due to the fact that this side collapsed prior to it being backfilled. 
Table 38 T01 Phase W: contexts and finds

\begin{tabular}{ll}
\hline Context & Context description \\
\hline 1108 & Tumbled mixed upper fill of the Great Ditch. \\
& $\begin{array}{l}\text { Moderate to loosely compacted mid-brown clayey } \\
\text { loam with large angular blocks and small slates }\end{array}$
\end{tabular}

1109 Silt located at the south end of the Great Ditch

1110 Possible silt fill of the ditch

1111 Grey-brown silty clay with shillet and large stones Finds

One abraded B-ware amphora sherd (RF 4183) and one post-medieval SR (RF 4185), three fragments of mortar adhering to stone (RFs 4177 and 4187), modern terracotta drainpipe (RF 4181), perforated slate disc (RF 4186), grooved slate (RF 4203) and modern glass (RFs 4174, 4182). Sheep/goat teeth: upper and lower molar (RF 4212), two land snail shell fragments, four unidentified charred fragments and charcoal + Animal bone fragment (RF 4184) and one indeterminate medium mammal lumbar vertebra One unidentified B-ware amphora sherd (RF 4188), five fragments of mortar (eg RFs 4189, 4190, 4199), one sheep/goat femur fragment and indeterminate medium mammal long bone fragment (RFs 4191, 4192), charcoal (RFs 4193, 4198). One cf. barley (cf. Hordeum sp.) grain and two unidentified charred plant fragments, charcoal ++

One unidentified B-ware amphora sherd (RF 4207) and one $\mathrm{Bv}$ (RF 4213). Animal bone fragments (RFs 4204, 4208) and 12 mortar fragments (eg RFs $4205,4210,4211$ )

Charcoal + , including one oak (Quercus sp.)

1112 Mid-grey-brown silty clay with shillet

1113 Firm, light to mid-grey-brown clayey silt

1114 Mid-yellowish-brown clayey silt

1115 Moderate to firmly compact, silty clay

1118 Mid-greyish-brown (greenish hue) clayey silt

1119 Massive boulder

$1120 \quad$ Firm greenish-grey clayey silt

1121 Compact, mid-brown clayey silt

1124 Large sub-angular stone tumble

1126 Moderately compact, mid-grey-brown clayey silt Two grass family (Poaceae) caryopsis fragments, two oat (Avena sp.) grains, charcoal + One oak (Quercus sp.), charcoal fragment

One Bi amphora disc (RF 4215), medieval SA8 sherds (rim RF 4217; neck 4218), iron object (RF 4214), pebble (RF 4216) and 13 indeterminate medium mammal bone fragments (RF 4219)

One Bi amphora sherd (RF 4272), one Bii (RF 4248), two unidentified B-ware (RFs 4273, 4274), two medieval SA (RF 4227), one medieval OK (RF 4228), one (three conjoining) medieval LO (RF 4229), eight medieval UU (RFs 4243, 4252 and rim RF 4249) and one mortar (RF 4244). Pig canine teeth fragments and 14 indeterminate medium/large mammal bone fragments (eg RFs $4230,4246,4251$ )

One medieval SA sherd (RF 4247), one notched architectural structural slate (RF 4245) and one water-worn stone (RF 4285)

Five conjoining sherds of unidentified B-ware amphora (RF 4224) and one medieval SA (RF 4226) 


\begin{tabular}{lll}
\hline Context & Context description & Finds \\
\hline 1141 & Moderately compact, mid-grey-brown clayey silt & $\begin{array}{l}\text { One oat (Avena sp.) grain and one unidentified } \\
\text { fragment } \\
\text { Charcoal (RF 4275) }\end{array}$ \\
1142 & Mid-brown-grey, clayey loam with stones & \\
1146 & Large stones and clay below turf and topsoil & \\
1147 & Loamy earth with gravel and stones & \\
1149 & Similar to 1120, with many of angular stones & \\
1150 & Loose, grey-brown clayey silt with stones & Sixteen land snail shell fragments, charcoal + \\
1152 & Silty clay and stones on north bank & \\
1162 & Greenstone slab in section of north bank & \\
1163 & Greenstone slab in section of north bank & \\
1164 & Greenstone slab in section of north bank & \\
1166 & Light grey, silty clay band within 1146 & \\
\hline
\end{tabular}

Charcoal fragments $>2 \mathrm{~mm}:+1-10 ;++>10$

The cut may have survived better towards the bottom of the deposits but, as safety requirements militated against further excavation through 1081, this cannot be known except where it was evident in a small section at the north side (see figure 96). This small section suggested the cut was vertical and only about $1 \mathrm{~m}$ wide.

The cut at the east was also ragged, due to the volume of stone protruding through the section, but could be traced running near-vertically downwards and was much clearer at both the north and south ends of the trench. The north end-terminal of the Radford trench was some $10 \mathrm{~m}$ from the top of the bank on which the Lower Ward stands. The cut ranged from $1.2 \mathrm{~m}$ to $1.5 \mathrm{~m}$ wide, and the sides were vertical and ran to a depth of $1.9 \mathrm{~m}$. The south end terminal was at the top of the south bank and again the width of the cut ranged from $1.2 \mathrm{~m}$ to $1.5 \mathrm{~m}$ (although the edges were far less stable than at the north), and the sides were vertical to a depth of $1.8 \mathrm{~m}$.

Other contexts associated with this phase of activity included trampled turf lines 1082, at the south of 1080 on the south bank, and 1095 at the west. Also on the south bank were three layers of trample: 1116, 1093 and 1092. These contexts relate to the cutting and backfilling of the trench located immediately north.

\section{PhaSe X: ARTEFACTS, ECOFACTS AND DATING}

\section{(table 39)}

A large mixed artefactual assemblage was recovered from Radford's backfill. This included architectural stone fragments, some possibly from the surrounding medieval Castle walls (see Kelly and Jefferson, Chapter 10).

Amongst the other stone finds were non-structural stones which were mostly pick-marked (eg RF 4299: see Chapter 10, figure 118), perforated slates (eg RF 4148: see Chapter 10, figure 119), shaped slates (eg RF 4298: see Chapter 10, figure 120), notched slates, pebbles and slate discs (RFs 4106 and 4320: see Chapter 10, figure 117). The pick-markings are interpreted as damage caused by Radford's workmen, as noted elsewhere on the site (see Chapters 3 and 6).

The ceramic assemblage from this context is also mixed. It includes post-Roman imported Mediterranean amphora $\mathrm{Bi}$, and $\mathrm{Biv}$, as well as medieval $\mathrm{SA}$ and $\mathrm{OK}$ (OK11; RF 4057).

From finds of modern bottle glass, fragments of modern teracotta drainpipe, glazed and transfer-printed ceramic, mortar and a corroded iron object (possibly a hinge) it is clear that this material is significantly mixed.

Ecofactual material from this phase includes one oat grain, one cf. barley grain and charcoal fragments which included hazel.

PHASE Y: POST-1938 SLUMP (see figure 96)

Slumped earth and stones 1079 obscured the line of Radford's cut, particularly at the west side. This may have been the collapsed residue of spoil-heaps from his excavations which had not been thrown back into the open trench.

\section{PHASE Y: ARTEFACTS, ECOFACTS AND DATING}

$$
\text { (table 40) }
$$

Finds recovered from the scree slip include predominantly modern ones: terracotta drainpipe, modern white-glazed pottery, modern glass and a sherd of post- 
Table 39 T01 Phase X: contexts and finds

\begin{tabular}{|c|c|c|}
\hline Context & Context description & Finds \\
\hline 1080 & Cut of Radford 1938 trench & \\
\hline 1081 & Fill of Radford 1938 trench & $\begin{array}{l}\text { Three sherds of Bi amphora (RFs } 4039,4053 \text { and } 4100 \text { ), one Biv } \\
\text { (RF 4043), one medieval OK11 rim (RF 4057), two medieval SA } \\
\text { (RFs } 4115 \text { base and } 4116 \text { ), } 11 \text { fragments of modern terracotta } \\
\text { drainpipe (eg RFs } 4060,4104 \text { and } 4112 \text { ) and eight sherds of } \\
\text { modern pottery (eg RFs } 4071,4102 \text { and } 4114 \text { ). } 14 \text { architectural } \\
\text { greenstone fragments (eg RFs } 4037,4149,4150 \text { ), three notched } \\
\text { structural slates (RFs } 4048,4081 \text { and } 4297 \text { ), } 15 \text { notched slates (eg } \\
\text { RFs } 4035,4084 \text { and } 4146 \text { ), two perforated slates (RFs } 4080 \text { and } \\
4148 \text { ), two slate discs (RFs } 4106 \text { and } 4320 \text { ), two shaped slates } \\
\text { (RFs } 4298 \text { and 4299) and three pebbles (RFs } 4058 \text { and } 4118 \text { ). } \\
15 \text { finds of modern glass (eg RFs } 4046,4077 \text { and } 4113 \text { ), } \\
10 \text { fragments of mortar (RFs } 4072,4085 \text { and } 4119 \text { ), one iron } \\
\text { hinge (RF } 4078 \text { ), indeterminate mammal long bone fragment } \\
\text { and sheep/goat mandible (RFs } 4101 \text { and } 4120 \text { ) }\end{array}$ \\
\hline 1082 & Decayed turf line & Modern terracotta drainpipe (RF 4051) \\
\hline 1092 & Clayey loam with stones & $\begin{array}{l}\text { Notched slate (RF 4254). One oat (Avena sp.), one cf. barley (cf. } \\
\text { Hordeum sp.), two hazel (Corylus avellana) charcoalt }\end{array}$ \\
\hline 1093 & $\begin{array}{l}\text { Loose, mid-yellow-brown, clayey } \\
\text { loam }\end{array}$ & \\
\hline 1094 & $\begin{array}{l}\text { Fill of Radford } 1938 \text { trench through } \\
\text { south bank of Great Ditch }\end{array}$ & $\begin{array}{l}\text { Six notched slates (RFs } 4169,4173 \text { and } 4197 \mathrm{a} \text { ), slate disc } \\
\text { (RF } 4170 \text { ), modern terracotta drainpipe (RF } 4171 \text { ), two pebbles } \\
\text { (RFs } 4172 \text { and } 4197 \mathrm{~b} \text { ), modern iron spike (RF } 4194 \text { ), wood } \\
\text { fragments (RFs } 4195 \text { and } 4253 \text { ), quartz crystal (RF 4088) }\end{array}$ \\
\hline 1095 & Decayed turf & \\
\hline 1116 & $\begin{array}{l}\text { Firmly compact, yellow-brown silty } \\
\text { clay }\end{array}$ & \\
\hline 1139 & $\begin{array}{l}\text { Loose, mid-brown loam with } \\
\text { medium/large slates }\end{array}$ & Notched slate disc (RF 4321) \\
\hline 1145 & $\begin{array}{l}\text { Backfill within } 1938 \text { Radford trench } \\
\text { on north bank }\end{array}$ & $\begin{array}{l}\text { One Bi amphora sherd (RF 4268), two pebbles (RF 4267a) and } \\
\text { two modern glass fragments (RF 4267b) }\end{array}$ \\
\hline
\end{tabular}

Charcoal fragments $>2 \mathrm{~mm}:+1-10$

medieval Sandy Redware of sixteenth- to seventeenthcentury date.

PHASE Z: TURF AND TOPSOIL

The entire area was covered by turf and topsoil 1078 .

\section{PHASE Z: ARTEFACTS, ECOFACTS AND DATING (table 41)}

Notched slates (eg RF 4029: see Chapter 10, figure 118) and a perforated slate (RF 4004: see Chapter 10, figure 119) were recovered from this layer. Finds of several rounded pebbles may represent items brought to the site as tourist tokens, or elements eroded out of mortar deposits in the case of smaller examples.

Modern finds of tile, glass, glazed pottery, terracotta drainpipe, a graffito slate, and corroded iron objects (a gate hinge, a piece of iron pipe, and a fragment) clearly date to the twentieth century or the end of the nineteenth. Mortar and a sherd of medieval Saintonge Polychrome (SP) ceramic, each dating to before the eighteenth century, once again demonstrate the mixed nature of the finds assemblage. 
Table 40 T01 Phase Y: contexts and finds

\begin{tabular}{lll}
\hline Context & Context description & Finds \\
\hline 1079 & $\begin{array}{l}\text { Scree slips and } \\
\text { accumulation } \\
\text { post-1938 }\end{array}$ & $\begin{array}{l}\text { Post-medieval SR pottery (RF 4042), modern pottery (RF 4041), ten } \\
\text { modern terracotta drainpipe fragments (RFs 4040, 4044 and 4045) and } \\
\text { modern glass (RF 4196) }\end{array}$ \\
\hline
\end{tabular}

Table 41 T01 Phase Z: contexts and finds

\begin{tabular}{lll}
\hline Context & Context description & Finds \\
\hline 1078 & Turf and topsoil & One medieval SP pottery sherd (RF 4018), three of modern glazed pottery (RFs \\
& 4009,4180 and 4202), seven finds of modern glass (eg RFs 4000, 4012 and \\
& 4201 ), eight notched slates (eg RFs 4002, 4007, 4029 and 4031), one perforated \\
& slate (RF 4004), 37 pebbles (eg RFs 4005, 4166 and 4179), decayed granite (RF \\
& $4030 \mathrm{~b}), 14$ fragments of modern ceramic tile (eg RFs 4017, 4021 and 4022), 35 \\
& fragments of modern terracotta drainpipe (eg RFs 4038, 4165 and 4175), one \\
& graffiti slate (RF 4011), three modern corroded iron objects (RFs 4014, 4028 \\
& and 4176) and 10 fragments of mortar (eg RFs 4015,4030a and 4178)
\end{tabular}

\section{DISCUSSION}

In addition to understanding Radford's work in the Great Ditch, one of the fundamental aims of this work was to establish definitively both the nature and dating of the Great Ditch (as with the Little Ditch: see Chapter 7 ), in relation to the rest of the site. Although this was a complex excavation in terms of logistics, the stratigraphy recorded was relatively simple. Clearly, other than the natural deposits of Phase $\mathrm{T}$, the major element and structure is that of the cutting of the Great Ditch in Phase U. This was utilized and modified through quarrying the bedrock. Associated with this was a series of deposits on the south bank of the ditch, which appear to have been deliberately placed, presumably to heighten the bank in front of the ditch. It was less clear what happened on the north side, but two contexts that may represent the original ground surface were located there. Insofar as artefacts were recovered in association with this activity, they appear to be post-Roman, including imported B-ware pottery sherds.

It is argued above that primary silting deposits were uncovered, which have been divided between Phases V1 and V2. Phase V1, the lower of the two, had a series of fine silts with shillet. Artefacts indicate a post-Roman period in date, while radiocarbon dating on charcoal is consistent with this. The silting deposits of Phase V2 also contain post-Roman imported pottery.

Phase $\mathrm{W}$ represents the infilling of the Great Ditch, and either construction debris or later collapse from the medieval Castle on the north bank (ie the south wall of the Lower Ward). The time-span may well be considerable (especially if some of the north bank activity relates to Castle construction, rather than destruction), but it is clear that post-Roman material, often abraded, was residual and that the medieval pottery is to be associated with activity in this phase, followed by the post-medieval. The earlier material could easily have become mixed with later as the Castle walls collapsed, disturbing floor deposits and bringing collapse down the slope. Significant mortar finds, together with modern material, also demonstrate the longevity of the destruction process up to the time of Radford's intervention in 1938.

The only section-recordings known of the 1938 trench show just three contexts making up the fill of the area of maximum depth in the ditch. Indeed, the whole fill was dominated by a layer of clay with large stones. After the 1999 excavations had dealt with about $1.2 \mathrm{~m}$ of the 1938 backfill, which was, as one would 
expect, a very mixed deposit with finds ranging from the fifth-seventh centuries to the twentieth century, the undisturbed deposits at the east end showed a more varied picture.

Unfortunately little can be said about the economy and environment of the inhabitants at Tintagel because sampling (see Straker in Chapter 11) produced minimal cereal chaff and very few crop weeds; the range of taxa is generally very small. As with other assemblages recovered from Tintagel, there is evidence of oats and barley; the charred plant macrofossil evidence is suggestive of open grassland and bog and the most common components of the charcoal assemblage are hazel and oak. A new and unexpected aspect of the assemblage from Site $T$ is, however, the recovery of land mollusc fragments, which although only found in small numbers have added a new dimension to the study of the habitat of the site.

\section{CONCLUSION}

As argued above by Jefferson, the Great Ditch appears to be sited in proximity to what has been previously considered to be a geological fault, but is more likely to be a shallow valley. There is strong evidence that the deepening and modifying of the Ditch occurred in the fifth to seventh centuries, as demonstrated by the inclusions of imported early medieval ceramics in the primary silt layers. Thomas has argued that the later medieval Castle was more symbolic than real as a fortification, and the field remains do not suggest that such a large feat of engineering would have been carried out as part of its building programme. ${ }^{3}$ Considered in conjunction with the archaeological and dating evidence, the Great Ditch sits firmly as the landward boundary of the fifth- to seventh-century site at Tintagel. 


\title{
CHAPTER 9
}

\section{ARCHAEOLOGICAL ASSESSMENT IN 1999 OF C A RALEGH RADFORD'S TRENCHES IN THE LOWER WARD, SITE T}

\author{
with contributions from PAUL G JOHNSON
}

\begin{abstract}
Dr Ralegh Radford investigated part of the medieval Lower Ward at Tintagel Castle as part of his excavations through the Great Ditch and the surrounding area of 'Site T' in 1938 and 1955. In 1999 examination of the layers below the consolidated surface revealed examples of imported ceramics and glass, and radiocarbon dating has confirmed a fifth-/sixth-century AD date. Later material is notably absent, due to the clearance of the Lower Ward during more recent consolidation activity.
\end{abstract}

\section{FIELDWORK METHODOLOGY AND SYNOPSIS OF WORK UNDERTAKEN}

Trench T01 ext was situated within the curtain wall of the Lower Ward and delimited on its southern and western sides by that wall and an internal buttress (see Chapter 7, figure 83), that is within the easternmost corner of the Lower Ward of the Castle. The purpose of the trench was to confirm the position and re-examine the stratigraphy of a trench or pit excavated in 1938 under the supervision of Ralegh Radford. The position of the trench was determined by reference to a drawing made by J A Wright in September 1938 (see Chapter 1, figure 15). This depicts the north-east-facing section of the trench cut across the Great Ditch (re-excavated as trench T01 in 1999), and a further section of an excavation within the curtain wall of the Castle (see Chapter 1, figure 16), presented as though it was an interrupted continuation of the Great Ditch trench. ${ }^{1}$

As noted above (Chapter 8 and table 1, Chapter 1), it is considered likely that the 1938 Great Ditch trench was not backfilled, remaining open into 1939. It is quite possible that the situation was the same in the Lower Ward. As a result there was considerable doubt over the precise location and dimensions of this latter trench and so a substantial area within the corner of the Lower
Ward was deturfed in 1999. This resulted in the discovery of an additional trench in the area, which appeared to cut the backfilled remains of the 1938/9 trench. It would appear that this later trench was probably cut in the campaign undertaken by Radford in 1955 in order to confirm or reappraise the findings of his 1938 excavations (see Chapter 1). The entire 1955 trench was not uncovered within the limits of trench T01 ext.

Once the fills of the 1938 and 1955 trenches had been identified, a segment of the latter was removed to the bottom of the cut. Radford's 1955 trench was demonstrated to have cut stratified deposits in the south-west-facing section of the sondage, and this was the section that was recorded in preference to the northeast-facing section which still contained backfill from the 1938 trench. It was also apparent that the bottom of Radford's 1955 trench did not correspond with natural geological deposits or, indeed, with the bottom of the 1938 trench.

Although the much larger 1955 trench had all but obscured any trace of the small 1938 'box trench', it was successfully located. Radford had opened the 1938 trench to link contexts noted in the Great Ditch area with those in the adjacent Lower Ward. The Health and Safety implications of cutting a trench too close to the standing remains of the Castle walls outside the Lower 
Ward led to this 'keyhole' approach in 1938. Similar constraints led the 1999 campaign to stop where Radford had. Below a considerable depth of levelling deposits associated with the backfilling of that previous excavation, undisturbed archaeological deposits were encountered. These included evidence of burning, industrial material and fifth- to seventh-century imported Mediterranean pottery and glass.

One important phase in Tintagel Castle's history is completely absent from the stratigraphic sequence identified in trench T0l ext. Evidence for the disuse and ruination of the Castle that might normally have been expected in this area was missing. It appears that all such evidence was destroyed as the result of the clearance of destruction debris and other consolidation works undertaken by the MoW in the 1930s and beyond.

As with every season and area of the excavations at Tintagel, a comprehensive sampling strategy was employed in 1999 (see Chapter 11).

\section{SUMMARY OF STRATIGRAPHY AND STRUCTURES IN TRENCH TOI EXT}

\section{Phase V: UnEXCAVATED, ?NATURAL DEPOSITS} (figure 99)

The earliest deposits encountered in this trench, 1137 and 1138, were composed of dense pale blue clay containing slate fragments. These deposits were essentially similar but remained unexcavated due to pressure of time, and it is suggested that they were both natural deposits.

Adjacent to 1137 and 1138 a deposit of bright yellow sandy clay with slate fragments, 1136 , also remained unexcavated and, therefore, its precise stratigraphic relationship with the other layers in this phase remains uncertain (figure 100).

PHASE V: ARTEFACTS, ECOFACTS AND DATING

Pollen samples were taken from contexts 1137 and 1138 and were once again dominated by dandelion and related Asteraceae. Sedges, ribwort plantain and a grain of Scots pine pollen were also present (see Chapter 11).

\section{Phase W: PRE-CAstle features and deposits (see figures 99 and 100)}

Clays 1136 and 1137 of Phase V were cut by 1139 , a possible pre-Castle feature showing signs of in situ burning, at the northern end of the sondage. Cut 1139 was filled by a deposit of shillet and silty clay and charcoal matrix, 1135, which included bloomery slag, burnt clay, pottery and glass.

1135 was sealed by a further layer of blue clay, 1132, which also sealed a yellow sandy clay, 1136. The clay deposit dipped at an angle of about 15 degrees from west to east and bore the impressions of spade- and pickstrokes on its upper surface, probably resulting from Ralegh Radford's 1955 work.

\section{PHASE W: ARTEFACTS, ECOFACTS AND DATING} (table 42)

The assemblages recovered from this phase confirm an early date, with imported pottery and exciting finds of early medieval glass being recovered. The imported pottery finds included not only six sherds of Bi amphora and seven sherds of Bii, but also one sherd of African Red slipped ware (ARSW). In addition, a sherd of Romano-British Local ware was recovered from this phase. The two finds of early medieval glass recovered from samples of contexts 1132 and 1135 are discussed by Campbell in Chapter 10, and include an example from the Anglo-Saxon/Frankish tradition (RF 4335).

Six fragments from this phase were identified as bloomery slag (see Photos-Jones, Chapter 10). A further sample when analysed was shown to be a severely corroded iron object. A single whetstone made from an elongated pebble (RF 4294: see Chapter 10, figure 117) was recovered from context 1135 .

Charcoal fragments from fill 1135 were submitted for radiocarbon dating. Two radiocarbon dates were obtained (OxA-10388 and OxA-10389) and a weighted mean taken before calibration. This gave a date for the feature of cal $\mathrm{AD}$ 340-530 (95 per cent confidence), which can be refined to AD $390-430$ at a 68 per cent confidence level. However, Bayliss suggests this latter range is most likely (see radiocarbon dating section, Chapter 11).

Charcoal was identified from two Phase W contexts and includes hazel, blackthorn, hawthorn/Sorbus group, oak and birch. Charred plant macrofossils include one cf. Persicaria achene, one grass family caryopsis, two barley grains, one wheat grain, one clover/medick seed, and five cherry/sloe shell fragments. One land snail shell fragment was also recovered.

\section{PhaSe X: FEATURES AND DEPOSITS ASSOCIATED} WITH THE MEDiEval CASTLE (see figures 99 and 100) A series of soil and slate dump deposits representing terrace levelling sealed the clay layer 1132 of the previous 


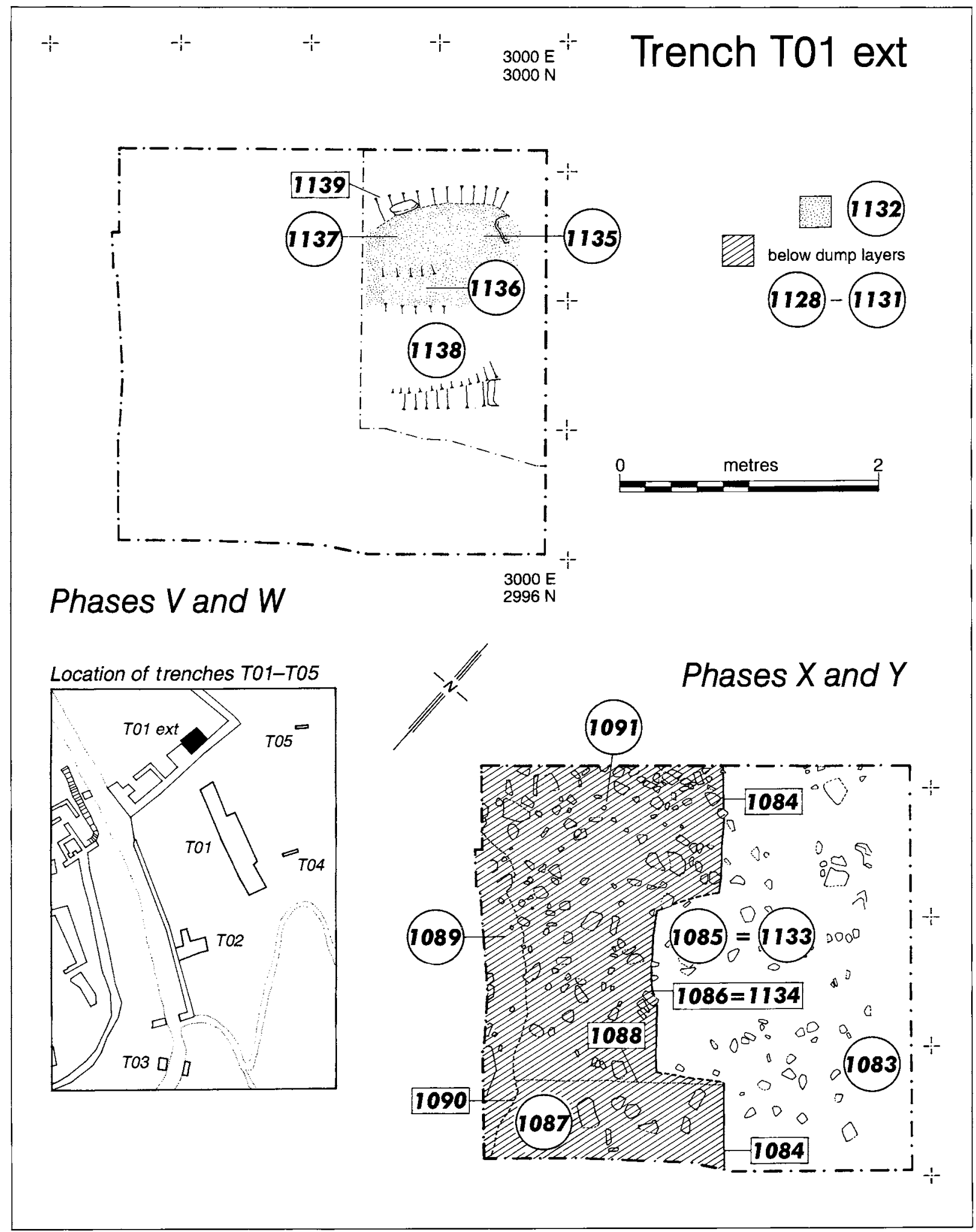

99 T01 ext Phases $V$ and $W$, and $X$ and $Y$ phase plans. Drawing: $C$ Evans 


\section{Trench T01 ext West-facing section}

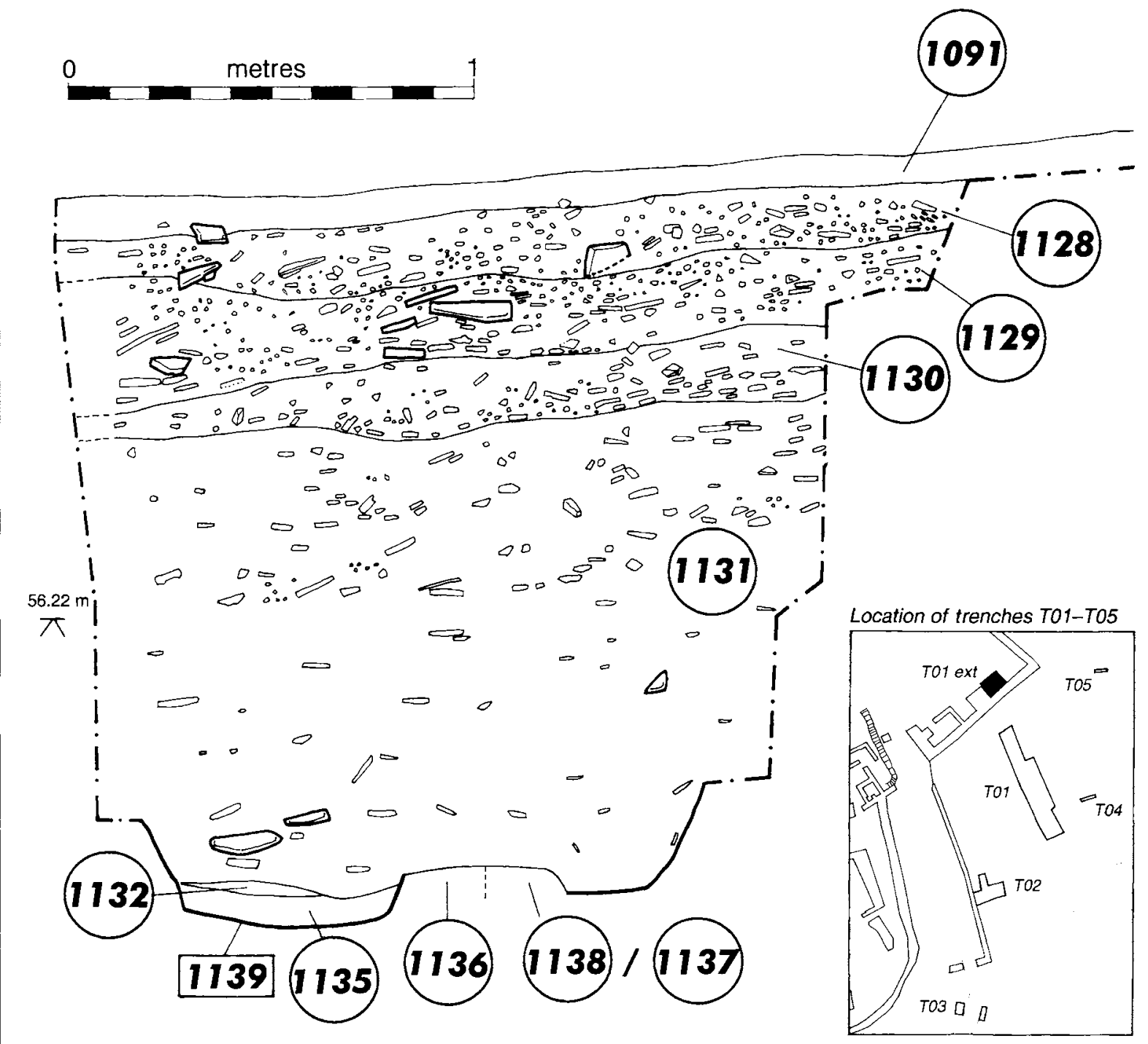

100 T01 ext west-facing section. Drawing: C Evans

phase. The lowest and thickest of these, 1131, was sealed by 1130 and less stony 1129 and, above this, 1128. This series of dump deposits was rich in artefacts.

The uppermost archaeological deposit noted within this trench was soil and shillet 1091, which was probably truncated by the general clearance of destruction debris from the Lower Ward in the 1930s.

Two putative wall-foundation trenches, 1088 and 1090, were noted adjacent to the south and west (buttress) walls of the Lower Ward at the periphery of trench T01 ext. Although these were not examined fully, both could be demonstrated to cut 1091, and were filled 
Table 42 T01 ext Phase W: contexts and finds

\begin{tabular}{|c|c|c|}
\hline Context & Context description & Finds \\
\hline 1132 & Deposit of clean pale blue clay & $\begin{array}{l}\text { Four Bi amphora sherds (RFs 4287, 4288, } 4290 \text { and 4291), one } \\
\text { Bii (RF 4328) and one Romano-British Local ware (RF 4329). } \\
\text { One sherd of pale green Frankish/Saxon glass from a ?palm cup } \\
\text { (RF 4335). One cf. Persicaria achene, one grass family (Poaceae) } \\
\text { caryopsis and five unidentified fragments, two barley (Hordeum } \\
\text { sp.) grains, one wheat (Triticum sp.) grain, one clover /medick } \\
\text { (Trifolium/Medicago sp.) seed, five cherry/sloe (Prunus sp.) shell } \\
\text { fragments, one land snail shell fragment and charcoal+ }\end{array}$ \\
\hline 1135 & $\begin{array}{l}\text { Pale blue shillet/slate in silty clay. } \\
\text { Fill of } 1139\end{array}$ & $\begin{array}{l}\text { Two Bi amphora sherds (RFs } 4292 \text { and 4296), six Bii (RFs } 4295 \text {, } \\
4331,4332,4333 \text { and } 4334 \text { ) and one ARSW (RF 4330). One } \\
\text { sherd of Mediterranean 5th-/6th-century etched glass from a } \\
\text { ?bowl (RF 4336). Six lumps of bloomery slag (RFs 4293, 4337, } \\
4338 \text { and 4339), one whetstone (RF 4294) and a corroded iron } \\
\text { nail (RF 4303). Hazel (Corylus avellana), blackthorn (Prunus } \\
\text { spinosa), hawthorn/Sorbus group (Pomoideae), oak (Quercus sp.) } \\
\text { and birch (Betula sp.) charcoal }\end{array}$ \\
\hline 1139 & Cut through 1136 and filled by 1135 & \\
\hline
\end{tabular}

Charcoal fragments $>2 \mathrm{~mm}:+1-10$

with 1087 and 1089, identical deposits of shillety soils, and the walls themselves. They are representative of the construction of the Lower Ward of the Castle.

Phase X: ARTEFACTS, ECOFACTS AND DATING (table 43)

Once again, the finds from this phase include no later medieval pottery. Finds of imported pottery included $\mathrm{Bi}$, Bii and Biv amphorae and ARSW. A single notched slate may have served as a strike-a-light, and a notched slate disc could have served as a vessel lid, chipped to break open the seal.

Finds of animal bone fragments (including a cattle sacrum, sheep/goat pubis and rabbit femur) twentythree land snail fragments, six marine mollusc fragments and leached mortar were also recovered. Apart from unidentified charcoal, plant macrofossils from this phase include fifteen oat grains, one rye grain, four indeterminate cereal grains and three indeterminate cereal fragments.

PhASE Y: RADFORD'S TRENCHES (see figure 99) The remains of Radford's 1938 trench, 1086/1134, and its fill, 1085/1133, were noted cutting 1091 on the surface of trench $\mathrm{T} 01$ ext. The feature was truncated on its north-eastern side by 1084 , the cut of the 1955 trench.
The 1938 trench cut all of the deposits of Phase $X$ and part of 1137, the unexcavated deposit of Phase V, at the bottom of the sondage in T01 ext. The 1938 cut was slightly deeper than the 1955 cut.

Radford's 1955 cut, 1084, and its fill, 1083, also cut 1091. During excavation, the fill was subdivided into thirteen different contexts (1096-1107 and 1125). However, in post-excavation it was demonstrated that they are all the same layer of fill as 1083 . This feature also truncated the 1938 trench. The 1955 trench cut all of the deposits of Phase X, but did not cut the clean blue clay 1132 of Phase $W$.

\section{PhaSe Y: ARTEFACTS, ECOFACTS AND DATING (table 44)}

By far the bulk of the finds from T01 ext were recovered from this phase, which is Radford's backfilling of the trench. The large finds assemblage comprised both redeposited and modern material. Finds recovered from the 1938 backfill layers include modern glass, lumps of mortar and decayed granite, modern terracotta drainpipe, an iron nail, an animal bone fragment and one sherd of Bi pottery.

The artefacts recovered from the 1955 backfill were equally mixed and include sherds of $\mathrm{Bi}, \mathrm{Biv}$ and $\mathrm{Bv}$ amphorae and unidentified imported ceramics. The 
Table 43 T01 ext Phase X: contexts and finds

\begin{tabular}{|c|c|c|}
\hline Context & Context description & Finds \\
\hline 1087 & Shillet soil fill of 1088 . Not excavated & \\
\hline 1088 & Cut for possible wall-foundation. Not excavated & \\
\hline 1089 & Shillet soil fill of 1090 . Not excavated & \\
\hline 1090 & Cut for possible wall-foundation. Not excavated & Cattle sacrum fragment (RF 4121) \\
\hline 1091 & Mid-grey-brown, clayey soil with shillet inclusions & $\begin{array}{l}\text { Sheep/goat pubis fragment (RF 4231) and rabbit } \\
\text { femur fragment (RF 4232), five leached mortar } \\
\text { fragments (RFs } 4233 \text { and } 4322 \text { ). Fifteen oat (Avena } \\
\text { sp.) grains, one rye ( Secale cereale) grain, four } \\
\text { indeterminate cereal grains, } 23 \text { land snail shell and } \\
\text { six marine mollusc fragments. Charcoal+ }\end{array}$ \\
\hline 1128 & $\begin{array}{l}\text { Mid-greyish-brown clayey loam with slate } \\
\text { fragments }\end{array}$ & \\
\hline 1129 & Mid-greyish-brown clayey loam with large slates & $\begin{array}{l}\text { Four Bi amphora sherds (RFs } 4234,4235,4236 \text {, } \\
4238 \text { ) and one Biv (RF } 4237 \text { ). Three indeterminate } \\
\text { cereal fragments and one unidentified fragment. } \\
\text { Charcoal+ }\end{array}$ \\
\hline 1130 & Mid-greyish-brown clayey loam with slate & $\begin{array}{l}\text { Three Bi amphora sherds (RFs } 4239,4240 \text { and } \\
4256 \text { ) and two Bii (RFs } 4323 \text { and } 4324 \text { ). } \\
\text { Charcoal+ }\end{array}$ \\
\hline 1131 & Mid-brown, silty clay with slate fragments & $\begin{array}{l}\text { Eleven Bi amphora sherds (eg RFs } 4258 \text { and 4259) } \\
\text { and one ARSW (RF 4262), notched slate (RF 4257) } \\
\text { and notched slate disc (RF 4263) }\end{array}$ \\
\hline
\end{tabular}

Charcoal fragments $>2 \mathrm{~mm}:+1-10$

stone assemblage includes a notched slate disc, notched slates (eg RFs 4136, 4137 and 4139: see Chapter 10, figure 121) and pebbles. These had presumably been displaced from a variety of contexts through which Radford's workmen had dug during both 1938 and 1955.

Waterlogged wood, mortar and animal and fish bone fragments (including an ulna of a cf. Galliformes sp.), a coracoid of a cf. Scolopacidae sp. and gadid cf. cod exoccipital fragments and conger eel cranial element fragments were also recovered.

Phase Z: TURF AND TOPSOIL

A well manicured lawn and layer of rich black imported topsoil, 1078, sealed the area of the trench.

\section{DISCUSSION}

The background to and logistics of the excavation of this small area within the Lower Ward have been mentioned above. In the end, the early deposits were simply examined in a sondage, from which it was not easy to characterize the nature of the deposits encountered.
However, above the putatively natural Phase V, Phase W seems to be representative of an important phase of activity marked by the presence of bloomery slag, early medieval glass and post-Roman imported pottery (see Chapter 10). At the time of excavation, it was speculated that there might have been an industrial hearth present, but corroboration of this must await further, more extensive excavation in this area of the site. But the presence of the industrial material is certainly intriguing, and the radiocarbon date for charcoal of this phase gives a particularly early date in the late Roman/post-Roman period ( $\mathrm{cal} \mathrm{AD} \mathrm{390-430} \mathrm{at} \mathrm{the} 68$ per cent confidence level: see Bayliss and Bronk Ramsey, Chapter 11).

Succeeding Phase W was a series of dump deposits, and two putative wall-foundation trenches adjacent to the Castle walls. These must relate to the Castle construction in the later medieval period, although there was no pottery of this period recovered. In this context, it is suggested that the later deposits, representing usage (and then disuse and collapse) of the Castle, were cleared off during the MoW consolidation 
Table 44 T01 ext Phase Y: contexts and finds

\begin{tabular}{ll}
\hline Context & Context description \\
\hline 1083 & $\begin{array}{l}\text { Fill of Radford's } 1955 \text { trench: same as 1096-1107 } \\
\text { and } 1125\end{array}$
\end{tabular}

Finds

Six Bi amphora sherds (eg RF 4140), one Biv, one $\mathrm{Bv}$ and five unidentified B-ware (eg RF 4265b), notched slate disc (RF 4265a), waterlogged wood fragment (RF 4289b) and indeterminate mammal rib fragment (RF 4067)

1084 Cut of Radford's 1955 trench

1085 Fill of Radford's 1938 trench: same as 1133

1086 Cut of Radford's 1938 trench: same as 1134

1096 Rubble fill of Radford's 1955 trench: same as 1083

1097 Mixed fill of Radford's 1955 trench: same as 1083

1098 Mixed fill of Radford's 1955 trench: same as 1083

1099 Fill of 1955 Radford's 1955 trench: same as 1083

$1100 \quad$ Fill of Radford's 1955 trench: same as 1083

$1101 \quad$ Fill of Radford's 1955 trench: same as 1083

1102 Fill of Radford's 1955 trench: same as 1083

1103 Fill of Radford's 1955 trench: same as 1083

1104 Fill of Radford's 1955 trench: same as 1083

1105 Fill of Radford's 1955 trench: same as 1083

1106 Fill of Radford's 1955 trench: same as 1083

1107 Fill of Radford's 1955 trench: same as 1083

1125 Fill of Radford's 1955 trench: same as 1083

1133 Same as 1085

1134 Same as 1086

Modern glass (RF 4063), five lumps of decayed granite (RFs 4064 and 4069), modern terracotta drainpipe fragment (RF 4065), iron nail (RF 4066), mortar (RF 4142) and Bi sherd (RF 4141)

Notched slate (RF 4137)

One Bi amphora sherd (RF 4132) and two

unidentified B-ware (RF 4133)

Notched slate (RF 4136)

One Bi amphora sherd (RF 4126), two fragments of mortar (RFs 4127 and 4128), two pebbles (RF 4138) and one notched slate (RF 4139). Galliformes ulna fragment (RF 4122), Scolopacidae coracoid (RF 4123) and large gadid cf. cod exoccipital and conger eel cranial element (RFs 4124 and 4125) Two Bi amphora sherds (RFs 4129 and 4130) and one Biv (RF 4131)

Nine fragments of compacted sand (RF 4134) and indeterminate mammal bone fragment (RF 4135) One unidentified B-ware amphora sherd (RF 4144) and six fragments of leached mortar (RF 4143) One pebble (RF 4145)

One Bi amphora sherd (RF 4154), one notched slate (RF 4153), two leached mortar fragments (RF 4156) and snail shell (RF 4155)

Numerous leached mortar fragments (RF 4157) and notched slate (RF 4158)

Two unidentified B-ware amphora sherds (RF 4161), one notched slate (RF 4159) and leached mortar fragments (RF 4160) One Biv amphora sherd (RF 4163), three unidentified B-ware (RF 4164) and a notched slate (RF 4162)

One Bi amphora sherd (RF 4225) 
work of the 1930s and later. Ralegh Radford's own trenches included a miscellany of material (see Chapter 10) spanning the post-Roman to modern periods (but without medieval ceramics).

\section{CONCLUSION}

The picture emerging from the work in trench T01 ext on Site $\mathrm{T}$ is of a greater complexity than that previously suspected. Ralegh Radford extended his trench examining the Great Ditch in 1938 right up to the Castle wall, and then continued inside the Lower Ward. It is now also clear that Radford re-examined the area in 1955. Although directly associated with the later medieval Castle, this area produced no later medieval material, and it can only be concluded that later deposits here were cleared off during the consolidation works in the 1930 s and beyond.

In trench $\mathrm{T} 01$ ext, Phase $\mathrm{W}$ has produced both late Romano-British and post-Roman pottery as well as two sherds of early medieval glass, in association with activity which included industrial material such as iron bloomery slag. It is presumed that the Romano-British Local ware was probably residual (or less probably continued in use into the fifth to seventh centuries) because of its association with B-ware amphorae, ARSW and early medieval glass (see Chapter 10).

However, radiocarbon dating may suggest that activity in Phase $\mathrm{W}$ dates to the late fourth/early fifth centuries. Clearly, this at least raises the question for the future as to whether the essentially typological approach to dating of the pottery and glass should now be refined in relation to the radiocarbon determinations. All in all, there can be no doubt that post-Roman (if not earlier) activity took place in the Lower Ward area and that, as post-Roman material was also associated with the Great Ditch (see Chapter 8), these were originally connected, although now separated by the south wall of the later medieval Lower Ward. 


\section{PART IV}

ARTEFACTS AND ECOFACTS 



\title{
CHAPTER 10 The Artefactual Assemblages
}

\author{
with Ewan N Campbell, Catherine Freeman, David Jefferson, Jennifer Jones, \\ Richard Jones, Francis Kelly, Timothy J Palmer, Effie Photos-Jones, \\ Charles Thomas and Carl M Thorpe
}

\author{
STONE: THE INSCRIBED SLATE FROM \\ THE SITE C BUILDING (SEE FRONTISPIECE) \\ by Charles Thomas \\ with a contribution from David Jefferson
}

\begin{abstract}
A thin slate plaque (RF 3486) trimmed and re-used as a drain cover, was found adjacent to the Site $C$ building (see Chapter 6). It has two apparently distinct incised inscriptions upon it: the earlier is late Roman and dates from the turn of the fourth and fifth centuries, possibly relating to the Emperor Honorius, and the later appears to be a series of names, likely to date from the sixth century. The names in question are Paternus or Paterninus, Coliauus and Artognou, and the inscription is a remarkable recovery of evidence for postRoman literacy.
\end{abstract}

\section{GEOLOGICAL OBSERVATIONS} by David Jefferson

It would appear likely that the stone is of local origin, from the Delabole or Woolgarden slates. Comparison of a photomicrograph of a thin section of a minute flake of the stone (which became detached when it was cleaned) with a thin section of Delabole roofing slate from Buckland Mor church shows the typical phyllosilicate minerals, oriented in two directions, set in a largely siliceous groundmass containing small grains of pyrite and haematite. ${ }^{1}$

There are two foliations in the stone, one forming the surface upon which the inscriptions have been cut, the other, apparently at about 2 to 3 degrees to the first, has resulted in the wedge-shaped cross-section to the slab. It appears possible that the most important of the two is the first, a significant geological feature of which is the presence of mineralization on its surface. The second foliation, which makes up the 'back' of the fragment, and the cracks within it, does not show this development. This suggests that the inscribed surface could have originally been the surface of a slightly mineralized joint.

The various 'pits' which are present on the inscribed face of the stone, within the area indicated as ' $A$ ' on Figure 101, all appear to be natural and are probably the locations of small spherical bodies of sulphide, possibly pyrite. Once exposed to the atmosphere and moisture, this material is attacked by sulphur oxidizing bacteria, such as Thiobacillus ferrooxidans, and changed into a mixture of sulphate and sulphuric acid. The small holes surrounded by unlabelled circles on the figure are of similar origin. The two larger holes, labelled 'B', although apparently similar in origin to the other pits, may conceivably have been enlarged by rotating a knife or similar tool in the original natural cavities.

The scrape marks identified as ' $C$ ' on Figure 101 appear to be recent. The area marked as ' $D$ ' is a patch of sulphide in vein-like form. Although this material may well be pyrite, iron sulphide, the colour of the mineral is reminiscent of the iridescent tarnish found on chalcopyrite, the sulphide of copper and iron. This 


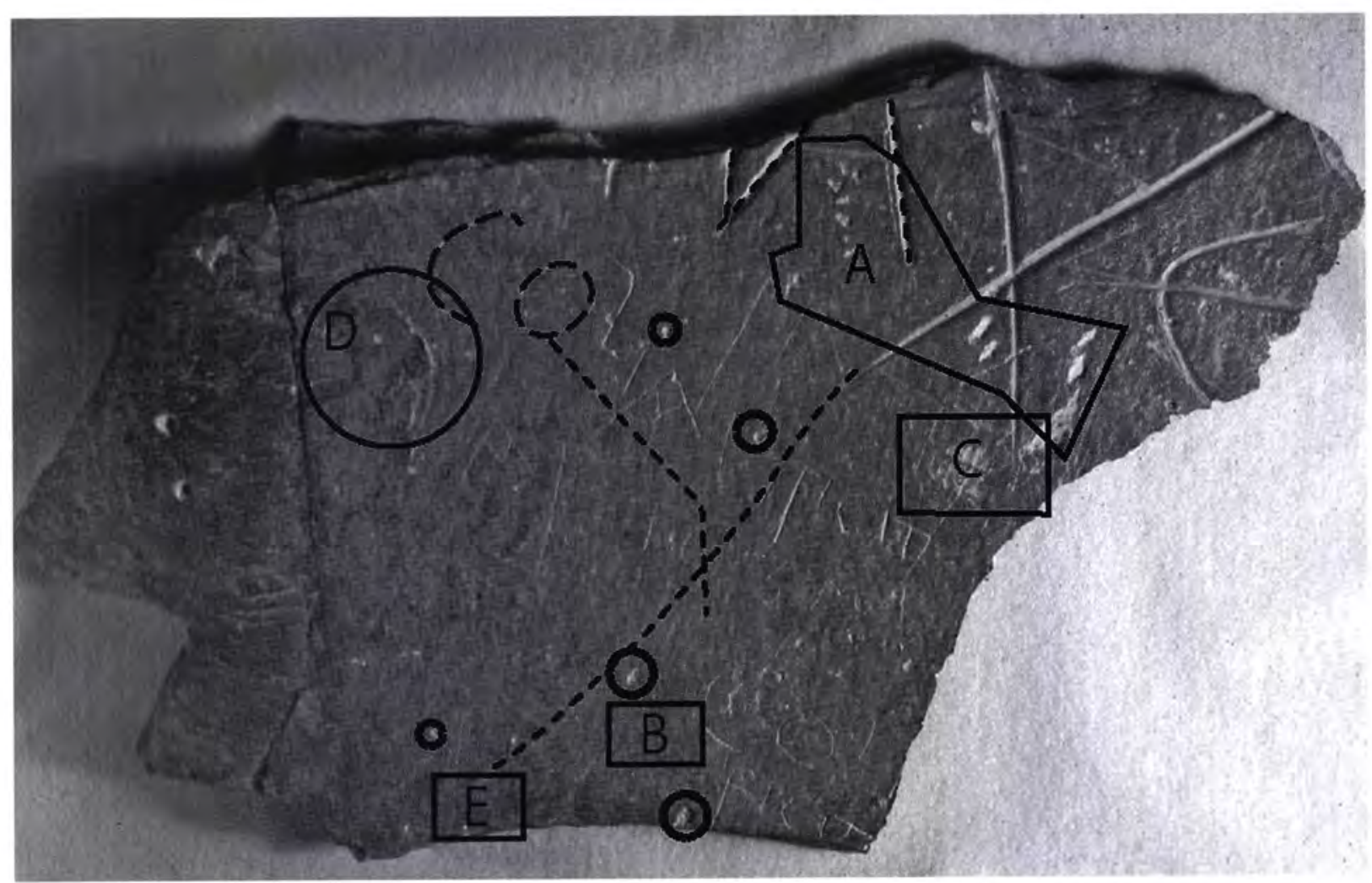

101 Areas of pits, scratches and markings on inscribed slate, RF 3486. Annotated photograph: D Jefferson after P G Johnson

sheet-like mass of sulphide supports the suggestion that the inscribed surface was originally the side of a mineralized joint.

Although the stone is highly siliceous, it does not require any special tools to cut the type of lettering found on the stone. An experiment with a piece of Delabole slate indicated that it could be cut quite easily and without undue pressure, with either the blade of a knife (albeit steel) or with a flake of vein quartz. The micro-features observed when Delabole slate is cut with a sharp edge are similar to those in the finer script of the lower inscription. The larger, more obvious letters of the upper inscription do not appear to have been cut with a mason's tool. They appear to be grooves cut by multiple scraping with a similar sharp instrument to that which made the finer lettering, the form of the individual grooves which make up the deeper cut apparently being very similar to the single grooves which form the cursive script on the remainder of the stone.

Apart from the two separate inscriptions, and the natural discontinuity labelled ' $E$ ' on the figure, there appear to be no other linear features which could not be attributed to normal mineralogical variation, or to 'wear and tear' on a piece of stone in the ground. When the inscribed slate was cleaned and photographed at the University of Durham, linear features were noted on the surface of the stone and it was suggested that these could be tool-marks. These features are completely natural, however, and are a result of the various compressional forces which have acted on the stone.

\section{THE INSCRIPTIONS by Charles Thomas}

\section{Introduction}

This small thin slate plaque differs from countless pieces of the same size, naturally detached and quarried from outcrops, in having been trimmed for use as a drain cover and in bearing incised letters. The left side (arrowed on figure 102) is an original natural or geological edge. The bottom, below the second FICIT, may not have been trimmed very much. The top has clearly lost several centimetres, and the right side, whose original edge was perhaps approximately parallel to the 


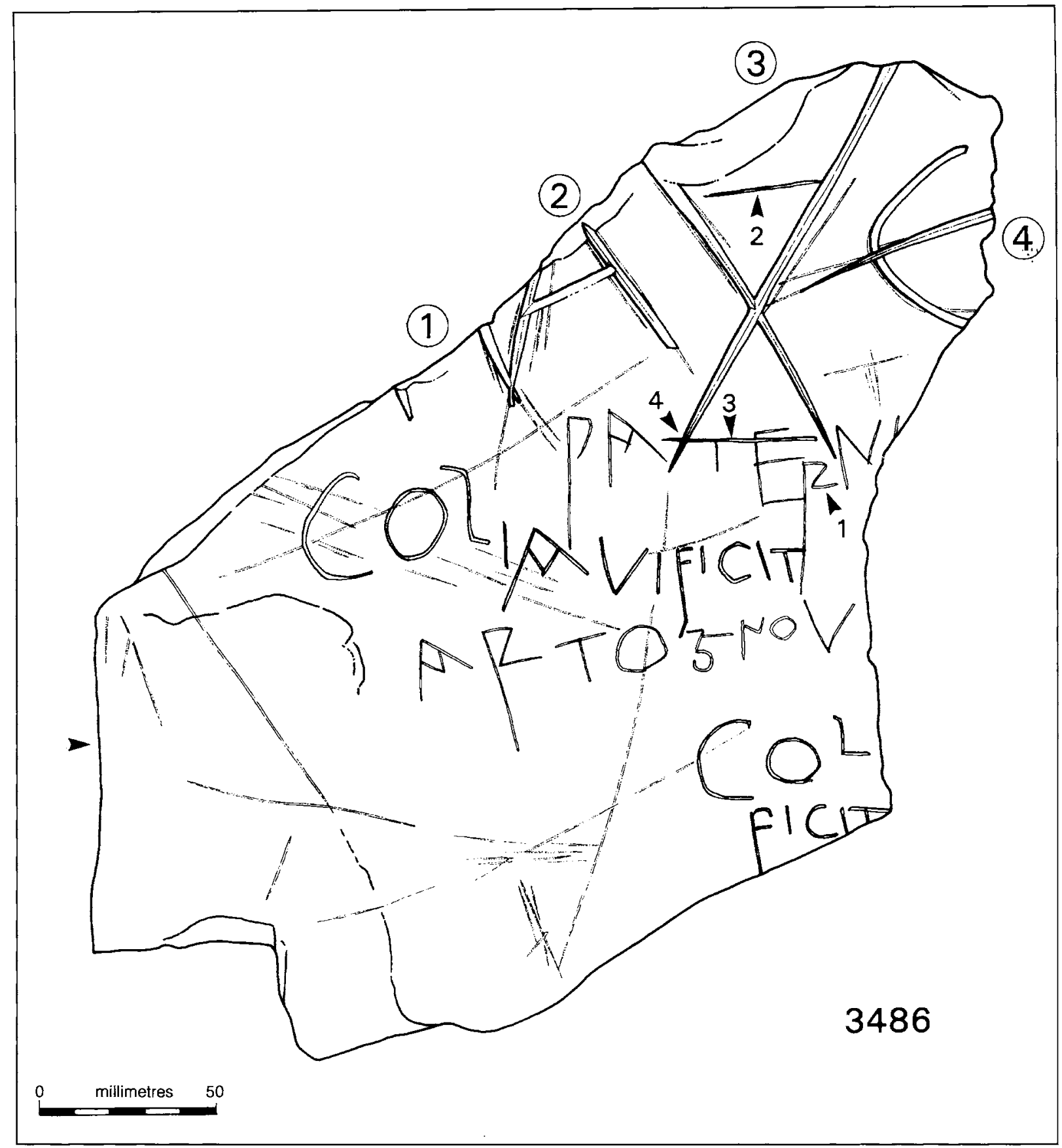

102 Reconstruction drawing (annotated) of inscribed slate, RF 3486. Ringed numbers $=$ the four larger upper letters. Plain arrow $=$ original left edge. Numbered arrows = features suggesting sequence of lettering. Drawing: $L M c E w a n$ and $A C$ Thomas, after $C$ Thorpe

left side, must have lost enough to accommodate the completion of the second COL (IAVI), perhaps a minimum of $50 \mathrm{~mm}$.

Repeated inspection, beginning with a microscopic examination at Glasgow University by Paul Johnson and continued at the RCM, by Carl Thorpe (in the process of drawing) and by myself, indicates that many faint lines and intersections underlying the detectable letters comprise natural fractures on the surface and casual scratchings from antiquity (as discussed by Jefferson 
above). The letters are divisible into an incomplete larger set at the top and a less incomplete array of smaller characters in five lines below. The principal concern here is to offer readings of these two texts, insofar as that is now possible, with epigraphic and linguistic comments.

While the upper text may bring the slate into a broad category of Roman-period antefixes and labels, the lower five lines' inscription presents difficulties. It is related by its letterforms and content to the hundred and more inscribed memorial slabs and pillars of Cornwall and Devon, Wales and southern Scotland of the fifth to eighth centuries $\mathrm{AD},{ }^{2}$ but must stand apart from these very much larger monuments in being miniaturized, and more closely akin to pictorial and lettered trialpieces. In this respect it will remain uncertain what function is represented.

\section{Textual sequence}

At no point is there obvious and incontrovertible evidence, in the shape of telling intersections, as to which text was cut first. What follows is inferential but represents the consensus of those who have examined and studied the piece. The relationship between the larger upper letters and the smaller lower letters is implied by the top line of the latter. Smaller PA and NI (the I incomplete from trimming) were cut level outside the diagonal descenders of the larger X-shaped letter; for the TER between the descenders, the $\mathrm{R}$ had to be dropped to avoid the right descender (see figure 102, 1). Apparently when the smaller letters were cut, two horizontal lines were lightly incised across the $\mathrm{X}$-shaped letter (see figure 102, 2 and 3). The lower line was imposed directly upon, and horizontally prolonged, the upper bar of the smaller T, running 'right' across the adjoining $\mathrm{E}$ (see figure 102, 3) and, left, crossing the existing diagonal descender (see figure 102,4).

\section{The larger upper letters (Text I)}

For convenience and without prejudice as to their identities these letters, four in all, are denoted in Figure 102 as circled 1 to 4 . Inspection suggested, and practical experiment on similar slate tended to confirm, use of some tool like a modern bradawl with a tiny oblique chisel-point, the main lines being gouged out with several successive strokes.

Letter 2 is Roman capital ' $A$ ', possibly first rendered as an 'open- $A$ ' ( $=$ an inverted $V$ ) with the cross-bar secondarily added; its left diagonal descender overrides a descender of letter 1 , merely showing that these letters were cut in a left-to-right order. Letter 3 is not an ' $\mathrm{X}$ '. Its top is lost but suggests an original height above the intersection about three times that of the height below it, and the intersection is level with the cross-bar of the ' $A$ '. Letter 3 is accordingly read as ' $V$ ', with unusual downwards prolongation. Letter 4 is a curve whose upper terminal is clear and undamaged. The long nearhorizontal cut running across it is secondary and of unascertainable date. In no sense could this comprise an 'E', which would in any case be an inappropriate Greek epsilon. There is enough missing space on the right for the rest of the curve; it is suggested that its lower terminal was a downwards hook, making a letter ' $G$ ' of the kind called 'sickle-G'.

For letter 1, all that remain are the bottoms of two seemingly parallel descenders, near-vertical in relation to letter 2 as ' $\mathrm{A}$ '. In the 20-letter range of Roman capitalis, the style represented by 2 to 4 , allowing for some improbably thin characters, the range of possibilities would seem to be FI H II IF IT PF PI PP TF TI TP TT. ' $M$ ' can be ruled out (what remains is too narrow) and so can ' $N$ ', in which the lower right angle would have been apparent. Given the scale of the other three letters, F P and T all seem very unlikely. The conclusion offered is that letter 1 represents either 'I I' or ' $H$ ', and that these upper four characters (Text 1) may be read as Roman capitals 'I I A V G', or 'H A V G'.

\section{The smaller lower letters (Text II)}

These are treated here as secondary in both space and time to Text I, and for the moment presented as unitary, though there is a possibility that two hands were involved (on the same occasion). ${ }^{3}$ With the exception of a singular ' $g$ ' in line (iii) all letters represent, or are derivative forms of, Roman capitals. In the transcription below, $\mathrm{P}$ indicates a complete legible letter; $\mathrm{P}$, underdotted, a damaged but apparently identifiable letter; P?, underdotted with query, a damaged and ambiguous letter. A probability of further letters to the right, trimmed off, is shown by an outwards bracket (, and - beyond it - dots suggest a total of such missing letters. The five lines are marked (i) to (v) for immediate reference.

(i) P A TER NI? (

(ii) COL I AVIF I C I T

(iii) A R T O G OV

(iv) $\mathrm{COL}(\ldots$

(v) F I C I T. 
An immediate comment must be that, since with any personal name in Patern- and with a third singular perfect verb ficit ( = fecit, from facere 'do, make', etc) this text is effectively in Latin, and since in that language a semantic structure is largely conveyed by nominal caseendings, the loss of final right-side letters in line (i), and just conceivably in line (iii) as well, probably makes any firm and indisputable 'translation' impossible. The discussion below should be accepted in that light.

A second observation is that Text II may not be entirely unitary. This arose in the course of Carl Thorpe's own examination in drawing the stone (see figure 102) and I am grateful to him for discussion. All the lower smaller letters were incised with a sharp narrow knife-point, and on the relatively soft slate were formed with controlled and careful single strokes. However, there is an indication of cutting with two different degrees of manual pressure. In lines (i) and (iii) with PATERNI (and ARTOGNOV the hand at work pressed very lightly; for display purposes (in Royal Cornwall Museum, Truro) these letters, after cleaning, proved so faint that it was necessary to dust a neutral talcum powder over them to make them visible. In line (ii), with COLIAVI FICIT particularly, and slightly less obviously so in lines (iv) and (v), the cutting pressure was noticeably greater and the letters are deeper and clearer.

It can then be seen (see figure 102) that line (ii) commences COL, but the following IA is dropped to avoid the descender of initial $\mathrm{P}$ above. Further on, FICIT may be laterally compressed a little to avoid the descender of the (dropped) $\mathrm{R}$ in line (i); there is a tiny indication that the right end of the horizontal in the $\mathrm{T}$ of FICIT goes across the descender of the $\mathrm{R}$; and the descender of the F in FICIT is slewed left as if to avoid the ' $\mathrm{g}$ ' of ARTOGNOV.

A conclusion can be no more than tentative. It is nevertheless suggested that two hands were at work here, probably at the same time and using the same knifepoint. The first hand cut line (i) with PATERNI ( avoiding the upper larger Text I letters - and also line (iii), ARTOGNOV. The second hand then cut the complete line (ii), COLIAVI FICIT, accommodating the letters to the extant lines (i) above and (iii) below and then proceeded to repeat this, as two lines reading COL(IAVI / FICIT, lower right to the edge of the stone as lines (iv) and (v). Were the inscription longer, or even complete, it might have been possible to suggest that the putative separate writers reproduced the same letters in different ways (figure 103), but this aspect cannot be pressed very far.

\section{Interpretation of Text I}

Upper letters 2 to 4 are read as AVG. There is no warrant to propose any further, trimmed off, right-side letters. In Roman capitals, AVG (Aug) is the conventional abbreviation of Augustus, Augusti, as an Imperial title. Figure 104 shows a selection of these three-letter

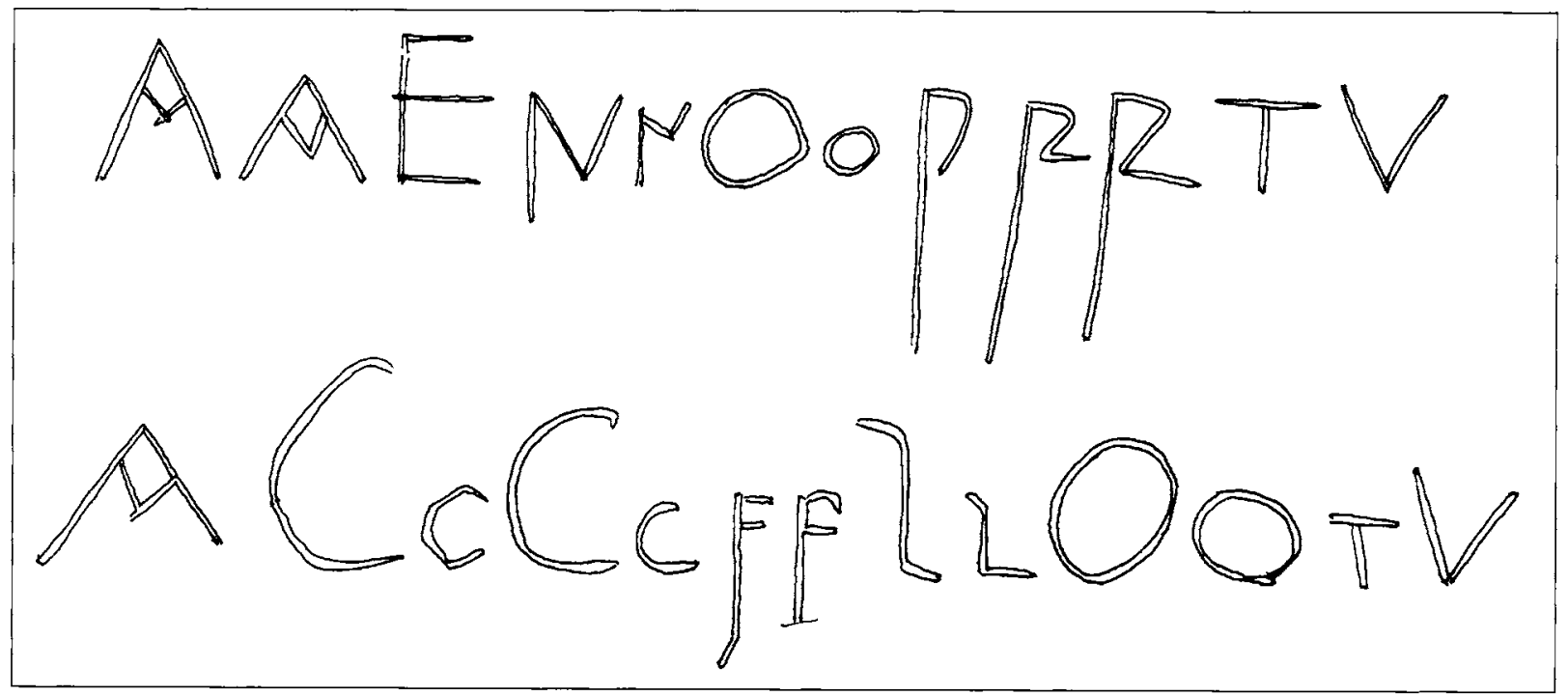

103 The lower smaller letters. Above: from lines (i) and (iii); below: from lines (ii), (iv) and (v). Drawing: A C Thomas 


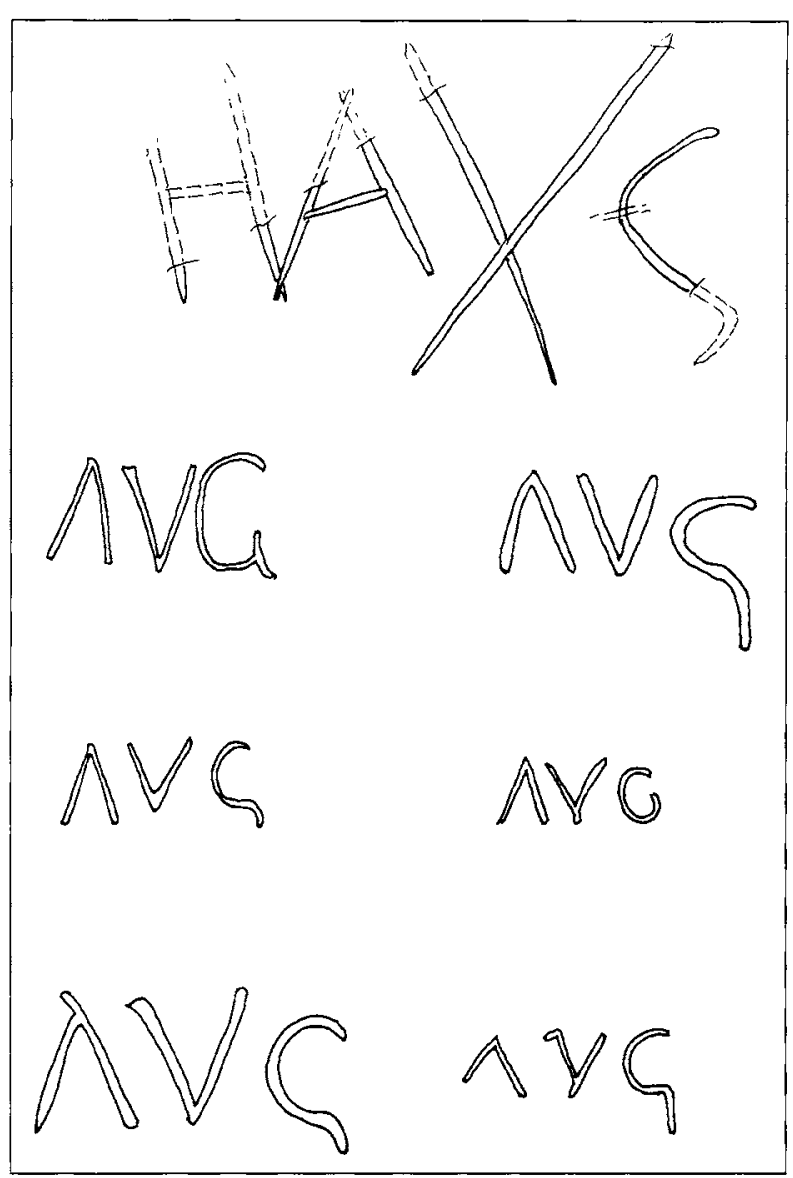

104 Provisional completion of the four larger upper letters as H AV G, with examples of abbreviation AVG on RomanoBritish milestones redrawn from RIB I (numbers, reading down, are left: $2252,2270,2275$, third century; right: 2280 , 2242,2285 , late third and early fourth centuries).

Drawing: A C Thomas

abbreviations from Roman Britain and of various thirdand early fourth-century dates, as they appear on socalled milestones, route-markers or records of official route construction and upkeep. ${ }^{4}$ The incidences of both 'open- $A$ ' and 'sickle-G' may be noted.

Letter 1, it was concluded, might best be read as 'II' or ' $\mathrm{H}$ '. For the first, as I I A V G, the reading would suggest the title of [LEGIO] II AVG [VSTA], the Second Legion Augusta, an abbreviation commonly found with a superscript bar above the II. ${ }^{5}$ Here the top of the first letter has been trimmed off. There is no warrant, beyond mere speculation, to propose an extra additional line at the top of the stone, similarly missing; for a complete LEG II AVG one might suppose two lines, LEG above II
AVG. For the second reading, the four letters $\mathrm{H} \mathrm{A} \mathrm{V} \mathrm{G}$ would suggest an Imperial name with initial $\mathrm{H}$.

After the first-century phase when all or part of Legio II Augusta garrisoned Isca Dumnoniorum, Roman Exeter, and presumably exercised as detachments within present Devon and Cornwall, the history of this legion is bound up with the other Isca (Caerleon). ${ }^{6}$ The status of the Tintagel site-complex during the Roman period is admittedly still unclear but insofar as Tintagel has a specifically Roman aspect this is predominantly late, third and fourth centuries. ${ }^{7}$ In excavations from 1933 onwards at Tintagel, sherds of locally made pottery have been found (most from undiagnostic provenances) and are generally matched in Cornwall from native sites thought to have been occupied during the third to fifth centuries AD. Specifically, in 1981, re-examination of a mass of pre-1938 ceramic finds revealed, from $\mathrm{Dr}$ Radford's excavations on the Island, sherds of Oxford Red Colour Coated ware, fourth-century strays to the south west, wrongly identified as post-Roman imports (Phocaean Red slipped ware). ${ }^{8}$ Lastly, still unpublished and in a private museum at Tintagel, there is a small coin hoard apparently found in a shrivelled leather drawstring purse, in a rock-cleft, during Dr Radford's 1955 re-excavation of the landward-side Great Ditch. Examination showed a total of ten low-denomination coins from Tetricus I (AD 270 to 273/4) to Constantius II as Augustus (AD 337-61) (see Chapter 1). ${ }^{9}$

However these finds are to be interpreted, the present balance of probability is tipped towards seeing any kind of Roman involvement at Tintagel not in the first century, but during the third and fourth, and perhaps with some measure of continuity into the period of use (later fifth) indicated by the long series of excavations (see further discussion in Chapter 12). On that basis, Text $I$ is preferably read $\mathrm{H} \mathrm{A} \mathrm{V} \mathrm{G} \mathrm{and} \mathrm{interpreted} \mathrm{(if} \mathrm{in}$ the nominative) as an Imperial ascription, $\mathrm{H}$ [onorius] AUG[ustus]. It could of course be in the dative (H[onorio] AUG[usto]), as on most milestones. The emperor in question was Augustus from 393 and died at Ravenna in 423.

If this is correct - and no other Imperial name starting with ' $\mathrm{H}$ ' can be proposed - this little ascription would be unique in late Roman Britain. Collingwood and Wright list nothing later than a milestone, 2239, to Constantine II (337-61). Purpose and function remain unknown. The unbroken slate, perhaps an approximate rectangle with these four letters in a row about $70 \mathrm{~mm}$ high cut across its upper part, could have served as a 
label fixed to the front of a building. The lettering itself may look irregular but is not markedly more so than on certain milestones; the $\mathrm{X}$-like ' $\mathrm{V}$ ' appears very occasionally in post-Roman Insular lettering but here is probably no more than an idiosyncratic cutting. An implication could be the existence, on the Island and around $\mathrm{AD} 400$, of a labelled store, tax office or even dwelling that was regarded as still within some administrative system under official and Imperial control, and (for Roman Cornwall) the production and any marketing of streamed tin would suggest itself. Beyond that lies uninformed guessing. The archaeological context may be just enough to imply that, if the slate had served as a kind of antefix for any structure, its matrix building was disused or had collapsed before Text II was incised and before the piece itself ended up as a Site $\mathrm{C}$ drain cover.

\section{Interpretation of Text II}

The five lines contain representations of thirteen letters; A C E F g I L N O P R T V. In line (iii) the anomalous ' $\mathrm{g}$ ' resembles a script or bookhand form. The other twelve may be classed as capitals. Figure 103 sets out all the letters, separating (above) those from lines (i) and (iii), putatively by a first writer, from (below) those in lines (ii), (iv) and (v), putatively by a second hand.

If two writers were involved, they had been taught capitals in the same style or fashion, a suite of letters somewhat removed from the normal or standard capitalis seen on the majority of Romano-British inscriptions up to the mid-fourth century. In alphabetical order, one can single out $\mathrm{A}$ as 'angle-bar A' with its prominent $\mathrm{V}$-shaped centre; $\mathrm{F}$ with a long descender; narrow sinuous $\mathrm{L}$ with bent-over top; $\mathrm{N}$ with long left descender and splayed right ascender; P with long descender (and its loop slightly open) and R with long descender, which is also a 'sideways $\mathrm{R}$ ' in that its loop is open and the right diagonal descender is raised to point sideways horizontally. In lines (ii) and (iv) there is also a size variation between initial $\mathrm{C}$ and medial $\mathrm{C}$ (as in FICIT),

Two opening assumptions only as to date are permissible. The first is that if Text II is demonstrably secondary on contextual grounds to Text $\mathrm{I}$ it is not earlier than the reign of Honorius and presumably also post-dates any use of the slate as a public display of Text I. The second is that most of the capital letters are visually different from or 'devolved' from those generally used in fourth-century Britannia and together suggest prima facie some period after AD 400.

For the considerable and important corpus of western and northern British inscribed memorial (or occasionally commemorative) stones, the earliest being fifth century, absolute or single-year dating of inscriptions is impossible. High-probability estimates of date, to a given century or less, are not, but must be drawn from detailed converging arguments. ${ }^{10}$ Figure 105 brings together versions of capital A C E F L M N O P R T V (most of the letters represented in Text II) as they appear on four inscriptions where the high probability is that all belong to the fifth century: 520 Latinus (Whithorn), 435 Clutorigi (Llandyssilio West, Pembroke), 421 Rostece (Llanerfyl, Montgomery) and 479 Cunaide (Hayle, Cornwall). ${ }^{11}$ Whether derived from surviving Romano-British models,

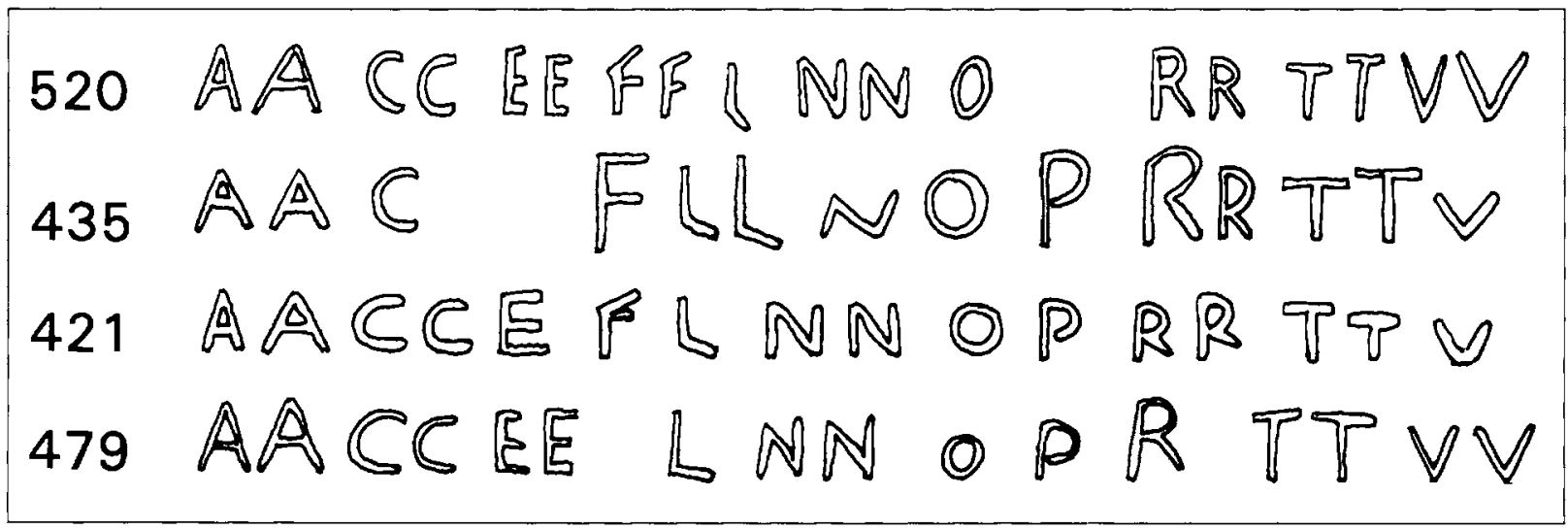

105 Capital letters of continuing Romano-British type from four Insular memorial stones of the fifth century (numbers as in Macalister 1945-9). Drawing: A C Thomas 
contemporary Gaulish models or written capitals on nonstone media, these inscribed letterings all show ordinary, conventional, perhaps slightly provincial, late Roman capitalis.

Figure 106, however, shows the same range of letters as they appear on two memorials from north-west Wales, 391 Senacus and 392 Veracius (both at Aberdaron), and three from Kirkmadrine, south-west Scotland; 516 Viventius, 517 Florentius and 518 Initium et Finis. What these five have in common is that they are associated with specific sites, Capel Anelog near Aberdaron and somewhere in the Kirkmadrine locality, that can be interpreted as post $-\mathrm{AD} 500$ 'mission stations' of clerics from Christian Gaul, either incomers or Insular clerics returning home. ${ }^{12}$ What the inscriptions have in common is a use of distinctive letterforms, updated fashions or styles in the portrayal of certain letters, imitating epigraphic developments on the Continent during the fifth century. The resemblance between Figure 106 and the Tintagel letters in Figure 103 are obvious, down to the appearance on the Kirkmadrine 518 Initium et Finis (late sixth century) of a long-tailed splayed $\mathrm{N}$.
Appropriate parallels from Continental inscriptions - in Spain, France, Switzerland and the Rhineland - can be found in standard corpora; a good instance would be the elaborate dedication-stone, later sixth century, at Acauna (St-Maurice-d'Agaune, on the French-Swiss border), ${ }^{13}$ which well illustrates the currency of these developed letterforms, notably the vertical elongation of $\mathrm{N}$ and $\mathrm{P}$.

For Cornwall, inscribed memorials for Christian individuals seem first to have appeared around the entry-point of the Camel estuary (near modern Padstow), spreading thence into north and east Cornwall and south Devon, as one by-product of casual immigration from parts of south Wales starting around the end of the fifth century. ${ }^{14}$ This may also be the best estimate of date for an introduction to south-west Wales, early Demetia, and presumably through Carmarthen Bay and the Tenby area, of new Continental letter fashions, notably both 'angle-bar A' and 'sidewaysR.' ${ }^{15}$ A conclusion, therefore, would be that the style of lettering illustrated by Figure 106 was known in north Cornwall, with the Tintagel area and its hinterland, by

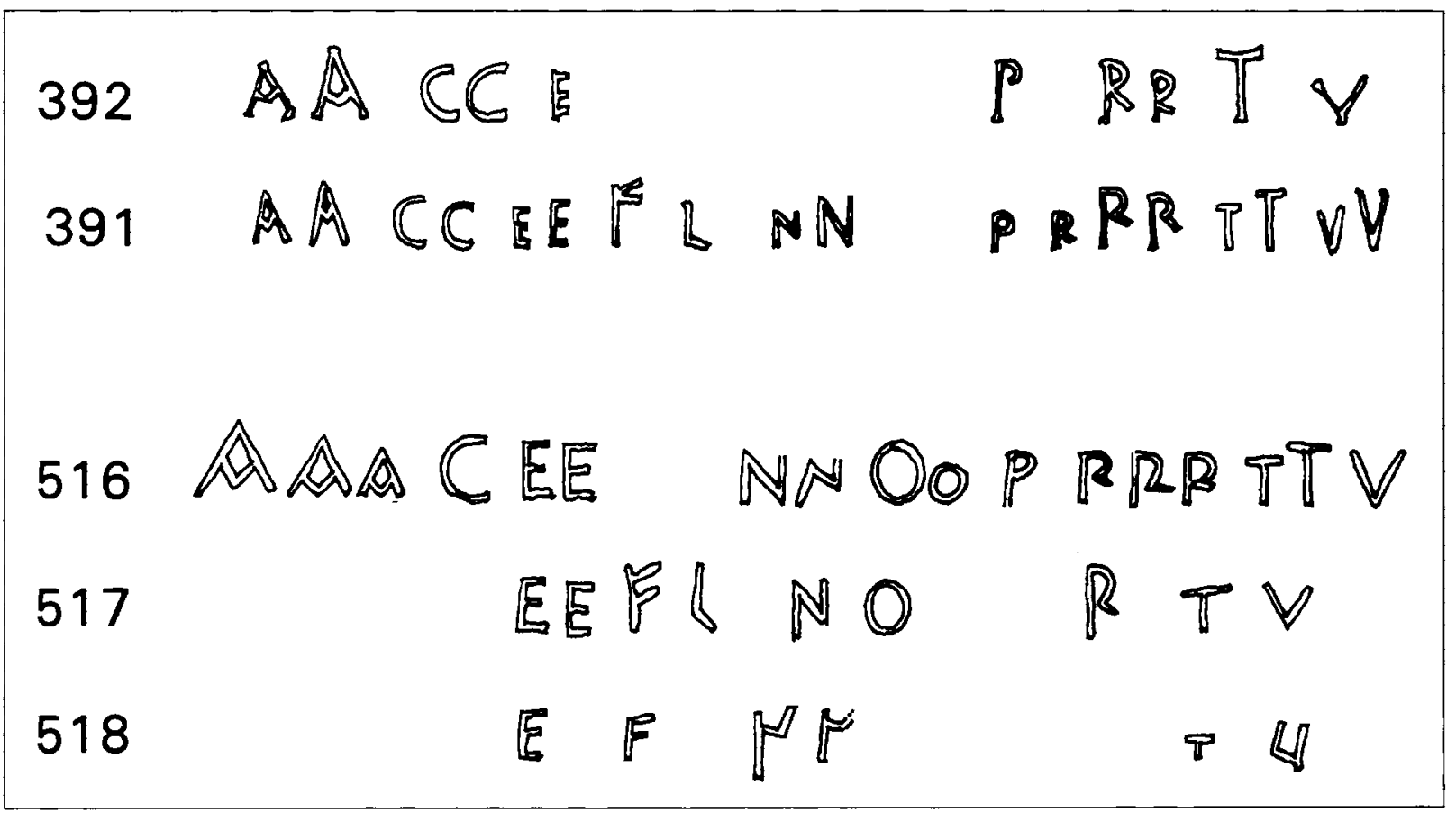

106 Capital letters suggesting introduction of new Continental fashions, probably from Christian Gaul, on five Insular stones of the sixth century; upper two lines from Aberdaron, Wales, lower three lines from Kirkmadrine, south-west Scotland (numbers as in Macalister 1945-9). Drawing: A C Thomas 
the first half of the sixth century (but not demonstrably earlier). Its reproduction on stone, as Text II, by one writer or by two contemporary writers could be provisionally assigned to $c 550$, plus or minus a generation. The further implication might be that the little piece of slate, long abandoned from whatever position it enjoyed around 400, was re-used in situ during the sixth century; a date in accord with the ceramic evidence for occupation at Site C.

In this light, we return to Text II, which seems to consist mainly of proper (male) names. In the top line (i) the last letter (damaged) is surely an I; the pattern of ARTOGNOV shows that a V, here, would have exhibited a greater splay. The supposition that line (iv) read COL(IAVI, in full, allows space in line (i) for extra letters. The alternatives are thus PATERNI, genitive of Paternus; PATERNINVS, nominative, or its genitive PATERNINI; less probably, because far less common, PATERNIVS (or its genitive PATERNI); quite improbably, because the last letter is not apparently A or $\mathrm{E}$, the feminine PATERNA, with genitive PATERNE. In favour of PATERNI must be the observation that the name Paternus, in the Roman world, was widespread and far more common that Paterninus; ${ }^{16}$ in favour of the latter, both the indication that at least three further letters could have been incised, and the attested PATERNINI (late fifth century?) as the deceased girl's father on the Welsh memorial, 421 Rostece. ${ }^{17}$

In line (iii) the name ARTOGNOV - or, allowably, ARTOGNOV(S; the spacing here makes it possible that a final $S$ has been lost - is Celtic (British). It comprises *artos 'bear' (the European brown bear Ursus europaeus, thought by some to have been still extant in parts of Britain in Roman times), ${ }^{18}$ with the stem-vowel -ocontinued as the compositional vowel, and a second element-gnous, earlier ${ }^{*}$ gnawos, the sense of which is 'know' - perhaps 'known-as, known-to-be'. The element art- appears in other early Welsh male names like Arthfael, older Artmail (from *Arto-maglos 'BearPrince'). Names terminating in -gnou(s) led, later in the first millennium, to other Old Welsh forms like Elgnou and Iudnou (with iud 'Lord'). Others are found in Old Breton: Haelnou, Gurgnou, Carantnou, and a record for $\mathrm{AD} 882$ of Arthnou $^{19}$ which is the expected later spelling of ARTOGNOV.

The particular linguistic interest here is that, $c 550$, this name incised as ARTOGNOV was not a correspondingly spoken trisyllable, /art-og-noo/, but because of the known development in speech from
Roman-period British to what, at Tintagel, must be called 'Primitive' or 'Archaic Old' Cornish had almost certainly become a spoken /arth-no/; softening or aspirating the $\mathrm{T}$, losing the internal compositional $\mathrm{O}$ by the process called syncope, and also losing the prefixed $G$. In other words, whoever committed this name to writing knew its older and fuller form, as it would have been in the fourth or third century. This deliberate archaism, otherwise known as IOC ('Inscriptional Old Celtic'), ${ }^{20}$ characterizes the treatment of Celtic as opposed to Latin names on many post-Roman inscriptions. An interesting parallel is the remarkable inscribed pillar or stele at Louannec, Côtes-du-Nord (Brittany); $;^{21}$ no earlier than the late sixth century, probably commemorating a firstor second-generation British settler in Armorica, it has two lines of vertically set lettering. The text reads DISIDERI FILI / BODOGNOVS '[Stone, or memorial] of-Desiderius; of-a-son of-Bodognous'. The father's name was, by this date, probably spoken as /bodh-no/. If both here and at Tintagel the archaizing IOC tendency preserved any knowledge of the former British caseendings, the expected declension would have been nominative Artognous (from ${ }^{*}$ Artognawos), genitive Artognou (from ${ }^{*}$ Artognawi). We cannot be sure which is actually represented. On the Louannec stone, BODOGNOVS looks like a nominative, semantically functioning as a genitive after FILI.

Line (ii), which is complete, shows a name in a latinized second-declension genitive - Coliauus, as Coliaui - followed by a verb, for which the preceding name ought to form the subject. This is not a Roman name. It comprises an element Col-, conceivably the same as Coll-, meaning uncertain, found in Celtic nameformation; for example, an Irish ogam inscription with 117 COLLOS (Co Cork). This has been extended with a known British hypocoristic or 'pet-name' ending, -iau, in a written Latin context presented as -iauus (the first ' $u$ ' is a /w/sound). The verb FICIT, for fecit 'has made, has done, has brought into being', shows a widespread vowel-substitution in post-Classical Insular Latin, long $i$ for long $e .^{22}$ An example from a Cornish memorial, late sixth- or early seventh-century, is 461 Ercilinci (Cuby), which shows TRIS FILI = tres filii 'three children'.

On many Insular memorials, where there is no doubt that a given inscription marks the death and burial of a named person, the name itself even when followed by a finite verb like HIC IACIT 'here [he or she] lies' is given in the genitive, not the expected nominative; as 457 (Lancarffe, Bodmin) DVNOCATI HIC IACIT FILI 
MESCAGNI. A rather forced translation would have to supply an extra noun - '[The stone, or memorial] ofDunocatus; here he lies; [the stone] of-a-son ofMescagnus'. There is no suggestion that the Tintagel piece has any funerary significance. As stated above, any explanation or translation now cannot hope to be better than an informed guess. However, following the principle that restoration of supposed missing letters should be minimal, and allowing that distinct possibility that two hands were at work, a tentative solution can be offered.

At what is now 'Site C', Tintagel Island, and at some time in the sixth century $\mathrm{AD}$ - perhaps after rather than before 550 - three or more people noticed a piece of slate whose upper face bore the letters H A V G; letters which they may or may not have been able to read. Using a knife, the first man, who knew that his own name should be rendered in Latin capitals as PATERNVS or PATERNINVS and who also knew a particular style of forming certain of the letters, scratched 'PATERNI' or 'PATERNINI'. ${ }^{3}$ He then proceeded to add below the name of a companion, a British name with no obvious Latin form, and in so doing managed partly to reconstruct an older spelling and (strangely) to use, not capital G, but a letter much closer to a non-capital script; the result was 'ARTOgNOV'. A second hand then took up the knife and fitted in 'COLIAVI FICIT'; then, possibly because the FICIT struck him as small and cramped (see figure 102) he scratched it again below, in two lines (and the word separation proves that he knew what the Latin meant). If it is allowed that both scribes also know the basic difference between second-declension nominative in $-u s$ and genitive in $-i$, and if a (provisional) rendering has to be put forward, one could propose:

'[The mark, or name] of-Paternus / Paterninus'

'[The mark] of-Coliauus - he made [it]'

'[The mark] of-Artognou'

'[The mark] of-Coliauus'

'He made [it]'

\section{Comment}

Nothing of this can inform us who these people were. In Cornwall from the fifth to eighth centuries a catalogue of personal names, most of them male, is provided by nearly fifty inscriptions. The mix here of Paternus or Paterninus (continuing-Roman), with Artognou and Coliauus (Late British or 'Neo-Brittonic' on its way to becoming Cornish), is entirely in accord with names known already. The implication that occupants of Tintagel at this period, men other than clerics and monastic brethren - and there is not the slightest indication of any such status here - still knew at least some Latin, knew how to write in what might be called both upper and lower case, and knew how to read, is no longer either startling or unacceptable. Nor in all probability does that lead to a conclusion that the postulated scribes must have been household officials to Dumnonian royalty, or the like; they may have been skilled craftsmen.

Since 1933, at a rough estimate, about one-twentieth of the surface area of Tintagel Island has been excavated, or has suffered repair and maintenance interventions, or has been surveyed in great detail or combed for surface finds. Hundreds of thousands of bits of slate, much the same size as this inscribed piece, have been moved or seen (though not necessarily inspected at length). From here, as also from the landward-side Lower Ward and (1990-1) Tintagel parish churchyard, quite a collection of incised or pictorial slate fragments large and small has been amassed; board-games of the Nine Men's Morris type, geometric and zoomorphic drawings and doodles, primary grave-markers with linear crosses-of-arcs. ${ }^{24}$ Some are patently medieval, linked to the building and later use of the thirteenth-century Castle; others, however, may be earlier, and in the case of the churchyard as early as the sixth century.

The Site C lettered slate is of course fascinating in its own right and has aroused great public interest (including misleading and ill-informed speculations, which can now be set aside). Its two, separable, texts pose new questions about the place at the end of the fourth century and then probably in the sixth century; a clear bonus is that it was found in the course of a controlled excavation and in a definite and meaningful context. It cannot be claimed that this discovery has actually solved any of the archaeological problems still adhering to Tintagel. A detached view is that the really extraordinary feature here should not be overlooked. Sixty-plus years after the late Ralegh Radford inaugurated modern investigations on the Island, the slate is the first (and so far the sole) hard evidence for post-Roman literacy, at the one place where, above all others, precisely such evidence could long have been expected.

$$
\begin{gathered}
\text { STONE } \\
\text { by Colleen E Batey }
\end{gathered}
$$

Throughout the stone identifications, there has been a distinction made between smaller notched slates which 
may have served a variety of functions, such as percussion stones used as strike-a-lights, and those with larger notches, which may have served as structural supports for wooden stakes (as noted from the Lower Terrace). ${ }^{25}$ Perforated slates may have served as roofing slates; crudely chipped discs may be vessel lids or amphora-stoppers. Water-worn slate and quartz pebbles are common finds, some possibly introduced by visitors to the site, others as part of the beach sand aggregate for mortars. A small group of worked flints is distinguished from the Site $C$ building and $C 15$ on the Middle Terrace, Site C. A small category of stone finds includes whetstones, whorls, inscribed slates and shaped stones.

\section{Site C, Upper Terrace: RADFord trenches}

The stone finds from trench $\mathrm{C} 19$ are limited in number and lack distinction, sharing the range of items identified from other areas of excavation, although in far fewer numbers. The small assemblage of nine finds of stone is divided between two phases. From Phase Z, a water-worn pebble and two slate discs (eg RF 1229: figure 107) were recovered, and from Phase Y three slate discs, probably amphora-stoppers; a perforated slate, probably a roofing slate and a pebble. The slight preponderance of finds from Phase $\mathrm{Y}$ is not unexpected, since this was Radford's backfill.

The stone assemblage from $\mathrm{Cl} 8$ is somewhat larger (forty-four pieces in all) and more diverse than that from $\mathrm{C} 19$ and probably has more affinity with the assemblages from trenches $\mathrm{C} 17$ and $\mathrm{C} 15$ from the Middle Terrace, which lie down-slope and east of C18. Fifteen water-worn pebbles were found from Phase $Z$ and a further five in Phase Y, Radford's backfill. The remaining twenty-four finds of slate can be subdivided into slate discs, perforated and notched slates, as indicated in table 45 .

In the case of the notched slates, four examples have very large and pronounced notches, and are likely to be structural pieces, but the remaining seven have smaller notches presumed to be from use as strike-a-lights. ${ }^{26}$

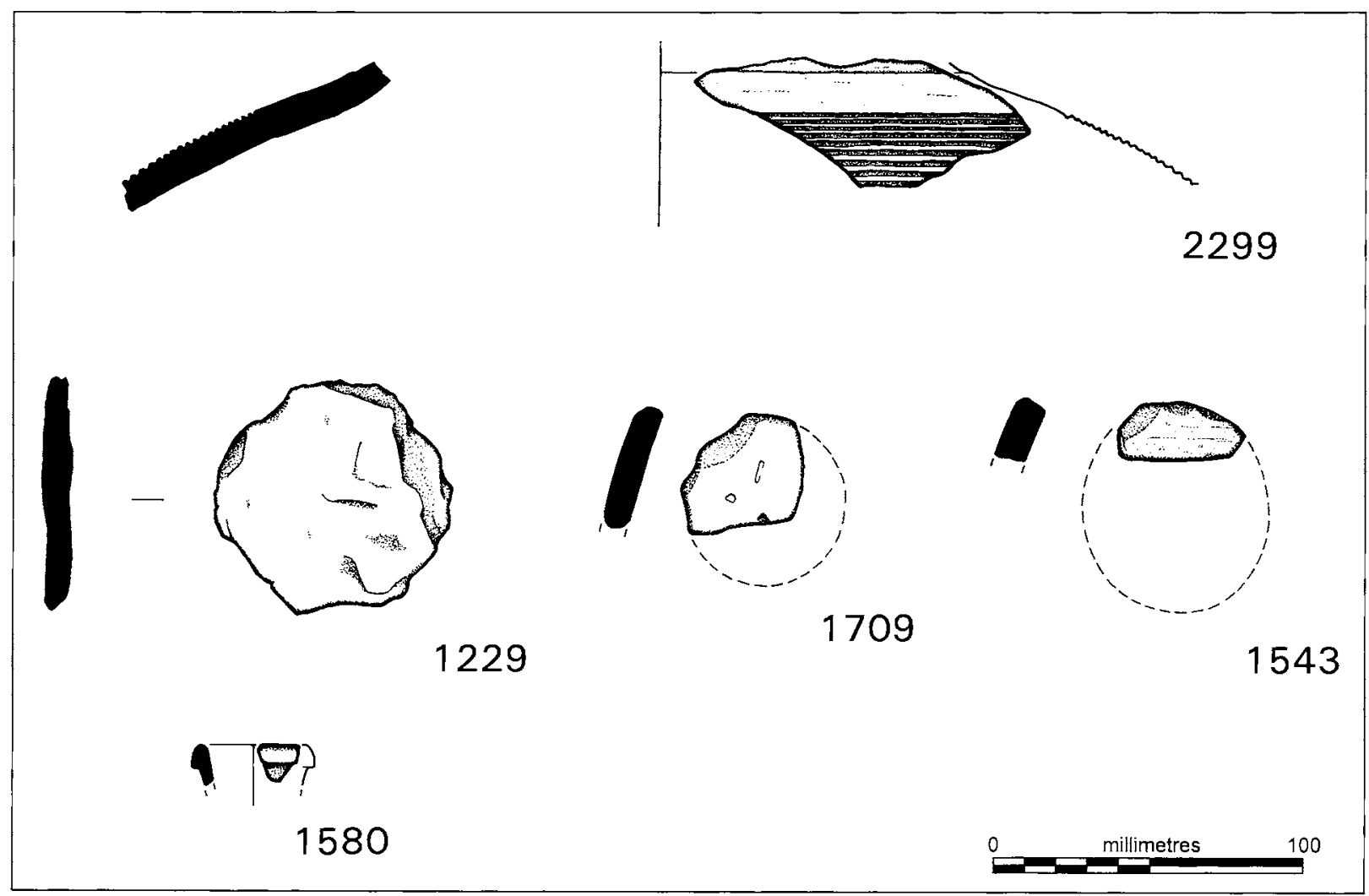

107 Imported Bii pottery: RFs 1580 (C15) and 2299 (C15); pottery amphora discs: RFs 1543 and 1709 (C15); slate amphora disc: RF 1229 (C19). Drawing: C Thorpe 
Table 45 Slate finds from trench C18

\begin{tabular}{llcccr}
\hline Phase & Context & Notched & Perforated & Disc & Total \\
\hline $\mathrm{X}$ & $\mathbf{8 0 1}$ & 2 & - & 2 & 4 \\
$\mathrm{Y}$ & 803 & 8 & 1 & 7 & 16 \\
$\mathrm{Z}$ & 800 & 1 & - & 3 & 4 \\
Total & & 11 & 1 & 12 & 24 \\
\hline
\end{tabular}

The single perforated slate from Phase Y (RF 3003) has a small, very irregular perforation and the best suggestion would be a roofing slate, although it is less regular than the large number found in the vicinity of the 'Steps' area, which are interpreted as roofing material from the adjacent medieval structure on Site $\mathrm{F}^{27}$

The slate discs (see figure 107) are a little more interesting in that the suggestion is that they were amphora-stoppers $^{28}$ (see also figure 33, Chapter 2). Several ceramic examples have been recorded elsewhere, for instance at Carthage, ${ }^{29}$ and have been identified in the Tintagel material both previously and in this report. ${ }^{30}$ The size of these discs seems usually to be in the $30 \mathrm{~mm}$ to $50 \mathrm{~mm}$ range, but six are incomplete, one remains as a half and the rest are virtually whole.

\section{Site C, Middle TerRaCe: Radford tRenChes}

The small assemblage of stone artefacts from trench $\mathrm{C} 05$ includes four water-worn quartz pebbles from Phase X. These are clearly not in situ and formed part of material which was predominantly scree-based and washed down the slope. A single slate disc from Phase V (RF 1225), may well have served as an amphora-stopper. The perforated slate pieces from Radford's backfill in Phase $Y$ include one with a small, very even, perforation, which could suggest it had been used as a strike-a-light, and two possible roofing slate fragments from Phases $\mathrm{X}$ and $\mathrm{Y}$.

Five quartzite and slate pebbles were recovered from trial trench $\mathrm{C} 15$, Phase $\mathrm{Y}$, and when considered with the larger pebbles found in $\mathrm{C} 18$, which lies up-slope, it is possible that this relative concentration may reflect the presence of the footpath above this part of the site.

The bulk of the stone material from trial trench $\mathrm{C} 15$ can be subdivided into groups of slate discs, notched slates and structural slates. Of the seven discs, one was unstratified, one from Phase $X$, four from Phase $Y$ and one from Phase $Z$. They are interpreted as replacement bungs for opened amphora or other vessels. ${ }^{31}$ The notched/perforated slates, which are differentiated from structural slates by the smallness of the notches, can be subdivided as follows: one from Phase $Z$, twenty from Phase Y (eg RF 2195: figure 108) and eight from Phase X. Those stone finds which are most likely to be structural, ie post-supports, include three, along with a roofing slab, from Phase $Y$ and a single roofing slab from Phase $\mathrm{X}$. The preponderance of material in this category from the scree and topsoil phases suggests movement from elsewhere up the slope. Presumably those finds from Radford's backfill had a similar original provenance from an earlier phase of movement, since the scree material post-dates the fill of Radford's trenches.

The single most significant piece of worked stone from trial trench C15 is from Phase Y, scree slip, and is part of a small Nine Men's Morris, or Merrells, gaming board (RF 2172: see figure 108). This parallels another example from the Island found in the 1933-8 work of Radford ${ }^{32}$ and could be dated with those examples in Cornwall noted from the eleventh century onwards (see Chapter 4). It is a particularly noteworthy find as it adds a personal dimension to the site.

Three water-worn pebbles were recovered from trench $\mathrm{C} 17$, two from Phase $\mathrm{Z}$ and one from Phase Y. In addition, a single perforated slate was unstratified, in the turf horizon. A potentially more significant stone find from this area was RF 2828, a slab with apparent graffiti marks (from Phase X, Radford's backfill: figure 109).

\section{Site C, Middle TerRace: Trench C15}

From the period of building collapse (Phase W), a single slate with incisions was recorded (RF 3731). As the illustration indicates (figure 110), it is not possible to define the nature of the original image created, possibly because, as it is located at one edge of the slate, it is incomplete. As noted above, there are several slates with incised images from previous work at Tintagel and the inscribed stone from $\mathrm{C} 09$ ( $\mathrm{RF}$ 3486) containing the name ARTOGNOU has indeed excited much discussion 


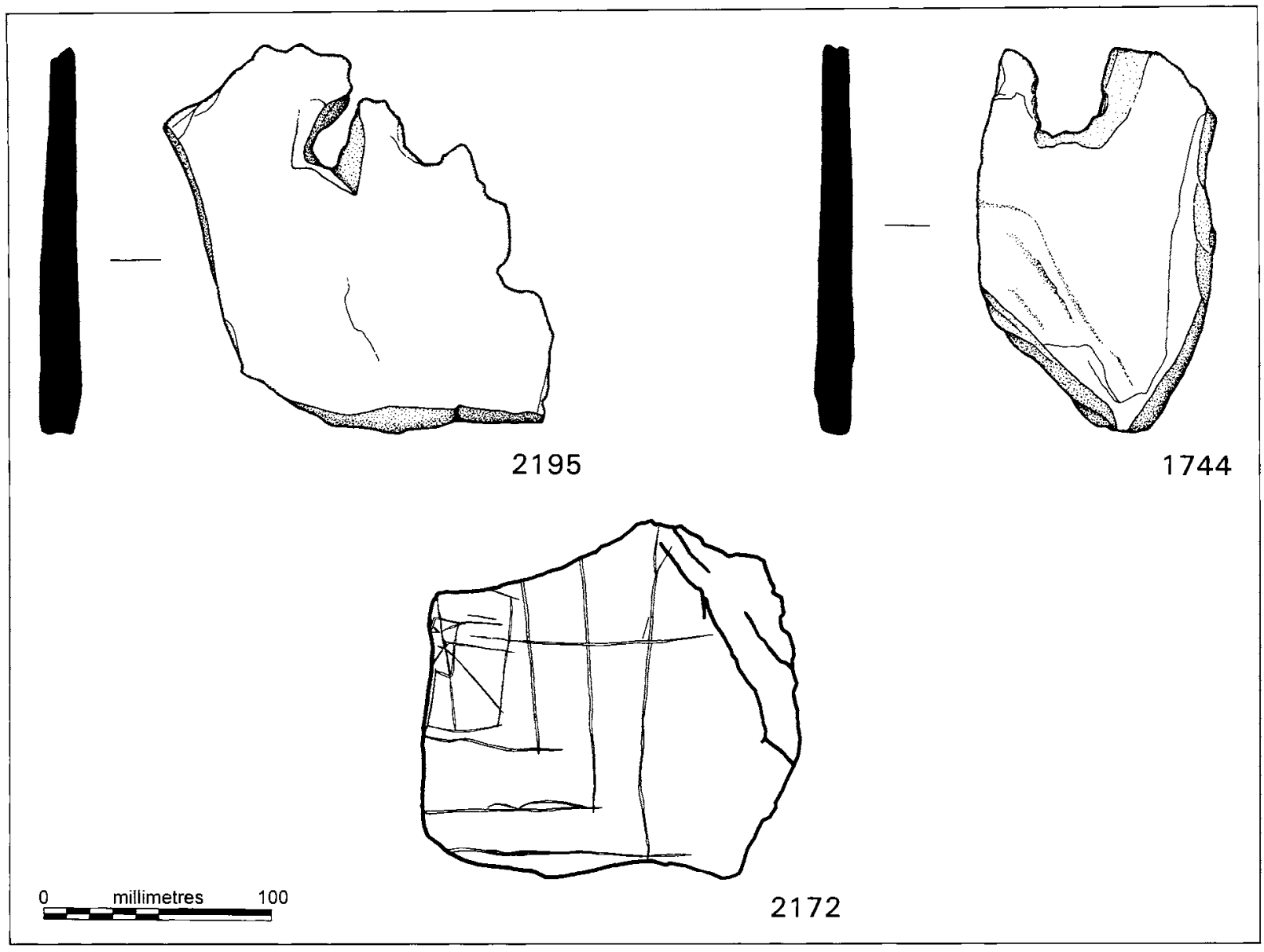

108 Worked slate: RFs 2172 (C15: 'Merrells' board), 1744 and 2195 (C15: notched). Drawing: C Thorpe

(see Thomas above and Chapter 6). Unfortunately this piece from $\mathrm{C} 15$ is not comparable.

The group of pebbles (table 46) from this site, thirtytwo in number, are scattered through several phases and are predominantly quartzite with just nine of slate. The single find from Phase U (RF 3615), a period of traces of occupation associated with imported ceramics, is in fact of a different nature to the rest of this part of the assemblage being made of sandstone and exhibiting traces of burning. ${ }^{33}$

Eight pebbles from Phase $V$ and a further eight from Phase $\mathrm{W}$ were recovered. These phases represent periods of collapse of the structure in this area and the pebbles may not have been found in situ. Although it might be useful to think of these in terms of the remains of a pebbled surface, or perhaps inclusions within the walling, it cannot be confirmed. Phase $\mathrm{X}$, related to Radford's excavations, yielded ten pebbles and it is once again presumed that they were not located in situ, presumably having been disturbed from an horizon cut by the earlier excavation work. Indeed, the lack of pebbles from Phase $Y$, post-Radford scree, would support the theory that the pebbles in Phase X come from earlier phases. The final part of the assemblage is five pebbles from the turf and topsoil of Phase $Z$ and these may perhaps be interpreted as introductions by tourists to the Island.

It is clear that these water-worn pebbles are an introduction to the site. In the case of the work in and around the Site $C$ building it was suggested that they were brought to the site as part of the mortar mix.

Twelve slate discs (see table 46) have been identified across Phases T, V, W and Z with a single unstratified piece. They are mostly very crudely chipped and some show signs of pecked perforations near the surviving edge, eg Phase V RF 6088, or a large central pecked 


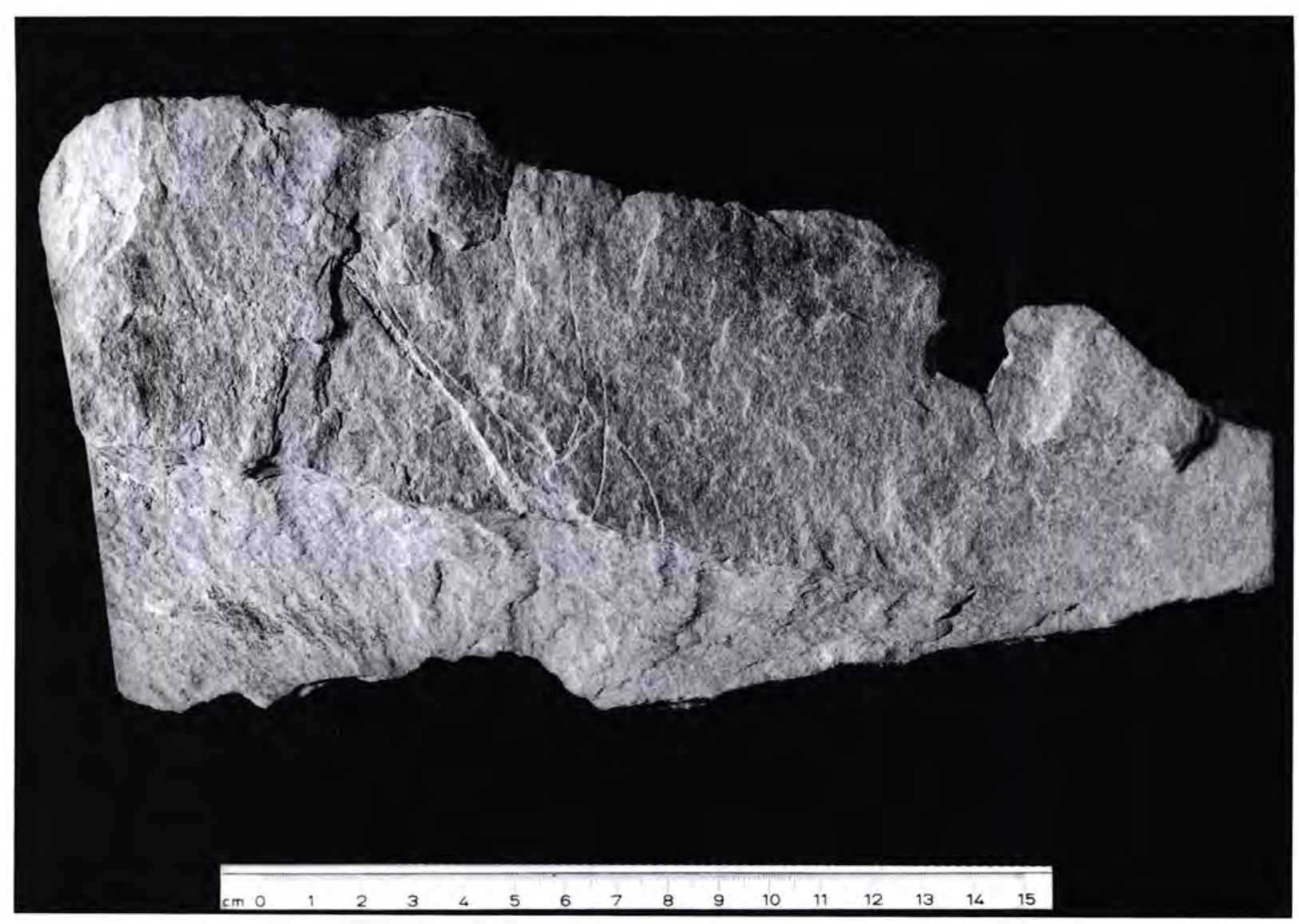

109 Trench C17. RF 2828 graffiti slate from Phase X. Photograph: E Howden

perforation which has led to breakage, eg Phase V RF 3948. The size range is quite consistent: ten fall within the diameter of $70 \mathrm{~mm}$ to $95 \mathrm{~mm}$ and two are more than $100 \mathrm{~mm}$ in diameter. These are interpreted as makeshift replacement bungs for amphorae. Several have already been noted from the Island and these have included ceramic examples (see above).

The notched slates (see table 46) can be subdivided into those which may have had a structural function and those which may have acted as strike-a-lights; the most obvious distinction is usually in the size of the notch. The single example from Phase $U$ came from occupation deposits associated with imported ceramics. Five strikea-lights and a single structural stone were recovered from Phase W, a phase of building collapse. The final example, a large flat structural slab, came from the turf and topsoil of Phase Z. The two structural pieces, RF 3739 and RF 3530 (figure 111) may have acted as postsupports. The find from Phase Z (RF 3530) is a large stone which may well have been moved from its original location to act as a levelling stone in more recent remodelling at the site. The simple strike-a-lights have been found throughout many contexts on the Island, most particularly around the building of Site C (discussed below).

The category of perforated slates includes four perforated stones and two that may be suggested as roofing slates (see table 46 ). They are scattered through four different phases, and there is one unstratified piece in addition. The two roofing slates were identified from Phase T (RF 6067), a period of midden dumping, and Phase X (RF 3971b), Radford's excavations. It is possible that the Phase T example may have been recovered from the interface with a floor level and midden dump and it is not impossible that the find from X, clearly not in its original location, may have been from this earlier phase.

Four possible slate spindle whorls have been identified in the assemblage from phases $\mathrm{U}, \mathrm{V}$ and $\mathrm{W}$. 


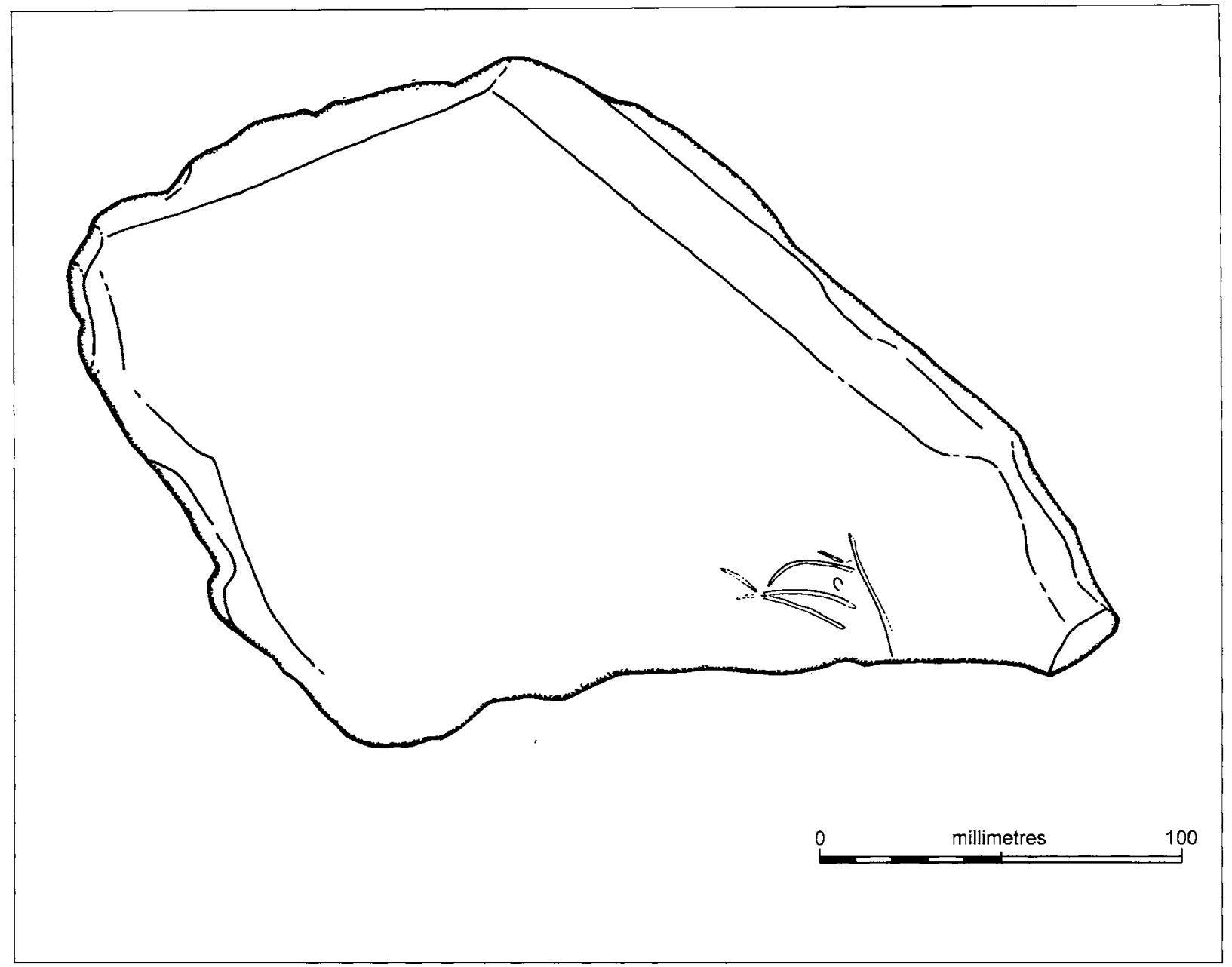

110 Graffiti slate: RF 3731 (659). Drawing: C Thorpe

Table 46 Stone finds from C15 by type and phase

\begin{tabular}{lcllc}
\hline Phase & Pebbles & $\begin{array}{l}\text { Notched slates } \\
\text { [structural] }\end{array}$ & $\begin{array}{l}\text { Perforated slates } \\
\text { [roofing] }\end{array}$ & Discs \\
\hline $\mathrm{T}$ & & & {$[1]$} & 2 \\
$\mathrm{U}$ & - & - & - & - \\
$\mathrm{V}$ & 1 & 1 & - & 4 \\
$\mathrm{~W}$ & 8 & - & 1 & 3 \\
$\mathrm{X}$ & 8 & $5[1]$ & $1[1]$ & - \\
$\mathrm{Y}$ & 10 & - & 1 & - \\
$\mathrm{Z}$ & - & - & - & 2 \\
$\mathrm{u} / \mathrm{s}$ & 5 & - & 1 & 1 \\
Total & - & $6[2]$ & $4[2]$ & 12 \\
\hline
\end{tabular}




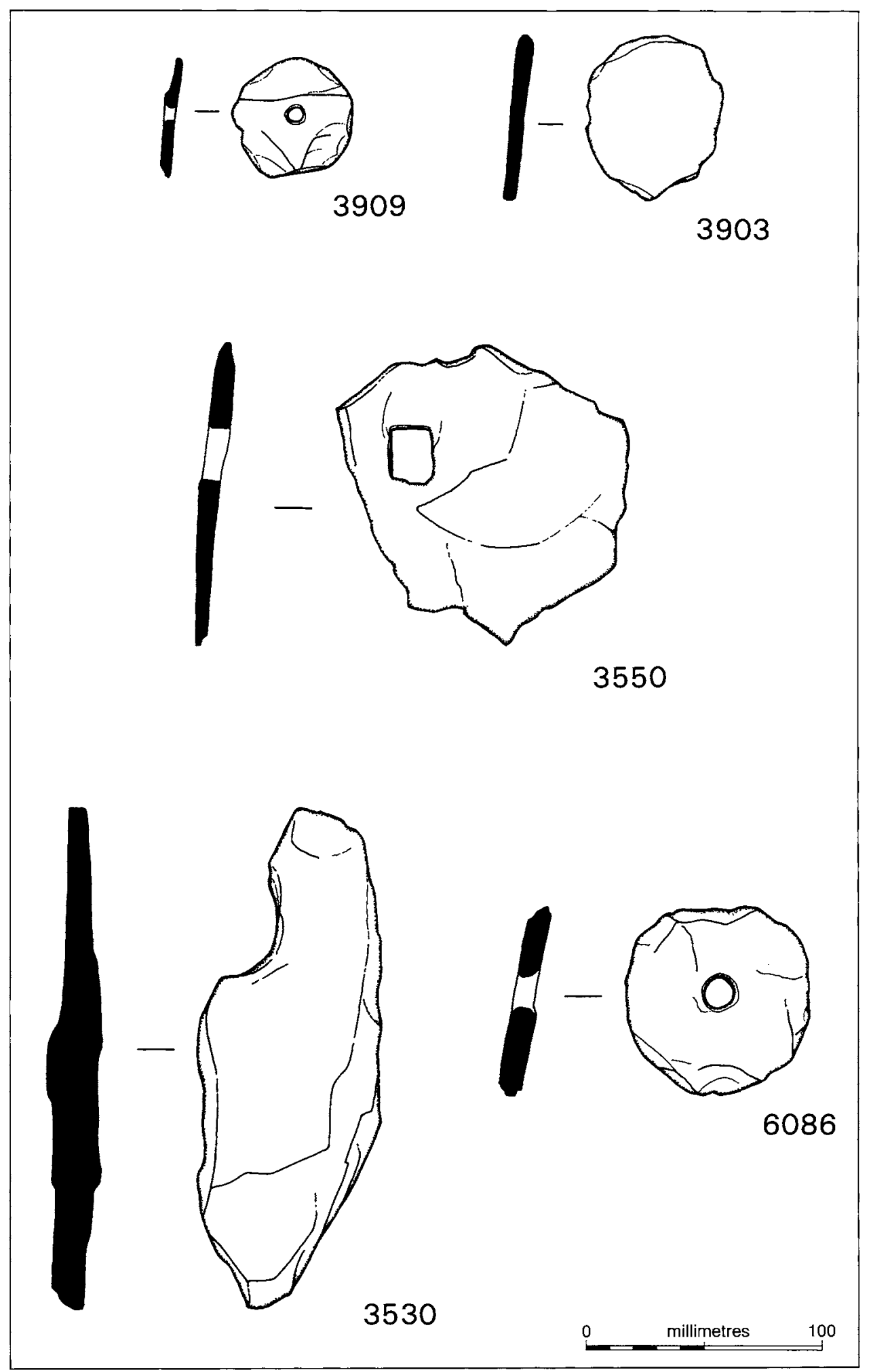

111 Stone artefacts: RFs 3909 (spindle whorl, 666), 3903 (slate disc, 687), 3550 (perforated slate, 650), 3530 (notched slate, 500) and 6086 (spindle whorl, u/s). Drawing: C Thorpe 
One unstratified find was also included (RF 6086). Of these, it is possible that RF 3830 (Phase U) is in fact an amphora-stopper (ie a slate disc) with a diameter of about $50 \mathrm{~mm}$ and that the central pecking (figure 112) is in fact not unfinished pecking for a perforation - the spread of hits is too diverse - but activity related to breaking the seal. RF 3623b (Phase W) is a little questionable in this category as it is incomplete. RF 6086 with a diameter of $75 \mathrm{~mm}$ and RF 3909 with a diameter of $50 \mathrm{~mm}$ (see figure 111) are better candidates. There are others recorded from the work at Tintagel, for example, a complete example in spotted slate was recovered from the Steps area ${ }^{34}$ and elsewhere this simple form has been noted at $\mathrm{C} 10$ and $\mathrm{Cl} 6$ (see Chapter 6).

Three miscellaneous items in this category include a pick-marked stone, RF 3508 from Phase Z, and two nonartefactual pieces of what was originally considered nonlocal stone, but on identification was a local 'greenstone' (RF 3649, Phase W) and a granitic stone (RF 3820, Phase W). The pick-marked stone was most likely the result of clearance activity by Radford's workmen and as such has little bearing on the archaeology of the area.

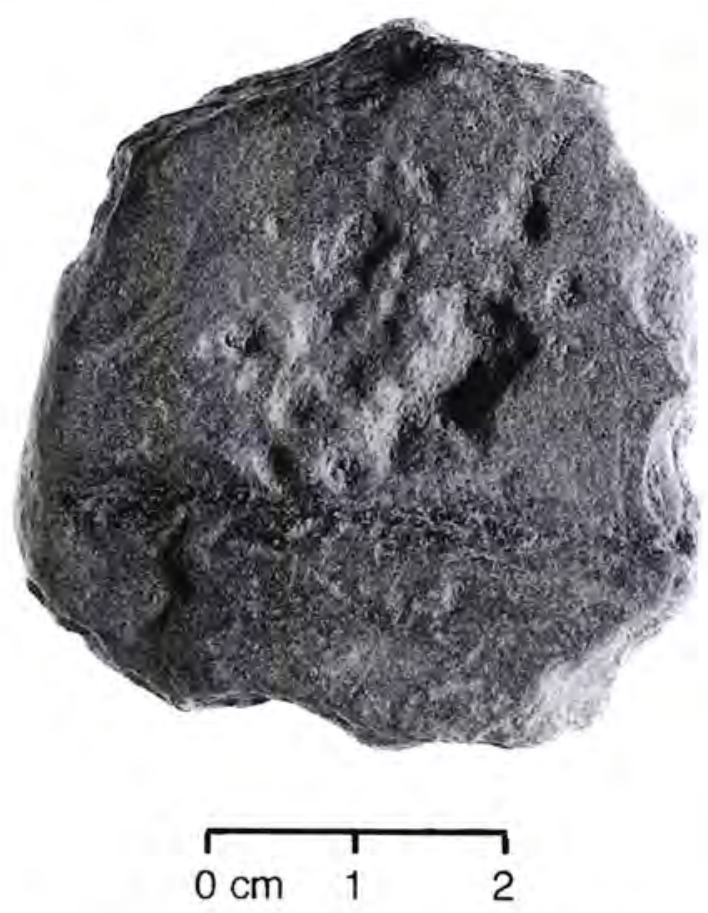

112 Photograph of incomplete spindle whorl RF 3830 (685).

Photograph: E Howden

\section{Site C, Middle Terrace: Site C building}

Two hundred and forty-one individual stone finds have been recovered, dividing into 144 pebbles, thirty slate discs, fifty notched slates, eight perforated slates, three incised and inscribed stones and six miscellaneous artefacts, including hones, whorls and flint tools. With the exception of the imported ceramic assemblage, this is numerically the largest category of material type from this site as a whole.

One hundred and forty-four pebbles were found in and around the Site $\mathrm{C}$ building. Of the total number, 69.44 per cent were recovered from Phase $\mathrm{Y}$, being related to the MoW levelling and reconstruction of Site $\mathrm{C}$ building. This predominance suggests that in this period the introduction of beach pebbles to the site may have been related to the introduction to the site of buildup material or beach sand used for making up mortar (see Palmer below). The smaller scatters in the upper contexts could be representative of tourist keepsakes being brought up to the site and children collecting from the beach etc. Only two pebbles relate to the in situ activity of the building use, too small a sample to make further comment.

Thirty slate discs were found (table 47; see figure 113 for examples). Of the total, Phases Z and Y (Turf and topsoil and MoW levelling etc) account for fifteen, and five are unstratified. From the earlier phases, W (screetips and collapse of building) has three and X (Radford's backfill) has four. Four discs from $\mathrm{C10}$, Phase $\mathrm{X}$, are most likely to have been gaming counters. These have a diameter of roughly $30-35 \mathrm{~mm}$ and are somewhat small for use as amphora-stoppers, which have diameters of approximately $60-80 \mathrm{~mm}$. These have been identified elsewhere on the site (see above), and are common finds in areas of amphora production and usage (figure 114).

\section{Table 47 Slate discs from the Site $\mathrm{C}$ building}

\begin{tabular}{|c|c|c|c|c|}
\hline Phase & Trench & Number & Total & \\
\hline $\mathrm{T}$ & $\mathrm{C} 12$ & 1 & 1 & \\
\hline $\mathrm{U} 2$ & $\mathrm{C} 09$ & 2 & 2 & \\
\hline W & $\mathrm{C} 09$ & 3 & 3 & \\
\hline$X$ & $\mathrm{C} 10$ & 4 & 4 & \\
\hline $\mathrm{Y}$ & $\mathrm{C} 10$ & 4 & - & \\
\hline $\mathrm{Y}$ & C11 & 6 & - & \\
\hline $\mathrm{Y}$ & $\mathrm{C} 12$ & 4 & 14 & \\
\hline $\mathrm{Z}$ & $\mathrm{C} 09$ & 1 & 1 & \\
\hline $\mathrm{u} / \mathrm{s}$ & $\mathrm{C} 09$ & 5 & 5 & Overall total: 30 \\
\hline
\end{tabular}




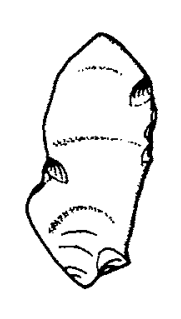

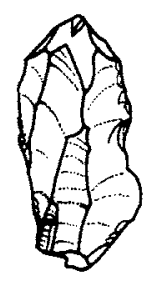

2609
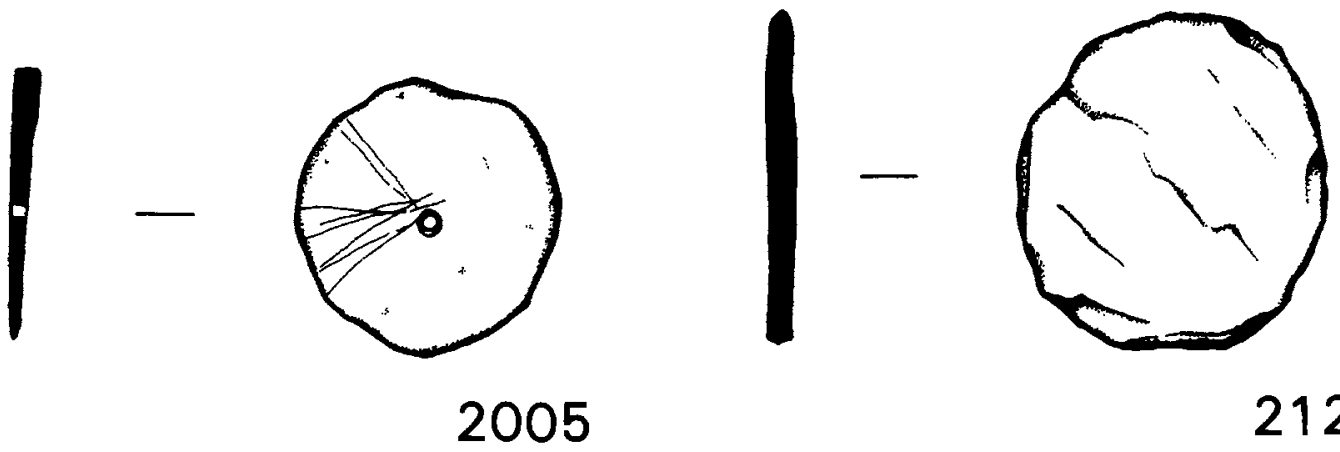

2123
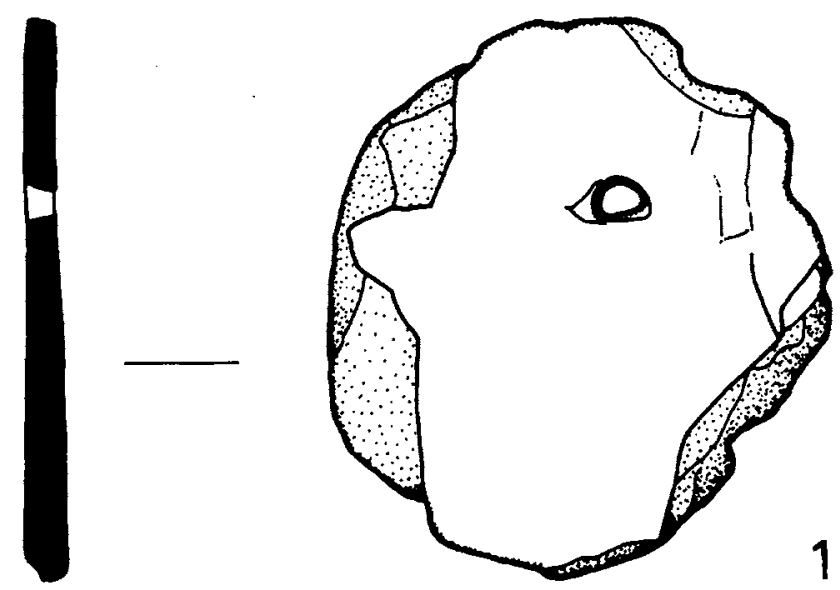

1804

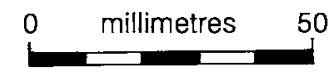

113 Slate amphora discs, flint and spindle whorls: RFs 2365 and 2609 (C16), 2005 (C10), 1804 (C11) and 2123 (C09). Drawing: C Thorpe 

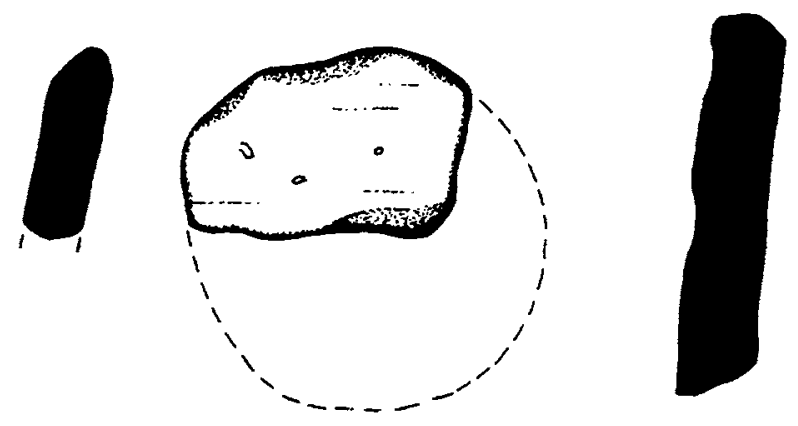

2004
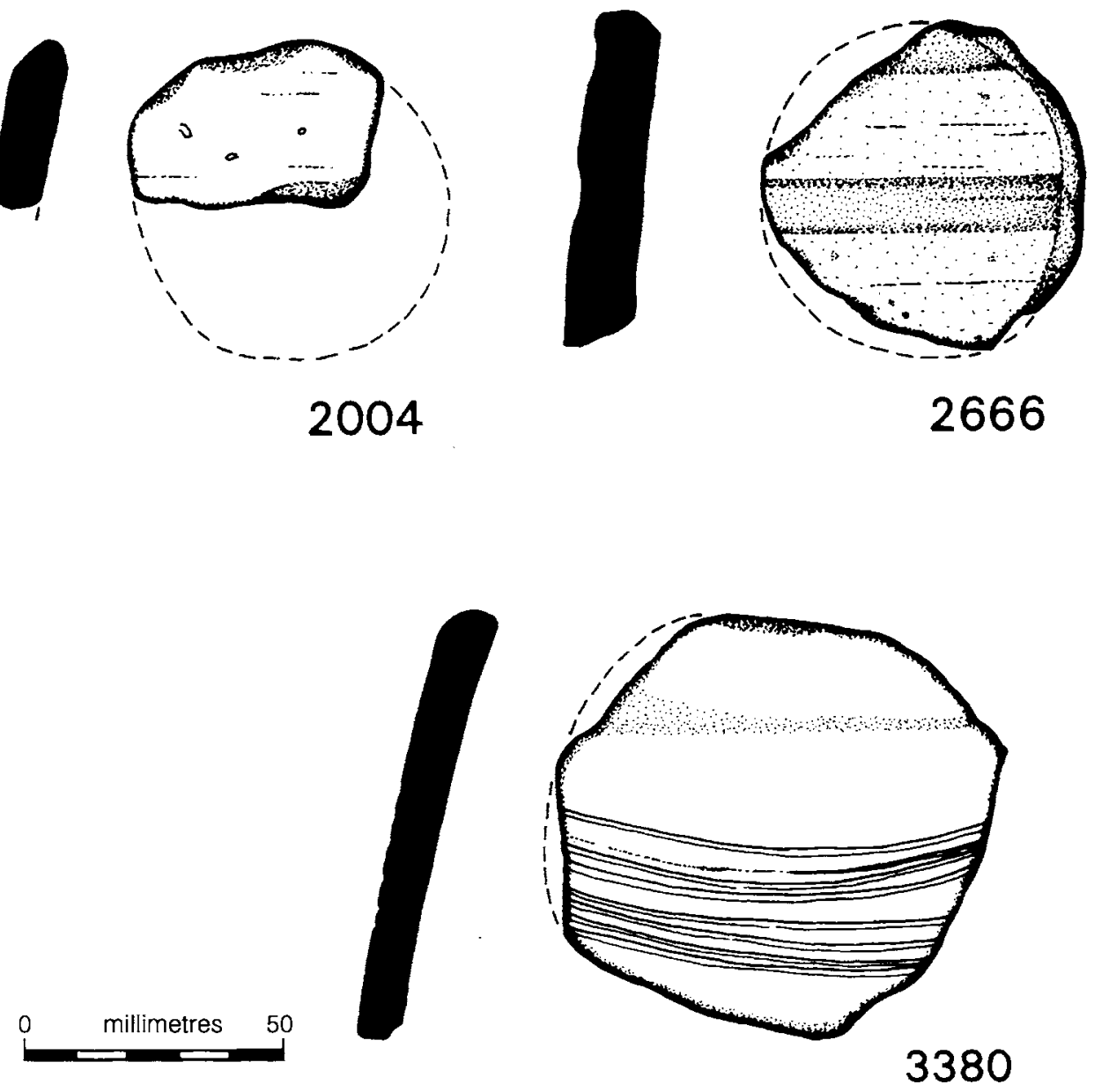

114 Pottery amphora discs: RFs 2004 (C10), 2666 and 3380 (C09). Drawing: C Thorpe

Fifty notched slates were found in and around the Site C building (table 48 ), and they comprise slate pieces which have one or more chipped notches at their edges. In some cases, these might have been structural, acting as post-supports - as on the Lower Terrace and in the Radford trenches, discussed above. ${ }^{35}$ A large quantity of similar stones was recovered at the site of Mawgan Porth, ${ }^{36}$ and it is likely that several examples from other sites may have been overlooked as their innocuous appearance belies their significance. In other cases, their function is less clear and could have been used as percussion stones for lighting fires.

In the overall total, two are possibly structural from Phases $\mathrm{S}$ and $\mathrm{T}$, and it is presumed that the example from Phase S (bedrock) was actually either sitting directly on bedrock or was a broken part of the bedrock. The
Table 48 Notched slates from the Site $\mathrm{C}$ building

\begin{tabular}{llll}
\hline Phase & \multicolumn{2}{l}{ Trench Number } & Total \\
\hline S & C11 & 1 ?structural & 1 \\
T & C09 & 3 and 1 structural? & - \\
T & C12 & 1 with perforation & - \\
T & C13 & 1 & 6 \\
V & C09 & 3 & 3 \\
W & C09 & 2 & 2 \\
X & C10 & 3 & - \\
X & C11 & 4 & 7 \\
Y & C10 & $7+2$ structural & - \\
Y & C11 & 19 & - \\
Y & C12 & 2 perforated & - \\
Y & C16 & 1 & 31 Overall total: 50 \\
\hline
\end{tabular}




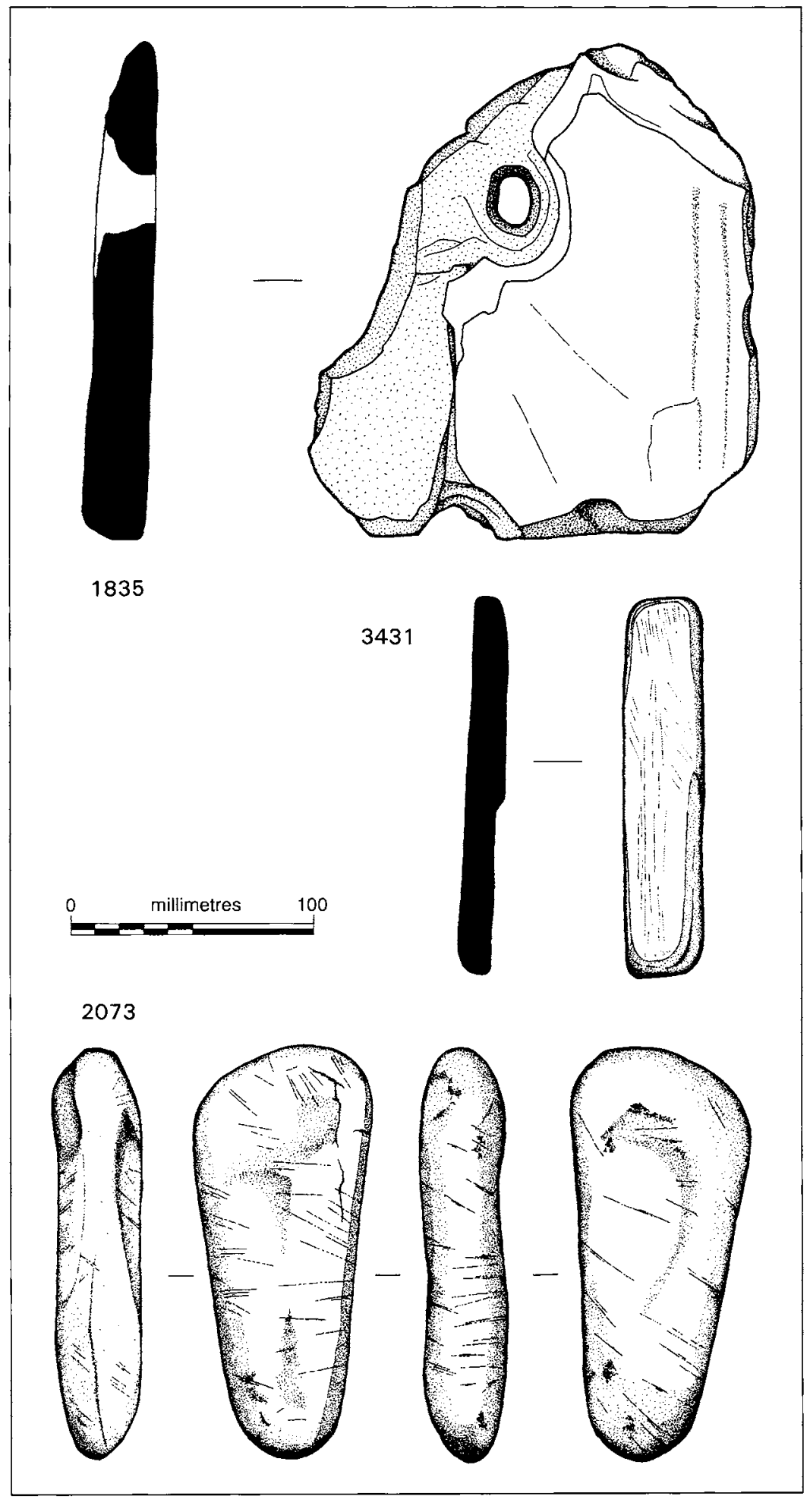

115 Whetstones and a perforated slate: RFs 2073 (C10), 3431 (CO9) and 1835 (C11).

Drawing: C Thorpe 
Table 49 Perforated slates from the Site $\mathrm{C}$ building

\begin{tabular}{llll}
\hline Phase & Trench & Number & Total \\
\hline $\mathrm{T}$ & $\mathrm{C} 09$ & 1 structural & 1 \\
$\mathrm{~W}$ & $\mathrm{C} 09$ & 2 & 2 \\
$\mathrm{X}$ & $\mathrm{C} 09$ & 1 & - \\
$\mathrm{X}$ & $\mathrm{C} 10$ & 1 & - \\
$\mathrm{X}$ & $\mathrm{C} 11$ & 1 with peck marks & 3 \\
$\mathrm{Y}$ & $\mathrm{C} 10$ & 1 roofing & 1 \\
$\mathrm{u} / \mathrm{s}$ & $\mathrm{C} 09$ & 1 roofing & 1 Overall total: 8 \\
\hline
\end{tabular}

examples from Phase $\mathrm{Y}$ (MoW levelling and reconstruction) are not likely to be in their original positions, and may have been brought to the site as part of a load of flat stones for levelling up the floor levels prior to grass coverage.

The assemblage of perforated slates includes stones which have perforations rather than notches, but can also include possible structural stones, roofing slates or strike-a-lights. Eight perforated slates were found in and around the Site $\mathrm{C}$ building (table 49; figure 115: RF 1835). Of the total, two are roofing slates (one unstratified, and the other in MoW levelling and presumed not to be in its original position), and one is

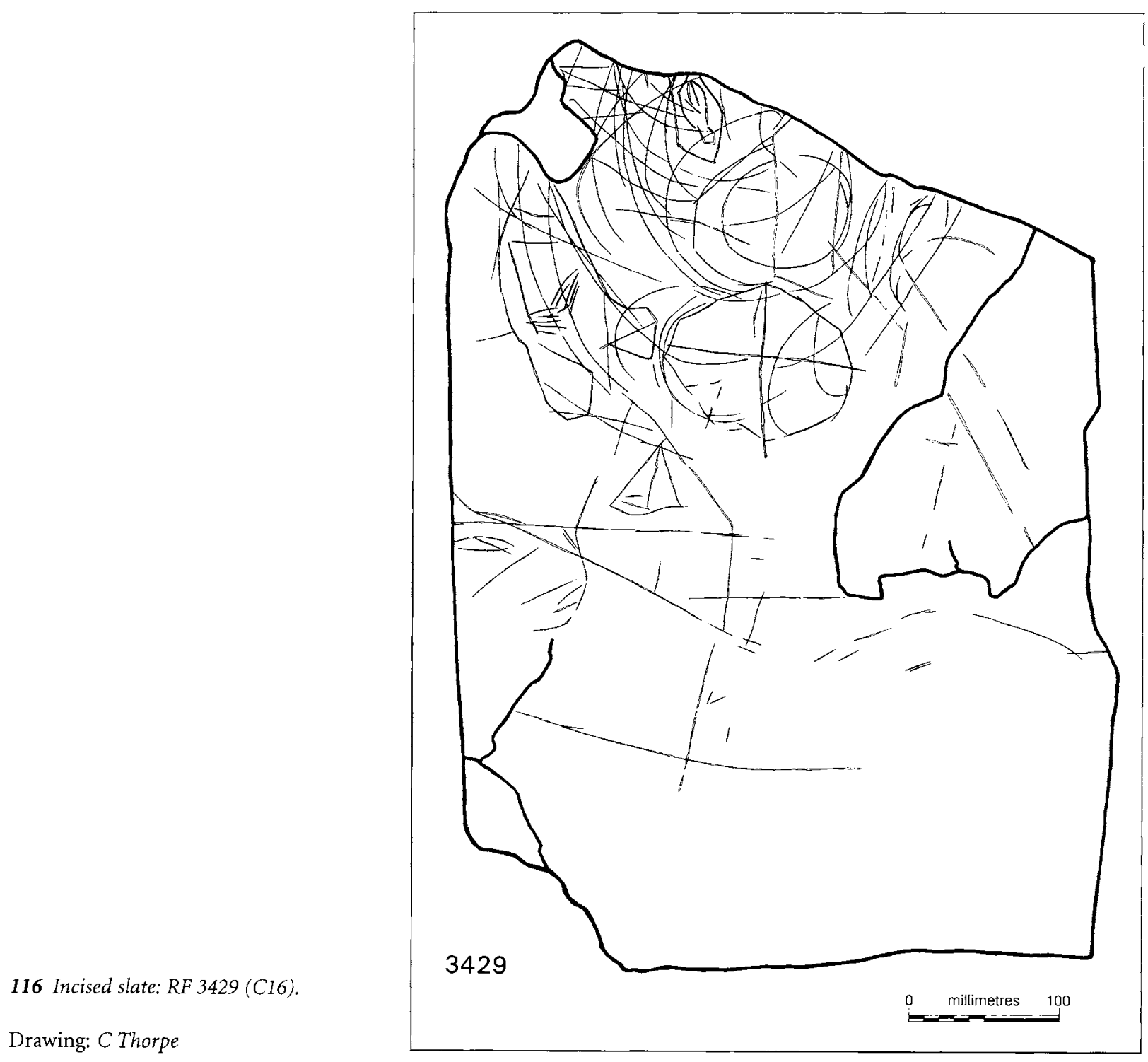


Table 50 Stone finds from Site $\mathrm{T}$

\begin{tabular}{|c|c|c|c|c|c|c|}
\hline $\begin{array}{l}\text { Trench } \\
\text { Phase }\end{array}$ & Pebbles & $\begin{array}{l}\text { Notched } \\
\text { slates }\end{array}$ & $\begin{array}{l}\text { Perforated } \\
\text { slates }\end{array}$ & Slate discs & $\begin{array}{l}\text { Shaped } \\
\text { slates }\end{array}$ & Whetstones \\
\hline $\mathrm{U}$ & 1 & 3 & 1 & - & - & - \\
\hline W & 2 & - & 1 & - & 1 & - \\
\hline $\mathrm{X}$ & 7 & 21 & 2 & 4 & 2 & - \\
\hline Z & 37 & 8 & 1 & - & - & - \\
\hline Total & 47 & 32 & 5 & 4 & 3 & - \\
\hline \multicolumn{7}{|c|}{ Trench T01 ext } \\
\hline Phase & Pebbles & $\begin{array}{l}\text { Notched } \\
\text { slates }\end{array}$ & $\begin{array}{l}\text { Perforated } \\
\text { slates }\end{array}$ & Slate discs & $\begin{array}{l}\text { Shaped } \\
\text { slates }\end{array}$ & Whetstones \\
\hline W & - & - & - & - & - & 1 \\
\hline $\mathrm{X}$ & - & 1 & - & 1 & - & - \\
\hline $\mathrm{Y}$ & 3 & 7 & - & 1 & - & - \\
\hline Total & 3 & 8 & - & 2 & - & 1 \\
\hline \multicolumn{7}{|c|}{ Trench T02 } \\
\hline Phase & Pebbles & $\begin{array}{l}\text { Notched } \\
\text { slates }\end{array}$ & $\begin{array}{l}\text { Perforated } \\
\text { slates }\end{array}$ & Slate discs & $\begin{array}{l}\text { Shaped } \\
\text { slates }\end{array}$ & Whetstones \\
\hline $\mathrm{Y}$ & - & 2 & - & - & - & - \\
\hline Z & 1 & - & - & 1 & - & - \\
\hline Total & 1 & 2 & - & 1 & - & - \\
\hline
\end{tabular}

structural, acting as a post-support in Phase T, probably in situ. The stone with three peck-marks could have been damaged by Radford's workmen using heavy picks to remove debris.

A small part of the stone assemblage is of more significance. In particular the inscribed stone RF 3486 from Phase $\mathrm{U}$ of the drain in $\mathrm{C} 09$ (with the inscriptions discussed above by Thomas) has excited much discussion. However, the two graffiti slabs, RF 3448 of Phase V, C09 and RF 3429 of Phase Y, C16 (figure 116) are also noteworthy. They are clearly related to the series of incised pictorial slabs already noted from Tintagel Castle. ${ }^{37}$ Thomas ascribes a date-bracket beginning in the early part of the twelfth century to such 'doodling' activities on Tintagel Island and at the nearby churchyard. ${ }^{38}$ However, the relatively late phasing identified here would suggest that, although this slab is comparable with this group and also those stratified from the churchyard site (but of a different group from those more clearly incised with 'primary' crossdesigns), ${ }^{39}$ it has been re-placed, sometime from the 1930s onwards. The inscribed slates tell of more obviously personal activities on the site, as do the few hones and spindle whorls. These latter finds (see figure 113) are generally of undiagnostic forms and virtually undatable except by the context of their recovery.

Site T: THE LitTle Ditch - TRENCH T02

Four stone finds were recorded in the stone assemblage from this trench (table 50). From Phase Y, Radford's disturbance, two notched slates both had irregular form and do not appear to have been structural. In the turf and topsoil of Phase $Z$, a quartz pebble and half a slate disc are also probably displaced from their original context. These are artefact types which are commonly found elsewhere at Tintagel. 


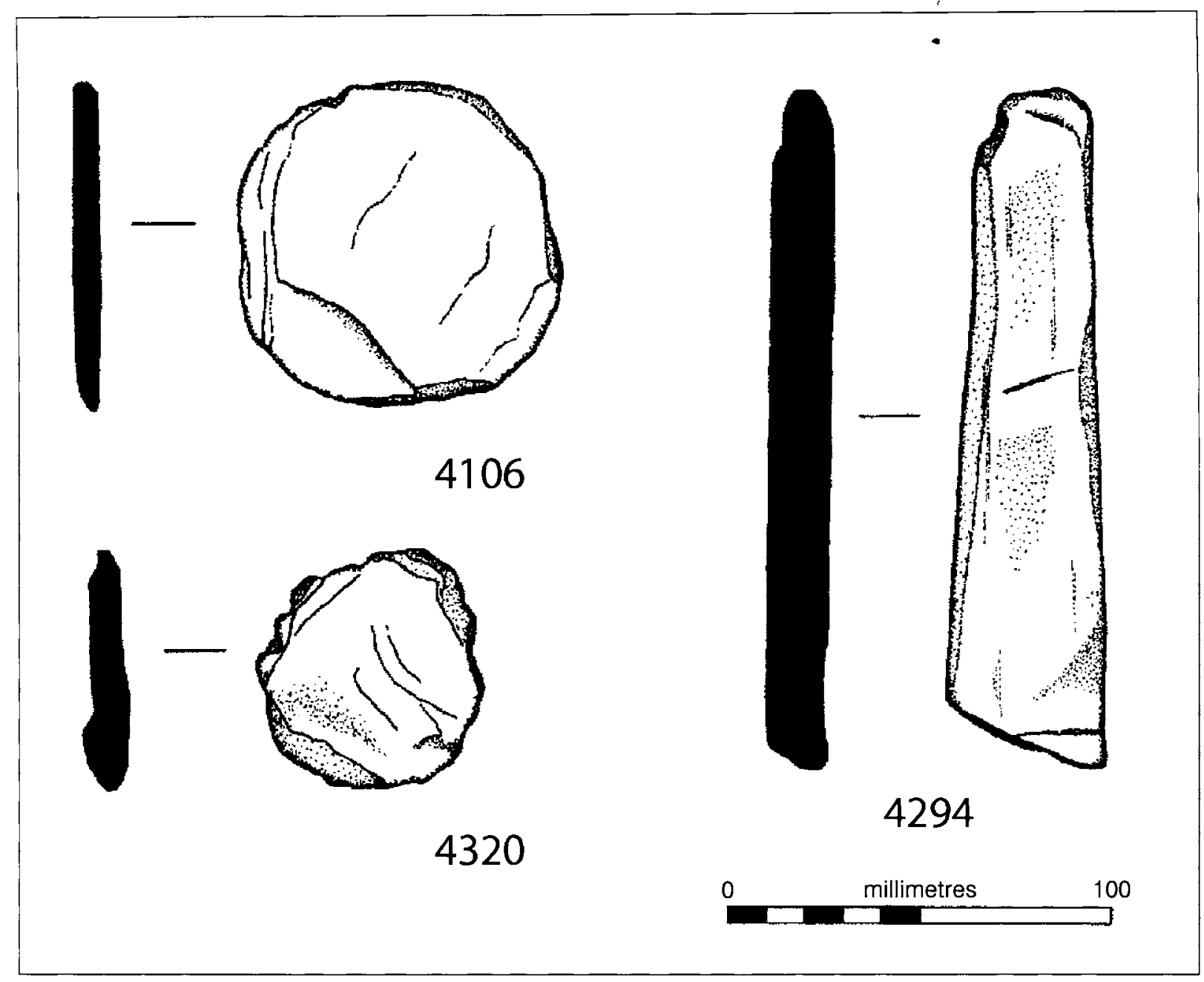

117 Pot lids and whetstone from T01 and T01 ext: RFs 4106, 4294 and 4320. Drawing: C Thorpe

\section{Site T: the Great Ditch - TRENCh T01}

Several water-worn pebbles have been recovered from this part of the site (table 50): a single find from Phase $\mathrm{U}$, two from Phase $\mathrm{W}$ and seven from Phase X. The bulk in numerical terms are, however, from Phase $Z$, the turf and topsoil, where five finds units include thirty-seven individual pebbles in total. In all cases these items have been brought to the site and their significance in archaeological terms may not be great. Some of the larger ones may have come at the hands of visitors to the site, following an age-old tradition of personal deposition at special locations, although others may have been introduced during repair works at the Castle.

There are three variants within the overall heading of 'slate discs': simple complete slate discs (eg RF 4320 from Phase X: figure 117), perforated slate discs and a single notched slate disc (also from Phase $\mathrm{X}$ ). These were all likely to have been amphora-stoppers of local stone. The single notched example may simply be a variant on the method used to open the re-sealed lid. Such slate discs previously recorded in the area of the Great Ditch are all from the 1938 intervention and therefore to be considered virtually unstratified.

There are thirty-two notched slates in the stone assemblage. Of these, three are from Phase $U$, the cutting of the Ditch and modification of the banks, twenty-one from Phase X, the 1938 Trench, and the remaining eight from Phase $Z$, turf and topsoil (eg RF 4029: figure 118). Two of the three examples from the earlier deposits are double-notched and, in the case of RF 4221, one edge of the slate is trimmed as well. Those from Phase X include 


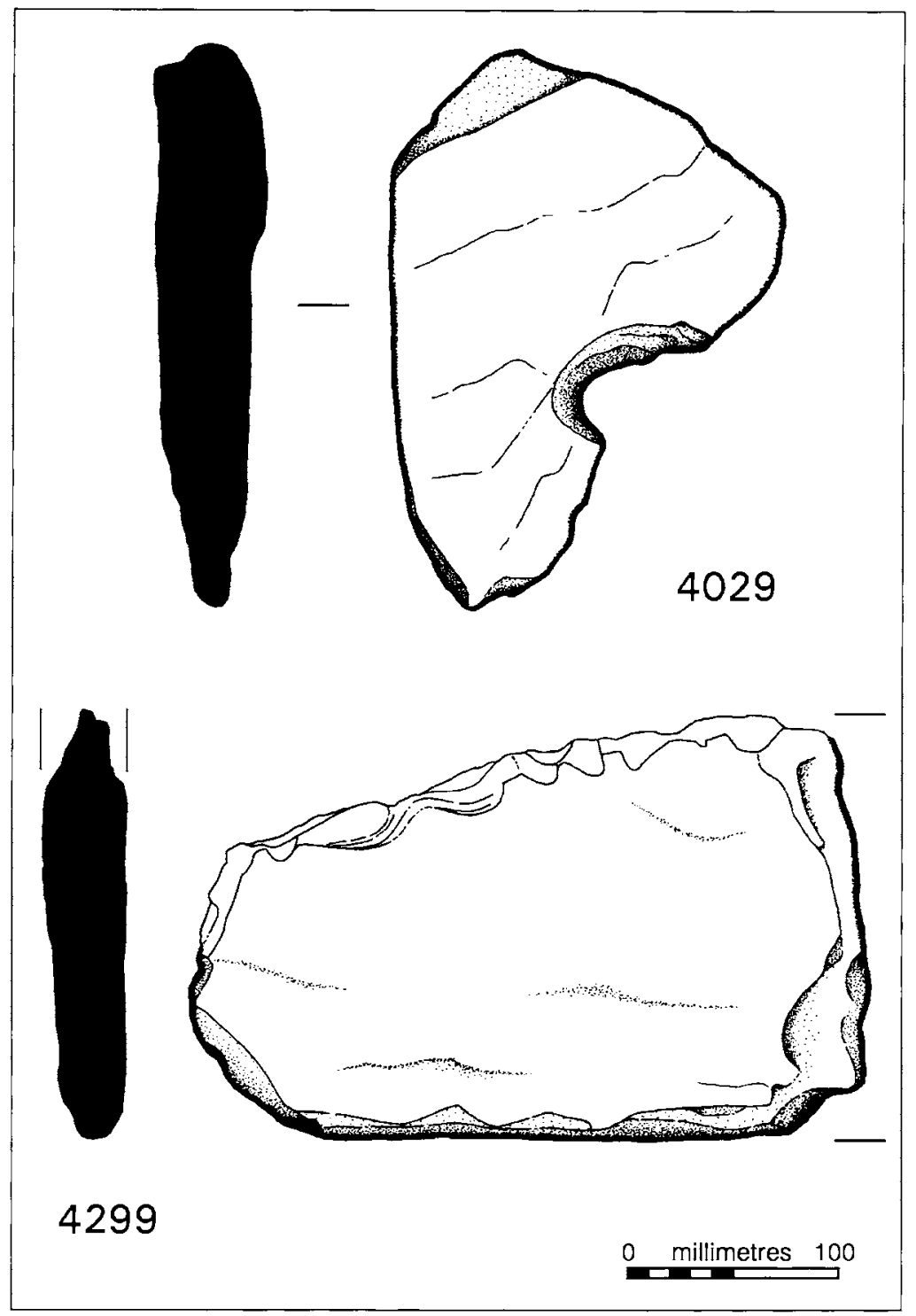

118 Notched/shaped slates from T01: RFs 4029 and 4299.

Drawing: C Thorpe a number which are pick-marked due to the actions of Radford's workers, such as RFs 4047 and 4089, and others from that phase include substantial notches in excess of $10 \mathrm{~mm}$ in diameter, which are more likely to be originally structural, as noted from the Lower Terrace (see Chapter 2). Others have much smaller edge notches and are more explicable as percussion stones serving as strike-a-lights. There is a similar mixture of types from the upper Phase $Z$, including pick-axe damage and a substantial notch which is likely to be structural in function (RF 4029).

The five finds of perforated slates, probably strike-alights, are scattered through four phases $U, W, X$ and $Z$ (eg RFs 4004 and 4148; figure 119). It can be assumed that those from Phase $\mathrm{X}$ in both these categories of finds are in a disturbed context, whereas that from Phase $U$ appears to be in an original location, albeit having slipped from up-slope into the base of the ditch. They do not, therefore, necessarily indicate a function related to the activities within the ditch in Phase U.

There are two pieces of shaped slate which have worked shapes (see RFs 4298 and 4299: figures 120 and 118 ), although their significance is not clear. RF 4298, from the 1938 work (Phase X), is a clipped slate in the form of a 'racquet'. From the same phase, RF 4299 has been shaped to have one end rounded and the other 
119 Perforated slates from TOI and T01 ext: RFs 4004, 4186, 4148 and 4265.

Drawing: C Thorpe
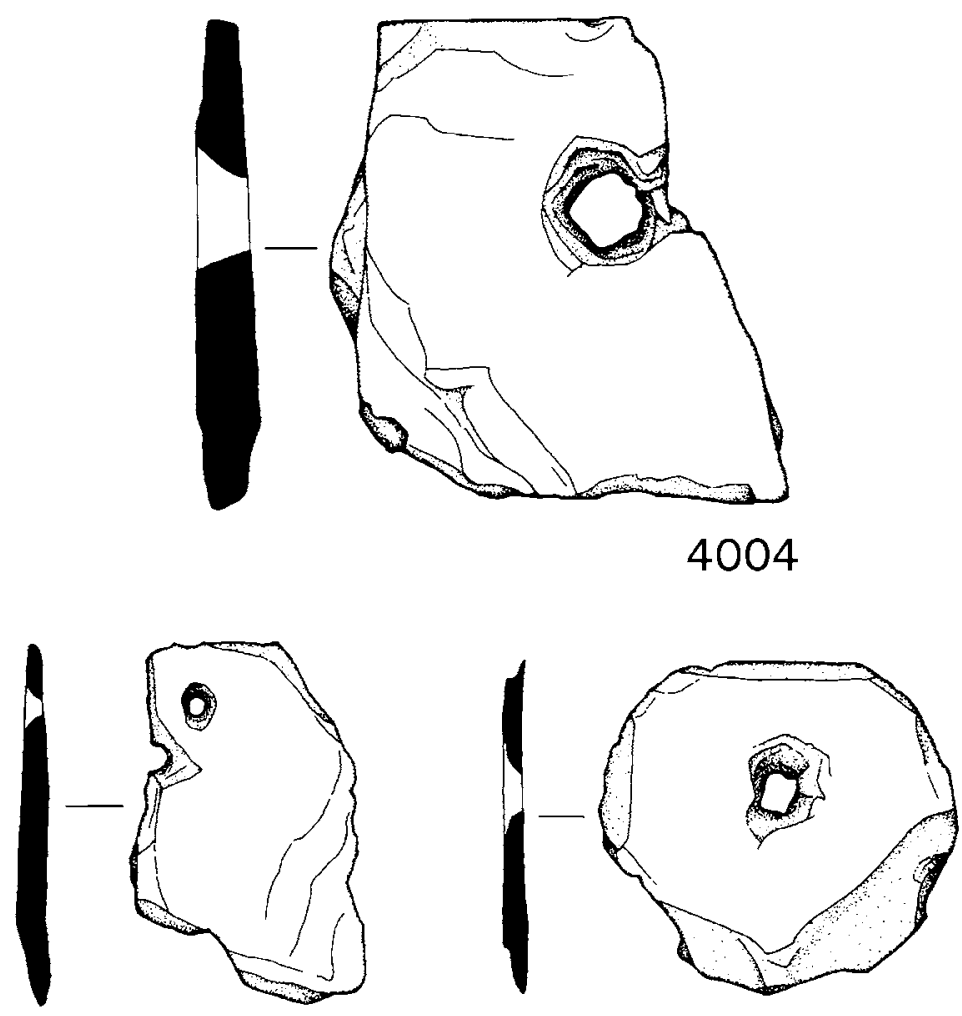

4148

4186

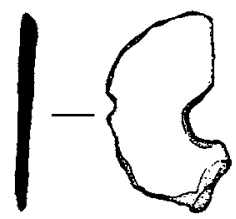

4265

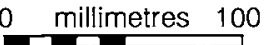

squared: this may perhaps have served as a roofing slate. RF 4203 from Phase W, a phase of later Castle collapse, is an oval-shaped slate, with a deeply incised groove on one face. Its function is not obvious.

\section{SITE T: THE LOWER WARD - TRENCH T01 EXT}

This small stone assemblage (see table 50) comprises four categories of artefacts which are in all ways comparable to material already known from the excavations at Tintagel. Two broken slate discs with notches, RFs 4263 from Phase $\mathrm{X}$ and $4265 \mathrm{~b}$ from Phase $\mathrm{Y}$, suggest vessel lids for opened amphora. Three pebbles from Phase Y, Radford's backfill, are introductions to the site (see above).
The largest part of this stone assemblage is in the form of notched slates. There are seven from Phase Y, Radford's work and one from Phase X, later medieval Castle activity. The variety of functions served by notched slates is discussed above in relation to the Site $\mathrm{C}$ building. Here, RFs 4137 and 4139 (figure 121) have large notches which are more likely to suggest a structural function than that of an ad hoc usage as a strike-a-light.

The most significant item is the whetstone RF 4294 (see figure 117), made from an elongated pebble recovered from context 1135 , Phase $\mathrm{W}$. The casual use of a readily available hone is of greater significance here because of its association with industrial debris and its 


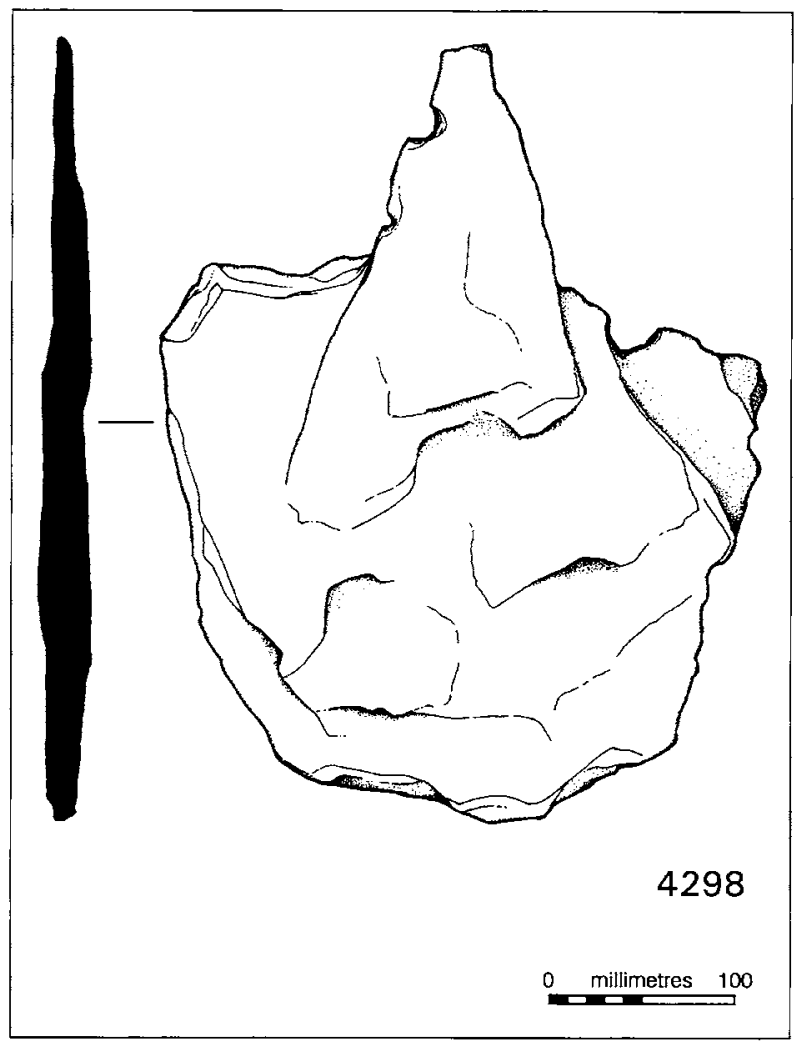

120 Worked stone from T01: RF 4298. Drawing: C Thorpe

evident early dating (Phase $\mathrm{W}$ ). This could support the identification of industrial activity within the area of the trench in the Inner Ward in a pre-Castle context as indicated also by the industrial debris (see Photos-Jones below). Other examples have been noted from Tintagel, for instance from the Lower Terrace of Site $\mathrm{C}^{40}$ and the area of the Steps. ${ }^{41}$

\section{FLINT \\ by Christopher S Barrowman}

This small assemblage of lithics (see, for example, RF 2609 on figure 113) is noteworthy as prehistoric material on the Island is scarce. It is plausible to assign an early medieval date and use to these pieces, although they could equally be residual.

The seven lithics from Phases $\mathrm{U} 2$ and $\mathrm{W}$ of the Site $\mathrm{C}$ building excavations (RF 2609, C16: figure 113 and RF 2699, C09) and from Phases T, V, X and Y of Trench C15 (RFs 3562, 3563, 3853, 3965, 6054) are undiagnostic and show crude working (especially RF 3562 and RF 6054). Such working has previously been assigned to later prehistoric lithic assemblages, where a lack of skill and knowledge of lithic working is apparent in the crude forms represented. ${ }^{42}$ Such assemblages usually show 'a decrease in the level of visible knapping control, as evidenced by increased flake thickness, increasing bulbar angle and a decrease in the number of regular fractures on flakes. ${ }^{33}$

This lack of quality is a result of a simple core/flake technology, using a hard hammer and direct percussion technique, set within an environment where people had no direct need for working lithics. Although these effects are visible and indeed a component of later prehistoric assemblages (Bronze Age and Iron Age), it is clear that the techniques used then would be present throughout later periods, being a result of unskilled knapping.

As stated in the discussion of the previous small lithic assemblage from Tintagel, ${ }^{44}$ there is no reason why an early medieval date cannot therefore be given to these lithics, rather than regarding them as residual elements of earlier activity on the Island. Useful and practical items such as scrapers, blades and knives would no doubt be common in earlier medieval life, especially when beach flint is available (as represented by RF 3853), and alternatives might be expensive and/or difficult to produce. ${ }^{45}$

\section{ARCHITECTURAL STONE FROM THE GREAT DITCH, SITE T by Francis Kelly with David Jefferson}

Of the nineteen stones recovered, sixteen came from a backfill context. One might sympathize with the excavators in the 1930s for rejecting this material. However, while none is of significant art-historical merit or of great architectural interest, close study allows insights not only into geological provenance but also, in some cases, into structural purpose.

Twelve pieces are of 'greenstone' (more accurately both epidiorite and tuff are represented in this assemblage, although often identified as greenstone: see Jefferson below), all of probably very local geological extraction, but none in a primary structural location. They are all broken fragments with, in some cases, evidence of secondary uses. One fragment (RF 4300) is from a local geological variant and has evidence both of erosion and of refashioning which is remarkable for stopping short of a harder, quartz-like veinlet. Four of the 'greenstone' 
121 Notched/shaped slates from T01 ext: RFs 4136,4137 and 4139.

Drawing: $C$ Thorpe

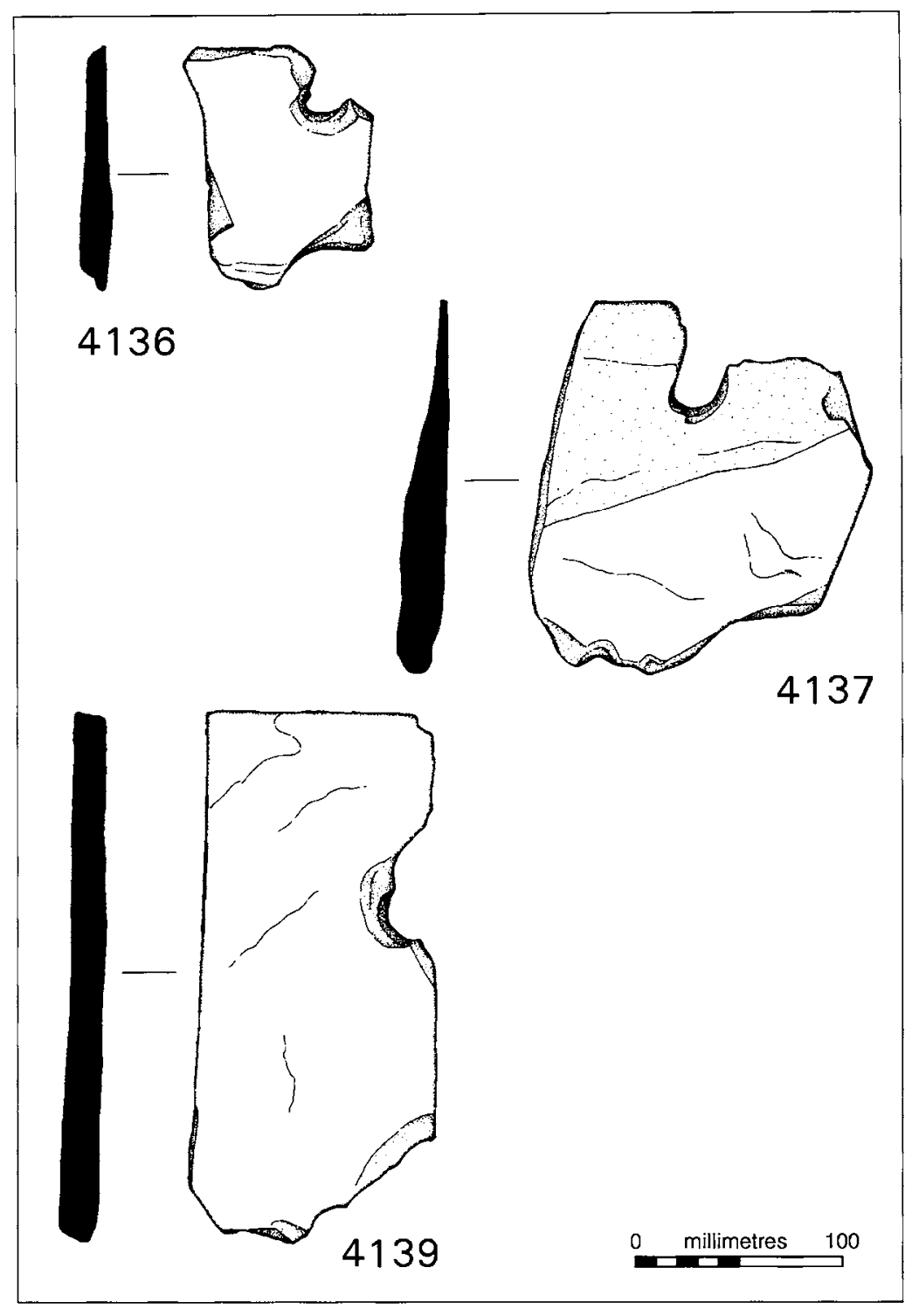

the remaining 'greenstones', RF 4033 has evidence of drilled holes, one well made, and could have been reused as a thatch weight, while RF 4034 has one halfworked side and a second irregularly, and therefore secondary, worked side and may be a chamfer. RF 4036 is sub-rectangular with an irregular slanted cut-out leaving a thicker end. RF 4037 (see figure 122) appears to be a damaged section of string course. RF 4111 (figure 123 ) is an architectural fragment which in secondary use was crudely incised with a D-plan sinking and containing a further crude heart-shaped incision or sinking, perhaps as a result of damage. RF 4149 (see figure 123) is part of a roll-mould, whose back is rebated for a secondary use. 


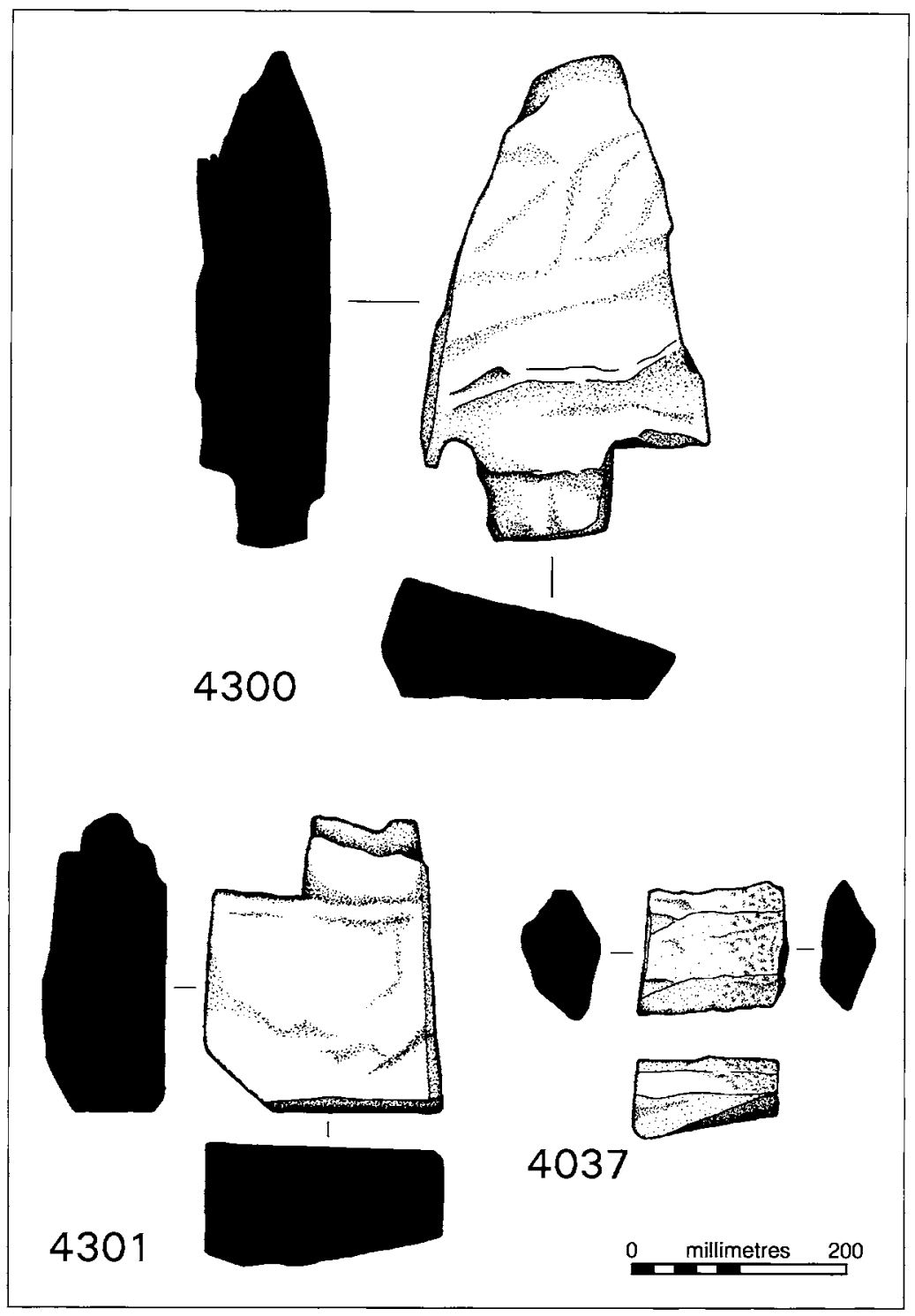

122 Architectural stone finds from T01 (1): RFs 4037, 4300, 4301 .

Drawing: C Thorpe

Three structural slate pieces were also examined. RF 4047 is regular enough to have been either a pavior or a capping slate to a wall. It is one that bears pick-axe marks, but they appear relatively recent and were all made from the same angle. RF 4048 has a curved edge which may have been part of a deliberately drilled hole. It is worn and was probably a pavior. The third, RF 4081, is also a possible structural slate with a perforation with a slightly square facing edge.

Seven pieces are of slate, one of them (RF 4048) with a worn surface. The slates have pick-marks and drillmarks whose significance cannot now be assessed; some of it is probably damage suffered during recovery.
None now retain evidence of saw-cutting; several betray evidence of chisel-point tooling but so worn that it is not always possible to say whether one is looking at a dressed face or simply a roughly reworked face that has been heavily damaged and weathered.

Of these excavated fragments, the 'greenstone' pieces appear to have come from a constructional context, from the simplest walling stone (eg RF 4245) to more sophisticated locations such as an opening in a battered plinth (RF 4031) or a roll-mould expressing an opening. The battered section may relate to a battered panel below a bridge or other feature in the ditch-face (as in the beautifully cut 1130 s masonry below the 


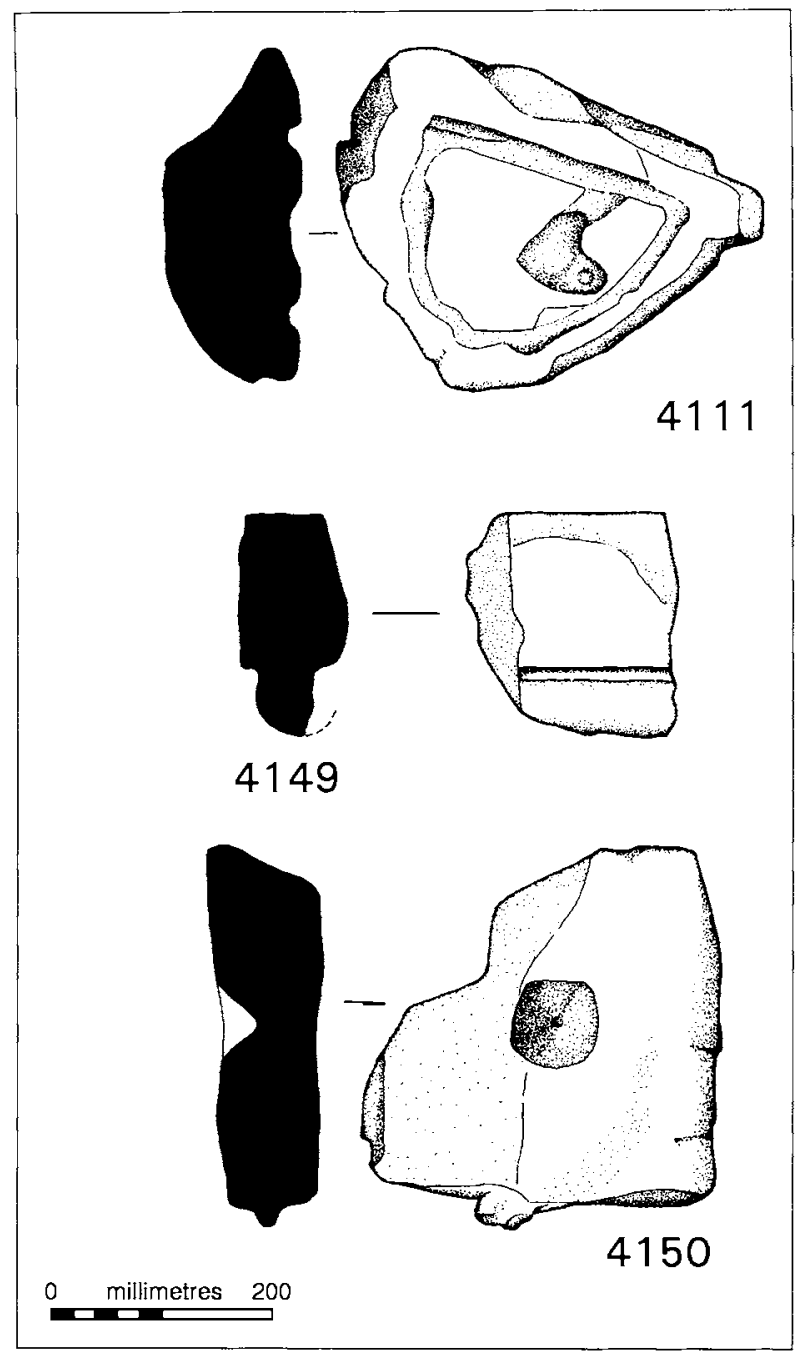

123 Architectural stone finds from TO1 (2): RFs 4149, 4111 and 4150. Drawing: $C$ Thorpe

north-east and south-west towers of Sherborne Old Castle).

The fragments are not closely datable, but a date in the mid-thirteenth century would not be out of place. Some were clearly re-used for less sophisticated secondary uses, eg as jambs for openings. RF 4150 (see figure 123) with its deep central conical depression, may have been a pivot-stone either in its primary or in a secondary use. The likelihood is that these stones mostly came from the twelfth- or thirteenth-century Castle walls or ditch.

The slates are presumably from constructional contexts, one (RF 4047) probably from a building. The others could well have started as paviors. Several have intriguing notches which may have a relevance in use; others, however, appear accidental and may relate to damage during excavation.

\section{Petrographic analysis and geological OBSERVATIONS ON THE BUILDING STONES by David Jefferson}

Although the bulk of the stone used for construction, both on the post-Roman sites and the medieval Castle, are local Devonian slates, the Carboniferous volcanic rocks have also been used from at least Norman times. Being somewhat thicker-bedded and less brittle, these rocks are capable of being dressed and have, therefore, been used as quoins and key-stones. This special quality has clearly made it worthwhile bringing the stone some distance up to the construction site, despite the easy availability of the slate building material. Whereas the slates are to be found on the upper part of the Island, the volcanic rocks are found at sea level around the coast of the Island, on Barras Nose, and on the ridge of land which extends towards the Island from the east side of Tintagel Haven. There are signs that the volcanic rocks have been worked from this ridge, and possibly even from the hillside above it. It is conceivable that the stone from the east side of the Haven could have been carried by boat to the 'Iron Gate', rather than being transported up the cliffs and then overland to the Castle.

Relatively large quantities of stone were required for the medieval Castle. Although some of the building material may well be re-used stone from the earlier buildings, much would have to be quarried. The nature of the outcrop north of Radford's 'Site G' would appear to confirm the suggestion of a major quarry here. The hillside beneath this area has the appearance of a detritus slope, a feature which would be expected when quarrying stone of which perhaps only 50 per cent was suitable for building. It is possible, however, that the excavations at Sites ' $\mathrm{B}$ ' and ' $\mathrm{C}$ ' have overemphasized the talus-like landform here.

During the excavations of the Great Ditch, situated on the south-east side of the Castle complex, a number of pieces of masonry were found (see discussion by Kelly above). All the stone has a greenish-grey hue and had been recorded as 'greenstone', as at the nearby churchyard excavations at Tintagel. ${ }^{46}$ Similar material occurs throughout those parts of the Castle which are still standing, found as structural elements, such as the voussoirs of the arches, as well as scattered throughout the walls. The predominant building stone in the Castle 
is the local slate, the outcrop of which covers most of the Island as well as the adjacent mainland, but where larger blocks were required, for example for use as quoins, this was not suitable. Visual comparison of the blocks in the Castle with stone from the Tintagel Volcanic Formation from the Haven suggest use of that source. These volcanic strata are variable and in some areas have been further altered by the complex thrust-faulting which has affected the area around the Castle. In fact, this faulting is the reason for the separation of the Island from the mainland and provides the host zone for the copper, lead and zinc mineralization beneath the Castle.

In order to characterize the masonry stone from the excavation, two samples were subjected to petrographic analysis (RFs 4302 and 4300). These were selected on the basis of a visual appraisal of all the 'greenstone' finds. One was a coarsely crystalline material, the other a somewhat sheared sample of what appeared to be typical volcanic tuff. Although all the samples of 'greenstone' found in the Great Ditch are of a relatively similar colour, typically greyish blue-green, there is a range of textures. These range from granular materials, typical of sedimentary tuff, to massive relatively featureless stone. There is also a quantity of schistose material which has clearly been sheared during the thrust faulting. This range of textures would not be unusual in the rock types known to occur in the Tintagel Volcanic Formation. However, close examination of a relatively featureless sample of 'greenstone' indicated that, rather than being an extrusive volcanic material such as tuff or lava, it was a hard crystalline intrusive rock. Two different sources of building stone were therefore indicated.

RF 4302, in hand sample and confirmed by thin section, is very hard; iron staining is common throughout the rock. Analysis reveals that this stone is an epidiorite (see full report in Research Archive Report). Although unusual in this area, some small outcrops of epidiorite do occur close to Tintagel, for example, east of Barras Nose, in the Smith's Cliff area, there is an exposure on the coast. However, this material is fresh and does not show the weathering features, such as iron oxides, which are present in the masonry block from the Great Ditch. Blocks of material similar to that from Smith's Cliff have been found in the stream between the Haven and Tintagel village. An outcrop of epidiorite is indicated on the geological map immediately east of the parish church of St Materiana, less than $1 \mathrm{~km}$ south of the Castle. Although no exposures were identified, the stone walls alongside the road to the church contain cobbles of epidiorite, many of which are weathered and appear identical to the stone from the ditch. A petrographic analysis of this stone has shown it to be identical with the sample described above.

RF 4300, in hand sample, is dark to medium greenish grey. The stone appears to be a metamorphosed sediment, the mineral assemblage being indicative of greenschist facies. The mineralogy would be consistent with a regionally metamorphosed tuffaceous sediment. The sample has been termed 'tuffaceous' both on the basis of its appearance in the hand sample, and because of its similarity to the volcanic tuff of the Tintagel Volcanic Formation. A petrographic thin section of a sample of the tuff from these beds, confirmed this identification. This tuff, which is much less deformed than the sample from the Great Ditch and can be clearly identified as a crystal tuff, contains the same assemblage of minerals as RF 4300 but, in addition, contains large crystals of plagioclase feldspar. There is little doubt that the masonry block studied was worked from these Carboniferous volcanic strata.

The fact that stone from which the masonry block found in the Great Ditch had been produced is much more sheared than the stone seen in situ is a result of the location from which it was obtained. The ridge of rock projecting out from Barras Nose into the Haven is some distance from the actual thrust planes associated with the low angle faults. Stone worked on the south-east side of the Island close to the thrust faults is much more sheared. The range of deformation displayed in the masonry blocks found in the Great Ditch suggests that the stone was obtained at outcrop from a number of locations. However, all these variations can be found within a very short distance of the Castle - less than $1 \mathrm{~km}$. The most likely source of the stone found in the Great Ditch is the area south east of the parish church. It is interesting to note that not only the dressings on the church, but also the font in the church, also appear to be made of the epidiorite. Furthermore, the method of dressing the stone, apparently by using a 'point tool', leaving a pock-marked surface, can be seen both in the finds from the Great Ditch and in the church. This similarity, both in stone type and masonry technique, between the church and the material in the Great Ditch, raises the question as to whether the epidiorite used in the Castle was freshly quarried stone or whether it was recycled material from old buildings in the area. 
The use of the very hard epidiorite is perhaps surprising when the volcanic tuff was available. However, the stone had already been used in the church and it is possible that the original source was still available. Its earlier use at the church - and possibly elsewhere - would not have been unreasonable, since it was available immediately adjacent to the site. Use of the tuff for these earlier buildings, although a more easily worked material, would have involved hauling it up from the beach, as it is only exposed at sea level.

Not only was all the building stone for walls, paving and roofing available immediately adjacent to the site, but the lime and aggregate for the mortar was also available. Thin limestone bands are not uncommon in the slates, for example a $150 \mathrm{~mm}$ band occurs on Barras Nose. A $610 \mathrm{~mm}$-thick band of limestone occurs at Willapark, west of Boscastle. All these limestones are rather impure and would probably have produced a lime which was hydraulic to a greater or lesser extent. Although the aggregate in the mortar has been analysed (see Palmer below), the nature of the binder itself has not been determined and it is not possible at this time to determine the exact provenance of the calcium source.

The local extraction of all the building materials for the Castle therefore continued the quarrying and mining tradition of the area, which probably started with the mining of copper beneath the area upon which the Castle was to be built some 700 years later, and continues today in Delabole quarry.

\section{MORTARS \\ by Timothy J Palmer}

Site C: Site C BUILDING

Four samples of mortar were recorded from Phase $Y$, the period of MoW levelling and building reconstruction. Two, RF 1963 (Trench C10) and RF 1496 (Trench C11), are pure lime mortars with plentiful free lime, probably dating to the 1930s. In contrast, two finds from Phase $Y$, RFs 1510 from C13 and 1957 from C10, are almost identical to each other, and have been identified as either hydraulic lime mortars or modern cements. The suspicion that 'historic' mortars have been mixed with cements or concretes used for restoration earlier in the twentieth century is fully in keeping with these results. It is also possible that reconstruction activity was undertaken in two stages, particularly in $\mathrm{C} 10$ where the same context in Phase Y produced mortars from each of the two categories distinguished. This may well represent repair work since the main building work of the 1930s, probably into the 1950s (see Appendix 3: Modern Material: 1951 shilling).

\section{Site T: THE GREAT DitCH, TRENCH T01}

Twenty samples of mortar were examined from trench T01, eleven of which (all from Phase W) were analysed in thin section. Analysis has demonstrated that in all cases the sand used in the mortars from trench T01 is typical beach sand, a mixture of quartz and lithic fragments showing varying degrees of rounding and shell fragments. The shelly material is all derived from plant and invertebrate groups typical of a mixed rocky/sandy shore such as occurs around Tintagel, and there is no doubt that local beaches were the source of the aggregate.

The mortars appear to have been produced according to conventional practices that span the period of time from the Classical world to the present day. They consist fundamentally of a mixture of medium to coarse sand (modal grain size typically of around $1 \mathrm{~mm}$, though a few much larger fragments are often present) in a set matrix of fine material that fills the pore spaces between the aggregate grains. Typically, such mortars display a ratio of about three parts aggregate to one part matrix by volume. There is no indication that fibrous organic material such as hair or straw was part of the original mix.

The matrix in these samples appears to be of a somewhat variable composition. In some samples, it is dominated by lime (eg most of the material from trench T01 seen in thin section). The recognizable lime lumps that are still evident in some of the samples show no clear internal ghost structures that throw light on the provenance of the limestone that was originally burnt in the kiln. However, it can be said that it was not imported from one of the other obvious limestone sources up the Bristol Channel (the Jurassic or the South Wales shallow-water Carboniferous, for example). Restricted developments of somewhat impure limestones occur in the Lower Carboniferous rocks seen in the coves near to the excavation site, so it is highly likely that such thin limestone beds provided the limestone for burning. The single lump of unburnt limestone seen in thin section has a saccharoidal, somewhat recrystallized appearance that ties in with the mildly metamorphosed character of the local rocks. The mortar samples are all fairly soft which suggests that the set came from lime carbonation rather than from the formation of cementitious 
minerals. With the inferred clay-rich impure source limestones, this in turn suggests that the lime-burning in the kiln was at the basic minimum temperature for the calcining of the limestone, rather than at the higher temperatures at which calcium silicates would have formed.

Locally sourced aggregate would not have required sieving. One or two of the mortar samples have the odd small granite lump mixed in with the matrix, and there are several larger granite lumps that were originally misidentified as mortar lumps during the excavation. This suggests that granite was imported to the building site as a building stone, worked by the masons, and incorporated into the original structure of the Castle although none was recovered during the excavations. The waste material from the masons was added to the aggregate in the mortar and to the rubble fills of the walls. Local rock types were also used for walling and for rubble fill.

Lime-based mortar is a conservative material and cannot be readily dated by its petrographic character, unless it contains certain characteristic cementitious minerals (some typical of hydraulic limes and usually post-1800; others typical of Portland Cement and usually post-mid-nineteenth century) or crushed pozzolanic material (eg tile sometimes seen in Roman work; crushed slag in mortar from industrial sites). The mortars studied here are all simple lime or lime and mud mixes that could have been produced at any time, although a pre-eighteenth-century date, possibly going back into the medieval period, would be consistent with the conservative methods employed in their preparation.

\section{SITE T: THE LOWER WARD, TRENCH T01 EXT}

Of the nine samples recovered, the matrix appears to be of a somewhat variable composition. Unlike the samples from T01 (Great Ditch), those from T01 ext (Lower Ward) show a matrix dominated by clastic mud. No chemical analyses of these mortars was undertaken, because the mix of carbonate and clastic material in the sand aggregate would smother any signal from the matrix. However, it is likely that either all the mortars were prepared with a mix of lime and mud, or some of the samples have had the lime matrix leached out of them more than others during burial. Lime leaching has certainly increased the apparent pore-space between the aggregate grains in some of the samples. Alternatively (and more likely in the light of traditional mortar preparation practices), the amount of lime was varied, more being put into material where greater strength was required (larger structures; defensive sites; external stonework, etc) and less into less critical areas (nonstructural walls; rubble fill).

As with the samples from trench T01, the mortars studied here are all simple lime or lime and mud mixes that could have been produced at any time up to the eighteenth century.

\section{GLASS}

by Ewan N Campbell

with a contribution from Jennifer Jones

In order to more fully understand the glass assemblage from the excavations reported here (figure 124), a survey of all known sherds from the site was undertaken (a full catalogue can be found in the Research Archive Report). Although not containing a large number of vessels, the Tintagel glass assemblage does contain a number of unique vessels, and a somewhat different range and provenance of vessels compared to other sites in western Britain. The excavations from the 1930s onwards produced a total of thirty vessel sherds, four beads and one miscellaneous piece, all of which were brought together for examination in order to compare the forms and metals (figure 125). One missing bead and one sherd in the British Museum could not be included in this programme.

Nineteen vessels are represented, of which two or three probably belong to the Roman period (Vessels 1 and 2), sixteen are imports of the fifth to seventh centuries (Vessels 3 to 16,18 and 19), and one is of the eighth/ninth century (Vessel 17). Only five out of some fifty sites with early medieval imports in the west have produced a greater number of fifth- to seventh-century vessels, namely Whithorn, the Mote of Mark, Dinas Powys, Longbury Bank and Cadbury Congresbury. ${ }^{47}$ It is likely, however, that this total represents only a small fraction of the number of vessels originally present.

Most of the sherds come from modern small-scale excavations: by the Cornwall Archaeological Unit in 1985 and 1986, and by the University of Glasgow between 1990 and 1999, each of which has produced at least one sherd. Only five sherds are recorded from Radford's extensive excavations in the 1930s, but all are large (by the standards of glass) rim sherds. Analysis of the recovery rate of ceramic sherds from Radford's excavations shows that only large or decorated sherds were retained by the 1930 s workmen, ${ }^{48}$ and it seems likely that the same applied to the glass finds. 


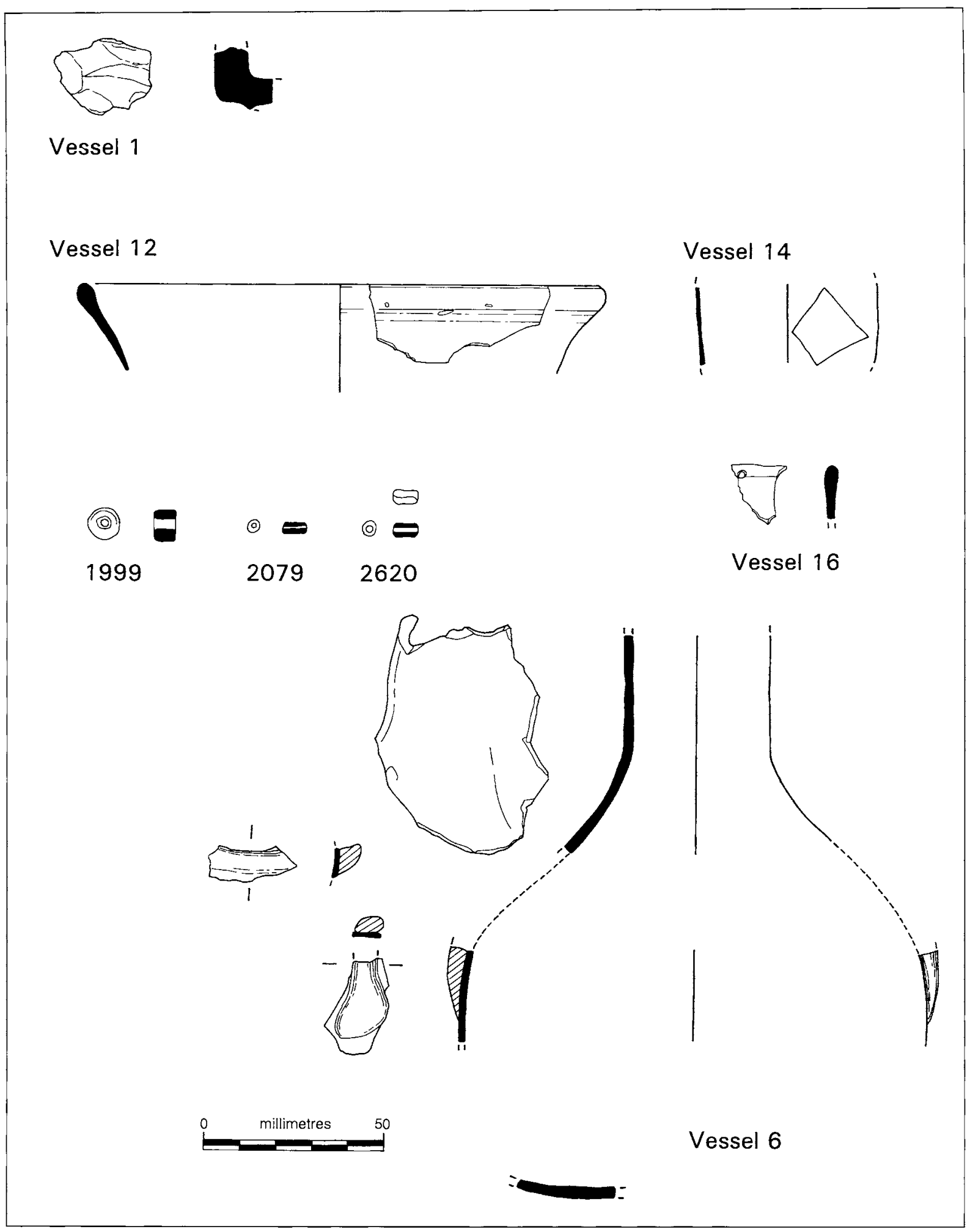

124 Glass finds from the Site C building (Vessels 1, 6, 12, 14 and 16 and glass beads). Drawing: E Campbell, C Thorpe, $L M c$ Ewan and $C$ Evans 


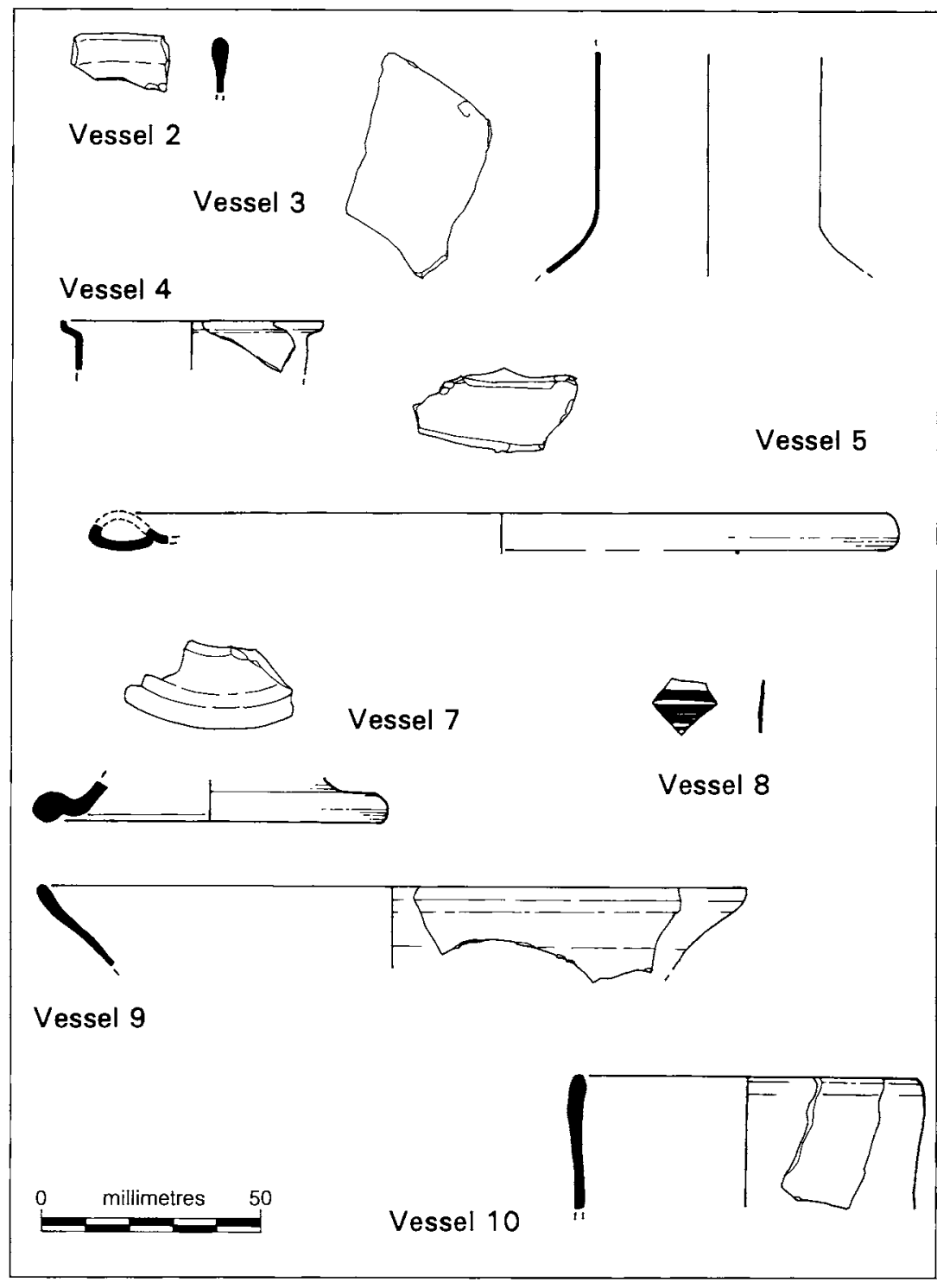

125 Glass finds from Tintagel, other than Site C building (Vessels 2, 3, 4, 5, $7,8,9$ and 10).

Drawing: E Campbell, C Thorpe, $L$ McEwan and C Evans
ROMANO-BRITISH

Vessels 1 and 2 are of a blue/green colour typical of Romano-British glass in the first to third centuries AD. ${ }^{49}$ Vessel 1 is a basal sherd from a bottle (from trench C16, RF 2355 from Phase $Y$, see figure 124), probably of Isings form $50^{50}$ and likely to be in a residual context. Vessel 2 is an indeterminate form recovered from the plateau area after the fire (T85.31 now in the collection of RCM, see figure 125). Such finds would not be unexpected on a Romano-British settlement, even such a rural one as Tintagel, and might therefore indicate contemporary occupation of the site although clearly found in a residual context (see Chapter 12). However, it is perhaps more likely that the sherd was brought to Site $\mathrm{C}$ at a later period, particularly in view of the fact that the first-second centuries are not otherwise attested at Tintagel.

As noted below, Vessels 3 and 4 could belong to the late Romano-British period, but the balance of evidence suggests they are later in date.

\section{EARLY MEDIEVAL IMPORTS}

Of the sixteen vessels (3-16, 18 and 19), the forms that can be identified with some certainty consist of three bowls, three beakers, one deep bowl or plate and three flagons/bottles. This is in itself unusual as conical 
beakers are by far the commonest form on most other western sites. ${ }^{51}$ No other western site has produced a flagon/bottle or tubular-rimmed bowls or plates. Also noticeable is the lack of trailed decoration on the vessels, with only three out of sixteen having opaque white trails, whereas white-trailed vessels usually outnumber plain vessels on western sites. ${ }^{52}$ Another unusual feature is the thickness of the walls of Vessels 6, 7, 10 and 11, often up to $2 \mathrm{~mm}$, whereas most other vessels are in the range $0.5-1 \mathrm{~mm}$. The metal is of uniform high quality, mainly shades of pale yellow, amber and green, with one greenish-blue sherd.

The glass has basic similarities to the imported vessels found throughout the west, and is quite different in metal and forms from that found in Anglo-Saxon England or the adjacent areas of north-western Europe. The majority of the western imports, comprising Campbell's Groups C and D, have recently been identified as being produced in the Bordeaux area in the sixth and seventh centuries, ${ }^{53}$ and this would seem to be a likely source for much of the Tintagel material although, as pointed out above, the differences from the normal western imports suggest that some of this assemblage might be of a different date and/or origin from the glass on other Atlantic sites. White-trailed glass becomes dominant in Aquitaine and the south of France at some point in the sixth century, but the exact chronology is not defined. At Whithorn it is common by around $550 .{ }^{54}$ The unmarvered white trail of Vessel 16 also suggests an early date as most later vessels have marvered trails. The Tintagel vessels, particularly Vessels 9-16, may therefore date to the period from the late fifth to the early sixth century and originate from Aquitaine. Another possibility is that they originate in areas further to the south, in Spain or North Africa. At Carthage, for example, white trailing is not found, even in the seventh century, and similar bowls and cones are common. ${ }^{55}$ Only Vessel 8, and possibly 10, belongs to the later sixth/seventh-century horizon, and can be confidently ascribed to an Aquitanian origin. Vessel 17 belongs to a quite different glass-making tradition, of deeply coloured, almost opaque glass, which was developed in the eighth/ninth centuries in mid-Saxon England and Carolingian contexts.

Vessel 3 (TLW 1986, Site D, see figure 125) is a flagon, but has no diagnostic features. It was attributed to the third or fourth centuries by Price on the basis that the flagon form is common in Britain at that period, but is almost unknown in post-Roman British contexts. ${ }^{56}$
However, given the occurrence on the site of a probable post-Roman imported flagon (Vessel 6), it is possible that Vessel 3 is also a post-Roman import. As with Vessel 4 , it is extremely difficult to separate some fourth- and fifth-century forms in areas where production was continuous. The context of Vessel 3, in a layer of ashy soil with hearths which produced a quantity of sixth-century imported ceramics and archaeomagnetic dates of the fifth/sixth centuries, ${ }^{57}$ might support the later dating of this vessel.

Vessel 4 (TTG 1994, trench C03/04, Lower Terrace, RF 2376 of Phase Q2, see figure 125) was described by $\mathrm{Cool}^{58}$ as an indented truncated conical bowl, typical of the late fourth and early fifth century in Britain. However, the diameter of the vessel, at around $50 \mathrm{~mm}$, is very small for a bowl, there is no trace of indentation on the body and the wall is vertical, all features suggesting that it is a beaker. Beakers with this rim form are common in fourth-century contexts in Britain, but were not produced there after the collapse of the Roman economy around $\mathrm{AD} 410 .^{59}$ The same form was widespread on the Continent, and continued in production much later. It is found in the Bordeaux area in the late fourth and first half of the fifth centuries, ${ }^{60}$ and at Marseilles in the mid-fifth century.61 Similar forms at Carthage have the rims ground smooth, and mainly date to the sixth century. ${ }^{62}$ It is possible, therefore, that this is an early medieval import rather than a late Romano-British vessel in a residual context. Although the Phase (Q2) in which it was found predates the Mediterranean ceramic imports, radiocarbon dates would support a date in the first half of the fifth century (cal AD 395-460). ${ }^{63}$

Vessel 5 ('Site T, near base of Moat' in the RCM Collection, Tintagel T G6, see figure 125) is from a late Roman form of tubular rimmed plate or wide bowl, depending on the orientation of the rim, which is difficult to determine from the fragment. Shallow tubular-rimmed bowls are found in Roman Britain at a number of periods, ${ }^{64}$ but none seems very close in form to Vessel 5. Similar forms are found in the Mediterranean region, and Harden thought this was a fourth-/fifth-century 'Eastern' import. They are fairly common at Carthage in the fifth and particularly sixth centuries, ${ }^{65}$ and are also found at Conimbriga in Portugal in fourth-fifth-century contexts. ${ }^{66}$ The Carthage example is the closest in form to Vessel 5.

Vessel 6 (Tintagel 1998, trench C09 Phase T: RF 3500, RF 3501 and RF 3426, see figure 124), a flagon surviving 
as thirteen sherds, including a substantial neck and shoulder section, is a unique form in the post-Roman assemblages of western Britain (see analysis by Jennifer Jones below). The form is of a fairly wide-necked, shouldered flagon, with what appears to be a simple oval-sectioned rod handle. Another curved attachment may belong to a decorative swirl at one end of the handle, or a spiral neck trail. Without details of the base and lip it is difficult to be certain about the provenance of this vessel. Handled vessels do not appear to have been produced in the post-Roman industries of northwestern Europe. None are recorded from Anglo-Saxon England, and only a handful from Frankish cemeteries on the Continent. ${ }^{67}$ Production of the common Roman handled forms of bottles and flagons appears to have continued in areas further south, however, for example in the south of France well into the fifth century ${ }^{68}$ and in Aquitaine possibly into the early sixth century, ${ }^{69}$ but the published descriptions of these vessels do not correspond to the thick glass, wide neck and simple handle of the Tintagel vessel. A closer comparison is with southern Spanish vessels which may imitate local ceramic forms. ${ }^{70}$ Two illustrated forms are from sites in Malaga and Cadiz in sixth-/seventh-century cemeteries. ${ }^{71}$ Without examining these finds, it is impossible to be certain of attributing a Spanish origin to this vessel, but given that the Mediterranean traders who brought the eastern pottery amphorae and fine wares to Tintagel were supplying the same wares to ports in Cadiz and Malaga, ${ }^{72}$ it is not an unlikely source.

Vessel 7 (Site $\mathrm{B} / \mathrm{C}$, trench $\mathrm{H}$ under debris. RCM Collection, Tintagel B G5, see figure 125) is either a bottle/flagon rim or, less likely, the base-ring of a stemmed goblet. Stemmed vessels are not as rare as flagons, but they are uncommon, particularly in England..$^{73}$ Stemmed beakers are found in post-Roman cemeteries in the fifth and early sixth centuries, but these are formed in one piece, by folding in the base of the vessel. Vessel 7 differs in that the foot has been separately blown, with its own infolded and rounded rim, to be attached to the main body of the glass. This technique is not found in any of the known north-western European assemblages, but it does occur in the Mediterranean, developing from the single-piece footed vessel in the sixth century in southern France, ${ }^{74}$ and also appearing in Italy in the sixth century, ${ }^{75}$ and in North Africa starting in the fifth century and being commonest in the seventh. ${ }^{76}$ Harden apparently thought this was from a bowl, and related it to vessels from Karanis with which he was familiar, suggesting it was an Egyptian import. ${ }^{77}$ However, the diameter is far too small, and the flattening of the underside of the rim shows that it was orientated wrongly by Harden. Again, without examining the relevant material, it is difficult to be sure of a southern European or North African attribution, but the recent recognition of a very distinctive blue-rimmed vessel from Whithorn as coming from southern France in the seventh century shows that glass was reaching Britain from this region. ${ }^{78}$ Whithorn is the only other site in western Britain to have produced a stemmed goblet with separate foot-ring, a vessel which also may be from southern Europe. ${ }^{79}$

Vessels 11-16 (TTG 1990, Steps, RF 1047; TTG 1994, RF 2058, see figure 124; TTG 1990, Steps, RF 1351; TTG 1994, C10, RF 2076; TTG 1990, Steps, RF 1046, see figure 124): these bowls and cones are similar in colour, decoration and form to the majority of the western imports, comprising Campbell's Groups C and D, which have recently been identified as being produced in the Bordeaux area in the sixth and seventh centuries. ${ }^{80}$ This would seem to be a likely source of these vessels. On the other hand, minor differences from the normal western imports suggest that some of this assemblage might be of a different date and/or origin from the glass on other western sites. The lack of decoration in particular suggests that the assemblage as a whole is earlier in date than the bulk of the sixth-/seventh-century glass in western Britain, and perhaps dates to the earlier sixth century.

Vessel 18 (TTG 1999, T01 ext, RF 4336), a sherd with wheel-abraded curvilinear decoration on the probable exterior surface, is almost flat and from the wall of a large bowl or plate of Campbell's Group A. The sherd slightly expands in thickness towards one end, indicating that it is from just below a fire-rounded rim. The metal is fine, almost colourless, with few bubbles and only slight surface decay. It is the first example of a vessel with abraded decoration from the site. It is from a shallow open form such as a wide bowl, possibly similar to the well-known Holme Pierrepoint truncated conical bowl. ${ }^{81}$ There is a band of curvilinear decoration below the rim, possibly running scrolls similar to those on the Highdown flask, ${ }^{82}$ and further decoration below, either lettering or circles. RF 4336 is decorated in a similar manner to vessels found on an increasing number of western British post-Roman sites, including Whithorn, Galloway, ${ }^{83}$ Trethurgy, Cornwall, ${ }^{84}$ Cadbury Congresbury, Somerset, ${ }^{85}$ and also possibly at Traprain Law. ${ }^{86}$ All these sites were occupied in the fifth/sixth centuries, and the Whithorn sherds are well stratified 
with Mediterranean amphorae of the sixth century and Continental pottery of the later sixth/seventh century. The decoration on one Whithorn example ${ }^{87}$ is almost identical to the Tintagel fragment, emphasizing the close links between the sites shown by both ceramic and glass finds. The Whithorn example was from a late sixth/seventh-century context (Period 1.10), though other examples of wheel-abraded sherds came from secure early sixth-century contexts. The provenance of these wheel-abraded vessels is at present unclear, with parallels from Iberia to the Black Sea. It is not surprising to find such a vessel at Tintagel, given the large quantity of Mediterranean ceramic imports, and the presence there of other western Mediterranean glass, some possibly of Iberian origin. Inscribed vessels such as these are rare and costly pieces, and perhaps give some support to the evidence for a literate elite at the site which has been suggested by the discovery of the inscribed 'Artognou' stone (see Thomas above).

Vessel 19 (TTG 1999, T01 ext, RF 4335) is represented by a tiny sherd with optic blown ribbing and pale green metal in good condition with no bubbles. It is unusual for western sites, although it is so small it is impossible to be sure of the form of vessel represented. The optic blown ribbing, however, is characteristic of vessels of this period of Campbell's Group $B^{88}$ which belong to an Anglo-Saxon/Frankish tradition. The commonest form with this type of decoration is the palm cup. Sherds of palm cups with similar decoration have been found only at Whithorn in the west of Britain, ${ }^{89}$ although other types of mould-blown decoration which may be from palm cups are found at the Mote of Mark, Kirkcudbrightshire. ${ }^{90}$ Palm cups are commonly found in Anglo-Saxon and Continental Frankish contexts of the sixth and seventh centuries. ${ }^{91}$ However, there are earlier (fifth-/sixth-century) vessels with mould-blown ribbing, particularly from France, so it is difficult to be sure that this sherd belongs to a palm cup. This sherd could therefore be an Anglo-Saxon import, or from northern or western France.

Neither of these latter two sherds is likely to be from any of the previous vessels recorded from the site, increasing the number of fifth-/sixth-century vessels from Tintagel to sixteen.

\section{MID-SAXON}

Vessel 17 (TTG 1994, trench C16, RF 2619) stands apart from all the other sherds in terms of its deep, almost opaque, colour. It belongs to a quite different glass- making tradition, of deeply coloured glass, which was developed in the eighth-ninth centuries in mid-Saxon English and Carolingian contexts. The metal is also of poorer quality, with a vesicular inner surface. The deep red colour is characteristic of eighth-/ninth-century glass in England and the Continent. ${ }^{92}$ The red colour is not the streaked red which was a common decorative trait, ${ }^{93}$ but translucent red or 'copper ruby'. This is technically difficult to produce, and this sherd may be a failed attempt which turned out too dark, as has been suggested for some of the Hamwic glass. ${ }^{94}$ The sherd is too small to be sure of the form, but is possibly from a jar. There are few records of material of this date in western areas, but it is significant that the three sites with this material, Lagore, ${ }^{95}$ Dumbarton Rock ${ }^{96}$ and Dundurn, ${ }^{97}$ are known from documentary records to be royal sites at this period. Other records are mainly in areas which had come under Anglo-Saxon control by this period, for example, two fragments from Anglian deposits at Whithorn. ${ }^{98}$

\section{Discussion}

In summary, the Tintagel imported glass can be ascribed to Campbell's groups representing broad glass-making traditions: Group A (Vessels 3-7, and 18), Group C (Vessels 8,10 and 16), Group B (Vessels 17 and possibly 19), with Vessels 9 and 11-15 belonging either to Group A or D. ${ }^{99}$ These imported vessels are indicators of the developing economies of western Britain and Ireland in the post-Roman period. There were two main trading networks operating in early medieval Atlantic areas, the first in the late fifth and early sixth century which brought amphorae and tablewares from the Aegean and North Africa, and a second in the later sixth and seventh century bringing luxury goods and Coarsewares from south-west France. ${ }^{100}$ Most of the glass imports from other sites in western areas are associated with Continental ceramics from south-west France, Thomas's Class E-ware and more particularly Radford's D-ware, ${ }^{101}$ and were presumably manufactured in the Bordeaux area as there is evidence of glass-making there at this period.

It is now clear from the Tintagel evidence that there were some glass imports in the period before 550 . This was also the case at Whithorn, the best stratified site of the period, where some glass is associated with Mediterranean ceramics. ${ }^{102}$ Some of this early glass has been ascribed to Mediterranean sources, ${ }^{103}$ though these are different forms from the Tintagel material. It is not 
surprising, therefore, that there are Mediterranean parallels for some of the Tintagel glass. The route taken by the eastern merchants can be tracked from the find spots of ceramics to North Africa, southern Spain, Portugal and south-west France to Britain, ${ }^{104}$ and glass vessels could have been picked up anywhere along this route. It is probable also that the small amounts of Dware from Tintagel were picked up at the same time. ${ }^{105}$ In contrast to the ceramics, it is more difficult to separate the Continental from the Mediterranean glass, as they belong to the same broad tradition. It can now be suggested, however, that there was a short period of overlap between the two trading networks in the midsixth century.

Taken as a whole the Tintagel glass presents a coherent story, which accords well with what is known of the site through the ceramic finds. There are a few vessels possibly of the late fourth/early fifth century, most belong to the late fifth/early sixth century, with at least one vessel of later sixth- or seventh-century date, and an outlier of the eighth/ninth century. The provenance of the material includes the western Mediterranean littoral from North Africa, Spain and possibly southern France, and Aquitaine. This dating does not conflict with the 'traditional' dating of the Mediterranean ceramics, ${ }^{106}$ but does leave open the possibility of occupation on the site continuing into the seventh century, as has been suggested by an analysis of the radiocarbon dates. ${ }^{107}$ If this is the case, the lack of white trailed glass and E-ware is striking, and suggests the function and status of the site had undergone a significant change, isolating it from the Continental trading network which was supplying goods to most of western Britain and Ireland at this period. The possible reasons for this change lie outside the scope of this report.

\section{ANALYSIS OF GLASS VESSEL 6 by Jennifer Jones ${ }^{108}$}

Energy Dispersive X-ray Fluorescence (EDXRF) analysis of these glass sherds was undertaken to determine whether all fragments came from the same vessel and also to identify the colourants used (table 51). The XRF results suggest that the material is a soda-lime glass. Very little sodium was detected, due to the loss through leaching on the weathered surfaces. However, the material is very stable, having deteriorated little, probably due to the relatively high level of calcium oxide present in the glass (about 6-9 per cent), which acts as a stabilizer of the glass matrix. Iron is present at a level of around $0.4-0.5$ per cent and may be responsible for the yellowish colour of the material. Manganese is present at levels of around 1.3-1.9 per cent, and may have been used as a decolourant to achieve the pale colour. ${ }^{109}$ The analysis of the fragments, while showing some variability, is similar enough to strongly suggest that all originally came from the same vessel, thus confirming visual conclusions.

Table 51 Surface analysis of glass Vessel 6 sherds by EDXRF

\begin{tabular}{|c|c|c|c|c|c|c|c|c|c|}
\hline Fragment & $\mathrm{Na}_{2} \mathrm{O}$ & $\mathrm{MgO}$ & $\mathrm{SiO}_{2}$ & $\mathrm{CaO}$ & $\mathrm{MnO}$ & $\mathrm{FeO}$ & $\mathrm{CuO}$ & $\mathrm{K}_{2} \mathrm{O}$ & Total \\
\hline 1 & & $581 \mathrm{ppm}$ & 74.5 & 7.08 & 1.39 & 0.465 & 202ppm & 0.583 & 88.29 \\
\hline 2 & & & 66.1 & 6.41 & 1.29 & 0.432 & 117ppm & 0.577 & 78.57 \\
\hline 3 & & & 83.21 & 8.48 & 1.64 & 0.585 & $180 \mathrm{ppm}$ & 0.918 & 100.52 \\
\hline 4 & & $991 \mathrm{ppm}$ & 87.83 & 8.69 & 1.72 & 0.569 & $146 \mathrm{ppm}$ & 0.786 & 104.81 \\
\hline 5 & & $646 \mathrm{ppm}$ & 76.99 & 8.91 & 1.47 & 0.489 & & 0.714 & 92.58 \\
\hline 6 & & $603 \mathrm{ppm}$ & 77.16 & 8.75 & 1.44 & 0.500 & & 0.881 & 93.11 \\
\hline 7 & & $590 \mathrm{ppm}$ & 83.05 & 8.38 & 1.63 & 0.570 & $159 \mathrm{ppm}$ & 0.821 & 99.25 \\
\hline 8 & & & 87.66 & 9.45 & 1.89 & 0.663 & $305 \mathrm{ppm}$ & 0.995 & 106.7 \\
\hline 9 & & & 80.14 & 9.15 & 1.51 & 0.518 & $158 \mathrm{ppm}$ & 0.786 & 96.21 \\
\hline 10 & 2.51 & $941 \mathrm{ppm}$ & 81.13 & 9.26 & 1.53 & 0.522 & 172ppm & 0.739 & 100.77 \\
\hline 11 & & 764 ppm & 80.12 & 7.71 & 1.51 & 0.513 & $133 p p m$ & 0.698 & 95.27 \\
\hline 12 & & & 71.85 & 9.22 & 1.57 & 0.563 & & 0.825 & 88.29 \\
\hline 13 & & & 83.59 & 9.62 & 1.56 & 0.539 & & 0.284 & 100.74 \\
\hline
\end{tabular}

All figures are in percentages unless otherwise stated.

Fragments 1-6 and 8 are RF 3500; Fragment 7 is RF 3426; Fragments 9-13 are RF 3501 
GLASS BEADS

by Ewan N Campbell

Three glass beads were recovered from the Site $C$ building: C10, Phases Y and V (RFs 1999 and 2079), and from C16, Phase T (RF 2620). They are all of very similar material, probably contemporary products and conceivably from a single necklace made on the site. The small cylindrical glass bead (RF 2620 from 540 in C16: see figure 124) has metal streaked lengthways of opaque red, brown and black and large mineral inclusions. This is similar to Germanic beads but is probably of local manufacture of the fifth-seventh centuries. It would seem likely to have been found in its original location, unlike the small glass bead (RF 2079: see figure 124, from 703) and the squat cylindrical glass bead of opaque terracotta metal with blackish streaks (RF 1999 from 514) from Phases $V$ and $Y$ in $C 10$.

Although there are a couple of opaque terracotta rod beads from Roman contexts, Guido's work places beads of similar material in a fifth-seventh-century timeframe, commonly found in Anglo-Saxon graves of eastern England, possibly made in Alamannic Germany. ${ }^{110}$ If the Tintagel beads are of Germanic origin, they would be the only objects of this provenance from the stratified deposits on the site. It seems possible, from the very mixed nature of the glass, that these are local products of the post-Roman period rather than Germanic imports. A single glass droplet has been found elsewhere on the site (where it was misidentified as a bead), ${ }^{111}$ but it is not certain evidence of glass-working at Tintagel, as it could be the result of vitrification of crucibles from metal-working activities. It does, however, look similar to droplets from sites such as Dinas Powys with proven glass-working. ${ }^{112}$ If indeed it is glass-working residue, it is likely to be from glassmelting activities rather than glass-making.

$$
\begin{gathered}
\text { CERAMICS: ROMANO-BRITISH } \\
\text { by Carl Thorpe }
\end{gathered}
$$

Three main fabrics have been distinguished in this small assemblage of twenty-one sherds: Gabbroic (comprising only five sherds across $C 15$ and the Site $C$ building), Granitic (a single sherd from the Site $C$ building) and Local fabric (fifteen sherds across T01 ext: the Lower Ward, C15 and the Site C building, table 52). There is a potential date range for these fabric types from the third century into the sixth century $A D$ with continuity of use suggested in the Gabbroic and Local groups alongside the early medieval imported wares discussed by Thorpe in the following section.

Granitic fabric resembles South Devon Ware, Exeter Fabric 5. ${ }^{113}$ It is hand-made and wheel-finished, with fairly coarse grits commonly quartz and mica. The fabric is buff-grey to black in colour, with burnishing on the exterior, often with cordons or lightly incised lines forming a lattice pattern, sometimes both. It dates from the third-fourth centuries.

Gabbroic fabric is hand-made, thin-walled, wheelfinished, often with a black coating on the exterior, and sometimes burnished. ${ }^{114}$ It is sometimes coarse-grained, containing a large quantity of white angular grits (feldspars) and other dark minerals such as amphibole and black tourmaline. These fabrics are found from the late Iron Age through to the late Roman period, possibly continuing into the fifth century.

Local fabric was first recognized by Quinnell and Thorpe during a brief reassessment of the native wares from Radford's excavations in the 1930s. ${ }^{115}$ It is brownbuff to grey-black in colour and, macroscopically, the matrix of the clay seems well-sorted with few inclusions of local slate. It is hand-made, well-finished, thin-walled and hard-fired and the vessels appear to have been carefully manufactured, with high-quality burnishing. Bowls and jars are the most common forms. The significance of this type, following on the excavations at Trethurgy, is that the production of native wares in the Roman style continued in Cornwall into the sixth century AD. ${ }^{116}$

\section{Site C, Middle Terrace: trench C15}

Thirteen Romano-British sherds were recovered in the course of excavating the Middle Terrace, Site C15 (see Chapters 4 and 5). Most of these were undiagnostic or from long-lived forms (Trethurgy Type 4 Jar, second to fifth centuries AD). However, the presence of two 'Cornish Flanged Bowl' rims (Trethurgy Type 22) ) $^{117}$ from Phase W (RF 3609) further support a fourthcentury AD date (figure 126). A Gabbroic sherd from the same phase of collapse prior to the work of Radford, and two further example from scree-tips, Phase $\mathrm{Y}$ in the C15 trial trench, may lend further support to the fourthcentury dating for this phase.

\section{Site C, Middle Terrace: Site C building}

Among the sherds of pottery from this area of the site all three of the fabric types were noted (see table 52). One of the two Gabbroic sherds recovered is a flanged bowl 
Table 52 Romano-British pottery

\begin{tabular}{|c|c|c|c|c|}
\hline Phase & Trench & Type & Number & Phase total \\
\hline \multicolumn{5}{|c|}{ Site C, Middle Terrace: Site C building } \\
\hline $\mathrm{T}$ & $\mathrm{C} 11$ & Gabbroic & 1 & \\
\hline $\mathrm{T}$ & $\mathrm{C} 16$ & Gabbroic & 1 & 2 \\
\hline U1 & $\mathrm{C} 09$ & Local & 1 & 1 \\
\hline $\mathrm{U} 2$ & $\mathrm{CO9}$ & Granitic & 1 & 1 \\
\hline Y & $\mathrm{C} 11$ & Local & 2 & \\
\hline Y & $\mathrm{C} 12$ & Local & 1 & 3 \\
\hline
\end{tabular}

Site C, Middle Terrace: Radford trenches
$\mathrm{Y}$
C15
Gabbroic
2
Overall total: 2

Site C, Middle Terrace: Trench C15

$\begin{array}{lll}\text { T } & \text { Local } & 1 \\ \text { W } & \text { Local } & 5 \\ \text { W } & \text { Gabbroic } & 1 \\ \text { X } & \text { Local } & 3 \\ \text { u/s } & & 1\end{array}$

1

5

1

3

1

Overall total: 11

Site T: Lower Ward, Trench T01 ext

W

Local

1

1

Overall total: 1

rim ( $\mathrm{RF} 3400$, Phase T: figure 127) of fourth-century form (and associated with two sherds of Bii). The single sherd of Granitic fabric from Phase U2 of C09 and the four sherds of Local fabric from Phases U1 and Y were either too abraded or not in themselves diagnostic as to form. This small collection of seven sherds of RomanoBritish pottery suggests a presence or activity somewhere on the Island in the period $c$ AD 300-400 onwards, as previously indicated by excavations on the Lower Terrace where a fire-pit was radiocarbon dated to cal AD 395-460 (95 per cent confidence). ${ }^{18}$ However, given the association with post-Roman material here on the Site C Middle Terrace, a later date is more likely.

SITE T: THE LOWER WARD, TRENCH T01 EXT A single sherd of Local ware was found redeposited in Phase W, 1132 of the Lower Ward (see Chapter 9). It was associated with early medieval sherds, including African Red slipped ware (ARSW), Bi and Bii, as well as early medieval glass fragments - including one of the AngloSaxon Frankish tradition (RF 4335).

\section{DisCUSSION}

The occurrence of Roman wheel-made wares at Tintagel, such as mortaria of Oxford Colour Coated wares (Young Form 100) and flanged bowls (Young Form C.51.1) dating from the late third to fourth centuries $A D$, has long been recognized from previous work (especially that of Radford). ${ }^{119}$ It was observed that these were accompanied by a large number of sherds of Romano-British native ware which, when examined, were found to be in three distinct fabrics, Gabbroic, Granitic and Local. As noted above, evidence from Trethurgy indicates the production of these native wares in the Roman style in Cornwall continuing well into the sixth century AD. ${ }^{120}$

The contexts of these wares were always uncertain ${ }^{121}$ as it could not be determined if these were chance, 


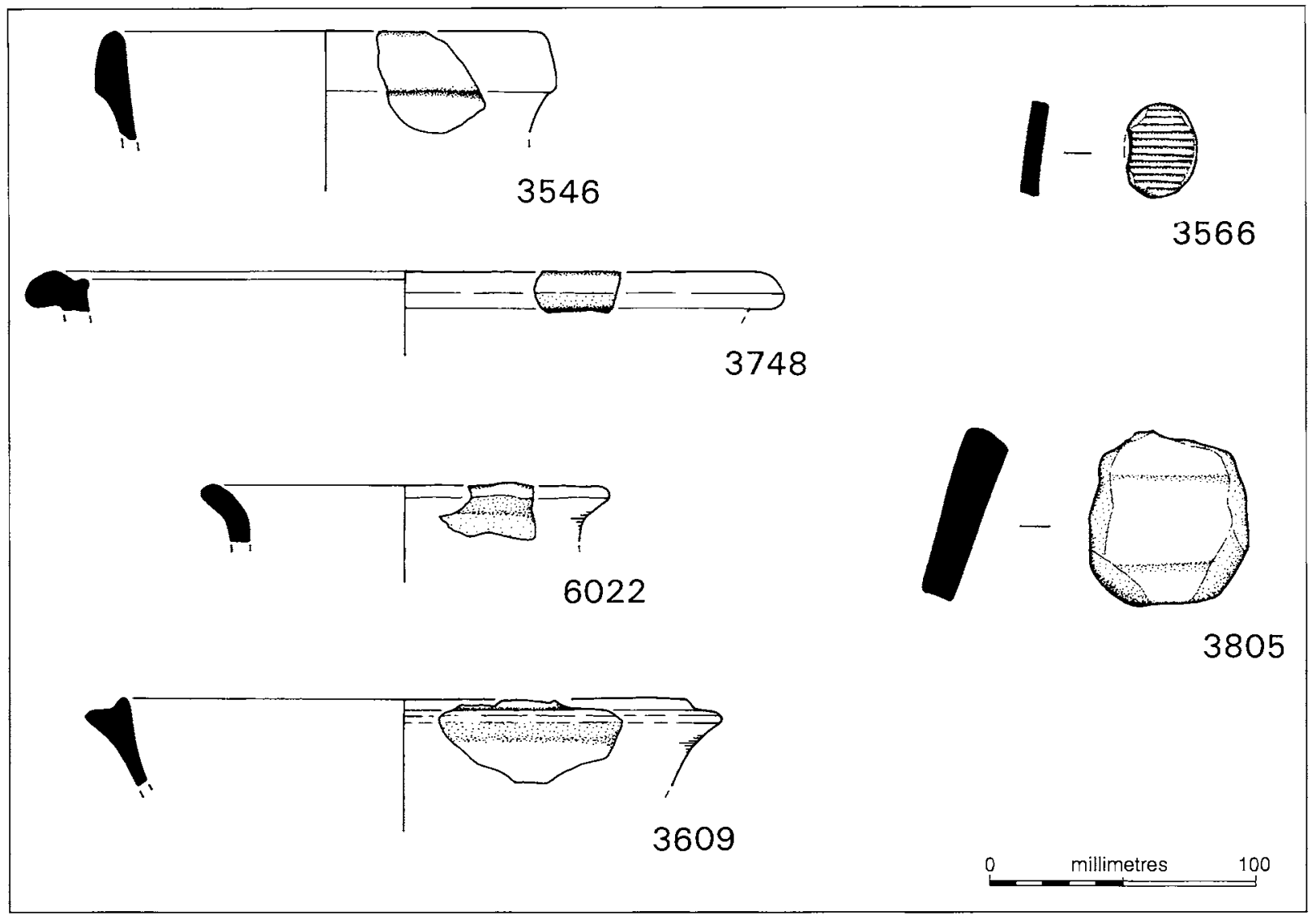

126 Romano-British and imported post-Roman ceramics: RFs 6022 (R-B local, 697), 3609 (R-B local, 667), 3748 (D-ware, 675), $3546(B v, u / s), 3566$ (Bi amphora-stopper, 650) and 3805 (Bv amphora-stopper, 681). Drawing: C Thorpe

accidental breakages from occasional visitors to the site, or if there was an actual settlement on the headland at that time. Clarification came with the excavation on the Lower Terrace, Site C (see Chapter 2). 122 Twenty-four stratified Romano-British native ware sherds were identified in that work, with all three fabric types being represented (fourteen coming from a single vessel, a Trethurgy Type 4 jar in Local fabric). The excavators also revealed associated structures and features from which a radiocarbon date of cal AD 395-460 (95 per cent confidence) was obtained.

The nature of this late Romano-British settlement is still uncertain, but the fact that material occurs on both the Island and mainland shows that it was extensive and likely originally to have spread over the entire headland in the late Roman period. This would seem to confirm the observations made at Trethurgy, where production of Romano-British style native ware pottery continued to be used well into the fifth and possibly sixth centuries alongside the imported Mediterranean pottery. However, whilst this may be relevant to the small number of sherds that originate from Phase $\mathrm{T}$ in $\mathrm{C} 15$ and the Site $\mathrm{C}$ building, the majority of the small assemblage from the current investigations is redeposited and is not evidence that these areas were occupied during the Romano-British period.

\section{CERAMICS: POST-ROMAN IMPORTED by Carl Thorpe with Colleen E Batey}

A comprehensive range of imported pottery sherds from the post-Roman period has been found from the site, commencing in the fifth century and continuing until about $A D$ 600. They comprise amphorae, imported Coarsewares and imported fine table-wares, as well as a group of 


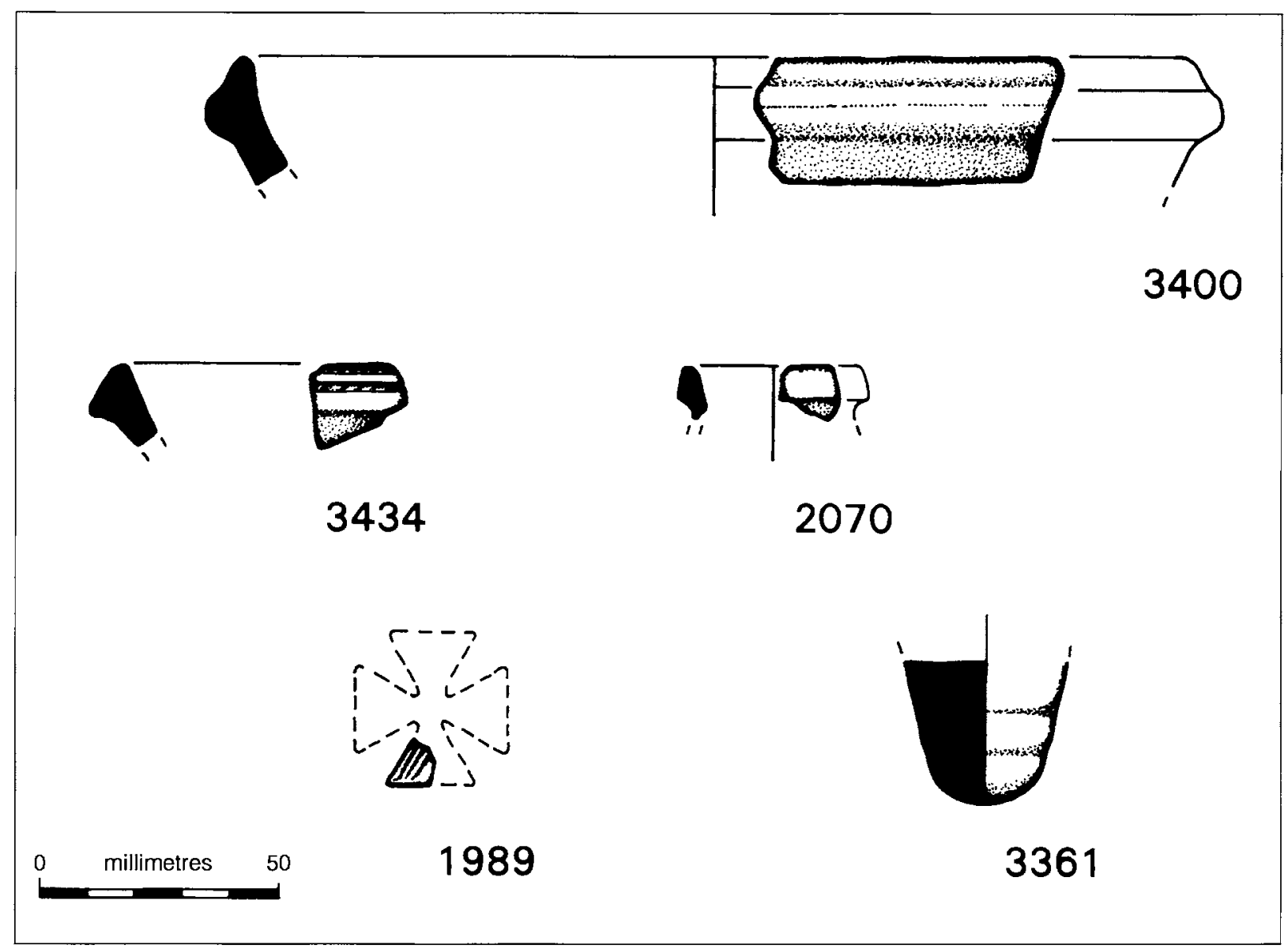

127 Imported and Roman native pottery: RFs 3361 and 3434 (C09), 1989 and 2070 (C10), and 3400 (C16). Drawing: C Thorpe

currently unknown fabrics: in total 1,821 sherds were recovered across all areas examined. Measurements and attrition details have not been included in this report as they are available in the finds register that forms part of the original site archive.

\section{AMPHORAE}

Class Bi (Peacock and Williams Form 43 = Late Roman Amphora 2)

This is a widespread form, with production sites known in the Argolid region of the Peloponnese, although other sites on the Greek mainland, Crete and the wineproducing Greek islands may have produced similar forms ${ }^{123}$ (see $\mathrm{R}$ Jones below, however). A globularshaped vessel with basal knob, short conical neck and highly everted rim is characterized by combed ribbing, often fairly deep in a band on the shoulder region. The fabric is fine-grained, well-sorted with white grains of limestone often visible, and pink-buff to orange-brown in colour. Both graffiti and dipinti are known on vessel surfaces, perhaps as traders' or makers' marks. Although a fairly long-lived form, current from the early fifth century to the late sixth century, the peak of its use and distribution was reached around the mid-fifth to midsixth centuries, that is between $A D 450$ and 550 . It is suggested that it was used for carrying wine, although a possible secondary re-use for other commodities, for example wax, may be reflected in the chemical analysis (see $\mathrm{R}$ Jones below). Across the whole assemblage recovered from all areas, comprising sixty-six sherds from the Upper Terrace, 792 from the Middle Terrace and fifty-six from the area of the Great Ditch, this represents 50.19 per cent of the overall sherd count. Diagnostic sherds include rims, a foot nipple, neck sherds and a handle scar. 
Class Bii (Peacock and Williams Form $44=$ Late Roman Amphora 1)

This is known from several kiln sites from the coastal plain of Calico in south-east Turkey. ${ }^{124}$ An ovoid shape with rounded base, broad neck and twisted asymmetrical handles, the vessel is characterized by tegulated ribbing that covers the body. The fabric is hard, sandy and variable in colour from pinkish-cream to reddish-yellow. Examples with graffiti and dipinti are known. Traditionally, the date range is $\mathrm{AD} 450-550 .{ }^{125}$ The contents are uncertain, although the olive oil industry of the Antioch region may have made use of such vessels. A total of forty sherds from the Upper Terrace, 325 from the Middle and ten from the area of the Great Ditch account for 20.59 per cent of the overall sherd count. Diagnostic sherds include rims, neck sherds and handles.

Class Biv (Peacock and Williams Form 45)

This type probably originates from Asia Minor. ${ }^{126}$ They are small carrot-shaped vessels with tegulated ribbing on the body and a distinctive hard, highly micaceous fine fabric, red-brown in colour. The two-handled form seen at Tintagel came into use by the middle of the fifth century $\mathrm{AD}$ and became rare after the middle of the sixth century. The contents are uncertain but wine or fine oils are the most likely. Only fourteen sherds from the Middle Terrace and five from the area of the Great Ditch were recovered, forming 1.04 per cent of the total sherd count. Diagnostic sherds include rims and a footspike. This very thin-walled vessel form is probably under-represented due to the poor conditions of preservation.

\section{Class Bv}

This type is still unprovenanced; it does, however, resemble Tunisian Africana Grande (Peacock and Williams Class 34-5 from Byzacena) as well as Africana Piccolo (Peacock and Williams Class 33). ${ }^{127}$ The Grande is of large cylindrical form, up to $1 \mathrm{~m}$ high, with a pronounced foot-spike and large handles. Characterized by thick ridged walls, the fabric is very sandy, pale buffbrown in colour. Recent residue analysis reported below by Richard Jones has suggested these were used for carrying olive oil, although other commodities may also have been transported in this form. Two sherds from the Upper Terrace, 112 from the Middle and four from the area of the Great Ditch make up 6.48 per cent of the total sherd count. Diagnostic sherds include rims and a handle-shoulder segment from trench $\mathrm{C} 15$, Phases $\mathrm{U}$ and $\mathrm{W}$ (see Chapter 5) which assists in the identification of the overall form for the first time in a British context.

\section{IMPORTED COARSEWARES}

Although the amphora fabrics have been identified and provenanced, with the exception of $\mathrm{Bv}$ fabric, a further group, sixty-two sherds in total from this assemblage as a whole ( 3.4 per cent excluding the Unknown fabrics), are imported Coarsewares which apparently originate from the same areas as the more well-known amphora fabrics. These Coarsewares have only recently been recognized by Thomas and Thorpe, although this work is awaiting full publication. ${ }^{128}$ Two of the Coarseware fabrics have been identified in this assemblage, and each is fully described here.

\section{Fabric 1: Eastern Mediterranean Red Ware}

This is a similar form to North African Red Ware ${ }^{129}$ and is purple-red to reddish-orange in colour. It has a hard smooth texture, and is micaceous, with numerous wellrounded quartz grains. Some white limestone specks are present but not common. Forms include casseroles, storage jars and jugs. Seventeen sherds from the Upper Terrace, thirty-nine from the Middle and one from the area of the Great Ditch make up 3.13 per cent of the total sherd count. Diagnostic sherds include a handle fragment.

\section{Fabric 5: Eastern Mediterranean Sandy Cream Ware}

This is similar to North African Cream Ware ${ }^{130}$ and is cream or buff coloured throughout, with an occasionally darker buff or grey core and has a hard rough texture with common sand inclusions. Only five sherds were recovered, all from the Middle Terrace and representing 0.28 per cent of the total sherd count. Diagnostic sherds include a rim and a foot-ring.

\section{Miscellaneous}

The single large sherd of a thick-walled vessel from C09 Phase U (RF 3477) is perhaps a ceramic type not previously identified at the site or locality, possibly part of a very substantial imported vessel of amphoratype (figure 128). At the time of writing there is no suggestion for its origin.

More generally, overall there are twenty-nine sherds of Unknown fabric from the Upper Terrace, 227 from the Middle and thirty-one from the area of the Great Ditch, forming a significant 15.76 per cent of the total 

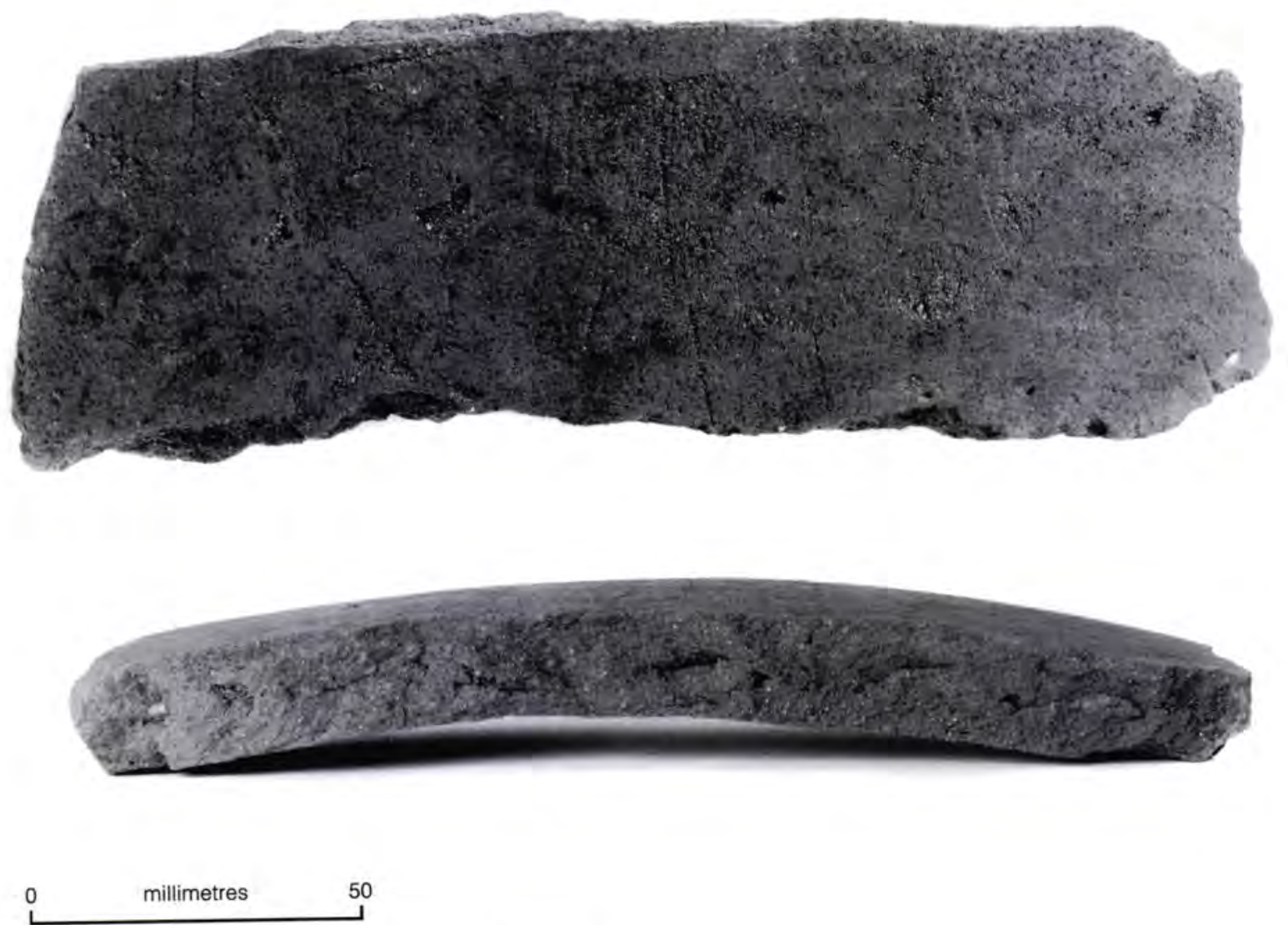

128 Large sherd of pottery: RF 3477. Photograph: E Howden

sherd count. Interestingly, two of these sherds of unknown fabric have cruciform decoration (RF 1989: see figure 127).

\section{IMPORTED FINE TABLE-WARES}

Phocaean Red slipped ware (PRSW) $)^{131}$

This fabric originates in Phocaea in western Turkey, and the only form to have been imported to Tintagel is a bowl of Hayes Form 3. ${ }^{132}$ It is a fine, well-sorted sandy fabric, often soft and friable, a pale pink to buff in colour. The decoration consists of a collared or straightedged rim, ${ }^{133}$ which is often embellished with rouletted designs. The base is sometimes decorated with a stamp, often cruciform in shape. The entire surface is covered in an even red slip. Overall, three sherds from the Upper Terrace and twenty-five sherds from the Middle Terrace were recovered (although none from the area of the Great Ditch), representing 1.54 per cent of the total sherd count. Diagnostic sherds include rims, eg RF 3434 (see figure 127) with rouletted decoration, from Phase T of C09, dated to the late fifth-early sixth century and also basal angles.

African Red slipped ware (ARSW)

This fabric originates in the Carthage region of Tunisia, and the forms imported include both dishes and bowls. ${ }^{134}$ The forms of this ware changed quite rapidly in response to fashion trends, which makes this a good material for dating purposes, based on the Carthage sequence. ${ }^{135}$ Forms found at Tintagel suggest a date around $\mathrm{AD} 530$, although there are earlier examples that may suggest that it was actually coming into the country in some quantity by the third century AD. ${ }^{136}$ The date range given for this form by Fulford and Peacock is $c \mathrm{AD}$ $474-500,{ }^{137}$ and the basal angle and partly stamped area of a base sherd from a Form 76 ARSW bowl was recovered from Tintagel during excavations by Radford, who reconstructs the bowl. ${ }^{138}$ Two conjoining rim sherds of this form of bowl, each marked A33, were recovered during Radford's excavations at Site A, Room 11 'floor level'; it is reconstructed by Thomas. ${ }^{139}$ 
This is a fine-grained well-sorted fabric, hard, orange-red to buff-red in colour. Rim forms vary from simple beaded to straight edged. ${ }^{140}$ Decoration, if present, consists of basal stamps, mostly cruciform in shape, though several animal forms are known. The whole surface is covered in an even overall slip. Two sherds from the Upper Terrace, twelve sherds from the Middle Terrace and a further three from the area of the Great Ditch form 0.93 per cent of the overall sherd count. Diagnostic sherds include rims (eg RF 1850) and a neck sherd (RF 1849) of very small size.

\section{D-ware}

Only one example of $\mathrm{D}$-ware was found during this programme of work at Tintagel. This fabric originates in the Bordeaux region of western Gaul and is a rare import to Tintagel, although a single sherd had previously been identified from the 'Steps' area. ${ }^{141}$ It is hard, fine-grained and well-sorted, with a few small dark inclusions (often weathered out, giving a pitted appearance) and homogeneous light grey in colour with traces of a dark grey slip or colour wash. Forms include mortaria, thick-rimmed bowls and fine bowls (often with distinct shoulder and foot-ring). Decoration, where present, consists of horizontal grooves and applied cordons, while fine wares may be rouletted or stamped with a variety of motifs including palmettes, animals and chi-rho crosses on the basal interior. Dating of Dware is uncertain, though the evidence from other insular sites such as Dinas Powys supports a sixthcentury date. ${ }^{142}$ The single sherd RF 3748 from Area C15 of the Middle Terrace is the rim of either a mortaria or a large bowl, Form D1 or D2 (see figure 126). ${ }^{143}$ This makes up just 0.06 per cent of the overall sherd count.

\section{DISCUSSION}

\section{Site C, Upper Terrace: Radford's trenches}

Unlike the assemblages recovered from the Lower Terrace (see Chapter 2) and the trenches in and around the Site $C$ building (see Chapter 6 ), the ceramic assemblage from the Upper Terrace trenches is split almost equally between post-Roman and medieval fabrics.

A total of twenty sherds of imported Mediterranean wares were identified from trench $\mathrm{C19}$, as shown in Table 53. This amounts to eight from Phase Z, including

Table 53 Fabric types of imported pottery, Radford trenches, Upper Terrace (summary)

\begin{tabular}{|c|c|c|c|c|c|c|c|c|c|c|c|}
\hline \multicolumn{12}{|c|}{ Trench C19 20 sherds } \\
\hline Context & Unknown & $B i$ & $B i i$ & Biv & $B v$ & Fabric 1 & Fabric 5 & PRSW & ARSW & Phasing & Total \\
\hline 410 & 1 & 6 & - & - & - & - & - & 1 & - & $\mathrm{Z}$ & 8 \\
\hline 411 & - & 1 & - & - & - & - & - & - & - & $\mathrm{X}$ & 1 \\
\hline 412 & 2 & 7 & - & - & - & - & - & - & - & $\mathrm{Y}$ & 9 \\
\hline 414 & 2 & - & - & - & - & - & - & - & - & $\mathrm{Y}$ & 2 \\
\hline Overall & 5 & 14 & - & - & - & - & - & 1 & - & & 20 \\
\hline
\end{tabular}

\begin{tabular}{|c|c|c|c|c|c|c|c|c|c|c|c|}
\hline \multicolumn{12}{|c|}{ Trench C18 139 sherds } \\
\hline Context & Unknown & $B i$ & $B i i$ & Biv & $B v$ & Fabric 1 & Fabric 5 & PRSW & $A R S W$ & Phasing & Total \\
\hline 800 & 9 & 31 & 17 & - & - & 8 & - & 2 & 1 & $\mathrm{Z}$ & 68 \\
\hline 801 & 15 & 15 & 9 & - & - & 8 & - & - & - & $\mathrm{X}$ & 47 \\
\hline 803 & - & 6 & 14 & - & 2 & 1 & - & - & 1 & $\mathrm{Y}$ & 24 \\
\hline Overall & 24 & 52 & 40 & - & 2 & 17 & - & 2 & 2 & & 139 \\
\hline \multicolumn{12}{|c|}{ Cumulative totals } \\
\hline & Unknown & $B i$ & $B i i$ & Biv & $B v$ & Fabric 1 & Fabric 5 & PRSW & ARSW & & Total \\
\hline & 29 & 66 & 40 & - & 2 & 17 & - & 3 & 2 & & 159 \\
\hline per cent & 18.24 & 41.50 & 25.16 & - & 1.26 & 10.69 & - & 1.89 & 1.26 & & 100 \\
\hline
\end{tabular}


six Bi amphora sherds, a single PRSW sherd and one of unknown fabric; eleven from Phase Y (Radford's backfill), including seven $\mathrm{Bi}$ and four of unknown imported fabric and one $\mathrm{Bi}$ amphora fragment from Phase X (layers cut by Radford). In trench C18, sixtyeight sherds were identified from Phase $Z$, twenty-four from Phase $Y$ and forty-seven from Phase $X:$ in all, 139 sherds of imported fabrics (see table 53). This is in marked contrast to those trenches elsewhere on this Upper Terrace and once again underlines the relationship that this more southerly part of the area must have had with the adjacent trenches to the east (eg with $\mathrm{C} 17$ with thirty-one sherds, but more markedly with $\mathrm{C} 15$ with its 225 sherds). The sixty-eight sherds from Phase $\mathrm{Z}$ break down into thirty-one of $\mathrm{Bi}$ amphora, seventeen Bii, one ARSW, two PRSW, eight Coarseware Fabric 1 and nine currently unidentified. Phase $\mathrm{Y}$, with only twenty-four sherds in total, includes six of $\mathrm{Bi}$, fourteen of $\mathrm{Bii}$, two $\mathrm{Bv}$, one ARSW and one of Coarseware Fabric 1. Phase $\mathrm{X}$ includes fifteen $\mathrm{Bi}$ amphora pieces, nine Bii, eight Coarseware Fabric 1 and fifteen of unknown imported type. The contexts from which these were recovered can all be classed as disturbed or scree material.

The dominant fabrics of the Upper Terrace assemblage are amphorae. The near absence of Red Slipped Wares is significant, and the situation is mirrored particularly on the Middle Terrace (see below). Sixty-six sherds are identified as Bi, forty as Bii and two as Bv. Only two sherds of ARSW were identified in the Upper Terrace assemblage (from Phases $Y$ and $Z$ ), and three sherds of PRSW (all from Phase Z). In addition, seventeen sherds of a coarse fabric (Fabric 1) were found in trench C18 scattered through the phases. All fabrics originate in the East Mediterranean or North Africa. A further category of twenty-nine sherds has not been identifiable to type.

Site C, Middle Terrace: Radford's trenches

The picture here is consistent with the trenches elsewhere on the Middle Terrace. Ceramics dominate the finds assemblage although, unlike the Upper Terrace trenches (see above), post-Roman fabrics dominate the medieval. However, as there, within the post-Roman the dominant fabrics are amphorae. Two Romano-British sherds were also recovered (see above).

Nineteen sherds of imported ceramic were identified from trench $\mathrm{C05}$ (table 54). Numerically, Phase X, a scree-tip sequence, was the most significant, producing eleven sherds including $\mathrm{Bv}, \mathrm{Bi}$ and Bii. Seven sherds from Phase Y, Radford's backfill, comprised three sherds of Bi, three sherds of Bii and one of Coarseware Fabric 1. The single sherd from Phase $\mathrm{W}$, unexcavated features within Radford's excavated area, was identified as Bii.

One hundred and ninety-six sherds of imported fabrics have been distinguished from trial trench $\mathrm{C} 15$, all from redeposited contexts either in Radford's backfill or from scree-tips. An additional twenty-nine sherds were of unidentifiable fabrics, probably imported but too small to identify to type (see table 54 ). Phase $X$, Radford's backfill, produced twenty-eight Bi, twenty Bii, four Bv, one Biv and two PRSW sherds; Phase Y, screetips, fifty-eight Bi, fifty-six Bii, one Biv (RF 1580: see figure 107), three Bv, four PRSW, five Coarseware Fabric 1 and two Coarseware Fabric 5 and Phase Z, turf and topsoil, produced one sherd of Bii and two PRSW. A total of 131 sherds out of 225 were from context 650 , the scree-tips from terraces above. Sherds of types $\mathrm{Bi}$, Bii (RF 2299: see figure 107) and Bv have been scientifically examined in detail for indications of their contents and details of their potential origins (see $\mathrm{R}$ Jones below). Two pieces of B-ware amphora had also been clipped into disc-forms, to be used as amphora-stoppers (RFs 1543 (Bii) and 1709 (Bi) from Phase Y: see figure 107).

A total of thirty sherds of imported wares were recovered from trench $\mathrm{C} 17$, of which eighteen were unstratified but within Phase $\mathrm{X}$ and twelve came from Phase $Y$, the scree slip material (see table 54). These can be further subdivided into twenty-three of type $\mathrm{Bi}$ amphora, one of $\mathrm{Bii}$, two of $\mathrm{Bv}$ and two of Coarseware Fabric 1.

\section{Site C, Middle Terrace: trench C15}

In total 740 sherds of pottery belonging to the postRoman period, and an additional eleven sherds of Romano-British material (see above) were recovered from trench $\mathrm{C} 15$. A wide range of different fabrics was identified within the assemblage (table 55). Computation of vessel numbers is difficult because most of the sherds are medium to small in size, and in no case was it possible to reconstruct a full profile.

Work in progress by Richard Jones, while reinforcing the already well-documented evidence for the transportation of olive oil, suggests that one Bi sherd (RF 2290 from $\mathrm{C15}$ ) originally held a different substance, as yet unidentified. All but one of the sherds (an example of Dware) from this part of the site are of imported Mediterranean wares and, as elsewhere on the site, form 
Table 54 Fabric types of imported pottery, Radford trenches, Middle Terrace (summary)

\begin{tabular}{|c|c|c|c|c|c|c|c|c|c|c|c|}
\hline \multicolumn{12}{|c|}{ Trench C05 19 sherds } \\
\hline Context & Unknown & $B i$ & $B i i$ & Biv & $B v$ & Fabric 1 & Fabric 5 & PRSW & ARSW & Phasing & Total \\
\hline 301 & - & - & - & - & 2 & - & - & - & - & $\mathrm{X}$ & 2 \\
\hline 302 & - & 3 & 3 & - & - & 1 & - & - & - & $\mathrm{Y}$ & 7 \\
\hline 303 & - & 1 & - & - & - & - & - & - & - & $\mathrm{X}$ & 1 \\
\hline 308 & - & 1 & 5 & - & 1 & - & - & - & - & $\mathrm{X}$ & 7 \\
\hline 315 & - & - & 1 & - & - & - & - & - & - & $\mathrm{W}$ & 1 \\
\hline 316 & - & 1 & - & - & - & - & - & - & - & $\mathrm{X}$ & 1 \\
\hline Overall & - & 6 & 9 & - & 3 & 1 & - & - & - & & 19 \\
\hline
\end{tabular}

Trial trench C15 225 sherds

Context Unknown Bi

$\begin{array}{lrrrrrrrrrrrr}\text { u/s } & - & 9 & - & - & - & - & - & - & - & - & 9 \\ 650 & 21 & 47 & 49 & 1 & 3 & 4 & 2 & 4 & - & \mathrm{Y} & 131 \\ 651 & 1 & - & 1 & - & - & - & - & 2 & - & \mathrm{Z} & 4 \\ 652 & - & 1 & 1 & - & - & - & - & - & - & \mathrm{Y} & 2 \\ 653 & 4 & 10 & 6 & - & - & 1 & - & - & - & \mathrm{Y} & 21 \\ 660 & - & 1 & 3 & - & - & - & - & - & - & \mathrm{X} & 4 \\ 661 & 3 & 11 & 6 & - & - & - & - & - & - & \mathrm{X} & 20 \\ 662 & - & 6 & - & - & 3 & - & - & 2 & - & \mathrm{X} & 11 \\ 664 & - & 1 & 9 & - & - & - & - & - & - & \mathrm{X} & 10 \\ 672 & - & 9 & 2 & 1 & 1 & - & - & - & - & \mathrm{X} & 13 \\ \text { Overall } & 29 & 95 & 77 & 2 & 7 & 5 & 2 & 8 & - & & 225\end{array}$

Trench $\mathrm{C17} 30$ sherds

\begin{tabular}{llrlllllllll} 
Context & Unknown & $B i$ & Bii & Biv & Bv & Fabric 1 & Fabric 5 & PRSW & ARSW & Phasing & Total \\
\hline $\mathrm{u} / \mathrm{s}$ & - & 15 & 1 & - & 2 & - & - & - & - & $\mathrm{X}$ & 18 \\
900 & 2 & 8 & - & - & - & 2 & - & - & - & $\mathrm{Y}$ & 12 \\
Overall & 2 & 23 & 1 & - & 2 & 2 & - & - & - & & 30
\end{tabular}

\begin{tabular}{lllllllllll}
\hline $\begin{array}{l}\text { Cumulative totals } \\
\text { Unknown }\end{array}$ & Bi & Bii & Biv & Bv & Fabric 1 & Fabric 5 & PRSW & ARSW & Total \\
\hline per cent & 31 & 124 & 87 & 2 & 12 & 8 & 2 & 8 & - & 274 \\
\hline
\end{tabular}

two main groups: large storage jars or amphorae and fine table-wares. A small group of table Coarsewares or kitchen-wares is also represented. A total of $460 \mathrm{Bi}$ sherds, some 61.25 per cent of the total assemblage, were recovered, including four rim sherds, three handle sherds and a foot-spike scar. Six amphora-stoppers made of this material were also found (see figure 126). A total of 119 sherds of $\mathrm{Bii}, 15.85$ per cent of the total assemblage, were also discovered, including five rim sherds and an amphora-stopper (figures 126 and 129). Only six sherds of Biv were recovered, this very thin-walled vessel probably being under-represented due to the poor 
Table 55 Imported pottery from trench $\mathrm{C} 15$, Middle Terrace, by fabric and context

Trench C15 740 sherds

\begin{tabular}{|c|c|c|c|c|c|c|c|c|c|c|c|}
\hline Context & Unk & $B i$ & $B i i$ & Biv & $B v$ & $D$-ware & Fabric 1 & PRSW & ARSW & Phasing & Total \\
\hline $\mathrm{u} / \mathrm{s}$ & - & 3 & 3 & - & 1 & - & - & - & - & - & 7 \\
\hline 500 & 8 & 19 & 5 & - & 1 & - & - & - & - & $\mathrm{Z}$ & 33 \\
\hline 650 & - & 1 & - & - & - & - & - & - & - & $\mathrm{Y}$ & 1 \\
\hline $650 ; 652 ; 653$ & 1 & 42 & 16 & 4 & 4 & - & - & - & - & $\mathrm{Y}$ & 67 \\
\hline 653 & - & - & 2 & - & - & - & - & - & - & $\mathrm{Y}$ & 2 \\
\hline 654 & 12 & 19 & 9 & 1 & 2 & - & - & 4 & 1 & $\mathrm{~W}$ & 48 \\
\hline 655 & 5 & 3 & 4 & - & - & - & 1 & 1 & - & W & 14 \\
\hline 656 & 1 & 1 & 1 & - & - & - & - & - & - & $\mathrm{Z}$ & 3 \\
\hline 658 & 2 & 6 & 2 & - & 1 & - & 1 & - & - & $\mathrm{W}$ & 12 \\
\hline 659 & 2 & 15 & - & - & - & - & 1 & - & - & W & 18 \\
\hline $659 ; 669$ & - & 7 & 1 & - & - & - & - & - & - & W & 8 \\
\hline 662 & - & 12 & - & - & - & - & - & - & - & $\mathrm{X}$ & 12 \\
\hline 665 & 2 & 1 & 3 & - & 1 & - & - & - & - & $\mathrm{X}$ & 7 \\
\hline 666 & 1 & 2 & 2 & - & - & - & - & - & - & $\mathrm{V}$ & 5 \\
\hline 667 & 1 & 42 & 4 & - & 8 & - & 1 & - & - & W & 56 \\
\hline 669 & 18 & 34 & 16 & - & 2 & - & - & - & - & W & 70 \\
\hline 672 & 4 & 42 & 8 & - & - & - & - & - & - & $\mathrm{X}$ & 54 \\
\hline 674 & 7 & 33 & 10 & - & 2 & - & - & - & - & W & 52 \\
\hline 675 & 5 & 30 & 6 & - & 3 & 1 & 1 & - & - & $\mathrm{U}$ & 46 \\
\hline 678 & 1 & 8 & 1 & - & 3 & - & - & - & - & W & 13 \\
\hline $655 ; 678$ & - & 26 & 2 & - & 7 & - & - & 1 & - & W & 36 \\
\hline 681 & - & 2 & 1 & - & 1 & - & - & - & - & $\mathrm{X}$ & 4 \\
\hline 682 & 1 & 25 & 3 & 1 & 2 & - & - & - & - & $\mathrm{U}$ & 32 \\
\hline 685 & - & - & 3 & - & - & - & - & - & - & $\mathrm{U}$ & 3 \\
\hline 686 & - & 1 & - & - & - & - & - & - & - & $\mathrm{P}$ & 1 \\
\hline 687 & 12 & 57 & 13 & - & 1 & - & - & - & 1 & $\mathrm{~V}$ & 84 \\
\hline 694 & - & 2 & - & - & - & - & - & - & - & $\mathrm{X}$ & 2 \\
\hline 695 & 1 & 4 & - & - & - & - & - & - & - & $\mathrm{T}$ & 5 \\
\hline 697 & 2 & 17 & 4 & - & 1 & - & - & - & - & $\mathrm{T}$ & 24 \\
\hline 699 & - & 1 & - & - & - & - & - & - & - & $S$ & 1 \\
\hline 721 & - & 1 & - & - & - & - & - & - & - & $\mathrm{R}$ & 1 \\
\hline 722 & - & 4 & - & - & 14 & - & - & - & - & $\mathrm{R}$ & 18 \\
\hline 725 & 1 & - & - & - & - & - & - & - & - & $\mathrm{R}$ & 1 \\
\hline
\end{tabular}

Cumulative totals

\begin{tabular}{lllllllllll} 
& Unknown Bi & Bii & Biv & Bv & D-ware & Fabric 1 & PRSW & ARSW & Total \\
\hline \multirow{3}{*}{ per cent } & 87 & 460 & 119 & 6 & 54 & 1 & 5 & 6 & 2 & 740 \\
\hline
\end{tabular}

conditions for preservation. Fifty-four Bv sherds (7.19 per cent of the total assemblage), including a rim and two handle sherds, were recovered (figure 130). Finds of rim, basal and handle/shoulder sherds from C15 enable the reconstruction of a full profile of this vessel type (eg RFs 3595 and 3723: Phases $U$ and $W$; see figure 130) and identification of this type of amphora. This is the first time this has been possible in a British context. 


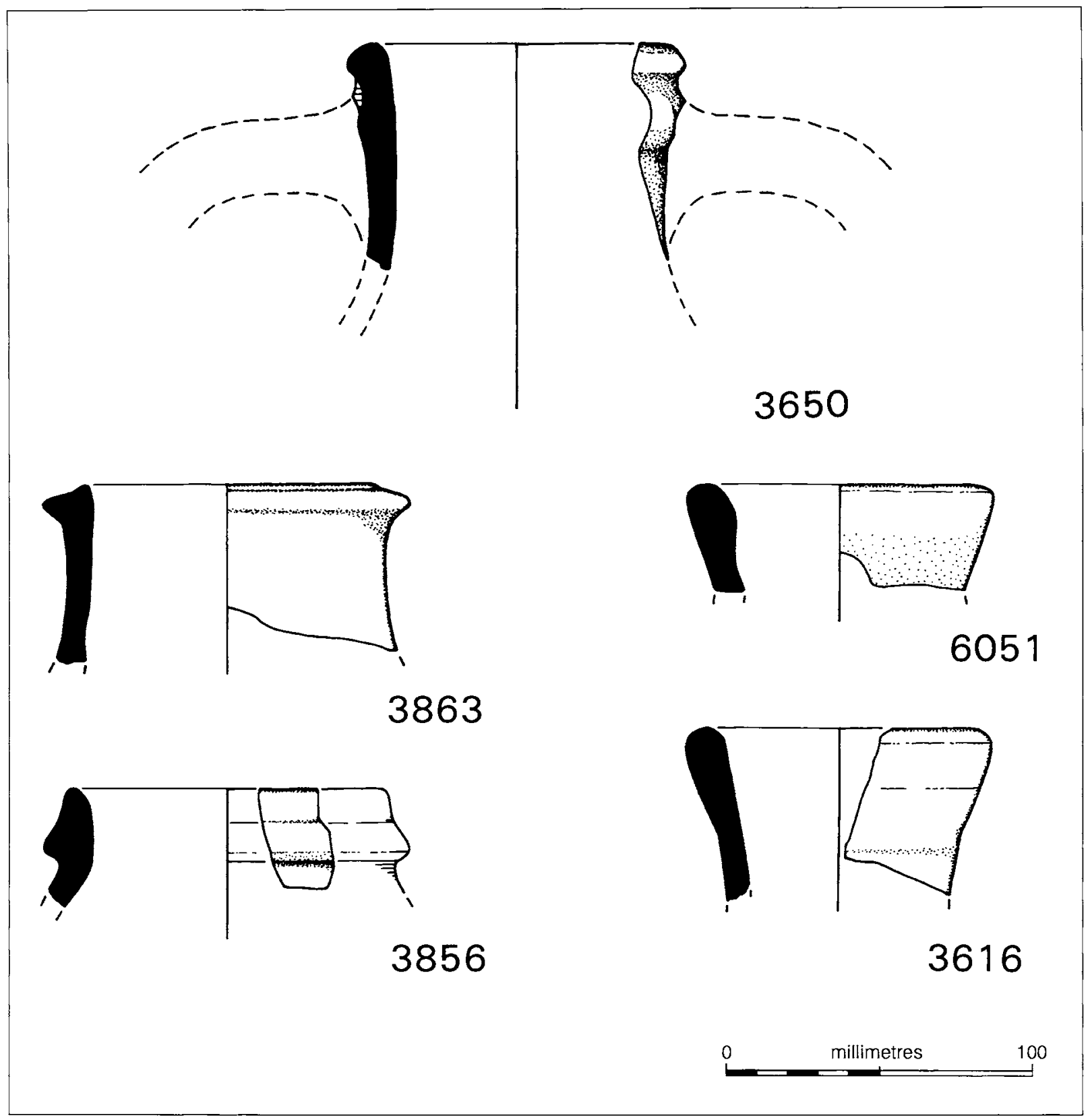

129 Imported post-Roman ceramics: RFs 3650 (Bii, 655/678), 3863 (Bii, 669), 3856 (Bii, 681), 605I (Bi, 697) and 3616 (Bi, 672). Drawing: $C$ Thorpe

Most of the fabrics noted above have been identified and provenanced from sites throughout south-west Britain and elsewhere. However, a further five sherds are imported Coarsewares apparently originating from the same regions as these other well-known wares. A single fabric type of the imported Coarseware has been identified in this assemblage, that of Fabric 1, Eastern
Mediterranean Red Ware. Five sherds of this material were recovered, but none was diagnostic. Apart from the above sherds of recognizable imported postRoman Mediterranean fabrics, there were eightyseven unidentifiable ones ( 11.58 per cent of the total assemblage), which are too small and abraded to clarify further. 

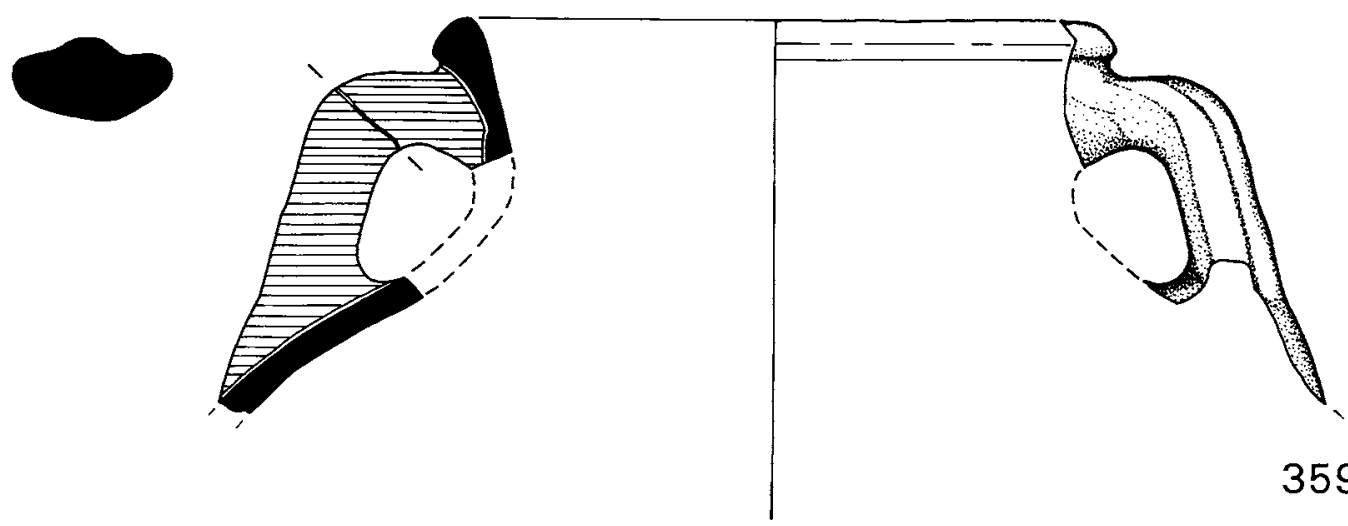

3595,3723
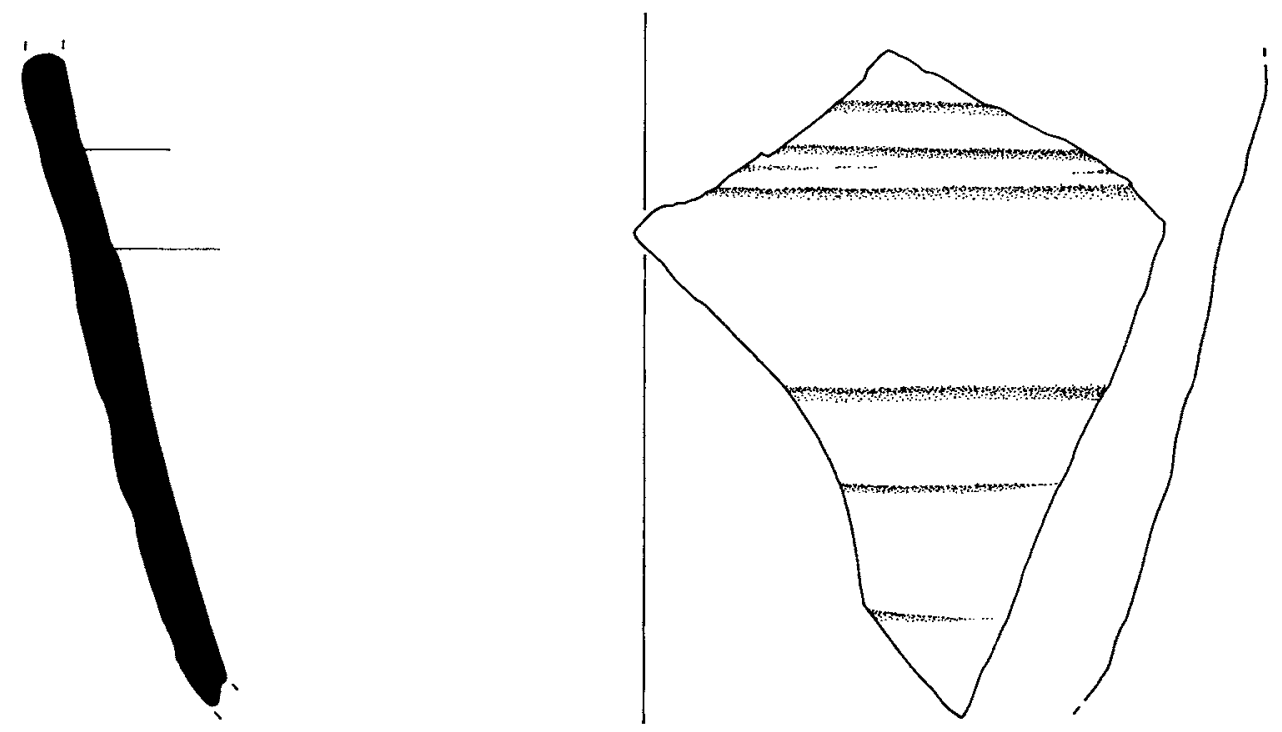

6072

130 Imported post-Roman ceramics: RFs 3595 (Bv rim/handle, 655/678), 3723 (Bv handle, 675) and 6072 (Bv conjoining, 722). Drawing: C Thorpe

Small numbers of the fine table-wares PRSW and ARSW have been noted from this area. Six sherds of PRSW were recovered, some 0.81 per cent of the entire assemblage, although none were diagnostic. Two sherds of ARSW were recovered, including one basal sherd RF 3900 (with part of a foot-ring) most likely of Hayes Form 50 bowl ${ }^{144}$ dating from $c$ AD 525-33.
Area $\mathrm{C} 15$ forms the largest single area opened on the Middle Terrace and was excavated to bedrock. Phase P, the natural shillet and scree, produced a single sherd of $\mathrm{Bi}$ amphora. Phase $\mathrm{R}$, described as a dump of material or possible surface, produced twenty sherds, all of which were post-Roman fifth- to seventh-century imported ware, five being $\mathrm{Bi}$, fourteen $\mathrm{Bv}$ and one unidentifiable. 
A single sherd of $\mathrm{Bi}$ was recovered from among the stones forming the paving of Phase $S$. Phase $T$ of dumped material forming a possible surface produced thirty sherds of both post-Roman fifth- to seventhcentury and Romano-British native wares. Rim sherd RF 6022 of Local ware was recovered from context 697 of this phase, and is from a jar with a simple everted rim. Although it is of a long-lived form the slack profile suggests a fourth-century date. It is clearly associated with seventeen B-ware amphora sherds of fifth- to seventh-century date. This could indicate that the rim may be redeposited or possibly was a form of native ware that continued in use into the fifth century. A similar vessel was recovered during excavations on the Lower Terrace of Site C. ${ }^{145}$

The traces of early occupation evidenced in Phase $U$ produced eighty-one sherds, the majority of which came from contexts 675 and 682 . The bulk of the pottery was post-Roman amphorae (all types being represented). A single rim-sherd of $\mathrm{D}$-ware was recovered from context 675. The presence of D-ware - rarely identified at Tintagel - represents a different branch of trade, that with the western coast of Gaul. Less than a handful of sherds have been recognized at Tintagel, ${ }^{146}$ and may perhaps represent a minor accompaniment to a trade in Gaulish wine supplied in casks. ${ }^{147}$

The collapse of the building is represented by two phases: $V$ and $W$. Phase $V$ produced eighty-nine sherds, all of which are from post-Roman imported wares. Bware amphorae (all but Biv being represented) formed the bulk, though a single basal sherd (RF 3900) of ARSW was recovered from context 687 . Phase $\mathrm{W}$ produced 333 sherds of both Romano-British native wares and postRoman fifth- to seventh-century imported wares. Five sherds of Romano-British Local ware, including the rim of a flanged bowl (RF 3609), were recovered, three from context 667 and two from context 669, while from context 655/678 (building collapse) came a single sherd of Romano-British Gabbroic ware. B-ware amphorae (all apart from Biv) formed the bulk of the remainder with only a few sherds of imported Coarseware (four sherds) being present. Much of this material was not in situ, but redeposited, as medieval pottery was also recovered from the scree-tips of this phase.

Radford's trenches and backfill across the site, Phase $\mathrm{X}$, produced seventy-nine sherds, all of which are postRoman imported wares. These were all redeposited. Phase $Y$, the scree slips subsequent to Radford's excavations, produced a further seventy sherds, while from the turf and topsoil, Phase Z, thirty-six sherds were recovered. All were post-Roman imported wares and redeposited.

It appears that the earliest features and make-up of the terrace were constructed while B-ware amphorae were already circulating on Tintagel, the RomanoBritish native wares being either residual, or possibly continuing in use into the fifth to seventh centuries $A D$, the former being the most likely. Finds of only postRoman and Romano-British wares from phases concerning ephemeral traces of the construction and occupation of a building at the south end of the Middle Terrace in the area of trench C15 clearly indicate that such activity took place during the post-Roman centuries. The subsequent layers of collapse and tipping scree that concealed these ephemeral building remains include medieval material in their make-up. It is most likely that all the post-Roman material in the scree-tips, like the medieval material, is derived from occupation material from the Upper Terrace above.

The near absence of Red Slipped Wares from the post-Roman occupation levels is significant. This was also observed from excavations on the Lower Terrace. ${ }^{148}$ Although this could be due to poor preservation conditions (even the sherd of ARSW was slightly abraded), it is more probable that this reflects the form of occupation on this particular terrace. Either the occupants did not have access to fine table-wares or perhaps these structures were devoted to the storage of amphorae.

The large number of sherds recovered add considerably to the assemblage already collected from the site since Radford's excavations. Many of the sherds from trench $\mathrm{C} 15$ were in good condition, with clean breaks, and of particular note are the rim, handle, neck and basal sherds of Bv amphorae used to further identify this form.

\section{Site C, Middle Terrace: Site C building}

A total of 591 sherds of imported fabrics were identified from this part of the site (see figures 127 and 131 for examples). The greatest concentration (404 sherds) was in $\mathrm{C} 09$ which included most notably deposits surviving below the area of Radford's spoil-heaps. The further breakdown of the numbers by phase and fabric type demonstrates clearly the dominance of amphora-type sherds over others, 427 of the total of 591, approximately 72.25 per cent (table 56). Of the imported sherds reported on here, 241 were identified as Bi amphora, 129 


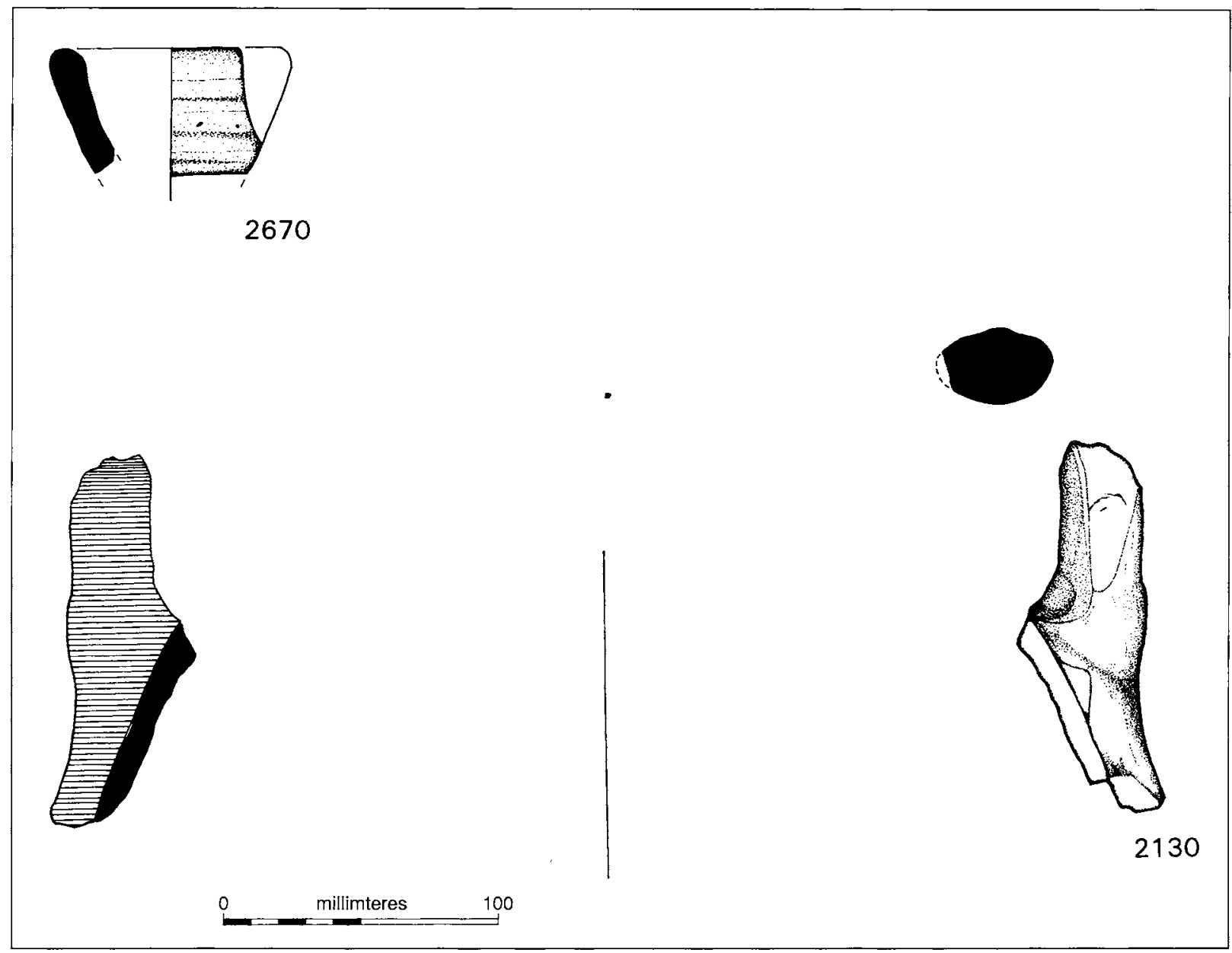

131 Imported Bi pottery: RFs 2130 and 2670 (C09). Drawing: C Thorpe

Table 56 Fabric types of imported pottery by phase, Site C building, Middle Terrace (summary)

\begin{tabular}{|c|c|c|c|c|c|c|c|c|c|c|}
\hline \multicolumn{11}{|c|}{ Trench C09 404 sherds } \\
\hline Phase & Unknown & $B i$ & $B i i$ & Biv & $B v$ & Fabric 1 & Fabric 5 & PRSW & ARSW & Total \\
\hline $\mathrm{T}$ & 1 & 4 & 16 & - & 2 & 3 & - & 2 & - & 28 \\
\hline $\mathrm{U} 1$ & - & 4 & - & - & 1 & - & - & - & - & 5 \\
\hline $\mathrm{U} 2$ & 3 & 29 & 12 & 1 & 5 & 2 & - & 2 & - & 54 \\
\hline $\mathrm{V}$ & - & 5 & - & - & - & - & - & - & - & 5 \\
\hline W & 41 & 118 & 32 & - & 32 & 1 & 2 & 1 & 1 & 228 \\
\hline $\mathrm{X}$ & - & 3 & 4 & - & 1 & - & - & - & 1 & 9 \\
\hline $\mathrm{Y}$ & 1 & 7 & 5 & - & 1 & 5 & - & 1 & - & 20 \\
\hline $\mathrm{Z}$ & 5 & 15 & 7 & - & - & 4 & 1 & - & - & 32 \\
\hline $\mathrm{u} / \mathrm{s}$ & 6 & 8 & 9 & - & - & - & - & - & - & 23 \\
\hline Overall & 57 & 193 & 85 & 1 & 42 & 15 & 3 & 6 & 2 & 404 \\
\hline
\end{tabular}




\begin{tabular}{|c|c|c|c|c|c|c|c|c|c|c|}
\hline \multicolumn{11}{|c|}{ Trench C10 114 sherds } \\
\hline Phase & Unknown & $B i$ & $B i i$ & Biv & $B v$ & Fabric 1 & Fabric 5 & PRSW & $A R S W$ & Total \\
\hline $\mathrm{Y}$ & 34 & 20 & 15 & 2 & 4 & 12 & - & 3 & - & 90 \\
\hline $\mathrm{X}$ & 3 & 8 & 5 & 1 & - & 2 & - & - & - & 19 \\
\hline $\mathrm{T}$ & 1 & 1 & 2 & - & - & - & - & 1 & - & 5 \\
\hline Overall & 38 & 29 & 22 & 3 & 4 & 14 & - & 4 & - & 114 \\
\hline
\end{tabular}

\section{Trench C11 33 sherds}

\begin{tabular}{|c|c|c|c|c|c|c|c|c|c|c|}
\hline Phase & Unknown & $B i$ & $B i i$ & $B i v$ & $B v$ & Fabric 1 & Fabric 5 & PRSW & $A R S W$ & Total \\
\hline $\mathrm{T}$ & - & 1 & 1 & - & - & - & - & - & 8 & 10 \\
\hline $\mathrm{X}$ & - & 2 & - & - & - & - & - & - & - & 2 \\
\hline$Y$ & 8 & 8 & 4 & - & - & - & - & 1 & - & 21 \\
\hline Overall & 8 & 11 & 5 & - & - & - & - & 1 & 8 & 33 \\
\hline \multicolumn{11}{|c|}{ Trench C12 4 sherds } \\
\hline Phase & Unknown & $B i$ & $B i i$ & $B i v$ & $B v$ & Fabric 1 & Fabric 5 & PRSW & $A R S W$ & Total \\
\hline $\mathrm{T}$ & - & - & 2 & - & - & - & - & - & - & 2 \\
\hline $\mathrm{Y}$ & 1 & 1 & - & - & - & - & - & - & - & 2 \\
\hline Overall & 1 & 1 & 2 & - & - & - & - & - & - & 4 \\
\hline
\end{tabular}

Trench C13 1 sherd

Phase Unknown Bi Bii Biv Bv Fabric 1 Fabric 5 PRSW ARSW Total

\begin{tabular}{|c|c|c|c|c|c|c|c|c|c|c|}
\hline $\mathrm{T}$ & - & - & 1 & - & - & - & - & - & - & 1 \\
\hline Overall & - & - & 1 & - & - & - & - & - & - & 1 \\
\hline
\end{tabular}

Trench C16 35 sherds

\begin{tabular}{|c|c|c|c|c|c|c|c|c|c|c|}
\hline Phase & Unknown & $B i$ & $B i i$ & Biv & $B v$ & Fabric 1 & Fabric 5 & PRSW & $A R S W$ & Total \\
\hline $\mathrm{T}$ & - & 2 & 14 & 2 & 1 & - & - & - & - & 19 \\
\hline V & 3 & - & - & - & - & - & - & - & - & 3 \\
\hline W & 4 & 4 & - & - & 4 & - & - & - & - & 12 \\
\hline Z & - & 1 & - & - & - & - & - & - & - & 1 \\
\hline Overall & 7 & 7 & 14 & 2 & 5 & - & - & - & - & 35 \\
\hline
\end{tabular}

Cumulative totals

\begin{tabular}{lllllllllll} 
& Unknown & $B i$ & Bii & Biv & Bv & Fabric 1 & Fabric 5 & PRSW & ARSW & Total \\
\hline \multirow{2}{*}{ percent } & 111 & 241 & 129 & 6 & 51 & 29 & 3 & 11 & 10 & 591 \\
\hline & 18.78 & 40.78 & 21.83 & 1.02 & 8.63 & 4.91 & 0.51 & 1.86 & 1.69 & 100 \\
\hline
\end{tabular}


as Bii, six as Biv and fifty-one as Bv. The large quantity of amphora sherds in relation to the fine table-wares and indeed coarse table- or kitchen-wares is a reflection on the proportions of imported material in use on this part of the site. It is, however, also a reflection on the size of the storage vessels in relation to the table-wares, since each amphora has the potential to break into a considerable number of sherds (and as has been shown in these excavations, several of these can be almost hand-sized), whereas the finer wares are of smaller size. Computation of actual vessel numbers is difficult because most of the sherds are medium to small in size, and in no case was it possible to reconstruct a full profile. What is clear, however, is that the imported fine wares are very few in number, only twenty-one in this assemblage (3.55 per cent): ARSW (ten sherds) and PRSW (eleven sherds). In addition, two coarse fabric types were recognized in small numbers (Fabric 1, twenty-nine sherds; Fabric 5, three sherds). All fabrics originate in the Eastern Mediterranean or North Africa. A further category of ceramic material, 111 sherds in all, has not been identifiable to type, a high percentage (18.78 per cent) of the total figure. This is clearly exacerbated by the fact that so many of the sherds are from scree deposits, and probably redeposited in many cases, which has led to considerable abrasion and removal of distinguishing elements.

The construction and occupation of the Middle Terrace took place during the fifth to seventh centuries, with the collapse and concealment of the building on Site $\mathrm{C}$ beneath a scree overburden which incorporated medieval material. It is most likely that all the postRoman material in the scree-tips is derived from occupation material on the Upper Terrace above. The near absence of Red Slipped Wares from the postRoman occupation levels is significant, although those from the Radford backfill presumably related to the trenches in question. This situation was mirrored on the Lower Terrace. ${ }^{149}$ This under-representation could be due to poor preservation conditions, but it is more probable that it reflects the form of occupation on this particular terrace. Either the occupants did not have access to fine table-wares or perhaps these structures were devoted to the storage of amphorae.

\section{Site T: the Great Ditch, trench T01}

The distribution of imported ceramics through the phases in trench T01 can be seen in Table 57. The earliest phase represented was Phase U, contexts 1117 and 1143, described as being part of the cutting of the Great Ditch and modification of the banks. These produced four sherds, all of which were post-Roman fifth- to seventhcentury imported ware, although all were small and too heavily abraded to be readily identifiable.

The primary infilling of the Great Ditch has been divided into two phases. Phase V1 produced two contexts that yielded pottery. Context 1140 contained a single unidentifiable sherd of B-ware while four sherds were recovered from 1144 including $\mathrm{Bi}$ amphora and ARSW. Phase V2 was represented by three contexts that produced pottery, 1151, 1153 and 1156. From these sixteen sherds of post-Roman fifth- to seventh-century wares were retrieved including $\mathrm{Bi}, \mathrm{Bv}$ and a single sherd of Coarseware Fabric 1.

Phase $\mathrm{W}$, representing the post-Castle fill of the ditch and collapse evident on the north bank, produced fourteen sherds of post-Roman fifth- to seventh-century imported wares. All of this material was redeposited and consisted of Bii amphora, as well as the Bi and Bv already identified in earlier phases. Radford's trenches and backfill across the site, Phase X, produced five sherds, four $\mathrm{Bi}$ and one Biv. These were also all redeposited.

The defensive nature of the post-Roman occupation of Tintagel has been further emphasized. The presence of post-Roman ceramics in the primary ditch-fills demonstrates that the Great Ditch was in existence (if not actually dug) during the post-Roman period.

\section{Site T: the Lower Ward, trench T01 ext}

The distribution of Romano-British and imported ceramics through the phase of trench T01 ext is demonstrated in Table 58. The trench was excavated to what appeared to be natural shillet and clays. The earliest phase that produced pottery was Phase W, representing various pre-Norman Castle features and deposits. It produced fourteen sherds of post-Roman fifth- to seventh-century date and a single sherd of Romano-British Local ware (in a highly abraded condition and probably redeposited). The bulk of this is from amphorae (excluding Biv or $\mathrm{Bv}$ ), although one sherd of ARSW was recovered from context 1135. This latter was small in size and heavily abraded, and thus probably redeposited from elsewhere.

Phase $\mathrm{X}$, representing the terrace levelling and Castle construction, produced twenty-two sherds of pottery, all of it post-Roman imported wares, the majority being Bware amphorae (all types are represented). There was one small heavily abraded body sherd of ARSW from 
Table 57 Imported pottery from trench T01, Great Ditch, Site T by fabric and context

\begin{tabular}{|c|c|c|c|c|c|c|c|c|c|c|}
\hline \multicolumn{11}{|c|}{ Trench T01 44 sherds } \\
\hline Context & $\begin{array}{l}\text { Unknown } \\
\text { B-ware }\end{array}$ & $B i$ & $B i i$ & $B i v$ & $B v$ & Fabric 1 & PRSW & $A R S W$ & Phasing & Total \\
\hline 1081 & - & 3 & - & 1 & - & - & - & - & $\mathrm{X}$ & 4 \\
\hline 1108 & 1 & - & - & - & - & - & - & - & W & 1 \\
\hline 1110 & 1 & - & - & - & - & - & - & - & W & 1 \\
\hline 1111 & 1 & - & - & - & 1 & - & - & - & W & 2 \\
\hline 1117 & 3 & - & - & - & - & - & - & - & $\mathrm{U}$ & 3 \\
\hline 1118 & - & 1 & - & - & - & - & - & - & W & 1 \\
\hline 1120 & 2 & 1 & 1 & - & - & - & - & - & $\mathrm{W}$ & 4 \\
\hline 1126 & 5 & - & - & - & - & - & - & - & W & 5 \\
\hline 1140 & 1 & - & - & - & - & - & - & - & $\mathrm{V} 1$ & 1 \\
\hline 1143 & - & 1 & - & - & - & - & - & - & $\mathrm{U}$ & 1 \\
\hline 1144 & 1 & 2 & - & - & - & - & - & 1 & $\mathrm{Vl}$ & 4 \\
\hline 1145 & - & 1 & - & - & - & - & - & - & $\mathrm{X}$ & 1 \\
\hline 1151 & 1 & 6 & - & - & - & - & - & - & $\mathrm{V} 2$ & 7 \\
\hline 1153 & 2 & 1 & - & - & 2 & - & - & - & $\mathrm{V} 2$ & 5 \\
\hline 1156 & - & 3 & - & - & - & 1 & - & - & $\mathrm{V} 2$ & 4 \\
\hline \multicolumn{11}{|c|}{ Cumulative totals } \\
\hline & Unknown & $B i$ & $B i i$ & Biv & $B v$ & Fabric 1 & PRSW & ARSW & & Total \\
\hline & 18 & 19 & 1 & 1 & 3 & 1 & - & 1 & & 44 \\
\hline per cent & 40.91 & 43.18 & 2.27 & 2.27 & 6.82 & 2.27 & - & 2.27 & & \\
\hline
\end{tabular}

context 1131, which was obviously not in situ. Radford's trenches and backfill (Phase $\mathrm{Y}$ ) produced thirty sherds all post-Roman, imported B-wares, all redeposited.

It appears that the earliest feature was cut while Bware amphorae were already circulating on Tintagel, with the Romano-British native ware most likely to be residual if not continuing in use into the fifth to seventh centuries AD. The levelling of the terrace and construction of the Castle during the medieval period included post-Roman material within its make-up. It is most likely that all this material was derived from occupation material on the terrace forming the Lower Ward.

The early radiocarbon date of cal AD $340-530$ at 95 per cent confidence level (refined to cal AD 390-430 at 68 per cent confidence) for the Phase $W$ deposit 1135 from T01 ext inside the Lower Ward, from which both a sherd of ARSW (RF 4330) and two sherds of Bi and six sherds of Bii amphorae were recovered, is most intriguing. ARSW is usually dated to the sixth century $\mathrm{AD}$ on the basis of the forms found, and $\mathrm{Bi}$ and $\mathrm{Bii}$ amphorae to the mid-fifth to mid-sixth century, but this is not true of all forms. At least one form of ARSW bowl found at Tintagel, Form 96, can be dated to $c \mathrm{AD} 470,{ }^{150}$ although a range of $c \mathrm{AD} 490-575$ has also been given. ${ }^{151}$

\section{Conclusion}

The excavations have confirmed that it is likely that imported material was coming in to Tintagel in some quantity from around $\mathrm{AD} 450$ onwards, with the bulk $c$ AD 500-550. On the Lower Terrace, however, imported material was associated with structures and features that exhibited two phases of occupation, the first dated with modelling to cal AD 415-535 (95 per cent confidence), the second to cal AD 560-670 ( 95 per cent confidence). ${ }^{152}$ This radiocarbon date from the second phase of occupation on the Lower Terrace of Site $\mathrm{C}$ is much later than expected for the end of importation into Tintagel ( $c \mathrm{AD} 570$ ). Evidence from Carthage and elsewhere shows that production of this pottery (for most of the wares found at Tintagel) did indeed continue into the seventh century, ${ }^{153}$ but the generally accepted view has been that 
Excavations at Tintagel Castle, Cornwall, 1990-9

Table 58 Imported pottery from trench T01 ext, Lower Ward, Site T by fabric and context

\begin{tabular}{|c|c|c|c|c|c|c|c|c|c|c|}
\hline \multicolumn{11}{|c|}{ Trench T01 ext 66 sherds } \\
\hline Context & \multicolumn{9}{|l|}{$B$-ware } & Total \\
\hline 1083 & 5 & 6 & - & 1 & 1 & - & - & - & $\mathrm{Y}$ & 13 \\
\hline 1085 & - & 1 & - & - & - & - & - & - & $\mathrm{Y}$ & 1 \\
\hline 1097 & 2 & 1 & - & - & - & - & - & - & $\mathrm{Y}$ & 3 \\
\hline 1099 & - & 1 & - & - & - & - & - & - & $\mathrm{Y}$ & 1 \\
\hline 1100 & - & 2 & - & 1 & - & - & - & - & $\mathrm{Y}$ & 3 \\
\hline 1102 & 1 & - & - & - & - & - & - & - & $\mathrm{Y}$ & 1 \\
\hline 1104 & - & 1 & - & - & - & - & - & - & $\mathrm{Y}$ & 1 \\
\hline 1106 & 2 & - & - & - & - & - & - & - & $\mathrm{Y}$ & 2 \\
\hline 1107 & 3 & - & - & 1 & - & - & - & - & $\mathrm{Y}$ & 4 \\
\hline 1125 & - & 1 & - & - & - & - & - & - & $\mathrm{Y}$ & 1 \\
\hline 1129 & - & 4 & - & 1 & - & - & - & - & $\mathrm{X}$ & 5 \\
\hline 1130 & - & 3 & 2 & - & - & - & - & - & $\mathrm{X}$ & 5 \\
\hline 1131 & - & 11 & - & - & - & - & - & 1 & $\mathrm{X}$ & 12 \\
\hline 1132 & - & 4 & 1 & - & - & - & - & - & W & 5 \\
\hline 1135 & - & 2 & 6 & - & - & - & - & 1 & W & 9 \\
\hline \multicolumn{11}{|c|}{ Cumulative totals } \\
\hline & Unknown & $B i$ & $B i i$ & $B i v$ & $B v$ & Fabric 1 & PRSW & $A R S W$ & & Total \\
\hline & 13 & 37 & 9 & 4 & 1 & - & - & 2 & & 66 \\
\hline per cent & 19.70 & 56.06 & 13.64 & 6.06 & 1.51 & - & - & 3.03 & & 100 \\
\hline
\end{tabular}

this trade into Britain had ceased by the end of the sixth century.

The most numerous sherds are of amphorae of varying categories ( $\mathrm{Bi}, \mathrm{Bii}, \mathrm{Biv}$ and $\mathrm{Bv}$ ), which were accompanied by two types of fine table-wares, ARSW and PRSW, and several Coarsewares (first identified in 1988 by Thomas and Thorpe). The remarkable nature of the post-Roman occupation of Tintagel has been further demonstrated by this excavation, despite the comparatively small area opened. The substantial quantity of post-Roman imported ceramics recovered during these excavations, some 1,821 sherds in total (excluding Lower Terrace (128) and the Steps area (286 plus indeterminates)), dwarfs the quantity and exceeds in range of fabrics those from larger excavation areas such as Dinas Powys (256 sherds), South Cadbury (163 sherds) and settlements such as Whithorn (220 sherds). ${ }^{154}$

Although 159 sherds were recovered in the course of excavating the Upper Terrace of Site C, which included the entire range of vessel types with the exception of Biv amphora, the greatest concentration of material (1,556 sherds) was retrieved from the Middle Terrace of Site C. All categories of vessel types were observed, being associated with at least two phases of structural activity. At Tintagel overall, so far, the fragmentary remains of well over 150 amphora of all types, and 80 of fine tablewares, as well as numerous Coarseware vessels, have been recovered. ${ }^{155}$ This almost certainly involved more than one voyage in the period $A D$ 500-600. Each shipment was probably heterogeneous in character, with cargo being collected at more than one port in the Eastern Mediterranean and North Africa (see discussion below by $\mathrm{R}$ Jones). Indeed the chemical results suggest considerable complexity in terms of origins of the amphorae: $\mathrm{Bv}$ coming from Tunisia and probably southern Spain, but also the eastern Aegean; Bi probably from the Aegean and the origins of Bii somewhat of a mystery (see $\mathrm{R}$ Jones below). It is clear that the amphorae were imported for their contents, some vessels having 
been recycled to carry secondary commodities. Several discoidal amphora-stoppers, which originally fitted the seal of the neck of the vessels during shipment, have been recognized (eg RFs 2004, 2666 and 3380: see figure 114). This trade would not have been one way; it is uncertain what would have been exchanged, but Cornish tin would seem an obvious candidate. It must, surely, be in this context that the find of at least forty tin ingots (weighing a total of $84.67 \mathrm{~kg}$ ) from Bigbury Bay, on the south Devon coast, must be seen. ${ }^{156}$ The fact that Tintagel was at the end of this complex trade route suggests that the occupants would have wielded far-reaching influence during the fifth to seventh centuries $\mathrm{AD}$.

There seems to be some support for spatial differentiation in the use of or status of areas and buildings within the citadel of Tintagel as proposed by Charles Thomas. ${ }^{157}$ It is distinctly noticeable that the fine high quality red slipped table-wares (both ARSW and PRSW) are absent from both the Upper Terrace and the Lower Terrace (except as a rare abraded element in later scree deposits), and are scarce from the Middle Terrace Site C structures, especially when compared to the large number (about thirteen vessels) found in Radford's small-scale (approximately $1 \mathrm{~m}^{2}$ ) excavation at Site $Z^{158}$ below the Great Hall of the later thirteenth-century Castle (the site that is believed to be the nucleus of the post-Roman citadel). This lack of fine table-wares from Site $\mathrm{C}$ may be due to the vagaries of site preservation resulting in a poor representation of this material in the record, but is more likely to be a reflection of the use of the area. The lack of these fine wares may suggest that these structures were for the storage of amphora, that they involved some sort of occupational activity that heavily depended on the use of amphora or that the occupants of these structures did not have access to the use of fine table-wares (perhaps being of low social status or servants).

Finally, the ceramic evidence (forty-four sherds) has confirmed that the Great Ditch on the mainland side of the complex was in existence (if not actually cut) in the post-Roman period, and cut across the narrow isthmus. This provided a landward defensive boundary, defining a citadel comparable to known post-Roman citadels such as Dunadd, Cadbury Congresbury or South Cadbury. In addition, excavation within the 'Lower Ward' (Site T) produced sixty-six sherds representing most categories of vessel. At least some were associated with features dated to cal AD 390-430 (68 per cent confidence) and clearly indicative of pre-Castle occupation.

\section{CERAMICS: CHEMICAL AND ORGANIC RESIDUE ANALYSIS OF TYPES BI, BII AND BV AMPHORAE FROM TINTAGEL by Richard Jones}

The relatively frequent finds of some of the B-type amphorae - Bi (Late Roman Amphora 2: Peacock and Williams form 43), Bii (Late Roman Amphora 1: Peacock and Williams form 44) and $B v$ (North African type: Peacock and Williams forms 33-5) ${ }^{159}$ - from the recent excavations at Tintagel reported here presented a valuable opportunity, first, to shed further light on their probable origins by characterizing the fabrics chemically and, second, to investigate their contents.

The petrographic approach to fabric characterization of amphorae is well known and has been much used, ${ }^{160}$ but it was decided to begin the characterization process in this study with chemical analysis. The reasons for this were practical, the main one being that the writer had greater access to chemical reference data than to comparative thin sections. Petrographic analysis together, where possible, with colour close-up photographs of the fabrics, will feature in the next stage of the study, and its results will be presented separately. ${ }^{161}$ This point is taken up further in the discussion below.

The scope of the chemical study needs to be clearly defined at the outset. As a first step, chemical characterization can act as a valid check on the typological assignments, bearing in mind that a particular amphora type may have been produced at more than one centre. Second, classification of the chemical data can reveal associations between individual amphorae. Only at a third stage can comment be made about the possible origin of a chemically defined amphora group. This latter step is the hardest to confront in view of the absence of a comprehensive, uniformly obtained chemical database of known late Roman amphora kiln sites around the Mediterranean. In this situation, the present study has adopted a pragmatic approach: for comparative purposes, it uses available reference data at a first level for amphora production sites and at a second level for contemporary related pottery classes such as Sigillata. At a third level, it draws on the data for pottery of earlier or later data but from the same general locality in order to give a guide to the range of compositions expected in the clays from that locality. As explained below, while the geographical range of the amphora reference sites is wide, the depth 
of coverage is limited and there are many gaps; furthermore, there is an inherent bias in this study towards those areas of the Mediterranean that are currently believed to be relevant to $\mathrm{Bi}$, Bii and Bv production.

Turning to the organic residue analysis, an exploratory study by gas chromatography (GC) was undertaken on six sherds with a view to assessing whether any residue remained, and if so the broad identity of that residue. Three sherds were from $\mathrm{Bi}$ and two from Bv amphorae; there is still little consensus on the contents of the former type although wine or olive oil are likely candidates. North African (Bv) amphorae, on the other hand, probably carried mainly olive oil but, in the light of recent work, other commodities as well. ${ }^{162}$ There was one unclassified B amphora. Finally, there was an analysis of a black coating (possibly dipinti) on one amphora fragment.

\section{CHEMICAL CHARACTERIZATION}

Table 59 lists the thirty-eight type B amphorae sherds, covering types $\mathrm{Bi}, \mathrm{Bii}$ and $\mathrm{Bv}$, selected for analysis by Carl Thorpe. The sherds, which were variable in size, included some from diagnostic parts of the amphora, as indicated in Table 59. For the majority of sherds, fabric descriptions and colour estimations (table 60) were made on a fresh break with a $\times 15$ magnifier, using, with some modifications, the system outlined by Tomber and Dore. ${ }^{163}$ It should be noted that the sherds had not been

Table 59 The samples analysed chemically

\begin{tabular}{llll}
\hline Type Bi & Type Bii & Type Bv & Type B \\
\hline 1777 & $1738^{*}$ & 2616 & 2654 \\
2130 & $1751^{*}$ & 2618 & 3457 \\
$2290^{*}$ & 2000 & $2648^{*}$ & \\
3519 & $3650^{*}$ & 2914 & \\
3589 & 3663 & 3426 & \\
3683 & 3744 & 3591 & \\
3721 & 3962 & 3667 & \\
3816 & & $3680^{*}$ & \\
3861 & & 3689 & \\
3977 & & 3720 & \\
$6030^{*}$ & & $3875^{*}$ & \\
6037 & & 3876 & \\
6038 & & 6021 & \\
6081 & & $6072^{*}$ & \\
& & 6079 &
\end{tabular}

* denotes a shape-diagnostic sherd washed prior to sampling owing to the abraded, fragile condition of their surfaces.

A fragment from each sherd was sawn off, cleaned and crushed to give at least $1 \mathrm{~g}$ of powder. Following heat treatment at 450 degrees Centigrade for four hours, the samples were dissolved in acid prior to analysis by inductively coupled plasma emission spectroscopy (ICPES) at the Department of Geology, Royal Holloway College, University of London. ${ }^{164}$ The compositions are set out in Appendix 1.

In assembling the reference data (table 61; see Appendix 2), account was taken of the expected or proposed source areas: $\mathrm{Bi}$ (Late Roman 2) in the Aegean, ${ }^{165}$ Bii (Late Roman 1) in the Eastern Mediterranean ${ }^{166}$ and Bv in North Africa. ${ }^{167}$ On the one hand, there was published reference data that was at least relevant typologically and chronologically to the test samples; this data set, although obtained at different times and by different analytical techniques, was valuable in giving a good indication of the range of compositions expected for clays used for amphora production at the site or locality concerned. Much of the North Tunisian data fell into this category. ${ }^{168}$ On the issue of comparability of that reference data with the compositions of the test samples, the writer has recently assessed a large corpus of chemical data for Mediterranean pottery obtained from inter-laboratory and inter-technique comparisons: the agreement is satisfactory so long as data generated by different techniques are compared element by element and not combined for the purposes of sophisticated multivariate statistical treatment. ${ }^{169}$ On the other hand, some reference data - for Chios and Seleucia of Pieria in Cilicia ${ }^{170}$ - was prepared specifically for this study and so could be more systematically compared with the compositions of the test samples. The Aegean is represented by a seventh-century amphora kiln site at Kounoupi on the east coast of the Peloponnese, ${ }^{171}$ a late Roman amphora kiln in Chios Town, ${ }^{172}$ and local pottery at Phocaea (Roman) and Pergamon (Byzantine). Recourse was also made, where relevant, to the corpus of chemical data for Aegean pottery mainly of pre-Roman date. ${ }^{173}$ Moving to the Sea of Marmara, the important recent discoveries in the form of extensive evidence of large-scale amphora production at Ganos, dated to the seventh century and later, have been recognized in this study. ${ }^{174} \mathrm{~A}$ single chemical 'marker' has been adopted for the western Black Sea, using data for Istria. Some data sets, such as those for amphorae found at Iesso 
Table 60 Fabric descriptions

\begin{tabular}{|c|c|c|}
\hline Type & Colour & Fabric \\
\hline \multicolumn{3}{|c|}{ Type Bi } \\
\hline 1777 & 5 YR $7 / 11$ pink & Like 3721 below \\
\hline 2290 & $\begin{array}{l}5 \mathrm{YR} 7 / 6-6 / 8 \\
\text { reddish-yellow }\end{array}$ & $\begin{array}{l}\text { Hard well-fired fabric. Common inclusions are poorly sorted, most of them white } \\
\text { calcareous and sub-angular to sub-rounded size up to } 1 \mathrm{~mm} \text {. Very occasional gold } \\
\text { mica. Several small elongate voids size up to } 1 \mathrm{~mm} \text { long due to burnt out calcareous } \\
\text { grains. Common small quartz grains. Sparse orange sub-rounded siltstone or textural } \\
\text { concentration features up to } 1.5 \mathrm{~mm} \text { long but usually smaller }\end{array}$ \\
\hline 3519 & $2.5 \mathrm{YR} 4 / 8 \mathrm{red}$ & $\begin{array}{l}\text { Evenly fired; moderate hardness. Sparse black and pale inclusions up to } 0.4 \mathrm{~mm} \text { of } \\
\text { irregular shape. Common scatter of much smaller inclusions mainly quartz. Few voids. } \\
\text { No mica }\end{array}$ \\
\hline 3683 & $\begin{array}{l}2.5 \text { YR } 5 / 8 \\
\text { brown red }\end{array}$ & $\begin{array}{l}\text { Distinctive are the common white calcareous inclusions up to } 1 \mathrm{~mm} \text {. Sparse dark grits. } \\
\text { Common small quartz. Small voids }\end{array}$ \\
\hline 3721 & $\begin{array}{l}5 \text { YR } 7 / 6-6 / 6- \\
2.5 \text { YR } 6 / 8 \\
\text { orange red }\end{array}$ & $\begin{array}{l}\text { Evenly fired. Very similar to } 3977 \text {; quite hard fabric. Sparse small sub-angular dark and } \\
\text { red grits up to } 0.6 \mathrm{~mm} \text {. Sparse quartz grains of irregular shape up to } 1 \mathrm{~mm} \text {. But } \\
\text { common quartz grains of smaller size. Common very fine gold mica }\end{array}$ \\
\hline 3816 & $2.5 \mathrm{YR} 5 / 8 \mathrm{red}$ & $\begin{array}{l}\text { Evenly fired; quite hard. Large (up to } 2 \mathrm{~mm} \text { ) calcareous inclusions with frequent small } \\
\text { voids. Some larger voids, some associated with black grits }\end{array}$ \\
\hline 3861 & $\begin{array}{l}7.5 \mathrm{YR} 7 / 6 \\
\text { reddish-yellow }\end{array}$ & $\begin{array}{l}\text { Sandy fabric. Sparse quartz grains of irregular shape up to } 0.5 \mathrm{~mm} \text {, and sparse red } \\
\text { sub-rounded grains of same size. Distinctive are black ghost remains/voids }\end{array}$ \\
\hline 3977 & $\begin{array}{l}5 \text { YR } 7 / 6-6 / 6- \\
2.5 \text { YR } 6 / 8 \\
\text { orange red }\end{array}$ & $\begin{array}{l}\text { Distinctive fabric; hard; common large irregular-sized quartz, poorly sorted up to } \\
0.8 \mathrm{~mm} \text {. Some quartzite; few laminate-like voids parallel to wall. Sparse gold mica and } \\
\text { rounded to sub-rounded dark inclusions. Very similar to } 3721\end{array}$ \\
\hline 6030 & $\begin{array}{l}2.5 \text { YR } 6 / 8 \\
\text { light red }\end{array}$ & Similar to 2290 \\
\hline 6038 & $2.5 \mathrm{YR} 5 / 8 \mathrm{red}$ & $\begin{array}{l}\text { Evenly fired. Sparse large white calcareous inclusions up to } 1 \mathrm{~mm} \text {. Frequent well-sorted } \\
\text { small quartz. Common dark small inclusions. Some linear voids parallel to side of the } \\
\text { sherd }\end{array}$ \\
\hline 6081 & $\begin{array}{l}10 \text { YR } 7 / 4 \\
\text { very pale brown }\end{array}$ & $\begin{array}{l}\text { Solid, well fired. Common moderately sorted quartz. Sparse white calcareous } \\
\text { sub-angular inclusions up to } 1 \mathrm{~mm} \text {, and round red pellets up to } 0.2 \mathrm{~mm} \text {. Distinctive are } \\
\text { (a) the dark ghosts of the ?red inclusion being burnt out, and (b) the common narrow, } \\
\text { thin small voids aligned parallel to side of sherd. Sparse gold mica }\end{array}$ \\
\hline
\end{tabular}

Type Bii

1738

1751

3650

3663

3744

3962

Type Bv 2616
2.5 YR 5/8 red

5 YR $7 / 4$ pink

5 YR 6/6 reddish-yellow 2.5 YR $5 / 8$ to $10 \mathrm{R} 5 / 8 \mathrm{red}$

7.5 YR 7/6-6/6

5 YR $6 / 6$ reddish-yeilow
Very light weight; common scatter of red, black and white calcareous inclusions up to $0.5 \mathrm{~mm}$; well-sorted. Sparse gold mica

Evenly fired. See 3650

Common small quartz giving speckled effect. Common very small voids. Sparse gold mica

Red 'metamorphic' fabric. Well fired but not hard. Sparse red mica and small schistlike fragments up to $0.5 \mathrm{~mm}$ long. Common quartz grains of uniform size. Rare voids Resembles 1738

Evenly fired; resembles 1751 in sandy texture. Common black and red grits of uniform size up to $0.2 \mathrm{~mm}$, but some up to $0.6 \mathrm{~mm}$. Frequent voids

Sparse large $(2 \mathrm{~mm})$ quartz and large red grits. Common very small white calcareous and darker grits. Small voids 


\begin{tabular}{|c|c|c|}
\hline Type & Colour & Fabric \\
\hline 2618 & $\begin{array}{l}5 \text { YR } 6 / 6 \\
\text { reddish-yellow }\end{array}$ & $\begin{array}{l}\text { Common small inclusions up to } 0.2 \mathrm{~mm} \text {. Less common are red ?quartz grains of } \\
0.5 \mathrm{~mm} \text { size. Few examples of red grains that have burnt out. Spare gold mica. Few } \\
\text { angular voids }\end{array}$ \\
\hline 2648 & $\begin{array}{l}10 \text { YR } 7 / 4 \\
\text { very pale brown }\end{array}$ & See 6081 above, Type Bi \\
\hline 2914 & $\begin{array}{l}5 \mathrm{YR} 6 / 6 \\
\text { reddish-yellow }\end{array}$ & $\begin{array}{l}\text { Like } 2616 \text { but more common red grits among the larger inclusions; no large quartz. } \\
\text { Same small white calcareous inclusions }\end{array}$ \\
\hline 3591 & $\begin{array}{l}7.5 \text { YR } 6 / 4 \\
\text { light brown }\end{array}$ & $\begin{array}{l}\text { Sandy soft feel. Common very fine quartz. Visible inclusions are sparse mica, few dark } \\
\text { rounded inclusions that have partly burnt out, and very sparse of micaceous fragment } \\
0.8 \mathrm{~mm} \text {. Few small elongate voids }\end{array}$ \\
\hline 3667 & $\begin{array}{l}10 \text { YR } 6 / 4 \\
\text { light yellowish- } \\
\text { brown }\end{array}$ & $\begin{array}{l}\text { Sandy feel. Speckled with small dark grits. Common small quartz; sparse larger orange } \\
\text { grains. Distinctive are many small rounded voids. Very sparse gold mica }\end{array}$ \\
\hline 3680 & $\begin{array}{l}10 \text { YR } 7 / 4 \mathrm{v} \\
\text { pale brown }\end{array}$ & $\begin{array}{l}\text { Similar to } 3875 \text { but more dark inclusions and many more voids from the calcareous } \\
\text { material }\end{array}$ \\
\hline 3720 & $\begin{array}{l}5 \text { Y } 7 / 8 \\
\text { yellowish-red }\end{array}$ & $\begin{array}{l}\text { Well fired, but sandy feel. Common small }(<0.1 \mathrm{~mm}) \text { quartz grains; less common red } \\
\text { and calcareous inclusions. Sparse grains of large inclusions }(1 \mathrm{~mm}) \text { of irregular shape }\end{array}$ \\
\hline 3875 & $\begin{array}{l}10 \text { YR } 7 / 4 \\
\mathrm{v} \text { pale brown }\end{array}$ & $\begin{array}{l}\text { Well fired, but soft feel. Common poorly sorted quartz. Sparse small silver mica. } \\
\text { Distinctive are the red rounded to angular reddish iron oxide grains up to } 1 \mathrm{~mm} \text { long, } \\
\text { some of them having decayed leaving a hollowed-out shell. Sparse black small } \\
(0.1 \mathrm{~mm}) \text { grains }\end{array}$ \\
\hline 6021 & & $\begin{array}{l}\text { Sandy, well fired. Sparse large mainly quartz grains and dark grains } c 1 \mathrm{~mm} \text {. Common } \\
\text { small quartz and dark grains. Few small voids. Rare mica }\end{array}$ \\
\hline 6072 & $\begin{array}{l}10 \mathrm{YR} 7 / 4 \mathrm{v} \\
\text { pale brown }\end{array}$ & See 3875 \\
\hline 6079 & $\begin{array}{l}2.5 \text { YR } 7 / 6 \\
\text { light red }\end{array}$ & \\
\hline \multicolumn{3}{|l|}{ Type B } \\
\hline 2654 & $\begin{array}{l}7.5 \text { YR } 7 / 6 \\
\text { reddish-yellow }\end{array}$ & Resembles 3875 of Type Bv \\
\hline 3457 & $\begin{array}{l}5 \text { YR } 6 / 8 \\
\text { reddish-yellow }\end{array}$ & Common small quartz. Sparse dark red and calcareous up to $0.5 \mathrm{~mm}$ \\
\hline \multicolumn{3}{|c|}{ Reference material } \\
\hline $\begin{array}{l}\text { Chiot } \\
\text { amphorae }\end{array}$ & $\begin{array}{l}10 \mathrm{R} 6 / 8 \text { to } \\
2.5 \mathrm{YR} 6 / 8 \\
\text { light red }\end{array}$ & $\begin{array}{l}\text { Common calcareous inclusions up to } 0.5 \mathrm{~mm} \text {; common sub-rounded dark, red and } \\
\text { pale grits, most of them apparently quartz and poorly sorted, size up to } 1 \mathrm{~mm} \text {, rarely } \\
\text { up to } 2 \mathrm{~mm} \text {. Sparse small gold mica flakes. Rare voids }\end{array}$ \\
\hline $\begin{array}{l}\text { Late } \\
\text { Roman } \\
\text { amphorae } \\
\text { from } \\
\text { Seleucia of } \\
\text { Pieria }\end{array}$ & $\begin{array}{l}2.5 \text { YR } 6 / 6 \text { to } \\
7.5 \text { YR } 6 / 4 \\
\text { light red to } \\
\text { light brown } \\
\text { f }\end{array}$ & $\begin{array}{l}\text { Hard, well-fired fabric. Distinctive are the sparse, sub-rounded to angular dark } \\
\text { inclusions up to } 1 \mathrm{~mm} \text {. Quartz and calcareous inclusions are visible, occasionally up to } \\
1 \mathrm{~mm} \text {. Voids, where present, tend to be small and notably narrow }\end{array}$ \\
\hline
\end{tabular}

(Guissona) in Catalonia and Sinop, ${ }^{175}$ arrived too late to be incorporated into the data treatment.

The compositions of the test samples were first classified by average link cluster analysis (CA) and principal components analysis (PCA) (figure 132). The latter analysis is a multivariate data reduction technique, providing a convenient two-dimensional representation of the compositional variation in the data set; similarity 
Table 61 Reference material

\begin{tabular}{|c|c|c|c|}
\hline Pottery class & Find spot & $\begin{array}{l}\text { Technique } \\
\text { of analysis }\end{array}$ & Publication \\
\hline Baetican Late Roman amphorae & $\begin{array}{l}\text { La Mesquida (Mallorca), } \\
\text { Balearic Island }\end{array}$ & XRF & Buxeda i Garrigós et al 1999 \\
\hline African Red Slipped ware & $\begin{array}{l}\text { Oudhna and El Mahrine } \\
\text { (North Tunisia) }\end{array}$ & $\mathrm{XRF}$ & Mackensen and Schneider 2002 \\
\hline $\begin{array}{l}\text { African Red Slipped ware } \\
\text { and amphorae }\end{array}$ & $\begin{array}{l}\text { Outdone, El Maklouba, } \\
\text { El Mokaida, Salakta }\end{array}$ & INAA & $\begin{array}{l}\text { Taylor 1993; Taylor and } \\
\text { Robinson 1996a, 1996b, 1996c }\end{array}$ \\
\hline Late Roman amphora 2 & $\begin{array}{l}\text { Kounoupi, Argolid: kiln } \\
\text { site (late } 6 \text { th-early } 7 \text { th } \\
\text { century) }\end{array}$ & ICP-ES & Armstrong and Hatcher 1997 \\
\hline Late Roman C-ware & Phocaea & $\mathrm{XRF}$ & Mayet and Picon 1986 \\
\hline Local Byzantine pottery & Pergamon & INAA-PIXE & $\begin{array}{l}\text { Waksman and Spieser } 1997 \\
\text { Group 1: Appendix III } \\
\text { Poblome et al } 2001\end{array}$ \\
\hline Pergamene Sigillata & & AAS & \\
\hline Late Roman amphorae & $\begin{array}{l}\text { Chios Town, Chios: kiln } \\
\text { site }\end{array}$ & ICP-ES & Tsaravopoulos 1986 \\
\hline Late Roman amphorae & $\begin{array}{l}\text { Keratokambos kiln site, } \\
\text { South Crete }\end{array}$ & $\begin{array}{l}\text { INAA } \\
\text { OES }\end{array}$ & $\begin{array}{l}\text { Krywonos et al } 1982 \\
\text { Jones (1986: 243) }\end{array}$ \\
\hline 7th-13th-century amphorae & Ganos, Sea of Marmara & ICP-ES & Günsenin and Hatcher 1997 \\
\hline $\begin{array}{l}\text { Kiln and related debris, mainly } \\
\text { 4th century BC }\end{array}$ & Istria, Romania & $\mathrm{XRF}$ & Coja and Dupont 1979, 137 \\
\hline Late Roman 1C amphorae & $\begin{array}{l}\text { Cyprus - Kalavassos and } \\
\text { Paphos }\end{array}$ & INAA & Gomez et al 2002 \\
\hline $\begin{array}{l}\text { Late Roman carrot-shaped } \\
\text { amphorae }\end{array}$ & Cilicia: Seleucia of Pieria & $\begin{array}{l}\text { XRF; reanalysed } \\
\text { in this study by } \\
\text { ICP-ES }\end{array}$ & $\begin{array}{l}\text { Empereur and Picon } 1989 \text {, } \\
\text { figs } 16,17\end{array}$ \\
\hline
\end{tabular}

between individual compositions samples can be viewed as spatial proximity on the plot. Recourse was then made to bi-variate plots (figures 133-136) of combinations of elements including those that are known to be origin sensitive ( $\mathrm{Mg}, \mathrm{Cr}$ and $\mathrm{Co}$ ) - $\mathrm{CaO}-\mathrm{MgO}, \mathrm{Cr}-\mathrm{Co}, \mathrm{MgO}-\mathrm{Cr}$ and $\mathrm{CaO}-\mathrm{MnO}$ - incorporating both the test samples and the reference groups (the latter represented by their mean value only) to establish associations between the former and the latter. The concentration ranges of each reference group can be established from the mean and standard deviation given in Table 5, Chapter 2. Having examined the bi-variate plots, comparison was extended to the remaining elements using the visual-comparative method with the aim of confirming or otherwise the validity of the associations. The conventions adopted in presenting figures 132-136 are (1) the sample number appears to the right of the sample's position, except (2) where the positions of two samples are very similar in which case one of the sample numbers is moved upwards or sideways in order to become legible or (3) where the position is close to the boundary of the plot in which case the sample number is moved inwards, and (4) because the sample points in some of the plots cluster closely together, additional plots of the same data but with different scales are presented to lend greater clarity.

\section{RESULTS}

CA and PCA both gave classifications into two main groups together with two small ones. Figure 132 shows the results of PCA, a plot of the first two principal components. The extent to which these groups, A-D, correlate with the typological groups can be assessed in Table 62: Groups A and B account for a majority of 


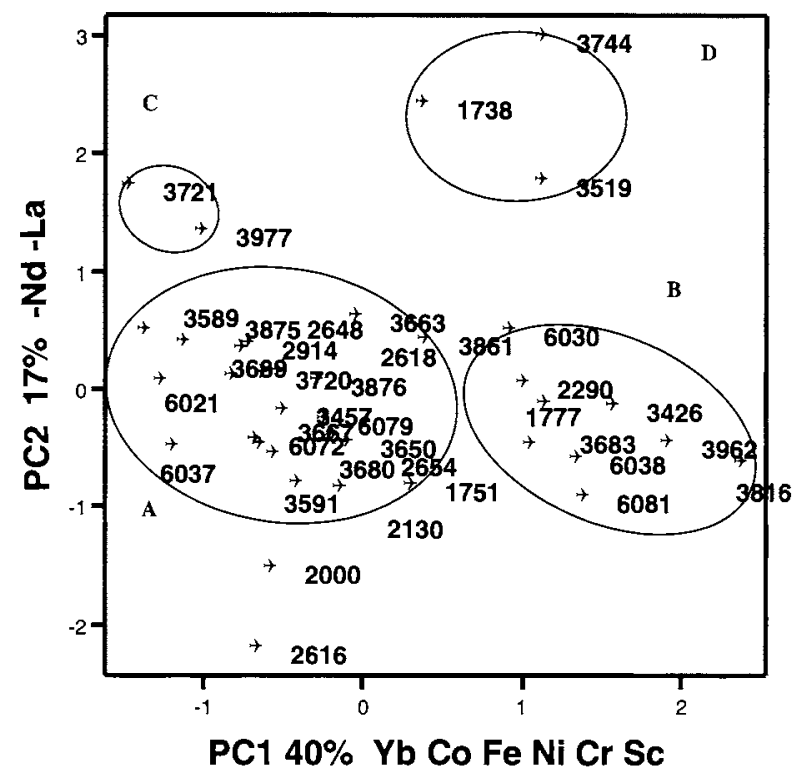

132 Principal components analysis plot of the Tintagel amphorae. The main elements loading the first two principal components, $P C 1$ and $P C 2$, are shown, as are Groups $A-D$

the $\mathrm{Bi}$ and $\mathrm{Bv}$ amphorae respectively, but neither group is uniform typologically. Moreover Bii amphorae distribute significantly across the groups. The two amphorae not attributed to a type, 2654 and 3457, seem to associate chemically with Type Bv in Group A.

Two notable features of the compositions as a whole are apparent, first the variable but high phosphorus content (many values are in excess of 3 per cent oxide) and the relatively high rare earth element contents by comparison with the reference material. Both these features are probably related to the burial conditions at Tintagel but, until this has been confirmed, the element contents concerned are not considered further in the data treatment. In any case, PCA on the reduced element set reveals only minor changes: 3721 and 3977 form a distinctly separate group, Groups B and D tend to merge, and 2000 and 2616 merge into Group A.

Most of the reference groups (Appendix 2) are satisfactorily coherent, to judge from their concentration ranges, but there are some exceptions, for instance the Chios and Cyprus groups which, for different reasons, have wide ranges in several elements.

Examining the groups in more detail, Groups A and $\mathrm{C}$ have the following chemical characteristics: low to medium $\mathrm{Ca}$, low to medium $\mathrm{Mn}$ and low $\mathrm{Cr}$, $\mathrm{Co}$ and $\mathrm{Ni}$. Since this group contains several examples of type $\mathrm{Bv}$, which is thought to originate in North Africa, the reference material from North Tunisia can be introduced. Straightaway it is clear that the XRF-defined Oudhna and El Mahrine groups share the features of very low $\mathrm{Ca}$ and $\mathrm{Mn}$ with 3721 and 3977, as observed in Figure 135; a North Tunisian origin seems likely despite the apparent discrepancy between their fabric description and those of North African lime-poor amphorae given by Peacock and by Tomber and Dore. ${ }^{176}$ The corresponding INAA data from North Tunisia is useful in the way it demonstrates the presence of limerich amphora groups with low Mn contents (Appendix 2: El Maklouba): this feature is reflected in the following samples having $\mathrm{Mn}$ contents up to 0.10 per cent: 2616 , $2618,2648,3591,3689,3720$. These may be North African but from different areas, and the same applies to 3875 and 3876 , although these two have affinities with the Seleucia group.

More difficult to place are the supposed $\mathrm{Bv}$ amphorae $2914,3426,3667,3680,6021,6072$ and 6079. Although they all belong to Group A, their compositions are not greatly different from those of other areas, notably parts of western Asia Minor (Phocaea and Pergamon) and southern Spain (figures 133-136); in the event, however, only those amphorae having higher $\mathrm{Ca}$ relate to the

Table 62 Correlation between chemical groups A-D and amphora types

\begin{tabular}{llll}
\hline Chemical group & Type $B i$ & $B i i$ & $B v$ \\
\hline A & 3589,6037 & $1751,2130,3650,3663$ & $2618,2648,2654,2914,3457,3591,3667,3680$, \\
& & $3689,3720,3875,3876,6021,6072,6079$ \\
B & $1777,2290,3683$, & 3962 & 3426 \\
& $3816,6030,6038,6081$ & \\
C & 3721,3977 & \\
D & 3519 & 1738,3744 & \\
Outliers & & 2000 & 2616 \\
\hline
\end{tabular}



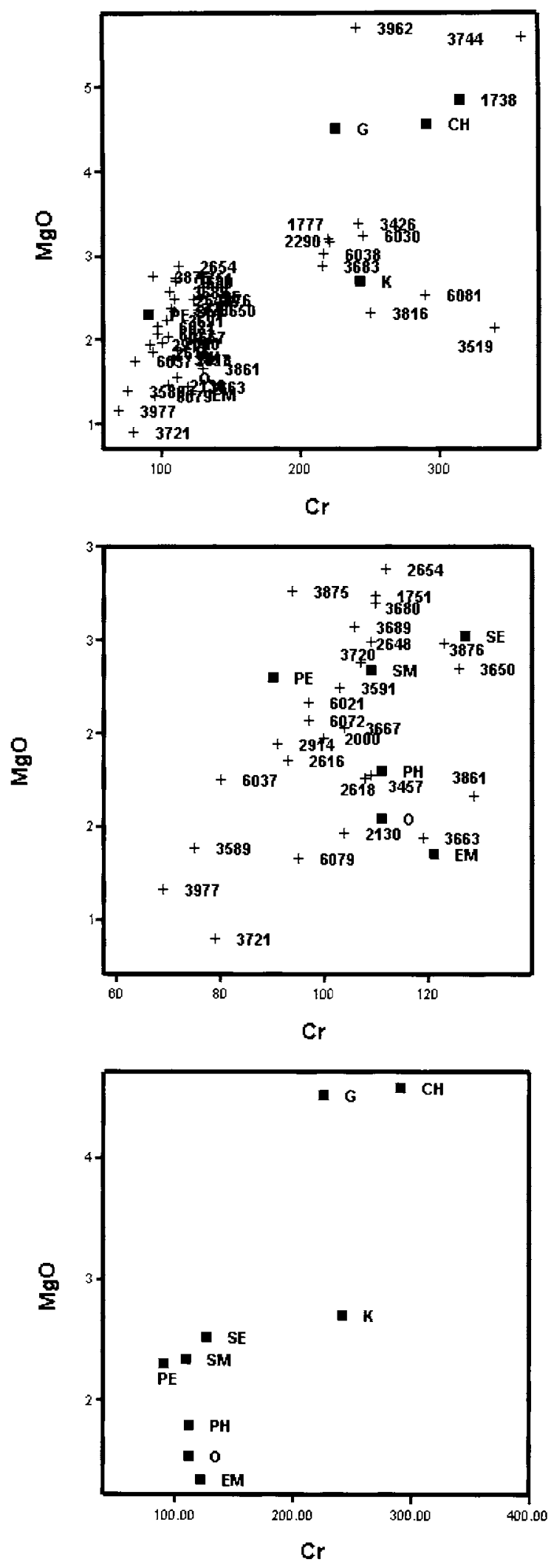

southern Spanish group (figure 133). Since the fabrics among these seven samples are not uniform in hand specimen it is likely that several sources are implicated, some of which are North African. 3861, which lies on the boundary of Group A owing to its relatively high $\mathrm{Cr}$ and Co contents, cannot be associated with any reference group. In Group A that leaves 3663, which is quite similar to 3721 and 3977 as all three are non-calcareous, but on account of its micaceous fabric 3663 should have a different origin. In any case 3721 and 3977, standing well apart owing to their high $\mathrm{Rb}$ contents, should be regarded as 'unplaced'; with such low $\mathrm{Cr}$, $\mathrm{Co}$ and $\mathrm{Ni}$ contents they cannot be accommodated within the Aegean or the Sea of Marmara.

With one exception, 3816, which has a non-calcareous fabric, Group B is characterized by medium Ca, high Mn and higher $\mathrm{Fe}, \mathrm{Co}, \mathrm{Cr}$ and $\mathrm{Ni}$ than Group A. These Group $\mathrm{B}$ composition features are familiar in the Aegean and nearby, but the present reference data for Kounoupi, Chios and Ganos does not offer consistent similarity with Group B. With respect to the $\mathrm{Cr}$-Co plot (figure 136) the resemblance is certainly apparent, but in the $\mathrm{MgO}-\mathrm{CaO}$ and $\mathrm{MnO}-\mathrm{CaO}$ plots (figures 134-135) Kounoupi is excluded because of its very high $\mathrm{Ca}$. If the Istria reference group is a reliable marker for the west coast of the Black Sea, that region seems an unlikely candidate for Group B production owing to its high calcium content.

Group D members share high $\mathrm{Co}, \mathrm{Cr}$ and $\mathrm{Ni}$, and low to very low $\mathrm{Ca}$ contents. $\mathrm{Mg}$ is high but not uniform. 1738 is close to Chios, 3744 could be south central Cretan owing to its resemblance to the albeit limited data for Keratokambos, while there is no match for the non-calcareous 3519.

As for the outliers, 2000 and 2616 could relate to the North African group.

$133 \mathrm{MgO}-\mathrm{Cr}$ plots of (top) the Tintagel amphorae (+) and the reference groups ( $\mathbf{\square}$ ); (middle) the same data but plotted on a different scale; and (bottom) the reference groups only. CH Chios; EM El Mokaida; G Ganos; K Kounoupi; O Oudhna; PE Pergamon Byzantine; PH Phocaea; SE Seleucia; $S M$ La Mesquida, Spain. The reference groups are indicated by their mean value only; the concentration ranges of each group can be estimated from the standard deviation values given in Appendix 2 

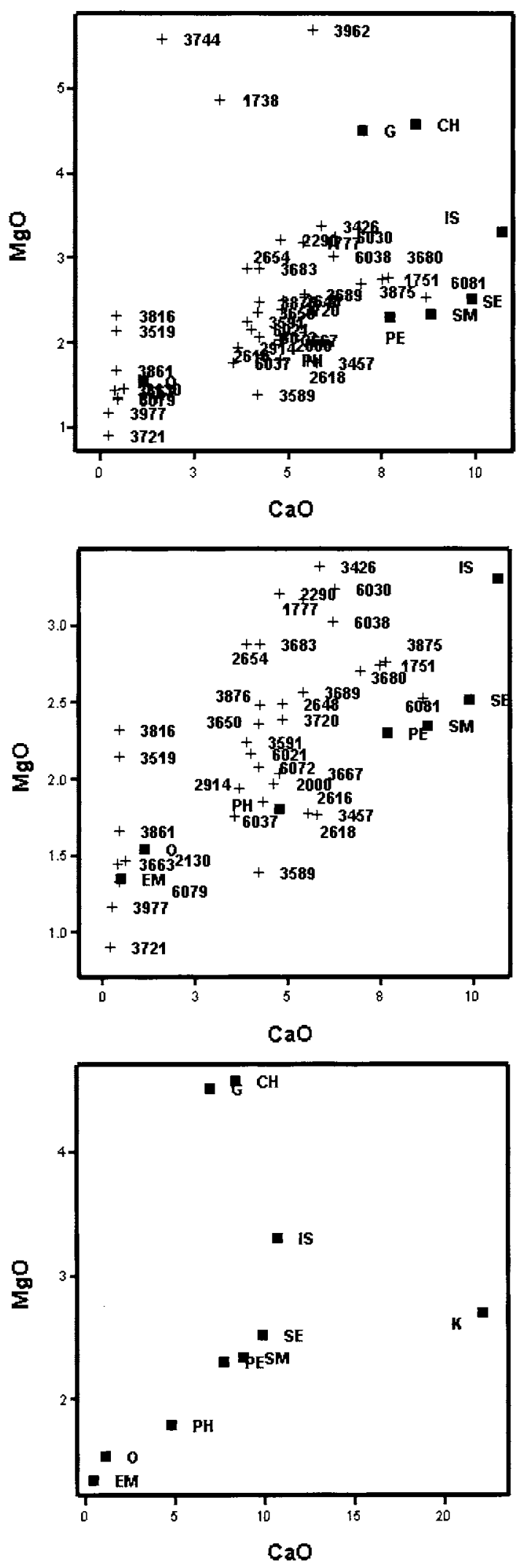

DISCUSSION

A positive outcome of this study has been to provide some support both for the typological classification of the amphorae and the current views on their source areas. At the same time, the results have demonstrated a level of complexity which has prevented secure assignment of origin being made to either individual amphorae or groups of amphorae. Instead, the situation allows a few general remarks to be made.

First, the identification of two main chemical groups and two small ones cannot be simply associated with four potential production zones; indeed, it is very likely that Groups A and B each represent more than one production zone. The overriding conclusion then is that the amphorae analysed are from several different sources, a finding which is in fact well in keeping with the trends emerging from research on Late Roman amphorae during the last two decades, namely diversity and multiplicity of production areas/sites.

Second, of the three $B$ types investigated, $B v$ is the more coherent chemically, but the appearance of $\mathrm{Bi}$ (Late Roman 2) and Bii (Late Roman 1) examples in different chemical groups suggests some typological misidentifications may have taken place; in view of the small size of some of the sherds this need not cause surprise.

Third, while northern Tunisia is a source of $\mathrm{Bv}$ amphorae, the inclusion in this study of the Baetican reference group is a reminder that southern Spain may also be a relevant potential source; its compositions are not greatly different from those in North Africa. It is ironic that although the $\mathrm{Bv}$ amphorae form a reasonably coherent group chemically it is possible to find comparanda elsewhere in the Mediterranean, namely the eastern Aegean.

Fourth, at least it can be said with confidence that no Cypriot products have been identified; the very high $\mathrm{Cr}$ contents in Late Roman $1 \mathrm{C}$ amphorae on Cyprus find no counterparts at Tintagel. ${ }^{177}$

Fifth, many of the Bi (Late Roman 2) amphorae are 'at home' in the Aegean or nearby although no good

$134 \mathrm{MgO}-\mathrm{CaO}$ plots of (top) the Tintagel amphorae (+) and the reference groups (䍒; (middle) the same data but plotted on a different scale; and (bottom) the reference groups only. CH Chios; EM El Mokaida; G Ganos; IS Istria; K Kounoupi; O Oudhna; PE Pergamon Byzantine; PH Phocaea; SE Seleucia; SM La Mesquida, Spain 

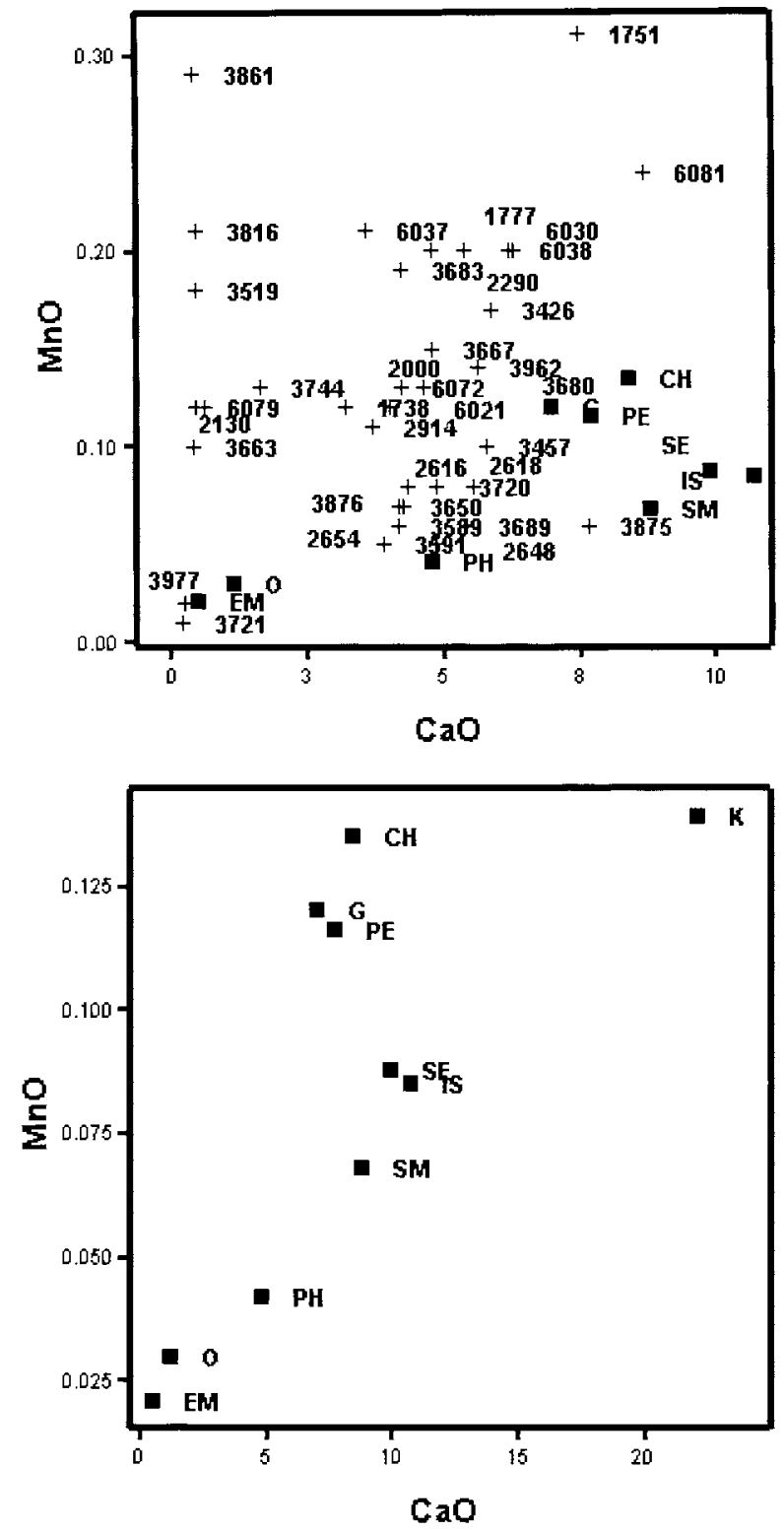

$135 \mathrm{MnO}-\mathrm{CaO}$ plots of (top) the Tintagel amphorae (+) and the reference groups ( $\square$ ); and (bottom) the reference groups only. CH Chios; EM El Mokaida; G Ganos; IS Istria; K Kounoupi; O Oudhna; PE Pergamon Byzantine; PH Phocaea; SE Seleucia; SM La Mesquida, Spain

'matches' have been established; on balance, Kounoupi is unlikely to have been a source. ${ }^{178}$ The Bii (Late Roman 1) amphorae are a disparate group with little to convincingly support an eastern Mediterranean source. One of the Bii amphorae, 3744, if Aegean, associates in composition with Keratokambos in southern Crete, although typologically such a source appears unlikely. ${ }^{179}$
A number of amphorae resemble the Seleucia group, but of them only one, 3650, is Late Roman 1 typologically. There is, however, an issue regarding the chemical definition of that source area: Williams has drawn attention to the distinctive inclusions associated with ophiolite (such as lava and - occasional - serpentine) present in amphorae found in the Gulf of Iskenderum area of Cilicia including the site of Seleucia of Pieria. ${ }^{180}$ Yet the chemical compositions of samples (carrotshaped rather than Late Roman 1 amphorae) from that same site do not bear the expected chemical signature, that is, high $\mathrm{Mg}$ and $\mathrm{Cr}$ contents. A probable explanation, and one with potentially important implications for further chemical work, lies in the relative texture: the amphorae from Seleucia analysed petrographically were coarser than those analysed chemically. ${ }^{181}$

In sum, indecisive though some of the results may be, they at least form a good working basis for the next stage of the study which is drawing in petrographic analysis and, in the light of the wealth of newly published finds and data, ${ }^{182}$ typological analysis as well. The relative lack of precision in many of the statements about origin made in this study is a product of several factors; the fact that some potential sources around the Mediterranean have yet to be located on the ground, yet alone their products characterized by physico-chemical analysis, has already been alluded to, if indirectly. Another factor is that, excellent though recent and current chemical studies have been in characterizing production centres on a regional basis - in Iberia, central North Africa, the Aegean (and vicinity) and the East Mediterranean - more effort needs to be expended on making their output more systematic. This in turn would optimize the comparability of chemical data obtained Mediterranean-wide in different laboratories and thus allow statistical treatment of the rich multielement data set rather than of selective elements, as has been the case in the present study. Those involved at a practical level in chemical analysis are keenly aware of this methodological issue and yet it is one which needs to be raised here. There is too the factor which affects petrographic as much as chemical analysis and that is the 'distinctiveness' or otherwise of the signature. In chemical terms, a chemical group representing a given production location may not appear distinctive either because its concentration ranges are broad (for natural reasons as well as how the potters treated the clays) and so overlap with those of neighbouring groups, or 

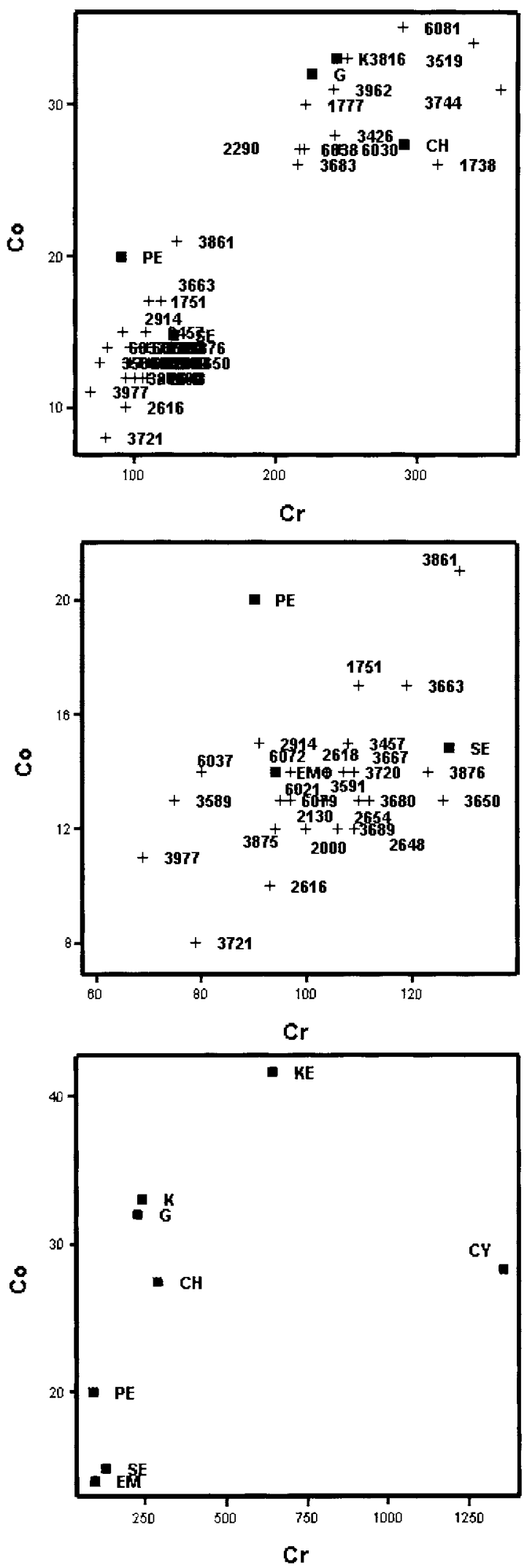

because the location is situated in a region of geochemical uniformity. This factor, which has affected the present study but in an as yet unquantifiable manner, is related to one last point, and that is the interpretation of an (often observed) 'small' difference in composition between an amphora of unknown origin and a reference group representing a particular producing centre - does it signify that the amphora is perhaps an atypical example of that centre or a product from a neighbouring centre? This question is not usually possible to answer and, indeed, should be regarded as inappropriate since the limit of resolution of provenance assignment is normally at the regional rather than the individual site level. In any case, there is room for investigation of those cases where neighbouring amphora workshops have been characterized both chemically and petrographically, as is the situation, for example, on Thasos for Greek transport amphorae. ${ }^{183}$ The upshot of these several factors is that, for the time being, the provenance determination by chemical analysis of amphorae found at consumption centres like Tintagel will operate more at the level of negative rather than positive statement of origin.

Finally, it is noted that the black coating on Bi stopper 4215 is not a resin. Analysis by Fourier Transform Infra Red spectroscopy revealed the lack of indicative peaks expected for a (pine) resin; instead, it is more likely to be a black painted layer, presumed to be dipinti.

\section{ORGANIC RESIDUE ANALYSIS}

The aims of this exploratory study by gas chromatography (GC) have been summarized in the Introduction above. If a lipid-based residue were detected, this could suggest an oil- or wax-rich commodity, while the absence of lipid would be more consistent with a liquid such as wine. These unambitious aims were considered to be appropriate in view of two factors: the soil conditions at Tintagel and the disappointing track record on the part of other workers in making reliable positive identifications of residues in transport amphorae. One of the main difficulties has been the degradation over time of the potentially diagnostic unsaturated fatty acids present in oils such as oleic acid to dicarboxylic acids.

$136 \mathrm{Co}-\mathrm{Cr}$ plots of (top) the Tintagel amphorae (+) and the reference groups $(\square)$; the same data but plotted on a different scale (middle); and (bottom) the reference groups only. CH Chios; CY Cyprus; EM El Mokaida; G Ganos; KE Keratokambos; K Kounoupi; PE Pergamon Byzantine; SE Seleucia 
The GC analyses, which were carried out in the Chemistry Department at the University of Glasgow, followed the procedures described recently by Jones, Cole and Jones. ${ }^{184}$

The samples were selected to meet two criteria: they had to encompass more than one of the B types, and they had to be of suitably sized body sherds. They are listed in Table 63. From each sherd a fragment was broken off and ground to powder (approximately $10 \mathrm{~g}$ ). The residue was extracted with n-hexane in a soxhlet system, and then derivatized with a methylating agent, followed by reaction with pyridine and the silating agent, N, O-bis(trimethylsilyl)trifluoroacetamide. The gas chromatograms were obtained on a Hewlett Packard 6890 instrument, using a fused Silica 25MXO.32MM ID coating CP-SIL 5CB column. Qualitative identification of some of the main peaks in the chromatograms were made with the aid of standards.

\section{RESULTS}

The first point to note is that all but one of the sherds, 1777, yielded a residue, albeit small (less than $1 \mathrm{mg}$ ). The residues in four of the samples - 2023, 2654, 2914 and 3426 - could be consistent with a lipid since they contained very low concentrations of two common and non-specific saturated fatty acids, stearic and palmitic acids (C16 and C18, table 63). In addition 3426, together with 2290 , contained small concentrations of what are likely to be long-chain $(\mathrm{C}>20)$ hydrocarbons and alcohols; these are found in, for example, waxes. Whatever their precise identity, these long-chain compounds are not identical in the two samples.

From these few results it can be proposed that the contents of 2290 and 3426 were different from those in the remainder, but whether they were the original contents of the amphorae it is impossible to say. The difficult soil conditions and the small amounts of recoverable residue have adversely affected the analyses. There is furthermore the complication arising from possible re-use, and in this context it is tempting to recall here the translation of a third-century AD papyrus from Fayum quoted in Hayes's discussion of Roman amphorae: "When ... received ... they probably no longer contained wine from their areas of production, but had been reused. ${ }^{185}$

\section{CERAMICS: MEDIEVAL AND POST-MEDIEVAL by Catherine Freeman}

There is only a small amount of medieval pottery compared to post-Roman, and it is generally less spectacular and important. It is mainly interesting because it broadly reflects the pattern of that already found by Radford in the 1930s, with the same main pottery fabrics being found in roughly the same proportions as before. ${ }^{186}$ It adds a further 43 per cent to the previous total by sherd count, and new evidence, as there is a significant difference in the material found in some different trenches. In total there are 452 sherds from the various areas investigated in and around Site $C$, and twenty-seven from Site $T$, mainly from the Great Ditch (altogether 479 compared to the 1,105 sherds previously examined). Indeed, the numbers of sherds from trench C18 on the Upper Terrace, and trench C15 and trial trench C15 on the Middle Terrace, support the hypothesis that there has been later medieval occupation to the south and south west of the Site $C$ building.

\section{INTRODUCTION}

This is the first collection of medieval pottery known positively to have come from Site C, and is certainly the first stratified material. Recent examination of the Radford archive by Batey (see Chapter 1) has uncovered

Table 63 Results of organic residue analysis

\begin{tabular}{lcl}
\hline$R F$ number & Type & Residue \\
\hline 1777 & $\mathrm{Bi}$ & None \\
2023 & $\mathrm{Bi}$ & Very low concentrations of C16 and C18 acids \\
2290 & $\mathrm{Bi}$ & Homologous series of probable hydrocarbons and alcohols (both with C $>20)$ \\
2654 & $\mathrm{~B}$ & Very low concentrations of C16 and C18 acids \\
2914 & $\mathrm{Bv}$ & Very low concentrations of C16 and C18 acids \\
3426 & $\mathrm{Bv}$ & Very low concentrations of C16 and C18 acids; homologous series of probable \\
& & hydrocarbons and alcohols (both with C $>20)$
\end{tabular}


a letter concerning the finds from Site $\mathrm{C}$ and their division between Truro and the British Museum. In February 1949 Bruce Mitford writes to Radford 'I confirm that we were to keep all the material from Site $\mathrm{C}$ (pre 1100), and that you were to send from Truro the rest of Site $\mathrm{C}$ material and a representative series of Medieval wares' (TINBOX 46, 16r). Unfortunately, this is ambiguous as to whether the medieval wares in question were from site $C$ originally. Most of the previous collection was unmarked, although a proportion was marked with Site letters (most sherds coming from Sites $\mathrm{A}, \mathrm{X}$ and $\mathrm{Z}$ ). Some of the unmarked material could have come from Site $\mathrm{C}$ as it was excavated at the same time.

The stratification of this assemblage appears to be of little significance, all sherds only occurring in Phases $W$, $X, Y$ and $Z$ (which represent different activities in different trenches), where they must be residual. However, in several cases large numbers of sherds of individual vessels found together suggest that they have not travelled far from their original place of deposition.

As could be expected, Cornish wares predominate, again providing approximately twice the quantity of those from Devon. Chert-tempered wares from Somerset are found in greater quantities of sherds than previously, although only a few vessels are represented. The proportion of regional and foreign imported jugs and post-medieval material is again small, the latter found only at Site T.

\section{METHODOLOGY}

The types are briefly described first, using the same terminology and letter coding as in the report on Radford's pottery. The material in each trench is then analysed in detail, following summary tables showing proportions of each type, with numbers for each Phase, and if appropriate, context. The abraded condition of much of the material dictates that the overall method of quantification is sherd count, with vessel reference numbers being given only to individual vessels represented by more than one sherd, when these can be identified, or a diagnostic sherd. Even sherd count is of limited value here, as the (apparently) dominant fabric, Stuffle Fabric A, breaks more easily, and into smaller sherds, than the other types. Variations in firing and sherd condition in most fabrics make it difficult to identify sherds of individual vessels unless sherds actually join. The tables thus show numbers of sherds only, rather than percentages, which can give a false impression of the proportions of types of pottery in use. There is a summary of conclusions at the end, including a discussion of the relationships between some types, and dating.

\section{THE TYPES: MEDIEVAL FABRICS}

These are placed in rough chronological order:

\section{Chert-tempered ware (SO)}

This comes from Somerset or East Devon and ranges in date from the early eleventh to the fourteenth century. ${ }^{187}$ All sherds at Tintagel appear to be from cooking-pots, although a variety of other forms were made. It is thought that the Chert-tempered wares with oxidized surfaces are the earliest, of eleventh- or twelfth-century date, and were imported before local pottery industries began.

\section{Ham Green ware (HG)}

This well-known hand-made pottery from the Ham Green kilns, near Bristol, has a wide distribution in south-west England and south Wales. Both cooking-pots and glazed jugs were made but the only sherds found at Tintagel are from a type B jug with a frilled base, on which the glaze no longer remains. An illustration showing how this form would appear in profile and from beneath is in the original publication of the kiln material. ${ }^{188}$ The date range for this type of pottery is now late twelfth-early thirteenth century. ${ }^{189}$

\section{Stuffle-type ware (SA)}

This was made in the Lostwithiel area from the thirteenth century until the end of the medieval period. The sherds from these excavations and from the previous collection are all of Stuffle Fabric A, varyingly micaceous, hand-made wares first identified at the Cornish site now known as Bunning's Park, ${ }^{190}$ although for several years prior to publication it was known as Stuffle. All the diagnostic sherds are from jugs, but many of the small body sherds may represent cookingpots.

\section{North Devon Medieval Coarseware (OK)}

This hand-made material was first identified at Okehampton. ${ }^{191}$ Kilns have now been found for the general type known as North Devon Medieval Coarseware at Barnstaple, ${ }^{192}$ although the variety previously known as Okehampton Fabric 1, to which these sherds most closely correspond, was probably made elsewhere. Production is thought to have begun in 
the early thirteenth century, with jugs not being made until 1250, and continued into the fifteenth century. Again, at Tintagel more of these sherds can be positively assigned to jugs than cooking-pots.

\section{Bristol Redcliffe ware (RE)}

These finer wheel-made glazed jugs replaced Ham Green wares in the mid-thirteenth century and were also widely exported. There is a lengthy classification and description of Redcliffe varieties in the original Bristol Pottery Type (BPT) series created in $1980 .{ }^{193}$ The vessels from these excavations have applied vertical strips in a different coloured clay and correspond most closely to BPT 118A, dated 1250-1350.

\section{Saintonge ware (SP)}

There is just one example of this well-known French import, of the most common variety, fine wheel-made white-firing jugs partially covered with a coppermottled green glaze, ${ }^{194}$ now given a date range of $1250-1450 .{ }^{195}$

\section{Unclassified unsourced ware (UU)}

This group includes a possible Dorset whiteware sherd, similar to Bristol Redcliffe ware, and six conjoining sherds (RF 4249: figure 137), possibly from a source in Somerset. The fabric of these is hard-fired and orange with red external surface where it is not covered by an orange-green glaze.

\section{Lostwithiel ware (LO)}

These are thought to replace Stuffle types in the fifteenth century, although production probably started before and continued after this. ${ }^{196}$ They are coarse and may be wheel-thrown, although this is difficult to discern when material is abraded. The Tintagel sherds were compared with those from Colliford, where Lostwithiel wares and related types were submitted to a comprehensive and complicated classification. Some sherds here have been assigned to type $\mathrm{C}$, by far the commonest type there, and others to type $\mathrm{D}$, there called Lostwithiel-type rather than Lostwithiel ware. There is a discussion of the latest research concerning these wares and their relation to Stuffle fabrics in the conclusion below.

THE TYPES: POST-MEDIEVAL FABRICS

\section{North Devon Calcareous ware (NC)}

This is a well-known ware which was also widely exported. The sherds from these excavations are from thin-walled green-glazed jars or jugs, with splashes of slip and glaze on the exterior surface only. They are generally dated to the sixteenth-early seventeenth centuries. ${ }^{197}$

\section{Sandy Redware (SR)}

There are two abraded redware sherds in a hard sandy fabric, a piece of glaze remaining on the interior surface of one, suggesting it may be from a bowl or dish where the interior surface only was on show. Their condition and anonymous fabric prohibits further interpretation. They are probably also of sixteenth- to seventeenthcentury date.

\section{ANALYSIS OF POTTERY IN EACH TRENCH}

\section{Site C, Upper Terrace: Radford's trenches}

One hundred and thirty-one sherds were recovered from Radford's trenches on the Upper Terrace (table 64) of which just one was from trench $\mathrm{C} 19$, the others being from trench C18. Unusually, in C18 the number of medieval sherds recovered is comparable to the postRoman sherds. One hundred and three sherds of medieval pottery were recovered from Phase X, disturbed scree deposits, two from Phase Y, Radford's trenches and backfill, and twenty-five from Phase $Z$, topsoil. Of the total of 130 , sixty-two are SA, sixty OK, one SO and seven LO (table 64).

Within the assemblage of SA, there are two main portions of individual vessels in this area: SA3 has fourteen sherds from Phase X (RF 2559) and one from Phase Z (RF 2551), and SA4 twenty-four sherds from Phase X (RF 2541).

Of the sixty sherds of OK from this area, forty-nine are from context 801 in Phase $\mathrm{X}$ and all from one vessel (OK1). This comprises a large portion $(200 \mathrm{~mm})$ of the profile of a jug decorated with irregular horizontal grooving to a height of 70 or $80 \mathrm{~mm}$ above the base. At Okehampton Castle, this type of decoration was commonest in the late thirteenth and fourteenth centuries. The rim with external ridge does not actually join the body sherds, but a full profile can be conjectured, with a rim diameter of $140 \mathrm{~mm}$ and a base diameter of $220 \mathrm{~mm}$. There is only one vessel which is definitely a cooking-pot (OK5: RF 2550), consisting of rim and shoulder sherds from context 801 , Phase $\mathrm{X}$. The rim is too short to determine the diameter, but the form is comparable to no. 100 in the previous collection 


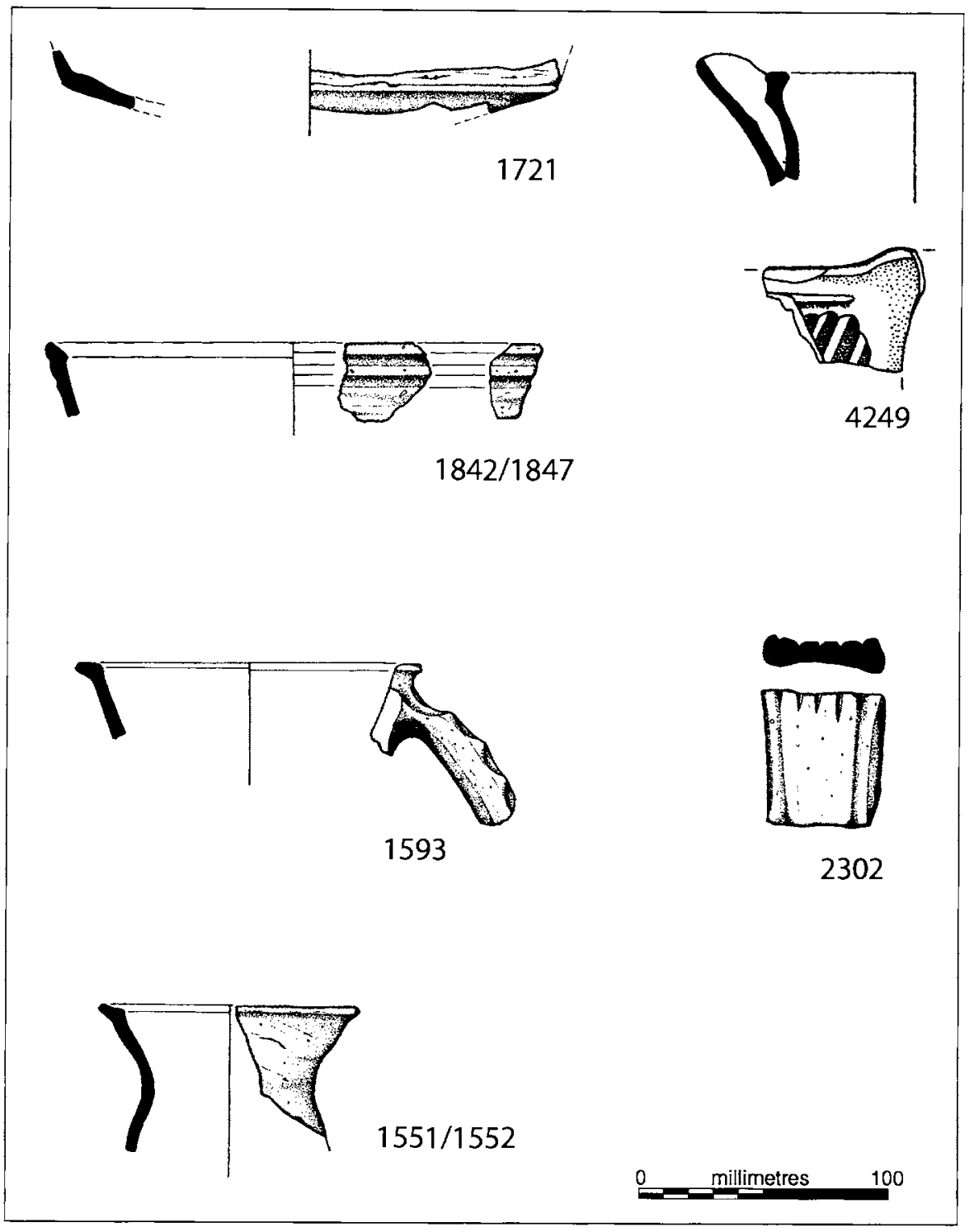

137 Medieval pottery: $R F 1721$ (= LOD1); RFs 1551/1552 (= $O K 3$ ); $R F 1593$ (= OK2); $R F$ 2302 (= SA5); RFs 1842/1847 (=SO2); RF 4249 (=UU; stippling indicates glazing).

Drawing: C Thorpe

from Radford's work. ${ }^{198}$ There may also be a sherd from this vessel in Phase $Z$ (RF 2540) of C18, and two other conjoining body sherds from Phase $Z$ represent another vessel (OK6: RF 2539). These are decorated with a single, wide horizontal groove, but the form is uncertain.

Seven sherds of LO have been identified from C18, with both $\mathrm{C}$ and $\mathrm{D}$ fabrics represented. Conjoining sherds with abraded brown surfaces from Phase $\mathrm{X}$ form a neck and shoulder, probably of a jar (LOC1: RF 2496), and a further sherd from Phase $Z$ is probably from the same vessel (RF 2432). An unglazed body sherd from Phase Z (LOD2: RF 2436) has decoration of incised wavy and horizontal lines, and may be from a jug or jar.

There was only a single sherd of SO here, but another, which was the only medieval sherd, was found in trench $\mathrm{C} 19$.

Site C, Middle Terrace: Radford's trenches

One hundred and twenty-four sherds of five types of medieval wares were recorded from trial trench $\mathrm{C} 15$ (table 65). Phase X, Radford's trenches and backfill, produced twenty-seven sherds, Phase $Y$, scree slip, sixtyeight sherds, and Phase $Z$, turf and topsoil, and unstratified, twenty-nine sherds. As with the Upper 
Table 64 Medieval pottery from the Upper Terrace, Radford trenches, by fabric type and context

\begin{tabular}{|c|c|c|c|c|c|c|c|c|}
\hline \multicolumn{9}{|c|}{ Trench C18 130 sherds } \\
\hline Context & SO & $H G$ & $S A$ & $O K$ & $R E$ & $L O$ & Phasing & Total \\
\hline 801 & - & - & 43 & 55 & - & 5 & $\mathrm{X}$ & 103 \\
\hline 803 & - & - & 1 & 1 & - & - & $\mathrm{Y}$ & 2 \\
\hline 800 & 1 & - & 18 & 4 & - & 2 & $\mathrm{Z}$ & 25 \\
\hline Overall & 1 & - & 62 & 60 & - & 7 & & 130 \\
\hline \multicolumn{9}{|c|}{ Trench C191 sherd } \\
\hline Context & SO & $H G$ & $S A$ & $O K$ & $R E$ & $L O$ & Phasing & Total \\
\hline 412 & 1 & - & - & - & - & - & $\mathrm{Y}$ & 1 \\
\hline Overall & 1 & - & - & - & - & - & & 1 \\
\hline \multicolumn{9}{|c|}{ Cumulative totals } \\
\hline & SO & $H G$ & $S A$ & $O K$ & $R E$ & $L O$ & & Total \\
\hline & 2 & - & 62 & 60 & - & 7 & & 131 \\
\hline
\end{tabular}

Key: $\mathrm{SO}=$ Chert-tempered wares; $\mathrm{HG}=\mathrm{Ham}$ Green wares; $\mathrm{SA}=$ Stuffle-type wares; $\mathrm{OK}=$ North Devon Medieval Coarsewares; $\mathrm{RE}=$ Redcliffe wares; $\mathrm{LO}=$ Lostwithiel wares

Terrace Radford trenches (see above), there is an overall dominance of SA (sixty-two sherds from the Upper Terrace, seventy-five from the Middle) and OK (sixty sherds from the Upper Terrace, thirty-seven from the Middle). There are no examples of SO here. The only examples of HG (six sherds) occur here, and RE (nine sherds) and LO (seven sherds), which are rare elsewhere on the site, are also represented, but all three types occur only in context 650 , containing half of the total sherds in this trench.

Twenty-three SA sherds were recovered from Phase $X$ (Radford backfill), twenty-four from Phase Y (screetips), with a further six from Phase Z. There is one lidseated collared jug rim and ten sherds of the same vessel from Phase X (Vessel SA1: RF 2721) and an identical unstratified rim and body sherd are probably from the same vessel. The form is similar to nos 55,56 and 57 in the previous collection from Radford's excavations. ${ }^{199}$ Other individual vessels are represented by conjoining base sherds within Phase Y (Vessel SA2) and one large strap handle (Vessel SA5 RF 2302 U/S: see figure 137).

Four sherds of OK were found in Phase X, twentytwo in Phase $Y$ and seven in Phase $Z$. A substantial part of a single vessel, a jug with a rim and strap handle (eg RFs 1592, 1593 and 1712: OK2; see figure 137) comprising sixteen sherds in all, came from 650 of Phase Y. The handle is slashed down the centre and thumbed along either side, as no. 121 from the previous collection from Radford's work. ${ }^{200}$ Three of the body sherds are decorated with irregular horizontal grooving, as for example on vessel OK1 from C18 on the Upper Terrace. An abraded upright jug rim (OK3: see figure 137, consisting of two sherds from C15 Phase Z) corresponds to Form $\mathrm{M}$ at Okehampton Castle, which was found there in all periods from the late thirteenth to the fifteenth century. A further jug rim (OK4) is represented by a single sherd from $\mathrm{C} 15$ Phase Z. This is heavily blackened on the exterior surface, indicating that it was used to heat its contents. Further jug neck sherds from Phases $\mathrm{Y}$ and $\mathrm{Z}$ may all be from one vessel. RFs 2281, 2285 and 2297 from context 644 in Phase X may also all be from one vessel, and two sherds from different trenches (RFs 2158 from Phase Z of C15 and 2540 from Phase Z of C18 Upper Terrace) may also be from one vessel.

The LO sherds, which form a basal angle (RF 1721: C15 Phase Y, LOD1: see figure 137) are from a jug or jar, with small spots of glaze on the base.

Of twelve sherds from trench C17 (see table 65), five were unstratified. Three of these were SA and two OK. From Phase Y, scree material, there were three sherds of 
Table 65 Medieval pottery from the Middle Terrace, Radford trenches, by fabric type and context

\begin{tabular}{|c|c|c|c|c|c|c|c|c|}
\hline \multicolumn{9}{|c|}{ Trial trench C15 124 sherds } \\
\hline Context & SO & $H G$ & $S A$ & $O K$ & $R E$ & LO & Phasing & Total \\
\hline 660 & - & - & 1 & - & - & - & $\mathrm{X}$ & 1 \\
\hline 661 & - & - & 10 & - & - & - & $\mathrm{X}$ & 10 \\
\hline 662 & - & - & 1 & - & - & - & $\mathrm{X}$ & 1 \\
\hline 664 & - & - & & 4 & - & - & $\mathrm{X}$ & 4 \\
\hline 672 & - & - & 11 & - & - & - & $\mathrm{X}$ & 11 \\
\hline 650 & - & 6 & 18 & 22 & 9 & 7 & $\mathrm{Y}$ & 62 \\
\hline 652 & - & - & 1 & - & - & - & $\mathrm{Y}$ & 1 \\
\hline 653 & - & - & 5 & - & - & - & $\mathrm{Y}$ & 5 \\
\hline 500 & - & - & 4 & 3 & - & - & $\mathrm{Z}$ & 7 \\
\hline 651 & - & - & 2 & 4 & - & - & $\mathrm{Z}$ & 6 \\
\hline $\mathrm{u} / \mathrm{s}$ & - & - & 16 & - & - & - & - & 16 \\
\hline Overall & - & 6 & 69 & 33 & 9 & 7 & & 124 \\
\hline \multicolumn{9}{|c|}{ Trench C17 12 sherds } \\
\hline Context & SO & $H G$ & $S A$ & $O K$ & $R E$ & $L O$ & Phasing & Total \\
\hline $\mathrm{u} / \mathrm{s}$ & - & - & 3 & 2 & - & - & $\mathrm{X}$ & 5 \\
\hline 900 & - & - & 3 & 2 & 2 & - & $\mathrm{Y}$ & 7 \\
\hline Overall & - & - & 6 & 4 & 2 & - & & 12 \\
\hline \multicolumn{9}{|c|}{ Cumulative totals } \\
\hline & SO & $H G$ & $S A$ & $O K$ & $R E$ & $L O$ & Phasing & Total \\
\hline & - & 6 & 75 & 37 & 11 & 7 & & 136 \\
\hline
\end{tabular}

Key: SO=Chert-tempered wares; HG=Ham Green wares; $\mathrm{SA}=$ Stuffle-type wares; $\mathrm{OK}=$ North Devon Medieval Coarsewares; $\mathrm{RE}=$ Redcliffe wares; $\mathrm{LO}=$ Lostwithiel wares

SA, two OK and two sherds of RE (Vessel RE2). All four $\mathrm{OK}$ sherds may be from one vessel.

Site C, Middle Terrace: trench C15

In 1999 ninety-five sherds of medieval pottery were recovered from trench $\mathrm{Cl} 5$ (table 66). Of these, seventeen are unstratified, thirty-four are from Phase W, collapse and scree slip, thirty-five from Phase $\mathrm{X}$, Radford's trenches, six from Phase $Y$, scree slip, and three from Phase Z, topsoil.

The material from the 1994 excavations of Radford's trench in trial trench $\mathrm{C} 15$ (discussed above) was also reexamined, and some sherds of the same vessel, a Redcliffe ware jug (RE2), have been found in the collections from both years.
Medieval pottery in Phase W (building collapse), consists of the North Devon jugs (OK7 and OK10), sherds of the Redcliffe ware jug (RE2), and eighteen abraded SA base and body sherds which cannot be assigned to vessels. It is difficult to see any distinction between this material and that in the later phases. Of the individual vessels, those thought to be latest in date, SA7 and OK8, do occur in the latest phase, $Z$, but as the medieval material there is all residual this may have little significance.

Seventy-four sherds of SA were identified in all. Again there are more sherds of this than any other type, and few diagnostic sherds. Most of the material may come from only one or two main vessels, with other vessels being represented by single body sherds. Twentytwo sherds (RF 3616) from context 672, Phase X, may 
Table 66 Medieval pottery from trench C15, Middle Terrace, by fabric type and context

\begin{tabular}{llrrrr}
\hline Phase & Context & $S A$ & OK & $R E$ & Total \\
\hline $\mathrm{u} / \mathrm{s}$ & & 17 & - & - & 17 \\
$\mathrm{~W}$ & 654 & 13 & 2 & - & 15 \\
$\mathrm{~W}$ & 678 & - & - & - & - \\
$\mathrm{W}$ & $655 / 678$ & - & 1 & - & 1 \\
$\mathrm{~W}$ & 667 & - & 6 & - & 6 \\
$\mathrm{~W}$ & 659 & 2 & - & - & 2 \\
$\mathrm{~W}$ & 674 & - & - & - & - \\
$\mathrm{W}$ & 669 & - & - & - & - \\
$\mathrm{W}$ & $659 / 669$ & - & - & 7 & 7 \\
$\mathrm{~W}$ & 658 & 3 & - & - & 3 \\
$\mathrm{X}$ & 662 & 1 & - & - & 1 \\
$\mathrm{X}$ & 672 & 22 & 2 & - & 24 \\
$\mathrm{X}$ & 681 & 10 & - & - & 10 \\
$\mathrm{X}$ & 665 & - & - & - & - \\
$\mathrm{Y}$ & $650 / 2 / 3$ & 4 & - & 2 & 6 \\
$\mathrm{Z}$ & 500 & 2 & 1 & - & 3 \\
Overall & & 74 & 12 & 9 & 95 \\
\hline
\end{tabular}

Key: SA=Stuffle-type wares; $\mathrm{OK}=$ North Devon Medieval Coarsewares; $\mathrm{RE}=$ Redcliffe wares

comprise one vessel, SA6, although there are only joining basal angles and part of the edge of a strap handle to give an indication of form. Most of the rest of the material is fairly homogeneous, apart from a basal angle (RF 3509) and joining body sherd (RF 3522) (SA7) from context 500 , Phase $Z$, which are finer and lighter in weight, and more like the later Lostwithiel ware, although still considered a variant of SA here. There are no rims in this collection and, although SA6 is probably a jug, it is not possible to say what form the other sherds come from.

There are twelve sherds of OK which can confidently be assigned to four vessels. Five sherds from 667 and two from 654, both contexts in Phase $\mathrm{W}$, form the rim and shoulder of a lid-seated collared jug (OK7), and a further non-joining sherd from 667 (RF 3631) is part of the same vessel. This has a diameter of approximately $180 \mathrm{~mm}$. The shoulder of this vessel is again decorated with irregular horizontal grooving. There is also a rim of a smaller collared jug without lid-seating (OK10), represented by only one sherd, from context $655 / 678$ in
Phase W. This has a diameter of only approximately $90 \mathrm{~mm}$. One vessel (OK8) has slip and glaze on the exterior surface, and is the only vessel of this type on the site to show traces of either, giving it a fourteenth- or fifteenth-century date. It is represented by only one sherd, from Phase Z, a shallowly thumbed flared basal angle similar in form to no. 9 in the Okehampton Deer Park assemblage, although that is unglazed. ${ }^{201}$ The diameter is quite small, about $100 \mathrm{~mm}$, and it is presumably from a jug. The single cooking-pot present (OK9) is represented by joining rim- and shouldersherds (RF 3616) from 672, Phase X. This is of the typical 'bell-mouthed' or cup-shaped form noted in previous collections from Radford's work ${ }^{202}$ and has a diameter of approximately $200 \mathrm{~mm}$.

Nine sherds in total of RE were identified, of which seven further sherds of RE2, the jug in the 1994 assemblage which is decorated with applied vertical strips in a white-firing clay, were found in Phase W. There is an actual join between RF 2809 from the 1994 excavation (context 900, trench $\mathrm{C} 17$, Phase $\mathrm{Y}$ ) and the four sherds (RF 3918) from the 1999 excavation (context $659 / 669$, Phase $\mathrm{W}$ ). The remaining two sherds (RF 3584) from context $650 / 2 / 3$ in Phase $Y$ may be part of RE1 from 1994 but this cannot be certain.

The previous assemblages from the assessment of Radford's trench in $\mathrm{C} 15$ at the south end of Site C contained HG and LO in Phase $Y$, as well as the above types, giving an overall date range of late twelfth to fifteenth century for $\mathrm{C} 15$. There were no examples of the earlier type $\mathrm{SO}$ in $\mathrm{C} 15$ in either phase of work. The widest date range for this trench in 1999 could be thirteenth to fifteenth century. However, the sample is possibly too small for the absence of certain types to be significant.

\section{Site C, Middle Terrace: Site C building}

Medieval ceramics were recovered only from trenches $\mathrm{C} 10$ and $\mathrm{C11}$, the two larger rooms of the building (table 67). Ninety sherds in total were recovered, of which sixty-seven are SO from Somerset/East Devon. However, this figure is misleading as these sherds can be assigned to a mere three vessels. The remaining twenty-three sherds consist of nineteen of SA and four of LO.

As can be seen from table 67, the SO wares are spread across two phases in trenches $\mathrm{ClO}$ and 11: three sherds from Phase Y, a period of scree build-up and reconstruction in $\mathrm{C} 10$, together with sixteen sherds from C11, and forty-eight from Phase X (Radford's backfill) 
in C11. Three different vessels are represented: one by the only three sherds of this type from $\mathrm{C} 10$ (Vessel SO1); a second from C11 (Vessel SO2), represented by fiftynine sherds from a single vessel across Phases $\mathrm{X}$ and $\mathrm{Y}$ and a third vessel with no diagnostic features (Vessel $\mathrm{SO} 3$ ), represented by five small sherds from $\mathrm{C} 11$. The rim of the vessel from $\mathrm{C} 10$ (SO1) has abraded brown surfaces and it is not possible to determine the diameter. Five rims from $\mathrm{C} 11$ (SO2: see figure 137), contexts 568 and 555 , have red surfaces and distinct horizontal ridges on the exterior surface from being turned, although the vessels were not wheel-made. The diameter of this vessel is quite large, around $280 \mathrm{~mm}$. Base sherds from context 568 would appear to be from the same vessel. Other sherds from this vessel are distributed between Phases $\mathrm{X}$ and Y. Both rims correspond most closely to Allan's rim form $\mathrm{X}$, which is one of the most common rim forms found from the start of production at Exeter to the late thirteenth century.

Table 67 Medieval pottery from the Site $\mathrm{C}$ building, by fabric type and context

\begin{tabular}{lccccc}
\hline \multicolumn{2}{l}{ Trench C10 } & sherds & & & \\
Context & SO & SA & LO & Phasing & Total \\
\hline 511 & 3 & - & - & $\mathrm{Y}$ & 3 \\
515 & - & 1 & - & $\mathrm{Y}$ & 1 \\
Overall & 3 & 1 & - & & 4
\end{tabular}

\begin{tabular}{|c|c|c|c|c|c|}
\hline \multicolumn{6}{|c|}{ Trench C11 86 sherds } \\
\hline Context & SO & $S A$ & $L O$ & Phasing & Total \\
\hline 568 & 46 & 18 & - & $\mathrm{X}$ & 64 \\
\hline 579 & 2 & - & - & $\mathrm{X}$ & 2 \\
\hline 551 & 9 & - & 4 & $\mathrm{Y}$ & 13 \\
\hline $552 / 554$ & 2 & - & - & $\mathrm{Y}$ & 2 \\
\hline 555 & 5 & - & - & $\mathrm{Y}$ & 5 \\
\hline Overall & 64 & 18 & 4 & & 86 \\
\hline \multicolumn{6}{|c|}{ Cumulative totals } \\
\hline & SO & $S A$ & $L O$ & & Total \\
\hline & 67 & 19 & 4 & & 90 \\
\hline
\end{tabular}

Key: $\mathrm{SO}=$ Chert-tempered wares; $\mathrm{SA}=$ Stuffle-type wares; $\mathrm{LO}=$ Lostwithiel wares
SA ware is represented on this part of the Middle Terrace by eighteen sherds from Radford's backfill in Phase $\mathrm{X}$ of $\mathrm{C} 11$ and a single sherd from reconstruction and scree build-up in Phase $\mathrm{Y}$ of $\mathrm{C} 10$. LO ware is represented by four sherds of one vessel of Fabric C, from Phase $\mathrm{Y}$ in $\mathrm{C} 11$.

\section{Site T: Radford's trenches, trench T02}

Three sherds of medieval and post-medieval pottery were found in trench T02 (table 68). The medieval pottery comprises one abraded sherd from the topsoil of an SA vessel that is possibly part of a handle rather than a rim. The post-medieval pottery comprises two sherds of $\mathrm{NC}$ from jars or jugs, with splashes of slip and glaze on the exterior surface only. Since these sherds are the only other pottery from T02, being from contexts 1204 and 1211, Phase X, they give a sixteenth- to early seventeenth-century date to these deposits accumulated within the ditch.

Site T: the Great Ditch, trench T01

The earliest phase here from which medieval ceramics were identified is Phase W. Six sherds of SA were recovered from this phase, including a collared jug neck and rim sherds from a jug (SA8; RF 4217). A sherd of OK was also found. Eight sherds of unclassified unsourced wares (UU) were identified. This category comprises sherds of three different types of jugs found in context 1120. All are wheel-thrown and not local. RF 4243 is a body sherd from near the base of a jug, with part of a thumb indentation just visible. Most of the exterior surface is covered with green glaze, flecked with copper, and there are small splashes of glaze on the interior. The fabric is sandy and white, becoming pink on the interior surface and margin. It is superficially similar to RE, but may be a Dorset whiteware. Six conjoining sherds, RF 4249 (see figure 137), in a different sandy fabric, form a rim with part of a bridge spout remaining. The diameter appears to be about $110 \mathrm{~mm}$. This jug is in a hard-fired orange fabric, and tool-marks where the spout joins the body create the appearance of applied triangular sectioned strips running down at an angle from the rim. This area of the exterior and part of the rim and spout are covered with an orange-green glaze, with darker spots on the unglazed area of the spout. A Somerset source is likely. The other unclassified sherd, RF 4252, is in a fine hard-fired pink fabric. This is streaky, with lenses of white and red clay, and finely micaceous. There is an external amber glaze. 
Table 68 Medieval and post-medieval pottery from Site T, trenches T01 and T02, by fabric type and context

\begin{tabular}{rrrlllllllr}
\hline $\begin{array}{r}\text { Context } \\
\text { Trench T01 24 sherds }\end{array}$ & SA & OK & $S P$ & $U U$ & LO & NC & SR & Phasing & Total \\
\hline 1108 & - & - & - & - & - & - & 1 & W & 1 \\
1120 & 2 & 1 & - & 8 & 3 & - & - & W & 14 \\
1124 & 1 & - & - & - & - & - & - & W & 1 \\
1126 & 1 & - & - & - & - & - & - & W & 1 \\
1118 & 2 & - & - & - & - & - & - & W & 2 \\
& 1081 & 2 & 1 & - & - & - & - & - & $\mathrm{X}$ & 3 \\
& 1079 & - & - & - & - & - & - & 1 & $\mathrm{Y}$ & 1 \\
Overall & 1078 & - & - & 1 & - & - & - & - & $\mathrm{Z}$ & 1 \\
& & 8 & 2 & 1 & 8 & 3 & - & 2 & & 24
\end{tabular}

Trench T02 3 sherds

\begin{tabular}{|c|c|c|c|c|c|c|c|c|c|c|}
\hline & 1204 & - & - & - & - & - & 1 & - & $\mathrm{X}$ & 1 \\
\hline & 1211 & - & - & - & - & - & 1 & - & $\mathrm{X}$ & 1 \\
\hline & 1200 & 1 & - & - & - & - & - & - & $\mathrm{Z}$ & 1 \\
\hline Overall & & 1 & - & - & - & - & 2 & - & & 3 \\
\hline \multicolumn{11}{|c|}{ Cumulative totals } \\
\hline & & $S A$ & $O K$ & $S P$ & $U U$ & $L O$ & $N C$ & $S R$ & & Total \\
\hline & & 9 & 2 & 1 & 8 & 3 & 2 & 2 & & 27 \\
\hline
\end{tabular}

Key: SA=Stuffle-type wares; $\mathrm{OK}=$ North Devon Medieval Coarsewares; $\mathrm{SP}=$ Saintonge Ware; UU=unclassified unsourced wares; $\mathrm{LO}=$ Lostwithiel wares; $\mathrm{NC}=$ North Devon Calcareous Ware; $\mathrm{SR}=$ Sandy Redware

Three joining sherds of LO corresponding to variation Colliford fabric C (LOC) were also found in context 1120 of Phase W. It is not possible to determine the form of the vessel, although the curvature of the sherds suggests a large hollow-ware. It has oxidized surfaces, suggesting a late medieval rather than postmedieval date.

Medieval SA and OK (OK 11; RF 4057) were also both recovered from Phase $\mathrm{X}$, where they are the only medieval pottery. The angle of the Phase $X$ OK rim sherd is very shallow and there is a possibility that this sherd is part of a lid or a flanged bowl, although with a diameter of $100 \mathrm{~mm}$ this would be very small.

It is difficult to draw conclusions from a small sample of pottery (see table 68). As would be expected, context 1120 , containing fourteen sherds, has a wider variety of types than contexts with only one sherd, but it is remarkable nonetheless. It is also interesting that there are no SO wares in this collection, and that none was found on Site X, the Mainland Ward of the Castle, in the previous collection either (no medieval pottery was recovered at all in the present investigations of T01 ext in the Lower Ward). ${ }^{203}$ The predominance of jugs could reflect the use and status of the buildings and site, but again the sample is small. Apart from the sherd of postmedieval SR in context 1108, which may be from a bowl or dish and date from the sixteenth to seventeenth centuries, the date range for the Phase $\mathrm{W}$ contexts on present evidence is 1250 to 1500 .

\section{CONCLUSION}

The larger quantity of sherds of SO, most of which are from rooms $\mathrm{C} 10$ and $\mathrm{C} 11$ on the Middle Terrace, comprise only three main vessels (sixty-seven sherds). A further two sherds represent two vessels from trenches C18 and C19 (table 69). Fifty-nine sherds of one vessel 
Table 69 Total sherds of medieval and post-medieval pottery by fabric type and trench

\begin{tabular}{lccrrrrrrrrr}
\hline Trench & SO & $H G$ & $S A$ & $O K$ & $R E$ & $S P$ & $U U$ & $L O$ & $N C$ & $S R$ & Total \\
\hline C18, C19 & 2 & - & 62 & 60 & - & - & - & 7 & - & - & 131 \\
C15, C17 & - & 6 & 75 & 37 & 11 & - & - & 7 & - & - & 136 \\
C15 & - & - & 74 & 12 & 9 & - & - & - & - & - & 95 \\
C10, C11 & 67 & - & 19 & - & - & - & - & 4 & - & - & 90 \\
T01, T02 & - & - & 9 & 2 & - & 1 & 8 & 3 & 2 & 2 & 27 \\
Total & 69 & 6 & 239 & 111 & 20 & 1 & 8 & 21 & 2 & 2 & 479 \\
\hline
\end{tabular}

Key: $\mathrm{SO}=$ Chert-tempered wares; $\mathrm{HG}=$ Ham Green wares; $\mathrm{SA}=$ Stuffle-type wares; $\mathrm{OK}=$ North Devon Medieval Coarsewares; RE=Redcliffe wares; $\mathrm{SP}=$ Saintonge Ware; $\mathrm{UU}=$ unclassified unsourced wares; $\mathrm{LO}=$ Lostwithiel wares; $\mathrm{NC}=$ North Devon Calcareous Ware; $\mathrm{SR}=$ Sandy Redware

found close together in C11 could suggest that this was the area where it was used and broken. However, they would seem to have been dumped by Radford's workmen, so this large part of a single vessel is not considered likely to have been in situ. The oxidized surfaces of these wares date them to the eleventh or twelfth century, before the construction of the Castle. It seems likely that the builders of the Castle brought this material with them, and that the area around Site $\mathrm{C}$ may have been one of the areas where they squatted or lived while they were building it. The SO wares are not found in association with HG wares, the only other pottery that could be twelfth century, although this could be a reflection of the use of the areas rather than date. None of the SO sherds from the previous excavations could be attributed to the sites given letters, so they may also have come from this area. There are no sherds of this material from Site T. However, one sherd of SO examined at the same time as Radford's material (excavated by CAU in 1988) 204 $^{0}$ came from below the Hall, supporting the idea that they are pre-Castle. Analysis of the exact source of this type of material and its relationship to previously defined fabrics, including Sherborne Fabric A/B and Ilchester Fabric B, using a combination of petrology and chemical analysis, is still in progress. ${ }^{205}$

Recent ICP-AES analysis, combined with ICP-MS 206 has demonstrated that there is only a slight difference in the chemical composition of SA (Bunnings Park) and LO wares, and that samples of Tintagel material from Radford's excavations previously assigned to SA are closer to LO. In view of this, the term South-West Micaceous ware, already used for material from Launceston Castle $\mathrm{e}^{207}$ and Plymouth, ${ }^{208}$ might seem more appropriate. The results are confusing, however, as Stuffle Fabric B, which is quite distinct visually and petrologically from Stuffle A and Lostwithiel types, and only rarely found elsewhere, shares a similar chemistry. For the time being, conclusions arising from any previously claimed petrological or visual difference between Stuffle A and Lostwithiel ware should be modified, although those relating to wheel-throwing, glaze, decoration and forms will still hold. The fact that only a few sherds here have been attributed to LO may reflect their later date and some chronological overlap between SA and LO wares has always been acknowledged.

The medieval material from Devon, previously described as Okehampton Fabric 1, is now broadly classified as North Devon Medieval Coarseware. The only known kiln for this material is that at Barnstaple, but material from there is visually and petrologically distinct. Recent ICP-AES and ICP-MS analysis has shown that it is also chemically distinct. ${ }^{209}$

The dating of the Somerset, Cornish and Devon types above is largely derived from occurrences of forms and fabric variations in Devon, which have been used to build a framework for Cornish pottery. However, native Cornish pottery could have adopted new forms earlier than Devon, as with such a large coastline it would have been open to other influences. The dating of the Bristol wares comes from Bristol itself, from where there was a direct route down the Bristol Channel.

Minor types of unclassified Cornish and Devon wares found in the previous collection are not present here, and there are no examples of Somerset Sandy ware tripod pitchers. Foreign imports present in the previous collection but absent here are Saintonge Polychrome and 
Aardenburg ware. It is now quite common to find isolated sherds of Saintonge mottled green-glaze at remote sites as here.

The medieval collection consists almost entirely of cooking-pots and jugs; there are no definite examples of other forms. As before, more sherds can be positively assigned to jugs than to cooking-pots. The absence of cisterns, costrels, bowls or any other forms which can be found in the late medieval period, and the general lack of glazed material and wheel-thrown wares may suggest a thirteenth-fourteenth-century date for most of the Stuffle and North Devon material, although it could reflect temporary or spasmodic use of the buildings (or terraces/slopes above them), as cheese-making and brewing are products of long-term occupation. Most of the glazed vessels are the regional imports, $H G, R E$ and $\mathrm{UU}$, and the foreign import SP, obviously attractive at that date when glazed wares were not available locally. The only exceptions are the spots of glaze on the base of the LO sherds, which could have come from another vessel being fired in the same kiln, and vessel OK8 where glaze is combined with white-slip decoration which is common on OK wares after 1300. It is also common on later LO wares, although in the case of both fabrics it may have worn off, as indeed has the glaze on the only $\mathrm{HG}$ vessel.

Jugs form most of the identifiable forms on Site $T$ (Great Ditch) and this is consistent with the fact that five different types of regional and foreign imported jugs were previously found on Site Z, the Island Ward, where imported jugs formed approximately 20 per cent of the total vessels. Remarkably, all three unsourced regionally imported jugs come from one context, 1120 on Site T. The only foreign import in this collection, a single sherd of Saintonge, is also from Site T, as are the only four post-medieval sherds, which do represent other forms of vessels.

As could be expected, little differentiation can be seen in the material from different phases, and it would not be wise to lay any interpretation on any that did exist. Perhaps surprisingly, as much of the material is thought to be residual (either from Radford's backfill or from scree deposits) there are no joins between sherds from different trenches. Also, there are only a few instances of sherds of the same vessel coming from different phases of the same trench: for example, a join between sherds from Phases $\mathrm{X}$ and $\mathrm{Z}$ in $\mathrm{C18}$, and the sherds of LOC1, also thought to be from one vessel, coming from the same contexts in $\mathrm{C} 18$.
In view of the disturbed nature of the deposits excavated, the possible redeposition of excavated sherds on Site C15 (see Chapter 5) remains speculative, and if they were redeposited, it is puzzling why no sherds were ever marked with the letter $C$ at the time of original discovery by Radford. The phenomenon of there being more sherds of SA, but fewer diagnostic sherds than of $\mathrm{OK}$, has been noted from the other trenches as well as C15. It is worth considering what has happened to the other sherds of the four distinct $O K$ vessels found there. In the 1930s, and for many years after, pottery was collected selectively: rims and decorated sherds were prized, while body sherds were ignored. It may be possible that the definitive OK material was redeposited after being examined and selected by Radford's workmen; the body sherds being discarded elsewhere (possibly thrown into the sea) or not collected at the time of excavation. This presumes that sherds from 654 and its equivalents in Phase $\mathrm{W}$, where two of the $\mathrm{OK}$ vessels occur, could come from Radford's backfill, Phase $\mathrm{X}$. Why the same did not happen to the SA ware is difficult to explain, but perhaps prime sherds were retained and remain somewhere or, possibly, it was considered less important, and the diagnostic sherds were not replaced. However, given the cryptic reference in the Introduction to material being selectively kept, some may have been reburied.

\section{IRON \\ with Jennifer Jones ${ }^{210}$}

In all cases, the small amount of iron recovered from these excavations was in very poor condition, heavily corroded and in most cases only identifiable to a limited extent by $x$ ray. All items were $x$-rayed as they were highly corroded with little metal remaining. Of those items which could be identified, most were nails or parts of nails. The shape of the heads are only visible in $x$-ray (ie in two dimensions) and little further comment can be made. Only items which are of an identifiable form are included in the discussions below.

\section{Site C, Middle Terrace: Trench C15}

Eight finds in total were examined, including five finds of nail fragments or indeterminate corroded pieces from Phase V, two nail shanks from Phase W (RF 3795) and two possible nail shank fragments with one nail with traces of head of indeterminate form (RF 3974) from Phase X. 


\section{Site C, Middle Terrace: Site C building}

A small number of iron finds were recovered: one from Phase V (RF 3443, an iron nail-head); one from Phase X (RF 6093, an iron nail); and the rest from Phase Y. From $\mathrm{x}$-ray, RF 1944 from C10, comprising three small fragments, included a curving sheet fragment and a nailhead. RF 1673 from $\mathrm{Cl1}$ appears to be part of a horseshoe, with two possible sub-triangular holes visible on x-ray. Two finds from C12, RFs 1644 and 1647, are pieces of sheet metal of unclear form. These pieces are very undiagnostic but all from the same phase, a period of MoW levelling and reconstruction on the site. It is possible that they may have been from relatively recent repair equipment, conceivably with a local pony being used to bring things to the site. It is possible that the curving metal fragments could be parts of tool shafts, as identified in the 1999 season in the Site T, Great Ditch area (RF 4020). RF 3443 from Phase V, which has been identified as a nail-head, is the only example which is likely to be in an early context, being associated with the building and related features.

\section{SITE T: THE GREAT DitCH, TRENCH T01}

Six finds were analysed from trench T01. Of these, a plate-fragment (RF 4078), possibly from a hinge, and a modern iron bar (RF 4194) came from Phase X. Three modern items came from Phase $Z$, including a corroded iron pipe ( $R F$ 4028) and a corroded gate-hinge ( $R F$ 4014). All items $\mathrm{X}$-rayed appeared denser and had more iron in them than was seen on other sites at Tintagel, suggesting that the majority of the finds are relatively modern in origin.

\section{SITE T: LOWER WARD, TRENCH T01 EXT}

Two finds of iron were identified from trench T01 ext. RF 4066 (Phase Y) was thought to be a lump of mortar, but analysis showed it to be a square-headed iron nail. RF 4303 (Phase W) is an iron nail identified during the analysis of bloomery slag from the same context. This find is likely to be earlier in date than the rest of the iron examined.

\section{INDUSTRIAL WASTE \\ by Effie Photos-Jones}

\section{METHODOLOGY}

Those items which were identified on site as being potentially of industrial significance were prepared as polished blocks for examination with the stereo optical microscope and, following this, in several cases were analysed with the scanning electron microscope with the energy dispersive analyser (SEM-EDAX). Each sample was mounted on metallographic resin and ground and polished with 6 and 3 microns diamond paste and subsequently carbon coated. In one case, RF 3563b (C15, Phase $\mathrm{X}$ ) was analysed mineralogically with $\mathrm{X}$-ray diffraction (XRD).

Metallurgical slags contain a number of distinct mineralogical phases, which become apparent when the sample is examined with reflected light. SEM-EDAX analyses are undertaken firstly on the entire surface of the polished block. This type of analysis, area analysis, reflects the 'bulk' chemical composition of the sample. The bulk chemical analysis is considered to be representative of the composition of the artefact as a whole. It identifies the slag as a metallurgical slag of one kind or another, that is ferrous versus non-ferrous (taken over a mean of three).

Subsequently, spot analyses are carried out on each of the different mineralogical phases present. This is aimed at establishing the composition of each of the mineralogical phases within and so identifying the process that generated it. Each mineralogical phase contains, apart from the main constituents, a suite of other minor and trace elements (see, for example, table 74). The 'spot' analyses are aimed at identifying the process that generated each type: that is bloomery iron, smelting or smithing.

Bloomery slags whether smelting or smithing are characterized by a number of distinct mineralogical phases. These include dendrites of wustite ( $\mathrm{FeO}$ ), long or broken-up needles of fayalite $\left(2 \mathrm{FeO} . \mathrm{SiO}_{2}\right)$, angular grains of hercynite $\left(\mathrm{FeO} . \mathrm{Al}_{2} \mathrm{O}_{3}\right)$ and a glassy phase, which grows interstitially within the other phases. This last phase may be composed of more than one phase. Each phase contains, apart from the main constituents, a suite of other minor and trace elements. The SEMEDAX analyses (tables 70, 73 and 74) aimed to characterize the samples as smithing or smelting. Further detail can be found in the Research Archive Report, with cross-reference to specific finds assisted by the inclusion of laboratory work numbers included in this report (eg TINT 1 or TTG 99.1)

\section{SITE C, UPPER TERRACE: RADFORD'S TRENCHES}

Three finds of potential industrial origin were recovered from this area. RF 1242, Phase Y of trench C19 (TINT 12), was a piece of glassy, magnetic metallurgical slag, 
Table 70 SEM-EDAX analyses of industrial waste from trench $\mathrm{C} 15$ (composition in weight per cent)

\begin{tabular}{|c|c|c|c|c|c|c|c|c|c|c|c|c|c|c|c|}
\hline & $\mathrm{Na}_{2} \mathrm{O}$ & $\mathrm{MgO}$ & $\mathrm{Al}_{2} \mathrm{O}_{3}$ & $\mathrm{SiO}_{2}$ & $\mathrm{SO}_{3}$ & $\mathrm{P}_{2} \mathrm{O}_{5}$ & $\mathrm{~K}_{2} \mathrm{O}$ & $\mathrm{CaO}$ & $\mathrm{TiO}_{2}$ & $\mathrm{MnO}$ & $\mathrm{FeO}$ & $\mathrm{BaO}$ & $\mathrm{NiO}$ & Total & $N$ \\
\hline \multicolumn{16}{|l|}{ Bloomery slags } \\
\hline \multicolumn{16}{|l|}{ RF 3956b } \\
\hline TTG1 wustite & 0 & 0.17 & 0.62 & 0.34 & 0.08 & 0.02 & 0 & 0.05 & 0.31 & 0.23 & 98.15 & 0.04 & $\mathrm{~nm}$ & 100.01 & $\mathrm{~N}$ \\
\hline TTG1 fayalite & 2.53 & 0.27 & 19.5 & 38.44 & 0.5 & 3.34 & 9.93 & 6.28 & 0.21 & 0.19 & 18.62 & 0.21 & $\mathrm{~nm}$ & 100.02 & $\mathrm{~N}$ \\
\hline TTG1 matrix & 2.45 & 0.31 & 20.19 & 37.12 & 0.52 & 3.24 & 9.38 & 6.64 & 0.22 & 0.19 & 19.71 & 0.04 & $\mathrm{~nm}$ & 100.01 & $\mathrm{~N}$ \\
\hline \multicolumn{16}{|l|}{ RF 3682} \\
\hline $\begin{array}{l}\text { TTG7 area } \\
\text { analysis }\end{array}$ & 0.95 & 1.07 & 8.74 & 25.41 & 0.23 & 0.97 & 2.97 & 3 & 0.48 & 0.32 & 55.7 & 0.16 & $\mathrm{~nm}$ & 100 & $\mathrm{~N}$ \\
\hline TTG7 fayalite & 0 & 3.3 & 4.13 & 24.69 & 0.02 & 0.36 & 0.08 & 0.59 & 0.26 & 0.49 & 66 & 0.12 & $\mathrm{~nm}$ & 100.04 & $\mathrm{~N}$ \\
\hline TTG7 matrix & 0.96 & 0.34 & 11.75 & 34.36 & 0.5 & 2.39 & 6.32 & 10.87 & 0.58 & 0.16 & 31.46 & 0.31 & $\mathrm{~nm}$ & 100 & $\mathrm{~N}$ \\
\hline \multicolumn{16}{|c|}{ Manganese nodule } \\
\hline \multicolumn{16}{|l|}{ RF 6092} \\
\hline \multicolumn{2}{|c|}{$\begin{array}{l}\text { TTG3 manganese } 0 \\
\text { nodule, area analysis }\end{array}$} & 0.02 & 0.34 & 0.53 & 0 & 0.03 & 0.04 & 0.22 & 0.03 & 97.8 & 0.82 & 0.18 & $\mathrm{~nm}$ & 100.02 & $\mathrm{~N}$ \\
\hline $\begin{array}{l}\text { TTG3 iron } \\
\text { silicate }\end{array}$ & 0.57 & 11.33 & 23.01 & 27.33 & 0.04 & 0 & 0.12 & 0 & 0.04 & 0.47 & 37.01 & 0.09 & $\mathrm{~nm}$ & 100.01 & $\mathrm{~N}$ \\
\hline $\begin{array}{l}\text { TTG3 } \\
\text { manganese } \\
\text { oxide phase }\end{array}$ & 0.36 & 0.81 & 4.54 & 5.86 & 0.06 & 0.37 & 0.51 & 0.3 & 0.15 & 79.9 & 7.17 & 0.01 & $\mathrm{~nm}$ & 100.01 & $\mathrm{~N}$ \\
\hline $\begin{array}{l}\text { TTG3 iron } \\
\text { silicate phase }\end{array}$ & 0.53 & 11.3 & 22.98 & 27.43 & 0.03 & 0 & 0.09 & 0.04 & 0.09 & 0.39 & 37.02 & 0.11 & $\mathrm{~nm}$ & 100.01 & $\mathrm{~N}$ \\
\hline $\begin{array}{l}\text { TTG3 } \\
\text { aluminium } \\
\text { silicate phase }\end{array}$ & 5.1 & 0.21 & 20.21 & 69.38 & 0.08 & 0.06 & 0.24 & 3.13 & 0 & 0.07 & 1.5 & 0.04 & $\mathrm{~nm}$ & 100.02 & $\mathrm{~N}$ \\
\hline
\end{tabular}

$\mathrm{nm}=$ not measured; $\mathrm{N}=$ normalized; all analyses = spot analyses unless otherwise reported

possibly related to iron-making activity. Its isolated presence precludes further comment, except to note that it is presumed to be part of a procedure which was taking place in the general vicinity and where one would expect considerably more material of this nature to be concentrated. Two further pieces of potential metallurgical debris were examined from trench $\mathrm{C} 18$ and confirmed as being related to metallurgical activity (RFs 2447, slag, and 2514, furnace-lining, TINT 16 and 15 respectively). That from Phase $Z$ (RF 2447) can be confirmed as iron slag, possibly relating to smithing or smelting activity, whereas that from Phase X (RF 2514), the disturbed scree, is likely to be furnace-lining. Once more, in isolation these finds have only limited significance, pointing to activity in areas outwith those in the current programme of work.
It is possible that the two iron fragments, from Phases $\mathrm{Z}$ and $\mathrm{X}$ of Trench C18 respectively (see Chapter 3 , table 7), may have been the product of localized ironworking, but the sample is too small to do more than suggest this association.

\section{Site C, Middle Terrace: Radford's trenches} Two pieces from trench $\mathrm{C} 17$ were studied. An unstratified piece was identified as natural (iron pan), whilst a piece from Phase $Y$ was a very small piece which is likely to be a fragment of crucible rather than metallic (RF 2816).

A number of samples were examined from trial trench $\mathrm{C15}$, but several were not industrial in character. However, SEM-EDAX work was undertaken on promising samples. Figure 138 ( $a$ and $b$ ) illustrates SEM 
sections from RF 3301, trial trench C15, Phase X (TINT 2) which was considered on site to be a slag, but which on analysis proved to be a highly fired ceramic-type fabric of unspecified process. This small fragment was highly vesicular with ranging pore size, varied size of quartz inclusions and non-magnetic. SEM examination has shown that the material consists of a largely glassy alumino-silicate matrix containing high levels of potassium and iron. It also contains largely undigested quartz grains and a large number of iron oxide inclusions (seen as bright specks in a dull matrix). The number of iron oxide inclusions must have formed under reducing conditions because of the large quantity of iron available in the matrix in the first place. The combined presence of potassium and iron - both acting as fluxes - must have lowered the temperature of fusion/melting point of this material. On the basis of this analysis, this fragment appears to have been a ceramic-type fabric which has been exposed to a high temperature but in a largely reducing environment (table 71).

In contrast, TINT 3 (RF 1758, trial trench C15, Phase Y: see figure 138c) is a largish fragment of hearth/furnace-wall or, possibly but less likely, part of a thick crucible. The gradient of vitrification runs along in a decreasing manner from top to bottom. Four distinct layers are obvious, in order from the top: first, a highly vitrified layer displaying little porosity; second, a glassy layer; third, a sintered layer; and finally a reddish-orange layer showing only partial heating. The SEM investigations determine that this ceramic fabric consists largely of glassy, alumino-silicate matrix. The SEM photos show only a section of the polished block from near the surface (the first layer). Fayalitic (iron-silicate) needles are seen growing within the glassy matrix but more importantly - large metallic iron prills are still present (the bright phase at the centre of the photograph) as well as oxidized ones ( $\mathrm{cf}$ the ghosts thereof on either side of the bright inclusion). The presence of metallic iron inclusions of that shape and size suggest the presence of metallurgical slag having reacted with the hearth/furnace-wall, and/or the exposure of this ceramic fabric in a severely reducing environment. This fragment, therefore, shows direct association with an iron-making process.

\section{Site C, Middle Terrace: trench C15}

Eight samples were presented for examination and analysis (table 72). They derive from four different
Phases: T, V, W and X. All samples were weighed and a description of their morphology and texture provided. In general, the samples were small (c 10-20 mm, long axis), porous, mostly light and dark brown to black in colour. A heavy layer of encrustation masked their internal porosity and texture. Each find was sampled, and one (RF 3563b) was analysed mineralogically with $\mathrm{x}$-ray diffraction. The materials fall into three distinct groups: bloomery slags (RFs 3956b: figure 139a-b, 3682 and 3563b), a manganese oxide nodule (RF 6092: figure 140a-b) and highly siliceous materials (RFs 3968, 3981, 6019 and 6093: figure 141a-b), identified as vitrified waste/fuel ash.

Area analysis for RFs $3956 \mathrm{~b}$ and 3682 shows that the samples are fayalitic types of slag with traces of manganese and small amounts of calcium and potassium (see figure 139). The matrix does not contain any unusual elements indicating a particular type of deposit. Fayalitic bloomery slags can be associated with both smelting and smithing practices. Conclusions therefore regarding the predominance of one practice versus the other must be based on associated evidence, be it the presence of samples of ores or metallurgical ceramics, for instance. RF $3563 \mathrm{~b}$ is another bloomery type slag consisting of similar phases to the latter two samples, namely fayalite and wustite. The phosphorus may point to the use of a bog ore in addition to other (haematite) sources. The evidence can only be suggestive given the small number of samples available for analysis. It is clear that there is metallurgical waste on this part of the site, but the question is to what extent metallurgical practices were carried out there. To that end, evidence for hearths with an associated spread of hammerscale, and metallurgical ceramics would be expected elsewhere in the vicinity.

It was originally thought that TTG99.3 = RF 6092 (although non-magnetic) might be metallic on account of the sheen on the surface of the polished block. Area analysis revealed 98 per cent $\mathrm{MnO}$ (see table 72). Subsequently, spot analyses were carried out on various inclusions/phases to determine the elemental composition of each. The nodule was shown to be primarily $\mathrm{MnO}$, but included minerals which are rich in iron or aluminium silicate (see figure 140a-b). Small manganese nodules have been observed in bloomery sites such as Allt na Ceardaich, Loch Eck. ${ }^{211}$ Manganese nodules are normally associated with bog iron ores, although their content within these ores tends to be variable. Manganese-rich accumulations are likely to be related to locally enriched source rocks such as 
EHT: $20.0 \mathrm{KV}$ WD= 25 in MAG= $\times 18.8 \quad$ PHOTO= $45 \quad R=40 B S D$

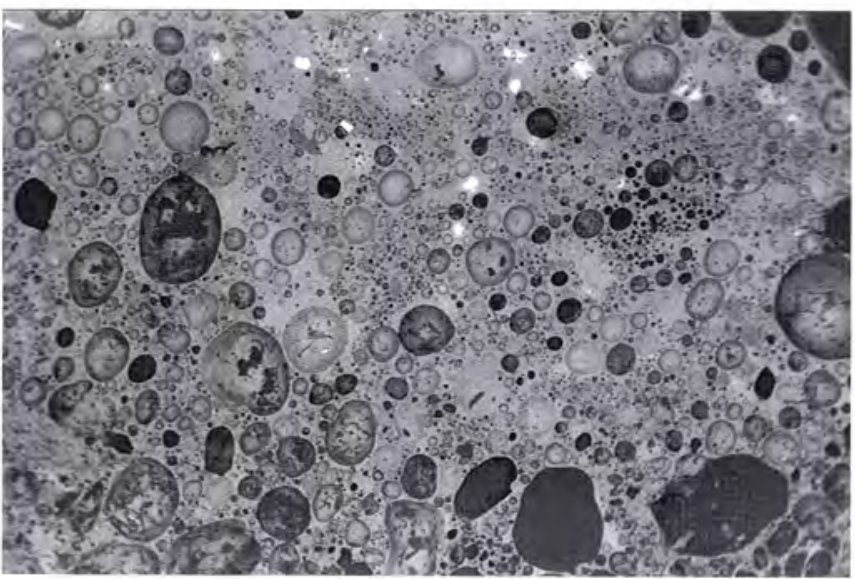

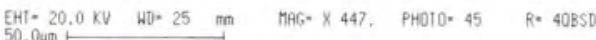
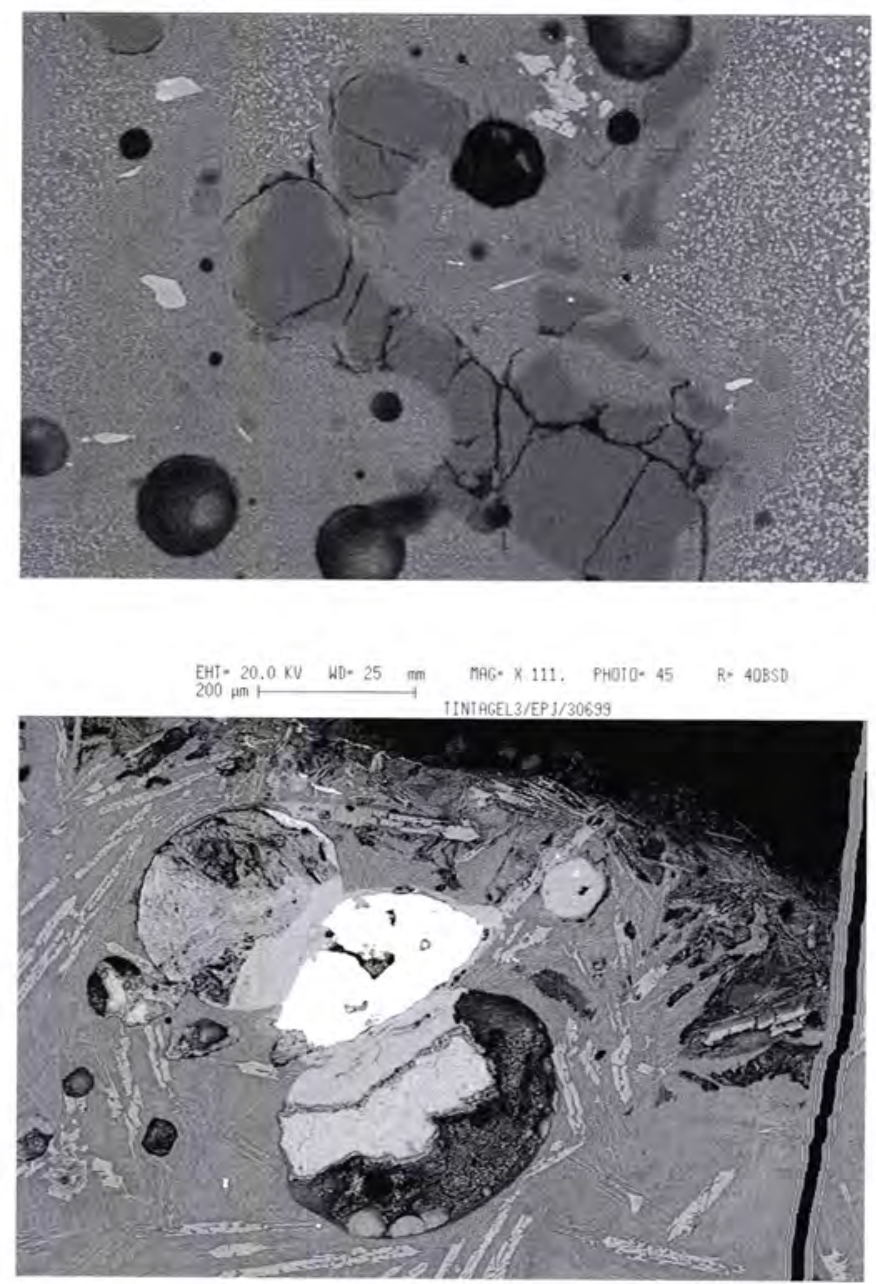

a SEM-BS image of a section of RF 3301 (TINT 2) showing an alumino-silicate matrix containing high levels of potassium and iron and showing extensive porosity. The fragment is a highly vitrified ceramic of unspecified function (bar $=2 \mathrm{~mm})$ b Another SEM-BS image of a section of RF 3301 (TINT 2) showing largely undigested quartz grains and a large number of iron oxide inclusions (seen as bright specks in the dull grey alumino-silicate matrix). The glassy matrix shows, at places, micro-crystallinity (bar $=50$ microns)

c SEM-BS image of a section of RF 1758 (TINT 3), the highly vitrified area. The bright metallic iron inclusion in the centre of the image and the ghost images of other round iron inclusions, presently weathered, suggests that this fragment was part of a furnace-wall (bar = 200 microns).

138 SEM sections of two samples of industrial waste: TINT 2 (RF 3301, C15) and TINT 3 (RF 1758, C15). Photographs: E Photos-Jones 
Table 71 SEM-EDAX analyses of fragment of vitrified ceramic (RF 3301) from trench C15 (composition in weight per cent)

\begin{tabular}{lcccccccccccc}
\hline Sample TINT 2 & $\mathrm{Na}_{2} \mathrm{O}$ & $\mathrm{MgO}^{2}$ & $\mathrm{AI}_{2} \mathrm{O}_{3}$ & $\mathrm{SiO}_{2}$ & $\mathrm{P}_{2} \mathrm{O}_{5}$ & $\mathrm{SO}_{3}$ & $\mathrm{~K}_{2} \mathrm{O}$ & $\mathrm{CaO}$ & $\mathrm{TiO}_{2}$ & $\mathrm{MnO}$ & $\mathrm{FeO}$ & Total \\
\hline Area analysis & 0.64 & 3.05 & 21.37 & 47.7 & 0.32 & 0.16 & 7.02 & 0.83 & 2.16 & 0.15 & 14.39 & 97.79 \\
FeO-rich inclusion & 0.28 & 0.25 & 0.12 & 0.26 & 0 & 0 & 0.05 & 0.04 & 0.09 & 0 & 98.92 & 100.0 \\
\hline
\end{tabular}

Table 72 Industrial material analysed from trench $\mathrm{Cl} 5$

\begin{tabular}{|c|c|c|c|c|c|c|c|c|c|}
\hline $\begin{array}{l}\text { SASAA } \\
\text { sample } \\
\text { no. }\end{array}$ & $\begin{array}{l}\text { RF } \\
\text { no. }\end{array}$ & Description & Identification & Trench & Context & Bearings & $\begin{array}{l}\text { Weight } \\
(g)\end{array}$ & Phase & $\begin{array}{l}\text { Polished } \\
\text { block }\end{array}$ \\
\hline TTG99.1 & $3956 b$ & $\begin{array}{l}\text { Ferruginous, brown- } \\
\text { black, porous, less than } \\
20 \mathrm{~mm} \text { (long axis) }\end{array}$ & $\begin{array}{l}\text { Bloomery } \\
\text { slag }\end{array}$ & $\mathrm{C} 15$ & 687 & $\begin{array}{c}\mathrm{C} 998.19 \mathrm{E} / \\
994.88 \mathrm{~N}\end{array}$ & 10.0 & V & 3 \\
\hline TTG99.2 & 3968 & $\begin{array}{l}\text { Dark grey/blue in } \\
\text { colour, occasional large } \\
\text { pores, relatively uniform } \\
\text { make-up, glassy; less } \\
\text { than } 10 \mathrm{~mm} \text { (long axis) }\end{array}$ & $\begin{array}{l}\text { Vitrified } \\
\text { fuel ash } \\
\text { slag }\end{array}$ & C15 & 687 & $\begin{array}{l}\mathrm{C} 996.96 \mathrm{E} / \\
\mathrm{C} 992.70 \mathrm{~N}\end{array}$ & 4.2 & V & 3 \\
\hline TTG99.3 & 6092 & $\begin{array}{l}\text { Two fragments: } \\
\text { a) brown-black with } \\
\text { occasional medium } \\
\text { sized pores; b) grey-black } \\
\text { with few visible pores }\end{array}$ & $\begin{array}{l}\text { Manganese } \\
\text { oxide }\end{array}$ & & 697 & & 6.8 & $\mathrm{~T}$ & 3 \\
\hline TTG99.4 & 3981 & $\begin{array}{l}\text { Dark brown in colour, } \\
\text { occasional lighter } \\
\text { inclusions, appears } \\
\text { relatively non-porous }\end{array}$ & $\begin{array}{l}\text { Vitrified } \\
\text { fuel ash } \\
\text { slag }\end{array}$ & $\mathrm{C} 15$ & 687 & $\begin{array}{l}\mathrm{C} 996.78 \mathrm{E} / \\
\mathrm{C} 992.93 \mathrm{~N}\end{array}$ & 4.0 & V & 3 \\
\hline TTG99.5 & 6019 & $\begin{array}{l}\text { Dark brown in surface } \\
\text { with black glassy } \\
\text { interior, white inclusions } \\
\text { and fine pores. } \\
\text { Less than } 10 \mathrm{~mm} \text { (long } \\
\text { axis) }\end{array}$ & $\begin{array}{l}\text { Vitrified } \\
\text { fuel ash } \\
\text { slag }\end{array}$ & $\mathrm{C} 15$ & 697 & $\begin{array}{l}\mathrm{C} 997.28 \mathrm{E} / \\
\mathrm{C} 991.38 \mathrm{~N}\end{array}$ & 2.7 & $\mathrm{~T}$ & 3 \\
\hline TTG99.6 & 6093 & $\begin{array}{l}\text { Small fragments, } \\
\text { brown-black in colour, } \\
\text { porous; less than } 10 \mathrm{~mm}\end{array}$ & $\begin{array}{l}\text { Vitrified } \\
\text { fuel ash } \\
\text { slag }\end{array}$ & C15 & 697 & & 0.1 & $\mathrm{~T}$ & 3 \\
\hline TTG99.7 & 3682 & $\begin{array}{l}\text { A single fragment of } \\
\text { slag, brown-black with } \\
\text { medium sized pores; less } \\
\text { than } 20 \mathrm{~mm} \text { (long axis) }\end{array}$ & $\begin{array}{l}\text { Bloomery } \\
\text { slag }\end{array}$ & $\mathrm{C} 15$ & 667 & $\begin{array}{l}\mathrm{C} 994.50 \mathrm{E} / \\
\mathrm{C} 993.09 \mathrm{~N}\end{array}$ & 21.7 & $\mathrm{~W}$ & 3 \\
\hline TTG99.8 & $3563 b$ & Not available & $\begin{array}{l}\text { Bloomery } \\
\text { slag }\end{array}$ & $\mathrm{C} 15$ & 662 & & 5.0 & $\mathrm{X}$ & XRD \\
\hline
\end{tabular}



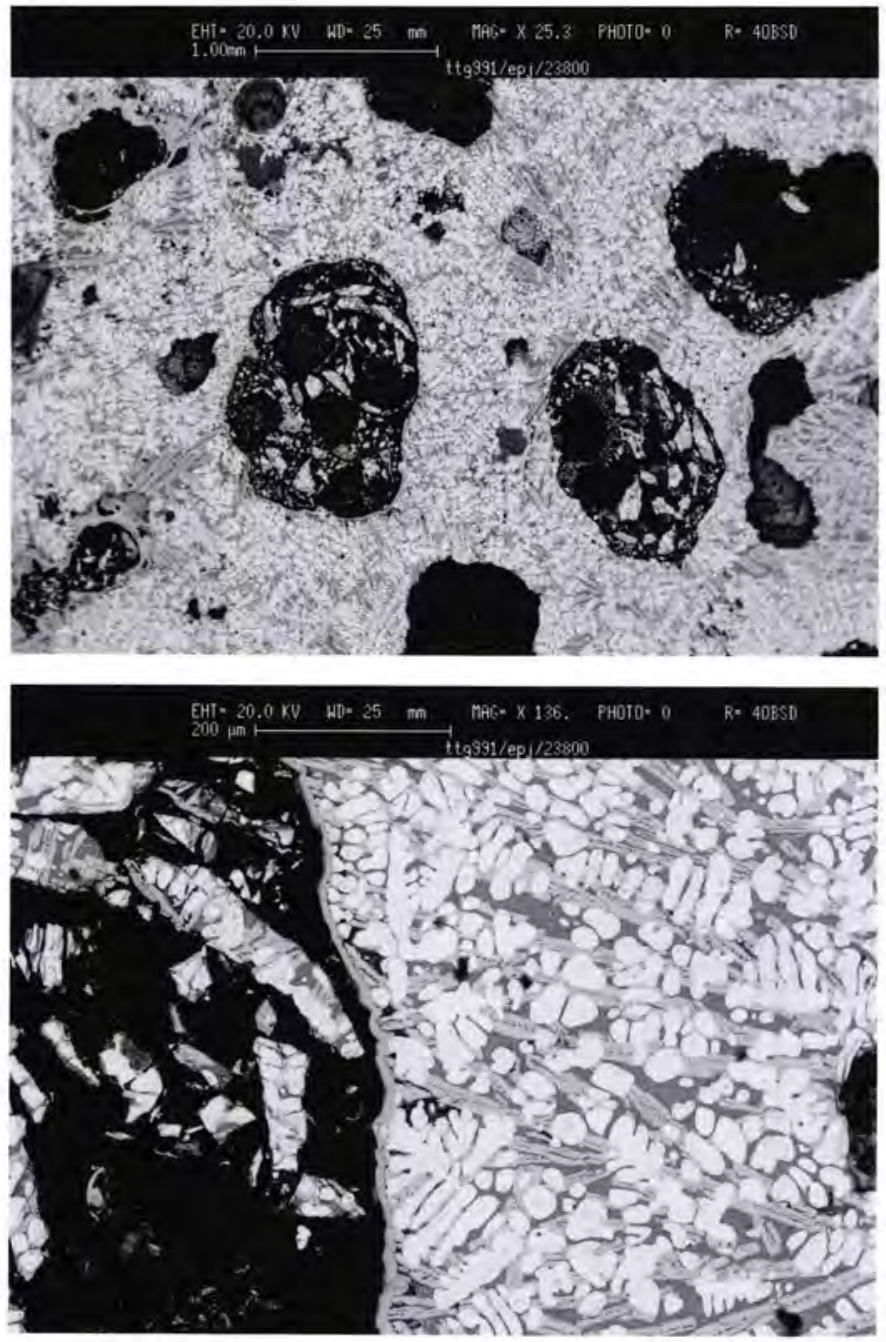

a SEM-BS image of TTG99.1 (RF 3956b) showing a three-phase polished block consisting of needles of fayalite, globular wustite and an interstitial phase, which is non-crystalline. Chemical analysis and the appropriate mineralogy suggest that this is a fragment of bloomery slag $($ bar $=1 \mathrm{~mm})$

b SEM-BS image of TTG99.1, an area of the section illustrated above but at higher magnification with dendrites of wustite, needles of fayalite and an interstitial glassy phase (bar $=200$ microns)

139 SEM-BS images of RF 3956b. Photographs: E Photos-Jones

manganiferous limestones or schists. ${ }^{212}$ The Allt na Ceardaich slags are rich in manganese corroborating the intentional or unintentional use of these nodules as part of the 'ore'. None of the slags analysed from Tintagel are rich in manganese. It is suggested that these nodules could not have been common amidst the 'iron ore' at Tintagel.

The four samples of vitrified fuel ash slags examined were light and highly vesicular, of grey or black colour. Area analysis revealed the presence of iron aluminium silicates with potassium (originating from fuel ash) and small amounts of calcium and magnesium (table 73). A 'skin' of the same composition as the 'body' is evident in two samples resulting from the melting and subsequent cooling/crystallization of the outer surface (see figure 14la-b). The 'skin' is no more than 100-200 microns thick. Small quartz or quartzite grains are trapped and occasionally digested by the surrounding matrix. Iron oxide surface layers are formed and metallic inclusions within are also evident. The composition of these materials points to them being vitrified fuel ash slag.

Fuel ash from plants rich in alkalis, sodium and potassium oxides will react with silica both in the soil as well as in clay (quartz inclusions) resulting in the production of what is normally called vitrified fuel ash slag. Because similar materials have been found within domestic hearths, it has been suggested that they can be produced in relatively low temperatures but under reducing conditions. ${ }^{213}$ Indeed, in Scotland, these 

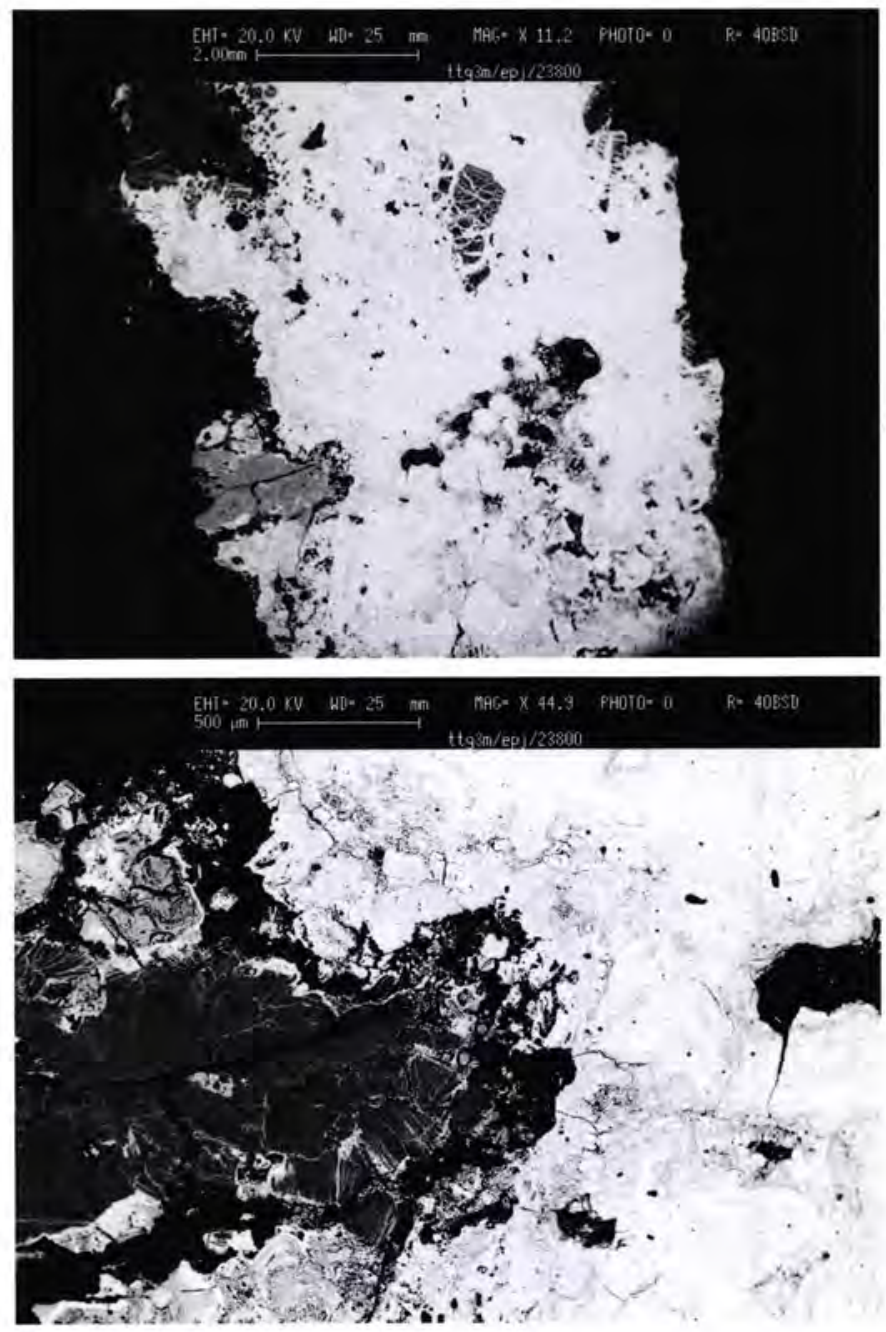

a SEM-BS image of sample TTG99.3 (RF 6092), a nodule of manganese oxide with a number of silica and iron aluminium silicate inclusions (bar $=2 \mathrm{~mm}$ ) b SEM-BS image of TTG99.3 (the same sample as above), focusing on the area of the iron silicate inclusion (bar $=500$ microns)

140 SEM-BS images of RF 6092. Photographs: E Photos-Jones

materials originating from cremation pyres have been called cramp. ${ }^{214}$ Vitrified fuel ash slags alone, however, cannot be used as the sole indicators of metallurgical processes.

To conclude, there is clear evidence for industrial activity in Phase V (context 687) as represented by a single sample of slag (TTG99.1 = RF 3956b), although it is not clear whether it represents smelting or smithing. Two additional samples, also deriving from the same context (TTG99.2 = RF 3968 and TTG99.4 = RF 3981) as well as context 697 of Phase T (TTG99.5 and TTG99.6 = RFs 6019 and 6093), included vitrified fuel ash. However, the latter may or may not be of metallurgical origin. Metallurgical slag (smelting or smithing) is also evident in two additional contexts (667: TTG99.7 $=$ RF 3682, Phase W and 662: TTG99.8 = RF 3563, Phase X). The single fragment of slag (TTG99.1 = RF 3956b), provides the limited but nevertheless unambiguous proof of metal-working on this part of the site.

\section{Site C, Middle Terrace: Site C building}

Seven finds that were identified as being potentially industrial in origin were examined. Four were found to be natural in origin, although ferruginous in nature: RF 3367 from Phase U2 of C09 (TINT 9); RFs 1967 (TINT 10 ) and 2300 (TINT 11) from Phase $Y$ of $\mathrm{C} 10$ and RF 2622 (TINT 13) from Phase $\mathrm{T}$ of $\mathrm{C} 16$. Of the remaining pieces, RF 2621 from Phase T of C16 (siliceous-type 

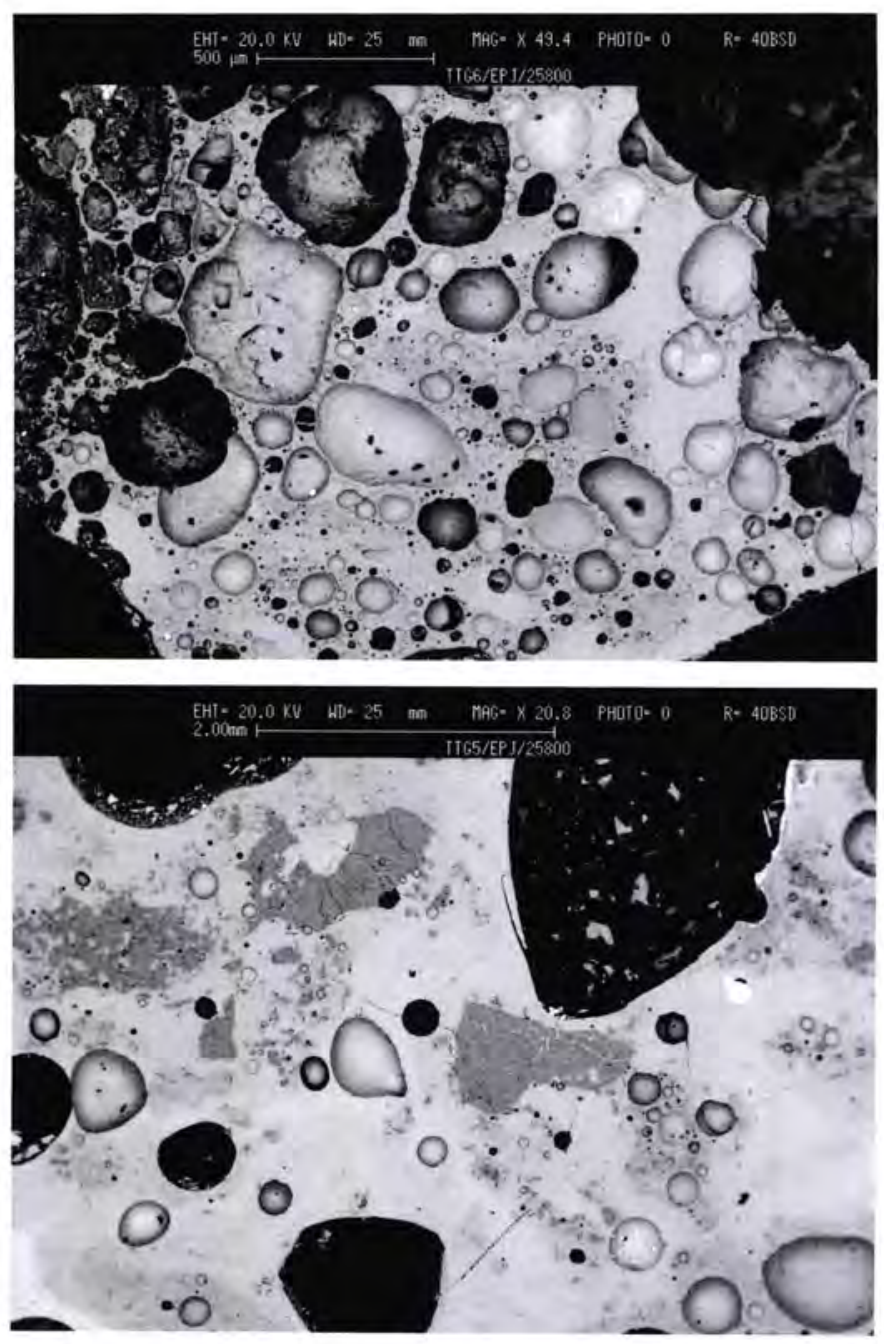

a SEM-BS image of TTG99.6 (RF 6093), consisting of a glassy but very porous matrix in agreement with VFA texture and morphology (bar $=500$ microns) b SEM-BS image of TTG99.5 (RF 6019), also a fragment of VFA, showing unreacted quartz grains (angular dark inclusions) and bright metallic inclusions (bar $=2 \mathrm{~mm}$ )

141 SEM-BS images of RFs 6093 and 6019. Photographs: E Photos-Jones

material TINT 6) and RF 1434 from Phase Y of C10 (ceramic-type material TINT 8) are heat-related, but this could simply be domestic hearth activity. RF 1121 from Phase W in C09 may be metallurgical debris associated with iron production (TINT 5). This sample was a small fragment of dark brown, vesicular and most likely metallurgical slag, possibly containing weathered remains of metallic inclusions. On sectioning it, a 'halo' of extensively weathered slag surrounded a black, nonglassy, spongy-looking core.

SITE T: THE LOWER WARD, TRENCH T01 EXT RF 4293 and RFs 4337-4339 (combined from same sample 3460) from context 1135, Phase W, consisted of two to three small fragments each. Following examination with SEM-EDAX, the chemical composition of individual fragments is shown in table 74 and the data are accompanied by SEM-BS images of appropriate areas within the polished blocks (figures 142a-c and 143a-c).

Both samples are shown to be fragments of bloomery smelting slags. The presence of unusual elements like chromium may, given further work, point to particular sources of iron ore. Earlier analyses of the industrial waste from the excavations at Tintage ${ }^{215}$ have offered only a tentative suggestion for evidence of ironworking. With the above analyses, and the association of the finds with a rich burnt deposit, this suggestion can now be strengthened. 
Table 73 SEM-EDAX analyses of industrial waste from trench C15 (composition in weight per cent)

\begin{tabular}{|c|c|c|c|c|c|c|c|c|c|c|c|c|c|c|}
\hline & $\mathrm{Na}_{2} \mathrm{O}$ & $\mathrm{MgO}$ & $\mathrm{Al}_{2} \mathrm{O}_{3}$ & $\mathrm{SiO}_{2}$ & $\mathrm{SO}_{3}$ & $\mathrm{P}_{2} \mathrm{O}_{5}$ & $\mathrm{~K}_{2} \mathrm{O}$ & $\mathrm{CaO}$ & $\mathrm{TiO}_{2}$ & $\mathrm{MnO}$ & $\mathrm{FeO}$ & $\mathrm{BaO}$ & Total & $N$ \\
\hline \multicolumn{15}{|l|}{ Vitrified fuel ash slag } \\
\hline \multicolumn{15}{|l|}{ RF 3968} \\
\hline $\begin{array}{l}\text { TTG2 area analysis over } \\
\text { the all-glass section }\end{array}$ & 0.48 & 2.14 & 24.06 & 52.7 & 0 & 0.24 & 6.61 & 0.37 & 1.22 & 0.27 & 11.7 & 0.21 & 100.03 & $\mathrm{~N}$ \\
\hline $\begin{array}{l}\text { TTG2 area analysis over } \\
\text { the porous section }\end{array}$ & 0.94 & 2.3 & 15.57 & 51.9 & 0.09 & 1.16 & 5.69 & 0.94 & 1.21 & 1.39 & 18.6 & 0.26 & 100.02 & $\mathrm{~N}$ \\
\hline \multicolumn{15}{|l|}{ RF 3981} \\
\hline TTG4 area analysis & 0.5 & 1.92 & 19.65 & 53.8 & 0.13 & 1.08 & 6.28 & 1.51 & 1.17 & 0.62 & 13.4 & 0 & 100 & $\mathrm{~N}$ \\
\hline $\begin{array}{l}\text { TTG4 spot analysis on } \\
\text { the porous section }\end{array}$ & 0.69 & 4.05 & 18.11 & 41.4 & 0 & 2.41 & 4.29 & 4.56 & 1.06 & 1.27 & 22 & 0.25 & 100.02 & $\mathrm{~N}$ \\
\hline \multicolumn{15}{|l|}{ RF 6019} \\
\hline $\begin{array}{l}\text { TTG5 area analysis over } \\
\text { the all-glass section }\end{array}$ & 0.33 & 1.92 & 16.59 & 54.6 & 0.01 & 0.71 & 5.94 & 1.38 & 1.16 & 0.18 & 16.7 & 0.45 & 99.98 & $\mathrm{~N}$ \\
\hline TTG5 matrix & 0.7 & 2.18 & 17.6 & 46.9 & 0.06 & 1.02 & 6.52 & 3.21 & 1.15 & 0.48 & 20 & 0.23 & 100.01 & $N$ \\
\hline TTG5 metallic iron prill & 0 & 0.08 & 0.05 & 0.11 & 0.03 & 1.02 & 0 & 0.02 & 0 & 0 & 98.7 & 0.02 & 100.01 & $\mathrm{~N}$ \\
\hline $\begin{array}{l}\text { TTG5 iron oxide } \\
\text { inclusion }\end{array}$ & 0.44 & 0.08 & 0.11 & 2.23 & 0.16 & 0.57 & 0.04 & 0.03 & 0 & 0.05 & 96.1 & 0.22 & 99.99 & $\mathrm{~N}$ \\
\hline $\begin{array}{l}\text { TTG5 spot analysis over } \\
\text { the porous section }\end{array}$ & 0.54 & 3.24 & 18.36 & 45.6 & 0.08 & 1.61 & 4.03 & 12.8 & 1.54 & 1.08 & 10.9 & 0.26 & 100.01 & $\mathrm{~N}$ \\
\hline \multicolumn{15}{|l|}{ RF 6093} \\
\hline TTG6 area analysis & 0.13 & 2.24 & 22.55 & 49.4 & 0.13 & 1.17 & 6.54 & 1.5 & 1.67 & 0.49 & 13.8 & 0.36 & 99.98 & $\mathrm{~N}$ \\
\hline TTG6 metallic inclusion & 0 & 0.28 & 1.97 & 6.43 & 0.24 & 0.07 & 0.61 & 0 & 0.02 & 0.79 & 89.6 & 0 & 100 & $\mathrm{~N}$ \\
\hline $\begin{array}{l}\text { TTG6 spot analysis over } \\
\text { the porous section }\end{array}$ & 0.57 & 1.44 & 16.98 & 64.4 & 0.05 & 0.27 & 6.87 & 0.15 & 0.94 & 0.03 & 8.14 & 0.13 & 100.01 & $\mathrm{~N}$ \\
\hline
\end{tabular}

$\mathrm{N}=$ normalized; all analyses $=$ spot analyses unless otherwise reported

\section{OVERALL COMMENT}

Metallurgical activity dated to the fifth-seventh centuries $\mathrm{AD}$ at Tintagel has up until now been suggested but not really confirmed by the evidence available. Pieces of slag from the Upper Terrace were from later phases ( $Y$ and Z) and probably not in situ. However, the pieces from the Middle Terrace trial trench C15 (TINT $3=\mathrm{RF}$ 1758, furnace-walling) and also from the Site C building C09 Phase W (TINT $5=$ RF 1121) appear to indicate actual metal-working on this part of the site. Bloomery slag RF 3563b (from Phase X) and possible smelting slag RFs 3956b (Phase V) and 3682 (Phase W) from the Middle Terrace Site C15, in addition to the vitrified fuel ash material from Phase $\mathrm{T}$ of that area, also suggest working in the vicinity. This suggestion is reinforced by the evidence from the Lower Terrace. ${ }^{216}$ There have been industrial finds elsewhere, such as the sprue for copper alloy working from the area of the Steps ${ }^{217}$ and the smithing hearth base, TINT1, found on the path through Site B. In combination with these, and the small amount of debris from the Lower Ward, it would seem that there are tantalizing indications of industrial activity throughout various parts of the Island complex. This industrial activity should not be seen as something out of the ordinary, however, as a 'settlement' site like Tintagel would have had a need for, and indeed would have accommodated, iron-making facilities to meet its daily needs in iron implements. 

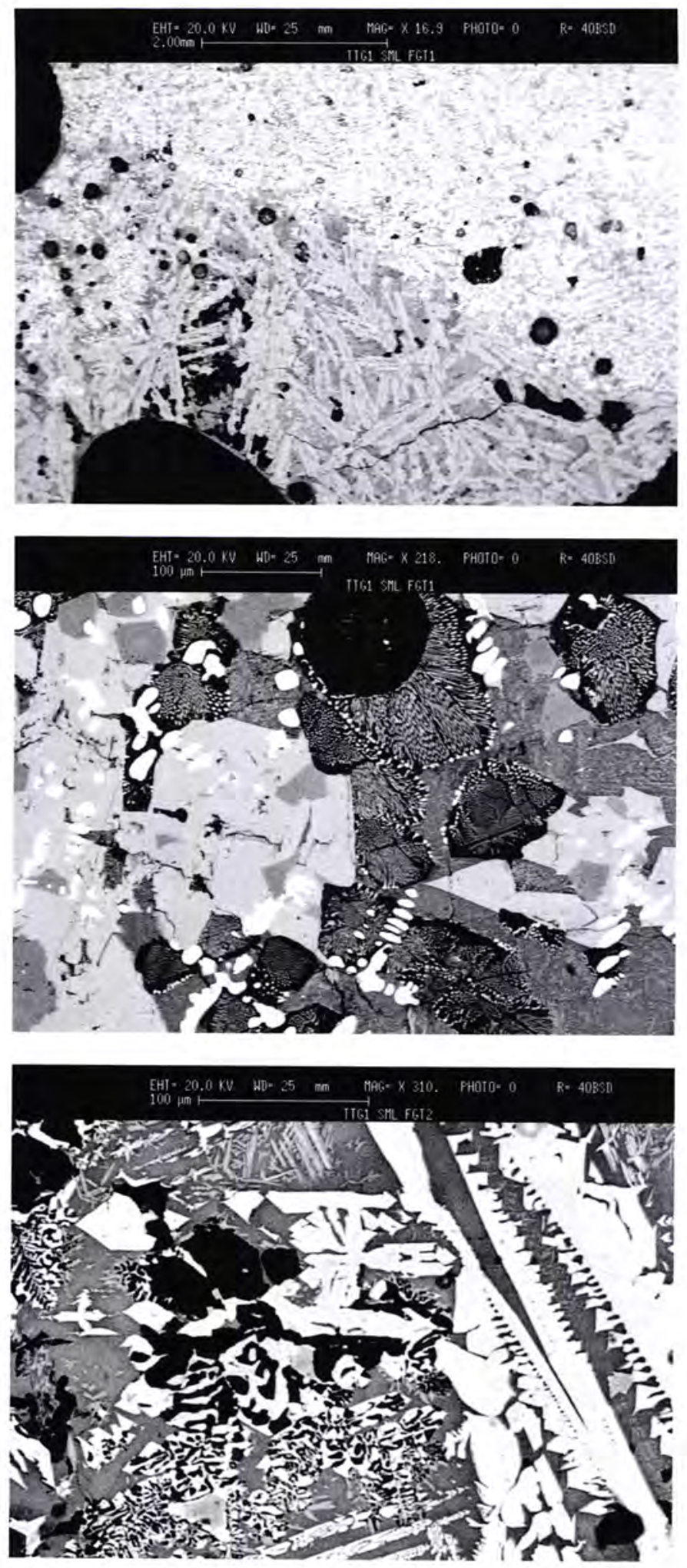

142 SEM-BS images of RFs 4293. Photographs: E Photos-Jones a SEM-BS image of TTG1/1 RF 4293 fragment 1, displaying phases typical of a wustitic/fayalitic type $\left(\mathrm{FeO} / \mathrm{FeSiO}_{2}\right)$ bloomery slag. This sample contains, on are analysis, a total of $\mathrm{c} 70$ percent iron as $\mathrm{FeO}$ $($ see table 74$)($ bar $=2 \mathrm{~mm})$

b SEM-BS image of same sample as above at higher magnification, showing wustite, fayalite, hercynite and interstitial glass. The presence of hercynite (small dark grey angular grains) suggests that the sample was a fragment of a smelting slag. The presence of tiny globular wustite radiating outwards from the hole (top of photograph) and emerging out of the glass suggests excess of iron in combination with long cooling times (bar $=100$ microns)

c SEM-BS image of TTG1/1 RF 4293 fragment 2, displaying long needles of fayalite, angular grains of hercynite and an interstitial glass (see table 74). Of interest are the dark angular grains of a potassium alumino-silicate (centre of the image), normally a high temperature-forming phase, corroborating the hypothesis that this sample was formed within a bloomery furnace. The light phase is an iron-rich silicate, ie fayalite. The source of the ore is high in phosphorus (see table 69) (bar $=100$ microns) 

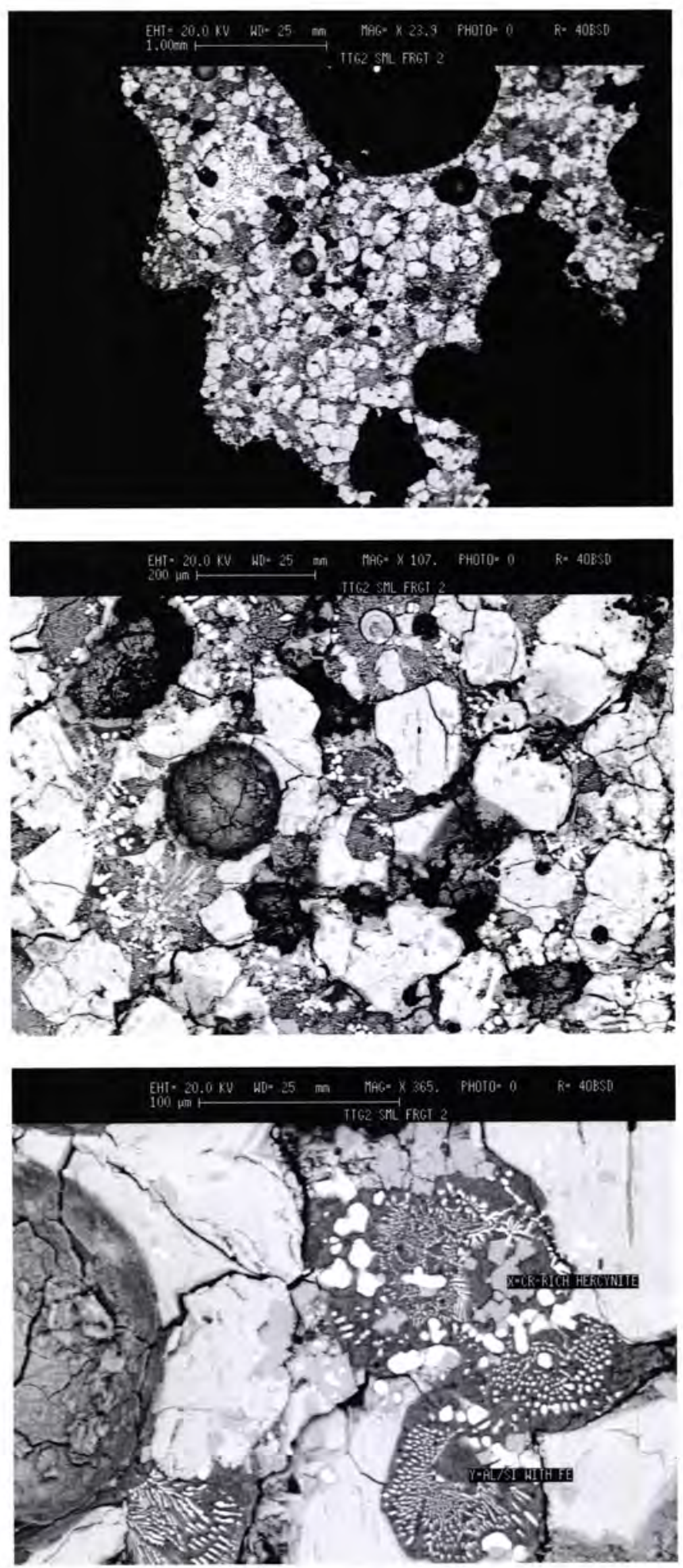

143 SEM-BS images of RFs 4337/4339. Photographs: E Photos-Jones a SEM-BS image of sample TTG1/2 RFs 4337/4339, showing fragmented fayalite, hercynite and interstitial glass $($ bar $=1 \mathrm{~mm})$

b SEM-BS image of sample TTG1/2 RFs 4337/4339 at higher magnification, showing dendrites of iron oxide (wustite), fragmented needles of fayalite (light grey) and hercynite. Analysis (table 69) showed that the hercynite was chromium-rich (see image below). Chromium may have originated from either the ore or the clay. Titanium, another element, is probably derived from the clay used in the making of the furnace. The above analyses point to the samples being fragments of bloomery (smelting) slags (bar $=200$ microns)

c SEM-BS image of same sample as above at higher magnification, showing analysed phases. Spot X (top) is the chromium-rich hercynite and spot $Y$ (bottom) is an iron-rich alumino-silicate (see table 69). Relatively high phosphorus and calcium levels are seen in the matrix, which can serve, given further work, to fingerprint the type of ore source (bar $=100$ microns) 
Table 74 SEM-EDAX analyses of industrial waste from trench T01 ext (composition in weight per cent)

\begin{tabular}{|c|c|c|c|c|c|c|c|c|c|c|c|c|c|c|c|}
\hline & $\mathrm{Na}_{2} \mathrm{O}$ & $\mathrm{MgO}$ & $\mathrm{Al}_{2} \mathrm{O}_{3}$ & $\mathrm{SiO}_{2}$ & $\mathrm{SO}_{3}$ & $\mathrm{P}_{2} \mathrm{O}_{5}$ & $\mathrm{~K}_{2} \mathrm{O}$ & $\mathrm{CaO}$ & $\mathrm{TiO}_{2}$ & $\mathrm{MnO}$ & $\mathrm{FeO}$ & $\mathrm{BaO}$ & $\mathrm{Cr}_{2} \mathrm{O}_{3}$ & Total & $N$ \\
\hline \multicolumn{16}{|l|}{ RF 4293} \\
\hline $\begin{array}{l}\text { TTG1/1 small fragment } 1 \text {; } \\
\text { area } 1\end{array}$ & 0 & 0.2 & 2.88 & 10.65 & 0.18 & 0.56 & 2.22 & 2.8 & 0.24 & 0.82 & 79.34 & 0.11 & nd & 100 & $\mathrm{~N}$ \\
\hline $\begin{array}{l}\text { TTG1/1 small fragment } 1 \text {; } \\
\text { area } 2\end{array}$ & 0.22 & 0.33 & 4.57 & 15.35 & 0.12 & 0.74 & 3.04 & 3.68 & 0.5 & 0.48 & 70.68 & 0.3 & nd & 100.01 & $\mathrm{~N}$ \\
\hline $\begin{array}{l}\text { TTG1/1 small fragment } 1 \text {; } \\
\text { fayalite }\end{array}$ & 0.12 & 0.89 & 0.29 & 16.87 & 0 & 0.08 & 0.01 & 0.92 & 0 & 1.02 & 79.39 & 0.41 & nd & 100 & $\mathrm{~N}$ \\
\hline $\begin{array}{l}\text { TTG1/1 small fragment } 1 \text {; } \\
\text { hercynite }\end{array}$ & 0.07 & 1.09 & 23.37 & 0.09 & 0.03 & 0.17 & 0.02 & 0.16 & 0.99 & 0.33 & 73.67 & 0 & nd & 99.99 & $\mathrm{~N}$ \\
\hline $\begin{array}{l}\text { TTG1/1 small fragment } 1 \text {; } \\
\text { matrix }\end{array}$ & 0.11 & 0.2 & 7.41 & 25.4 & 0.41 & 2.68 & 7.11 & 18.41 & 1.12 & 0.41 & 36.01 & 0.74 & nd & 100.01 & $\mathrm{~N}$ \\
\hline $\begin{array}{l}\text { TTG1/1 small fragment } 2 \text {; } \\
\text { area }\end{array}$ & 0.32 & 0.48 & 5.64 & 23.22 & 0.02 & 1.48 & 4.41 & 7.59 & 1.28 & 0.35 & 54.9 & 0.33 & nd & 100.02 & $\mathrm{~N}$ \\
\hline $\begin{array}{l}\text { TTG1/1 small fragment } 2 \text {; } \\
\text { matrix }\end{array}$ & 0.25 & 0.2 & 9.29 & 27.51 & 0.12 & 2.68 & 6.85 & 15.78 & 1.97 & 0.17 & 34.44 & 0.75 & nd & 100.01 & $\mathrm{~N}$ \\
\hline $\begin{array}{l}\text { TTG1/1 small fragment } 2 \text {; } \\
\text { dark phase: } \\
\text { potassium iron silicate }\end{array}$ & 0 & 0 & 13.33 & 46.74 & 0.23 & 0.12 & 36.76 & 0 & 0.25 & 0.1 & 2.23 & 0.25 & nd & 100.01 & $\mathrm{~N}$ \\
\hline $\begin{array}{l}\text { TTG1/1 small fragment } 2 \text {; } \\
\text { light phase: } \\
\text { iron silicate }\end{array}$ & 0.07 & 1.55 & 0.09 & 18.1 & 0.06 & 0.12 & 0.08 & 0.93 & 0.11 & 0.91 & 77.77 & 0.21 & nd & 100 & $\mathrm{~N}$ \\
\hline \multicolumn{16}{|l|}{ RFs $4337 / 4339$} \\
\hline $\begin{array}{l}\text { TTG1/2 small } \\
\text { fragment } 2 \text {; } \\
\text { Cr-rich } \\
\text { hercynite }\end{array}$ & 0 & 0.72 & 20.98 & 0.22 & 0 & 0.07 & 0.04 & 0 & 1.94 & 0.42 & 73.02 & 0 & 2.6 & 100.01 & $\mathrm{~N}$ \\
\hline $\begin{array}{l}\text { TTG1/2 small } \\
\text { fragment } 2 ; \\
\text { matrix }\end{array}$ & 0.09 & 0.99 & 9.09 & 41.08 & 0.29 & 2.5 & 2.44 & 14.36 & 6.27 & 0.06 & 22.84 & 0 & nd & 100.01 & $\mathrm{~N}$ \\
\hline
\end{tabular}

nd = not detected; $\mathrm{N}$ = normalized; all analyses = spot analyses unless otherwise reported 


\title{
CHAPTER 11 \\ The Ecofactual Assemblages
}

\author{
by VANESSA STRAKER \\ with contributions from Polydora BaKer, Alex Bayliss, ChristopHer BRONK RAMSEY, \\ Rowena Gale, Jennifer Heathcote, Julie Jones, Mark Robinson and Heather Tinsley
}

\begin{abstract}
As indicated in the previously published report of the work on the Lower Terrace the sampling of ecofactual material has been one of the major contributions of the project to the reassessment of Tintagel. The recovery of material from small samples taken during the watching brief on the Steps site had already indicated the potential, ${ }^{2}$ but since then a systematic programme of ecofactual recovery has been undertaken on all trenches excavated at the site, except those on the Upper Terrace of Site $C$, where no extensive excavation of new deposits was attempted. In addition to the plant macrofossils, small assemblages of land snails and mammal bone and teeth have been collected, and radiocarbon dating undertaken on samples of carbonized plant remains recovered from secure primary deposits in trenches T01 and T01 ext, Site T- the area of the Great Ditch and Lower Ward of the Castle.
\end{abstract}

\section{METHODOLOGIES}

The aim of the environmental flotation programme on site was to recover evidence relating to the economy of the fifth- to seventh-century inhabitants and the environment they lived in. Previous work at Tintagel has demonstrated that plant remains are generally scarce, ${ }^{3}$ except in a few features, and this combined with the large amount of stone in the sediments made the taking of large samples essential. Where sufficient material was available, the preferred sample size of at least 40 litres was obtained. Some samples were dry-sieved on site to remove large stones prior to transportation off the site and any stone removed was quantified and recorded. Most of the samples were processed by flotation on site, although a small number were processed at the Environmental Archaeology Laboratory at the School of Geographical Sciences, Bristol University. The floats were collected on a 250 micron sieve and residues on a $1 \mathrm{~mm}$ mesh.

Residues were scanned rapidly during the sieving process to recover finds, bone and charcoal fragments. All residues were then returned to Bristol at the end of each excavation season and 25 per cent were re-sorted fully in the laboratory. (As the project has progressed over the years, experience demonstrated that the length of time taken to fully sort all residues could not be justified. The standard procedure developed for Tintagel, after early consideration of the effectiveness of the sieving process and the potential benefits of sorting large stony sample residues, was that in addition to the rapid scan on site, 25 per cent of the heavy residues were fully sorted in the laboratory.) In fact, for Site T, because some small fragments of glass were found during the 25 per cent laboratory sorting, most of the remaining residues were then fully sorted to check for finds.

All plant remains were preserved by charring, despite the possibility that wet silts in part of the trench afforded the potential for waterlogged preservation. Floats were assessed using a low-powered binocular microscope and as the numbers of macrofossils present was so small they were extracted and identified. The environmental summary tables (see Appendices in the Research Archive Report) give details of sample sizes and note the presence of plant macrofossils and charcoal. All tables are ordered by phase. Nomenclature refers to Stace ${ }^{4}$ and 
the identification criteria for the cereals are those described by Jacomet. ${ }^{5}$

During the excavation of Trench T01, T01 ext and T02, in addition to the fifty samples taken for wetsieving on site, a number were taken for specialist examination at the laboratory. These included samples taken from the section of trench T01 for pollen analysis, and from the banks on the north and south sides of the Great Ditch. The thin bands of fine silty clay sediments exposed in the north bank of the Great Ditch (T01) did not appear to have been reworked and small monolith tins or Kubiena tins were taken from vertical sections to allow assessment of potential for pollen analysis. The Devonian slate-derived soils at Tintagel are generally acid and bone and shell does not survive well, which suggested that pollen might persist in the undisturbed silty clays.

Pollen samples were prepared using standard techniques as described by Moore $e t a l^{6}$ and included treatment with cold hydrofluoric acid for one week following potassium hydroxide digestion. Two tablets of Lycopodium spores ${ }^{7}$ were added at the start of preparation to allow assessment of pollen concentration. Samples were counted at a magnification of $\times 400$. The assessment aimed to count at least 100 grains of land pollen or complete ten traverses of the slide for each sample to determine the range of taxa present, the state of pollen preservation and suitability for full analysis. In the event, pollen concentrations were low and preservation heavily biased towards the survival of grains of particularly resistant taxa such as Cichorium intybus-type (dandelion and related Asteraceae) and full analysis was not recommended. The brief comments in this report are based on limited assessment counts and not full analysis.

Charcoal was identified in order to provide material suitable for radiocarbon dating for the primary fill of the Great Ditch (T01), and from a burnt feature at the base of trench T01 ext where no other suitable plant macrofossils were available. The results of the dating are discussed by Bayliss (see below). Charcoal fragments were fractured to expose fresh transverse surfaces and sorted into groups based on the anatomical features observed using a $\times 20$ hand lens. Representative fragments from each sample were selected for detailed study at high magnification. Additional surfaces to show the wood structure in the tangential and radial planes were also prepared. The fragments were supported in washed sand and examined using a Nikon Labophot microscope at magnifications of up to $\times 400$. The anatomical structures were matched to prepared reference slides.

The zooarchaeological specimens were identified with the aid of the skeleton reference collection at the Centre for Archaeology, English Heritage, Fort Cumberland. Given the pronounced fragmentation, for identifiable specimens the Minimum Number of Elements (MNE) was calculated also, based on the most common element or tooth feature; for cattle, this is based on the infundibulums of upper or lower molars. MNE is aggregated by context. The wear stage of cattle teeth, where identifiable, was recorded after Grant. ${ }^{8}$ No measurements could be taken.

The remains were primarily hand-collected, with a few recovered from the flotation residues. A complete list of the identified and unidentified fragments is provided in the zooarchaeological archive and the identified specimens are listed below. All bones and teeth were identified to element and taxon where possible. Tooth wear in sheep/goat was recorded following Payne ${ }^{9}$ and measurements were taken following von den Driesch. ${ }^{10}$

\section{SITE C, MIDDLE TERRACE: RADFORD'S TRENCHES}

\section{INTRODUCTION}

Seventeen bulk samples were taken for environmental analysis from contexts excavated in trench $\mathrm{C} 05$ and four from trial trench $\mathrm{C} 15$. Plant macrofossils other than charcoal were present in eight of the fifteen contexts sampled in $\mathrm{C} 05$ and two in $\mathrm{C} 15$; the rest contained charcoal fragments only. No animal bone was recovered due to the acidity of the soils at the site and a lack of waterlogged deposits excavated in these trenches.

\section{CHARRED PLANT MACROFOSSILS}

Although the assemblage recovered is in overall terms small there are some significant individual deposits. Table 75 lists the plant macrofossils identified, but the numbers of plant macrofossils recovered are very small and this restricts the depth of interpretation that can be made.

Cereal remains from trench $\mathrm{C} 05$ were represented by a few grains of oats (Avena sp.) and hulled barley (Hordeum sp.) present in four of the eight samples. As reported previously for the Lower Terrace of Site $C$ at Tintagel, ${ }^{11}$ oat chaff was not recovered. As oat grains on 
Table 75 Plant macrofossils from Radford trenches C05 and trial trench $\mathrm{C} 15$

\begin{tabular}{|c|c|c|c|c|c|c|c|c|c|c|c|c|}
\hline Taxon & Common name & $\begin{array}{l}\text { Trench } \\
\text { Phase } \\
\text { Context } \\
\text { Item }\end{array}$ & $\begin{array}{l}C 05 \\
X \\
301\end{array}$ & $\begin{array}{l}\text { C05 } \\
X \\
308\end{array}$ & $\begin{array}{l}C 05 \\
X \\
316\end{array}$ & $\begin{array}{l}C 05 \\
X \\
318\end{array}$ & $\begin{array}{l}C 05 \\
V \\
310\end{array}$ & $\begin{array}{l}C 05 \\
W \\
315\end{array}$ & $\begin{array}{l}C 05 \\
W \\
319\end{array}$ & $\begin{array}{l}C 05 \\
W \\
320\end{array}$ & $\begin{array}{l}C 15 \\
X \\
660\end{array}$ & $\begin{array}{l}C 15 \\
Y \\
650\end{array}$ \\
\hline \multicolumn{13}{|l|}{ Cereals } \\
\hline $\begin{array}{l}\text { Avena sp } \\
\text { cf. Avena sp. } \\
\text { Hordeum sp. } \\
\text { Cereal, species indeterminate }\end{array}$ & $\begin{array}{l}\text { oats } \\
\text { cf. oats } \\
\text { barley }\end{array}$ & $\begin{array}{l}\text { grain } \\
\text { grain } \\
\text { hulled grair } \\
\text { grain }\end{array}$ & ${ }^{n}$ & $\begin{array}{l}12 \\
2 \\
+2\end{array}$ & 2 & 1 & & & & & 1 & \\
\hline $\begin{array}{l}\text { Other taxa } \\
\text { Corylus avellana }\end{array}$ & \multicolumn{11}{|c|}{ Other taxa } & \\
\hline $\begin{array}{l}\text { Chenopodium rubrum / } \\
\text { glaucum }\end{array}$ & $\begin{array}{l}\text { red / glaucous } \\
\text { goosefoot }\end{array}$ & seed & & & & & & & 1 & & & \\
\hline Chenopodium sp. & goosefoot & seed & & & & & & & & 1 & & \\
\hline Atriplex sp. & orache & seed & & & & & & & & 1 & & \\
\hline Silene sp. & campion & seed & & & & & & & & & & 1 \\
\hline Polygonum aviculare & knotgrass & achene & & & & & & 1 & & & & \\
\hline Fallopia convolvulus & black bindweed & achene & & 1 & & & & & & & & \\
\hline Rumex cf. maritimus & golden dock & achene & & & & & 1 & & & & & \\
\hline Rumex sp. & sorrel & achene & & & 1 & & 1 & & & & & \\
\hline Rubus sect. glandulosus & bramble & drupe (pip) & & 1 & & & & 1 & & & & \\
\hline Rosaceae & rose family & spine & & & & & & 1 & & & & \\
\hline Carexsp. & sedge & nut & & & & & & & & 2 & & \\
\hline Poaceae & grass family & caryopsis & 1 & & & & & & & & & \\
\hline Unidentified fruits / seeds & & & & & 1 & & 3 & & & 2 & & \\
\hline Other unidentified items & & & & 5 & 4 & & & & & 7 & & \\
\hline Total (excl fragments) & & & 1 & 21 & 9 & 2 & 5 & 3 & 1 & 13 & 1 & 1 \\
\hline Items per litre soil & & & 0.2 & 1 & 0.4 & 0.3 & 0.2 & 6 & 0.3 & 11.8 & 0.03 & 0.1 \\
\hline Unidentified ? stem fragments & & & & 30 & 6 & 5 & & & & & & \\
\hline
\end{tabular}

Key: (+) 1 fragment

their own are not readily identifiable to species, in the absence of floret bases it is not possible to state whether the oats are the remnants of a crop or are wild oats that infested other arable crops.

The other taxa identified include a range of common plants of waste or arable ground, such as knotgrass, black bindweed, orache and goosefoot. These could have grown on the Island in the past, depending on the degree of local soil disturbance. Alternatively they could have been brought to the Island as weeds of a partially cleaned cereal crop. Sedge and grass could have been part of the Island flora or been brought in with crops. The only hint of gathered foodstuffs comes from a blackberry pip and a fragment of hazel nutshell. Blackberry (bramble) could have grown on the Island or elsewhere in the locality. However, the Island was probably too exposed for the growth of hazel, which would have grown readily in the immediate locality.

Evidence from trial trench $\mathrm{C} 15$ was restricted to a single oat grain and seed of Silene sp. (campion). It is not possible to identify campion to species, but several species grow on the Island today. 


\section{SITE C, MIDDLE TERRACE: TRENCH C15}

\section{INTRODUCTION}

Thirty bulk samples were taken from twenty-six contexts during excavation of trench C15 in 1999. Plant macrofossils other than wood charcoal fragments were present in ten contexts (38 per cent) and their concentration was extremely low. Fragmentary animal bone and tooth enamel was, however, recovered from a small number of contexts, and charcoal was identified with a view to possible radiocarbon dating (the latter not ultimately approved by the English Heritage due to lack of in situ burnt deposits).

\section{ChARRED PLANT MACROFOSSILS AND CHARCOAL}

\section{Plant macrofossils}

The taxa identified are listed in Table 76. The plant remains were only found in contexts from Phases $U-Z$, related to a slipped occupation layer, collapse of the building and infill of Radford's trench. None survived in contexts 695 and 697, a midden dump or possible surface (Phase T), although bone fragments were present.

Crop plants are represented by a few grains of oats and barley, some of which was definitely of the hulled form, and wheat. Oats, which could be from a wild species such as Avena fatua or domesticated species such as A. sativa or strigosa, were more numerous than barley or wheat, a typical feature of cereal remains from Tintagel, though the overall percentage presence of oats and barley is usually fairly similar. The only other plants represented by a few seeds only, were campions (Silene sp.), probably growing on grassland or rough ground and corn marigold (Chrysanthemum segetum), an arable or disturbed ground weed. Both have been found at Tintagel before.

\section{Charcoal}

Charcoal fragments of greater than $2 \mathrm{~mm}$ minimum dimensions were noted in nineteen contexts (73 per cent), but even smaller fragments were present in all except context 507. The detailed results are presented in Table 77 and a summary by phase given in Table 78 .

Birch, hazel, oak, Pomoideae and Prunoideae were identified. The members of the Pomoideae group, which includes apple, pear, rowan, whitebeam and hawthorn, cannot be distinguished between on the basis of wood anatomy. Likewise, the fragments hand-collected from Phase V were identified as Prunoideae, a group that includes blackthorn (sloe) and wild or bird cherry. If

Table 76 Charred plant macrofossils from trench C15

\begin{tabular}{|c|c|c|c|c|c|c|c|c|c|c|c|c|}
\hline Taxon & $\begin{array}{l}\text { Common } \\
\text { name }\end{array}$ & $\begin{array}{l}\text { Phase } \\
\text { Context } \\
\text { Item }\end{array}$ & $\begin{array}{l}U \\
675\end{array}$ & $\begin{array}{l}U \\
685\end{array}$ & $\begin{array}{l}V \\
687\end{array}$ & $\begin{array}{l}W \\
658\end{array}$ & $\begin{array}{l}W \\
669\end{array}$ & $\begin{array}{l}W \\
678\end{array}$ & $\begin{array}{l}X \\
665\end{array}$ & $\begin{array}{l}X \\
679\end{array}$ & $\begin{array}{l}X \\
720\end{array}$ & $\begin{array}{l}Z \\
656\end{array}$ \\
\hline \multicolumn{13}{|l|}{ Cereals } \\
\hline Avena sp. & oats & grain & & & 2 & 1 & 17 & 2 & 7 & & $7(+1)$ & 7 \\
\hline Hordeum sp. & barley & grain & 2 & & & & $1(+5)$ & 1 & 2 & 2 & & 1 \\
\hline Hordeurn sp. & barley & hulled grain & 1 & & & 1 (twi & risted) & & & $(+1)$ & & \\
\hline Triticum sp. & wheat & grain & & & & & & 1 & 4 & & & 1 \\
\hline Cereal, species indeterminate & & grain & & 1 & & & & $(+2)$ & $(+1)$ & & & \\
\hline \multicolumn{13}{|l|}{ Other taxa } \\
\hline Silene sp. & campion & seed & & 2 & & & & & & & & \\
\hline Chrysanthemum segetum & $\begin{array}{l}\text { corn } \\
\text { marigold }\end{array}$ & achene & & & & & & & 1 & & & \\
\hline Tubers (including fragments) & & & $(+1)$ & & & & & & & & & \\
\hline Unidentified fruits / seeds & & & & & & & $(+1)$ & & & & & \\
\hline Other unidentified items & & & & & & & & & & & 1 & \\
\hline Total (excl cereal fragments) & & & 4 & 3 & 2 & 2 & 19 & 4 & 14 & 2 & 8 & 9 \\
\hline Items per litre soil & & & 0.09 & 0.2 & 0.2 & 0.07 & 0.4 & 0.2 & 0.5 & 0.1 & 0.3 & 0.3 \\
\hline
\end{tabular}


Excavations at Tintagel Castle, Cornwall, 1990-9

Table 77 Charcoal identification from trench C15

\begin{tabular}{|c|c|c|c|c|c|}
\hline Context & $\begin{array}{l}\text { Sample } \\
(\triangle: R F)\end{array}$ & Phase & Context & $\begin{array}{l}\text { Identification } \\
(>2 \mathrm{~mm})\end{array}$ & Fragments \\
\hline 695 & 3191 & $\mathrm{~T}$ & Dump and possible surface & $\begin{array}{l}\text { hazel } \\
\text { oak } \\
\text { Pomoidae } \\
\text { unidentified }\end{array}$ & $\begin{array}{l}8 \\
2 \\
1 \\
2\end{array}$ \\
\hline 697 & 3190 & $\mathrm{~T}$ & Dump and possible surface & $\begin{array}{l}\text { hazel } \\
\text { Pomoidae } \\
\text { unidentified }\end{array}$ & $\begin{array}{r}38 \\
1 \\
2\end{array}$ \\
\hline 697 & $6027 \triangle$ & $\mathrm{T}$ & Dump and possible surface & birch & 1 \\
\hline 697 & $6053 \triangle$ & $\mathrm{T}$ & Dump and possible surface & oak & 1 \\
\hline 697 & $6058 \triangle$ & $\mathrm{T}$ & Dump and possible surface & hazel & 1 \\
\hline 697 & $6061 \triangle$ & $\mathrm{T}$ & Dump and possible surface & hazel & 1 \\
\hline 682 & 3172 & $\mathrm{U}$ & Traces of earlier occupation & $\begin{array}{l}\text { hazel } \\
\text { oak } \\
\text { Pomoidae } \\
\text { unidentified }\end{array}$ & $\begin{array}{r}11 \\
2 \\
4 \\
2\end{array}$ \\
\hline 675 & 3174 & $\mathrm{U}$ & Traces of earlier occupation & $\begin{array}{l}\text { hazel } \\
\text { oak } \\
\text { Pomoidae } \\
\text { unidentified }\end{array}$ & $\begin{array}{r}13 \\
1 \\
2 \\
6\end{array}$ \\
\hline 675 & $3764 \wedge$ & $\mathrm{U}$ & Traces of earlier occupation & hazel & 1 \\
\hline 687 & $3958 \triangle$ & $\mathrm{V}$ & Collapsed building & Prunoidae & 8 \\
\hline 667 & 3126 & W & Collapse of building & hazel & 1 \\
\hline 669 & $3818 \triangle$ & W & Collapse of building & oak & 1 \\
\hline 669 & $3844 \triangle$ & W & Collapse of building & oak & 1 \\
\hline 674 & 3175 & W & Collapse of building & $\begin{array}{l}\text { hazel } \\
\text { oak } \\
\text { Pomoidae } \\
\text { unidentified }\end{array}$ & $\begin{array}{l}9 \\
2 \\
2 \\
2\end{array}$ \\
\hline
\end{tabular}

Key: birch: Betula sp.; hazel: Corylus avellana; oak: Quercus sp.; Pomoidae: group including apple, pear, rowan, whitebeam, hawthorn; Prunoidae: group including blackthorn (sloe), wild cherry, bird cherry

Charcoal identified includes hand-collected fragments ('small finds') denoted by $\triangle$, and charcoal from floats and residues where the residues have been sorted. Samples where the residues were not sorted have been excluded unless an artefactual find was recorded. Charcoal from the infill of Radford's trench has also been excluded

preservation is suitable, they can sometimes be distinguished between, but not in this instance. As the fragments were so small, it was not generally possible to tell whether they originated from small round wood or more mature timber. One of the samples from 697, a possible surface or midden dump within the building, produced definite evidence for the burning of hazel round wood.
All the taxa or groups of taxa identified have been found at Tintagel before and all could have been collected locally on the 'mainland'. Small stands of trees or patches of scrub could have grown in isolated sheltered spots on the Island. Whether the wood represents burnt structural material or the usual domestic waste associated with wood fires is unclear, given the nature of the stratigraphy but, as there was no 
Table 78 Wood charcoal identified from Phases T-W, trench C15

\begin{tabular}{|c|c|c|c|c|c|}
\hline Taxon & Phase & $\begin{array}{l}\text { T } \\
\text { Dump and } \\
\text { possible surface } \\
695,697\end{array}$ & $\begin{array}{l}U \\
\text { Traces of } \\
\text { earlier } \\
\text { occupation } \\
675,682\end{array}$ & $\begin{array}{l}V \\
\text { Collapsed } \\
\text { building } \\
687\end{array}$ & $\begin{array}{l}\text { W } \\
\text { Collapse of } \\
\text { building } \\
667,669,674\end{array}$ \\
\hline Birch & & + & & & \\
\hline Hazel & & + & + & & + \\
\hline Oak & & + & + & & + \\
\hline Pomoideae & & + & + & & + \\
\hline Prunoideae & & & & + & \\
\hline
\end{tabular}

+ : present

other evidence for burning, the latter is probably more likely. However, previous work on charcoal from directly structural contexts on the Lower Terrace ${ }^{12}$ suggested that oak and hazel, in particular, could have been used for structural timbers, small posts and wattles. As elsewhere at Tintagel, hazel was the most common find in terms of numbers of fragments and percentage presence in contexts from $\mathrm{Cl} 5$.

\section{Conclusion}

As the remains of cereals and weeds are so scarce in C15, and the contexts relate to the collapse of the building and infilling of Radford's trench, few conclusions can be drawn about their significance. Similar taxa were identified from the Phase $\mathrm{U}$ and $\mathrm{W}$ contexts associated with the comparable Lower Terrace buildings, but here the assemblages were larger and the range of wild plants associated with the crops much greater. These suggest that the final stages of processing of oat, barley and wheat crops may have taken place on the Island, and provide probable evidence for the use of rushes for roofing or flooring material. If the burning of cooking or crop processing waste, animal fodder or dung was taking place, it has left little trace in what survived of the C15 building. The charcoal was not recovered from directly structural contexts such as post-holes and beam-slots, and is likely to represent the scattering of ash from domestic fires.

On balance, the $\mathrm{C} 15$ building does not appear to have been used in the same way as the Lower Terrace buildings, but this could simply be a result of lack of survival in situ of floor layers and domestic waste.

\section{THE ZOOARCHAEOLOGICAL REMAINS by Polydora Baker}

\section{Provenance and preservation}

The bones and sediment samples were from a structure and collapsed phases of occupation through the postRoman period, and from fills of Radford's excavations. Most of the faunal remains are very poorly preserved and a large proportion of the material consists of tooth enamel fragments. Teeth are amongst the densest structures in the vertebrate skeleton, ${ }^{13}$ and tooth enamel being almost entirely mineral in content may preserve better than dentine or bone. ${ }^{14}$ The soils at Tintagel are acidic, which probably explains in large part the very poor preservation and, consequently, the very low number of identifiable vertebrate remains from the site.

\section{Results}

The vast majority of the fragments are under $10 \mathrm{~mm}$ in length and probably result from post-depositional or recent breakage of very fragile larger fragments. The few identified hand-collected specimens include tooth fragments of cattle, caprine and pig (table 79) and are listed by phase, context and RF number (table 80). A complete list of identified and unidentified remains is provided in the zooarchaeological archive in the Research Archive Report. 
Table 79 Distribution of identified and unidentified specimens by phase: hand-collected assemblage from trench $\mathrm{C} 15$

\begin{tabular}{llllll}
\hline Phase & $T$ & $V$ & $W$ & $X 2$ & Total \\
No. contexts & 2 & 1 & 4 & 3 & \\
\hline Cattle, Bos taurus & $3(2)$ & & $5(3)$ & 1 & 9 \\
cf. cattle, Bos taurus & $6(3)$ & & & & 1 \\
Sheep / goat, Ovis aries / Capra hircus & 1 & & & 36 \\
Pig, Sus scrofa & $35(2)$ & 1 & 5 & 52 \\
Total & 45 & 1 & 5 & 1 & 5 \\
\hline
\end{tabular}

( ): minimum no. of elements

Table 80 Identified hand-collected specimens listed by phase, context and RF number, trench C15

\begin{tabular}{llll}
\hline Phase & Context & RF no. & Identification \\
\hline $\mathrm{T}$ & 695 & 6026 & pig, left upper third molar fragments, worn but dentine not exposed \\
$\mathrm{T}$ & 697 & 6041 & pig, upper or lower molar fragments, worn but dentine not exposed \\
$\mathrm{T}$ & 697 & 6040 & cattle, fused middle phalanx \\
$\mathrm{T}$ & 697 & 6023 & cf. cattle, right lower molar, enamel folds, wear stage $\mathrm{k}$ (after Grant 1982) \\
$\mathrm{T}$ & 697 & 6043 & sheep / goat, upper molar \\
$\mathrm{T}$ & 697 & 6043 & cf. cattle, lower molar, two internal enamel folds (infundibulums) \\
$\mathrm{T}$ & 697 & 6047 & cattle, upper molar, two internal enamel folds (infundibulums) \\
$\mathrm{T}$ & 697 & 6060 & cf. cattle, lower molar, two internal enamel folds (infundibulums) \\
$\mathrm{V}$ & 687 & 3940 & pig upper / lower molar, enamel fragment \\
$\mathrm{W}$ & 667 & 3664 & cattle right third molar, wear stage g (after Grant 1982) \\
$\mathrm{W}$ & 669 & 3849 & cattle, upper molar, two internal enamel folds (infundibulums) \\
$\mathrm{W}$ & 669 & 3873 & cattle, left lower third molar, hypoconulid probably unworn \\
$\mathrm{X}$ & 672 & $3971 \mathrm{~d}$ & cattle, left lower third molar, wear stage a-b (after Grant 1982) \\
\hline
\end{tabular}

\section{Conclusion}

The animal remains from Tintagel are very poorly preserved and include few identifiable specimens. Although many fragments were recovered, most of these are probably from a few highly degraded bones or teeth. The few identifiable teeth are from cattle, caprines and pigs, suggesting the use of domestic livestock but little else about husbandry, economy or environment. The cattle teeth from Phase $T$ show moderate-advanced wear, suggesting that they are from adult animals, while the specimens from Phase $\mathrm{W}$ include one tooth from a sub-adult animal. The lightly worn specimen from Radford's backfill is from a juvenile/sub-adult animal. The pig molar fragments from Phase $\mathrm{T}$ are probably also from a sub-adult animal.

The material from the 1990-4 excavations on the
Lower Terrace was poorly preserved and yielded few identifications, including a sheep/goat molar and two unerupted pig teeth from the same jaw. ${ }^{15}$ The 1999 data add little to this information and it is not possible to discuss species, element or age distribution on the basis of these very small and biased assemblages.

\section{SITE C, MIDDLE TERRACE: SITE C BUILDING}

\section{INTRODUCTION}

Although the assemblage recovered is, in overall terms, small there are some significant individual deposits with surviving archaeobotanical material (table 81 and see Chapter 6, tables 23 and 28). In addition, unusually there was a presence of uncarbonized animal bone found in Phases $U$ onwards of the trenches in and around the Site 
Table 81 Plant macrofossils from the Site $\mathrm{C}$ building

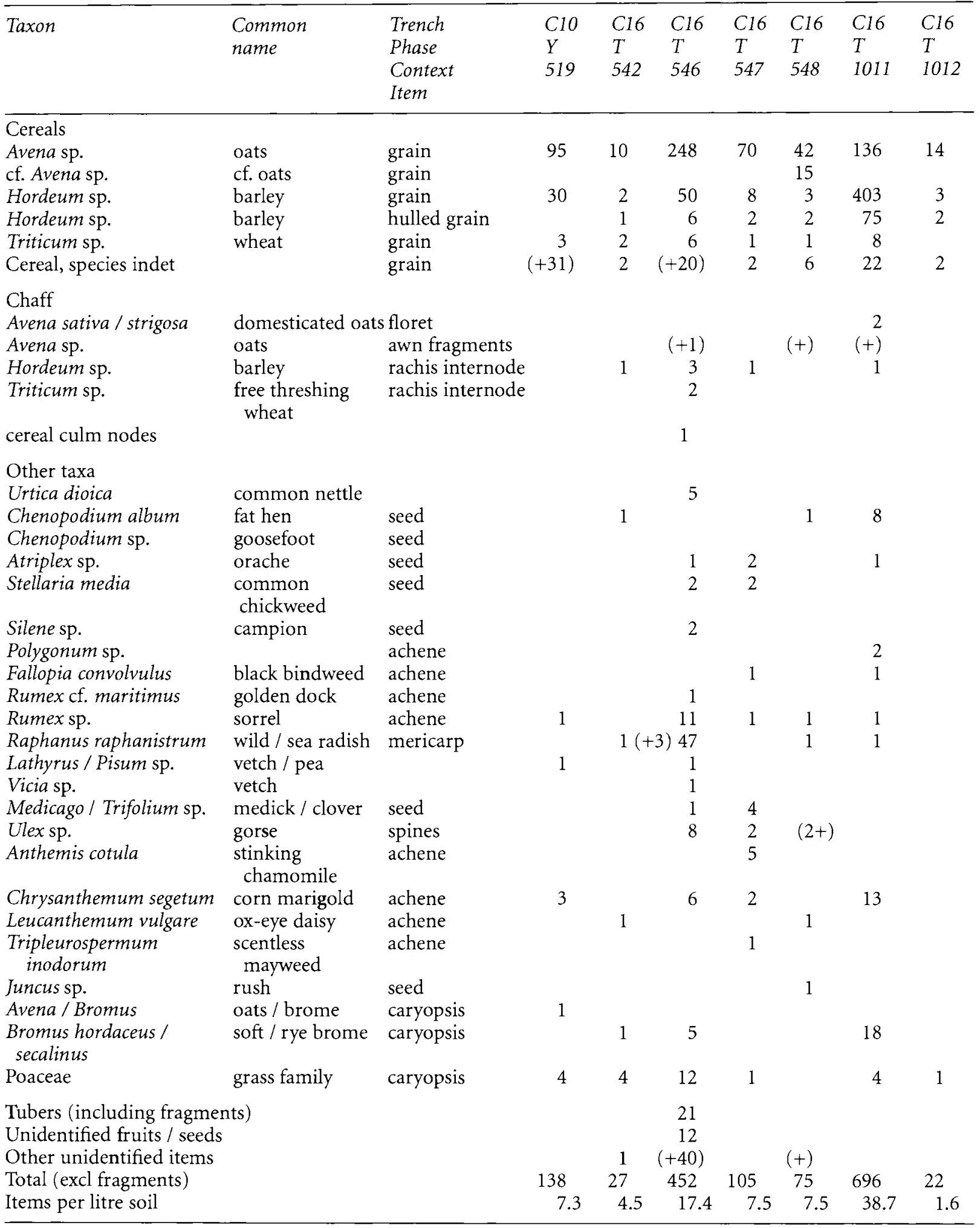

(+) 1 fragment 
$\mathrm{C}$ building, often in association with waterlogged features such as drains around the building. Presumably we have here a small reflection of the meat consumed. However, as with the assemblage from trench $\mathrm{C} 15$, the majority of the bone is in too fragmentary a state to be identifiable to species. The assemblage does not appear to include any human material such as was identified from the Lower Terrace. ${ }^{16}$

In all, eighty-eight contexts (109 samples) were examined. Charcoal of greater than $2 \mathrm{~mm}$ in size was present in sixty-nine of the contexts (78 per cent) whereas plant macrofossils other than charcoal (mainly fruits and seeds) were found in thirty-six contexts (40 per cent). The macrofossils from particular deposits have been mentioned as appropriate in Chapter 6, and the following is a general discussion of the evidence from the Site C Building area on the Middle Terrace as a whole.

\section{DISCUSSION OF CHARRED PLANT MACROFOSSILS with Julie Jones}

The numbers of plant macrofossils recovered are generally low, and this restricts the depth of interpretation that can be made. Table 81 and Tables 23 and 28 (Chapter 6 ) list the plant macrofossils identified.

Most of the thirty contexts sampled in $\mathrm{C} 09$ were layers, or areas of burning within layers. Apart from charcoal fragments, the only plant macrofossils were occasional grains of oats (Avena sp.) and barley (Hordeum sp.). The other contexts were fills of rock-cut slots $(1036,1048$ and 1006), which contained no identifiable plant macrofossils and very few charcoal fragments, and some of the fills of the drain (1022, Phase $\mathrm{W}$ ). The species identified from the drain (see table 28) seem to have accumulated from a range of habitats, all of which could have been found at Tintagel. This context is the only one from Tintagel to preserve 'waterlogged' plant macrofossils; all the others survived because they are charred.

The nineteen contexts sampled from $\mathrm{C} 10$ were all from layers apart from 701, which was the fill of a posthole. Charcoal fragments were present in most contexts, but generally other plant macrofossils were scarce, consisting of occasional grains of oats and barley including hulled barley, and a single grain of wheat with a rounded profile and steeply angled embryo suggestive of free threshing wheat such as bread wheat. A single hazelnut shell fragment also survived. In contrast to the other samples, context 519, a layer running alongside the west wall, attributed to Phase Y contained, for Tintagel, a relatively large assemblage of plant macrofossils. These are listed in Table 81. Although this phase comprises layers affected by MoW levelling, this is likely to be a relatively undisturbed context. It is cereal graindominated, with oats more common than barley and wheat present just as a trace (74:23.5:2.5 per cent). No chaff was recovered and wild species comprise only 7 per cent of the assemblage.

Nineteen contexts were examined from $\mathrm{C} 11$, again mainly from layers. Context 569 was the fill of a posthole and contexts 587 and 588 the Phase T fills and 585 the Phase $\mathrm{Z}$ fill of the drain. Charcoal fragments were frequent in most contexts. The other plant macrofossils from the trench present a similar range of taxa irrespective of context, which includes occasional grains of oats, barley and wheat, but also corn marigold (Chrysanthemum segetum), an arable weed and sorrel (Rumex sp.). Without the perianth segments, which do not survive charring, the species of sorrel cannot be identified. A single charred leaf of bell heather (Erica cinerea) was found in context 565, this species is characteristic of dry heaths and moors.

Four layers were examined from $\mathrm{C} 12$, and contained few plant remains. A few oat grains were recovered from contexts 603 and 606 and three achenes of stinking chamomile (Anthemis cotula), a plant typical of arable soils and farmyards.

Trench C16 was the area between the west wall (512) of $\mathrm{C} 10$ and the bedrock face to the west. Fifteen contexts were sampled. Contexts $542,546-8$ and 1011-2 were the fills of a rock-cut fissure, 538 and 540 were the fills of possible post-settings, and the remaining samples came from layers. Apart from the fissure, the macrofossil assemblage was similar to those from the other trenches, comprising occasional grains of oats and barley and medick or clover, and a grass. The fills of the fissure contained much greater concentrations of charred plant remains. These are listed in Tables 81 and 23 (Chapter $6)$. These are some of the largest assemblages recovered to date from either the Lower or Middle Terraces. Each fill is dominated by grain, ranging from 70 to 92 per cent, with only 1-2 per cent chaff and 7-28 per cent weed seeds.

Table 82 gives the percentage presence by context of plant macrofossils, other than charcoal, in each phase. Although they are preserved in most phases, the concentrations are very low and they represent no more than a limited glimpse of the types of plants available to 
Table 82 Percentage presence by context of plant macrofossils other than charcoal, Site C building

\begin{tabular}{lcc}
\hline Phase & $\begin{array}{l}\text { No. of contexts } \\
\text { with macrofossils }\end{array}$ & $\begin{array}{l}\text { Per cent of total } \\
\text { sampled contexts }\end{array}$ \\
\hline Z: Turf and topsoil & 1 & 50 \\
Y: MoW levelling / reconstruction of Site C building and scree build-up & 4 & 44 \\
X: Radford's trenches and backfill & 7 & 44 \\
W: Scree-tips and building collapse & 5 & 71 \\
V: Site C building and associated features & 2 & 50 \\
U: Drainage & 0 & 0 \\
T: Earlier make-up and rock-cut features & 17 & 40 \\
S: Natural bedrock & 0 & 0 \\
& 36 & 41 \\
\hline
\end{tabular}

the inhabitants of the Site C settlement. The three most useful groups have been described above from Phase $\mathrm{Y}$, a layer running along wall 512 in $\mathrm{C} 10$, Phase $\mathrm{W}$, drain in $\mathrm{C} 09$, and Phase $\mathrm{T}$, the fills of the fissure in C16.

In general, the most useful contexts are from features at the base of the sequence where disturbance has been avoided and they have been protected to some extent by the scree and overlying layers. Despite the fact that several rich samples were recovered, it is still not possible, because of the varied nature of the contexts excavated, to say much about the importance of plants to the inhabitants of Tintagel. Once again no exotic plants were found although, as noted for the Lower Terrace, if these were the remains of fruits, herbs and spices, they are less likely to come into contact with fire and survive through charring than cereals. Status may be related particularly to the meat component of the diet and, as bone survives very poorly indeed, it is therefore impossible to gauge the diversity or importance of this aspect of the economy.
Crops

In common with the evidence from the Lower Terrace, ${ }^{17}$ barley and oats were the most commonly found cereals with wheat present occasionally, as shown in Table 83 .

Barley (Hordeum sp.) was represented mainly by grain, most of which was generally poorly preserved. Some angular grains preserved lemma fragments and were characteristic of hulled barley and, as grains with both twisted and straight ventral furrows were recognized, the six-row form was definitely represented and the two-row form may also have been. Occasional poorly preserved barley rachis internodes survived in the fills of the Cl6 fissure.

The problems of identifying oats (Avena sp.) to species without floret bases were discussed in the Lower Terrace report. ${ }^{18}$ Here again oats are mainly represented by grain but, as noted in the $\mathrm{C} 16$ summary above, there are two floret bases which are identifiable as common/bristle oat, domestic rather than a wild species, in one of the fills of the fissure.

Table 83 Crop macrofossils by phase and context, Site $\mathrm{C}$ building

\begin{tabular}{llllllr}
\hline Phase / no. & \multicolumn{2}{l}{ Oats (Avena sp.) } & \multicolumn{2}{l}{ Barley (Hordeum sp.) } & \multicolumn{2}{l}{ Wheat (Triticum sp.) } \\
contexts with & No. of & Percent & No. of & Per cent & No. of & Per cent \\
macrofossils & contexts & presence & contexts & presence & contexts & presence \\
\hline Z/ 1 & 1 & 100 & 1 & 100 & 0 & 0 \\
Y / 4 & 4 & 100 & 1 & 25 & 1 & 25 \\
X/ 7 & 5 & 71 & 3 & 43 & 1 & 14 \\
W / 5 & 3 & 60 & 1 & 20 & 0 & 0 \\
V / 2 & 1 & 50 & 1 & 50 & 0 & 0 \\
T/ 17 & 13 & 77 & 12 & 71 & 7 & 41 \\
\hline
\end{tabular}


Wheat (Triticum sp.) is represented by a few grains only and a single rachis internode from one of the fills of the C16 fissure. The internode is poorly preserved and can only be identified as that of free-threshing wheat, but whether hexaploid, such as bread wheat ( $T$. aestivum) or tetraploid, such as rivet or macaroni wheat (T. durum) is not known. The grains themselves, however, are small and rounded and rather more typical of a compact form of bread wheat than tetraploid wheat.

\section{The weeds}

These have been discussed briefly above in relation to context 1022 in C09, 519 in $\mathrm{C} 10$ and the layers of the fissure in C16. A broadly comparable range of arable and disturbed ground plants to that found on the Lower Terrace occurs on the Middle Terrace, with the addition of stinking chamomile, which was not recorded previously. This plant is uncommon today but has a preference for disturbed ground and arable fields, and heavy soils in particular.

The radish, represented by mericarps (one-seeded pod segments) could be either the sea radish, which grows commonly in coastal areas, or the wild radish, which is a common weed of arable fields, or both. The mericarps are both rounded, more typical of the sea radish, and relatively straight, which can be a feature of the pods of the wild radish. These tall (up to $800 \mathrm{~mm}$ in height) white or yellow-flowered plants do not have a particularly swollen root like the garden radish but as with many plants in the Brassicaceae family the seeds could be used as food flavouring.

There is little evidence for the collection of wild fruits and nuts, with only a fragment of hazel nutshell recovered. Utilization of heathland plants is also barely attested, with the finding of a single charred leaf of bell heather (Erica cinerea) and a few gorse (Ulex sp.) spines. Whether these were collected locally or not is unknown.

\section{Charcoal}

Although charcoal was present in most ( 78 per cent) of the contexts sampled from in and around the Site $\mathrm{C}$ building, it was not identified. None of the contexts from which charcoal was recovered represented a distinct structural feature or event and the considerable time and expense required was not justified in this case. Charcoal is almost always present in most contexts on most archaeological sites even as a tiny trace. At Tintagel it is rarely related directly to a function or particular structural element. The charcoal identified from Site
C15 (see Chapter 5) did not suggest any changes from the general picture established for Tintagel from the work done for the Site C Lower Terrace (see Chapter 2).

\section{Conclusion}

In summary, it is suggested that barley, oats and wheat were all consumed. The relative lack of free-threshing wheat may be a genuine reflection of its importance, as its post-harvest processing is not necessarily different from oats or barley. The oats in particular are well suited to the poor acid soils in the vicinity of Tintagel and on the Island itself. However, as on the Lower Terrace, the absence of culm nodes, chaff and large-seeded weeds suggest that the crops may have been grown inland and transported partially cleaned to the settlement. Certainly, apart from on the sheltered eastern terraces where most of the settlement appears to be, the windy exposed conditions would have made the growth of crops, particularly tall crops like oats, difficult without windbreaks.

The spring-sown oats and barley-dominated crop repertoire at Tintagel could represent both human food and animal fodder. On settlement sites of Roman and medieval date, wheat is represented much more extensively than in the fifth- to seventh-century deposits of Tintagel. The dominance of oats and barley in all the contexts yielding plant macrofossils, and the lack of cereal chaff, must imply that the crops do not simply represent the remains of animal fodder, but human food too. Without a good body of comparable data we cannot be sure whether this is a local cultural preference, perhaps dictated by the local soils and climate or whether in these centuries wheat was less popular in all areas. When it becomes common again from about the ninth century onwards, the free-threshing forms have almost completely replaced the hulled wheats, which dominate the Roman record for the species.

\section{THE ZOOARCHAEOLOGICAL REMAINS by Polydora Baker}

\section{Provenance and preservation}

The assemblages from trenches C09-C16 are small and include very few identifiable bones or teeth. Severe fragmentation and poor preservation impede identification beyond size class for much of the material. Most of the remains are from Radford's excavations in the 1930s or from deposits which span broad time periods. Consequently the assemblages may 
include redeposited as well as modern waste and no attempt is made to interpret the economic significance of the data.

\section{Results}

Excavations of trenches $\mathrm{C} 09, \mathrm{C} 10, \mathrm{C} 11$ and $\mathrm{C} 16$ yielded mainly fragments of cancellous bone and tooth enamel. Only three fragments are identifiable to species. These included two cattle teeth and a bird bone, probably of domestic fowl. RF 3465 (C09, Phase U, context 1006) is a cattle upper molar, $\mathrm{M}_{1 / 2 / 3}$, RF 1513 (C11, Phase Y, context 551) a cattle, lower molar $\mathrm{M}_{1 / 2}$, of indeterminate wear stage.

The third was a bird bone, RF 1449 (C10, Phase Y, context 511), a medium Galliformes, large humerus. The bone is not fully ossified and comparison to reference skeletons shows that it is considerably larger than an adult male bantam. As it is from a phase of rebuilding in the twentieth century, the bone may be from a modern breed of domestic fowl.

\section{SITE T: RADFORD'S TRENCHES}

\section{INTRODUCTION}

No new, undisturbed deposits were excavated and therefore no environmental bulk samples taken from trenches T03-T05. However, two bulk samples were processed from the Little Ditch, T02, and occasional finds of shell and fragmentary animal bone were recovered. In addition, as the thin bands of fine silty clay sediments exposed in $\mathrm{T} 02$ did not appear to have been reworked, small monolith tins or Kubiena tins were taken from the vertical section to allow assessment of potential for pollen analysis.

\section{CHARRED PLANT MACROFOSSILS AND POLLEN SAMPLING FROM TRENCH T02}

The only plant macrofossils from T02 to survive the acidic conditions are small fragments of charred cereal grain (table 84); a single shell of Helix aspera was recorded from context 1202 (RF 5017). The presence of acid soils suggested that pollen might persist in the undisturbed silty clays (table 85 ).

Small monolith tins $(5 \times 5 \times 20 \mathrm{~cm})$ were taken through silts (contexts 1210,1211 and 1209) in the Little Ditch. Pollen samples were assessed at 0-1, 12-13, 21-2 and $33-4 \mathrm{~cm}$ depths, the lowest, from context 1209 , regarded as a natural deposit pre-dating the ditch. The silts above this relate to accumulation after the ditch went out of use and all three levels are probably sixteenth-early seventeenth-century in date. The results of the assessment are given in Table 85. Pollen preservation was very poor in the basal two samples and restricted to Cichorium intybus-type (dandelion and related Asteraceae). The upper two samples were also dominated by this type but, in common with the assemblages from T01 ext and the north bank of T01, also included a few sedges, grasses and grains of ribwort plantain. The impression is of open, disturbed grassland, but the poor preservation has resulted in only a partial representation of the original pollen flora so this may not be a fair reflection of the vegetation.

\section{ZOOARCHAEOLOGICAL REMAINS FROM TRENCH T02 by Polydora Baker}

None of the few bone and tooth fragments recovered from $\mathrm{T} 02$ could be identified to species and no interpretation could be made of the zoological data.

\section{SITE T: THE GREAT DITCH, TRENCH T01}

\section{INTRODUCTION}

In addition to 45 bulk samples taken from trench T01 in the Great Ditch for wet-sieving on site, a number of samples were taken for specialist examination at the laboratory and charcoal identified from one sample for radiocarbon dating of a primary silting layer. The survival of mollusc shells as well as bone fragments was new for Tintagel and its acidic soils. The charcoal identification on the contexts selected for radiocarbon dating produced a similar range of taxa to other areas of the site. ${ }^{19}$

\section{CharRED PLANT MACROFOSSILS AND CHARCOAL with Rowena Gale}

The lack of cereal chaff and scarcity of crop weeds is typical of Tintagel but much more marked in the Site $\mathrm{T}$ samples than elsewhere. This limits any inferences about farming practice and the origin of the crops. We cannot tell from a few oat caryopses lacking floret bases whether they were from a wild (and therefore weed) species or a crop. The case for the latter was advanced by Straker ${ }^{20}$ but the evidence is so slight from Site $\mathrm{T}$ that no additional insight can be gained. It remains most likely that the cereal crops (principally oats and barley) were brought to the settlements at least partially processed or more evidence of cleaning in the form of cereal chaff such as culm nodes, rachis fragments and large-seeded 
Table 84 Site T: charred plant macrofossils from T01 (Great Ditch), T01 ext and T02

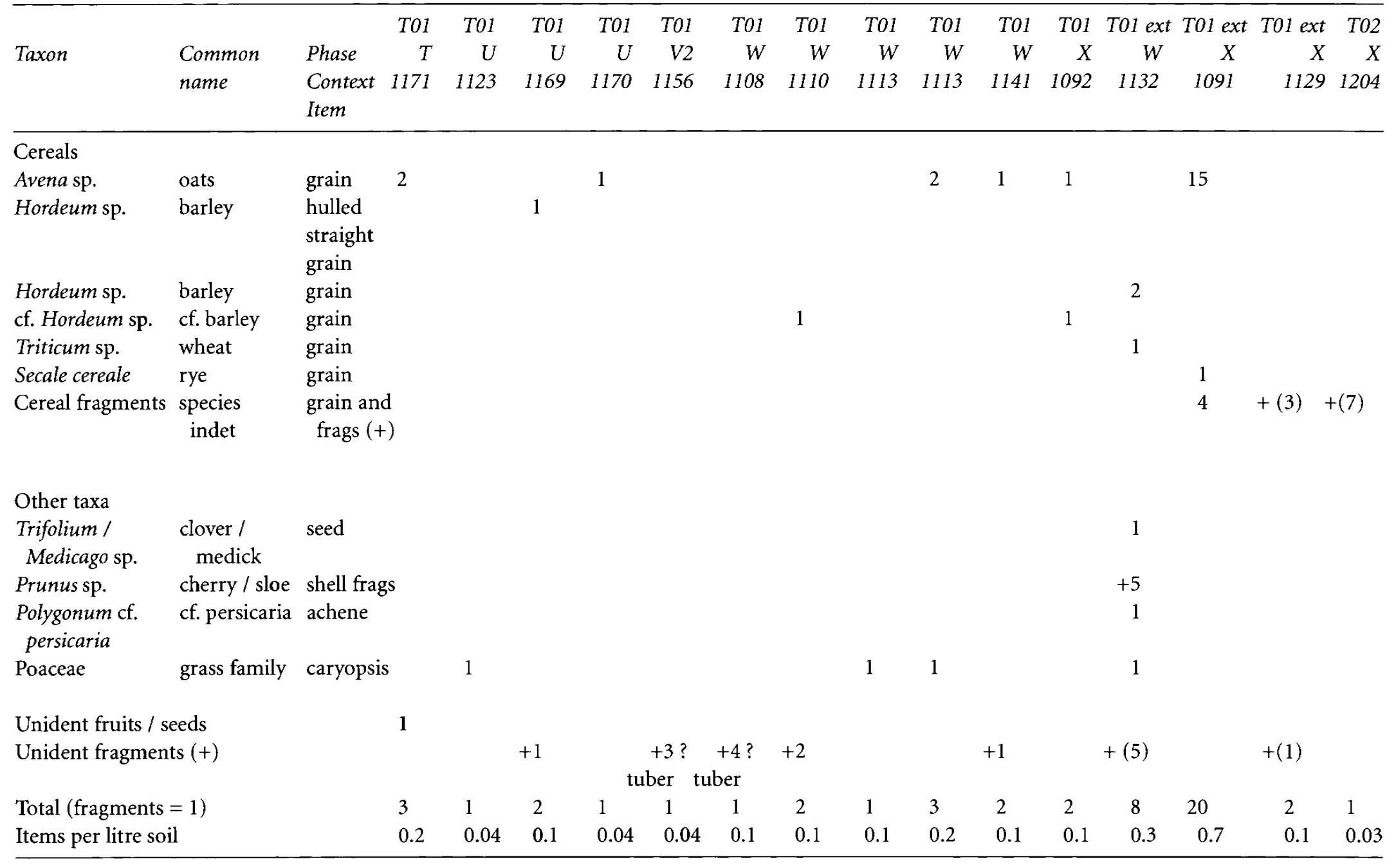


Table 85 T02: pollen assessment

\begin{tabular}{|c|c|c|c|c|c|}
\hline Pollen / spore type & Common name & $\begin{array}{l}0-1 \mathrm{~cm} \\
1210 \\
\text { Phase X }\end{array}$ & $\begin{array}{l}12-13 \mathrm{~cm} \\
1211 \\
\text { Phase X }\end{array}$ & $\begin{array}{l}21-22 \mathrm{~cm} \\
1211 \\
\text { Phase X }\end{array}$ & $\begin{array}{l}33-34 \mathrm{~cm} \\
1209 \\
\text { Phase V }\end{array}$ \\
\hline \multicolumn{6}{|l|}{ Herbs } \\
\hline Cichorium intybus-type & dandelion-type & 106 & 99 & 31 & 36 \\
\hline Plantago lanceolata & ribwort plantain & 2 & 3 & & \\
\hline Cyperaceae & sedge family & & 1 & & \\
\hline Poaceae & grasses & & 6 & & \\
\hline Total pollen & & 108 & 109 & 31 & 36 \\
\hline \multicolumn{6}{|l|}{ Spores } \\
\hline Pteropsida undiff (monolete) & ferns & 2 & 2 & & \\
\hline Pteridium & bracken & 2 & & & \\
\hline Sphagnum & bog moss & 1 & & & \\
\hline Unknown & & & & 10 & 9 \\
\hline Total pollen and spores & & 113 & 111 & 41 & 45 \\
\hline Lycopodium (exotic) & & 18 & 18 & 14 & 28 \\
\hline Traverses & & 7 & 7 & 10 & 10 \\
\hline Degraded & & 5 & 8 & 6 & 1 \\
\hline Folded / crumpled & & 1 & & & \\
\hline Charcoal (<50 microns) & & occasional & occasional & rare & rare \\
\hline
\end{tabular}

See Table 87 for key to pollen types

weeds would be expected. Oats (in particular) and barley would tolerate the poor acid soils and exposed nature of the north Cornwall coast.

The fills of the Great Ditch contained a high percentage of slate and shale fragments and very little in the way of charred plant macrofossils and charcoal. Tables 84 and 86 give the plant macrofossil and charcoal identifications.

The earliest deposit to contain any macrofossils was context 1171, a grey silty clay presumed to be natural. The presence of two grains of oats (Avena sp.) suggests that it may have been redeposited or disturbed on its surface. Phase $\mathrm{U}$, thought to date from the fifth to seventh centuries $\mathrm{AD}$, only contained single oat, barley and grass caryopsis and occasional fragments of hazel charcoal. Context 1161, the context selected for radiocarbon dating in Phase V1, contained fragments of oak heartwood, birch and hazel, and is thought to date to the sixth-seventh centuries (see Bayliss below). No other macrofossils were recovered from $\mathrm{V} 1$ and from $\mathrm{V} 2$ only unidentified fragments. Occasional oat, barley and grass caryopsis from Phase $\mathrm{W}$ are thought to relate to thirteenth-fifteenth-century activity in the Castle and the barley, oats and hazel charcoal from Phase $\mathrm{X}$ are thought to be from a mixed deposit related to the backfilling of Radford's trench.

The concentration of plant macrofossils and charcoal in the Site $T$ trenches (see tables 84 and 86) is extremely low, lower than that seen in other areas at Tintagel. The only observations that can be made are that the Great Ditch was not generally being used for disposal of domestic food waste or hearth debris at any of the stages in which the ditch silts accumulated, at least at the point that the 1999 section was cut. None of the assemblages can be attributed to any particular activity and comprise a 'background' flora, which gives a general impression of the crops and wood in common use. Dry ditches frequently contain only low concentrations of plant macrofossils except where excavation happens upon particular localized disposal events. ${ }^{21}$ The range of taxa from the Great Ditch (eg oats, barley, grasses, hazel and oak charcoal) is typical of most assemblages found at Tintagel dating from the late Roman period onwards. 
Table 86 Site T: charcoal identification

\begin{tabular}{|c|c|c|c|c|c|c|}
\hline Taxon & $\begin{array}{l}\text { Trench } \\
\text { Phase } \\
\text { Context } \\
\text { Common name }\end{array}$ & $\begin{array}{l}\text { T01 } \\
U \\
1169 \\
\text { no. fragments }\end{array}$ & $\begin{array}{l}\text { T01 } \\
\text { V1 } \\
1161 \\
\text { no. fragments }\end{array}$ & $\begin{array}{l}\text { T01 } \\
W \\
1114 \\
\text { no. fragments }\end{array}$ & $\begin{array}{l}\text { T01 } \\
X \\
1092 \\
\text { no. fragments }\end{array}$ & $\begin{array}{l}\text { T01 ext } \\
W \\
1135 \\
\text { weight }\end{array}$ \\
\hline Corylus avellana & hazel & 1 & & & 2 & $c 12 \mathrm{~g}$ \\
\hline $\begin{array}{l}\text { Corylus avellana or } \\
\text { Alnus glutinosa }\end{array}$ & hazel or alder & & 6 & & & \\
\hline Prunus spinosa & blackthorn & & & & & $<\lg$ \\
\hline Pomoideae & $\begin{array}{l}\text { hawthorn / } \\
\text { Sorbus group }\end{array}$ & & & & & $c \lg$ \\
\hline Quercus sp. & oak & & $\begin{array}{l}\text { 1, heartwood, } \\
\text { unknown } \\
\text { maturity }\end{array}$ & $\begin{array}{l}\text { 1, heartwood } \\
\text { unknown } \\
\text { maturity }\end{array}$ & & $\begin{array}{c}\text { heartwood, } \\
\text { unknown } \\
\text { maturity } \\
\text { and }<1 \mathrm{~g} \\
\text { sapwood }\end{array}$ \\
\hline Betula sp. & birch & & 1 & & & $<\lg$ \\
\hline $\begin{array}{l}\text { cf. Rosaceae, probably } \\
\text { Prunus spinosa, } \\
\text { Rubus sp. or Rosa sp. }\end{array}$ & $\begin{array}{l}\text { rose family, } \\
\text { probably black- } \\
\text { thorn, bramble } \\
\text { or briar, twiggy } \\
1.5 \mathrm{~mm} \text { diameter }\end{array}$ & & 1 & & & \\
\hline Unidentified bark & & & 1 & & & \\
\hline
\end{tabular}

Charcoal was generally very rare. The environmental summary table (in the Research Archive Report) lists the contexts that contained fragments which were greater than $2 \mathrm{~mm}$ in all dimensions, however, even these fragments were scarcely larger than $2 \mathrm{~mm}$ and these contexts also contained fragments smaller than $2 \mathrm{~mm}$. Identified charcoal is listed in Table 86. The charcoal from this group was dated to the sixth-seventh century at the latest (see Bayliss below) and all the taxa identified have been found before at Tintagel from deposits of this date. They include predominantly hazel or alder (Corylus avellana or Alnus glutinosa), with single fragments of oak (Quercus sp.) heartwood, birch (Betula sp.), cf. Rosaceae and unidentified bark.

\section{POLLEN ASSESSMENT \\ with Heather Tinsley}

The results of the pollen assessment are given in Table 87. The pollen sample from context 1155 , Phase $\mathrm{T}$, a blue-grey silty clay below a thin iron pan exposed in the north bank section, is probably from the lower part of a natural soil profile above the bedrock. Pollen did survive in this but was dominated by herb pollen, overwhelmingly by Cichorium intybus-type, a morphologically similar group within the daisy family, which includes dandelion, and other species (see table 87). Pollen taxa vary in their resistance to decay in soils; dandelion and related plants produce very robust pollen grains, which often remain in the sediment when less robust types have decayed. Other pollen taxa present included a ribwort plantain, grasses, the campion family and a sedge. The only trees represented are elm and birch with only single grains recorded in the counts. Very occasional spores of polypody fern, bracken and bogmoss were also noted. Ecological interpretation must be limited because of the extreme bias towards the resistant Cichorium intybus-type, but the general impression is of largely open, disturbed ground immediately adjacent to the ditch.

\section{MOLLUSC SHELLS}

by Mark Robinson

Somewhat surprisingly some of the contexts in the Great Ditch were sufficiently calcareous for the preservation of 
Table 87 Site T: pollen assessment from T01 (Great Ditch, north bank), and T01 ext

\begin{tabular}{|c|c|c|c|c|}
\hline Pollen type & $\begin{array}{l}\text { Trench } \\
\text { Phase } \\
\text { Context } \\
\text { Common name }\end{array}$ & $\begin{array}{l}\text { T01 } \\
T \\
1155 \\
\text { north bank } \\
\text { no. of fragments }\end{array}$ & $\begin{array}{l}\text { T01 ext } \\
V \\
1137-8, \\
0-1 \mathrm{~cm} \\
\text { no. of fragments }\end{array}$ & $\begin{array}{l}\text { T01 ext } \\
V \\
1137-8, \\
3-4 \mathrm{~cm} \\
\text { no. of fragments }\end{array}$ \\
\hline \multicolumn{5}{|l|}{ Trees and shrubs } \\
\hline Betula & birch & 1 & & \\
\hline $\begin{array}{l}\text { Pinus sylvestris } \\
\text { Ulmus }\end{array}$ & $\begin{array}{l}\text { Scots pine } \\
\text { elm }\end{array}$ & 1 & & 1 \\
\hline \multicolumn{5}{|l|}{ Herbs } \\
\hline Caryophyllaceae & campion family & 1 & 1 & \\
\hline Cichorium intybus-type & dandelion-type & 91 & 78 & 98 \\
\hline Plantago lanceolata & ribwort plantain & 3 & 35 & 5 \\
\hline Polygonum aviculare-type & knotgrass-type & & & 1 \\
\hline Cyperaceae & sedge family & 1 & & 5 \\
\hline Poaceae & grasses & 2 & 4 & \\
\hline Total pollen & & 100 & 118 & 110 \\
\hline \multicolumn{5}{|l|}{ Spores } \\
\hline $\begin{array}{l}\text { Pteropsida undiff } \\
\text { (monolete) }\end{array}$ & ferns & & 4 & \\
\hline Polypodiaceae & polypody family & 1 & 1 & \\
\hline Pteridium & bracken & 2 & & \\
\hline Sphagnum & bog moss & 1 & 1 & \\
\hline Total pollen and spores & & 104 & 124 & 110 \\
\hline Lycopodium (exotic) & & 53 & 2 & 5 \\
\hline Traverses & & 10 & 3 & 3 \\
\hline Degraded & & 10 & 35 & 18 \\
\hline Folded / crumpled & & 3 & 10 & 2 \\
\hline Charcoal ( $<50$ microns) & & occasional & abundant & frequent \\
\hline
\end{tabular}

Pollen types follow Bennett (1994). Cichorium intybus-type includes Cichorium intybus, Lapsana communis, Hypochaeris, Leontodon, Picris, some Lactuca species, Cicerbita alpina, Taraxacum, Crepis, Pilosella, Hieracium; Solidago virgaurea-type includes Filago, Antennaria dioica, Gnaphalium, Inula, Pulicaria, Solidago virgaurea, Aster, Erigeron, Bellis perennis, Senecio, Tephroseries, Tussilago farfara, Petasites hybridus, Bidens, Eupatorium cannabinum

shell in Phase $\mathrm{W}$ contexts (table 88). Only robust fragments of the land snail Cepaea sp. survived in context 1108 but conditions of preservation were better in context 1152, where Oxychilus alliarius shells were the most numerous but other species including Lauria cylindracea and Discus rotundatus were also present. These species tend to be characteristic of shaded habitats but they would probably have gained sufficient shelter from stone scree in the ditch so need not imply the presence of any woodland.

\section{ZOOARCHAEOLOGICAL REMAINS by Polydora Baker}

Of the few fragments recovered from T01, five could be identified to species (table 89). Given the very small number of bones, very little interpretation is possible.

\section{SOILS ANALYSIS}

by Jennifer Heathcote

Primary silting deposits were encountered to a thickness of approximately $0.1 \mathrm{~m}$ at the base of the Great Ditch. 
Excavations at Tintagel Castle, Cornwall, 1990-9

Table 88 Site T: molluscs from T01 (Great Ditch) and T01 ext

\begin{tabular}{|c|c|c|c|c|c|}
\hline Taxon & $\begin{array}{l}\text { Phase } \\
\text { Context }\end{array}$ & $\begin{array}{l}\text { T01 } \\
W \\
1108\end{array}$ & $\begin{array}{l}\text { T01 } \\
W \\
1152\end{array}$ & $\begin{array}{l}\text { T01 ext } \\
W \\
1132\end{array}$ & $\begin{array}{l}\text { T01 ext } \\
X \\
1091\end{array}$ \\
\hline \multicolumn{6}{|c|}{ Marine molluscs } \\
\hline Diodor & aeca & - & - & - & 1 \\
\hline Mytilu. & ulis & - & - & - & 2 \\
\hline Chlam & istorta & - & - & - & 2 \\
\hline cf. Spis & & - & - & - & 1 \\
\hline \multicolumn{6}{|c|}{ Land snails } \\
\hline Cochlic & sp. & - & - & - & 4 \\
\hline Vertigo & maea & - & - & - & 2 \\
\hline Lauria & indracea & - & 2 & - & 11 \\
\hline Valloni & ccentrica & - & - & - & 1 \\
\hline Valloni & & - & - & - & 2 \\
\hline Discus & indatus & - & 1 & - & - \\
\hline Vitrea & & - & 2 & - & - \\
\hline Aegopi & a nitidula & - & 1 & - & - \\
\hline Oxychi & alliarius & - & 10 & - & - \\
\hline Oxychi & & - & - & - & 1 \\
\hline Arianto & bustorum & - & - & 1 & - \\
\hline Cepaea & & 2 & - & - & - \\
\hline Arianto & Cepaea sp. & - & - & - & 1 \\
\hline Helix a & & - & - & - & 1 \\
\hline
\end{tabular}

These were fine-grained, well embedded and had a considerably lower stone content than the surrounding material. Localized deposits with similar characteristics were noted in a pocket lying approximately $0.5 \mathrm{~m}$ above the base of the ditch. Both these deposits were sampled by Vanessa Straker to assess their potential for pollen preservation (see above). However, no soils analysis was deemed necessary.

A distinctive layer of blue-grey silty clay (1167) approximately $0.06 \mathrm{~m}$ thick was encountered at $1.55-1.61 \mathrm{~m}$ beneath the modern ground surface in trench T01. A layer with similar characteristics was found at a comparable level in trench T01 ext (see below). In both locations it was overlain by shillet containing anthropogenic material (pottery and charcoal flecks), underlain by highly weathered shillet and both the upper and lower boundaries showed strong iron pan development.

The characteristics of the material are most likely to be the consequence of weathering and localized drainage conditions. There is no evidence that human activity has created the deposit or that any anthropogenic material has been incorporated into it. Rather, the presence of an iron pan at the base of the context, together with its blue-grey colouration, suggests that it results from localized impeded drainage conditions.

Table 89 Identified hand-collected bone fragments from Site T

\begin{tabular}{lllll}
\hline RF no. & Trench & Notes / identifications & Context & Phase \\
\hline 4120 & T01 & Sheep / goat mandible. Wear stages: $\mathrm{P}_{4}$ 14S; $\mathrm{M}_{1} 15 \mathrm{~A} ; \mathrm{M}_{2} 13 \mathrm{~B} ; \mathrm{M}_{3} 11 \mathrm{G}$ & 1081 & $\mathrm{X}$ \\
4191 & T01 & cf. Sheep / goat femur, shaft & 1110 & $\mathrm{~W}$ \\
4212 & T01 & Sheep / goat upper molar $\mathrm{M}_{1 / 2}$, weathered; lower third molar $\mathrm{M}_{3}$ wear stage 6A 1108 & $\mathrm{W}$ \\
4230 & T01 & Pig canine, male, ?left: 2 fragments; 2 other fragments, probably associated & 1120 & $\mathrm{~W}$ \\
4121 & T01 ext & cf. cattle sacrum (S1), broken, epiphyseal surface unfused & 1090 & $\mathrm{X}$ \\
4122 & T01 ext & cf. Galliformes ulna, size large domestic fowl & 1099 & $\mathrm{Y}$ \\
4123 & T01 ext & cf. Scolopacidae coracoid & 1099 & $\mathrm{Y}$ \\
4124 & T01 ext & Large gadid, cf. cod, exoccipital & 1099 & $\mathrm{Y}$ \\
4125 & T01 ext & Large conger eel cranial element & 1099 & $\mathrm{Y}$ \\
4231 & T01 ext & Sheep / goat pubis, minimum diameter 6.1mm & 1091 & $\mathrm{X}$ \\
4232 & T01 ext & Rabbit femur: GL 82.4mm; Bp 15.9mm; SD 6.7mm; Bd 13.5mm DC 6.5mm, & 1091 & $\mathrm{X}$ \\
& & BTr 14.4mm & 1091 & $\mathrm{X}$ \\
Sample & T01 ext & From flot residue: rabbit atlas & &
\end{tabular}


THE RADIOCARBON DATING

by Alex Bayliss and Christopher Bronk Ramsey Six radiocarbon measurements have been taken on samples from trench T01. All were processed by the Oxford Radiocarbon Accelerator Unit in 2001, using methods described by Hedges et al ${ }^{22}$ and Bronk Ramsey and Hedges. ${ }^{23}$ Quality assurance data for these samples are provided in Bronk Ramsey et al. ${ }^{24}$ The results are given in Table 90, quoted in accordance with the international standard known as the Trondheim convention. ${ }^{25}$ They are conventional radiocarbon ages. ${ }^{26}$ The calibrated dates for these samples are also given in Table 90 and in Figure 144. They have been calculated using the datasets published by Stuiver et $a^{27}$ and the computer program OxCal (v3.5). ${ }^{28}$ The calibrated date ranges are those for 95 per cent confidence, quoted in the form recommended by Mook. ${ }^{29}$ The ranges have been calculated according to the maximum intercept method, ${ }^{30}$ the probability distributions have been calculated by the method of Stuiver and Reimer. ${ }^{31}$
As stated above, the Great Ditch appears to be a natural feature, which has been modified in antiquity. Little material suitable for dating was recovered from this feature, since no waterlogged material or bone was preserved, and only charred plant remains were available for dating from the primary silts. It is difficult to determine the taphonomy of this material. Consequently, a number of single-entity samples ${ }^{32}$ was taken from the lowest primary silt, in the hope that the latest of these would provide a terminus post quem for the final maintenance of the ditch.

The radiocarbon dates from this feature span a considerable period of time (see figure 144). The dated material seems to have been washed into the ditch from the contemporary ground surface after the final cutting of the ditch. A terminus post quem for this event is therefore provided by the latest of these dates, $\mathrm{Cal} A \mathrm{D}$ 530-670 (OxA-10483). The earlier material from this fill may indicate activity on the site in the Romano-British and immediately post-Roman periods. The taxa and

Table 90 Radiocarbon determinations from Site $\mathrm{T}$

\begin{tabular}{|c|c|c|c|c|c|}
\hline Laboratory no. & Sample reference & Context & $\begin{array}{l}\delta^{13} \mathrm{C} \\
(\% o)\end{array}$ & $\begin{array}{l}\text { Radiocarbon } \\
\text { age }(B P)\end{array}$ & $\begin{array}{l}\text { Calibrated date } \\
\text { range ( } 95 \text { per } \\
\text { cent confidence) }\end{array}$ \\
\hline OxA-10388 & T'TG99 T01 EX'T 1135(A) & $\begin{array}{l}\text { charcoal (Corylus sp.) from } \\
\text { the charcoal-rich fill (1135) } \\
\text { of a cut feature (1136) } \\
\text { capped by blue clay (1132) }\end{array}$ & -25.9 & $1667 \pm 39$ & $\mathrm{cal}$ AD $250-460$ \\
\hline OxA-10389 & TTG99 T01 EXT 1135(B) & $\begin{array}{l}\text { charcoal (Corylus sp.) } \\
\text { from (1135) }\end{array}$ & -25.5 & $1620 \pm 37$ & $\mathrm{cal}$ AD $340-540$ \\
\hline OxA-10390 & TTG99 T01 1161A & $\begin{array}{l}\text { charcoal (Corylus / Alnus } \\
\text { sp.) from the basal primary } \\
\text { fill of the Great Ditch (1161) }\end{array}$ & -24.3 & $1607 \pm 37$ & $\mathrm{Cal} \mathrm{AD} \mathrm{360-550}$ \\
\hline OxA-10482 & TTG99 T01 1161B & $\begin{array}{l}\text { charcoal (Corylus / Alnus } \\
\text { sp.) from (1161) }\end{array}$ & -24.5 & $1715 \pm 55$ & $\mathrm{cal} \mathrm{AD} 180-440$ \\
\hline OxA-10483 & TTG99 T01 1161C & $\begin{array}{l}\text { charcoal (Corylus / Alnus } \\
\text { sp.) from (1161) }\end{array}$ & -25.4 & $1450 \pm 45$ & $\mathrm{cal} \mathrm{AD} 530-670$ \\
\hline OxA-10484 & TTG99 T01 1161D & $\begin{array}{l}\text { charcoal (?Rosaceae) from } \\
\text { (1161) }\end{array}$ & -24.9 & $1985 \pm 45$ & $\begin{array}{l}100 \mathrm{cal} \mathrm{BC}-\mathrm{cal} \\
\text { AD } 130\end{array}$ \\
\hline OxA-10485 & TTG99 T01 1161E & $\begin{array}{l}\text { charcoal (Corylus / Alnus } \\
\text { sp.) from (1161) }\end{array}$ & -23.8 & $1710 \pm 45$ & $\mathrm{cal} \mathrm{AD} 230-430$ \\
\hline OxA-10486 & TTG99 T01 1161F & $\begin{array}{l}\text { charcoal (Betula sp.) } \\
\text { from }(1161)\end{array}$ & -26.6 & $1678 \pm 45$ & $\mathrm{cal} \mathrm{AD} 250-530$ \\
\hline
\end{tabular}




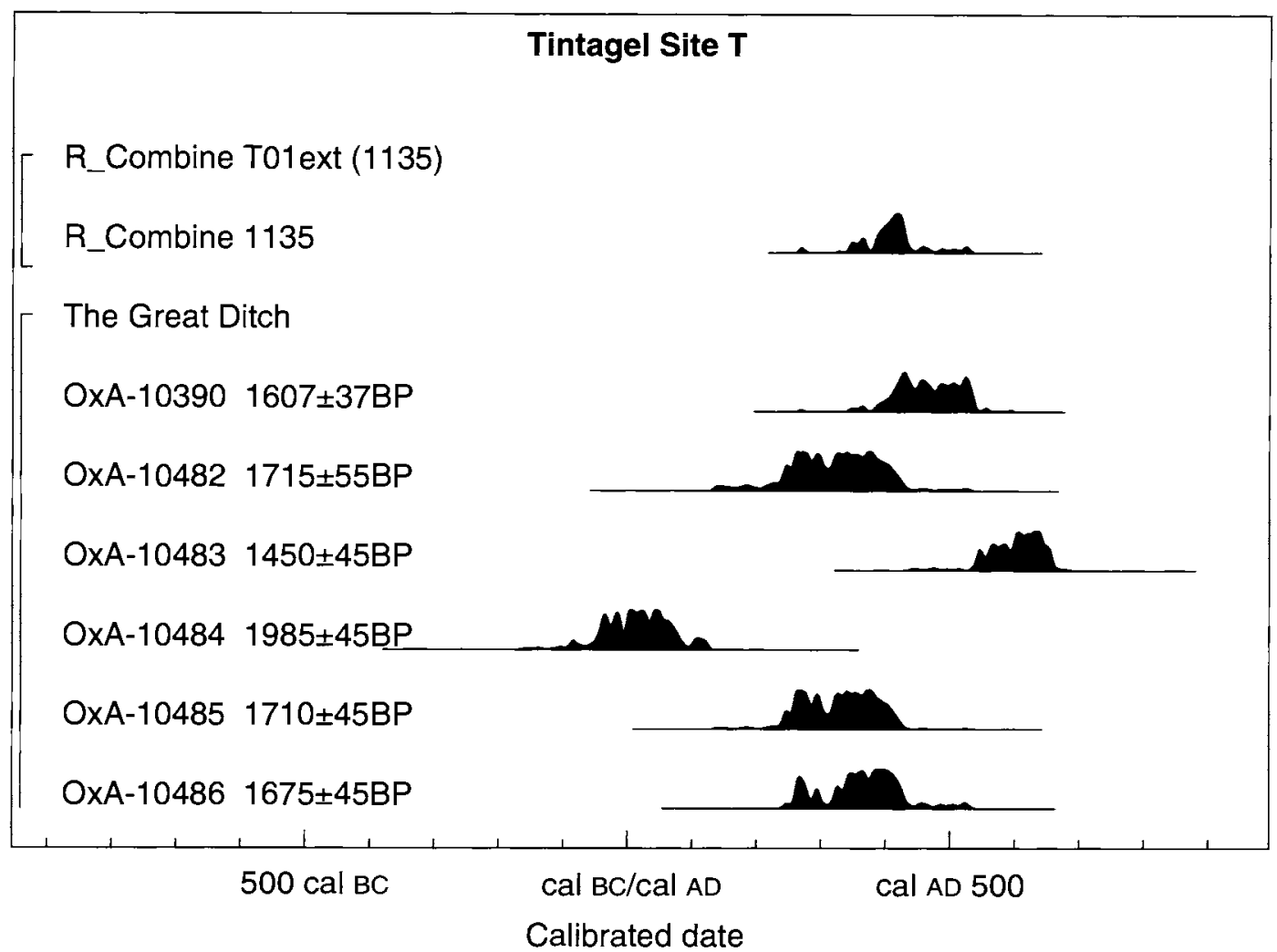

144 Radiocarbon dating: probability distributions of dates from Site $T$

ages of the dated samples make it extremely unlikely that the carbonized wood (Corylus/Alnus sp., ?Rosaceae and Betula sp.) was old when burnt.

\section{SITE T: THE LOWER WARD, TRENCH T01 EXT}

\section{INTRODUCTION}

In addition to the ten bulk samples taken for wet-sieving on site from trench T01 ext in the Lower Ward, a number of samples were taken for soils analysis. The thin bands of fine silty clay sediments exposed in T01 ext did not appear to have been reworked and small monolith tins or Kubiena tins were taken from vertical sections to allow assessment of potential for pollen analysis. As with trench T01 in the Great Ditch, mollusc shells and fragments of animal bone were also recovered, and charcoal was identified from the contexts selected for radiocarbon dating.

\section{CHARRED PLANT MACROFOSSILS AND CHARCOAL}

Plant macrofossils were only recovered from three contexts (see table 84), one from Phase W (1132) and two from Phase X (1091 and 1129). 1132 produced two barley grains and a single wheat grain and weed species including a species of grass, medick/clover and Persicaria, all of which are typical of Tintagel assemblages though usually more plentiful. These could be grassland or arable taxa. Charcoal was also present in 1135 in Phase W and dominated by hazel and fragments of oak (see table 86). Also present were smaller amounts of blackthorn, Pomoideae (a group of taxa with similar wood anatomy including rowan, whitebeam, apples and pears) and birch.

Charcoal from this group was dated to the late fourth-early fifth centuries (see Bayliss beiow). All these taxa have been found at Tintagel before in deposits of this date, and include predominantly hazel (Corylus avellana), but also single fragments of blackthorn (Prunus spinosa), Pomoideae, oak heartwood (Quercus 
sp.) and birch (Betula sp.). The macrofossils from context 1091, Phase X, include fifteen oat grains and one grain of rye (Secale cereale). This context does not contain any later medieval pottery and may well be of fifth-seventh-century date. Finds of rye and oats would not be unexpected at this time though, as stated in previous reports from Tintagel,,$^{33}$ deposits of this date are very rare in southern England.

\section{POLLEN ASSESSMENT with Heather Tinsley}

The earliest contexts examined were sampled for pollen assessment and the results are given in Table 87 . One cubic centimetre subsamples were taken from $0-1 \mathrm{~cm}$ and 3-4cm depth through contexts 1137-1138 (Phase $\mathrm{V})$; the blue silty clays are probably the remains of a truncated soil profile, seen at the base of the trench. Fragments of microscopic charcoal were present in all the pollen preparations but more common in T01 ext samples than elsewhere. These tiny fragments would have been the results of airborne flecks from the fire but do not suggest large-scale burning events. Once again, the pollen assemblages showed evidence of differential preservation, being dominated by Cichorium intybustype (dandelion and related Asteraceae). Sedges were only present in the lower sample, and could have grown in damp grassland; the upper sample contained quite abundant ribwort plantain, a grassland plant which responds well to grazing and trampling. The only grain of tree pollen was of Scots pine; this wind-pollinated species was not likely to have been growing locally as greater quantities would be expected if this were the case. This assemblage pre-dates Phases $\mathrm{W}$ and $\mathrm{X}$ and is therefore late fourth/early fifth-century or earlier (see Bayliss and Bronk Ramsey below).

\section{MOLLUSC SHELLS}

\section{by Mark Robinson}

The occasional very small fragments of marine bivalve mollusc shells and small land snails were recovered mainly from the floats. Shells from the sample flots and residues are listed in Table 88 . The marine mollusc shells were extremely fragmented and were probably from many more individuals than the minimum given in the table.

A fragment of the land snail Arianta arbustorum was found in context 1132 but context 1091 contained a much higher concentration of shells, from both marine and terrestrial species (see table 88). Although the fragments of marine shell included the edible species
Mytilus edulis (common mussel), the most numerous fragments were from Chlamys distorta, a bivalve both too small and too difficult to collect for consumption. The marine shell fragments had the character of debris from shell sand (see Palmer, Chapter 10). With the exception of cf. Spisula sp., which occurs in sand, all the marine molluscs require a firm substrate.

The occurrence of marine shell fragments in context 1091 probably indicates conditions conducive to the preservation of the more fragile shells of land snails. The most abundant shells were of Lauria cylindracea, a species of screes, woodland and, in the more oceanic western parts of England, grassland. The presence of Vertigo pygmaea and Vallonia excentrica suggested grassland prevailed. One species from context 1091, Helix aspersa, is regarded as a Roman introduction to Britain but it rapidly became widespread throughout Southern England and the Midlands so its presence is not inconsistent with the late Roman or Dark Age date proposed for this deposit.

\section{ZOOARCHAEOLOGICAL REMAINS by Polydora Baker}

Few fragments recovered from T01 ext could be identified to species (see table 89). The finds are from a range of taxa, but only four of these are from well-dated deposits (Phase X, medieval Castle, twelfth/thirteenth centuries). Consequently, little if any interpretation may be made of the data. The presence of rabbit (Oryctolagus cuniculus) is not surprising, as archaeological and historical evidence suggest that this species was introduced by the Normans in the twelfth century, ${ }^{34}$ or the bone could be from an intrusive animal. The unidentified remains from the flot residues include a few fragments of fish bone and small mammal long bones and incisors (see zooarchaeological archive).

\section{SOILS ANALYSIS \\ by Jennifer Heathcote}

A layer (1137) with similar characteristics to that analysed in T01 above was found at a comparable level in Trench T01 ext, beneath context 1135, although here it was only $0.01-0.02 \mathrm{~m}$ thick. As discussed above, in both locations it was underlain by highly weathered shillet, and both the upper and lower boundaries showed strong iron pan development. This, together with the blue-grey colouration, suggests that it results from localized impeded drainage conditions. 


\section{THE RADIOCARBON DATING}

by Alex Bayliss and Christopher Bronk Ramsey

The results are given in Table 90, quoted in accordance with the same standards and conventions given for the radiocarbon dating results for Site $\mathrm{T}$, the Great Ditch, above.

The fill 1135 of a single feature 1136 from trench T01 ext was dated. This contained evidence of in situ burning, together with bloomery slag, post-Roman imported pottery and a sherd of early medieval etched glass. The two measurements on short-lived charcoal from this feature are statistically consistent $\left(T^{\prime}=0.8 ; T^{\prime}\right.$ ( 5 per cent $)=3.8 ; \nu=1$ ), and so a weighted mean has been taken before calibration. ${ }^{35}$ This provides a date for the feature of cal AD 340-530 (95 per cent confidence). However, it can be seen from Figure 144 that the probability of this distribution is very uneven, and it is most likely that this activity dates from the end of the fourth/beginning of the fifth century (cal AD 390-430 at 68 per cent confidence). It is broadly contemporary with the occupation previously dated by radiocarbon on the Lower Terrace of Site C. ${ }^{36}$

\section{DISCUSSION}

The archaeobotanical assemblages from the various excavations at Tintagel, including the previously published Lower Terrace results, do not show any major differences between the earlier and later phases. The range of taxa is small and apart from a few rich contexts in the Site C settlement, such as the fills of the fissure in $\mathrm{C} 16$ and layer 512 in $\mathrm{C} 10$, the concentration of plant macrofossils is very low.

Oats, hulled barley and to a lesser extent freethreshing bread wheat are the only cultivars present, though naked (free-threshing) barley was recorded from the Lower Terrace. The presence of small-seeded weeds of arable or disturbed ground such as sorrel, stinking mayweed, corn marigold, knotgrass and goosefoot and the scarcity of chaff and large-seeded arable weeds suggest that the crops were brought to the Island partially processed and cleaned for consumption on site. Oats and barley dominate the cereal assemblage and, despite the lack of chaff, it has been argued ${ }^{37}$ that the presence of cultivated oats cannot be ruled out. In fact the only oat chaff from Tintagel, two floret bases from the fissure in $\mathrm{Cl6}$, is domesticated in form. The oats and barley could be for both human and animal consumption. The scarcity of wheat could be partly related to the possibility that wheat is more likely to be ground for flour than used whole and is therefore not visible in the plant macrofossil record. ${ }^{38}$

The presence of rough grassland species attests to the open areas surrounding the settlement. The scarcity of gathered wild fruits and seeds is surprising, with only occasional finds of hazel nutshell and bramble pips. The lack of hazelnuts is interesting as hazel is the most commonly found wood species in both structural contexts and general layers. This might suggest that it was not growing locally and that the wood was brought in for construction when needed, possibly from a managed coppice. The almost complete absence of heathland species such as heather and gorse also suggests that the Island landscape was mainly grasslanddominated. This is also reflected in the Lower Terrace charcoal assemblage where a detailed programme of analysis was carried out. Here, only a small amount of gorse or broom was found. ${ }^{39}$ It is unfortunate that pollen preservation is so poor in the Island sediments as pollen analysis would have helped to confirm whether the vegetation did include much in the way of trees and shrubs or not. While mollusc species were recovered for the first time at Tintagel from the Great Ditch and both shaded and grassland habitats are suggested, shelter was probably provided within the ditch, thus obviating the implication of the presence of woodland.

It was hoped that the long-distance trade evident from the ceramics would be reflected in the identification of exotics in the environmental assemblages. In the event, no non-native plants were found and the acid soils result in poor bone preservation. A small zooarchaeological assemblage comprising friable bone and teeth fragments was recovered but little other than the suggestion of domestic livestock (cattle, caprines and pigs) can be made. This means that if the status of the inhabitants of the fifth- to seventh-century settlement was reflected in the meat component of the diet, it has not yet been detected in the archaeological record. However, there is scope to throw further light on the plant and animal foods in the diet by analysing the lipid content of ceramic sherds from pots that might have been used for cooking or food storage (see R Jones, Chapter 10).

The radiocarbon measurements taken on samples from the Great Ditch (trench T01), while spanning a considerable period of time, indicate a date in the midsixth to mid-seventh post-Roman centuries for the latest silting in the ditch. In addition, two radiocarbon 
measurements taken on charcoal from a burnt feature in the bottom of trench T01 ext in the Lower Ward of the Castle give a mean date of the mid-fourth to mid-fifth centuries, which can be refined to cal $\mathrm{AD} 390-430$ at 68 per cent confidence. These dates confirm activity on the mainland side of the site contemporary with that already evidenced on the Island in the late Roman and postRoman centuries.
Before the campaign of excavations, we had no knowledge whatever of the likely local environment on the Island, or the resources available to it. The environmental analyses have shown, not surprisingly, that the greatest potential for recovery of good plant macrofossil assemblages is from features in the lower levels of the sequence at the settlements, and much may still remain untouched. 

PART V

\section{IN CONCLUSION}





\section{CHAPTER 12}

\section{Overview and Final Discussion}

\section{INTRODUCTION}

The preceding chapters have described archive research, detailed survey work and excavation carried out through the 1990s by members of the University of Glasgow on behalf of English Heritage. Although there is an enormous potential for purely research-based excavation on the site, since 'we now have a very fair idea of where, on the Island, area excavation ... might answer outstanding questions', 1 the focus of our work was firmly kept by English Heritage to a post-Radford agenda. This would enable, theoretically at least, the outcomes of his work to be maximized or, at the least, more fully understood. Thus work was initially concentrated on a series of three terraces on the eastern side of the 'Island' (Site C: Upper, Middle and Lower), together with the later addition of work on the Great Ditch and its environs (Site $\mathrm{T}$ ) adjacent to the Lower Ward of the thirteenth-century Castle on the mainland side of the complex. Further, through a combination of detailed examination of the scant surviving archival remains of Radford's excavations in the 1930s and into the mid-1950s, with extensive on-site survey work to relocate Radford's trenches, a clearer picture emerged of the extent of Radford's work, which was far more extensive across the site than had previously been appreciated.

To that extent, this report perhaps has some claim to represent a considered 'final report' of some parts of the site at Tintagel Castle which Ralegh Radford excavated. In this concluding discussion, we shall, first, try to present as objective an assessment as possible of Radford's contribution to the understanding of the site and, second, present an overview of his work at Tintagel.
Thereafter we shall look at what the results of almost a decade of research on the site from 1990 and further post-excavation analysis and archival work up to 2005 have contributed to our knowledge of the archaeology of Tintagel. This spans the prehistoric and Romano-British periods, through its floruit in the early medieval period and on into the later medieval era and beyond. As the bulk of the evidence relates to the immediately postRoman and early medieval periods, it is inevitable that much of this discussion will be concentrated upon the implications of the recent work for the general understanding of the position of the site at this time within the wider context in Cornwall, the British Isles and the Late Antique Mediterranean world.

\section{RADFORD AND THE MONASTIC PARADIGM}

As has been demonstrated in Chapter 1, Radford's involvement in Tintagel marked a shift in overall interpretation from an 'Arthurian' model to one focusing upon an Early Christian monastic context. This was bolstered both by the apparently isolated nature of the site and the buildings encountered ${ }^{2}$ and by the links with the Mediterranean late Roman Antique world which Radford showed clearly both in documentary terms $^{3}$ and from the pottery evidence, including incontrovertible Christian symbolism on sherds of pottery. ${ }^{4}$ In 1970, while briefly discussing the nature of $\mathrm{A}$ - and $\mathrm{B}$-ware pottery, he also pointed to the distribution pattern of the two classes of pottery in western Britain and Ireland and observed:

The British distribution of these two series corresponds closely to that of the early Christian inscriptions in Latin; 
the Irish distribution is comparable with that of the related inscriptions in ogham. This pattern ... illustrates the wider connexions of insular Celtic Christianity through the Atlantic seaways, which had regained their importance ... They draw attention to the fact that these connexions were seaborne. ${ }^{5}$

Radford had previously emphasized, from the documentary evidence, the 'normal' nature of the contacts between the Mediterranean and Cornwall. ${ }^{6}$ Indeed he continued to underline the importance of 'the written tradition' in interpreting archaeological evidence for early Christianity in western and northern Britain:

This is not necessarily undesirable. Monasticism was essentially a spiritual force and its essence escapes the necessarily material analysis of archaeology. But unexpected lights appear. The bequests of the Venerable Bede - pepper, incense and napkins - have been quoted in this context. I would suggest that the eastern products do at least bear out the contacts suggested by the imported east Mediterranean pottery.

As Charles Thomas has clearly delineated, this 'monastic' interpretation lasted fifty years from Radford's first exposition of it to the Society of Antiquaries of London, although subject to increasing challenge and criticism. ${ }^{8}$ Radford's response to such criticism at the Scottish Archaeological Forum in $1973^{9}$ was sharp and dismissive ${ }^{10}$ and undoubtedly was a factor (despite caveats expressed) in Tintagel's last appearance in extenso in a major academic work in Rosemary Cramp's chapter on 'Monastic sites' in The Archaeology of Anglo-Saxon England. ${ }^{11}$ At about the same time, Susan Pearce, while acknowledging that 'Tintagel remains one of the most important early Christian sites in the South West, and one of the most difficult to interpret', drew attention to a number of 'problems' in 'the classic interpretation' and noted that 'Tintagel has elements compatible with major secular occupation sites of the period'. ${ }^{12}$ Oliver Padel and Kenneth Dark had followed Ian Burrow in casting doubt on the monastic paradigm, ${ }^{13}$ and Charles Thomas himself, in revisiting his earlier analyses of the imported Mediterranean pottery, fully abandoned the monastic model in print by $1982 . .^{14}$

The shift away from this paradigm was completed, ironically, with the survey following the disastrous fire on the plateau of the 'Island' in 1983. This identified 'one vast and continuous site with a hundred or more components, something far more intricate than had ever been demonstrated ... Immediately, too, those concerned with monastic archaeology could see that no Celtic monastery so far identified elsewhere looked anything like this.' ${ }^{15}$ This revisionism was explicitly articulated thereafter in the pages of the standard 'Regional History' for the south west of England ${ }^{16}$ and, by 1989, this had reached the pages of an overview on Cornish monasteries. ${ }^{17}$ More recent general works dealing with the fifth century and south-western sites now either specifically mention the shift in interpretation ${ }^{18}$ or ignore the previous model entirely and omit Tintagel from consideration as a monastic site. ${ }^{19}$ However, even so, a highly respected historian has as recently as 2001 stated that 'sometimes, as with Tintagel, it may be difficult to see if we are looking at a secular or monastic site'. ${ }^{20}$

Radford did not publish any significant papers dealing with Tintagel after 1975, and so it is not clear in print whether he accepted this fundamental and final revision of his monastic paradigm. However, examination of his archive has revealed an exchange with Rosemary Cramp in January/February 1988 when he was 'disputing new interpretations of the site. ${ }^{21}$ Finally, it is perhaps significant that, when asked to participate in TV filming on the site (to which he was brought by helicopter) at the onset of the new campaign of excavations in April 1990, he repeated his earlier overall view of the site as monastic.

\section{RADFORD'S WORK AT TINTAGEL, 1933-55}

When one turns to the practicalities of the excavation programme undertaken under Radford's aegis, then there is no doubt that different attitudes in relation to recording procedures prevailed before the Second World War - and perhaps most notably on sites in Guardianship' - than do today. Two other major monastic sites from both the Early Christian and later medieval periods suffered a similar fate to Tintagel: Whitby Abbey and Lindisfarne Priory. ${ }^{22}$ The work of clearance that often took place largely unsupervised on these sites is in sharp contrast with the focused research strategies adopted, for instance, by contemporaries like Sir Mortimer Wheeler on sites such as Stanwick and Maiden Castle. ${ }^{23}$ Perhaps Radford was not free to develop such strategies himself in the face of institutional pressures to present the site in a coherent 
manner to the public. His work was undoubtedly successful in facilitating the latter to the benefit of visitors - even if its interpretation as an 'Early Christian' or 'Celtic Monastic' site has now been shown to be inappropriate. However, less successful were the inadequacies of recording and reporting which have bedevilled later scholars - not to mention more recent institutional efforts to present the site to the public.

It is also unfortunate for his reputation that Radford's work at Tintagel is so incompletely represented both in archive and in press. Radford's own archive of his work at Tintagel, which became accessible in 1998 after much of the recent work at the site was completed, is outlined in Chapter 1, and the scope of the surviving documentation was assessed for inclusion in this volume. Extant photographs and a sketch plan of Site F of a 'drain filled with silt with charcoal and burnt slates' provide useful parallels, for instance, for a feature re-examined in the Site $C$ building (Chapter 6). Similarly, the chance survival of a photograph of work on the Site C building with the location of a spoil-heap resolved the conundrum of the richness of the artefactual record from outside the south-west corner of the building in contrast with the rest of the area.

There is also a little more information to be gleaned concerning artefacts from the site, although most of the information for finds such as the Alfred coin from Site A, is still inconclusive. The archive sheds a little more light on the circumstances behind the discovery of an object thought to have been a fossil (and thus given by the workmen to a local schoolboy). This turned out to be a dehydrated leather bag containing Roman coins, recovered from the Great Ditch in 1955 (see Chapter 1).

Despite the evident deficiencies in both publication and archive, it is clear from studying Radford's archive that he had a deep-seated interest - and indeed commitment - to Tintagel from the inception of work in 1933, through the $1930 \mathrm{~s}$, and then on a more intermittent basis, including advice to the MoW in the 1940s, up to 1955. A definitive listing of his work by year at the site has at long last been possible (see Chapter 1, table 1). This demonstrates, for instance, that the Great Ditch, Site T, was examined in 1938 and 1939, and that the work there in 1955 was proposed as the last of Radford's work at Tintagel (with even the possibility of postponement until 1956). We now know that the 1955 excavations examined both the Great Ditch and a smaller ditch, now identified as 'the wall walk' at the base of the north-east Lower Ward wall. It can also be dated as post-Roman, later adapted in the thirteenth century, from pottery found during archive study among material in the Radford archive for Glastonbury.

Of major significance in the archive documentation for Radford's work is the presence of J A Wright's drawings, consisting of plans and sections undertaken mostly at the end of the excavation seasons. Paul Johnson's important research into the Wright archive, and his 1995 survey of Tintagel Island (Chapter 1) enabled a map to be produced of the 1930s excavations, where these were recorded (figure 21). Undoubtedly some of Radford's excavation 'slit' trenches were purely exploratory between visible features, often without apparent regard for the topography of the site. However, other trenches did relate to the extant remains of building foundations, and these were often extended into larger-scale clearance of the deposits from visible structures to allow them to be presented more clearly for the general public. This was plainly demonstrated by the differential results seen between the re-excavations in 1990-4 of the Radford exploratory trenches on the Upper and Middle Terraces (Chapters 3 and 4) and those undertaken in and around the Site $\mathrm{C}$ building (Chapter 6). Some of the archival records, especially Wright's plans, may well have been created primarily to record the structures to be presented to the public rather than the results of the excavations themselves.

Although the actual detail of Wright's plans and sections is sometimes cryptic, it is quite clear that in many cases where Radford opened trenches and work proceeded to bedrock levels, primary organic and loose stone deposits were noted at the base of the stratigraphical sequence on the sections. This is seen, for example in his work at Site F, recorded by Wright (figure 145) where deposits underlying standing walls and overlying slab levelling deposits are shown in section. This sequence has been mirrored in much more recent work by Cornwall Archaeology Unit in the area of the pathway down to the Iron Gate, where early medieval deposits and structural traces located on artificial terraces have been identified. ${ }^{24}$ All in all, thirty-two trenches on the 'Island' have been identified (see Chapter 1, figure 21) on the ground (including seven from Site $\mathrm{H}$, the location of which is now secure), together with those examined in Site $\mathrm{T}$ in 1999 (Chapters 7, 8 and 9).

It would not be honest of us to attempt to play down the inadequacies of the previous records of interventions at the site by Radford, or indeed to 


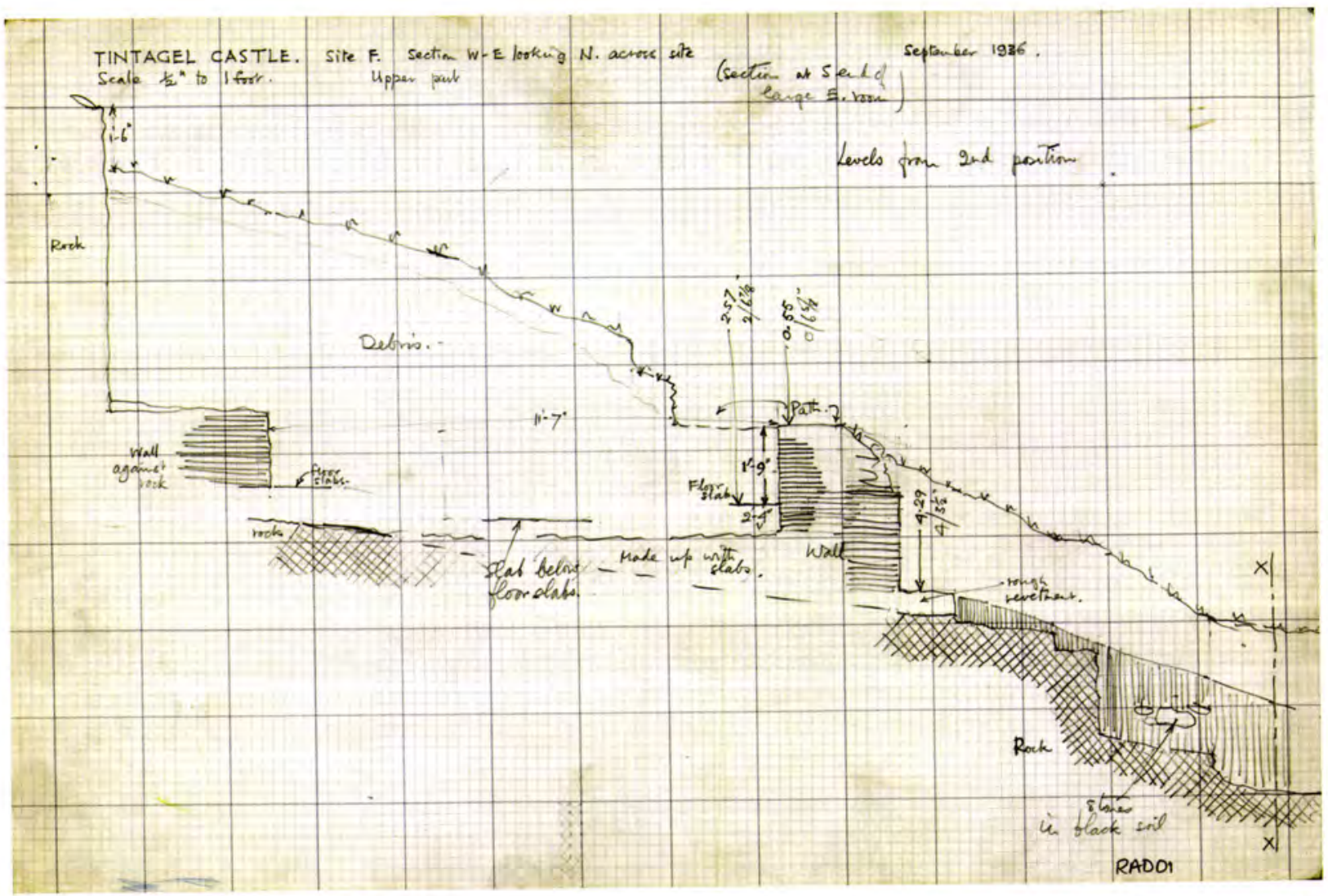

145 Wright's drawing of 'Tintagel Castle. Site F. Section W-E looking N across site. September 1936'. Reproduced by permission of English Heritage (NMR)

under-represent the difficulties that have been created by them over the years. The tragedy is that - for whatever reasons - Radford himself was not in a position to be able to fully document the archaeological evidence that lay behind his interpretation and general expositions. Although it might have been thought that a reconstructed 'final report' of his work could have been presented on the basis of the archival material, on initial examination of the material it was immediately evident that this was not feasible and subsequent more detailed examination has simply confirmed this. We have tried in our work not to judge the work of the past by present standards, and it is upon this basis that we can recognize the achievement of Courtney Arthur Ralegh Radford in bringing forward the importance of this unique site both to its visitors and to the more general antiquarian public of the British Isles and beyond.

As modern archaeologists we are charged with creating as faithful a record as possible of our efforts in intervening on such an important site. Radford was in no doubt of Tintagel's seminal importance and had a vision of the wider picture of the setting for the site, and he lost no opportunity to expound it. That his model radically different at the time - of Tintagel as an Early Christian monastic site lasted for fifty years is testimony to this. Although new investigations have emphasized different aspects of the site and come to different conclusions about its wider significance, there can be little doubt about the importance of his pioneering work. To that extent, we who have come after are standing upon his shoulders, and must salute the achievement of a man who stands in an honourable antiquarian tradition and who represents a different era from our own.

\section{OVERALL CHRONOLOGY}

When Thomas wrote his general book on Tintagel in 1993, he proposed an overall archaeological time-scale for the site and a division into five major periods. ${ }^{25}$ This 
remains a convenient structure within which to place the outcomes of the recent work. Period 0 was assigned to prehistory, Period I to the Roman period, Period II to post-Roman, Period III to late pre-Conquest (and early Norman), Period IV to the Castle and Period V to postmedieval to the present. There is nothing from the recent work that need clash with this, but more specific chronological refinement within these periods is referred to as appropriate in relation to the typological studies of groups of artefactual material and the outcomes of a limited radiocarbon dating programme undertaken on particular carbonized material from some of the sites excavated in the 1990s.

\section{PREHISTORY: PERIOD 0}

In Thomas's review of the history of occupation at Tintagel he notes the lack of any real prehistoric occupation' on the Island, save for occasional finds of flint chips picked up casually. ${ }^{26}$ There are a few additions from the recent work, although there is genuine doubt as to whether the presence of this material may be better explained by usage of flint and quartz extending into post-Roman Period II, as suggested for the Lower Terrace material ${ }^{27}$ and now also for the Middle Terrace from both the Building and Site C15 (Barrowman, Chapter 10).

The ubiquitous late Iron Age promontory fort, which appears to have a long chronological range, is represented in the vicinity by Willapark, near Boscastle, as well as possibly Barras Nose, near Tintagel. ${ }^{28}$ It is hard to understand how Tintagel Island could not also have been considered appropriate for such treatment in the Iron Age. As Thomas noted, ${ }^{29}$ rather surprisingly the natural valley across the neck of the original promontory, which was used to such excellent effect from the early medieval period onwards, does not seem to have been used then, and the detailed re-examination of the Great Ditch in the recent work could not confirm with certainty use prior to the early medieval period (Chapter 8).

However, it is conceivable that the remodelling at that stage (Phase $\mathrm{U}$ ) succeeded in removing all traces of pre-existing occupation debris. A small degree of support for this possibility is afforded by the radiocarbon dating, discussed by Bayliss and Bronk Ramsey in Chapter 11. Although the latest date (OxA10483) for the single entity samples from the primary silting deposit in the Great Ditch is cal AD 530-670 (95 per cent confidence), there are five other dates, all earlier (see table 90). Essentially these cluster in the Roman period, with two also spanning into the post-Roman period, together with one (OxA-10484), based on ?Rosaceae charcoal, dating to $100 \mathrm{cal} \mathrm{BC}-\mathrm{Cal} \mathrm{AD} 130$. Since it is also evident that the carbonized wood is highly unlikely to have been old when burnt, this would point to some degree of activity on the site earlier than the latest date that relates to the post-Roman usage and occupation. Although it has been assumed that there are some problems associated with the published radiocarbon dates from the 1986 excavations in the Lower Ward, ${ }^{30}$ nevertheless two of the dates (HAR 8277 and 8278 ) have a comparable date-span ( $30 \mathrm{BC}-\mathrm{cal} \mathrm{AD}$ 390 and $10 \mathrm{BC}-\mathrm{Cal} \mathrm{AD} 380$ ), and a third (HAR 8276) a little earlier (400 BC-Cal AD 200). A fourth date (HAR 8273 of $1250-790 \mathrm{cal} \mathrm{BC}$ ) is regarded as aberrant.

It would be highly speculative to go so far as to suggest that the modification of the "natural ditch-like feature' (Jefferson, Chapter 8) occurred initially at an earlier date, say in later prehistory. Nevertheless, it has to be concluded that it is conceivable, if unlikely, in view of the fact that the upcast from the ditch appears to have been deposited mainly on the southern bank, and no prehistoric material was recovered from investigations there - or indeed on the northern bank.

\section{ROMANO-BRITISH TINTAGEL: PERIOD I}

\section{BACKGROUND AND CONTEXT}

In 1993 Thomas emphasized that the nature of any occupation at Tintagel in the Romano-British period was 'elusive' and dependent upon interpretation of artefactual material against a context for Roman period activity. ${ }^{31}$ The immediate (and surprising) local context for this activity includes two Roman route markers: one from Trethevy (dated to the third century) and the other from the area of Tintagel churchyard (dated slightly later into the fourth century). ${ }^{32}$ Malcolm Todd considered this evidence problematic:

It is difficult to see what compelled the erection of these records in this district. There is no obvious route approaching Tintagel from the east ... More puzzling is the absence of any reason for such a route. Why should imperial officials be concerned with the maintenance of a road which terminated at Tintagel, or any other site on this rocky, inhospitable stretch of coast? No rich mineral deposits lay in this area and there was certainly no harbour 
which might have sheltered sea-borne traffic. This problem remains unresolved, along with much else connected with late Roman Tintagel. ${ }^{33}$

Since Todd was writing, an additional site has been noted on the east bank of the Camel Estuary at Padstow to the south of Tintagel, yielding material from the third to fourth centuries. ${ }^{34}$ Recent reconsideration of the overall picture in Cornwall in the Roman period has suggested that there might have been increased exploitation of tin in the area from the third century onwards; ${ }^{35}$ the fugitive and eclectic evidence from the Tintagel area may well be related to this. Thomas has even raised the possibility that the name ${ }^{*}$ Durocornovio postulated from an entry in the Ravenna Cosmographyin the absence of any conventional Roman settlement might have been applied to 'a small Late Roman establishment at Tintagel'.36 This would require the *duro element in the name to relate to a natural stronghold, or alternatively - as Todd has pointed out that "The name contains the element corn-, "horn" which has led to the suggestion that the Cornovii were seen as promontory dwellers or ... dwellers in promontory forts.' But this is speculative, for as Todd has also pointed out: "Equally plausibly, the "horn" may have been the peninsula itself, especially in its western reaches, the true home of the Cornovii. ${ }^{37}$

Previous assessment by Thorpe and Thomas of the ceramics from earlier phases of intervention at Tintagel has identified Roman wheel-made wares, such as mortaria of Oxford Colour Coated wares and flanged bowls which are assigned a date range of the third-fourth centuries. These were accompanied by native fabrics identified as Romano-British in origin, 'their forms clearly influenced by coarse Roman wares', and coming from the same chronological spectrum. ${ }^{38}$ The evidence they studied from Tintagel, however, was not conclusive as to whether the wares might have been circulating (or even produced) at a later date. Indeed, the local ceramic tradition apparently continued in such a fashion so that sherds of this type have been commonly found in association with Mediterranean imported wares. Thus although it is likely that some of these fabrics do indeed represent a Romano-British settlement context on this site (the explanation favoured by Thomas and Thorpe), ${ }^{39}$ this cannot be confirmed with certainty simply on the basis of ceramic types alone.

Equally, the chance recovery in 1955 of a small parcel of late Roman coins, now understood rather more clearly from work in the archive (see Chapter 1), probably wedged within a crevice somewhere in the vicinity of the Great Ditch of Site T, and dated to the period sometime after the second half of the fourth century, does in all likelihood indicate a presence on the site as a whole at this time, although clearly its find spot is not informative. ${ }^{40}$

This tantalizing evidence is supported in the more recent work, including insubstantial - but not insignificant - structural remains, but more particularly by an inscribed stone; glass; further ceramic assemblages from the Island; ecofactual evidence, particularly human bone, and radiocarbon determinations from the Lower Terrace of Site $\mathrm{C}$ and the Lower Ward of Site T.

\section{STRUCTURAL AND OCCUPATION EVIDENCE}

In terms of structural remains on the Lower Terrace of Site C (see Chapter 2), radiocarbon dating of deposits from an early fire-pit (Phase Q2) indicates an estimated date range and terminus ante quem of cal AD 395-460 (95 per cent confidence) for the primary structure of Phase $\mathrm{N}$, which it seals. This would appear to have been, as we described them in 1997, one of a type of 'modest but reasonably well-built buildings', based upon postsupports set into the bedrock and fragmentary wall remains. ${ }^{41}$ However, this and subsequent structures on the terrace are made of coursed slate walling, and the presence of timber stakes suggest a sheltering feature on the terrace edge, if not stakes for turf-walled structures. It has, therefore, been suggested that these were temporary in nature, perhaps seasonal. Deposits succeeding Phase $\mathrm{T}$ include both the Romano-British fabrics mentioned above and the first appearance on that part of the site of imported Mediterranean wares in Phase U2, radiocarbon dates from which gave an estimated date range of cal AD 425-535 (95 per cent confidence). The latest phase for which radiocarbon dating was obtained (Phase W), was distinguished by the presence of a large assemblage of imported Mediterranean sherds, and gave an estimated date range of cal AD 560-670 (95 per cent confidence). This phase was associated with more substantial stone-built structures. This is a very clear succession in terms of both dates and cultural material and would prima facie indicate the presence of the elusive Thomas Period I occupation, followed by the more readily recognizable occupation from Period II.

The important publication of Trethurgy includes a discussion of building types for this period, and there is 
clearly a focus on oval structures here and elsewhere, even though previously it had been assumed that the circular Iron Age form continued in the Roman period in Cornwall. ${ }^{42}$ However, although there is no clear footprint available for the structures of this period at Tintagel, the restricted form of the terraces would seem to have militated against this form in favour of a more rectangular or sub-rectangular plan (which was likely to be more significant than any suggestion of a distinctly Roman influence for the form). The previous report links these more substantial structures with contemporaneous structures from Bodmin Moor and Gwithian and they are more obviously Period II structures. ${ }^{43}$

\section{THE INSCRIPTION}

The most dramatic evidence is undoubtedly the inscribed stone found on Site C. As clearly indicated in Chapter 6, the stone was not found in situ in 1998, rather being re-used as part of the cover for a drain outside the Site $\mathrm{C}$ building. Charles Thomas has undertaken painstaking analysis of the inscription (Chapter 10) and concluded that, despite the fragmentary nature of the original inscription on the stone, it is most plausibly interpreted as referring to the Emperor Honorius ( $A D$ 393-423). He is inclined to see it as an antefix for a structure on the Island around $\mathrm{AD} 400$, perhaps 'a labelled store, tax office or even dwelling that was regarded as still within some administrative system under official and Imperial control'. As indicated above, recent analysis suggests that increased exploitation of tin may have occurred from the third century onwards, and this may suggest a plausible context (ie production and marketing of the mineral) for the putative official presence at Tintagel.

\section{GLASS}

In terms of the glass assemblage, two vessel fragments have been identified by Ewan Campbell as likely to be Romano-British (Vessels 1 and 2, discussed in Chapter 10). Unfortunately both are from insecure deposits (that from $\mathrm{C} 16$ is redeposited and the other is from the plateau area). However, Campbell is of the opinion that these two pieces are likely to have been brought to the site sometime later than their production, as there is no supporting evidence to date of any presence at Tintagel in the first or second centuries AD. Two further vessels ( 3 and 4), may also be Romano-British in origin, and indeed were taken to be so by earlier specialist commentators, Jennifer Price ${ }^{44}$ and Hilary Cool. ${ }^{45}$ On the other hand, as with some of the earlier pottery types, they could equally be later in date, and have been taken to be so by Campbell.

\section{Ceramics}

In the ceramics discussed by Thorpe in Chapter 10, there are three distinctive fabrics, which span the RomanoBritish into the early medieval periods. The Granitic fabric is largely confined to the third-fourth centuries, whereas the Gabbroic fabric spans the late Iron Age through to the late Roman period, possibly continuing into the fifth century. Of the Local fabric recorded, first recognized in the re-analysis of the 'Native' wares from Radford's work at Tintagel, ${ }^{46}$ the production of such wares in the Roman style into the sixth century is now suggested by the evidence from sites such as Trethurgy. ${ }^{47}$ Obviously there is considerable evidence in this of conservative pottery traditions, as well as the obvious possibility of some residuality of the material.

However, it is notable that in the Lower Terrace collection, although the sherds of Granitic and Gabbroic wares were small in number and size (and thus perhaps residual), the Local ware sherds were more obviously identifiable as to form, and may even be third or fourth century in date (or even earlier) and from stratified contexts in Phases U2 and V (although these are not the earliest on the site). The Local pottery from Phase U1 floor deposit was highly abraded (perhaps suggesting residuality), whereas there were fourteen sherds from one vessel of Local ware associated with eighteen sherds of post-Roman wares in Phase U2.48 In all, then, this ceramic evidence was not conclusive as to the existence of a Romano-British settlement at this part of the site, while pointing to its existence nearby.

Amongst the small group of Gabbroic RomanoBritish sherds from the Middle Terrace, C15, two 'Cornish Flanged Bowl' rims from Phase W (pre-Radford collapse) are assigned to a fourth-century date, and there is a further example of this form of rim from Phase $\mathrm{T}$ (ie the early make-up to the terrace, and the infill of rock-cut features) of the Site $\mathrm{C}$ building there. Interestingly, the latter was associated with two sherds of Bii amphora. Both areas also produced other, less diagnostic RomanoBritish sherds. The obvious inference is that the Gabbroic pottery is residual, although it is not inconceivable that both kinds of pottery may have co-existed at the very end of the Late Roman occupation here.

In the Lower Ward a single sherd of Romano-British Local ware was found in Phase W, possibly redeposited 
and also associated with imported Mediterranean Bwares, as well as a glass fragment of a possible later palm cup. In this context, it should be remembered that two similar sherds were found from the body of the bank during the $1986 \mathrm{CAU}$ excavations, but regarded as residual by Carl Thorpe. ${ }^{49}$

Again, the ceramic evidence has not been conclusive as to a distinct Romano-British occupation on the site (and in all cases it would be possible theoretically to argue for 'residuality'), although it is clear from Thorpe's discussions both in this volume and the previous report that he would wish to suggest this here.

\section{THE ECOFACTUAL ASSEMBLAGE}

In terms of the ecofactual assemblage from the earlier phases examined on the Lower Terrace, small amounts of barley cereal grain were recorded by Straker in Phase Q1 (early hearths and stake-holes), with the addition of more cereals (oats and barley) and weed seeds in Phase Q2 (a level of burning and concreted flooring). In Phase $\mathrm{R}$ scant cereal remains are noted but an increase in weeds typical of open ground, and wild seeds support the presence in the vicinity of broken ground, probably arable land. ${ }^{50}$ While the institution of a systematic sampling programme for ecofactual material has been fundamentally important, it remains the case that there is little from the material from the more recent excavations to modify the picture obtained earlier from the Lower Terrace. The best material, undoubtedly, is that from the Phase $\mathrm{T}$ fissure below the Site $\mathrm{C}$ building on the Middle Terrace, which produced some of the largest assemblages recovered to date. Here there is clear evidence of grain-dominated deposits, with little by way of chaff, but little collection of wild fruit and nuts, and no 'exotics'. Consequently, this evidence elaborates upon the picture already obtained from the Lower Terrace (Chapter 11) ${ }^{51}$ and, for reasons argued above, at present would seem to be more appropriately thought of as Period II than I.

In both parts of Phase $Q$ on the Lower Terrace, carbonized human bone fragments were noted, especially from one of the hearth fills (175 of Phase Q1), and Mays noted that the condition of this material would suggest cremation or deliberate burning. ${ }^{52}$ It might well be the case, therefore, that in this phase of activity at Tintagel the deliberate disposal of human remains had taken place in the vicinity of the Lower Terrace ${ }^{53}$ and had become incorporated into Phase Q1, Q2 and R, floor levels and hearths. Given that the radiocarbon sample from hearth fill from Q2 gave an estimated date range of cal AD 395-460 (95 per cent confidence), and the middle group of carbonized human bone came from this deposit, it is not unreasonable to consider the cremation practices as being an activity from Period I (as suggested in Chapter 2). David Petts has reviewed the usage of the cremation rite in Roman Britain, and it is clear that it was superseded by inhumation by the end of the period. ${ }^{54}$ The highly unusual nature of this evidence was emphasized in the 1997 report, although Petts pointed to contemporary evidence of cremation in Ireland and a possible example (unpublished) from Whithorn in Galloway. ${ }^{55}$ The further significance of this evidence lies in its contribution to the current lack of knowledge of burial practices from the late Roman period in Devon and Cornwall. ${ }^{56}$

\section{RADIOCARBON DATING}

The Lower Terrace dating sequence has been referred to above in relation to the sequence of structural and occupational remains there. However, from the more recent work elsewhere on the site, the structural evidence does include elements that can be assigned to the earlier Period I phase. On the Middle Terrace, underneath the later Site $\mathrm{C}$ building, were possible early structural remains surviving as rock-cut features: possible beam-slots (eg 1037), socket/post-holes (eg $1009,702,566$ or 567 ), stone groupings which may have been early walling (eg 707, 710) or indeed potential make-up layers or revetments (eg 574, 583) and potential floor layers (eg 582, 537). Despite the presence of rich organic deposits in fissures underlying the structure (Phase T), English Heritage advised against using the material for dating as it did not appear to have been burnt in the context in which it was found, and could not therefore be used to date that context. This is unfortunate, as it would have been desirable to have established the chronology here, as on the Lower Terrace, and whether this early pre-building (and putative structural) evidence on the terrace was indeed from the later Romano-British period. Even if it could not be used to accurately date the feature itself, it could have provided a terminus post quem for the construction of the succeeding building and, more importantly in this discussion, dated the carbonized seeds, and thereby perhaps indicated whether we were dealing with Period I or Period II ecofacts and subsistence and consumption activities. 
Artefactually, from Phase T, although there are the Gabbroic rims mentioned earlier, they are also associated with Bii ware, and indeed overlie the deposit with fragmentary early vessel glass from Bordeaux and a Bii amphora sherd. On balance we are assuming that the flanged bowl may have been in situ, whereas it is clear that the late Roman inscription discussed above is clearly not in situ - and indeed comes from Phase U2 (drain repair), which has to be at least the third phase of its existence. On the face of it, as indicated in Chapter 6 , this would appear to make it difficult to sustain a Late Roman date for this Phase or an argument for in situ presence of activity in the Romano-British period. But it does suggest that it had occurred in the vicinity. Alternatively (and controversially), the radiocarbon dating from the Lower Terrace for an apparently similar structural phase might be taken, by implication, to indicate that imported Mediterranean wares may have been arriving at the site earlier than had hitherto been expected from typological study.

On the other hand, as indicated in Chapters 9 and 11 above, the radiocarbon dating for carbonized material from Phase $\mathrm{W}$ of the Lower Ward has given a range at 68 per cent confidence level of cal AD 390-430, which could well be seen as supporting late Roman activity at the site. If so, then the fact that the ecofactual assemblage here, as with that from the fissure below the Site $\mathrm{C}$ building, is consistent with the picture already arrived at from the Lower Terrace assemblage, would suggest that a picture of continuity of exploitation of natural resources for food and fodder from late Roman to post-Roman periods should be entertained. Again, however, there is a complication in the presence alongside each other of a sherd of Romano-British Local ware, a range of imported Mediterranean pottery, and two finds of early medieval glass dated to the fifth-seventh centuries, together with industrial material including bloomery slag. In Chapter 9, we have concluded that the most economical explanation of the Local ware sherd is that it was residual in a later context, and that this deposit essentially represents Period II activity. As referred to in the previous section on prehistory, the CAU work in the Lower Ward area in 1986 has also provided radiocarbon dates which span the Romano-British period, although apparently associated with imported pottery. ${ }^{57}$ Here, too, the evidence is seen as pointing to Period II, rather than Period I. However, as we imply below in relation to the Period II chronologies, we feel that there is more work to be done in examining the implications arising from the often uneasy alliance between scientific dating and typological study, and we are open to the possibility that the scientific dating here should tip the balance in favour of a Period I occupation/activity with, again, uncomfortable implications for the type dating of imported Mediterranean ceramics in the Insular area.

\section{CONCLUSion}

This review of the (sometimes contradictory, conflicting or equivocal) evidence for late Romano-British presence at Tintagel has to conclude that, while the evidence is not substantial, cumulatively it is reasonable to support the identification of such a period of activity at the site. Scattered across the Island, present on the two main terraces examined in the recent excavations of Site $\mathrm{C}$, and probably present in Site $\mathrm{T}$ on the mainland side of the complex as well, there is evidence that this settlement was extensive and in touch with a wider world. It is clear from a recent survey of the evidence available in the south west for the Roman/post-Roman transition period, that this is an era which lacks concrete archaeological evidence. ${ }^{58}$ Hence, we have deliberately reviewed this material from Tintagel in detail, and submit that this evidence is probably of greater significance than even we, the latest excavators of the site, perhaps previously understood. It may also be capable of revision in the future as some of the issues that have arisen in this discussion are, we hope, pursued further.

\section{EARLY MEDIEVAL TINTAGEL: PERIOD II}

\section{INTRODUCTION}

While the previous section has been concerned to establish whether the evidence warrants an interpretation of activity on the site during the RomanoBritish period, for the post-Roman period there is no such problem. Structural evidence and artefactual material in abundance from the fifth to seventh centuries emerged from the Radford campaign. As discussed above, there has been a shift from an 'Arthurian' model to an Early Christian monastic model of explanation for the site, and now a reaction to this. Some of this is discussed further below, but this section will be concerned, primarily, to establish in summary what has emerged from the recent campaign of work to illuminate early medieval Tintagel between the fifth and seventh centuries. 


\section{STRUCTURAL AND OCCUPATION EVIDENCE}

As discussed in Chapters 7 to 9 the aim of renewed investigations at Site $\mathrm{T}$ was essentially to re-investigate work undertaken by Radford in 1938-9 and 1955 across and in the vicinity of the Great Ditch, a massive feature of imposing grandeur and proportions (Chapter 7). Although he asserted the bank and ditch to be a vallum monasterii for his postulated Early Christian monastery, ${ }^{59}$ it was difficult to maintain this in the absence of published data. Further, the juxtaposition of the Ditch to the medieval Castle raised legitimate questions as to their inter-relationship.

In addition, the Great Ditch of Site T appears to have been created by quarrying to enhance a shallow valley (Chapter 8). Manual deepening and modification of the valley into a defensive feature would have taken considerable effort and resources of labour. Thomas, while acknowledging that there was 'a large resident workforce' at the Castle, was clearly of the view that the massive remodelling of the valley would not have taken place during the later medieval phase of the site's history. The archaeological data now confirms this, suggesting that the original cutting and remodelling, creating a flat bottom and building up the south side with the upcast and heightening the north side in building up a platform beneath the Lower Ward, did in fact take place somewhat earlier.

Despite later scouring down the valley, some primary silt deposits remained on the north side. It is clear from recent investigations (Chapter 8 ), that there are three crucial phases at the beginning of the stratigraphical sequence here: $U$ (cutting of the ditch and modification of the bank), V1 (primary fill of the ditch) and V2 (separate deposits which may represent the primary fill of the ditch also). In none of them was any later medieval material found but, crucially, from all of them imported Mediterranean pottery was recovered. Though the imported ceramics from Phase $U$ are abraded (and therefore potentially residual), those from Phases Vl and $\mathrm{V} 2$ are not, and can be taken to represent contemporary activity hereabouts. Even more significant is the fact that absolute dating is provided from charcoal fragments from the rich primary silt 1161 of Phase V1. As emphasized in Chapter 11, this material from six samples was not of old wood, and is presumed to have been washed in from the contemporary ground surface after the final cutting of the ditch. The latest sample extends the range into the second half of the seventh century (cal AD 530-670 at the 95 per cent confidence level). All the other five samples were earlier and, with one exception, spanned the latter part of the Roman period or into the post-Roman period.

With secure radiocarbon dating at the latest to the sixth-seventh centuries $\mathrm{AD}$, the interpretation from the imported ceramic material is reinforced. There could be a legitimate discussion as to whether the other dates could indicate activity hereabouts in the later Roman period, and indeed as to whether the dates, in providing a terminus ante quem for the cutting of the ditch, could reflect re-use of a prehistoric feature rather than one created in the post-Roman period (see above). However, for the purposes of the present discussion, there can now be no doubt that the Great Ditch necessarily sits firmly as the enhanced landward boundary of the fifth- to seventh-century site at Tintagel.

Further, within the layers examined below the later medieval Lower Ward in following up Radford's work in 1938 and 1955 (trench T01 ext: Chapter 9), examples of imported ceramics (and - as discussed above - one local Romano-British sherd) and early medieval glass, in addition to bloomery slag and in situ burning, have been revealed in Phase $\mathrm{W}$. While the trench excavated was very small, the artefactual evidence is exciting and emphasizes the potential of this area to reveal new aspects of the postRoman archaeology of Tintagel. The glass, as discussed by Campbell (Chapter 10, Vessels 18 and 19) is interesting in representing both Mediterranean and Anglo-Saxon/ Frankish traditions and, indeed, one has decoration - the first example from the site (Vessel 18). The industrial material may even be related to an industrial hearth although it would require further work to corroborate this - and sits alongside a whetstone and an iron object. Chronologically, these finds come from a feature dated to cal AD 340-530 (95 per cent confidence), but if taken at the 68 per cent confidence level cal $\mathrm{AD} 390-430$ (see Bayliss and Bronk Ramsay in Chapter 11). This implies activity either late in the Romano-British period or very early in the post-Roman period.

The evidence certainly supplements that gained from the small-scale work undertaken in 1986 by CAU ${ }^{60}$ This found evidence of a series of superimposed hearths and an oven, together with a number of stake-holes from windbreaks or shelters, or even wattle structures, on a terrace. The Roman type of oven was interpreted as post-Roman, from association with imported ceramics, and the whole area interpreted as an area of intense food-preparation and cooking (animal bones, unusually for Tintagel, were found here). Imported pottery from 
layers overlying these features, and a thermo-remanent magnetic date of $\mathrm{AD} 450-500$ (68 per cent confidence), suggested to the excavators that (despite the radiocarbon dates, discussed above in relation to Romano-British Tintagel), this area was utilized in the first half of the sixth century.

Both Burrow and Dark in analysing Radford's excavations have suggested the possibility of a timber phase preceding the stone buildings that were uncovered on the Island terraces and laid out (if not actually reconstructed) for the benefit of visitors to the site. ${ }^{6 !}$ This possibility was essentially dismissed by Radford himself on grounds that it is not at present supported by evidence and in the conditions of the site proof would probably be difficult to obtain', ${ }^{62}$ However, it is worth emphasizing that the structural remains of both primary Phase N, and also those of Phases U2 and $\mathrm{W}$ of the Lower Terrace were far from substantial, and were not strictly comparable with the buildings which were excavated during the 1930s. ${ }^{63}$

These are more clearly paralleled in the more recent evidence for timber-slots in the bedrock from Phase $T$ on the Middle Terrace (ie below the laid-out building), which preceded the more substantial building there (Chapter 6). This may be evidence for modest but reasonably well-built structures of timber (at least in part) utilizing the terrace ledge and perhaps the face of the quarry behind, at an early stage in the structural history of the site. Other locations on the Island have yielded evidence of a series of small holes in the bedrock: Thomas first noted this at one point on the Burnt Area, suggesting that they represent the points where stakes were hammered through the low turf walls to keep them in place, perhaps the remains of a Period II 'bivouac' on a seasonal camp-site. ${ }^{64}$ Recently, as mentioned in Chapter 1, Paul Johnson has identified similar evidence at some other locations, including a rock-ledge above Site C (see Chapter 5, figure 52). In addition, there is the inferential evidence from structural slates found in some numbers on both the Lower and Middle Terraces.

The groups of structures uncovered during the disastrous fire of 1983, and subsequently surveyed, led to a distinction being made between fairly substantial, rectangular buildings and those which tended to a more 'square' plan, with walls consisting of 'lines of shillet ... "walls" ... but a few courses high and little more than footings, perhaps for turf walls and/or timber-framed structures ....65 Further, it was observed that 'structures proper to the 5 th -7 th centuries $\mathrm{AD}$ ought to be with low walling of curvilinear or miscellaneously-shaped ground plans and with evidence of post-holes as principal structural elements ....66 The structure(s) on the Lower Terrace - the low, rather irregularly shaped, but neatly built stone-walled structure of Phase U2 (subsequently rebuilt in Phase $W$ ) - quite readily conform to this model, and Thomas has also given a parallel in an example from Site B. ${ }^{67}$ As noted in 1997, these structures are similar to possible transhumance huts on Bodmin moor, and huts from Gwithian, further west. ${ }^{68}$ There is little from the Site $C$ building which would be in line with this - unless the most northerly room were to be seen in this context.

Elsewhere, on the Upper Terrace (Chapter 3), while there was evidence for occupation, there were no structural remains as such uncovered. However, equally, there was little to support Radford's assertion of it being 'a smaller terrace ... [used for] intensive cultivation'. ${ }^{69}$ On the other hand, the Middle Terrace trenches uncovered structural remains and earlier land surfaces (Chapter 4). The terrace was itself a broader ledge than the Upper Terrace, although clearly at the fringe of the settlement area at the north end (trench C05). Here, nevertheless, there was demonstrable presence of domestic waste in a primary context. To the south, in the trial trenches $\mathrm{Cl} 5$ and $\mathrm{C} 17$, it was clear that there had been a radical change to the topography of the area after the late medieval phase (by massive landslip, which included residual late medieval pottery, from the Upper Terrace) - and this had perhaps preserved the area for more recent, more systematic excavation than that of the 1930s. Interestingly, too, it produced evidence of metallurgical practices, with remains of a hearth or furnace-wall and a crucible.

The structure uncovered in trench C15 (Chapter 5) was a much less substantial one than those reconstructed elsewhere on the Island, rather than, as initially expected, a building comparable to that excavated and laid out on Site $\mathrm{C}$ to the north by Radford (Chapter 5 ). The remains were comparable with the structures excavated earlier in the 1990s on the Lower Terrace in both form and possible function, with walls composed of thin slates and earth cores, and utilizing the 'steps' formed in the slate bedrock at the back of the terrace. Such a small part of the internal area of the building was revealed that it is not surprising that no hearths were located. However, indications of floor layers and burning were recovered from layers of collapse. As with the Lower Terrace, the remains are relatively insubstantial, and it may not be unreasonable to 
conclude that the ephemeral structures and activity surfaces here are also to be associated with successive phases of short-lived activity, perhaps reflecting temporary or even seasonal occupation on the east side of the Island. On the Lower Terrace it was speculated that the original occupation might have been nearer the current cliff-edge, but that the occupants were forced to retreat back up the slope in the face of landslips and clifffalls.

Excavations within and around the Site $\mathrm{C}$ building, excavated by Radford in the 1930s (Chapter 6), produced unequivocal evidence that the building is of post-Roman, not later medieval, date. The major structures of Phase $\mathrm{V}$ and their associated features (such as the later drain to the west and south) appear to be associated with imported pottery of the fifth-seventh centuries, and with other material such as early medieval glass which may also extend the period into the seventh century. Thus the results confirm a general fifth-seventh-century AD date for a building recently suggested as later medieval, and show that structures which were 'stone-walled' as well as 'turf-walled on stone footings' were built in that period. ${ }^{70}$ We cannot be certain of the height of the walls, as only the bottom courses (usually one to two, three at most) can be demonstrated to be original rather than a 1930s reconstruction.

The inscribed slate with two periods of lettering late- and post-Roman; the unique post-Roman glass one group originating almost certainly from Spain, the other from the Bordeaux region; the evidence for an earlier structural phase to the building and the retrieval of rich carbonized grain deposits from below it; all these together make this a unique excavation. Unfortunately, although there is some palaeobotanical evidence of domestic occupation surviving in a fissure in the bedrock, and there is the evidence of the building phases, any other potential evidence concerning occupation, that is, the deposits inside the building, were removed by Radford's excavations.

These are certainly not buildings occupied by the upper echelons of society, except perhaps the later building on site $C$ which conforms to Thomas's description of what might be expected:

The entire east-facing sloping side of the Island, starting at the Inner Ward hollow and then continuing along to Site $\mathrm{C}$, possesses all the year round the greatest shelter from the wind, and catches any sunlight from early morn to mid- afternoon. Here, if anywhere, one would look for superior Period II accommodation, spaced out on natural ledges or man-improved platforms and connected by narrow pathways. In social terms, it should have been preferentially used by the upper reaches of a Post-Roman retinue...${ }^{71}$

The better-made building and the association of the area with high-status artefacts, such as the inscribed slate and the glass, not to mention the large number of sherds of pottery, would all support this. Unfortunately, when Thomas continues: 'Here, too, is by far the largest concentration of all kinds of Period II imported pottery, notably the fine-ware African and eastern Mediterranean dishes, ${ }^{72}$ the parallel weakens somewhat as there are few of the latter. However, it is worth reiterating the possibility of storage rooms and buildings for the containers of wine and olive oil, etc, represented by the amphora material, as was suggested at Longbury Bank, as well as in the original Lower Terrace report. ${ }^{73}$ Perhaps the Middle Terrace structures, as well as those from the Lower Terrace, could, at least in part, have performed that function.

This then raises the question of 'zoning' on the site at this period. Thomas, following up an approach adopted elsewhere by Alcock, has postulated a hypothetical model for internal organization of Tintagel as a postRoman citadel. ${ }^{74}$ As with contemporary sites elsewhere, it is dangerous to draw too many social implications when only a fragment of the site has been examined, ${ }^{75}$ and Thomas's model serves more as an agenda for research (and subsequent modification) on Tintagel than anything else. Even within the current programme of work, it is evident that the material recovered from a relatively extensive area of the Lower Terrace of Site C does not compare with the density and quality of artefacts recovered from the 'Steps' area, for instance. ${ }^{76}$ Similarly, although the material recovered from the Middle Terrace is generally more impressive than that from the Lower Terrace, it still does not seem unreasonable to argue that the Site $C$ complex was peripheral to the core activity further to the south in the area of the later Inner Ward. ${ }^{77}$

\section{CERAMICS}

As stated above, there is artefactual material in abundance from Period II. Pride of place has to be given to the ceramic assemblage, focusing especially upon the imported Mediterranean material. All areas excavated 
on the site have yielded early medieval ceramics and, even before the recent excavations, a formidable collection (often abraded material picked up by visitors and custodians of the site from the eroding pathways around the Island) was already available for study. ${ }^{78}$ This was supplemented by material, some stratified, some not, collected from the 'Steps' area in 1989 and $1990 .^{79}$ The Lower Terrace collection was published in 1997,80 and this has been followed by systematic cataloguing by Carl Thorpe of the material from all the recent excavation areas (Chapters 3 to 6,8 and 9), and subsequent analysis (Chapter 10). It is not intended here to repeat the data, but to draw out some aspects of the study that merit further consideration, and this will be followed in a later section (on 'The Wider World') by discussion of the economic implications.

Even in terms of the rather poor (by Tintagel standards) collection of 128 sherds of imported wares from the Lower Terrace, this is comparable in quantity with the amounts found at much larger excavations of contemporary sites such as Dinas Powys (256 sherds) or Cadbury Castle (163), and settlements such as Whithorn (200), and also comparable (if not exceeding) in the range of fabrics. However, in terms of overall quantities, Tintagel far outnumbers all other sites of this period in Britain. ${ }^{81}$ The further collection of 1,821 sherds of imported fabrics reported here are part of a large overall assemblage, over twice as large as that, for instance, from Cadbury Congresbury ( 877 sherds) ${ }^{82}$ Carl Thorpe has conservatively estimated, from all the recent work including CAU's activities on the Island since 1999, the number of vessels at 150 amphorae and eighty Red Slipped Ware (together with numerous Coarsewares). ${ }^{83}$

However, there are variations in the distribution patterns of the material, with, for instance, the greater majority of pottery recovered from both the Lower Terrace and the Site $\mathrm{C}$ building being from storage vessels rather than the finer table-wares associated with food consumption (the building area has no more than 3.55 per cent of the 591 sherds from fine wares). It has therefore been suggested (see above) that this has implications for the 'zoning' on the site of different activities, if not groups of residents. There is certainly a contrast with the incidence of fine table-wares from Site $Z$ below the Great Hall of the Castle, although trying to establish an internal social hierarchy on the site on the basis of the spatially limited modern excavations undertaken may well be a hazardous or too speculative an operation. ${ }^{84}$
The range of fabrics, while generally well known, has been extended from the recent work, with several new Eastern Mediterranean fabrics (Chapter 10) that are the subject of ongoing work by Thorpe and Thomas. ${ }^{85}$ Thorpe's analysis in Chapter 10 has underlined the extent to which the fine table-wares are a relatively minor aspect of the overall ceramic assemblage in Site C - albeit that they are interesting (eg two sherds of Phocaean Red slipped ware (PRSW) have cruciform decoration on them). It is perhaps significant that 15.8 per cent of the sherds are, as yet, in the category of 'Unknown Fabric', and that a particularly unusual and hitherto unrecognized fabric in the form of a large sherd of probably a very substantial amphora was recovered from Phase V of trench C09. These finds, while not as spectacular as the inscribed stone or the cache of early medieval glass, nevertheless point to the potential of even a small area of the site not already investigated by Radford (in this case where the spoil-heap had been placed) to expand our understanding of Tintagel during the early medieval period.

In terms of the probable sources of these amphorae, the traditional view has been that type $\mathrm{Bi}$ amphorae were most likely to be sourced in the Argolid region of Greece; Bii in the Eastern Mediterranean, probably south-east Turkey; Biv in Asia Minor; and Bv probably in North Africa. The analysis undertaken by Richard Jones (Chapter 10) enables some modifications to be made to this schema. In terms of $\mathrm{Bi}$ and $\mathrm{Bv}$ types, Jones notes that the chemical analysis does not suggest a single source for each of these types in the samples examined. With the caveat that it is possible that, due to the small sizes of some of the sherds examined, misidentification may be a possible cause of these differences, there is clearly inconformity within the types. In addition, type $\mathrm{Bii}$ spans both the chemical groups of $\mathrm{Bi}$ and $\mathrm{Bv}$. $\mathrm{Bi}$ is confirmed in these samples as having an origin in the Aegean; Bii may have several sources in the Eastern Mediterranean; and Bv includes sources in North Africa (Tunisia) and possibly southern Spain. This work indicates, therefore, multiple supply sources in addition to a number of different commodities being shipped (as shown in the organic residue analysis). Mixed sources of amphorae could easily suggest the gradual accumulation of a cargo or cargoes through stopping off at different ports throughout the Mediterranean (so-called 'tramping'); different journeys over a given time-frame can equally be indicated by the evidence. The repeated use of the vessels themselves, rather than simply being 
filled with either wine or olive oil in the traditional scenario, may have taken place en route or at Tintagel. This is perhaps supported by the (later) use of local slate discs as vessel lids in place of the original amphorastoppers - some of which are attested here, even in the topsoil of the building.

As has been emphasized in the relevant sections above, the recent work from trench $\mathrm{C} 15$ has enabled the form and profile of the $\mathrm{Bv}$ amphorae to be completed for the first time. Also Jones's work has indicated the probability, from residue analysis, of this form of amphora being used for olive oil. However, it is noticeable that these North African/Spanish vessels only account for 6.55 per cent of the material, whereas $\mathrm{Bi}$ from Greece and Bii from Turkey account for approximately 50 per cent and 21 per cent respectively. It has already been noted that, because of its thin walls, Biv may be under-represented. The importance of the Eastern Mediterranean is further emphasized by the assignment of some of the imported Coarsewares to that region.

By contrast, only two sherds of D-ware from the Bordeaux region were identified, one from the 'Steps' area $^{86}$ and the other from Phase $U$ of trench C15. Notably, the latter accompanies a sherd of glass also identified as coming from this area of Gaul.

\section{GLASS}

There is no doubt that, after the Mediterranean ceramics, the glass finds from Tintagel attest most obviously to the wide connections of the site (discussed further below). In the areas excavated as part of this campaign, a number of finds were made - most notably in trench $\mathrm{C} 09$, where thirteen sherds, including a substantial neck and shoulder section of a unique form of post-Roman flagon, were found (Vessel 6). Ewan Campbell's analysis (Chapter 10) demonstrates the parallels from southern Spain and the probability of this being a further facet of the demonstrable Mediterranean links shown by the imported pottery. In contrast, a number of other glass sherds (Vessels 11-16) from the recent work can be shown to have originated in the Bordeaux region. Both France and the Mediterranean area are represented by the two glass sherds (Vessels 18 and 19) from the Lower Ward (T01 ext: Chapter 9), and it must be remembered that one of the pre-existing sherds (Vessel 5) appears probably to have come from the Carthage area and ended up in the base of the Great Ditch. Overall, Campbell has allocated sixteen of the nineteen vessels identified so far from all work at Tintagel as coming from Period II - although as explained in the discussion of Period I material, two of these might be seen as late Roman instead. Some are unique forms, and the total (while probably only representing a fraction of the original) is only exceeded by five other sites in western Britain and Ireland, again attesting to the status and importance of Tintagel at this period. Unlike contemporary sites such as Dinas Powys, however, ${ }^{87}$ there is no evidence for glass-making activities here, although a single glass droplet recovered from the 'Steps' area (originally published as a tiny bead) may be a hint of glass-melting activity. Three glass beads found in and around the building on Site $\mathrm{C}$ complete the assemblage from this period (Campbell, Chapter 10). They may conceivably be of Germanic origin (ie from the Anglo-Saxon areas to the east), but are more likely to be of local manufacture.

\section{STONE ARTEFACTS}

Pride of place among the stone finds, clearly, must be accorded to the inscribed stone from trench C09. From detailed inspection and analysis Charles Thomas has identified the secondary inscription as containing the names of three individuals: Paternus (Paterninus), Coliavus and Artognou, and the language as attesting to the continuance of Latinate literacy in the immediately post-Roman centuries (Chapter 10). The likelihood is that these are essentially graffiti on a pre-existing inscribed stone no longer in use - and later to be consigned to tertiary usage as a cover for the drain around the building on Site $C$. (There is here a revision of the original transliteration of the inscription in 1999,88 while maintaining the general proposition.) There is also a clear implication for the high status of the site in general in the post-Roman period, even if not necessarily of the particular part of the site in which it was found.

Colleen Batey's analysis of the other stone finds (Chapter 10) has identified three major groups: notched slates, perforated stones and pebbles. The perforated slates in several cases may well have been slates from a roof, while a number of stones with large notches are seen as structural supports. Some small perforated stones (usually local slate) acted as amphora-stoppers (presumably for secondary re-use in Cornwall in place of the original pottery stoppers from the Mediterranean), and some notched slates were strike-alights. The pebbles were probably simply collected from 
the beach and brought up to the site as keepsakes or else formed part of the sand aggregate collected for mortar repairs. One or two other individual stone finds are of interest: for instance, a second fragmentary graffiti slab was found from the building area (Phase W: building collapse) and a third from Radford's backfill in trench C17, but in neither case can anything further meaningful be said about them. Otherwise, there are individual spindle whorls, gaming counters and whetstones from everyday domestic activities.

\section{INDUSTRIAL WASTE}

An area where the recent work has really shed some new light is in terms of industrial waste residues - albeit the evidence recovered is fragmentary and patchy. The traces of industrial material in the form of smithing or smelting slags from deposits contemporary with (as well as post-dating) the use of the building on Site $C$, and occasional finds of iron nails, provide for the first time conclusive proof of metal-working activities. Similarly, although small, the assemblage of industrial waste retrieved from trench $\mathrm{C} 15$ suggests for the first time the definite possibility of some metal-working activity here in the post-Roman period. Bloomery slag, vitrified fuel ash and possible smelting slag were identified by Effie Photos-Jones from several phases, along with a hearth furnace-wall or crucible (Chapter 10). This supplements the small amount of evidence of industrial waste from the Upper Terrace (trenches C18 and C19), fugitive traces from the Lower Terrace, including part of a crucible, ${ }^{89}$ and a copper sprue or crucible fragment from the 'Steps' area. ${ }^{90}$ Overall, it is notable that the evidence is not as rich as most sites of the period in this aspect. However, as the tantalizing evidence from the small area excavated in the Lower Ward indicates, the potential may not yet have been realized for this site, and indeed it may be another case of 'zoning' within the site as a whole, where industrial working areas have not yet been recognized and investigated.

\section{ENVIRONMENTAL SAMPLING}

This was undertaken de rigeur during the recent excavations and, as emphasized by Vanessa Straker, the $\mathrm{EH}$ environmental archaeology specialist for the southwest region, it has paid off in terms of producing evidence of the local environment, attesting to a range of locally growing trees and shrubs (oak, hazel and birch) exploited for fuel and building purposes. Residual tiny burnt fragments of animal and even human bone were also recovered from the initial work reported upon for the Lower Terrace (Chapter 2). Further sampling work elsewhere on site produced, for instance, environmental evidence from trench $\mathrm{C} 05$ at the northern end of the Middle Terrace which is consistent with the activity being on the fringe of a settlement area. It attested mainly to cereal and associated waste or arable plants, with some small evidence of fruits and seeds. From the Site $C$ building, the assemblage attests to locally produced grain and meat, although the bones themselves are not well enough preserved to demonstrate what cuts of meat were, in fact, eaten. On no individual site is there environmental evidence for exotic foodstuffs being brought to Tintagel in the early medieval period.

OVERALL ASSESSMENT OF THE ENVIRONMENTAL ASSEMBLAGE by Vanessa Straker

There is not much comparable evidence from other sites of the same period in Cornwall or elsewhere in southern England. The contemporary deposits from the excavations in the churchyard of St Materiana in Tintagel produced similar assemblages with a high proportion of oats and a weed flora with species such as corn marigold and chickweed, which would have grown with crops on the local circum-neutral soils. ${ }^{91}$ Unlike the Island assemblages reported on here, in the churchyard evidence for heathland and scrub such as gorse (Ulex sp.) and bell heather (Erica cinerea) was more convincing from the contexts associated with burial and feasting. ${ }^{92}$

The dominance of oats over other cereals in the extreme south west was also evident in the fourth- to seventh-century deposits at Duckpool near Morwenstow in North Cornwall and the seventh- to eighth-century midden layer at Tean on the Isles of Scilly. ${ }^{93}$ This may be due to cultural traditions and the tolerance of oats of poor soils and wet and windy growing conditions characteristic of parts of the south west. However, a recent review of the evidence for southern England does not show a particularly western bias for oats at this period, though the evidence base is still small. ${ }^{94}$

In other parts of southern England, much of the evidence for early medieval plant remains comes from towns, particularly Saxon settlements in London and Southampton. Here and elsewhere in the south there is evidence for the increasing cultivation of rye. ${ }^{95}$ 
Interestingly, this crop, which is also tolerant of poor growing conditions, has not yet been found at Tintagel. Here the range of arable crops is limited compared with central southern England where peas, beans and flax were also part of the arable system. The poor dating resolution for some early medieval sites, however, means that it is not easy to make very precise comparisons between assemblages. Archaeobotanical material is rare from secure fifth- to seventh-century deposits, and especially so in south-west Britain. ${ }^{96}$ Although the assemblage recovered from Tintagel is in overall terms small there are some significant individual deposits. Due to the general scarcity of ecofactual material both from the site itself and from comparable sites of the period, this new collection has an importance nationally as well as regionally, in addition to reinforcing the picture that has already emerged for the local situation.

\section{RADIOCARBON DATING}

The previous section on Romano-British Tintagel examined in some detail the evidence from radiocarbon dating from the site, and noted the difficulty in being absolutely conclusive as to whether there was or was not late Roman period activity here. Much of the problem centres on the implications of the radiocarbon dating on both the Lower Terrace and the Lower Ward, in relation to the artefactual assemblages. Equally, there are questions to be raised regarding the length of early medieval occupation at Tintagel.

As discussed above, excavations on the Lower Terrace of Site C (see Chapter 2) produced several phases of structural evidence: each building constructed of stone and turf, with associated floors, hearths and stake-holes, separated by periods of levelling. The later deposits produced imported Mediterranean pottery and pot-lids made of local slate. Three distinct date ranges of activity were identified by modelling of the radiocarbon data from hearth material from each structural phase (this is discussed in some detail in Chapter 2). The second structural phase exhibits both Romano-British, 'native' and the imported wares together and spans cal AD 415-535 and the third, the latest and best surviving structure with a large assemblage of imported pottery, dates to cal AD 560-670. Thus, the date range for the later structure on the Lower Terrace includes a strong likelihood that seventhcentury activity is represented. Within this time-frame, it is possible that there was continued importation of early medieval vessels to the site, albeit in small quantities (fifty-seven sherds predominantly of type Bi/Late Roman 2 and two possible African Red slipped ware (ARSW) sherds from the floor level and subsequent collapse phase), so the significance of probable occupation continuing well into the seventh century cannot be overlooked.

This now seems more likely than it did in 1997, in the light of the evidence discussed above from the 1999 excavations in the Great Ditch area, where the latest sample appears to support activity extending into the seventh century, even the second half of that century. In any case, the radiocarbon evidence from both the Great Ditch and the Lower Ward has demonstrated, from an independent basis, occupation and activity extending from the very end of the Roman period through until the seventh century.

\section{CONCLUSION}

Across the 'Island' and, as we now understand, on the 'mainland' as well, we now find an area of almost 30 acres [ $12 \mathrm{ha}$ ] defended by a massively enhanced natural feature creating a ditch (the Great Ditch), thus forming a single promontory fort. The investigations have established unequivocally that the Great Ditch should now be dated to the immediately post-Roman period, and the work of both this project and earlier work by $\mathrm{CAU}^{97}$ have uncovered activity areas, both domestic and possibly industrial, in and around what was to become the Lower Ward of the later medieval Castle. Scattered across the vast area of the promontory, terraces were created and, as in the case of Site $C$, enlarged by quarrying. Stone-built and less substantial stone and turf constructions nestled on these terraces, of which only a few can be seen today, due to the slippage of scree and later deposits. Renewed investigations of the Middle Terrace of Site C, which had been investigated in part in the 1930s, found extensive early medieval building and cultural deposits across the area, including an area to the south obscured by scree and slippage. Such slippage has been a continual occurrence and threat to the structures on the site, and perhaps explains why the indistinct Lower Terrace had earlier medieval structural remains as well as artefactual and ecofactual material, but no trace of later medieval occupation.

It is very clear that the occupation at Tintagel in the fifth to seventh centuries $\mathrm{AD}$ is both extensive and remarkable, and was of a high status. Artefactual evidence points to trade contacts in this period with the Mediterranean region, as well as south-west France and 
southern Spain. This trade in goods such as wine, olive oil and other luxuries has resulted in an extensive assemblage of imported ceramic wares as well as exotic glass being found at the site. In addition, the inscriptions made on the slate - which provides evidence for literacy - indicate high-status presence here during the late Roman and post-Roman centuries. Although there is little evidence of other facets of high-status activity on this part of the site, such as fine metalwork or glass production, there is now increasing evidence for industrial activity. Some of the implications of these matters will be further explored in later sections of this concluding chapter.

\section{LATER PRE-CONQUEST AND EARLY NORMAN: PERIOD III}

\section{INTRODUCTION}

The initial definition of Period III by Charles Thomas was essentially by reference to the end of events marked by post-Roman, early medieval, activity (Period II) and the onset of the building of the later medieval Castle (Period IV). For the site of Tintagel Castle, this was 'a long stage of virtual desertion'. ${ }^{98}$ However, in the light of his own and Jacqueline Nowakowski's work at Tintagel parish churchyard, ${ }^{99}$ summarized in his general book, ${ }^{100}$ he himself admitted that it became 'a time-division of convenience, embracing a whole series of events that are archaeologically distinctive or have left remains.' ${ }^{101}$ This is not the place to re-analyse these events, or redefine the periodization, but it is proposed to at least subdivide this period into the pre-Conquest (IIIA) and post-Conquest (IIIB) periods.

The ceramic and radiocarbon evidence discussed above for Period II has suggested that this period continues into the seventh century, rather than ending, as had previously been assumed, in about AD $600 .^{102}$ Nevertheless, this is followed by a period of quiescence (at least in the areas so far examined) on the Island. Although, as hinted at in the discussion above, the rather more elaborate form of the Site $\mathrm{C}$ building may hint at it looking forward to the building forms from the later settlement site of Mawgan Porth, ${ }^{103}$ there is no evidence to suggest that this building was occupied later. Although Radford's men cleared out much of the deposits, so that little stratified material remained, it is notable that only imported pottery is associated with it, rather than any of the later bar-lug type of pottery so important at Mawgan Porth.
Pre-Conquest: Period IIIA

There also continued to be imported wares (and no barlug) associated with the collapse of the Site $C$ building and the scree deposits over it, but the same clayey deposits which produced these have turned up a single sherd of glass dated to the eighth-ninth centuries (Phase W, Vessel 17, RF 2619). However, it is worth observing that there is no later medieval pottery in this phase, so it is arguable that it is a stratified deposit from Period IIIA. The sense is of a glimpse into a fugitive period hardly represented on the site as a whole. The glass was found in trench $\mathrm{C} 16$ (ie outside the building) and, as a single find, is likely simply to indicate casual presence on the Island. Ewan Campbell has observed that this sherd, part of a glass cup, although an 'outlier' in the overall collection from this site, does fit with other similar glass vessels from a limited range of 'royal' sites in western Britain and Ireland: Dumbarton and Dundurn hill-fort sites from northern Britain, Lagore crannog from Ireland, as well as the (erstwhile?) monastic site of Whithorn in Galloway. It is worth pointing out also that such mid-Saxon glass is well attested on 'productive' and trading sites in Anglo-Saxon England, such as the wic at Hamwic (Southampton). However, there is no evidence for production here at Tintagel, although Campbell does leave open the possibility that the small glass droplet from the Lower Ward (Vessel 19) may also be from his 'Group D' (Chapter 10).

Otherwise, although the vast majority of the evidence at Tintagel is for activity in the pre-Conquest period from the fifth to seventh centuries of Period II, another glimpse for later activity on site is given by the presence on Site A of a coin of Alfred. In the past, Charles Thomas has dismissed this: 'no credence can be placed on [it] ... allegedly picked up near the Chapel'. 104 However, the work on the Radford archive (Chapter 1) has shown that we can now place more credence on its location, even though it would appear to have been picked up by a visitor to the Castle in perhaps 1935, rather than being found during the excavations on Site A. Beyond this we dare not go at present, and no actual settlement on the Island from the late ninth century, or later, can at this stage be confirmed.

To an extent, this may simply reflect the fact that the focus shifted to the mainland side where Nowakowski and Thomas have demonstrated that there was at least one, and more probably two, phases of church building activity in the pre-Conquest period that preceded the Norman church, from at least the mid-tenth century. 
Historically, Thomas would argue for the inception of this 'parochial' activity from the first half of the tenth century, represented archaeologically by a tub-font and graves later than those of Period II. These have been found dating from the seventh century up to the thirteenth century. ${ }^{105}$ It is therefore curious that as yet we can recognize no settlement activity on the Island, particularly as Thomas is quite happy to postulate in the preceding Period II that 'this Early Christian burial ground can be assumed to hold the remains of Island communities.'106

\section{Post-Conquest: Period IIIB}

There appears, unsurprisingly, to have been a change in ownership of the area from a presumed local 'thegnly' family to the Bottreaux at the time of the Norman Conquest, and this may well be the impetus for the replacement of the late Saxon period church by the present-day Norman parish church structure dedicated to St Materiana. ${ }^{107}$ It would now be convenient to call this Period IIIB, recognizing that most activity is evidenced on the mainland side rather than on the Island. However, in due course a separate chapel was created on the plateau of the Island, arguably from the remains of a Period II building. Radford re-examined it in 1933, following earlier investigation there in the nineteenth century, and related it, as an early twelfthcentury structure, to the construction of the Castle (in his view) by Earl Reginald in 1141, extended later in the thirteenth century by Earl Richard about 1240.108 Architecturally and archaeologically this now appears to be from the eleventh century, and modified in the twelfth century, but perhaps eclipsed by the parish church from the mid-twelfth century onwards. Historically, Thomas argued for it as a privately built estate church from Bossiney. ${ }^{109}$

What was happening elsewhere on the Island during Period IIIB? Of course, Radford saw the first period of construction of the Castle as dating from then, also associated features beyond the Castle on the plateau, such as the Garden and a medieval well. He was clear that the other buildings which he examined on Site A (which he took to be entirely 'monastic', ie Period II, although he distinguished four phases within it) had gone into decay by then. ${ }^{110}$ Since Radford's time, of course, Oliver Padel has challenged the historical basis of the identification of the Castle building with Earl Reginald and proposed that it should be entirely associated with Earl Richard. Charles Thomas has accepted this in his account and associates all later medieval activity with this. ${ }^{111}$

Currently, then, there is an archaeological hiatus created by this re-interpretation, and Thomas was happy to emphasize that 'almost all' the ceramic evidence came from the thirteenth century or later. The material from before the thirteenth century, although a distinctive type of Somerset Chert-tempered ware from the twelfth century, was largely discounted as 'a few fragments', and dismissed in historical terms as perhaps representing 'a party of masons, or an occasionally-resident priest ... in and around the Chapel after 1100'.112 There is now, however, rather more of this material extant (see Freeman in Chapter 10). Table 69 shows how almost all this material came from the area of the later Site $C$ building (sixty-seven out of a total of sixty-nine sherds), although as Catherine Freeman points out, these actually need not represent more than three jugs, together with two sherds from the Upper Terrace trenches. From the rim-type (especially Vessel SO2) and the oxidized surfaces of the vessels, Freeman suggests these date from the eleventh-twelfth centuries, ie before the building of the Castle, although she then suggests that 'the builders of the Castle brought this material with them' and that Site $\mathrm{C}$ was an area of squatting for them while the Castle was built.

\section{LATER MEDIEVAL TINTAGEL: PERIOD IV}

\section{INTRODUCTION}

The previous section has briefly covered the issues surrounding the relationship of the parish church and churchyard of St Materiana on the mainland to the Island Chapel apparently dedicated to St Juliot. Historical and archaeological endeavours have begun to clarify the issues, even if a definitive understanding of the local context is not yet possible. ${ }^{113}$ There is little doubt that they co-existed through Periods IIIB and IV, and that whenever the Island Chapel was first erected and/or created out of pre-existing structures, it served 'after 1233 as an extra-parochial endowed chapel serving the Castle' for as long as the latter was in use. ${ }^{114}$

\section{The Castle}

The modern visitor to Tintagel is drawn by the massive stone walls which comprise this Castle. As indicated above, initially thought to represent the remains of a construction phase assigned to Earl Reginald in 1141, current thinking suggests that the Castle was completed 
and modified by Earl Richard in the thirteenth century. Further, Oliver Padel has argued that little remains of the Reginald foundation which Radford had identified, ${ }^{115}$ and even the Period IIIB Chapel may not be associated with him. ${ }^{116}$ It is interesting to note Charles Thomas's observations that the later medieval Castle was 'pointless yet conspicuous [and] must have ... involv[ed] great cost and a large resident workforce', even though it 'had no military value or function whatsoever ... Tintagel Castle is more fittingly described as a folly.' ${ }^{17}$ Indeed, he has noted that 'apart from its dramatic siting ... there is little to recommend it ... as far as it is known, nobody ever attacked or defended Tintagel [Castle],, 118 and while this may seem a somewhat harsh judgement, it is difficult to disagree with this view. His current view is that it was, in fact, symbolic rather than defensive. ${ }^{119}$ The successive history of the Castle is briefly summarized by him, with phases of major restoration and minor addition noted in the fourteenth century and contemporary accounts in the late 1400 s and in 1540 of its generally ruinous state. ${ }^{120}$

However, the importation to the site for castlebuilding purposes of locally quarried stone and slate (as discussed in Chapter 10 by Jefferson), was a large-scale undertaking, and must have involved a considerable work-force in the 1230s. The nature of the wall construction has been illuminated by the work of CAU in 1986 in trench D outside the Lower Ward. ${ }^{121}$ As argued above, the Great Ditch had already largely been modified - with considerable effort - in the early medieval period, and so the overall task of delimiting the landward side was considerably reduced by its existence. Also, Earl Richard appears to have had his major structures built on top of the earlier remains of pre-existing terraces. This has clearly been demonstrated, for example, by the CAU work in 1988 in the region of the Great Hall ${ }^{122}$ and in the Lower Ward, ${ }^{123}$ as well as our more recent work there (see Chapter 9). Archive evidence from Site $\mathrm{F}$ also has shown this, as referred to in a previous section and Chapter 1 above (see figure 145).

\section{The LitTle Ditch}

The investigations on Radford's 'Site T', while focusing upon his earlier work in sectioning the Great Ditch, and the continuance of this into the Lower Ward, in the context of clarifying the claim for an early medieval date for the feature (see Chapter 8), nevertheless had some interesting outcomes vis à vis the later medieval Castle. In the first place, the trial excavations (Chapter 7) identified the existence of a later medieval U-shaped Little Ditch to the south south east of the Lower Ward, and parallel with the road leading into the entrance to it. There was no imported early medieval pottery present, and a terminus ante quem for its usage is given by two sherds of a postmedieval North Devon Calcareous green-glazed jug, dated to the sixteenth to early seventeenth centuries. As noted above, this feature is consistent with those observed around the walls of the Lower Ward, one of which was excavated in $1986,{ }^{124}$ and probably also that apparently excavated by Radford in 1955 at the base of the north-east Lower Ward (Chapter 1).

There was no indication that the Little Ditch was earlier than the Castle, whereas the feature examined by Radford in 1955 appears to have had imported early medieval pottery associated with it, and so has been seen as a post-Roman feature adapted in the thirteenth century. However, it is unfortunate that (as explained in Chapter 1) there was no opportunity to re-investigate this ditch in front of the north-east Castle wall in 1999. It would have been useful to have checked, with modern techniques, whether early medieval pottery is actually found in stratified deposits associated with the ditch, is residual in later deposits infilling the ditch or comes from layers cut by the ditch. It is interesting that the 1986 excavations, further to the north west, did not provide conclusive evidence for the presence of a ditch associated with the Castle wall. ${ }^{125}$ The pottery assessment by Carl Thorpe concludes that the 'postRoman [pottery] ... must have been redeposited from earlier layers during the considerable disturbance that the construction must have involved.' ${ }^{26}$ Therefore it is not conclusive that the smaller 'ditches' outside the walls of the Lower Ward were an enhancement of pre-existing ditches, but were perhaps more likely - as with the Little Ditch - to be de novo constructions, and to be associated with the Castle-building activity.

\section{THE LOWER WARD}

The small-scale re-investigations in this campaign of the Lower Ward, from the area of T01 ext, have produced no direct evidence of later medieval features, or even indirect evidence from later medieval artefacts recovered. There were no medieval or post-medieval sherds at all, presumably because of consolidation activities from the 1930s onwards, and Radford's excavations in 1938 and 1955, rather than because it had not been occupied in the period, demonstrably not the case (see Chapter 9). 


\section{The Great DITCH}

Equally, while undoubtedly the Great Ditch operated as a landward barrier in front of the walls of the Lower Ward of the later medieval Castle, there is no direct evidence from the excavations of any enhancing of this feature in the thirteenth century. There is, of course, later medieval pottery from the infilling of the ditch but, even here, only small numbers of sherds were noted, just twenty-seven in all, with the earliest stratified material being from Phase $\mathrm{W}$ in the Great Ditch (the upper fill). These sherds were identified to Stuffle-type wares (SA), North Devon Medieval Coarsewares (OK), unclassified unsourced wares (UU), Lostwithiel wares (LO) and post-medieval Sandy Redware (SR), indicating a date range spanning the thirteenth into the seventeenth centuries (Freeman in Chapter 10). Unfortunately, there is not sufficient calibration of the deposits in the ditch (mainly because of scouring by water down-slope from west to east) to distinguish between those which might be associated with the construction of the Castle, as opposed to its usage and then disuse and destruction. A number of dislodged building stones were recovered there, which have been discussed (Chapter 10) by Francis Kelly, but are not hugely informative and relate to the ruination of the Castle. Fewer sherds of less variety were recovered from Radford's backfill, and only a single sherd from the overlying scree, an example of Saintonge Ware dated to the period 1250-1450 (Chapter 8).

\section{Site C: STRUCTURAL AND OCCUPATION EVIDENCE} Outside the area of the later medieval Castle, there is no other structural evidence to bring forward from the recent investigations. It was quite clear from the Lower Terrace excavations that by the later medieval period this terrace was no longer functional, and thus no structural evidence came from there for Period IV. It is also significant in this context to point out that just one single sherd of medieval pottery was recovered. This supports the view that no later medieval activity seems to have taken place at that particular part of the site. Perhaps this was in fact due to the almost invisible nature of that terrace - certainly the case prior to excavation - in contrast to those terraces higher upslope, which had been equally enhanced by quarrying of the rock face (see Chapter 2).

However, the contribution of the other renewed excavations on Site $C$ to this part of the story may well lie in the discovery that the stone building on that terrace at least was not part of the Castle complex, as what can be seen is from the early medieval period, apart from what has been reconstructed in the post-Radford era (see Chapter 6). In the light of the 1985 survey by RCHME and other work on the site, Charles Thomas raised the possibility that such buildings as those on display at Sites B, C, F, G, etc should now be seen as belonging to his Period IV (ie later medieval), rather than Period II (ie post-Roman). ${ }^{127}$ Because virtually the entire inside of the building was cleared out by Radford's workmen without regard to stratigraphy, there was no positive evidence to support or refute Thomas's suggestion. It is now quite clear from the $1990 \mathrm{~s}$ excavations that the later medieval pottery all occurs in Phases $\mathrm{X}$ and $\mathrm{Y}$, and it has been argued that some (if not all) of it came from the Upper Terrace above. There are no stratified contexts on the Site $\mathrm{C}$ building area associated with later medieval pottery, whereas the major structures of Phase $\mathrm{V}$ and their associated features (such as the later drain to the west and south), appear to be associated with early medieval imported pottery and glass.

As indicated earlier, excavations and assessment of Radford's small trenches in and around Site $\mathrm{C}$ raised the question of zones on the site in Period II. It has already been noted that the proportions of later medieval pottery to the earlier imported material is likely to be an artifice of recovery relative to landslip from the terraces above (see Freeman in Chapter 10). At the southern end of the Upper Terrace, for instance, both post-Roman and later medieval pottery was recovered, some of the latter being in situ, some having slipped from terraces (and presumably occupation and activity areas, if not eroding buildings) further up the slope. However, at the northern end of the same terrace, only post-Roman imported pottery was recovered. This situation was mirrored on the Middle Terrace below, where pottery of both periods was recovered from trenches at the southern end of the terrace, and only the earlier postRoman pottery was recovered from the northern end (see Chapters 3 and 4).

None of the trial trenches from either the Upper or Middle Terraces produced any direct structural evidence from the later medieval period (see Chapters 3 and 4), nor was there any from the area of C15. Indeed, it would seem likely that this end of the Middle Terrace had suffered much the same fate as the Lower Terrace in terms of landslip obscuring the original terrace-form in the topography here, presumably by the time of Period IV (Chapter 5). 
THE ARTEFACTUAL ASSEMBLAGES

Artefactual information, other than ceramics, recovered for this phase of activity includes a small number of incised stones. Finds of simple motifs incised at the site on pieces of slate have been catalogued previously from the Radford assemblage, ${ }^{128}$ and indeed several have been added to this corpus from the more recent excavations at Tintagel churchyard. ${ }^{129}$ Part of a Nine Men's Morris or Merrells gaming board (see Chapter 10, figure 108) was found in trial trench $\mathrm{C} 15$, from the scree slip of Phase $\mathrm{Y}$, and a date from the eleventh century onwards has been suggested (see Chapter 4). A further two incised graffiti slabs were recorded from the Site $\mathrm{C}$ Building - from Phases V and $Y$ (see Chapter 10, figure 116) but these are of a less formal style. However, we should be wary of applying too precise a dating or too tight a chronology to such simple designs and, even on the dates hazarded so far, they could be from either Period IIIB or Period IV.

\section{THE POTTERY}

Otherwise, the evidence is largely confined to the ceramics (see Freeman, Chapter 10), which usefully builds upon and amplifies the picture gained from the data set from previous excavations and casual collection around the site. This is especially so as few of those could even be identified as being from a particular part of the site worked upon by Radford's men in the 1930s or 1950s. ${ }^{130}$ Unfortunately, nevertheless, a large part of the current ceramic assemblage was recovered from phases considered to correspond with Radford's backfill and is, therefore, broadly unstratified. It does, however, enable an overview of the general distribution of the fabrics in terms of the site topography.

In the Upper Terrace area, Freeman has distinguished four main fabrics ( $\mathrm{SO}, \mathrm{SA}, \mathrm{OK}$ and $\mathrm{LO}$ ) with a potential date range spanning the eleventh to at least the fifteenth centuries. They are from later phases on the site, including disturbed scree, Radford's backfill and topsoil. Greater numbers of SA and OK sherds are noted (thirteenth to fifteenth centuries), and these include two main portions of individual vessels of SA fabric (SA3 and SA4). Within the OK group, forty-nine sherds are from a single vessel (OK1). All are from Radford or postRadford contexts, and thus it would seem that these may well have been discarded during the earlier excavations. It would seem reasonable to assume that they were originally essentially complete vessels in use in this immediate vicinity. Perhaps their use is contemporary with the incised pictorial slates found at both the Castle and the parish church and coincided with the presence here of masons employed for the building and early modification of the thirteenth-century Castle? ${ }^{131}$

On the Middle Terrace there was a preponderance of SA sherds dating from the thirteenth century onwards, and lesser numbers of Ham Green (HG) wares, OK, Bristol Redcliffe (RE) wares and LO types. In the building on Site $C$, as noted in the discussion of Period IIIB above, the predominance is with the Cherttempered (SO) wares of the eleventh to twelfth centuries (although only three individual vessels are indicated), including large amounts of a single vessel which appears to have been discarded by Radford's workmen (SO2). This material may well represent vessels in use during construction activities at the site, perhaps even associated with the elusive activities of Earl Reginald. As with trench $\mathrm{C} 15$, the recovery of this small assemblage from layers of collapse and scree slip down the slopes from above the site, attest to activity and/or occupation on the terraces above Site C. In C15 small numbers of sherds of SA, OK and RE are from Phase W, which is a period of collapse and scree slip, but all other phases indicated on this terrace are Radford contexts and later, and are likely in many cases to suggest slippage onto the site from the Upper Terrace above.

Taken together, these excavations produced a reasonable assemblage of local medieval pottery, and clearly indicate for the first time that activity, even conceivably occupation, took place during this period on the site outside the confines of the thirteenth-century Castle.

\section{THE ENVIRONMENTAL ASSEMBLAGE}

Although material was recovered for environmental analysis from this period, in common with the immediately preceding era, the range of taxa is small and there are no marked differences between the later and earlier phases of activity. In terms of evidence for the environmental situation in the later medieval period, from the Middle Terrace small numbers of oat grains from Phase X of $\mathrm{C} 05$ and traces of hulled barley are complemented by black bindweed, sorrel, bramble and grass caryopsis, a few wheat grains and campion add to the assemblage of carbonized material from C15. Charcoal indicates the presence of hazel and oak here (perhaps for fuel or from damaged structural elements). In addition, highly fragmented animal bone indicates the presence of cattle, but it does not survive well enough to be sure of which cuts are represented 
(although some teeth are present). There are negligible traces of oats, barley and grass family seeds from Phases $\mathrm{W}$ and $\mathrm{X}$ in the Great Ditch.

Although these quantities are too small to enable more detailed consideration of the local environment for the later medieval period, Straker discusses in Chapter 11 that there are few major changes visible across the periods represented at the site as a whole. However, prior to these archaeological investigations nothing at all was known of this aspect of life at Tintagel, so this is an unexpected bonus to the developing picture overall.

\section{FROM THE END OF THE LATER MEDIEVAL PERIOD TO THE PRESENT: PERIOD V}

'Period V' is a term which Charles Thomas coined for 'everything from about 1530 to now', but which he acknowledged was when the Castle was 'perceived and depicted as a spectacular ruin.' ${ }^{132}$ The ruination of the Castle has already been noted above, in the context of the dislodged building-stones in the Great Ditch (see Chapter 8). In fact only one of these (RF 4245) came from Phase W, the post-Castle fill of the ditch and the collapse on the north bank. The others came from the infill of Radford's trench (Phase X), so had presumably been initially collected by his workmen in 1938, and then discarded as he examined the finds from the investigations. Jefferson's work (see Chapter 10) shows clearly that the stone was derived from local sources (and quarried at places such as Barras Nose) and this is likely, too, for the mortar (Palmer, Chapter 10).

While some of this material may have come from later repair activities on the Castle walls, there is nothing to indicate any other activity in this region of the site in Period V. Phases W and X of the Great Ditch both have very mixed assemblages of artefactual material - up to virtually the present day - and so the presence of one abraded SR sherd in Phase W can tell us little other than that sixteenth- to seventeenth-century pottery subsequently made its way to the site. This is reinforced by the second sherd of the same pottery in Phase Y, which represents the post-1938 slump of Radford's spoil-heaps into the trench. Modern terracotta drainpipe material is also found in all phases from $W$ to $Z$. As indicated in Chapter 8 , with the degree of disturbance here it was virtually impossible to separate construction phase debris from structural collapse debris; the modern pipe and mortar is reinforced by the presence of modern glass and a number of modern iron finds.
In the case of the Little Ditch, trench T02, as noted above a terminus ante quem is given by post-medieval North Devon Calcareous ware green-glazed pottery from deposits which accumulated within the ditch in Phase X (Chapter 7). Like the SR sherds from the Great Ditch, these probably date from the sixteenth to seventeenth centuries, and are more obviously stratified, with no modern contaminants. However, as they stand, they simply attest to casual visitors to the site in the postmedieval era.

Cathy Freeman's analysis of the pottery has demonstrated that there is no other post-medieval pottery from the recent investigations on Site $C$ (Chapter 10, table 69), and so the casual deposition recorded on the mainland side of the site in the postmedieval era is not replicated here. Given that she had previously recorded some post-medieval North Devon material of the sixteenth century within the previous collection from Radford's work, ${ }^{133}$ possibly amounting to 'low level domestic use,'134 perhaps this is simply a reflection of differential activity across the site at this time. In fact, maybe the degree of landslip at the Site $\mathrm{C}$ terraces was such by then that most of what we now recognize as relatively level terraces was obscured? This is not to say that there was no material from after the later medieval period, but the impression as recorded in Chapter 3 for the Upper Terrace trenches, that there were bursts of high-status activity in this region of the site in Periods II and IV, with periods of stagnation in between and afterwards, appears to be reflected across Site $\mathrm{C}$ as a whole.

Otherwise, the only significant activity to be recorded in excavation relates to $\mathrm{MoW}$ reconstruction and levelling activity in Phase $\mathrm{Y}$ of the Site $\mathrm{C}$ building. It is sobering to think that the records of this activity in the Radford and Wright archives are such that the degree of reconstruction cannot be judged from them, so that it has only become clear through excavation in the 1990s, both in terms of scale and extent. Features such as the added drain and the (re)constructed bench are not immediately obvious to the visitor to the site as modern additions to an early medieval structure. As can be seen from the account in Chapter 6, the excavations uncovered not only evidence for consolidation and reconstruction of the building, but also significant differences between those parts of the walls which were mortar-bonded and those upper levels which were bonded with cement. The mortar samples from here and Site $\mathrm{T}$ have been analysed by Timothy Palmer and his 
results will clearly be of significance for future understanding of the integrity of the site as a whole. This clearly encompassed both wall- and bench(re)construction and erection of official sign-boards for visitors, as well as modern dating material, most notably a 1951 George VI shilling (RF 1962), arguably a deliberate deposition by the workmen in the east bench. On the other hand, metal foil and a small enamel brooch in the form of a $\operatorname{dog}$ (RF 1503) are presumably accidental losses, like both the plastic comb from $\mathrm{C} 07$ and the plastic ear-ring from $\mathrm{C} 18$ on the Upper Terrace. Virtually all other modern material from Site $\mathrm{C}$ comes into this category, although there may be occasional insights into picnicking activities - as with the Shippam's paste jar (RF 2537) from trench C18 at the southern end of the Upper Terrace (see Appendix 3 of Modern Material) This is still a good vantage point to sit and contemplate the Haven below and the sea and coast to the north while having lunch!

\section{THE LOCAL CONTEXT (figure 146)}

The previous report on excavations on the Lower Terrace drew attention to 'the widening local focus to the discussion of the nature of this site, ${ }^{135}$ and the points made then are still valid now, and can be elaborated upon in the light of the recent work.

In the first place, although present-day topography divides the 'Island' part of the site from the 'mainland' Lower and Upper Wards of the Castle, this not a reflection of either the early or later medieval situation, although John Norden in 1597-1604 showed a gulf between the two and referred to a 'Draw-Bridge' linking the two, even if this was an exaggeration of the real situation. ${ }^{136}$ It is self-evident that the Castle as conceived and constructed in the thirteenth century was a single entity which stretched across what is quite likely to have been 'a not too narrow grassy saddle linking mainland and Island, ${ }^{37}$ rather than what is now effectively a chasm dividing part of the Castle from the rest. This single entity is perhaps also obliquely referred to in the official OS name of 'Tintagel Head.'138 This is not to say that there was not a distinction between what is now the mainland and Island parts of the Castle, perhaps rather in the manner of an earlier motte and bailey. However, conclusively, as related above, the recent excavations on Site $\mathrm{T}$ have demonstrated that the Great Ditch was in use in the immediate post-Roman centuries, and essentially contemporary occupation is also attested archaeologically in the Lower
Ward from work by $\mathrm{CAU}^{139}$ and our excavations in T01 ext (see Chapter 9). Similarly, Thomas has shown clearly that both work under the Great Hall and examination of the rock-falls at the edge of the chasm confirm early medieval occupation on an artificially created terrace at the closest point of the Island to the mainland, ${ }^{140}$ suggesting that, at that time, this terrace extended across what is now the gap between the two.

Second, as indicated above, this wider focus is also in terms of the palaeo-environmental evidence from both the Lower and Middle Terraces of Site $C$ for the presence of cereals, and the implications this has for agriculture in the area (see Chapter 11). Archaeobotanical material is a rare survival in secure contexts in the fifth to seventh centuries $\mathrm{AD}$, especially in the south west of England, and so Tintagel provides a disproportionately significant contribution. Amounts are small in scattered contexts, oats and barley with occasional wheat seeds are identified, and all are generally carbonized. A single waterlogged deposit from Site $\mathrm{C}$ of the Middle Terrace (1022, Phase W: see Chapter 6, table 28) provided a different medium of preservation, but did not expand the species list. In addition, although these acidic soils militate against good preservation, for the first time small quantities of bone have been recovered. The various samples from Site $\mathrm{T}$ largely corroborated what had previously emerged from Site $C$, except that a single seed of rye (along with fifteen oat grains) was identified from a deposit from the Lower Ward (see Chapter 11, table 84).

The implication here is of agricultural activity in nearby fields in this general locality, and for the first time the potential for the collection of palaeo-environmental material from the area of the site has been clearly demonstrated. Vanessa Straker takes the presence of small-seeded weeds of arable or disturbed ground, and the scarcity of chaff and large-seeded weeds, to suggest that the crops were brought to the Island partially processed and cleaned for consumption on site (Chapter 11). For too long Tintagel 'Island' has been isolated and divorced from its immediate archaeological and environmental context, and it must be reiterated that the sites with which this report is concerned are but part of a much broader local area with contemporaneous human activity. All of these require to be explored further if we are to even begin to approach an understanding of the mechanisms and dynamics of human and site activity in this area in the earlier and later medieval periods. ${ }^{141}$ The potential has been 
indicated by Straker with her observations on the similarities of the churchyard and Island assemblages of seeds and weeds. The interdependence is also indicated by the presence of, for instance, hazel wood charcoal, possibly from managed coppice somewhere in the vicinity of this wider region of north Cornwall.

Third, there is also an immediate hinterland (see Chapter 1, figure 1), which includes a contemporary burial and ritual focus at the location of St Materiana's church, now the parish church. Charles Thomas had flagged up the potential importance of this site in his edited collection of papers in 1988 , with an investigation into the mounds within the churchyard, and the earlier 'excavations' of them by the local vicar with locally based RAF airmen. ${ }^{142}$ His persuasive approach to an oil company enabled the site to be seriously investigated for two seasons in 1990 and 1991, and for a coherent chronological account to be constructed from the outcomes, beginning with the burials, rituals and ceremonies of the post-Roman Period II, contemporary with the settlement on the Island, and then churchbuilding in Period IIIA, and expansion of the church post-Conquest in 1120-40 in Period IIIB. This later structure established there has to be seen as the major ecclesiastical focus in the vicinity, with the chapel on the Island, as discussed above, merely acting as an 'extraparochial endowed chapel serving the Castle. ${ }^{143}$

As has been emphasized at various points through this report, the human resources implied by the construction of both the early and later medieval sites are considerable. Jefferson, in Chapter 8 , while pointing to the natural valley that preceded the Great Ditch, has acknowledged the very considerable human effort required in reshaping both the ditch and the banks to create this major defensive barrier. Again, although it has been noted that the earliest turf and timber structures on both the Lower and the Middle Terraces were not major constructions, by the time that the stoneconstructed building of the Site $\mathrm{C}$ type was created, much more substantial resources were involved. Indeed, even prior to that, it is likely that some at least of the terraces had been quarried into the sloping cliff-sides on the east side of the Island, whose construction speaks for itself in terms of resources implied. Buildings like Site C were found scattered across the headland on all available terraces and we can now infer that these were constructed in Period II, rather than Period IV. Further, even allowing for the possible usage of this site on a seasonal basis, significant resources for maintenance are implied through the fifth to seventh centuries. Similarly, in Period IV, even if, as Thomas argues, the Castle was effectively a 'folly' and serving no real defensive purpose, simply constructing it was no mean achievement, especially given the particular considerations and constraints implied by the saddle-back topography (later to become a chasm).

In the next section, consideration will be given to the wider world with which Tintagel interacted. Especially in the early medieval period the trading contacts would imply a control and power, which while focused upon the headland site, would necessarily have had to look to the hinterland for support, if not an infrastructure of route-ways etc. If, as has been suggested above, in the later Romano-British period there was renewed exploitation of the mineral resources of the region, and if this then continued in the post-Roman period, then there are considerable implications regarding control of this hinterland and the nature of the power that exercised this control. That it might have had Imperial backing in the late Roman period is no longer tentative speculation based upon a couple of inscribed routemarkers in the vicinity and a possible place-name, but more substantive, given the nature of the inscription found at Site C. Further, it will be argued below that the post-Roman evidence is sufficiently impressive (especially by comparison with contemporary sites) to indicate a very high status indeed for the site, and pari passu the authority that was responsible for its construction and maintenance.

\section{THE WIDER WORLD}

\section{BEFORE THE EARLY MEDIEVAL PERIOD}

As discussed above, the evidence for any prehistoric activity on Tintagel Head is at best equivocal, even though its location makes it a prime candidate for Iron Age and possibly earlier activity, but we are certainly not in a position to offer even a glimpse of connections with the wider world then. However, we have a somewhat better basis when trying to ascertain the wider connections of Tintagel in the Romano-British period. As emphasized in general works of the region and period, there is little doubt that Cornish tin was exploited for use, and possibly export, in the Roman period, and this exploitation may have increased in the later Roman period (see above). Equally, although the mechanisms are not sufficiently understood, the presence of the place-name ${ }^{\star}$ Durocornovio and the 
presence of two Roman route-markers at Trethevy and Tintagel itself, would seem to point to the location having some sort of official function, perhaps in terms of oversight of taxation or tolls. The newly discovered inscription, apparently attesting to some sort of official presence, possibly even acting as an official 'label' on a building, in the time of the Emperor Honorius (AD 393-423) on Tintagel Island, immediately implies that there were wider contacts - perhaps to the Mediterranean world, but certainly with Roman Britain. Although not attested in these excavations, previous finds of ceramics, such as Oxford Colour Coated ware, already imply some sort of economic activity in respect of regions east of Cornwall at this period. Similarly, the evidence of human cremated material from the Lower Terrace of Site $C$ suggests connections with practices evidenced in the wider western British and Irish world at the very end of the Roman period.

\section{TRADE AND EXCHANGE IN THE EARLY MEDIEVAL PERIOD} When we move into the post-Roman period, the consideration of the nature of the site is, of course, inseparable from the consideration of the implications of the rich material arriving at the site, and its comparison with other similar sites of the period in western and northern Britain. Pre-eminent amongst this material is, of course, the imported pottery in which, in terms of quantities, Tintagel far outnumbers all other sites of this period in Britain and Ireland, with perhaps a quarter of the total. ${ }^{144}$ The total number of ceramic vessels, represented by surviving fragments at Tintagel, is conservatively estimated by Carl Thorpe at 150 amphorae and eighty Red Slipped wares (PRSW and ARSW), together with numerous Coarseware vessels. ${ }^{145}$ However, even in 1993, Charles Thomas talked of, variously, 'three or four thousand sherds' of B-ware amphorae amounting to 'a hundred vessels at least', and 'hundreds of jars and dishes. ${ }^{146}$ There is little doubt that Leslie Alcock felt there were more: 'the provisional figure for B-ware from Tintagel ... is certainly an underestimate, ${ }^{147}$ basing this upon his and Elizabeth Alcock's analysis of 'The recovery rate of Bi amphora sherds' from [South] Cadbury, Alt Clut, Clyde Rock, Dumbarton, and Degannwy. ${ }^{148}$ However, even so, it is difficult to substantiate his later statement that 'at least 1500 class $B$ vessels [our italics] - as distinct from sherds - have been recognized [from Tintagel].:149 It is clear that the amphorae were imported for their contents (ie wine or olive oil or other commodities: see $\mathrm{R}$ Jones, Chapter 10), and several discoidal amphora-stoppers, which originally fitted the seal of the neck of the vessels during shipment, have been recognized from all parts of the site, including a small but significant number from these excavations. The pottery from the excavations on Site $\mathrm{C}$ is incorporated into ongoing research at the University of Glasgow using chemical and organic residue analyses to study the origin and contents of the amphorae from the site in the wider context (see R Jones, Chapter 10). This will fit into ongoing research by Charles Thomas and Carl Thorpe into the nature of the evidence from Tintagel and, indeed, more generally for the trade routes into south-western Britain and Ireland from Europe and the Mediterranean in the post-Roman period. ${ }^{150}$

However, extraordinary concentrations such as this would seem to require extraordinary explanations and it is therefore not surprising that suggestions have been made in the past of Tintagel being a, if not the, primary point of entry to Britain and Ireland for this material, with subsequent redistribution elsewhere. ${ }^{151}$ Philip Rahtz at one stage saw Tintagel as 'the post-Roman equivalent' of 'the great international emporium' at preRoman Hengistbury Head in Dorset. ${ }^{152}$ In terms of access to Tintagel, the suggested landing point of the Iron Gate remains the favoured option, as 'a natural quay,' ${ }^{153}$ however improbable this may seem. Access into Tintagel Haven at most tides is very dangerous, and in 1927 King Arthur's Hotel above the Haven even provided a seat from which patrons could observe events below when 'it was not an uncommon occurrence for a small boat to load with slate on the beach during the day, and with a rising tide and ground swell to be smashed in pieces before getting afloat'. 154 This would appear rather to militate against the suggestion of Tintagel being a primary point of entry and distribution point in the early medieval period. However, Charles Thomas has stoutly asserted: 'Despite the occasional scepticism of archaeologists, or those who do not know Tintagel properly all the year round, there can be no doubt that during the entire period AD - certainly during Periods II, III and IV - the Island was fully accessible by sea.' ${ }^{155}$

Be that as it may, as Ewan Campbell and Christopher Bowles have put it: 'It is certainly true that the restricted harbour at Tintagel Haven would be difficult for a foreigner to find and negotiate safely without local support.'. ${ }^{156}$ So it might be feasible to suggest that a local pilot may have been taken on board, perhaps from the Scilly Isles, to facilitate safe harbourage; Thomas has noted that ships in the historic (later) Middle Ages 
stopped at the Isles for collecting fresh water. ${ }^{157}$ If indeed this were the case, it might well shed some light on the relationship between the site at Tintagel in mainland Dumnonia and contemporary locations in the Scilly Isles. ${ }^{158}$ However, later usage shows that it was not impossible to use the Haven as a harbour:

Of all the improbable ports mentioned in this book, Tintagel may be the most surprising, since the cliffs rise sheer and there is no indication of a harbour. Yet in 1583 Sir Richard Grenville reported that there was room for four or five of the largest ships to embark or disembark troops. Later, slate was quarried nearby and vessels beached themselves in the cove to be loaded by derricks from wooden staging projecting from the cliff, and there was a mine here also. ${ }^{159}$

If Tintagel was a primary point of entry for Mediterranean goods, then the distribution onwards may perhaps have been via individual 'voyages' up into the so-called 'Severn sea,' 160 whence then come the collections at accessible sites, such as Cadbury Congresbury and Dinas Powys. ${ }^{161}$ Long ago, other 'exotic' material, for instance the glass from Dinas Powys, ${ }^{162}$ was also recognized as having a particular importance, and could have fitted into such a schema, although at that time Alcock did not see it in the context of wider links and the mechanisms of exchange in the post-Roman period. ${ }^{163}$ However, with the significant expansion of work on sites of this period since Radford's work at Tintagel and Alcock's at Dinas Powys, and the consequent expansion of evidence from other such sites, it seems only logical now to see the extant archaeological material (particularly ceramics and glass) from places such as Tintagel, Bantham, Cadbury Congresbury, South Cadbury, Dinas Powys, Longbury Bank and Hen Gastell, ${ }^{164}$ as a representative sample of a larger whole.

The nature of the contact providing the imports has been much debated, however. Although Leslie Alcock and Charles Thomas tended to a minimalist interpretation of the scale of the implied economic activity with the Mediterranean, it is prima facie difficult to envisage it as involving only 'occasional ships, arriving irregularly with long intervals between each visit' ${ }^{165}$ or one or at most four voyages in the period $c$ AD 450-c 600. ${ }^{166}$ Rahtz described Thomas's 'bold hypothesis' as 'stimulating, if reductivist,' ${ }^{167}$ and by 1990 the Alcocks, while acknowledging Thomas's 'brilliantly imaginative discussion' had shifted to a position of 'planned voyages driven by consumer demand in the Mediterranean and Gaul'. 168

The report by the Alcocks on Alt Clut, Castle Rock, Dumbarton included a very useful gazetteer of coastal and inland sites of the period. ${ }^{169}$ They related these to the development of trade in this period, with an emphasis on the harbour-sites, and Leslie Alcock elaborated further on this in his Cadbury Castle report. They identified Alt Clut, Dunadd, Dunollie, Whithorn and Mote of Mark, as pre-eminent coastal or nearcoastal 'emporia' in northern Britain; Dinas Powys and Longbury Bank similarly so in Wales and Cadbury Castle (Cadbury 11), Cadbury Congresbury, Bantham, Trethurgy and Tintagel in western Britain. ${ }^{170}$ There is, then, little doubt that most specialists dealing with the imported 'exotic' material of this period would now assert the existence of a significant, even if not extensive, trade network into south-western Britain in the fifth and sixth centuries originating in the Mediterranean, although later superseded by connections with the Continent.

For Jonathan Wooding, utilizing a variety of documentary and archaeological sources, including the parallel of the Yassi Ada shipwreck of $c$ AD 625, the explanation lies in an irregular type of 'tramping' trade. It has sometimes been assumed that each shipment of goods was probably heterogeneous in character with, for instance, ceramic cargo and differing commodities being collected at more than one port in the Eastern Mediterranean and North Africa. ${ }^{171}$ The work of Richard Jones on the amphorae reported in Chapter 10 indicates multiple supply sources, adding in the possibility of the Iberian peninsula (which fits well with both the new glass evidence from the Site $\mathrm{C}$ building and the assemblage of pottery from Conimbriga in Portugal, ${ }^{172}$ in addition to a number of different commodities being shipped (as shown in the organic residue analysis). Mixed sources of amphorae could thus suggest the gradual accumulation of a cargo or cargoes through stopping off at different ports throughout the Mediterranean, although different journeys over a given time-frame could equally be indicated. The repeated use for different commodities of the amphorae themselves, rather than simply being filled with either wine or olive oil in the traditional scenario, may have taken place en route or at Tintagel (perhaps supported by the evidence for the use of slate discs as vessel lids).

Ewan Campbell has advocated an established protomercantile trade of a sustained character between the 
Byzantine empire and south-western Britain in the sixth century, an extension of large-scale commercial contacts with North Africa and Iberia. ${ }^{173}$ This more 'directional' contact with the Byzantine world ${ }^{174}$ can be perhaps seen in the coherent nature of the assemblages from Tintagel and Dinas Powys, where he would say that this is an argument against Wooding's 'tramping': 'The coherence of the Aegean package of wares at sites such as Dinas Powys and Tintagel ... some three thousand kilometres from the source, is clear evidence of direct trading contact between the areas.' ${ }^{\text {. }} 75$

Yet another mechanism for the material to come to western Britain would be via 'trans-shipment' through Gaul, something that has been advocated by both Leslie Alcock and Ann Bowman. ${ }^{176}$ The latter has also suggested that the evidence seems to indicate that a return journey from, for example, Turkey to south-west Britain, would take at least half the sailing season to complete. ${ }^{177}$ She has urged the need to distinguish between directional trade between producers and consumers, and material that ended up eventually in Britain as a result of a series of independent transactions. ${ }^{178}$ Indeed, she questions whether it should be assumed that the eastern Mediterranean pottery found in Britain got there as a result of commercial trade with the producers, and Dark has gone further in linking this with his putative Byzantine diplomatic function at Tintagel. ${ }^{179}$

Questions as to whether this Mediterranean material entered the western seaways of Britain and Ireland through direct contact with the eastern Mediterranean, Byzantine world, through trans-shipping, or through 'space-filling' on the fifth- to seventh-century equivalents of tramp-steamers or 'puffers', will no doubt continue for some time, but the reality of north Cornwall being at the heart of this enterprise would seem undoubted. ${ }^{180}$

This trade would not have been one way; indeed, all types of trading activity are predicated on the availability of a return cargo. It must, surely, be in this context that five ingots from Praa Sands, near St Michael's Mount, in a context thought to be seventh century, ${ }^{181}$ and the find of at least forty tin ingots (weighing a total of $84.67 \mathrm{~kg}$ ) from Mothecombe in Bigbury Bay, on the south Devon coast, must be seen, ${ }^{182}$ especially in the light of the evidence from what appears now to be a settlement site at Bantham Haven further round the bay. Indeed, Bantham may well have been another 'primary' redistribution point or 'gateway community?. ${ }^{183}$ Although there is no such evidence at Tintagel itself, ingots have now been found from inland sites such as Chun and Trethurgy, ${ }^{184}$ which Alcock considers 'may have been accumulated to send to the superior centre at 'Tintagel'. ${ }^{185}$

The question of the nature of the return cargoes is to some extent speculative, being largely based on documentary sources, such as the oft-quoted Life of St John the Almsgiver of Alexandria (AD 611-19), which refers to a cargo of tin, ${ }^{186}$ and Procopius. ${ }^{187}$ Other support comes from logical inferences, such as the juxtaposition of the imported pottery sites and areas of tin-streaming worked in antiquity in Cornwall, ${ }^{188}$ and earlier attested occurrences of, for instance, Cornish tin or Mendips lead. Several commentators have noted the Byzantine Empire's need for tin in the early medieval period. ${ }^{189}$ Although this was a rare commodity more generally in the sixth century, it was available in the south west of Britain ${ }^{190}$ and, of course, as noted above, had already been exploited in the Roman period. Other commodities which may have been part of the return load may have been slaves or organic and agricultural goods such as furs, leather goods or honey. ${ }^{191}$ Ken Dark has postulated a diplomatic element to the trade, and has subsequently elaborated upon this in terms of the possible establishment of a Byzantine mercantile community at Tintagel, ${ }^{192}$ similar to those in Marseilles and Bordeaux. ${ }^{193}$ There is even some possible direct evidence of the link in terms of Byzantine coins from Princetown, Dartmoor and Exeter ${ }^{194}$ and, further east, a bronze censer from Glastonbury. ${ }^{195}$

Although initial dating of the imported pottery was generally to the fifth and sixth centuries, ${ }^{196}$ some commentators have asserted that there was 'only a comparatively brief importation from the Mediterranean, lasting from $c$ AD 475- $c$ AD 550 at the most', ${ }^{197}$ and Charles Thomas himself at times has proposed a datebracket of AD 450-530. ${ }^{198}$ However, over thirty-five years ago Leslie Alcock, while accepting that 'parallels have been sought in Mediterranean contexts dated by coins or historical references, so that a precise dating might be transferred to sites in the Celtic west', also pointed out that 'This last study, so important for us, has been made difficult by the lack of attention to pottery, or even to modern techniques of excavation, on many Mediterranean sites. ${ }^{199}$ While the situation has improved since then (notably, for instance in the excavations at Carthage ${ }^{200}$ or in relation to underwater investigations, such as the Yassi Ada shipwreck), ${ }^{201}$ it 
cannot be said to be uniform, and would therefore lead one to be cautious in accepting too readily dates from the Mediterranean milieu being directly transferred to the western or northern British or Irish situation.

Further, it should be noted that the seventy-five-year 'window' was based upon the dating of the fine tablewares, rather than the amphorae, which it was admitted are difficult to date closely. ${ }^{202}$ Additionally, it is difficult to readily interpret the archaeological reflection of historical events, such as the impact of attacks by Vandal pirates in the western Mediterranean. Some have contended that they may have inhibited the initial contacts to western Britain (although there may have been earlier imports to the south east), while other commentators have asserted that the Vandal invasions and control of the western Mediterranean in the midfifth century did not seem to have affected trade as catastrophically as the later Arab conquest. ${ }^{203}$

This 'tight' chronology for the imports has recently been reasserted by Ewan Campbell and Christopher Bowles, and they suggest that the start of the phase of early medieval imports to the south west of Britain may well be in the decades from $c A D 475$ onwards. They have further proposed a 'North-Eastern Mediterranean package' of wares - comprising PRSW, and amphorae of types LR1 (Bii), LR2 (Bi) and LR3 (Biv) - imported during the period $c$ AD 475-525, which was then probably replaced by a package of wares from Tunisia (AD 525-50) which included, among other types, ARSW. ${ }^{204}$ However, back at Tintagel, it is worth reiterating that the excavations on the Lower Terrace of Site C (see Chapter 2) produced several phases of structural evidence. Here, while the second structural phase exhibits Romano-British 'native' and imported wares together and spans cal AD 415-535, the third (for the latest and best-surviving structure with a large assemblage of imported pottery) dates to cal $\mathrm{AD}$ 560-670. This is clearly in contrast with Campbell and Bowles' window of some seventy-five years (AD 475-550) for the import activity. Although the later date range given by the recent radiocarbon dating from archaeological deposits on Site C, Lower Terrace at Tintagel (and, at the other end, the earlier date range) would not necessarily challenge and directly amend their view, based upon essentially typological considerations in the Mediterranean region, it does raise questions about the basis for accepting such a very narrow chronological 'window' for this activity on the prime site in the British Isles and Ireland.
It has been noted above that the number of surviving imported ceramic fragments at Tintagel is the greatest concentration in Britain and Ireland, ${ }^{205}$ and indeed the total is apparently larger than that from all other contemporary sites elsewhere in western Britain and Ireland combined. ${ }^{206}$ Even in 1981 the material from south-western Britain, the 'Severn Sea' and the south Wales region accounted for nearly 65 per cent of the total material studied then, ${ }^{207}$ and there is no reason to think that this percentage will have gone down - in fact the reverse is likely. Nevertheless, the number of actual ceramic vessels represented is not huge, even if Thorpe's estimate above is seen as too conservative, and something between his and Alcock's figures is accepted. It could conceivably still equate to a relatively small number of cargoes in total. As Bowman has pointed out:

Even at Tintagel, where extensive excavation over fifty years has probably produced sherds in the region of one to two hundred vessels ... the number falls far short of a typical Mediterranean cargo of Byzantine amphorae. Wreck A at Yassi Ada, for example, produced eight hundred to nine hundred amphorae. ${ }^{208}$

However, both she and Campbell urge caution in this respect, referring to arguments in favour of the amphorae being a minor component or space-filler. ${ }^{209}$

While it has to be assumed that what survives is only part of the evidence available from the site as a whole (and that is one of the factors in Alcock and Alcock's analysis), when a chronological perspective is added even assuming Campbell's conservative seventy-fiveyear duration - the numbers are relatively small in overall terms and could perhaps be indicative of only partial cargoes being delivered to Tintagel. If this is indeed the case, the idea of Tintagel being a distribution centre becomes much less likely. An alternative scenario might then be of supply to an individual ruler - albeit possibly a Dumnonian 'over king', as Ken Dark would suggest ${ }^{210}$ - and retinue with his settlement area ${ }^{211}$ and/or trading voyages supplying several different rulers and/or locations.

A further issue arises with the longer date range from radiocarbon dating for the later structure on the Lower Terrace, and therefore a strong likelihood that seventh-century activity is represented. Within this time-frame, it may well be possible that there was continued importation of early medieval vessels to the 
site, albeit in small quantities. The recovery of fifty-seven sherds (predominantly of type Bi or LR2 and only two possible ARSW sherds) from the floor level and subsequent collapse phase is significant in terms of the implication of probable occupation continuing well into the seventh century. Unfortunately, it does not really supply sufficient evidence to test the Campbell and Bowles chronological sequence definitively. However, the lack of E-ware from Tintagel, which originates in coastal western France, ${ }^{212}$ has been seen hitherto as a definition of the site's demise prior to the seventh century. Further, Campbell has noted above that, if the site was occupied at that stage, it is indeed unexpected that there is a dearth of both white-trailed glass and, more particularly, E-ware on the site (Chapter 10). With an import horizon now dated to the period of the midsixth to seventh centuries for E-ware, ${ }^{213}$ there ought to have been an overlap between at least the last phase of the Site C Lower Terrace settlement and the arrival of Eware in the British Isles.

Although the reasons for the lack of this E-ware material here will require further analysis, Campbell and Bowles have raised the issue as they feel that it reflects an apparent sudden end to trade with western Britain in the mid-sixth century, which it is then necessary to explain. Consequentially, they cite annalistic evidence indicating the advent of plague and the possible impact of it spreading in the 540 s and 550 s at the ports of entry of Byzantine imports. They even suggest that: 'The greatest effects would have been felt at the ports of entry of the Byzantine imports. Thus it may have been that the Byzantine merchants killed off their clients, especially the nobility at sites such as Tintagel.'214 However, to support such an argument, there needs to be a precise dating of items of glass and ceramics (such as to enable a distinction to be made within a few decades) to militate against such issues as 'residuality', and indeed 'the life cycle of the artefact', ${ }^{215}$ and its assertion does not adequately address the issue of time-lag between place(s) of manufacture and place(s) of importation and usage. An alternative scenario could be that, if vessels were headed more for Ireland and western areas of northern Britain (now Scotland), the routeway for Eware from that region of France need not have required a stop at Tintagel. For the moment, we feel that the often uneasy alliance between scientific dating and typology may not yet be universally accepted for this period as a whole, and that the implication of the radiocarbon results from these excavations has to be given more serious consideration in the context of typological analyses and discussions.

\section{TINTAGEL IN THE LATER MEDIEVAL PERIOD}

AND ITS CONTACTS

After the seventh century Tintagel Island appears to be largely, if not completely, unoccupied, and only occasional stray finds have been from made from Period IIIA. However, by Period IIIB here - as at the parish church site - we find (as noted above) ceramic evidence that points to some degree of occupation, which testifies to links with east Devon or Somerset before the Castle was built in the thirteenth century. Later pottery evidence from Period IV, the period of the construction and occupation of the later medieval Castle, further emphasizes the regional aspect of the connections, with substantial amounts of pottery from Cornwall, Devon and other points eastwards as far as Dorset and Bristol, the great mercantile centre of the south west of Britain in the later Middle Ages. A single sherd of Saintonge ware joins previous finds of this French polychrome import and other foreign pottery collected by Radford's men, for instance Aardenburg-type ware, a Flemish import. $^{216}$

While the Castle structure at Tintagel may be regarded with some scepticism as functional (in terms of its defensive elements), nevertheless it appears to have had occupation, and contacts with both its hinterland and the wider south-western region, throughout the period up to the sixteenth century. Even if it was 'an elaborate, ambitious and largely pointless castle,' ${ }^{217}$ however, there is no question that now it had become essentially a regional centre of Duchy power, looking back to its apparently glorious past, and with only regional links instead of the international.

As time went on in Period V, of course, it appears to have reverted to being of only local importance, although industrial working of the slate quarries in the nineteenth century, but in some cases going back much earlier to the fifteenth or even thirteenth century, linked it to the wider region. ${ }^{218}$ We must not forget also that, until the arrival of the railways, Cornwall largely depended upon the sea for its transport and internal communications. ${ }^{219}$ It has only attained international significance again in the past 150 years or so, through the rekindling of interest in the Arthurian romances by Victorian literary and antiquarian figures, fuelling dubious Arthurian claims that have since been exploited to the full in the modern village of Tintagel. ${ }^{220}$ The 
wider world still comes to Tintagel to seek a glimpse of that glorious past and in search of the 'once and future king.

\section{CONCLUSION: WHAT WAS TINTAGEL?}

The status and importance of Tintagel, locally and to the wider world, fluctuated during the different periods of its history. In the Roman period (Period I) it may have had a particular role in relation to the exploitation and transport of tin, reflected perhaps in the enigmatic and fragmentary inscribed stone, with letters putatively referring to the Emperor Honorius, and by the late Roman ceramic material recovered from different areas of the site. There is, however, as yet no direct evidence in terms of structures or distinctively late Roman deposits.

The settlement of Tintagel was clearly at its height in the post-Roman period (Period II). However, after that it appears to have gone into what has been described above as a 'stagnation' phase, with very little direct evidence from Tintagel Island in the pre-Conquest phase of Thomas's Period III (IIIA). However, both before and after the Norman Conquest there is evidence for activity in the vicinity of the parish church of St Materiana on the headland opposite the Island, and there now is little doubt that a dense medieval settlement pattern developed here. ${ }^{221}$ There is only a muted reflection on the Island, seen in both the construction of the 'Island Chapel' and the recovery of Chert-tempered pottery. This was rarely in an undisturbed context, however, and may simply reflect as Cathy Freeman is inclined to suggest - material brought by the builders of the Castle in the thirteenth century.

During Period IV the site regained some of its status when the Castle was constructed and maintained by the rulers of Cornwall. Even if arguably only a 'folly', it would have kept the site in the consciousness of both nobility and ordinary people of the Duchy, if not reminding them of its 'royal' status in Period II. ${ }^{222}$ Thereafter, in Period V (another 'stagnation' phase) the site became a ruin, and only really came back into focus in the Victorian era onwards with the 'Arthurian' connections. Otherwise, there was simply the industrial slate-quarrying activity being engaged in on the cliffs nearby, and the use of the Haven as a port for export of the materials, with the local population engaged in this alongside the more conventional agricultural activity of the immediate area, and servicing the increasing tourist industry that grew up.

However, almost all of this is as a long coda to the position and status of the site in Period II, the centuries immediately after the Roman era. For long regarded as the archetypical early medieval monastic site, it was related to sites elsewhere in Britain and Ireland (eg Gateholm and the Brough of Deerness), ${ }^{223}$ although these are themselves subject to revision now, ${ }^{224}$ and the imported pottery had clearly, from the period of its first recognition, ${ }^{225}$ related the site to the erstwhile world of the Roman Empire. Now, it is scarcely possible for discussion of contemporary major sites in Britain, or of new discoveries in this period, to proceed without reference to either the site itself or the pottery from it. 226

Discussion of the site's status is inseparable from the consideration of the implications of the rich material arriving here, and its comparison with others of the period. Pre-eminent amongst this material is the imported pottery, and it is recognized by all concerned with this period that there is a disproportionate amount present at Tintagel compared to all others in Britain and Ireland. It is not surprising therefore that there should have been suggestions that Tintagel was an 'emporium' and the primary point of entry for this material in western Britain, with subsequent redistribution elsewhere, perhaps via individual 'voyages' up the socalled 'Severn sea' or further afield. ${ }^{227}$ Even if more recent work for the south west of Britain has begun to emphasize material from what appears to be a similarly important site at Bantham on the south coast of Devon, ${ }^{228}$ so that Tintagel might be one of a small number of 'gateways' into Britain and Ireland, nevertheless its important position is still undisputed.

In part Tintagel's perceived special position as an archaeological monument relates to the scale of the site as a whole. It is clear that in the post-Roman period, the overall settlement covered a huge area. As noted above, the Great Ditch defines the extent of the occupied site, with no obvious activity outside the Great Ditch, or between it and the churchyard area excavated in 1990 and 1991. This enclosed area covered not only the headland or Island (itself around 27 acres or 11 hectares), but also the narrow neck of land adjoining it, and the immediate environs of the later medieval Upper and Lower Castle Wards (an additional 2.5 acres or 1 hectare). Indeed, the area covered is larger than that of any other site from the same period, including the 
inland fort of Cadbury Castle, where the re-fortification in the post-Roman period encloses some 18 acres [7.3ha].

As Tintagel stands out in the sheer scale of both the area enclosed and the importation of material to the site from the Mediterranean area, and because it is now no longer interpreted as monastic, it would seem to require an alternative 'special explanation'. The comparable sites of 'enclosed places' are Cadbury Castle and the next largest, Cadbury Congresbury, ${ }^{229}$ together possibly with Alt Clut, Castle Rock, Dumbarton. ${ }^{230}$ These are the largest of the whole group, which are 'stone-walled, embanked, or palisaded - set frequently on hill-tops, promontories or cliff-edges', and arguably to be seen as 'the seats of potentates of varied rank, power and wealth,',231 with these very large sites (and their resident potentates) at the top of the social ranking. Henrietta Quinnell has suggested that, from places like Tintagel: 'high value artefacts may have spread, perhaps highlighting archaeologically the area under the control of, or with some obligation to, the community or individual living at Tintagel'. She has also usefully emphasized that there may have been a 'structured system of settlements with Tintagel at the top', and Rounds like Trethurgy as a representative middle social tier. ${ }^{232}$

However, if we are to interpret Tintagel as a major high-status enclosed post-Roman citadel along the lines of these contemporary sites, ${ }^{233}$ then it is appropriate to remind ourselves that there is not necessarily uniformity within them, as far as structures go. Within the apparently 'core' areas excavated at those sites, there were clearly subsidiary buildings with fewer of the obviously high-status artefacts present than in the area of the 'halls. ${ }^{234}$ There was also a smaller subsidiary building and several apparently external hearths at the smaller site of Dinas Powys, ${ }^{235}$ still considered to be a significant post-Roman high-status site in south Wales. ${ }^{236}$ This may well also have been the case at the 'aristocratic' site of Hen Gastell, where, despite extensive quarrying which has removed much of the site, there were fragmentary remains of different structural features and elements. ${ }^{237}$

We have suggested that some of the more fugitive Period II structures at Tintagel were only seasonally occupied, and that not all of the hundred or more buildings which have been recognized by survey on the site may have been coeval. Charles Thomas has also suggested 'zoning' of the site with different activities in different areas and presumably inhabitants of different status. ${ }^{238}$ Nevertheless, overall Tintagel is a remarkable site. Even though all these sites are obviously high status, with artefacts such as glass, metalwork and even, in some cases, coins, Tintagel Site $\mathrm{C}$ alone has produced more fifth- to seventh-century pottery than all of the others put together, yet in the areas excavated of Site C, there were no obviously major, high-status buildings - indeed it has been suggested that some of them may have been storehouses for amphorae (see above). It will be up to future investigations to determine if the suggestion of Ken Dark that Site A is likely to be the location of 'a royal residence or hall' is reasonable..$^{239}$

Most recent discussions of these comparable sites tend to place Tintagel in a key position in relation to both social organization and economic activity. Alcock, for instance, in his discussion of high-status sites relative to Cadbury Castle attributes a primacy to Tintagel, ${ }^{240}$ and this is even extended to his broader discussion of contemporary 'export and trade' in northern Britain. ${ }^{241}$ There can be little doubt that the tenor of Rahtz et al's consideration of the wider context of Cadbury Congresbury also implies a special position for the Cornish site, including contact by sea. ${ }^{242}$ Similarly, the discussion of Alt Clut, Castle Rock, Dumbarton, explicitly related early harbour sites and trade with naturally and artificially defended royal centres, with which Alcock identified it along with Dunollie and Dunadd $^{243}$ in northern Britain. Tintagel was - 'by implication' - another such site, referenced to Oliver Padel's short discussion of the site in the early medieval period. ${ }^{244}$

Turning to contemporary documentation for 'enclosed settlements' of these potentates, the term civitas is the term which appears to encapsulate their status most appropriately at this period, ${ }^{245}$ although, of course, Tintagel's own documentary history is lamentably absent for this period. This would then be a south-western British equivalent of the Northumbrian and northern British civitates at Bamburgh and Alt Clut (Castle Rock, Dumbarton), recorded by writers such as Bede and Eddius Stephanus. ${ }^{246}$ In the social context of post-Roman Britain, while acknowledging the inadequacy of attested terminology, it would nevertheless seem perverse not to accord sites such as Tintagel and Cadbury Castle 'royal' status (or 'princely' or 'magnate', depending upon the relationship of the relevant potentate with any other in the region), ${ }^{247}$ with a descending hierarchy of other highstatus sites, individually sometimes identified as an urbs or villa regis, and therefore meriting the term 'royal' and then 'aristocratic' establishments, largely unidentified in 
the documentary record, but identified archaeologically at smaller sites such as Dinas Powys ${ }^{248}$ and Hen Gastell, ${ }^{249}$ not to mention undefended sites such as Longbury Bank. $^{250}$

Whether or not the 'royal' label can be attached in strict historical terms to Tintagel, without doubt it (like the Cadbury sites) is of very 'high status' in western Britain in the post-Roman period. ${ }^{251}$ Archaeologically, the site is at the top of the social hierarchy in this period, and so it is difficult to envisage Tintagel as anything other than a site of the Dumnonian rulers. It was an enclosed settlement on a hilltop promontory, from which control could be maintained of passing shipping, and indeed of maritime-based trading activities, whether local, regional or long-range. However, this is not to imply year-round residency by the Dumnonian ruler. It is likely to have been one of a few such centres, comparable with the villae regales mentioned by Bede in relation to early Northumbria. At times when the ruler was not present, a 'care-taking' group must have still been in residence particularly if they were involved in oversight of any sort of exchange activity. Susan Pearce elaborates on the seasonal aspect: ' $\ldots$. this suggests that Tintagel was visited occasionally. This offers the attractive proposition that it functioned as the summer meeting place at which the local ruler met lesser men, transacted business and fostered the important personal relationships upon which, in part, his power depended. ${ }^{252}$

Tintagel has been recognized for many years by archaeologists and others as a special, if not unique, site, and there is no doubt that it is this quality that has led to its association in the popular imagination with that quintessential representative of the heroic and mythical British past: 'King Arthur'.

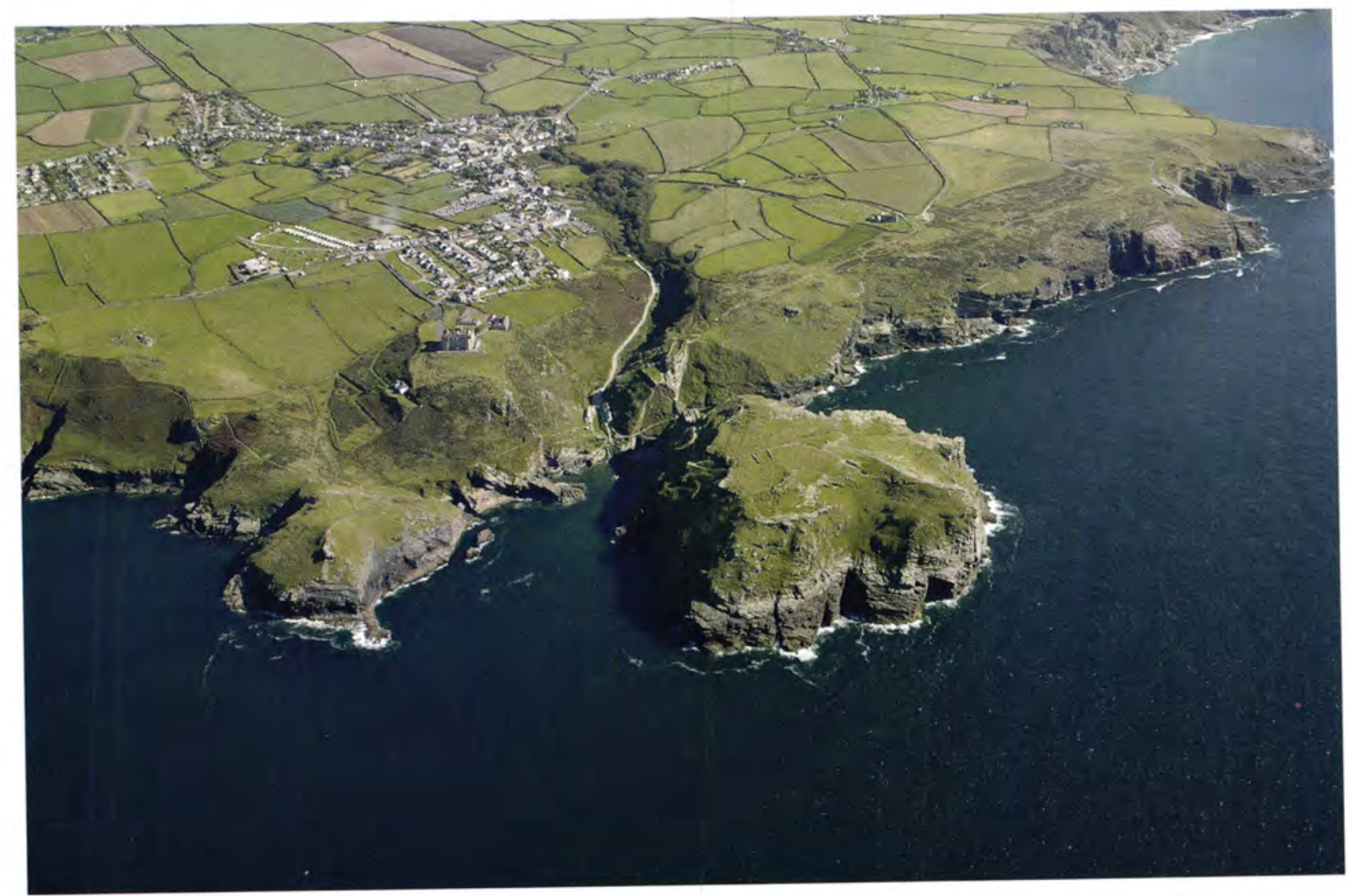

146 Aerial photograph of the local context for Tintagel Castle, showing the Haven, Barras Nose, Tintagel Village, St Materiana's Church and field systems (taken 31 August 2004). Copyright: Cornwall County Council (HER F66-015) 


\section{Appendix 1}

\section{Chemical Compositions}

\begin{tabular}{|c|c|c|c|c|c|c|c|c|c|c|c|c|c|c|c|c|}
\hline Sample & Type & $l_{2} \mathrm{O}_{3}$ & $\mathrm{Fe}_{2} \mathrm{O}_{3}$ & $\mathrm{MgO}$ & $\mathrm{CaO}$ & $\mathrm{Na}_{2} \mathrm{O}$ & $\mathrm{K}_{2} \mathrm{O}$ & $\mathrm{TiO}_{2}$ & $\mathrm{P}_{2} \mathrm{O}_{5}$ & $\mathrm{MnO}$ & $B a$ & Co & $\mathrm{Cr}$ & $\mathrm{Cu}$ & $L i$ & $\mathrm{Ni}$ \\
\hline ס & 2 & 16.8 & 9.2 & 4.00 & 0.2 & 1.03 & 1.99 & 0.85 & 1.87 & 2 & . & 26 & 314 & 39 & 56 & 298 \\
\hline 1751 & 2 & 18.5 & 7.3 & 2.74 & 7.5 & 0.4 & 1.67 & 0.81 & 2.83 & & - & 17 & & 49 & 44 & 57 \\
\hline 1777 & 1 & 21.2 & 8.48 & 3.17 & 5.41 & 0.24 & 2.28 & 0.84 & 2.27 & 0.2 & & 30 & 221 & 45 & 35 & 271 \\
\hline 2000 & 2 & 14.7 & 5.93 & 1.97 & 4.04 & 0.71 & 1.85 & 0.55 & 3.82 & & & 12 & 00 & 4 & 31 & 39 \\
\hline 30 & 1 & 15.1 & 6.29 & 1.46 & 0.63 & 0.64 & 2.2 & 0.74 & 3.01 & 0.12 & 0.9 & 13 & 104 & 35 & 43 & 50 \\
\hline 2290 & 1 & 20.4 & 8.43 & 3.21 & 4.78 & 0.34 & 2.52 & 0.81 & 2.64 & $0 ?$ & & 27 & 220 & 50 & 38 & 281 \\
\hline 616 & 5 & 13.3 & 5.93 & 1.85 & .35 & 0.53 & 1.78 & 0.47 & 3.23 & & & 10 & & 2 & 5 & 37 \\
\hline 2618 & 5 & 16.4 & 6.49 & 1.77 & 5.54 & 0.82 & 2.15 & 0.77 & 2.33 & 0. & & 14 & 109 & 35 & 28 & 42 \\
\hline 8 & 5 & 15.1 & 6.2 & 2.49 & 4.87 & 0.6 & 2.38 & 0.73 & 1.98 & & & 12 & 109 & & 42 & 43 \\
\hline 2654 & B & 15.2 & 6.6 & 2.88 & 3.89 & 0.47 & 1.9 & 0.77 & 2.57 & & & 13 & 112 & 6 & 41 & 50 \\
\hline 2914 & 5 & 16.1 & 6.19 & 1.94 & 3.68 & 0.93 & 2.26 & 0.74 & 1.51 & & & 15 & 91 & 0 & 36 & 46 \\
\hline 126 & 5 & 20.9 & 8.57 & 3.38 & 5.88 & 0.4 & 2.67 & 0.85 & 2.44 & & & 20 & 41 & 35 & 40 & 266 \\
\hline & B & 16.5 & 6.8 & 1.76 & 5.78 & 0.8 & 2.38 & 0.79 & 2.45 & 0 & & 15 & 108 & 101 & 36 & 45 \\
\hline 3519 & 1 & 20.7 & 10.54 & 2.14 & 0.45 & 0.29 & 2.48 & 0.94 & 3.35 & & & 34 & 339 & 2 & 44 & 404 \\
\hline 89 & 1 & 14 & & 1.38 & 4.2 & 1.06 & 2.19 & 0.7 & 2. & & & 3 & & & 14 & 36 \\
\hline 3591 & 5 & 15.8 & 6.13 & 2.2 & 3. & 0.5 & 1.97 & 0.8 & 3.32 & 0. & & 13 & 103 & 9 & 30 & 43 \\
\hline $3 t$ & 2 & 16.7 & 6.75 & 2.35 & 4 & 0.7 & 2.02 & 0.84 & 2.66 & & . & & & & 37 & 48 \\
\hline 3663 & 2 & 21.7 & 8.7 & 1.44 & 0.41 & 0.84 & 3.04 & 0.48 & 2.41 & 0 . & 46 & 17 & 19 & 1 & 37 & 54 \\
\hline 3667 & 5 & 14.6 & 6.08 & 2.03 & 4.8 & 0.56 & 1.69 & 0.73 & 4.36 & & & 14 & 4 & 4 & 38 & 41 \\
\hline 3680 & 5 & 15 & 6.26 & 27 & 6.96 & 0.6 & 1.83 & 0.68 & 3 & 0 . & & 3 & 0 & & 0 & 39 \\
\hline 3683 & 1 & 20 & 8.16 & 2 & 4.24 & 0.4 & 2.55 & 0.83 & 3.18 & & & 26 & 215 & 46 & 32 & 254 \\
\hline 3689 & 5 & 15. & 6.39 & & 5.44 & 0.5 & 2.45 & 0.71 & 2.67 & & & 12 & & 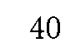 & 16 & 41 \\
\hline 3720 & 5 & 16.3 & 6.56 & 2.38 & 4.85 & 0.61 & 2.18 & 0.81 & 2.71 & 0 & .3 & 14 & 107 & 39 & 31 & 44 \\
\hline 3721 & 1 & & & 0.9 & 0.23 & 0.3 & 3.06 & 0.65 & 0.35 & & & 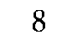 & & & 36 & 24 \\
\hline 3744 & 2 & 17.5 & & & & & & 0.82 & & & & 1 & 59 & 105 & 76 & 35 \\
\hline 3816 & 1 & 23 & 9.85 & 2.32 & 0.45 & 0.28 & 3.02 & 0.93 & 4.08 & 0 & & 33 & 250 & 92 & 48 & 335 \\
\hline 3861 & 1 & 17.9 & 7.09 & 1.66 & 0.44 & 0.59 & 2.76 & 0.86 & 2.84 & & .7 & 21 & 129 & 0 & 48 & 71 \\
\hline 3875 & 5 & 13.7 & 5.48 & 2.76 & 7.65 & 0.88 & 2.48 & 0.68 & 1.29 & 0. & 373.5 & 12 & 94 & 2 & 46 & 37 \\
\hline 3876 & 5 & 15.8 & 6.93 & 2.4 & 4.25 & 0.5 & 2.22 & 0.82 & 3.03 & 0. & & 14 & 123 & 9 & 41 & 43 \\
\hline 3962 & 2 & 18.8 & 9.76 & 5.6 & 5.64 & & 1.88 & 0.93 & 5.83 & & & 31 & 240 & 4 & 46 & 303 \\
\hline 3977 & 1 & 20.5 & 7.66 & 1.16 & 0.24 & 0.29 & 3.66 & 0.66 & 0.4 & 0.02 & 3.2 & 11 & 69 & 24 & 31 & 32 \\
\hline 6021 & 5 & 13.4 & 5.63 & 2.16 & 4.02 & 0.57 & 1.81 & 0.67 & 2.14 & 0.12 & 325.8 & 13 & 97 & 31 & 24 & 43 \\
\hline 6030 & 1 & 19.9 & 8.17 & 3.24 & 6.27 & 0.5 & 2.98 & 0.82 & 2.66 & 0. & 640.8 & 27 & 245 & 36 & 47 & 268 \\
\hline 6037 & 1 & 13.2 & 5.2 & 1.75 & 3.56 & 0.49 & 1.63 & 0.64 & 2.9 & 0.21 & 365.4 & 14 & 80 & 32 & 21 & 42 \\
\hline 6038 & 1 & 20.6 & 8.22 & 3.02 & 6.22 & 0.47 & 2.89 & 0.83 & 2.88 & 0. & 677.7 & 27 & 216 & 50 & 42 & 255 \\
\hline 6072 & 5 & 14.2 & 5.81 & 2.07 & 4.22 & 0.55 & 1.92 & 0.68 & 2.48 & 0.13 & 319.5 & 14 & 97 & 45 & 35 & 42 \\
\hline 6081 & 1 & 18.8 & 9.43 & 2.53 & 8.66 & 0.17 & 1.26 & 0.86 & 4.82 & 0.24 & 332.1 & 35 & 289 & 55 & 31 & 320 \\
\hline 6079 & 5 & 16.1 & 6.36 & 1.33 & 0.47 & 0.7 & 2.57 & 0.76 & 3.44 & 0.12 & 441 & 13 & 95 & 62 & 41 & 55 \\
\hline
\end{tabular}




\begin{tabular}{|c|c|c|c|c|c|c|c|c|c|c|c|c|c|c|c|c|}
\hline Sample & Type B & $S c$ & $S r$ & $V$ & $Y$ & $Z n$ & $Z r$ & $L a$ & $\mathrm{Ce}$ & $N d$ & $S m$ & $E u$ & $D y$ & $Y b$ & $P b$ & $R b$ \\
\hline 1738 & 2 & 24 & 128 & 115 & 26 & 307 & 88 & 33 & 64 & 35 & 7.1 & 1.7 & 4.8 & 2.5 & - & 67 \\
\hline 1751 & 2 & 18 & 223 & 86 & 33 & 209 & 91 & 68 & 101 & 65 & 11.5 & 2.3 & 6.3 & 2.6 & - & 45 \\
\hline 1777 & 1 & 22 & 206 & 102 & 37 & 311 & 94 & 73 & 119 & 60 & 13.1 & 2.5 & 6.5 & 3 & 35 & 105 \\
\hline 2000 & 2 & 15 & 246 & 63 & 31 & 250 & 53 & 88 & 87 & 71 & 14.5 & 2.4 & 6 & 2.4 & 16 & 64 \\
\hline 2130 & 1 & 15 & 113 & 83 & 32 & 299 & 61 & 84 & 105 & 77 & 14.3 & 2.6 & 6 & 2.6 & 13 & 89 \\
\hline 2290 & 1 & 20 & 183 & 94 & 34 & 558 & 96 & 73 & 109 & 65 & 12.9 & 2.5 & 6.1 & 2.8 & 29 & 114 \\
\hline 2616 & 5 & 13 & 225 & 55 & 33 & 287 & 51 & 101 & 76 & 86 & 16 & 2.9 & 5.9 & 2.4 & 13 & 65 \\
\hline 2618 & 5 & 16 & 263 & 93 & 23 & 126 & 53 & 59 & 75 & 53 & 10 & 1.9 & 4.2 & 1.9 & 47 & 85 \\
\hline 2648 & 5 & 15 & 226 & 99 & 26 & 258 & 64 & 58 & 76 & 56 & 9.4 & 1.8 & 4.5 & 2.1 & 13 & 100 \\
\hline 2654 & B & 16 & 157 & 94 & 29 & 503 & 63 & 74 & 85 & 68 & 13.4 & 2.4 & 5.5 & 2.4 & 16 & 71 \\
\hline 2914 & 5 & 15 & 179 & 91 & 25 & 254 & 57 & 56 & 84 & 52 & 9.6 & 1.6 & 4.8 & 2 & 31 & 96 \\
\hline 3426 & 5 & 21 & 144 & 107 & 52 & 212 & 114 & 73 & 124 & 64 & 12.9 & 2.3 & 7.4 & 4.1 & 35 & 163 \\
\hline 3457 & B & 16 & 314 & 84 & 25 & 136 & 54 & 69 & 80 & 57 & 11.7 & 2.2 & 4.9 & 2.2 & 58 & 102 \\
\hline 3519 & 1 & 25 & 85 & 105 & 24 & 297 & 102 & 45 & 102 & 45 & 10.4 & 2 & 5.4 & 2.8 & 32 & 101 \\
\hline 3589 & 1 & 15 & 216 & 82 & 19 & 94 & 44 & 53 & 76 & 46 & 9 & 1.7 & 3.7 & 1.7 & 21 & 90 \\
\hline 3591 & 5 & 16 & 130 & 74 & 29 & 213 & 69 & 77 & 94 & 68 & 12.7 & 2.4 & 5.5 & 2.3 & 14 & 73 \\
\hline 3650 & 2 & 16 & 163 & 94 & 30 & 282 & 88 & 60 & 91 & 60 & 10.4 & 5.2 & 5.2 & 2.4 & - & 64 \\
\hline 3663 & 2 & 22 & 304 & 136 & 32 & 123 & 38 & 62 & 100 & 56 & 11.2 & 2.3 & 6.1 & 3 & 15 & 144 \\
\hline 3667 & 5 & 15 & 289 & 84 & 27 & 360 & 64 & 65 & 79 & 54 & 11.2 & 2.1 & 5.1 & 2.2 & 13 & 60 \\
\hline 3680 & 5 & 15 & 264 & 79 & 29 & 164 & 77 & 65 & 80 & 58 & 11 & 2.1 & 5.3 & 2.5 & 10 & 84 \\
\hline 3683 & 1 & 19 & 208 & 86 & 33 & 290 & 125 & 87 & 128 & 63 & 14.3 & 2.5 & 6.5 & 2.9 & 35 & 116 \\
\hline 3689 & 5 & 16 & 222 & 103 & 27 & 193 & 66 & 63 & 84 & 56 & 11 & 2.1 & 5.2 & 2.3 & 13 & 109 \\
\hline 3720 & 5 & 16 & 197 & 92 & 25 & 216 & 64 & 56 & 84 & 49 & 11 & 1.9 & 4.8 & 2.1 & 19 & 85 \\
\hline 3721 & 1 & 15 & 80 & 83 & 14 & 75 & 54 & 41 & 64 & 37 & 7.9 & 1.6 & 3 & 1.4 & 21 & 247 \\
\hline 3744 & 2 & 26 & 163 & 115 & 27 & 980 & 68 & 53 & 60 & 32 & 9.8 & 2.2 & 5.2 & 2.7 & 18 & 129 \\
\hline 3816 & 1 & 24 & 131 & 92 & 41 & 446 & 124 & 109 & 136 & 86 & 18.8 & 3.3 & 8.1 & 3.8 & 30 & 139 \\
\hline 3861 & 1 & 18 & 97 & 118 & 28 & 308 & 69 & 71 & 96 & 59 & 13.1 & 2.1 & 6.8 & 2.5 & 15 & 118 \\
\hline 3875 & 5 & 15 & 257 & 76 & 23 & 122 & 58 & 50 & 71 & 40 & 9.2 & 1.9 & 4.4 & 2 & 18 & 110 \\
\hline 3876 & 5 & 17 & 182 & 103 & 28 & 220 & 67 & 68 & 86 & 52 & 12.1 & 2.2 & 5.3 & 2.4 & 16 & 77 \\
\hline 3962 & 2 & 28 & 218 & 88 & 44 & 581 & 84 & 105 & 81 & 77 & 17.5 & 3.3 & 7.5 & 3.6 & 22 & 76 \\
\hline 3977 & 1 & 17 & 57 & 76 & 22 & 115 & 43 & 47 & 73 & 41 & 9.4 & 2.1 & 4.3 & 1.8 & 16 & 250 \\
\hline 6021 & 5 & 13 & 216 & 68 & 22 & 421 & 59 & 48 & 68 & 35 & 8.7 & 1.8 & 4.3 & 1.8 & 13 & 68 \\
\hline 6030 & 1 & 20 & 231 & 102 & 33 & 302 & 115 & 73 & 109 & 50 & 12.5 & 2.3 & 6 & 2.7 & 35 & 133 \\
\hline 6037 & 1 & 13 & 184 & 66 & 23 & 270 & 56 & 58 & 68 & 44 & 9.3 & 1.8 & 4.8 & 1.9 & 12 & 58 \\
\hline 6038 & 1 & 20 & 234 & 105 & 37 & 279 & 113 & 98 & 121 & 77 & 16.2 & 2.5 & 7 & 3 & 35 & 142 \\
\hline 6072 & 5 & 14 & 178 & 84 & 27 & 312 & 60 & 66 & 80 & 55 & 11.9 & 2.1 & 5.3 & 2.2 & 11 & 71 \\
\hline 6081 & 1 & 25 & 122 & 88 & 40 & 137 & 79 & 77 & 89 & 63 & 15.3 & 2.9 & 8.3 & 3.1 & 13 & 54 \\
\hline 6079 & 5 & 16 & 108 & 79 & 29 & 324 & 69 & 78 & 78 & 66 & 13.1 & 2.6 & 5.7 & 2.6 & 25 & 103 \\
\hline
\end{tabular}




\section{Appendix 2}

\section{The Chemical Composition Characteristics of THE REFERENCE MATERIAL}

Mean (per cent for the oxides; ppm for the remaining elements) and standard deviation of the reference groups. Technique and number of samples are given in brackets

\begin{tabular}{|c|c|c|c|c|c|c|c|c|c|c|c|c|c|c|}
\hline Site group & $\mathrm{Al}_{2} \mathrm{O}_{3}$ & $\mathrm{Fe}_{2} \mathrm{O}_{3}$ & $\mathrm{MgO}$ & $\mathrm{CaO}$ & $\mathrm{Na}_{2} \mathrm{O}$ & $\mathrm{K}_{2} \mathrm{O}$ & $\mathrm{TiO}_{2}$ & $\mathrm{P}_{2} \mathrm{O}_{5}$ & $\mathrm{MnO}$ & $B a$ & Co & $\mathrm{Cr}$ & $\mathrm{Cu}$ & $L i$ \\
\hline Chios (ICP; 12) & 14.3 & 6.8 & 4.7 & 8.4 & 1.36 & 1.85 & 0.67 & 0.18 & 0.135 & 490 & 27 & 2905 & 53 & 41 \\
\hline sd & 2.3 & 0.6 & 1.3 & 3.2 & 0.28 & 0.74 & 0.09 & 0.06 & 0.04 & 110 & 7 & 82 & 9 & 10 \\
\hline Cyprus (NAA; 29) & - & 7 & - & 22.7 & 0.97 & 1.06 & 0.59 & - & 0.156 & 312 & 28 & 1355 & - & - \\
\hline sd & & 1.4 & & 3.9 & 0.41 & 0.15 & 0.16 & & 0.03 & 146 & 4.7 & 1081 & & \\
\hline Ganos (ICP; 20) & 16.6 & 6.8 & 4.5 & 7 & 1.92 & 3.05 & 0.75 & 0.18 & 0.12 & 473 & 32 & 2254 & 40 & 61 \\
\hline sd & 1 & 0.5 & 0.4 & 1.2 & 0.19 & 0.17 & 0.05 & 0.01 & 0.01 & 33 & 14 & 21 & & 37 \\
\hline Istria (XRF; 10) & 11.8 & 4.4 & 3.3 & 10.7 & & 2.2 & & & 0.085 & & & & & \\
\hline sd & 0.4 & 0.14 & 0.6 & 2 & & 0.21 & & & 0.006 & & & & & \\
\hline Keratokambos $1(\mathrm{NAA} ; 5)$ & - & 7.4 & - & - & 1.5 & - & - & - & - & - & 33 & 440 & - & - \\
\hline sd & & 0.73 & & & 0.36 & & & & & & 3 & 41 & & \\
\hline Kounoupi (ICP; 20) & 10.1 & 5.1 & 2.7 & 22.1 & 0.9 & 1.39 & 0.48 & 0.16 & 0.139 & 274 & 33 & 2424 & 45 & 32 \\
\hline sd & 1.2 & 0.6 & 0.6 & 3 & 0.2 & 0.46 & 0.07 & 0.02 & 0.019 & 54 & 7 & 58 & 6 & 6 \\
\hline El Maklouba (NAA; 23) & 13.2 & 5.15 & - & 9.02 & 0.42 & 2.51 & - & - & 0.028 & - & 14 & 100 & - & - \\
\hline sd & 1.23 & 0.31 & & 1.71 & 0.14 & 0.28 & & & 0.002 & & 1.4 & 9 & & \\
\hline La Mesquida (XRF; 6) & 14.5 & 5.3 & 2.3 & 8.8 & 0.99 & 2.88 & 0.74 & 0.44 & 0.068 & 0.04 & - & 1092 & 26 & - \\
\hline sd & 1.6 & 0.6 & 0.2 & 2.8 & 0.25 & 0.21 & 0.1 & 0.13 & 0.017 & 0.005 & & 13 & 4 & \\
\hline El Mokaida (NAA; 19) & 12.9 & 5.1 & & 12.9 & 0.42 & 2.3 & 0.7 & & 0.029 & & 14 & 94 & & \\
\hline sd & 0.9 & 0.36 & & 2.4 & 0.07 & 0.36 & 0.05 & & 0.003 & & 1.8 & 9.4 & & \\
\hline Oudhna (XRF; 15) & 16.3 & 5.83 & 1.54 & 1.15 & 0.53 & 2.35 & 0.94 & 0.07 & 0.03 & 338 & - & 111 & - & - \\
\hline sd & 1.4 & 0.58 & 0.33 & 0.46 & 0.07 & 0.08 & 0.05 & 0.09 & 0.007 & 37 & & 11 & & \\
\hline \multicolumn{15}{|l|}{$\begin{array}{l}\text { Pergamon } \\
\text { (Byzantine) }\end{array}$} \\
\hline (ICP/PIXE; 57) & 16.4 & 5.8 & 2.3 & 7.7 & 1.68 & 2.9 & 0.76 & - & 0.116 & 913 & 20 & 90 & - & - \\
\hline sd & 0.58 & 0.42 & 0.41 & 1.6 & 0.17 & 0.23 & 0.06 & & 0.008 & 169 & 2 & 11 & & \\
\hline Phocaea (XRF; 29) & 18.7 & 6.2 & 1.8 & 4.8 & 0.65 & 3 & 0.92 & 0.24 & 0.042 & 345 & - & 111 & - & - \\
\hline sd & 0.7 & 0.4 & 0.2 & 1.9 & 0.15 & 0.2 & 0.04 & 0.33 & 0.011 & 47 & & 25 & & \\
\hline Seleucia (XRF; 10) & 14 & 6.1 & 2.52 & 9.9 & 1.44 & 2.21 & 0.72 & 0.22 & 0.088 & - & 15 & 1273 & 38 & 55 \\
\hline sd & 0.6 & 0.3 & 0.16 & 1.3 & 0.16 & 0.1 & 0.03 & 0.14 & 0.025 & & 2.4 & 14.8 & 89 & 4 \\
\hline
\end{tabular}


Appendix 2 Chemical Compositions of Reference Material

\begin{tabular}{|c|c|c|c|c|c|c|c|c|c|c|c|c|c|c|c|}
\hline Site group & $\mathrm{Ni}$ & $S c$ & $S r$ & $V$ & $Y$ & $Z n$ & $Z r$ & $L a$ & $\mathrm{Ce}$ & $N d$ & $S m$ & $E u$ & Dy & $Y b$ & $R b$ \\
\hline Chios (ICP; 12) & 274 & 18 & 191 & 104 & 21 & 80 & 37 & 28 & 51 & 30 & 5.7 & 1.1 & 3.3 & 2.1 & 78 \\
\hline sd & 72 & 2.4 & 31 & 15 & 3.6 & 14 & 14 & 9 & 17 & 8.7 & 1.7 & 0 & 0.62 & 0.3 & 8 \\
\hline Cyprus (NAA; 29) & 119 & 24 & 721 & - & - & 89 & 65 & 13 & 24 & 11.4 & 2.9 & 0.8 & 2.8 & - & 26 \\
\hline sd & 50 & 5 & 204 & & & 20 & 15 & 1.4 & 2.9 & 1.6 & 0.24 & 0.08 & 0.37 & & 5.4 \\
\hline Ganos (ICP; 20) & 174 & 19 & 157 & 114 & 27 & 91 & 26 & 42 & 66 & 38 & 6.2 & 1.2 & 3.75 & 1.9 & - \\
\hline $\begin{array}{l}\text { sd } \\
\text { Istria (XRF; 10) } \\
\text { sd }\end{array}$ & 17 & 1.3 & 9 & 14 & 2.5 & 13 & 9 & 2 & 3.4 & 1.6 & 0.5 & 0.06 & 0.31 & 0.22 & \\
\hline $\begin{array}{l}\text { Keratokambos 1(NAA; } 5 \\
\text { sd }\end{array}$ & & - & - & - & - & - & - & - & $\begin{array}{r}30 \\
6\end{array}$ & 78 & - & $-\overline{0.13}$ & 1.26 & - & - \\
\hline Kounoupi (ICP; 20) & 205 & 13 & 263 & 82 & 18 & 67 & 47 & 17 & 36 & 13.8 & 3.9 & 0.6 & 2.5 & 1.3 & - \\
\hline sd & 25 & 1.5 & 37 & 11 & 3 & 7 & 25 & 4 & 7 & 3.2 & 0.5 & 0.1 & 0.4 & 0.3 & \\
\hline El Maklouba (NAA; 23) & - & 13 & - & 111 & - & - & - & 38 & 74 & - & 6.3 & 1.2 & 4.3 & 1.9 & 87 \\
\hline sd & & 0.7 & & 9 & & & & 1.9 & 5.4 & & 0.4 & 0.09 & 0.32 & 0.4 & 11 \\
\hline La Mesquida (XRF; 6) & 33 & - & 260 & - & - & - & 170 & - & 67 & - & - & - & - & - & 102 \\
\hline sd & 7 & & 8 & & & & 40 & & 0 & & & & & & 0 \\
\hline El Mokaida (NAA; 19) & & 12.5 & & 102 & & & & 37 & 70 & & 6 & 1.2 & 4.2 & & 77 \\
\hline sd & & 0.8 & & 11 & & & & 2.6 & 5.4 & & 0.4 & 0.1 & 0.35 & & 9 \\
\hline Oudhna (XRF; 15) & 31 & - & 219 & 102 & - & 73 & 353 & - & - & - & - & - & - & - & 88 \\
\hline $\begin{array}{l}\text { sd } \\
\text { Pergamon } \\
\text { (Byzantine) }\end{array}$ & 4.7 & & 39 & 12 & & 13 & 28 & & & & & & & & 9 \\
\hline (ICP/PIXE; 57) & 62 & 15 & 328 & 101 & 29 & - & 174 & 42 & 84 & 38 & - & 1.4 & - & - & 127 \\
\hline sd & 21 & 1 & 30 & 15 & 8 & & 49 & 2 & 4 & 5 & & 0.1 & & & 11 \\
\hline Phocaea (XRF; 29) & 52 & - & 219 & 109 & - & 94 & 244 & 72 & 77 & - & - & - & - & - & 157 \\
\hline sd & 22 & & 60 & 24 & & 11 & 12 & 59 & 11 & & & & & & 8 \\
\hline Seleucia (XRF; 10) & 88 & 18 & 289 & 122 & 23 & 76 & 48 & 26 & 50 & 28 & 4.8 & 3.9 & 3.9 & 2.1 & 86 \\
\hline sd & 6.6 & 1.1 & 44 & 7 & 1.2 & 7.6 & 8 & 1.3 & 4.9 & 1.3 & 0.2 & 0.2 & 0.2 & 0.2 & 6.5 \\
\hline
\end{tabular}




\title{
APPENDIX 3
}

\section{Modern Material}

\author{
with EWAN N CAMPBELL
}

\section{UPPER TERRACE (Chapter 3)}

Modern finds from Phase $\mathrm{Z}$ in this area include a plastic ear-ring (RF 2418) and a Shippam's Paste jar (RF 2537), the latter perhaps reflecting localized picnic activity! The rest of the material from this phase is dominated by several sherds of imported and medieval ceramic finds.

\section{SITE C BUILDING (Chapter 6)}

A small number of modern finds were recovered from trenches $\mathrm{C} 10, \mathrm{C} 11$ and $\mathrm{C} 16$. It is presumed that all are intrusive, related to Radford or post-Radford activities. These include pieces of metal foil from Phases W, X and $Y$ as well as a single piece of modern glass (RF 1980) from C10 Phase $Y$ (probably part of the base of a fluted bowl), modern ceramic (RF 2040) from C10 and a small enamel brooch in the form of a dog (RF 1503). These are all considered to be accidental losses. The most notable find was a George VI shilling of 1951 found in the reconstructed east bench in C10 (RF 1962), which is presumed to have been a deliberate deposition by the workmen, although there is no other extant record of such consolidation work taking place specifically in that year.

\section{LITTLE DITCH (Chapter 7)}

Finds of modern provenance were recovered from Phases $Y$ and $Z$. They include thirteen sherds of bottle glass, ten sherds of window glass, 302 fragments of modern terracotta drainpipe, a sherd of black-glazed stoneware pottery and a rim sherd of white-glazed stoneware.

\section{THE GREAT DITCH (Chapter 8)}

As would be anticipated, the modern assemblage is spread over later phases in the trench. From the collapse of the Castle up to the first part of the twentieth century, one fragment of terracotta drainpipe and two sherds of green bottle glass only date to this period. However, a larger proportion of the assemblages from the fill of Radford's 1938-9 (and indeed 1955) trench and the post-1938 slump over the site are modern. Twenty-three fragments of terracotta drainpipe and nine sherds of glazed and/or transfer-printed stoneware pottery are found in these phases. From the turf and topsoil, fourteen fragments of ceramic tile, thirty-five fragments of drainpipe and three sherds of glazed pottery complete the assemblage. Little can be said about these artefacts except their confirmation of modern disturbance in the area by both Ralegh Radford's excavations and MoW maintenance in the past. Perhaps the most eloquent find in this respect is RF 4011 from the turf and topsoil. This slab of slate, some $460 \mathrm{~mm} \times 300 \mathrm{~mm}$ in size, had the name MARTIN written on the underside in bold pencil lines. Its context cannot help us confirm whether Martin was actually working on the excavations in Radford's time, or whether he was a later visitor to the site anxious to leave his mark!

The glass material from the topsoil and turf is all late twentieth-century window and bottle glass. The glass from the ditch backfill (Phases $\mathrm{X}$ and $\mathrm{W}$ ) is an earlier group, consisting of mass-produced bottles of the earlier twentieth century. These include beer, ginger-beer and milk bottles, as well as two medicine bottles. Inscriptions show drinks manufacturers in Okehampton and Launceston, and a patent date gives a terminus post quem of 1922 for the deposit.

\section{LOWER WARD (Chapter 9)}

Two modern finds were recovered from T01 ext from Radford's 1938 backfill layer 1085. They comprise a sherd of green bottle glass and a fragment of terracotta drainpipe. 



\section{Notes}

\section{CHAPTER 1}

BACKGROUND, ARCHIVES AND SURVEY WORK

1 Evans and Dunn (trans) 1963; Thorpe (trans) 1966; see also Padel 1984.

2 Thomas 1993, 24.

3 Radford 1942, 40-1.

4 Jenner 1927.

5 Radford 1935b.

6 For the former see Thorpe 1966; Ashe 1969. For the latter see Jenner 1927; Radford 1935a, 1935b and 1942. See also Radford 1962, 1968a; Radford and Swanton 1975.

7 Radford 1935b.

8 Radford 1935a and 1939.

9 Radford 1942.

10 Radford 1956; RAD 01/01 TINBOX 46, 33 b-d.

11 Radford 1962, 1968a, 1968b and 1973; Radford and Swanton 1975.

12 Thomas 1993, 53.

13 Ibid.

14 TINBOX 46, 11.

15 Thomas 1993, 53.

16 TINBOX 46, 12.

17 Radford 1942.

18 Saunders 1999.

19 TINBOX $46,21 / \mathrm{b}$.

20 Eg Thomas 1993, 55-9.

21 TINBOX 46, 58 dda letter to Bushe Fox, 23 July 1935.

22 TINBOX 46, 58 uuf.

23 TINBOX 46, 58 uue.

24 TINBOX 46, 58 uus.

25 TINBOX 46, 21/b.

26 Radford 1935a and 1935b.

27 Thomas 1993, 115.

28 Grueber and Keary 1893; Gareth Williams, pers comm; TINBOX 46, 16 ii.

29 Batey et al 1993; see figure 2 for location of Modern Hut, Site F and Steps.
30 Charles Thomas, pers comm.

31 Thomas 1993, 61-2; see also Hartgroves and Walker 1988.

32 Thomas 1993, 59 (written before the Radford archive became available).

33 Ibid, 84.

34 TINBOX 46, $16 \mathrm{cc}$ and dd; 58 uus.

35 TINBOX 46, eg $16 \mathrm{z}$ and aa.

36 Cornish Archaeology forthcoming.

37 Batey et al 1993.

38 Harry and Morris 1997.

39 Thomas 1993, 92, figure 71.

40 Charles Thomas, pers comm.

41 Radford 1956.

42 Eg Thomas 1981b, 1982, 1988b and 1990; Thomas and Thorpe 1988; Fulford 1989.

43 Eg Hayes 1972 and 1980; Peacock and Williams 1986; Williams and Carreras 1995.

44 See Thomas 1993, ch 5.

45 Burrow 1973; Dark 1985; Thomas 1981a, 1982 and 1986.

46 Padel 1981a and 1981b.

47 Thomas 1982 and 1986.

48 Thomas and Fowler 1985.

49 Dark 1985.

50 Thomas and Fowler 1985 .

51 Thomas and Thorpe 1988; O'Mahoney 1988 and 1989.

52 Thomas (ed) 1988e.

53 Thomas 1988a and 1988b.

54 Thomas 1993.

55 Batey et al 1993.

56 Thomas 1993, 102-5; Nowakowski and Thomas 1990 and 1992.

57 All trench numbers and subdivisions referred to relate to the 1990s excavations, rather than Radford's from the 1930 s.

58 Radford 1939.

59 Christopher D Morris moved to the University of Glasgow in October 1990, and so all subsequent work was carried out under the aegis of that university. 
60 To be submitted for publication in due course to Cornish Archaeology.

\section{CHAPTER 2}

EXCavations on the Lower Terrace, Site C, 1990-4

1 This chapter is a summarized version of the publication in the Antiquaries Journal 1997 (Harry and Morris 1997). Readers are referred to that publication for fuller details.

2 Morris with Emery 1991.

3 See Thomas 1988b.

4 Morris with Harry and Johnson 1993.

5 Harry et al 1994.

6 Harry and Morris (eds) 1995.

7 See Thomas and Thorpe 1988.

8 Thorpe 1997, 77-8.

9 Batey et al 1993.

10 Thorpe 1997, 82.

11 Cool 1995, 13.

12 Foy and Hochuli-Geysel 1995, 159.

13 Cool 1997, 74.

14 Batey et al 1993.

15 Mays 1997, 107-8.

16 Lucy 2000; J McKinley, pers comm.

17 Bayliss and Harry et al 1997, 108-15.

18 Scott et al 1990; Rozanski et al 1992; Scott (ed) 2003.

19 McCormac et al 1992 and references therein.

20 Hedges et al 1989, 102.

21 Stuiver and Kra 1986.

22 Stuiver and Polach 1977.

23 Stuiver and Pearson 1986; Bronk Ramsey 1995 and 2001.

24 Mook 1986.

25 Stuiver and Reimer 1986.

26 Stuiver and Reimer 1993; van der Plicht 1993; Deckling and van der Plicht 1993.

27 See Bronk Ramsey 1994 and, for the methodology, 1995.

28 McCormac 1992.

29 Ward and Wilson 1978.

30 Thomas 1993, 72-3, 80 and 119.

31 Thomas and Fowler 1985, 17; see Thomas 1993, 75-6, figure 61.

32 Thomas 1993, 91-2, illus 71.

33 Thomas and Fowler 1985, 21.

34 Thomas 1993, 92-3, figure 72 .

35 Ibid, 91-2.

36 Quinnell 2004, esp 178-9.

37 Johnson and Rose 1994, 80-3.

38 Preston-Jones and Rose 1986, 146 and figure 6; Todd 1987, 264-5, figure 9.8; for full details, see Thomas 1954, 1956a, 1958 and 1964; Fowler and Thomas 1962.

39 Thomas 1993, 92-3.

40 Campbell and Lane 1993, 64.

\section{CHAPTER 3}

Trial ExCaVations 1990-4 ON C A Ralegh RadFord's

Trenches on the Upper Terrace, Site C

1 See Harry and Morris 1997 and ch 2 of this volume.

2 Radford 1965, 20-1.

3 Radford 1968b, 69.

4 Harry and Morris 1997, 26-52.

5 Ibid, 117; Thorpe 1997, 77.

\section{CHAPTER 4}

EXCAVATIONS 1990-4 ON C A RaLegh RadFord's

Trenches on the Middle Terrace, Site C

1 Batey et al 1997, 69.

2 Harry and Morris 1997, 66-7.

3 Thorpe 1988, 70, figure 26: IS2.

4 Ibid.

5 As at Carthage; see Bass and van Doorninck 1982, 160, figure 8.7.

6 Straker et al 1997.

7 Radford 1956.

8 Batey et al 1993, 62-3.

\section{CHAPTER 5}

Excavations In and Around the Middle Terrace:

TrenCH C15, 1999

1 Harry and Morris 1997, 122; see ch 2 of this volume.

2 Thomas 1993, 96.

3 Brady and Harry 1999, 13.

4 Jefferson 1999.

5 Harry and Morris 1997, 51.

6 Harry and Morris (eds) 1995, 49.

7 Harry and Morris 1997, 48.

8 See two of the sheets for September 1936: 'Tintagel Castle. Sites B and C and neighbouring trenches' (NMR: TINPUB2, Bundle 25, 1/1), and 'Tintagel Castle: Plan of Site C (Upper platform)' (Wright Archive).

9 Straker 1997, 99, and see Straker in ch 10 of this volume.

\section{CHAPTER 6}

Excavations In and Around the Middle Terrace:

SITE C BUILDING, 1991-8

1 Archive RAD 01/01 TINBOX 46, 55.

2 Batey et al 1993, 63, figure 10.

3 Radford 1965, 20-1.

4 Radford 1962, 8.

5 Radford 1935b, 415.

6 Eg Cramp 1976.

7 Bruce-Mitford 1997.

8 See, however, Preston-Jones and Rose 1986, for more general commentary.

9 Lane and Campbell 2000, 106ff. 


\section{CHAPTER 7}

TOPOGRAPHIC SURVEY AND TRIAL EXCAVATIONS 1999 ON

C A Ralegh RadFord's TREnches In and ARound Site T

1 Radford 1935a and 1935b.

2 Radford 1962.

3 Thomas 1993, 59.

4 Hartgroves and Walker 1988; Thomas 1993, 61-2.

\section{CHAPTER 8}

ArchaEOlogical Assessment in 1999 of C A Ralegh

RADFord'S TrEnChes IN THE GREAT Ditch, Site T

1 Charles Thomas, pers comm.

2 See ch 1 of this volume; RAD 01/01 TINBOX 46, 28c.

3 Thomas 1993, 118-19.

\section{CHAPTER 9}

ArChaEOlogical Assessment In 1999 of C A Ralegh

RADFORD's TRENCHES IN THE LOWER WARD, SITE T

1 Thomas 1993, 59, for a redrawn version of both.

\section{CHAPTER 10}

THE ARTEFACTUAL ASSEMBLAGES

1 See Research Archive Report.

2 The principal corpus volumes are Macalister 1945-9 and (for Wales alone) Nash-Williams 1950; also note on 'Further Reading' for ch 1, in Thomas 1998, 203 and 2003, 21; also see 1994, xix-xx.

3 I was grateful to be allowed to read preliminary reports made when the piece was at Glasgow University by Dr Elizabeth Okasha (August 1998) and Dr Katherine Forsyth (October 1998). Neither was able to offer a reading of the four larger letters, but both concurred that a 6th-century date is likely and that differing pressures in the smaller letters could suggest the work of two people; Dr Forsyth anticipated me in writing 'My imagined scenario is that of three people $[=\mathrm{P}, \mathrm{C}$ and $\mathrm{A}]$ taking turns at carving their names on a broken piece of slate, with $C$ having a second bite at the cherry'. I must also acknowledge gladly the expert assistance of Dr Forsyth in passing on various linguistic comments from Professor John T Koch, Aberystwyth, most of them used here.

4 These have been taken from Collingwood and Wright 1965 , in the section on 'Milestones', nos 2219 to 2314.

5 Boon 1984, figures 1-21.

6 Todd 1987; Fulford 1996 and (for Caerleon) Boon 1972; Knight 1994.

7 The two route-markers found at Trethevy and Tintagel Church (Collingwood and Wright 1965, nos 2230-2231) name Gallus and Volusian (AD 251-3) and Licinius (AD 308-24).

8 Thomas 1981a, 16; checked (1980) by Dr C J Young, after Young 1977.
9 By R D Penhallurick, Curator, Royal Cornwall Museum, Truro, and by (the late) Professor Anne Robertson, Glasgow; see also brief note in Thomas 1993, 84.

10 This is argued passim in Thomas 1994 and 1998.

11 Reference numbers, with key names (italicized) and locations are from Macalister 1945-9, I.

12 See Thomas 1997 (for Kirkmadrine), and 1998, 92-5, for north-west Wales; generally, Thomas 1994, ch 12.

13 Best illustration in Gauthier 1991, 160 ( $\mathrm{col} \mathrm{pl}$ ).

14 Thomas 1994, chs 14-16.

15 Ibid, maps, 99, figure 7.5, and 244, figure 15.6.

16 As a guide, see 'Index II, cognomina virorum et mulierum', in Dessau 1892-1916, III, pt 1: Paterninus (1 entry), Paternius ( 1 entry) but Paternus ( 31 entries).

17 This is fully analysed in Thomas 1998, 14-21.

18 Harting 1880 , still a fair summary of the few early records.

19 Loth 1890, 107, 133.

20 Discussed with illustrations and further references in Thomas 1998, 65-70.

21 Bernier 1982, 164-5, with photograph, 162; see also Davies et al 2000, 137-44, with new illustrations. Both Celtic names, Artognous and Coliavus, are now included in Sims-Williams 2003, the latest discussion.

22 See for earlier instances the listing in Mann 1971.

23 This is a revised reading from that supplied in 1999 by Thomas as 'Artognou, father of a descendant of Coll, has had (this) made/built/constructed'; Morris et al 1999, 214.

24 Thorpe 1988, for the first accurate drawings of most of these; for the further churchyard finds see Nowakowski and Thomas 1992.

25 Batey et al $1997,66-7$.

26 Ibid, 67.

27 Batey et al 1993, 63.

28 Batey et al 1997, 68-9, figure 51.

29 Bass and van Doorninck 1982, 160, figure 8.7.

30 Thomas 1993, 69, figure 56; Batey et al 1993, 60, figure 86.

31 Batey et al 1997.

32 Thorpe 1988, 70, figure 26: IS2.

33 Allan Hall, pers comm.

34 Batey et al 1993, 63, figure I0.

35 Batey et al 1997, 66.

36 Bruce-Mitford 1997, 123, figure 107; 124, figure 108; 126, figure 110.

37 Thorpe 1988 (eg IS3, IS4, IS7, IS8 and IS10).

38 Thomas 1993, 114-17.

39 Ibid, 103-5.

40 Harry and Morris 1997, 72-3.

41 Batey et al 1993, 62-3.

42 Ford et al 1984; Young and Humphrey 1999.

43 Young and Humphrey 1999, 232.

44 Harry and Morris 1997, 71.

45 Harper 1974, 39. 
46 See Thomas 1993, 107-8 and 118-20.

47 Campbell 2006, table 1.

48 Campbell 1991, 139-43.

49 Vessel numbers refer to the 19 vessels identified in the complete assemblage from Tintagel restudied by Campbell and recatalogued in the Research Archive Report.

50 Isings 1957.

51 Campbell 2006, table 4.

52 Ibid, table 5.

53 Campbell 1995 and 2006.

54 Hill 1997, 324.

55 Tatton-Brown 1984.

56 Price 1988, 25, and 1995.

57 Clark 1988, 28.

58 Cool 1997.

59 Cool 1995.

60 Foy and Hochuli-Geysel 1995, 156, figure 5.

61 Foy (ed) 1995b, 76, pl 9.

62 Tatton-Brown 1984, figure 66, no. 35.

63 Bayliss and Harry et al 1997, 115.

64 Price and Cottam 1999, 110-11.

65 Tatton-Brown 1984, 195, figure 654.

66 Alaracão 1976, 193, nos 198-199, pl XCl.

67 Feyeux 1995, 114.

68 Foy (ed) 1995b, pl 21.

69 Foy and Hochuli-Geysel 1995, 157.

70 Gamo Parras 1995, 306.

71 Ibid, pl 4.1 and 3.

72 Campbell 1996b, figure 1.

73 Harden 1956a, 139.

74 Foy (ed) 1995b, 207, pl 15.

75 Sternini 1995, figure 19.

76 Tatton-Brown 1984, 211.

77 Harden (ed) 1956b, 70, b.

78 Campbell 1997, 308, no. 51.

79 Ibid, 303-5, no. 20.

80 Campbell 1995, 1997, 297, and 2006.

81 Price 2000a, figure 9.3, pl 7.

82 Ibid, pl 5.

83 Campbell 1997, 300, figure 10.4: nos 1-5.

84 Price 2000a, pl 8.

85 Price 1992, 139, nos 10-11, figure 97.

86 Price 2000a, 26.

87 Campbell 1997, 300, figure 10.4: no. 3.

88 Campbell 2000, 39.

89 Campbell 1997, 301, figure 10.5: no. 9.

90 Campbell 2006.

91 Evison 2000, 68

92 Evison $1991,87,90$, nos $66 \mathrm{v}$ and $67 \mathrm{~m}$.

93 Evison 1990.

94 Hunter and Heyworth 1998, 35.

95 Bourke 1994, 163-209.

96 Alcock and Alcock 1990, 113-17.

97 Alcock et al 1989, illus 14.31.

98 Price and Hill 1997, 314-15.
99 Campbell 1997.

100 Campbell 1996b and 1997.

101 Campbell 2006.

102 Campbell 1997; Hill 1997, 323-4, Stage 1.

103 Campbell 1997, Group A.

104 Campbell 1996b, figure 1.

105 Campbell 1991, 383, illus 37; Batey et al 1993, 60.

106 Eg Campbell 1996b.

107 Bayliss and Harry et al 1997, 115.

108 See report in Research Archive.

109 Newton and Davison 1989.

110 Guido 1978, 96, and 1999, 59-61: types 8iii and 8iv. Type 8 iii beads are confined to eastern England, with none on the south coast: Guido 1999, 291.

111 RF 1352, 1990, 'Steps' site: Batey et al 1993, 62.

112 Harden 1963, 178.

113 Holbrook and Bidwell 1991.

114 Carlyon 1995.

115 Quinnell and Thorpe forthcoming.

116 Quinnell 2004.

117 1bid.

118 Harry and Morris 1997, 120.

119 Young 1977; see also <www.potsherd.uklinux.net/atlas/ Ware/OXRS $>$ ( 30 Oct 2006).

120 Quinnell 2004.

121 Thomas 1993.

122 Harry and Morris 1997.

123 Peacock and Williams 1986, 182-4.

124 Ibid, 186-7.

125 Ibid, 187.

126 Ibid, 188-90.

127 Thomas 1981b; Peacock and Williams 1986, 155.

128 Thomas and Thorpe forthcoming.

129 Fulford and Peacock 1984, 108-15.

130 Ibid, 15.

131 Hayes 1980.

132 Hayes 1972.

133 MPRG 1998.

134 Hayes 1980.

135 Fulford and Peacock 1984.

136 Tyers 1996; See Paul Tyers's work at <www.potsherd. uklinux.net/> and <www.potsherd.uklinux.net/atlas/ Ware/NARS $>$ (30 Oct 2006).

137 Hayes 1972 and 1980; Fulford and Peacock 1984.

138 Radford 1956.

139 Thomas $1981 \mathrm{~b}$.

140 MPRG 1998.

141 See Alcock 1993.

142 Campbell 1997.

143 Thomas 1981b; Alcock 1987.

144 Hayes 1980.

145 See figure 54 in Harry and Morris 1997.

146 See Alcock 1993.

147 See Wooding 1996b; see also Campbell 1996b.

148 Thorpe 1997. 
149 Ibid.

150 Hayes 1972 and 1980.

151 Fulford and Peacock 1984.

152 Thorpe 1997.

153 Fulford and Peacock 1984.

154 See Rahtz et al 1992; Alcock et al 1995; Hill 1997.

155 Carl Thorpe, pers comm.

156 Fox 1995. Reference kindly supplied by Lady Aileen Fox.

157 Thomas 1993.

158 Thomas 1988a.

159 Peacock and Williams 1986, 14-16; Williams 2005a.

160 Peacock and Williams 1986, 167.

161 As in Tomber and Dore 1998; for North African amphorae see Bonifay 2004, pl 1.

162 Bonifay 2005.

163 Tomber and Dore 1998, 6-7. For recent views see Bonifay 2004, 471, and 2005.

164 Thompson and Walsh, 2003.

165 Peacock and Williams 1986, 182.

166 Williams 2005a and 2005b.

167 Peacock and Williams 1986, $155 f$.

168 See Bonifay 2005, figure 19, for a map of known amphora production in north and south Tunisia.

169 Jones forthcoming.

170 Empereur and Picon 1988 and 1989, figure 19: site 15.

171 Site B19 in Jameson et al 1994. The material was first chemically characterized with optical emission spectroscopy by Megaw and Jones (1983).

172 Tsaravopoulos 1986.

173 Jones 1986.

174 Günsenin and Hatcher 1997; Francois and Spieser 2002, 600; van Doorninck 2002, 902.

175 Catalonia: Uscatescu and García Jiménez 2005; Sinop: Erten et al 2004.

176 Peacock 1984; Tomber and Dore 1998, 102.

177 Gomez et al 2002.

178 This finding seems to accord with the view expressed by Arthur $(1998,179)$.

179 Hayes $(2000,319$ and pl 4.67) refers to the shapes of amphorae at Keratokambos as Cretan.

180 Williams 2005a, 618.

181 M Picon, pers comm. It should be noted that Picon's group 1 (Empereur and Picon 1989, figure 17) contains both carrot-shaped and LR 1 amphorae. See also Reynolds 2005, 586 and table 4.

182 For example, Eiring and Lund (eds) 2004; Gurt et al (eds) 2005.

183 Products of several workshops on Thasos have been analysed chemically by M Picon (pers comm), and petrographically by Whitbread $(1995,167 f)$.

184 Jones et al 2003.

185 Rathbone 1991, 304; Hayes 1997.

186 O'Mahoney 1989 and 1994; one sherd of medieval pottery was also found on the Lower Terrace of Site $\mathrm{C}$ in 1990: Thorpe 1997, 77.
187 Allan 1984.

188 Barton 1963, figure 5: nos 1 and 2.

189 Ponsford 1991.

190 Vince and Brown 1989.

191 Allan and Perry 1982.

192 Allan 1994.

193 Ponsford 1980.

194 Barton 1964.

195 Allan and Langman 2003.

196 Litt and Austin 1989.

197 Allan 1984.

198 O’Mahoney 1989.

199 Ibid.

200 Ibid.

201 Allan 1978.

202 O’Mahoney 1989.

203 Ibid.

204 Thomas (ed) 1988e.

205 Allan 2003.

206 Hughes forthcoming.

207 Brown et al 2006.

208 Allan and Langman 2003.

209 Hughes 2005.

210 Department of Archaeology, University of Durham.

211 Photos-Jones et al 1998.

212 Hall and Photos-Jones 1998.

213 Photos-Jones 1999.

214 Fleet 1976.

215 Photos-Jones 2000.

216 Harry and Morris 1997, 72-3.

217 Batey et al 1993, 62-3.

\section{CHAPTER 11}

The Ecofactual Assemblages

1 Straker et al 1997.

2 Batey et al 1993.

3 Straker 1997.

4 Stace 1997.

5 Jacomet 1987.

6 Moore et al 1991.

7 Stockmarr 1971.

8 Grant 1982.

9 Payne 1973.

10 Driesch 1976.

11 Straker et al 1997, 97.

12 Gale and Straker 1997.

13 Reitz and Wing 1999, 47.

14 Hillson 1986, 119.

15 Listed in the zoological archive.

16 Mays 1997.

17 Straker et al 1997.

18 Ibid.

19 See above and Gale and Straker 1997.

20 Straker 1997.

21 Campbell and Straker 2003. 
22 Hedges et al 1989.

23 Bronk Ramsey and Hedges 1997.

24 Bronk Ramsey et al 2002.

25 Stuiver and Kra 1986.

26 Stuiver and Polach 1977.

27 Stuiver et al 1998.

28 Bronk Ramsey 1995 and 2001.

29 Mook 1986.

30 Stuiver and Reimer 1986.

31 Stuiver and Reimer 1993.

32 Ashmore 1999; Bayliss 1999.

33 Eg Straker 1997.

34 Albarella and Davis 1996; Yalden 1999.

35 Ward and Wilson 1978.

36 Bayliss and Harry et al 1997.

37 Straker 1997.

38 Campbell with Straker in prep.

39 Gale and Straker 1997.

\section{CHAPTER 12}

\section{OVERVIEW AND Final Discussion}

1 Thomas $1993,81$.

2 Radford 1942, 1962, 1968b and 1975.

3 Radford 1956, 68.

4 See esp Radford 1956, incl pl VIA; 1968b, 69-70; Thomas 1971, 116-17, incl figure 55.

5 Radford 1971, 11.

6 Radford 1956, 68 .

7 Radford 1973, 139.

8 Thomas $1993,67-76$.

9 Burrow 1973; see also 1981, 163-6.

10 Radford 1973, 137-8.

11 Cramp 1976, 209-12.

12 Pearce 1978, 76-80, and 1981, 191.

13 Padel 1981a, 28; Dark 1983 and 1985.

14 Thomas 1959, 1971, 24-6, 1981b, 4-5, and 1982, 17-21.

15 Thomas 1993, 76; Thomas and Fowler 1985; Thomas 1988a; contrast Thomas 1981a, 348.

16 Todd 1987, 247, 262-5.

17 Olson 1989, 34-5.

18 Eg Snyder 1996, 28-9, and 1998, 184; Alcock 1989b, 397; Esmonde Cleary 1989, 185-6; Dark 2000, 155.

19 Eg Dark 1994a, 80-6; Pearce 2004, 166-9.

20 James 2001, 203.

21 TINBOX 46, $24 \mathrm{a}$ and $\mathrm{b}$.

22 Peers 1925; Peers and Radford 1943; Cramp 1973 and 1976; Rahtz 1976; O’Sullivan 1989.

23 Wheeler 1943 and 1954.

24 Carl Thorpe, pers comm.

25 Thomas 1993, 13-15.

26 Ibid, 13; see aiso Thomas and Thorpe 1988.

27 Batey with Pollard 1997a and 1997b.

28 Quinnell 1986, 115; Todd 1987, 163-5.

29 Thomas 1993, 13.

30 Hartgroves and Walker 1988.
31 Thomas 1993, 13, 82-5.

32 Collingwood and Wright 1965, nos 2230-2234; Thomas 1993, 82 .

33 Todd 1987, 218; see also Collingwood 1924, 105-6.

34 Thomas 1993, 83-4.

35 Penhallurick 1986; Quinnell 1986, 129-30; Todd 1987, 231-3; Holbrook (ed) forthcoming; see also Fox 1964, $155-6$.

36 Thomas $1993,84$.

37 Todd 1987, 203; see also Rivet and Smith 1979, 324-5, 350.

38 Thomas 1993, 13, 84; Thomas and Thorpe 1988.

39 Thomas 1993, 84.

40 Ibid.

41 Morris 1997, 121, and summary in ch 2 of this volume.

42 Quinnell 2004, 182-9.

43 Morris 1997, 122.

44 Price 1988.

45 Cool 1997.

46 Quinnell and Thorpe forthcoming.

47 Quinnell 2004, 240-2.

48 Thorpe 1997, 82.

49 In Hartgroves and Walker 1988, 24.

50 Straker 1997, 86.

51 Ibid.

52 Mays 1997, 107-8.

53 Morris 1997, 119.

54 Petts 2000, 138-9.

55 Morris 1997, 119.

56 Holbrook (ed) forthcoming.

57 Hartgroves and Walker 1988.

58 Holbrook (ed) forthcoming.

59 Radford 1942, 28.

60 Hartgroves and Walker 1988.

61 Burrow 1973; Dark 1985.

62 Radford 1973, 138.

63 Morris 1997, 121-2.

64 Thomas 1993, 91-2, illus 71.

65 Thomas and Fowler 1985, 17; see Thomas 1993, 75-6, illus 61.

66 Thomas and Fowler 1985, 21.

67 Thomas 1993, 93, illus 72 .

68 Morris 1997, 122.

69 Radford 1968b, 69; see also 1939, 21, and 1942, 33.

70 Contra Thomas 1993, 72-3, 80, 119.

71 Ibid, 92.

72 Ibid; see also Thomas and Thorpe forthcoming.

73 Campbell and Lane 1993, 64; Thorpe 1997, 81.

74 Thomas 1993, 88-92.

75 See Alcock et al 1995, 126-7, 148.

76 See Batey et al 1993.

77 See Thomas 1988a.

78 Thomas and Thorpe 1988.

79 Thomas and Thorpe 1993.

80 Thorpe 1997; see ch 2 in this volume. 
81 Acknowledged, for instance, in Alcock et al 1995, 141.

82 Rahtz et al 1992, 160-79.

83 Carl Thorpe, pers comm.

84 Pace Thomas 1993, 88-92, and illus 68.

85 Thomas and Thorpe forthcoming.

86 Alcock 1993.

87 Alcock 1963; Campbell 1989.

88 Morris et al 1999.

89 Batey with Photos-Jones 1997.

90 Batey et al 1993,62-3.

91 Coppock 1971; Straker 1992.

92 Nowakowski and Thomas 1992.

93 Ratcliffe and Straker 1996; Straker 1998.

94 Campbell with Straker, in prep.

95 Ibid.

96 Jones et al 1991; Straker et al 1997.

97 Hartgroves and Walker 1988.

98 Thomas 1993, 15.

99 Morris et al 1990; Nowakowski and Thomas 1990 and 1992.

100 Thomas 1993, 100-5.

101 Ibid, 105.

102 Ibid, 15.

103 Bruce-Mitford 1997.

104 Thomas 1993, 115.

105 Nowakowski and Thomas 1990 and 1992; Thomas 1993, 100-9, esp Illus 84-86.

106 Thomas 1993, 105.

107 Ibid, 108-10, 112-13.

108 Radford 1935a, 23, and 1935b, 402-9.

109 Work by CAU, directed by Nic Appleton-Fox (unpublished): Thomas 1993, 110-14.

110 Radford 1935a and 1935b.

111 Padel 1988; Thomas 1993, 15, 116-24.

112 Thomas 1993, 114.

113 Appleton et al 1988; Thomas 1988c; Nowakowski and Thomas 1990 and 1992; Thomas 1993, 28-9, 109-24.

114 Thomas 1993, 114; see also proposed 13th-century reconstruction, 112 , illus 88 .

115 Radford 1935a; Padel 1981a; Preston-Jones and Rose $1986,172$.

116 Thomas 1993, 111, 114.

117 Ibid, 17-18.

118 Ibid, 116.

119 Charles Thomas, pers comm.

120 Thomas 1993, 116-24.

121 Hartgroves and Walker 1988, 21-2.

122 Appleton et al 1988; Thomas 1988a and 1988d.

123 Hartgroves and Walker 1988.

124 Ibid.

125 Ibid, 15, 21-2, figure 4.

126 Ibid, 24.

127 Thomas 1993, 72-3, 80, 119.

128 Thorpe 1988.

129 Thomas 1993, illus 92, 93.
130 O'Mahoney 1988, 67, and 1989; Thomas 1993, 119.

131 Thomas 1993, 114.

132 Ibid, 15.

133 O'Mahoney 1988, 67.

134 Ibid, 68.

135 Harry and Morris 1997, 123-4.

136 Thomas 1993, illus 17, 27, 37.

137 Ibid, 36.

138 Ibid, 34.

139 Hartgroves and Walker 1988.

140 Thomas 1988a.

141 See now Rose and Preston-Jones 1995, 54-5, figure 3.1.

142 Thomas 1988a, 430-1, and 1988c.

143 Morris et al 1990, 845-8; Nowakowski and Thomas 1990 and 1992; Thomas 1993, 18-22, 64-6, 99-110, 114.

144 Thomas 1982, 32 n 5; Alcock et al 1995, 141.

145 Updating overall figures from the 1988 study, which stood then at at least 91 amphorae and about 50 Red slipped ware vessels: Thomas and Thorpe 1988; Carl Thorpe, pers comm.

146 Thomas 1993, 62, 64, 85 .

147 Alcock et al 1995, 141.

148 Alcock and Alcock 1990, Appendix 2, 138-9.

149 Alcock 2003, 89; this does not appear to be a typographic error, as he was, necessarily, unaware of the recent estimate of 150 .

150 Thomas and Thorpe 1988 and forthcoming; Reynolds 1995.

151 See Thomas 1971, 24-5, and 1988b; Alcock et al 1995, 141-2; Bowman 1996, 103.

152 Rahtz 1983, 186.

153 See figure 3; Thomas 1993, 41.

154 William Taylor, JP, quoted in Thomas 1993, 41.

155 Ibid, 39.

156 Campbell and Bowles forthcoming.

157 Thomas 1990, 13.

158 Thomas 1985, 194-8; Campbell and Bowles forthcoming.

159 Anon 1994, 6; see also Sharpe 1990.

160 See Thomas 1988b.

161 Alcock 1963; Fowler et al 1970; Rahtz and Fowler 1972; Rahtz et al 1992, 239-42, figure 171.

162 Alcock 1963, 52-3; Harden 1963.

163 See now Alcock et al 1995, 142-3.

164 Eg see Fox 1955; Radford 1956; Thomas 1959, 1981b, 1982 and 1988b; Alcock 1963, 1971, 201-21, and 1992; Fowler et al 1970; Rahtz and Fowler 1972; Silvester 1981; Griffiths 1986; Campbell 1989, 1991, 1995, 1996a and 1996b; Rahtz et al 1992; Campbell and Lane 1993; Lane 1994; Alcock et al 1995; Wilkinson 1995; Wooding 1996b.

165 Alcock 1971, 206, and 1983, 51.

166 Thomas 1982, 25, $1988 \mathrm{~b}$ and $1993,85,96-7$.

167 Rahtz et al 1992, 233.

168 Alcock and Alcock 1990, 123, 128. 
169 Ibid, Appendix 1, 130-8.

170 Ibid, 121; Alcock et al 1995, 141-8.

171 Wooding 1996a and 1996b.

172 Fulford 1979, 127.

173 Campbell 1996b, 86-8, and 2000, 35.

174 Fulford 1989.

175 Campbell 1996b, 86.

176 Alcock 1987, 92; Bowman 1996, 102.

177 Bowman 1996, 101.

178 Ibid, 102-3.

179 Dark 2001, 92.

180 Eg Fulford 1989; Alcock and Alcock 1990, 119-30; Thomas 1990 and 1993, 93-6; Alcock 1992; Lane 1994; Alcock et al 1995, 141-8; Knight 1995, 43-5; Bowman 1996; Campbell 1996a and 1996b; Wooding 1996b.

181 Thomas 1982, 26-7; Biek 1994.

182 McDonald 1994; Fox 1995. Reference kindly supplied by Lady Aileen Fox.

183 Silvester 1981, 115-16; Griffiths 1986, 48-9; Pearce 2004, 239-40; Quinnell 2004, 241-2.

184 Leeds 1926; Thomas 1956b; Quinnell 2004, 72-6.

185 Alcock et al 1995, 142.

186 Fox 1955, 64; Radford 1956, 68, and later writers with the exception of Knight 1999, 157, who regards it as 'clearly fiction'. See translation in Penhallurick 1986, 245.

187 Fulford 1989, 5.

188 Thomas 1993, figure 76.

189 Eg Campbell 1996b, 88-9; Quinnell 2004, 73; Campbell and Bowles forthcoming.

190 Thomas 1993, 94-5; Alcock et al 1995, 142; Pearce 2004, 237-8.

191 Fox 1955, 64; Radford 1956, 69; Alcock and Alcock 1990, 127-8; Alcock et al 1995, 142; Wooding 1996b, 72-4, 82; Alcock 2003, 89-92; Campbell and Bowles forthcoming.

192 Dark 1994b, 210-11, and 2001, 91-2.

193 Harris 2003, 60-2, 146-7.

194 Boon 1991; Fox 1955, 64.

195 Dark 1994b, 211.

196 Radford 1956, 67-9; Thomas 1959, 105.

197 Fulford 1979, 127, and 1989, 4; Alcock 1983, 49.

198 Eg Thomas 1982, 25.

199 Alcock 1971, 201.

200 Fulford and Peacock 1984.

201 Bass and van Doorninck 1982.

202 Fulford 1989, 4.

203 Radford 1956, 69; Thomas 1959, 105; Alcock 1971, 208.

204 Campbell and Bowles forthcoming.

205 See also Alcock et al 1995, 141.

206 Thomas 1993, 71.

207 Thomas 1981b, 26-7.

208 Bowman 1996, 99.

209 Ibid, 100; Campbell 1996b, 88.

210 Dark 2000, 164.

211 Harris 2003, 146.

212 Thomas 1990, 1.
213 Campbell 2005, 56.

214 Campbell and Bowles forthcoming.

215 Barrett 2000, 45.

216 O'Mahoney 1989, 6.

217 Thomas 1982, 18

218 Sharpe 1990, 9; Thomas 1993, 38-9.

219 Anon 1994, 3.

220 Thomas 1993, 31-3, 47-9, 126-33.

221 Rose and Preston-Jones 1995, 54-5, figure 3.1.

222 Padel 1981a, 1984 and 1988.

223 Eg Radford 1962.

224 See eg Morris 1996.

225 Radford 1956.

226 Alcock and Alcock 1990; Campbell and Lane 1993; Alcock et al 1995; Wilkinson 1995.

227 See Thomas 1988b; Alcock 2003, 89-90.

228 See above and eg Alcock and Alcock 1990, 131; Alcock et al 1995, 144-5; Snyder 1996, 19; Quinnell 2004, 241.

229 Eg Alcock 1987, 210-11, figure 13.11.

230 Alcock and Alcock 1990.

231 Alcock 1988, 23, 29.

232 Quinnell 2004, 241.

233 It should be noted that both Rahtz and Burrow have offered a range of possibilities for Cadcong: Burrow 1981, 152-81; Rahtz et al 1992, 248-51.

234 Rahtz et al 1992, 214-34; Alcock et al 1995, 38-40, eg structures $\mathrm{S} 1$ and $\mathrm{E} 3$.

235 Alcock 1987, 16, figure 1.8, 56, figure 2.5.

236 Davies 1982, 23-4; Edwards and Lane 1988, 1, 4; Campbell and Lane 1993, 61-5; Alcock et al 1995, 47; Arnold and Davies 2000, 159, 164-5.

237 Wilkinson 1995.

238 Thomas 1993, 88-92.

239 Dark 1994a, 82, 86.

240 Alcock et al 1995, 141-8.

241 Alcock 2003, 89-90.

242 Rahtz et al 1992, see esp 239 and figure 163.

243 See now Lane and Campbell 2000.

244 Padel 1981a; Alcock and Alcock 1990.

245 Alcock et al 1995, 151.

246 For a broader discussion of these issues, see Alcock 1989a.

247 See Arnold and Davies 2000, 165, where they emphasize that 'royal' 'should ... be taken only to imply leadership'

248 Alcock 1987, 163; Alcock et al 1995, 151; Dark 1994a, 138 , allows the possibility of this being the homestead of a king or sub-king.

249 Wilkinson 1995, 35.

250 Campbell and Lane 1993, 61-9; Alcock et al 1995, 147-8.

251 One might wish to enter a caveat in relation to using terms such as this, or even a historically attested Welsh term like $l l y s$, in a not strictly contextualized historical manner: Davies 1982, 23-4; Alcock 1987, 17, 50, 57, 61, 84-6.

252 Pearce 2004, 231-2. 


\section{ABBREVIATIONS AND BIBLIOGRAPHY}

\section{ABBREVIATIONS}

$\begin{array}{ll}\text { AAS } & \text { Atomic Absorption Spectrometry } \\ \text { AMAC } & \text { Ancient Monuments Advisory } \\ & \text { Committee } \\ \text { AMS } & \text { Accelerator Mass Spectrometry } \\ \text { ARSW } & \text { African Red slipped ware } \\ \text { Bi (ii, etc) } & \text { B-ware imported pottery (type i, ii, etc) } \\ \text { BMC } & \text { British Museum Catalogue } \\ \text { BPT } & \text { Bristol Pottery Type } \\ \text { Ca } & \text { calcium } \\ \text { CA } & \text { cluster analysis } \\ \text { CAU } & \text { Cornwall Archaeology Unit } \\ \text { Co } & \text { cobalt } \\ \text { CO9 (etc) } & \text { Site C trench 09 (etc) } \\ \text { Cr } & \text { chromium } \\ \text { D } & \text { D-ware imported pottery } \\ \text { E } & \text { E-ware imported pottery } \\ \text { EDM } & \text { Electronic Distance Measurement } \\ \text { EDXRF } & \text { Energy Dispersive X-ray Fluorescence } \\ \text { EH } & \text { English Heritage } \\ \text { ext } & \text { extension } \\ \text { Fe } & \text { iron } \\ \text { GC } & \text { Gas chromatography } \\ \text { HBMCE } & \text { Historic Buildings and Monuments } \\ & \text { Commission for England } \\ \text { HG } & \text { Ham Green wares } \\ \text { ICP-ES } & \text { Inductive Coupled Plasma-Electro } \\ \text { ICP-AES } & \text { Spectroscopy } \\ \text { Inductive Coupled Plasma-Emission } \\ \text { ICP-MS } & \text { Spectrometry } \\ \text { Inductive Coupled Plasma-Mass } \\ \text { INAA } & \text { Spectrometry } \\ & \text { Instrumental neutron activation analysis } \\ & \end{array}$

INNA-PIXE Instrumental Neutron Activation Analysis-Proton Induced X-ray Emission

LO Lostwithiel-type wares

LOC Lostwithiel-type wares: Colliford fabric C

LOD Lostwithiel-type wares: Colliford fabric D

$\mathrm{Mg} \quad$ magnesium

$\mu \mathrm{m} \quad$ micrometre

$\mathrm{Mn} \quad$ manganese

MNE minimum number of elements

MoW Ministry (earlier Office) of Works

MPRG Medieval Pottery Research Group

NC post-medieval North Devon Calcareous ware

NFI not further identifiable

$\mathrm{Ni} \quad$ nickel

NMR National Monuments Record

OES Optical Emission Spectrometry

OK

OWS

PCA

PRSW

RCHME

North Devon Medieval Coarsewares

Offset Wenner Sounding

Principal components analysis

Phocaean Red slipped ware

Royal Commission on the Historical

Monuments of England

RCM Royal Cornwall Museum, Truro

RE Redcliffe wares

RF(s) Recorded Find(s)

RIB Roman Inscriptions of Britain

RIC Royal Institution of Cornwall

SA Stuffle-type wares

SASAA Scottish Analytical Services for Art and

Archaeology

SEM Scanning Electron Microscope (with

(-EDAX) Energy Dispersive Analyser) 


$\begin{array}{ll}\text { SEM (-BS) } & \begin{array}{l}\text { Scanning Electron Microscope (with } \\ \text { Back-scattered Mode) }\end{array} \\ \text { SO } & \begin{array}{l}\text { Chert-tempered wares } \\ \text { SP }\end{array} \\ \text { SR } & \begin{array}{l}\text { Saintonge Ware } \\ \text { post-medieval Sandy Redware }\end{array} \\ \text { T01 (etc) } & \text { Site T Trench 1 (etc) } \\ \text { TBM } & \text { temporary bench mark } \\ \text { UU } & \text { unclassified unsourced medieval ware } \\ \text { VESARP } & \text { Viking and Early Settlement } \\ & \text { Archaeological Research Project } \\ \text { VFA } & \text { vitrified fuel ash } \\ \text { XRF } & \text { X-ray fluorescence } \\ \text { XRD } & \text { X-ray diffraction } \\ \star & \text { hypothetical earlier linguistic form }\end{array}$

\section{BIBLIOGRAPHY}

Alaracão, J 1976. 'Verres', in Fouilles de Conimbriga, v1 (J Alaracão and J Etienne), 155-215, Paris

Albarella, U and Davis, S 1996. 'Mammals and birds from Launceston Castle, Cornwall: decline in status and the rise of agriculture', Circaea, 12 (1) (for 1994), 1-156

Alcock, L 1963. Dinas Powys. An Iron Age, Dark Age and Early Medieval Settlement in Glamorgan, Cardiff

Alcock, L 1971. Arthur's Britain, London

Alcock, L 1983. 'The archaeology of Celtic Britain, fifth to twelfth centuries A.D.', in 25 Years of Medieval Archaeology (ed D A Hinton), 48-66, Sheffield

Alcock, L 1987. Economy, Society and Warfare among the Britons and Saxons, Cardiff

Alcock, L 1988. 'The activities of potentates in Celtic Britain, AD 500-800: a positivist approach', in Power and Politics in Early Medieval Britain and Ireland (eds S T Driscoll and $M$ R Nieke), 22-46, Edinburgh

Alcock, L 1989a. Bede, Eddius, and the Forts of the North Britons, Jarrow Lecture 1988, Jarrow

Alcock, L 1989b. 'Supplementary bibliography 1987', in Arthur's Britain. History and Archaeology AD 367-634 (reprint with revised preface and supplementary bibliography), 386-408, London

Alcock, L 1992. 'Message from the dark side of the moon: western and northern Britain in the age of Sutton Hoo', in The Age of Sutton Hoo (ed M Carver), 205-15, Woodbridge

Alcock, L 1993. 'Comment by Leslie Alcock', in Batey et al 1993, 60

Alcock, L 2003. Kings and Warriors, Craftsmen and Priests in Northern Britain AD 550-850, Soc Antiq Scotl Monogr Ser 24, Edinburgh

Alcock, L and Alcock, E A 1990. 'Reconnaissance excavations on early historic fortifications and other royal sites in Scotland, 1974-84: 4, Excavations at Alt Clut, Clyde
Rock, Strathclyde, 1974-75', Proc Soc Antig Scotl, 120, 95-149

Alcock, L, Alcock, E A and Driscoll, S T 1989. 'Reconnaissance excavations on early historic fortifications and other royal sites in Scotland, 1974-84: 3, Excavations at Dundurn, Strathearn, Perthshire, 1976-77', Proc Soc Antig Scoth 119, 189-226

Alcock, L, with Stevenson, S J and Musson, C R 1995. Cadbury Castle, Somerset. The Early Medieval Archaeology, Cardiff

Allan, J P 1978. 'The pottery', in 'Excavations in Okehampton Deer Park, Devon, 1976-1978' (D Austin), Devon Archaeol Soc Proc, 36, 226-34

Allan, J P 1984. Medieval and Post-Medieval Finds from Exeter, Exeter Archaeol Rep 3, Exeter

Allan, J P 1994. 'Medieval pottery and the dating of deserted settlements on Dartmoor', Devon Archaeol Soc Proc, 52, $141-7$

Allan, J P 2003. 'A group of early 13th-century pottery from Sherborne Old Castle and its wider context', Dorset Natur Hist Archaeol Soc Proc, 125, 71-82

Allan, J P and Langman, G 2003. 'Appendix 1: the Dung Quay pottery', in 'Excavation of the medieval and later waterfront at Dung Quay, Plymouth' (P Stead), Devon Archaeol Soc Proc, 61, 47-61

Allan, J and Perry, I 1982. 'Pottery and tiles', in 'Excavations at Okehampton Castle, Devon. Part 2: the bailey' (R A Higham, J P Allan and S R Blaylock), Devon Archaeol Soc Proc, 40, 86-136

Anon 1994. The Lost Ports of Cornwall, Tor Mark Press, Penryn

Appleton, N, Fox, T and Waters, A 1988. 'Tintagel Castle. Survey and excavation at the Inner Ward, the Chapel, Site 4 and the Garden', 2 parts, unpublished site reports, CAU, Truro

Armstrong, $\mathrm{P}$ and Hatcher, $\mathrm{H}$ 1997. 'Byzantine and allied pottery, Phase 2: past work on materials analysis and future prospects', in Materials Analysis of Byzantine Pottery (ed H Maguire), 1-8, Washington, DC

Arnold, C J and Davies, J L 2000. Roman and Early Medieval Wales, Stroud

Arthur, P 1998. 'East Mediterranean amphorae between 500 and 700: a view from Italy', in Ceramica in Italia: VI-VII secolo. Atti del Colloquio in onore di John W. Hayes (Roma 1995) (ed L Saguì), 157-84, Florence

Ashe, G 1969. All about King Arthur, London

Ashmore, P 1999. 'Radiocarbon dating: avoiding errors by avoiding mixed samples', Antiquity, 73, 124-30

Austin, D, Gerrard, G A M and Greeves, T A P 1989. “Tin and agriculture in the Middle Ages and beyond: landscape archaeology in St Neot parish, Cornwall', Cornish Archaeol, 28, 5-251

Barrett, J C 2000. 'Material culture: the artefact categories', in Cadbury Castle Somerset. The Later Prehistoric and Early Historic Archaeology (J C Barrett, P W M Freeman and 
A Woodward), Eng Heritage Archaeol Rep 20, 44-5, London

Barton, K J 1963. 'A medieval pottery kiln at Ham Green, Bristol', Trans Bristol Gloucestershire Archaeol Soc, 82, 95-126

Barton, K J 1964. 'The medieval pottery of the Saintonge', Archaeol J, 120, 201-14

Bass, G F and van Doorninck, F H 1982. Yassi Ada. Vol. 1: a seventh-century Byzantine shipwreck, Texas

Batey, C E with Pollard, A 1997a. 'Flint', in Batey et al 1997, 71

Batey, C E with Pollard, A 1997b. 'Worked quartz', in Batey et al 1997,72

Batey, C E, Sharpe, A and Thorpe, C M 1993. 'Tintagel Castle: archaeological investigation of the Steps area 1989 and 1990', Cornish Archaeol, 32, 47-66

Batey, C E with Cool, H E M, Photos-Jones, E, Pollard, A and Straker, V 1997. 'The artefact assemblage: non-ceramic finds', in Harry and Morris 1997, 66-74

Batey, C E with Photos-Jones, E 1997. 'Industrial debris', in Batey et al 1997, 72-3

Bayliss, A 1999. 'On the taphonomy of charcoal samples for radiocarbon dating', in Actes du 3ème congrès international «Archéologie et 14C» Lyon, 6-10 Avril 1998 (eds J Evin, C Oberlin, J P Daugas and J F Salles), Revue d'Archéométrie Suppl 1999 et Soc Préhist Fr Mémoire 26, 51-6

Bayliss, A and Harry, R with Gale, R, McCormac, G and Pettitt, $\mathrm{P}$ 1997. 'The radiocarbon dating programme', in Harry and Morris 1997, 108-15

Bennett, K D 1994. 'Annotated catalogue of pollen and pteridophyte spores of the British Isles', unpublished report, Department of Plant Sciences, University of Cambridge

Bernier, G 1982. Les chrétientes bretonnes continentales depuis les origines jusqu'au IXème siécle, Rennes

Biek, L 1994. 'Tin ingots found at Praa Sands, Breage, 1974', Cornish Archaeol, 33, 57-70

Bonifay, M 2004. Etudes sur la céramique romaine tardive d'Afrique, BAR Int Ser 1301, Oxford

Bonifay, M 2005. 'Observations sur la typologie des amphores africaines de l'Antiquité tardive', in Gurt et al (eds) 2005, $451-72$

Boon, G C 1972. Isca. The Roman Legionary Fortress at Caerleon, Cardiff

Boon, G C 1984. Laterarium Iscanum: the antefixes, brick and tile stamps of the Second Augustan Legion, Cardiff

Boon, G C 1991. 'Byzantine and other exotic ancient bronze coins from Exeter', in Roman Finds from Exeter (eds N Holbrook and P T Bidwell), Exeter Archaeol Rep 4, 38-45, Exeter

Bourke, E 1994. 'Glass vessels of the first nine centuries AD in Ireland', J Roy Soc Antiq Ir, 124, 163-209

Bowman, A 1996. 'Post-Roman imports in Britain and Ireland: a maritime perspective', in Dark (ed) 1996, $97-108$
Brady, K and Harry, R 1999. Tintagel Castle: excavations to the south of Site $C$ and follow-up excavation on the Great Ditch area. Fieldwork Phase 3: a project design, Glasgow

Bronk Ramsey, C 1994. Oxcal (v 2.0): a radiocarbon calibration and analysis program, Radiocarbon Accelerator Unit, Oxford

Bronk Ramsey, C 1995. 'Radiocarbon calibration and analysis of stratigraphy: the OxCal Program', Radiocarbon, 37, $425-30$

Bronk Ramsey, C 2001. 'Development of the radiocarbon program OxCal', Radiocarbon, 43 (2A), 355-63

Bronk Ramsey, C and Hedges, R E M 1997. 'A gas ion source for radiocarbon dating', Nuclear Instruments and Methods in Physics Research, B29, 45-9

Bronk Ramsey, C, Higham, T F G, Owen, D C, Pike, A W G and Hedges, R E M 2002. 'Radiocarbon dates from the Oxford AMS system: Archaeometry datelist 31', Archaeometry, 44, 1-149

Brown, D, Thomson, R and Vince, A 2006. 'The pottery', in Excavations at Launceston Castle, Cornwall (ed A Saunders), Soc Medieval Archaeol Monogr Ser 24, 269-96, Leeds

Bruce-Mitford, R 1997. Mawgan Porth. A Settlement of the Late Saxon Period on the North Cornish Coast. Excavations 1949, 1952, 1954 and 1974, Engl Heritage Archaeol Rep 13, London

Burrow, I 1973. 'Tintagel - some problems', Scot Archaeol Forum, 5, 99-103

Burrow, I 1981. Hillfort and Hill-top Settlement in Somerset in the First to Eighth Centuries A.D., BAR Brit Ser 91, Oxford

Buxeda i Garrigós, J, Cau Ontiveros, M A, Loschi Ghittoni, A G and Medici, A 1999. 'Caracterización arqueométrica de las ánforas tardías de la cisterna de Sa Mesquida (Sta. Ponça, Calvià, Mallorca). Resultados preliminares', in $E l$ Vi al'Antiguitat. Economia, Producció $i$ Comerç al Mediterrani Occidental, Monografies Badalonines 14, Museu de Badalona, 530-42, Badalona

Campbell, $\mathrm{C}$ and Straker, V 2003. 'Plant use and regionality in southern England', in Archaeological Sciences 99 (ed K Robson Brown), BAR Int Ser 1111, 14-30, Oxford

Campbell, $\mathrm{C}$ with Straker, $\mathrm{V}$ in prep. A Review of Macroscopic Plant Remains Studies in Southern England

Campbell, E 1989. 'A blue glass squat jar from Dinas Powys, South Wales', Archaeol Cambrensis, 36, 239-45

Campbell, E 1991. 'Imported goods in the early medieval Celtic West: with special reference to Dinas Powys', unpublished $\mathrm{PhD}$ thesis, Cardiff University

Campbell, E 1995. 'New evidence for glass vessels in western Britain and Ireland in the 6th/7th centuries AD', in Foy (ed) 1995b, 35-40

Campbell, E 1996a. 'Trade in the Dark Age West: a peripheral activity?', in Crawford (ed) 1996, 79-92

Campbell, E 1996b. 'The archaeological evidence for contacts: imports, trade and economy in Celtic Britain AD 400-800', in Dark (ed) 1996, 83-96 
Campbell, E 1997. 'The early medieval imports', in Hill 1997, 297-322

Campbell, E 2000. 'A review of glass vessels in western Britain and Ireland AD 400-800', in Price (ed) 2000b, $33-46$

Campbell, E 2005. 'Imported continental pottery', in A Crannog of the 1st Millennium AD. Excavations by Jack Scott at Loch Glashan, Argyll, 1960 (A Crone and E Campbell), Soc Antiq Scotl Monogr, 56-61, Edinburgh

Campbell, E 2006. 'Imported glass and pottery', in The Mote of Mark: a Dark Age hillfort in southwest Scotland (L R Laing and D Longley), 104-13, Oxford

Campbell, E and Bowles, $\mathrm{C}$ forthcoming. 'Byzantine trade to the edge of the world: Mediterranean pottery imports to Atlantic Britain and Ireland in the sixth century', in Byzantine Trade (4th to 12th Century): recent archaeological work (ed M Mango)

Campbell, E and Lane, A 1993. 'Excavations at Longbury Bank, Dyfed, and early medieval settlement in South Wales', Medieval Archaeol, 37, 15-77

Carlyon, P M 1995. 'Romano-British Gabbroic pottery', unpublished report, CAU and RIC, Truro

Clark, T 1988. 'Archaeomagnetic dating of stone and clay hearths', in Hartgroves and Walker 1988, 28

Coja, M and Dupont, P 1979. Histria V: Ateliers Céramiques, Paris and Bucharest

Collingwood, R G 1924. 'Roman milestones in Cornwall', Antiq $J, 4,101-12$

Collingwood, R G and Wright, R P 1965. The Roman Inscriptions of Britain. I: inscriptions on stone, Oxford

Cool, H E M 1995. 'Glass vessels of the fourth and early fifth century in Roman Britain', in Foy (ed) 1995b, 11-23

Cool, H E M 1997. 'Glass', in Batey et al 1997, 73-4

Coppock, J T 1971. An Agricultural Geography of Great Britain, London

Cramp, R J 1973. 'Anglo-Saxon monasteries of the north', Scot Archaeol Forum, 5, 104-24

Cramp, R J 1976. 'Monastic sites', in Wilson (ed) 1976, 201-52

Crawford, B E (ed) 1996. Scotland in Dark Age Britain, Sir John's House Pap 6, St Andrews

Dark, K R 1983. 'Celtic monastic archaeology: fifth to eighth centuries', Monastic Studies, 14, 17-29

Dark, K R 1985. 'The plan and interpretation of Tintagel', Cambridge Medieval Celtic Stud, 9, 1-17

Dark, K R 1994a. Discovery by Design. The Identification of Secular Elite Settlements in Western Britain A.D. 400-700, BAR Brit Ser 237, Oxford

Dark, K R 1994b. Civitas to Kingdom. British Political Continuity 300-800, Stud Early Hist Brit, London and New York

Dark, K R (ed) 1996. External Contacts and the Economy of Late Roman and Post-Roman Britain, Woodbridge

Dark, K R 2000. Britain and the End of the Roman Empire, Stroud
Dark, K R 2001. Byzantine Pottery, Stroud

Davies, W 1982. Wales in the Early Middle Ages, Stud Early Hist Brit, Leicester

Davies, W, Graham-Campbell, J, Handley, M, Kershaw, P, Koch, J T, le Duc, G and Lockyear, K 2000. The Inscriptions of Early Medieval Brittany, Celtic Studies Publications, Oakville, Conn, and Aberystwyth

Deckling, $\mathrm{H}$ and van der Plicht, J 1993. 'Statistical problems in calibrating radiocarbon dates', Radiocarbon, 35, 239-44

Dessau, H 1892-1916. Inscriptiones Latinae Selectae, 3 vols, Berlin

Driesch, A von den 1976. A Guide to the Measurement of Animal Bones from Archaeological Sites, Peabody Museum Bulletin 1, Cambridge, Mass

Edwards, N and Lane, A 1988. Early Medieval Settlements in Wales AD 400-1100, Bangor and Cardiff

Eiring, J and Lund, J (eds) 2004. Transport Amphorae and Trade in the Eastern Mediterranean. Acts of the International Colloquium at the Danish Institute at Athens, September 26-29, 2002, Danish Institute at Athens monogr 5, Athens

Empereur, J-Y and Picon, M 1988. 'The production of Aegean amphorae: field and laboratory studies', in New Aspects of Archaeological Science in Greece (eds R E Jones and $\mathrm{H}$ W Catling), British School at Athens, Fitch Laboratory Occas Pap 3, 33-8, Athens

Empereur, J-Y and Picon, M 1989. 'Les régions de productions d'amphores impériales en Méditerranée orientale', in Amphores Romaines et histoire économique: dix ans de recherche, Colloque d l'École Française de Rome 214, 223-48, Rome

Erten, H N, Kassab Tezgör, D, Türkmen, I R and Zararsiz, A 2004. 'The typology and trade of the amphorae of Sinope. Archaeological study and scientific analyses', in Eiring and Lund (eds) 2004, 103-15

Esmonde Cleary, S 1989. The Ending of Roman Britain, London

Evans, S and Dunn, C W (trans) 1963. Geoffrey of Monmouth. History of the Kings of Britain, London

Evison, V I 1990. 'Red marbled glass, Roman to Carolingian', Annales du 1le Congrès de l'Association Internationale pour l'Histoire du Verre (Bâle 1988), 217-28, Amsterdam

Evison, V I 1991. Catalogue entries in 'The new learning' (L Webster), in The Making of England. Anglo-Saxon Art and Culture AD 600-900 (eds L Webster and J Backhouse), 87-8 (nos 66v-y), 90-3 (nos 67m-v), London

Evison, V I 2000. 'Glass vessels in England AD 400-1100', in Price (ed) 2000b, 47-104

Feyeux, J-Y 1995. 'La typologie de la verriere mérovingienne du nord de la France', in Foy (ed) 1995b, 109-38

Fleet, A J 1976. 'Cramp from the Stones of Stenness, Orkney', in 'The Stones of Stenness, Orkney' (J N G Ritchie), Proc Soc Antiq Scoth 107, 46-8 
Ford, S, Bradley, R, Hawkes, J and Fisher, P 1984. 'Flintworking in the metal age', Oxford J Archaeol, 3, 157-73

Fowler, P J, Gardner, K S and Rahtz, P A 1970. Cadbury Congresbury, Somerset, 1968 - An Introductory Report, Bristol

Fowler, P J and Thomas, A C 1962. 'Arable fields of the pre-Norman period at Gwithian', Cornish Archaeol, 1, 61-84

Fox, A 1955. 'Some evidence for a Dark Age trading site at Bantham, near Thurlestone', South Devon Antiq J, 35, 55-67

Fox, A 1964. South West England, Ancient People and Places 41, London

Fox, A 1995. 'Tin ingots from Bigbury Bay', Devon Archaeol Soc Proc, 53, 11-23

Foy, D 1995a. 'Le verre de la fin du IVe au VIIIe siècle en France méditerranéenne, premier essai de typochronologie', in Foy (ed) 1995b, 187-242

Foy, D (ed) 1995b. Le Verre de l'Antiquité tardive et du Haut Moyen Age, Association Française pour l'Archéologie du Verre/Musée Archéologique du Val d'Oise, CergyPontoise

Foy, D and Hochuli-Geysel, A 1995. 'Le Verre en Aquitaine du IVe au IXe siecle, un etat de la question', in Foy (ed) 1995b, 151-78

Francois, V and Spieser, J-M 2002. 'Pottery and glass in Byzantium', in The Economic History of Byzantium - The Seventh Through the Fifteenth Centuries (ed A E Liaou), 563-609, Washington, DC

Fulford, M G 1979. 'Pottery production and trade at the end of Roman Britain: the case against continuity', in The End of Roman Britain (ed P J Casey), BAR Brit Ser 71, 120-32, Oxford

Fulford, M G 1989. 'Byzantium and Britain: a Mediterranean perspective on post-Roman Mediterranean imports in western Britain and Ireland', Medieval Archaeol, 33, 1-6

Fulford, M G 1996. The Second Augustan Legion in the West of Britain, ninth annual Caerleon Lecture, Cardiff

Fulford, M G and Peacock, D P S 1984. Excavations at Carthage: the British mission. Vol. 1: The Avenue du President Habib Bourguiba, Salammbo. Part 2: the pottery and other ceramic objects from the sites, Sheffield

Gale, R and Straker, V 1997. 'Charcoal from hearths, layers, floors and stakeholes', in Straker et al 1997, 101-6

Gamo Parras, B 1995. 'Vidrios de época visigoda en España, una approximation', in Foy (ed) 1995b, 301-18

Gauthier, N 1991. 'L'épigraphie', in Naissances des arts chrétiens. Atlas des monuments paléochrétiens de la France, 154 (1.3), Paris

Gomez, B, Neff, H, Rautman, M L, Vaughan, S J and Glascock, M D 2002. 'The source provenance of Bronze Age and Roman pottery from Cyprus', Archaeometry, 41, 23-36

Grant, A 1982. 'The use of tooth wear as a guide to the age of the domestic ungulates', in Ageing and Sexing Animal
Bones from Archaeological Sites (eds B Wilson, C Grigson and S Payne), BAR Brit Ser 109, 91-108, Oxford

Grueber, H A and Keary, C F 1893. A Catalogue of English Coins in the British Museum. Anglo-Saxon Series, II (Wessex and England to the Norman Conquest), London

Griffiths, F M 1986. 'Salvage observations at the Dark Age site at Bantham Ham, Thurlestone in 1982', Devon Archaeol Soc Proc, 44, 39-57

Guido, M 1978. The Glass Beads of the Prehistoric and Roman Periods in Britain and Ireland, Rep Res Comm Soc Antiq London 35, London

Guido, M 1999. The Glass Beads of Anglo-Saxon England c AD 400-700 (ed M Welch), Rep Res Comm Soc Antiq London 56, London

Günsenin, N and Hatcher, H 1997. 'Analyses chimiques comparatives des amphores de Ganos, de l'îsle de Marmara et de l'épave de Serçe Limani (Glass wreck)', Anatolia Antiqua, 5, 249-60

Gurt i Esparraguera, J M, Buxeda i Garrigos, J and Cau Ontiveros, M A (eds) 2005. Late Roman Coarse Wares, Cooking Wares and Amphorae in the Mediterranean: archaeology and archaeometry, BAR Int Ser 1340, Oxford

Hall, A J and Photos-Jones, E 1998. 'The bloomery mounds of the Scottish Highlands: Part II - a review of iron mineralisation in relation', J Hist Metall Soc, 32 (2), 54-66

Harden, D B 1956a. 'Glass vessels in Britain and Ireland, AD 400-1000', in Harden (ed) 1956b, 132-67

Harden, D B (ed) 1956b. Dark Age Britain: studies presented to E T Leeds, London

Harden, D B 1963. 'Glass', in Alcock 1963, 178-88

Harper, A 1974. 'The excavation of a rath in Crossnacreey Townland, County Down', Ulster J Archaeol, 36/37 (1973-4), 32-41

Harris, A 2003. Byzantium, Britain and the West. The Archaeology of Cultural Identity AD 400-650, Stroud

Harry, R and Johnson, P 1994. Tintagel Castle Excavations 1993 (ed C D Morris), Glasgow

Harry, R and Morris, C D (eds) 1995. Tintagel Castle Excavations 1994, Glasgow

Harry, R and Morris, C D 1997. 'Excavations on the Lower Terrace, Site C, Tintagel Island 1990-4', Antiq J, 77, $1-143$

Hartgroves, S and Walker, R 1988. 'Excavations in the Lower Ward, Tintagel Castle, 1986', in Thomas (ed) 1988e, 9-30

Harting, J E 1880. British Animals Extinct Within Historic Times, London

Hayes, J W 1972. Late Roman Pottery, London

Hayes, J W 1980. A Supplement to Late Roman Pottery, London

Hayes, J W 1997. Handbook of Mediterranean Roman Pottery, London

Hayes, J W 2000. 'Roman pottery from the Sanctuary', in Kommos IV: the Greek Sanctuary. Part 1 (eds J W Shaw and M C Shaw), 312-20, Princeton 
Hedges, R E M, Bronk, C R and Housley, R A 1989. 'The Oxford Accelerator Mass Spectrometry facility: technical developments in routine dating, Archaeometry, 31, 99-113

Hill, P 1997. Whithorn and St Ninian: the excavation of a monastic town 1984-91, Stroud

Hillson, S 1986. Teeth, Cambridge

Holbrook, N (ed) forthcoming. 'The early medieval period', in South West Archaeology Research Framework: resource assessment and research agenda (ed C J Webster), Somerset County Council, Taunton

Holbrook, N and Bidwell, P T 1991. Roman Finds From Exeter, Exeter Archaeol Rep 4, Exeter

Hughes, M J 2005. 'The analysis by inductively coupled plasma-atomic emission analysis (ICP-AES) and -mass spectrometry analysis (ICP-MS) of medieval pottery from Pigs Paradise, Lundy Island', in 'Medieval pottery and other finds from Pigs Paradise, Lundy' (J P Allan and S R Blaylock), Devon Archaeol Soc Proc, 63, 65-91

Hughes, $\mathrm{M} J$ forthcoming. 'The analysis by inductively coupled plasma-atomic emission analysis (ICP-AES) and -mass spectrometry analysis (ICP-MS) of pottery from Lostwithiel, Bunnings Park and Tintagel', in 'On the waterfront; Quay Street excavations 2002' (J Gossip), Cornish Archaeol

Hunter, J R and Heyworth, M P 1998. The Hamwic Glass, CBA Res Rep 116, London

Isings, C 1957. Roman Glass from Dated Finds, Groningen Jacomet, S 1987. Prähistorisches Getreidefunde, Basle James, E 2001. Britain in the First Millennium, London Jameson, M H, Runnels, C N and van Andel, T H 1994. A Greek Countryside: the southern Argolid from prehistory to the present day, Stanford

Jefferson, D 1999. 'Geological and mineralogical aspects of parts of the site and the inscribed slate from Site "C"', unpublished archive report for English Heritage and University of Glasgow

Jenner, H 1927. 'Tintagel Castle in history and romance', J Roy Inst Cornwall, 22, 190-200

Johnson, $\mathrm{N}$ and Rose, $\mathrm{P}$ 1994. Bodmin Moor: an archaeological survey. Volume 1: the human landscape to $c 1800$, Engl Heritage Archaeol Rep 24/Roy Comm Hist Monuments Engl Suppl Ser 11, London

Jones, A, Cole, W J and Jones, R E 2003. 'Organic residue analysis of Grooved ware from Barnhouse', in Dwelling Among the Monuments (ed C Richards), McDonald Institute monogr, 283-92, Cambridge

Jones, G, Straker, V and Davis, A 1991. 'Early medieval plant use and ecology', in Aspects of Saxo-Norman London 2: finds and environmental evidence (ed A G Vince), London Middlesex Archaeol Soc Spec Pap 12, 347-88, London

Jones, R E 1986. Greek and Cypriot Pottery: a review of scientific studies, British School at Athens, Fitch Laboratory Occas Pap 1, Athens
Jones, R E forthcoming. 'Appendix on methodological issues', in The Mycenaeans and Italy: the archaeological and archaeometric dimensions (L Vagnetti, $\mathrm{R} E$ Jones, $S$ T Levi, M Betelli and L Alberti), Rome

Knight, J K 1994. Caerleon Roman Fortress, rev edn, Cardiff

Knight, J K 1995. 'Hen Gastell in its contemporary setting', in Wilkinson 1995, 36-45

Knight, J K 1999. The End of Antiquity. Archaeology, Society and Religion $A D$ 235-700, Stroud

Krywonos, W, Newton, G W A, Robinson, V J and Riley, J A 1982. 'NAA of some Roman and Islamic coarse wares of western Cyrenaica and Crete', J Archaeol Sci, 9, 63-78

Lane, A 1994. 'Trade, gifts and cultural exchange in Dark Age western Scotland', in Scotland in Dark Age Europe (ed B E Crawford), St John's House Pap 5, 103-15, St Andrews

Lane, A and Campbell, E 2000. Dunadd: an early Dalriadic capital, Cardiff Stud Archaeol 4, Oxford

Leeds, E T 1926 'Excavations at Chun Castle, in Penwith, Cornwall', Archaeologia, 76, 205-40

Litt, S and Austin, D 1989. 'Pottery: West Colliford Mill', in Austin et al 1989, 147-64

Loth, J 1890. Chrestomathie Bretonne; première partie, Breton Armoricain, Paris

Lucy, S 2000. The Anglo-Saxon Way of Death: burial rites in early England, Stroud

Macalister, R A S 1945-9. Corpus Inscriptionum Insularum Celticarum, 2 vols, Dublin

McCormac, F G 1992. 'Liquid scintillation counter characterization, optimization and benzene purity correction', Radiocarbon, 34, 37-45

McCormac, F G, Kalin, R M and Long, A 1992. 'Radiocarbon dating beyond 50,000 years by liquid scintillation counting', in 'Liquid scintillation spectrometry 1992' (eds J E Noakes, F Schonhofer and H A Polach), Radiocarbon, 34, 135-42

McDonald, K 1994. 'Devon's Bronze Age tin shipwreck', Diver Magazine, July/August, 22-8

Mackensen, M and Schneider, G 2002. 'Production centres of African red slip ware ( $3 r d-7$ th c.) in northern and central Tunisia', J Roman Archaeol, 15, 121-58

Mann, J C 1971. 'Spoken Latin in Britain as evidenced in the inscriptions', Britannia, 2, 218-24

Mayet, F and Picon, M 1986. 'Une sigilée phocéenne tardive ("Late Roman C ware") et sa diffusion en Occident', Figlina, 7, 129-42

Mays, S 1997. 'Bone fragments', in Straker et al 1997, 106-8

MPRG 1998. A Guide to the Classification of Medieval Ceramic Forms, MPRG Occas Pap 1, London

Megaw, A H S and Jones, R E 1983. 'Byzantine and allied pottery: a contribution by chemical analysis to problems of origin and distribution', Annu Brit Sch Athens, 78, 235-63

Mook, W G 1986. 'Business meeting: recommendations/ resolutions adopted by the Twelfth International Radiocarbon Conference', Radiocarbon, 28, 799 
Moore, P D, Webb, J A and Collinson, M E 1991. Pollen Analysis, Oxford

Morris, C D 1996. 'From Birsay to Tintagel: a personal view', in Crawford (ed) 1996, 37-78

Morris, C D 1997. 'Overall synthesis and discussion', in Harry and Morris 1997, 115-23

Morris, C D with Emery N 1991. Tintagel Castle Excavations 1990, Glasgow

Morris, C D with Harry, R and Johnson, P 1993. Tintagel Castle Excavations 1991, Glasgow

Morris, C D, Batey, C E, Brady, K, Harry, R, Johnson, P G and Thomas, A C 1999. 'Recent work at Tintagel', Medieval Archaeol, 43, 206-15

Morris, C D, Nowakowski, J A and Thomas, A C 1990. 'Tintagel, Cornwall: the 1990 excavations', Antiquity, 64, 843-9

Nash-Williams, V E 1950. The Early Christian Monuments of Wales, Cardiff

Newton, R and Davison, S 1989. Conservation of Glass, London

Nowakowski, J A and Thomas, A C 1990. Tintagel Churchyard. Excavations at Tintagel Parish Church, North Cornwall, Spring 1990. An Interim Report, Truro

Nowakowski, J A and Thomas, A C 1992. Grave News from Tintagel. An Account of a Second Season of Archaeological Excavation at Tintagel Churchyard, Cornwall, 1991, Truro

Olson, L 1989. Early Monasteries in Cornwall, Stud Celtic Hist 11 , Woodbridge

O'Mahoney, C 1988. 'Medieval pottery from Tintagel: a summary', Cornish Stud, 16, 67-8

O'Mahoney, C 1989. The Medieval Pottery From Tintagel Castle, Inst Cornish Stud Spec Rep 8, Redruth

O'Mahoney, C 1994. 'The pottery from Lammana: the mainland chapel, and Monks House', in 'Lammana, West Looe; C.K. Croft Andrew's excavations of the Chapel and Monks House. 1935-6' (L Olson), Cornish Archaeol, 33, 115-29

O'Sullivan, D 1989. 'The plan of the early Christian monastery on Lindisfarne: a fresh look at the evidence, in St Cuthbert, His Cult and His Community in AD 1200 (eds G Bonner, D Rollason and C Stancliffe), 125-42, Woodbridge

Padel, O J 1981a. 'Tintagel - an alternative view', in Thomas 1981b, 28-9

Padel, O J 1981b. 'The Cornish background of the Tristan stories', Cambridge Medieval Celtic Stud, 1, 1-20

Padel, O J 1984. 'Geoffrey of Monmouth and Cornwall', Cambridge Medieval Celtic Stud, 8, 1-28

Padel, O J 1988. 'Tintagel in the twelfth and thirteenth centuries', in Thomas (ed) 1988e, 61-6

Payne, S 1973. 'Kill-off patterns in sheep and goats: the mandibles from Asvan Kale', Anatolian Stud, 23, 281-303

Peacock, D P S 1984. 'Petrology origins, and amphorae', in Fulford and Peacock 1984, 116-40
Peacock, D P S and Williams, D F 1986. Amphorae and the Roman Economy. An Introductory Guide, London and New York

Pearce, S M 1978. The Kingdom of Dumnonia: studies in history and tradition in south-western Britain, $A D$ 350-1150, Padstow

Pearce, S M 1981. The Archaeology of South West Britain, London Pearce, S M 2004. South-western Britain in the Early Middle Ages, Stud Early Hist Brit, Leicester University Press, London and New York

Peers, C R 1925. 'The inscribed and sculptured stones of Lindisfarne', Archaeologia, 74, 255-70

Peers, C R and Radford, C A R 1943. 'The Saxon monastery of Whitby', Archaeologia, 89, 27-88

Penhallurick, R D 1986. Tin in Antiquity: its mining and trade throughout the ancient world with particular reference to Cornwall, London

Petts, D 2000. Christianity in Roman Britain, Stroud

Photos-Jones, E 1999. 'The technical characterisation of the Skara Brae Cramp', Scottish Analytical Services Art Archaeol Internal Rep 38, Glasgow

Photos-Jones, E 2000. 'The technical characterisation of industrial waste from 'Tintagel, 1999 excavations', Scottish Analytical Services Art Archaeol Internal Rep 39 (2), Glasgow

Photos-Jones, E, Atkinson, J A, Hall, A J and Banks, I 1998. 'The bloomery mounds of the Scottish Highlands. Part I: the archaeological background', J Hist Metall Soc, 32 (1), 15-32

Poblome, J, Bounegru, O, Degryse, P and Viaene, A 2001. 'The sigillata manufactories at Pergamon and Sagalassos', J Roman Archaeol, 14, 143-66

Ponsford, M 1980. 'Bristol Castle: archaeology and history of a royal castle', unpubiished MLitt thesis, Bristol University

Ponsford, M 1991. 'Dendrochronological dates from Dundas Wharf, Bristol, and the dating of Ham Green and other medieval pottery', in Custom and Ceramics: essays presented to Kenneth Barton (ed E Lewis), 81-103, Wickham

Preston-Jones, A and Rose, P 1986. 'Medieval Cornwall', Cornish Archaeol, 25, 135-85

Price, J 1988. 'The glass', in Hartgroves and Walker 1988, 9-30

Price, J 1992. 'Report on the vessel and window glass', in Rahtz, P A et al 1992, 132-43

Price, J 1995. 'Glass vessels with wheel-cut, engraved and abraded decoration found in Britain in the fourth and fifth centuries', in Foy (ed) 1995b, 25-33

Price, J 2000a. 'Late Roman glass vessels in Britain, from AD 350 to 410 and beyond', in Price (ed) 2000b, 1-32

Price, J (ed) 2000b. Glass in Britain and Ireland AD 350-1100, Brit Mus Occas Pap 127, London

Price, J and Cottam, S 1999. Romano-British Glass Vessels: a handbook, CBA Practical Handbook in Archaeology 14, London 
Price, J and Hill, P 1997. 'Additional early medieval vessels', in Hill 1997, 314-15

Quinnell, H 1986. 'Cornwall during the Iron Age and Roman period', Cornish Archaeol, 25, 111-34

Quinnell, H 2004. Trethurgy. Excavations at Trethurgy Round, St Austell: community and status in Roman and postRoman Cornwall, Truro

Quinnell, $\mathrm{H}$ and Thorpe, C M forthcoming. 'A survey of the "native" wares from Radford's excavations at Tintagel in the 1930s'

Radford, C A Ralegh 1935a. Tintagel Castle, Cornwall, 1st edn, London

Radford, C A Ralegh 1935b. 'Tintagel; the castle and Celtic monastery - interim report', Antiq J, 15, 401-19

Radford, C A Ralegh 1939. Tintagel Castle, Cornwall. Official Guide-book, 2nd edn, London

Radford, C A Ralegh 1942. 'Tintagel in history and legend', J Roy Inst Cornwall, 25, appendix, 26-41

Radford, C A Ralegh 1956. 'Imported pottery found at Tintagel, Cornwall', in Harden (ed) 1956b, 59-70

Radford, C A Ralegh 1962. 'The Celtic monastery in Britain', Archaeol Cambrensis, 111, 1-24

Radford, C A Ralegh 1965. Tintagel Castle. Cornwall. Official Guide-book, 12th imp, London

Radford, C A Ralegh 1968a. 'The archaeological background on the Continent', in Christianity in Britain, 300-700 (eds M W Barley and R P C Hanson), 19-36, London

Radford, C A Ralegh 1968b. 'Romance and reality in Cornwall', in The Quest for Arthur's Britain (ed G Ashe), 59-77, London

Radford, C A Ralegh 1971. 'Christian origins in Britain', Medieval Archaeol, 15, 1-12

Radford, C A Ralegh 1973. 'Summary and discussion', Scott Archaeol Forum, 5, 136-40

Radford, C A Ralegh and Swanton, M J 1975. Arthurian Sites in the West, Exeter

Rahtz, P A 1976. 'The building-plan of the Anglo-Saxon monastery of Whitby', in Wilson (ed) 1976, 459-62

Rahtz, P A 1983. 'Celtic society in Somerset A.D. 400-700', O’Donnell Lecture 1981, Bull Board Celtic Stud, 30, 176-200

Rahtz, P A and Fowler, P J 1972. 'Somerset A.D. 400-700', in Archaeology and the Landscape (ed P J Fowler), 187-221, London

Rahtz, P A, Woodward, A, Burrow, I, Everton, A, Watts, L, Leach, P, Hirst, S, Fowler, P J and Gardner, K S 1992. Cadbury Congresbury 1968-73. A Late/Post-Roman Hilltop Settlement in Somerset, BAR Brit Ser 223, Oxford

Ratcliffe, J and Straker, V 1996. The Early Environment of Scilly: palaeoenvironmental assessment of cliff-face and intertidal deposits, 1989-1993, CAU, Truro

Rathbone, D 1991. Economic Rationalism and Rural Society in 3rd-century AD Egypt, Cambridge

Reitz, E and Wing, E 1999. Zooarchaeology, Cambridge
Reynolds, $\mathrm{P}$ 1995. Trade in the Western Mediterranean $A D$ 400-700: the ceramic evidence, BAR Int Ser 604, Oxford

Reynolds, P 2005. 'Levantine amphorae from Cilicia to Gaza: a typology and analysis of regional trends from the 1st to 7th centuries', in Gurt et al (eds) 2005, 563-611

Rivet, A L F and Smith, C 1979. The Placenames of Roman Britain, London

Rose, P and Preston-Jones, A 1995. 'Changes in the Cornish countryside AD 400-1100', in Landscape and Settlement in Britain AD 400-1066 (eds D Hooke and S Burnell), 51-68, Exeter

Rozanski, K, Stichler, W, Gonfiantini, R, Scott, E M, Beukens, R P, Kromer, B and van der Plicht, J 1992. 'The IAEA $\mathrm{C}^{14}$ intercomparison exercise 1990', Radiocarbon, 34, 506-19

Saunders, A 1999. Obituary of C A Ralegh Radford, The Times, 27 Jan 1999, 21

Scott, E M (ed) 2003. 'The Third International Intercomparison (TIRI) and the Fourth International Intercomparison (FIRI) 1990-2002. Results, analyses and conclusions', Radiocarbon, 45 (2)

Scott, E M, Long, A and Kra, R 1990. 'Proceedings of the international workshop on intercomparison of radiocarbon laboratories', Radiocarbon, 32, 253-397

Sharpe, A 1990. Coastal Slate Quarries. Tintagel to Trebarwith, archaeological survey for the National Trust, CAU, Truro

Silvester, R J 1981. 'An excavation on the post-Roman site at Bantham, south Devon', Devon Archaeol Soc Proc, 39, 89-118

Sims-Williams, P 2003. The Celtic Inscriptions of Britain. Phonology and Chronology c. 400-1200, Publications of the Philological Society 37, Oxford

Snyder, C A 1996. Sub-Roman Britain (AD 400-600). A Gazetteer of Sites, BAR Brit Ser 247, Oxford

Snyder, C A 1998. An Age of Tyrants. Britain and the Britons A.D. 400-600, Stroud

Stace, C 1997. New Flora of the British Isles, Cambridge

Sternini, M 1995. 'Il vetro in Italia tra V-IX secoli', in Foy (ed) 1995b, 243-90

Stockmarr, J 1971. 'Tablets with spores used in absolute pollen analysis', Pollen et spores, 13, 615

Straker, V 1992. 'Charred plant macrofossils from Tintagel Churchyard excavations 1991', unpublished report to excavator, CAU

Straker, V 1997. 'Charred plant macrofossils', in Straker et al 1997, 83-101

Straker, V 1998. 'Charred plant macrofossils', in 'Duckpool Morwenstow: a Romano-British and early medieval industrial site and harbour' (J Ratcliffe), Cornish Archaeol, 34, 155-8

Straker, V with Gale, R, Payne, S and Mays, S 1997. 'The ecofactual assemblage', in Harry and Morris 1997, 82-108 
Stuiver, M and Kra, R S 1986. 'Editorial comment', Radiocarbon, 28 (2B), ii

Stuiver, M and Pearson, GW 1986. 'High-precision calibration of the radiocarbon time scale, AD 1950-500 BC', Radiocarbon, 28, 805-38

Stuiver, $\mathrm{M}$ and Polach, H A 1977. 'Reporting of ${ }^{14} \mathrm{C}$ data', Radiocarbon, 19, 355-63

Stuiver, M and Reimer, P J 1986. 'A computer program for radiocarbon age calculation', Radiocarbon, 28, 1022-30

Stuiver, $\mathrm{M}$ and Reimer, P J 1993. 'Extended ${ }^{14} \mathrm{C}$ data base and revised CALIB $3.0{ }^{14} \mathrm{C}$ age calibration program', Radiocarbon, 35, 215-30

Stuiver, M, Reimer, P J, Bard, E, Beck, J W, Burr, G S, Hughen, K A, Kromer, B, McCormac, F G, van der Plicht, J and Spurk, M 1998. 'INTCAL98 radiocarbon age calibration, $24,000-0$ cal BP', Radiocarbon, 40 , 1041-84

'Tatton-Brown, V A 1984. 'The glass', in Excavations at Carthage: the British mission. Vol. 1: The Avenue du President Habib Bourguiba, Salammbo. Part 1: the site and finds other than pottery (H Hurst and S P Roskams), 194-212, Sheffield

Taylor, R J 1993. 'The application of neutron activation analysis and multivariate statistics to the provenance of Roman ceramics', unpublished $\mathrm{PhD}$ thesis, University of Manchester

Taylor, R J and Robinson, V J 1996a. 'Neutron activation analysis of Roman African Red Slip ware kilns', Archaeometry, 38, 231-43

Taylor, R J and Robinson, V J 1996b. 'Provenance studies of Roman Red Slip ware using neutron activation analysis', Archaeometry, 38, 245-55

Taylor, R J and Robinson, V J 1996c. 'Neutron activation analysis of Roman North African amphora kilns', unpublished report, Department of Chemistry, University of Manchester

Thomas, A C 1954. 'Excavation of a Dark Ages site: Gwithian, Cornwall. Interim report, 1953-4', Proc West Cornwall Fld Club (Archaeol), new ser, 1 (2) (1953-4), 59-72

Thomas, A C 1956a. 'Excavations at Gwithian, Cornwall 1955', Appendix to Proc West Cornwall Fld Club, new ser, 1 (1953-6)

Thomas, A C 1956b. 'Evidence for post-Roman occupation of Chun Castle, Cornwall', Antiq J, 36, 75-8

Thomas, A C 1958. Gwithian. Ten Years' Work (1949-1958), West Cornwall Fld Club, Gwithian

Thomas, A C 1959. 'Imported pottery in Dark-Age western Britain', Medieval Archaeol, 3, 89-111

Thomas, A C 1964. 'Minor sites in the Gwithian area (Iron Age to recent times)', Cornish Archaeol, 3, 37-62

Thomas, A C 1971. The Early Christian Archaeology of North Britain, Hunter Marshall Lectures delivered at the University of Glasgow, Jan and Feb 1968, Oxford
Thomas, A C 1981a. Christianity in Roman Britain to AD 500, London

Thomas, A C 1981b. A Provisional List of Imported Pottery in Post-Roman Western Britain and Ireland, Inst Cornish Stud Spec Rep 7, Redruth

Thomas, A C 1982. 'East and West: 'Tintagel Mediterranean imports and the early insular Church', in The Early Church in Western Britain and Ireland (ed S M Pearce), BAR Brit Ser 102, 17-34, Oxford

Thomas, A C 1985. Exploration of a Drowned Landscape: archaeology and history of the Isles of Scilly, London

Thomas, A C 1986. Tintagel Castle. Official Guide-book, London

Thomas, A C 1988a. 'Tintagel Castle', Antiquity, 62, 421-34

Thomas, A C 1988b. 'The context of Tintagel: a new model for the diffusion of post-Roman Mediterranean imports', Cornish Archaeol, 27, 7-26

Thomas, A C 1988c. 'The archaeology of Tintagel parish churchyard', in Thomas (ed) 1988e, 79-91

Thomas, A C 1988d. 'The 1988 C.A.U. excavations at Tintagel Island: discoveries and their implications', in Thomas (ed) $1988 \mathrm{e}, 49-60$

Thomas, A C (ed) 1988e. Tintagel Papers, Cornish Stud 16, Redruth

Thomas, A C 1990. 'Gallici Nautae de Galliarum Provinciis. A sixth/seventh-century trade with Gaul reconsidered', Medieval Archaeol, 34, 1-26

Thomas, A C 1993. English Heritage Book of Tintagel: Arthur and archaeology, London

Thomas, A C 1994. And Shall These Mute Stones Speak? PostRoman Inscriptions in Western Britain, Dalrymple Archaeol Monogr, Cardiff

Thomas, A C 1997. 'The conversions of Scotland', Rec Scott Church Hist Soc, 27, 1-41

Thomas, A C 1998. Christian Celts. Messages and Images, Stroud

Thomas, A C 2003. Christian Celts. Messages and Images, 1st pbk edn, Stroud

Thomas, A C and Fowler, P J 1985. 'Tintagel: a new survey of the island', Annual Review 1984-5 of the Royal Commission on the Historical Monuments of England, 16-22, London

Thomas, A C and Thorpe, C M 1988. 'Catalogue of all nonmedieval finds from Tintagel', Tintagel Project 2, Inst Cornish Stud, Redruth

Thomas, A C and Thorpe, C M 1993. 'Comment', in Batey et al 1993, 58-60

Thomas, A C and Thorpe, C M forthcoming. "The imported Mediterranean coarsewares from Tintagel'

Thompson, M and Walsh, J N 2003. Handbook of Inductively Coupled Plasma Atomic Emission Spectrometry, Woking

Thorpe, C M 1988. 'Incised pictorial slates from Tintagel', in Thomas (ed) 1988e, 69-78

Thorpe, C M 1997. 'Ceramics', in Harry and Morris 1997, $74-82$ 
Thorpe, L (trans) 1966. Geoffrey of Monmouth. History of the Kings of Britain, London

Todd, M 1987. The South West to AD 1000, A Regional History of England, London

Tomber, R and Dore, J 1998. The National Roman Fabric Reference Classification: a handbook, London

Tsaravopoulos, A 1986. 'I archaeia poli tis Chiou', Choros, 4, 124-44

Tyers, P A 1996. Roman Pottery in Britain, London

Uscatescu, A and García Jiménez, R 2005. 'Pottery wares from a 5th-century deposit found at Iesso (Guissona, Lleida): archaeological and archaeometric analyses', in Gurt et al (eds) 2005, 81-103

van Doorninck, F 2002. 'Byzantine shipwrecks', in The Economic History of Byzantium - The Seventh Through the Fifteenth Centuries (ed A E Liaou), 899-905, Washington, DC

van der Plicht, J 1993. 'The Gröningen radiocarbon calibration program, Radiocarbon, 35, 231-7

Vince, A and Brown, D 1989. 'Pottery: petrological analysis of some pottery from south Cornwall', in Austin et al 1989, 165-7

Waksman, S Y and Spieser, J-M 1997. 'Byzantine ceramics excavated in Pergamon: archaeological classification and characterization of the local and imported productions by PIXE and INAA elemental analysis, mineralogy and petrography', in Materials Analysis of Byzantine Pottery (ed H Maguire), 105-34, Washington, DC

Ward, G K and Wilson, S R 1978. 'Procedures for comparing and combining radiocarbon age determinations: $\mathrm{a}$ critique', Archaeometry, 20, 19-31

Wheeler, R E M 1943. Maiden Castle, Rep Res Comm Soc Antiq London 12, London
Wheeler, R E M 1954. The Stanwick Fortifications, Rep Res Comm Soc Antiq London 17, London

Whitbread, I K 1995. Greek Transport Amphorae: a petrological and archaeological study, Athens

Wilkinson, P F 1995. 'Excavations at Hen Gastell, Briton Ferry, West Glamorgan, 1991-1992', Medieval Archaeol, $39,1-50$

Williams, D F 2005a. 'An integrated archaeometric approach to ceramic fabric recognition: a case study of Late Roman Amphora 1 from the East Mediterranean', in Gurt et al (eds) 2005, 613-24

Williams, D F 2005b. 'Late Roman Amphora 1: a study of diversification', in Trade Relations in the East Mediterranean from the Late Hellenistic period to Late Antiquity: the ceramic evidence (eds M B Briese and L E Vaag), Halicarnassian Studies 3, 157-68, Odense

Williams, D F and Carreras, C 1995. 'North African amphorae in Roman Britain: a re-appraisal', Britannia, 26, 231-52

Wilson, D M (ed) 1976. The Archaeology of Anglo-Saxon England, London

Wooding, J M 1996a. Communication and Commerce along the Western Sealanes, AD 400-800, BAR Int Ser 654, Oxford

Wooding, J M 1996b. "The archaeological evidence for external contacts: imports, trade and economy in Celtic Britain A.D. 400-800', in Dark (ed) 1996, 67-82

Yalden, D 1999. The History of British Mammals, London

Young, C J 1977. Oxfordshire Roman Pottery, BAR Brit Ser 43, Oxford

Young, R and Humphrey, J 1999. 'Flint use in England after the Bronze Age: time for a re-evaluation?', Proc Prehist Soc, $65,231-42$ 


\section{INDEX}

Illustrations are indicated by page numbers in italics. The letter ' $n$ ' following a page number denotes that the reference is in a note. Places are in Cornwall unless indicated otherwise.

Aberdaron (Gwynedd), inscription 198,198

agriculture 327-8; see also animal bones; plant remains

Alcock, Elizabeth 329, 330, 332

Alcock, Leslie 316, 329, 330, 331, 332, 335

Alfred, King 17, 307, 321

Allt na Ceardaich (Argyll), slag 270-3

Alt Clut see Dumbarton Rock

amphora-stoppers see pot-lids/ amphora-stoppers

animal bones

methodology 281

Site C, Lower Terrace 43, 52

Site C, Radford's trenches 71, 74

Site C, Site C Building

discussion 290-1

Phase U 121, 122

Phase V 129

Phase W 132, 133

Phase X 135

Site C, Trench C15

discussion 104, 105, 285-6

Phase R 84

Phase T 86-7

Phase U 88

Phase V 91-5

Phase W 96

Phase X 101

Site T, Great Ditch 174, 295, 296
Site T, Little Ditch 291

Site T, Lower Ward 184, 185, 299, 300

see also fish bones

antefix 125, 196-7,311

architectural stone description/discussion 216-17, 218-19, 220-1, 324, 326

petrographic analysis $219-21$

archive 36

Argolid 251,317

Arthfael 199

Arthur, King 3, 305, 313, 333-4, 336

Artmail 199

Artognou 125, 194, 195, 199, 200, 318

ash deposits 44

Augustus ('emperor') 125, 192, 193, $196,196,200$

Bamburgh (Northumb), civitas 335

Bantham (Devon), trading site 330, 331,334

bar fragment, iron 268

Barnstaple (Devon), pottery production 258,266

Barras Nose 336

building stone 219, 220, 221, 326

promontory fort 309

batter $217,218,219$

beads, glass $119,129,142,144,145$, 223, 229

beam-slots $10,28,31,109,114,119$, 312,315

Bede, the Venerable 306, 335, 336

Beer, Gilyard 24

Beornmær 17

Bersu, Gerhard 21

Bigbury Bay (Devon), tin ingots 247, 331
Bodmin Moor, structures 56, 311, 315

Bodognous 199

bones see animal bones; fish bones; human bones

Bordeaux (France) glass production $50,225,226,227$, $313,316,318$

mercantile community 331

Boscastle 221, 309

Bossiney 4

estate 322

bottle glass 341

Bottreaux family 322

Bowles, Christopher 329, 332, 333

Bowman, Ann 331, 332

Bristol

Channel 221

Redcliffe ware pottery production 259

British Museum 26, 222

Brockabarrow, structures 56

Brough of Deerness (Orkney), monastic site 334

Brown Willy, structures 56

Buckland Mor church, roofing slate 191

buildings see structures

Bunning's Park, Stuffle Fabric A pottery 258

Burnt Area 31, 34

Burrow, Ian 32, 306, 315

Bushe-Fox, J P 18

Byzantine empire 330-3

Cadbury Castle (Som)

pottery $50,246,317,329$

role $247,330,335$ 
Cadbury Congresbury (N Som)

glass 222,226

pottery 317

role $247,330,335,350 \mathrm{n} 223$

Cadiz (Spain), glass 226

Caerleon see Isca

Camel Estuary 198, 310

Capel Anelog (Caernarvon), mission station 198

Carantnou 199

Carbonifeous rocks 219, 220, 221

Carmarthen Bay 198

Carthage 202, 225, 245, 318, 331, $344 \mathrm{n} 5$

castle

building stone $219-21$

discussion 321, 322-3, 326-7, 328, 333,334

excavations $6,7,8,9,24,26,31$

location $5,6,336$

see also Site T, Lower Ward

cement 221,222

ceramics see pottery

chamfer 217

chapel of St Juliot

discussion $322,323,328,334$

excavations and recording $6,7,8,15$, $17,19,26$

location 6,15

charcoal

church of St Materiana 328

methodology 281

Site C, Lower Terrace 41, 43, 44, 45, 50

Site C, Radford's trenches $60,66,68$, 78

Site C, Site C Building 290

Phase T 112, 114, 118

Phase U 121, 122

Phase V 129

Phase W 133, 135

Phase X 135

Phase Z 143

Site C, Trench C15 105, 283-5

Phase P 84

Phase R 84

Phase T $86-7$

Phase U 88

Phase V 95

Phase W 96

Phase X 101

Phase Z 101

Site T, Great Ditch 179, 293, 294

Phase U 171

Phase V 172, 173

Phase W 174
Phase X 176

Site T, Lower Ward 181, 298-9

see also radiocarbon dating

Chios (Greece), amphorae 248, 251, $252,253,253,254,255,256,339$, 340

Christianity $305-7$

Chun, ingot 331

church of St Materiana

building stone 220,221

burial and ritual focus 328,334

dating $321-2$

excavations $33,321-2$

incised and pictorial stones 33,200 , 325

inscriptions $309,345 \mathrm{n} 7$

location 4,336

plant remains 319,328

pottery 33,333

relationship with chapel 322,328

Cilicia (Turkey), amphorae 248, 251, 255

civitates 335

clastic mud 227

clay deposits

Site C, Lower Terrace 43, 44, 47

Site C, Radford's trenches 71

Site C, Trench C15 96, 104

Site T, Lower Ward 181

coins

Roman 24-5, 196, 307, 310

Anglo-Saxon 17, 307, 321

Byzantine 331

post-medieval $137,142,145$

modern 221, 327, 341

Coliauus 125, 191, 193, 194, 195, 199, $200,318,345 \mathrm{n} 21$

Colliford, pottery 259, 265

comb, modern plastic 59, 327

concreted layers 72,82

Conimbriga (Portugal), vessels 225, 330

consolidation and/or repair work 9 , 221,341

Constantius II 196

Constantine II 196

copper alloy working 276

copper mining 221

copper sprue 319

coppice 300,328

Cool, Hilary 225, 311

Cornovii 310

Cornwall Archaeology Unit 5, 33, 50, $161,222,307,309,311,313$, $314,317,323,327,349$ n109

Cramp, Rosemary 306 cremations $52,55,312,329$

crucible fragments $47,78,80,319$

Cuby, inscription 199

Cyprus, amphorae 251, 252, 339, 340

Dark, Ken 5, 32, 306, 315, 331, 332, 335

Degannwy (Aberconwy), amphorae 329

Delabole quarry and slates 191,192 , 221

Demetia 198

Desiderius 199

Devonian slates 219

diet 52,300; see also animal bones; plant remains

Dinas Powys (Vale of Glam)

glass $222,229,318,330$

pottery $50,235,246,317$

role $330,331,336$

structures 335

dipinti 256

Dipping Hole 18

discs 201

gritstone 96

pottery $201,207,209$

slate 318,330

Site C, Lower Terrace 46, 47, 50

Site C, Radford's trenches 68,72 , $74,77,201,202$

Site C, Site C Building 119, 121, $.122,132,143,207,208$

Site C, Trench C15 91, 95, 96, 101, 203-4, 205, 206-7

Site C, Upper Terrace 59, 60, 61, 62

Site T, Great Ditch $174,176,212$, 213

Site T, Little Ditch 212

Site T, Lower Ward 184, 185, 212, 215

drainpipes $174,176,177,184,326,341$

drains

Site C, Site C Building

discussion 144,145

excavation evidence $119,120-2$, $123-5,124,127,129,130$,

131-3, 307

Site C, Trench C15 84, 104

Site F 21, 307

Duchy of Cornwall 36, 333, 334

Dumbarton Rock (Alt Clut, Castle Rock, Clyde Rock)

amphorae 329

glass 227,321

role 330,335

Dumnonia 330, 332, 336 
Dunadd (Argyll) 50, 145, 247, 330, 335

Dundurn (Perths), glass at hill-fort 227,321

Dunning, Gerald 17

Dunocatus 199, 200

Dunollie (Argyll), trading site 330,335

Durham University $192,347 \mathrm{n} 210$

Durocornovio $310,328-9$

ear-ring, plastic 327,341

Eddius Stephanus 335

El Mahrine (Tunisia), amphorae 251, 252

El Maklouba (Tunisia), amphorae 251, $252,339,340$

El Mokaida (Tunisia), amphorae 251, $253,254,255,256,339,340$

enamel brooch, modern $142,327,341$

English Heritage 5, 29, 33, 35, 36, 305, 312

environmental evidence

discussion $300-1$

local context $327-8$

Period I 312

Period II 319-20

Period IV 325-6

methodologies 280-1, 319

Site C, Radford's trenches 281-2

Site C, Site C Building 286-91

Site C, Trench C15 283-6

Site T, Great Ditch 291-8

Site T, Little Ditch 291

Site T, Lower Ward 298-300

epidiorite 220,221

excavations

chronological discussion 308-9

Period 0 (prehistoric) 309

Period I (Romano-British) 313; background and context 309-10; environmental evidence 312 ; glass 311 ; inscription 311 ; pottery $311-12$; radiocarbon dating 312-13; site role 334; structural and occupation evidence $310-11$

Period II (early medieval) 313, 320-1; environmental evidence 319-20; glass 318; industrial waste 319 ; pottery $316-18$; radiocarbon dating 320 ; site role 334-5; stone artefacts 318-19; structural and occupation evidence 314-16

Period III (later pre-Conquest and early Norman) 321
Period IIIA (pre-Conquest)

321-2, 334

Period IIIB (post-Conquest) 322, 334

Period IV (later medieval) 322; castle 322-3; environmental evidence 325-6; finds 325; Great Ditch 324; Little Ditch 323; Lower Ward 323; pottery 325; Site C, structural and occupation evidence 324 ; site role 334

Period V (later medieval to present) $326-7,334$

overview

context: local 327-8; wider 328-33

Radford's work 305-8

site role $334-6$

see also Cornwall Archaeology Unit;

Ralegh Radford, C A, excavations 1933-55; Site C, Lower Terrace; Site C, Middle Terrace; Site C, Site C Building; Site C, Trench C15; Site C, Upper Terrace; Site T, Great Ditch; Site T, Little Ditch; Site T, Lower Ward

Exeter (Devon)

bombing 5

coins 331

Radford house 5

Roman town see Isca Dumnoniorum

fire $198329,31,32,55,224,306,315$

fire-pit $41,43,44,54-5,310$

firelighting stones see strike-a-lights

fish bones 185,299

fissure $114,118-19,144,312,313$

flagstones $119,120-1,125$

flints 201

fragments in mortar 221

Site C, Lower Terrace 40, 47, 48, 309

Site C, Site C Building 122, 132, 207 , 208, 216, 309

Site C, Trench C15 86, 95, 101, 216, 309

flooring material 52, 285

Fowler, Peter 5, 21, 32

furnace-lining $61,80,269,319$

furs 331

Gallus $345 \mathrm{n} 7$

gaming board $74,79,200,202,203$, 325 gaming pieces $132,207,319$

Ganos (Turkey), amphorae 248, 251, $253,254,255,256,339,340$

Garden 6, 17, 19-21, 27, 34, 322

Gateholm (Pembs), monastic site 334

Geoffrey of Monmouth 3

George vI, shilling 142, 221, 327, 341

geophysical survey $57-8$

glass beads see beads, glass

glass fragments

report $222-8$

analysis 228

description: Romano-British 223, 224; early medieval imports 223, 224, 225-7; Mid-Saxon 227; modern $326,327,341$

discussion $227-8,311,318,321$

Site C, Lower Terrace 47, 50, 55

Site C, Site C Building 119, 132, 135 , $142,144-5,146,313,316,318$, 321

Site T, Great Ditch $174,176,177$

Site T, Lower Ward $181,184,185$, $187,314,318$

see also beads, glass; window glass

glass-working 229, 318, 321

Glastonbury (Som)

archive 307

censer 331

Radford excavations 24

Gorlois, Duke of Cornwall 3

graffiti

parish churchyard 200, 325

Site C, Radford's trenches 77, 202, 204, 319

Site C, Site C Building 129, 142, 211, $212,318,319,325$

Site C, Trench C15 96, 202-3, 205, 325

Site T, Great Ditch 177

see also gaming board

granite 222

grave-markers 200

Great Ditch see Site T, Great Ditch

Great Hall 33, 247, 317, 323, 327

greenschist 220

greenstone 216-17, 218, 219, 218-19, 220

Grenville, Sir Richard 330

Gulf of Oskendorum 255

gullies, $\mathrm{W}$ of Site A, excavation of 8

Guido, Margaret 229

Gurgnou 199

Gwithian, structures 56, 311, 315 
Haelnou 199

Hamwic (Southampton), glass 321

harbour 329-30, 334

Harden, Gerald 225, 226

Haven 4, 219, 220, 329-30, 334, 336

Hayle, inscription 197, 198

Headley Trust 17

hearths

1986 excavations 314

Site C, Lower Terrace 41, 56

Phase Q 43, 52

Phase U 43, 44, 53, 54, 55

Phase W 45

Site C, Site C Building 135

heating channel 23

Hen Gastell (Neath Port Talbot), role $330,335,336$

Hengistbury Head 329

Herb Garden see Garden

Highdown (W Sussex), flask 226

hinges, iron 268

hoard, Roman 24-5, 196, 307, 310

Holme Pierrepoint, glass 226

hones see whetstones/hones

honey 331

Honorius, emperor 125, 192, 193, 196, $196,200,311,329,334$

horseshoe fragment 268

human bones $43,52,55,312$

Iesso (Spain), amphorae 248-50, $347 \mathrm{n} 175$

Igerna, wife of Duke of Cornwail 3

industrial ceramic material $72,74,78$, 79,80 ; see also crucible fragments

industrial waste

analysis

methodology 268

Site C, Radford's trenches $268-70$, 271

Site C, Site C Building 274-5

Site C, Trench C15 270-2, 273-5, 276

Site T, Lower Ward $275,277-8$, 279,314

discussion 222, 276, 319, 321

excavation evidence

Site C, Radford's trenches 59,62 , 65

Site C, Site C Building 132

Site C, Trench C15 86, 91, 96, 101, 105

Site T, Lower Ward $181,185,187$

Inner Ward 6, 7, 9, 26, 31, 316 inscriptions

late Roman/post-Roman

archaeological context 120,121, $122,125,127,145,146$

comparative letters 197, 197, 198, 198

description frontispiece, 192-3,

194; larger upper letters 194,

196; smaller lower letters 194 ,

195; textual sequence 194

discussion $200,311,316,318,321$, $328,329,334$

geology 191-2

interpretation: Text I 195-7; Text II $197-200$

modern 341

see also gaming board; graffiti

iron fragments

Site C, Radford's trenches 79

Site C, Trench C15 84

Site C, Upper Terrace 62

Site T, Great Ditch $174,176,177,326$

Site T, Lower Ward 181

Iron Gate 7, 31, 219, 307, 329

iron objects 267-8; see also iron fragments; nails, iron

iron working $269,270,274,276,319$, 321

Isca (Caerleon) 196

Isca Dumnoniorum (Exeter) 196

Isolde see Tristan and Isolde

Istria (Croatia), amphorae 248, 251, $253,254,255,339,340$

jambs 219

Jenner, Henry 3

Jurassic 221

Kalavassos (Cyprus), amphorae 251, $252,254,256$

Karanis 226

Keratokambos (Crete), amphorae 251, $253,255,256,339,340,347 \mathrm{n} 179$

key-stones 219

kiln 221-2

King Arthur's Footprint 28, 31

King Arthur's Hotel 329

Kirkmadrine (Dum \& Gall), inscription $198,198,345 \mathrm{n} 12$

Kounoupi (Greece), amphorae 248 , $251,253,253,254,255,255,256$, 339,340

La Mesquida (Mallorca), amphorae $251,253,254,255,339,340$
Lagore (Co Meath), glass 227, 321

Lancarffe, Bodmin inscription 199-200

Launceston, modern glass 341

leather bag or purse $196,307,331$

Legio II Augusta 196

Licinius $345 \mathrm{n} 7$

lids see pot-lids/amphora-stoppers

Life of St John the Almsgiver of Alexandria 331

lime and limestone 221-2

Lindisfarne Priory (Northumb), recording 306

literacy $191,200,227,318,321$

lithics see flints and quartz

Little Ditch see Site T, Little Ditch

Llandyssilio West (Pembs), inscription 197, 197, 198

Llanerfyl (Montgom), inscription 197, 198,199

llys $350 \mathrm{n} 251$

Longbury Bank (Dyfed)

amphorae 56, 316, 330

glass 222,330

role 330,336

Lostwithiel, pottery production 258

Louannec (France), inscription 199

Lower Terrace

excavations see Site C, Lower Terrace

location 35,36

Lower Ward, excavations see Site T, Lower Ward

Maiden Castle (Dorset), excavations 306

Malaga (Spain), glass 226

Mallorca (Spain), amphorae 251

Marseilles (France)

glass 225

mercantile community 331

Mawgan Porth

pottery 321

structural slates 209

structures 144,321

Merrells 74, 202, 203, 325

Mescagnus 200

metal foil 135, 142, 143, 145, 327, 341

metal working see copper alloy working; crucible fragments; industrial waste; iron working

middens, medieval 33

Middle Terrace

excavations see Site $C$, Middle Terrace; Site C, Site C Building; Site C, Trench C15

location 35 
milestones 196, 197

Ministry/Office of Works 5, 6, 12, 17, $19,23,135-7,138,221,307$, 326,341

molluscan analysis $179,294-5,296$, 299,300

monastic interpretation $32,305-6,308$, $313,322,334,335$

mortar

report 221-2

Site C, Site C Building 137, 221, 326-7

Site T, Great Ditch $174,221-2$

Site T, Lower Ward 184, 185, 222

mortar repairs 319

mortaria 310

Mote of Mark (Dum \& Gall)

glass 222,227

role 330

nails, iron

Site C, Site C Building 129, 135, 268, 319

Site C, Trench C15 91, 96, 101, 105, 267

Site T, Lower Ward 184,268

Napoleonic period 6

National Monuments Record (at Swindon) 5, 7, 9-14, 16, 16, 17, 21-24, 24, 27, 36, 308

Nine Men's Morris 74, 202, 325

Norden, John 327

Nowakowski, Jacqueline 33, 321

Office of Works see Ministry/Office of Works

Okehampton (Devon)

modern glass 341

pottery $258,259,261,263$

olive oil $233,236,248,318,321,329$, 330

Oudhna (Tunisia), amphorae 251, 252, $253,254,255,339,340$

Outdone (Tunisia), amphorae 251

oven 314

Padel, Oliver 32, 306, 322, 323, 335

Padstow 198

route-marker 310

Paphos (Cyprus), amphorae 251, 252, 254

Paternus/Paterninus 125, 191, 193, 194, $195,199,200,318,345 \mathrm{n} 16$

paving slabs $84,85,104,109$

paviors 218,219
Pearce, Susan 306, 336

pebbles 318-19

Site C, Radford's trenches $68,74,78$, 202

Site C, Site C Building 119, 121, 132, 143, 207

Site C, Trench C15 91, 96, 101, 203, 205

Site C, Upper Terrace 59, 60, 61, 62, 201

Site T, Great Ditch $171,176,177$, 212, 213

Site T, Little Ditch 212

Site T, Lower Ward 185, 212, 215

Penrose, George 26

percussion stones 201

Pergamon (Turkey), amphorae 248, $251,252,253,254,255,256,339$, 340

petrographic analysis, building stone 219-21

Petts, David 312

Phocaea (Turkey), amphorae 248, 251, $252,253,254,255,339,340$

pipe, iron 268

pivot-stone 219,219

plague 333

plant remains

discussion 300

local context $327-8$

Period I 312

Period II 319-20

Period IV 325-6

methodology 280-1

Site C, Lower Terrace 50-2

Site C, Radford's trenches $68,71,74$, $77,79,281-2$

Site C, Site C Building 145, 287, 288-90

Phase T 114-18, 119

Phase W 132-3

Phase X 135

Phase Y 142

Phase Z 143

Site C, Trench C15 88, 95, 96, 101, 105, 283-5

Site T, Great Ditch $179,291-3$

Phase T 167

Phase U 171

Phase V 173

Phase W 174

Phase X 176

Site T, Lower Ward 181, 184, 298-9

plate fragment, iron 268

Plateau area 36 glass 224,224

Radford excavations $26-7,27$

plinth 217

pollen analysis

discussion 300

methodology 281

Site T, Great Ditch 167, 291, 293, 294, 295

Site T, Little Ditch 156,160

Site T, Lower Ward 181, 295, 299

Portland cement 222

post-settings/supports

Site C, Lower Terrace 44, 56, 310

Site C, Radford's trenches 71, 74

Site C, Site C Building 109, 113-14, $119,144,209,212,312$

Site C, Trench C15 204

pot-lids/amphora-stoppers 201,318, 329

Site C, Lower Terrace 40, 46, 47, 50

Site C, Radford's trenches

Middle Terrace 68, 72, 74, 77, 202

Upper Terrace 59, 61, 65, 201, 202

Site C, Site C Building 132, 142, 143, 207, 208-9

Site C, Trench C15 86, 101, 204, 207

Site T, Great Ditch $172,174,213$

Site T, Lower Ward 184, 215

pottery see also crucible fragments; industrial ceramic material; residue analysis

pottery, Romano-British

discussion 230-1,311-12,313

fabrics

gabbroic $144,229,230,311,313$

granitic $49,229,230,311$

local $49,229,230,311,313$

Oxford Colour Coated 196, 230, 310,329

Site C, Lower Terrace 48, 49, 311

Site C, Site C Building 229-30, 232, 311

Site C, Trench C15 229, 230, 231, 311

Site T, Lower Ward 230, 311, 314

pottery, post-Roman imported 231-2, $232,239,240,242$

amphorae

fabric descriptions 249-50

residue analysis $247-8$; chemical characterization $248-51,252$, 253-6; discussion 254-6; organic residue analysis $256-7$; results $251-3,337-40$ 
types: Class Bi 49, 231, 232-3, 239,

242; Class Bii 49, 201, 233, 239;

Class Biv 233; Class Bv 49, 201, 233, 239

coarsewares 233, 329

East Mediterranean Red ware 233

Eastern Mediterranean Sandy

Cream ware 233

miscellaneous 233,234

discussion 245-7, 316-18, 329, 331-3

Site C, Lower Terrace 48, 49, 50, 246

Site C, Middle Terrace 246

Site C, Radford's trenches 201, 235-6, 237

Site C, Site C Building 232, 241, $242,243-4,316$

Site C, Trench C15 231, 236-8, 239-40, 241

Site C, Upper Terrace 246

Site T, Great Ditch 244, 245

Site T, Lower Ward 244-5, 246, 246,314

Steps site 246

fine table-wares

African Red slipped ware 234-5, 320,329

D-ware 228, 231, 235

Phocaean Red slipped ware 232, 234,329

pottery, medieval-post-medieval 257-67

analysis

Site C, Radford's trenches 260 , 261-2

Site C, Site C Building 260, 263-4

Site C, Trench C15 262-3

Site C, Upper Terrace 259-60, 261

Site T, Great Ditch 260, 264-5, 341

Site T, Little Ditch 341

Site T, Radford's trenches 264 , 265

discussion $265-7,321,322,323,324$, 325,333

fabrics

Aardenburg-type 333

bar-lug 321

Bristol Redcliffe ware 259,325

Chert-tempered ware 258,260 , $322,325,334$

Ham Green ware 258, 325

Lostwithiel ware $259,260,324$, 325
North Devon Calcareous ware $259,323,325,326$

North Devon Medieval Coarseware 258-9, 260,324

Saintonge ware $259,324,333$

Sandy Redware 259, 324, 326

Stuffle-type ware 258, 260,324

unclassified 259, 324

methodology 258

pottery, modern 341

pozzolanic material 222

Praa Sands, ingots 331

Price, Jennifer 311

Princetown (Devon), coin 331

Procopius 331

promontory fort $309,310,320$

quarrying $219,320,324,326,330,333$, 334

quartz

pebbles 201

Site C, Radford's trenches 68,74 , 202

Site C, Site C Building 135

Site C, Trench C15 91, 203

Site C, Upper Terrace 60

sand in mortars 221

worked $47,48,309$

Quinnell, Henrietta 335

quoins 219, 220

radiocarbon dating

Site C, Lower Terrace 52-5, 53, 54, $312,313,320$

Site T, Great Ditch $209,297-8,298$, 300-1, 309, 314, 320

Site T, Lower Ward $181,185,187$, $298,300,309,310,313,320$

Site C, Site C Building 312

Rahtz, Philip 329, 330, 335

Ralegh Radford, C A, excavations 1933-55

archives 8-9, 307

Radford 16-17, 25-6; Site A 17; Site B 18-19, 19; Site C 18, 19, 20, 106-7; Site D 19; Site E 19-21; Site F 21-3; Site G 23; Site $\mathrm{H}$ 23; Site T $21,23,24-5$, $25,149,150$

Wright 5-16, 9-16,22, 26

background 3-5, 6

ceramic finds 196

coin hoard 196

location of trenches and survey 8 , $10,11,26,27-8,29-32,29$ overview and discussion $305-8,314$ re-examination 33-6

rampiers 6

Ravenna Cosmography 310

Reginald, Earl 322-3, 325

residue analysis $247-57$

chemical characterization 248-56 discussion 254-6 results $251-3,252-6,337-40$

organic residue analysis $256-7$ results 257

Richard, Earl 322, 323

road, excavation $9,11,29$

Robertson, Anne 25

roll-mould $217,218,219$

roofing material, organic 52, 285; see also slates

route-markers, Romano-British 196, 309-10, 328, 329, 345n7

Royal Commission on the Historical Monuments of England, survey $29,30,31,32,33,324$

Royal Cornwall Museum (Royal Institute of Cornwall) 5, 24, 26, $36,193,195,221,225,226$

Salakta (Tunisia), amphorae 251 sand deposit 72

Scilly Isles, trading 329-30; see also Tean

Scottish Archaeological Forum 306

Sea of Marmara 248, 251, 253

seasonality $310,316,335,336$

Second World War 5, 29, 306

Seleucia of Pieria (Turkey), amphorae $248,251,253,254,255,255,256$, $256,339,340$

Severn Sea 332, 334

shaped stones 201

sheet fragment, iron 268

shellfish 299

Sherborne Old Castle (Dorset) 219

Shippam's Paste jar 327, 341

Simmons Survey Partnership 29

Sinop (Turkey), amphorae 250 , $347 \mathrm{n} 175$

Site A, Radford's excavations

archives 31

Radford 17

Wright $7,8,10,11,13,14-15$

coin 321

interpretation 335

location of trenches $6,26,27,28,28$

structures 322

see also chapel of St Juliot; Garden 
Site B, Radford's excavations

archives 31

Radford 8, 9, 15, 18, 19

Wright $6,7,8,10,11,11,14,18$

location of trenches $6,6,14,28,28$, 29,34

structures 315,324

Site $B / C$, glass 224,226

Site $C$, Lower Terrace, excavations $1990-429,33-5,34,35,36,40$

dating $52-5$

discussion 55-6

Period 0309

Period I 310-13

Period II 315-16, 317, 319, 320

Period IV 324

ecofactual assemblage $50-2,312$

finds

glass $47,50,224,225$

lead 47

pottery $47-8,49,50$

stone $46,47,48,50$

phasing 41

radiocarbon dating $52-3,53,54,310$

sections 42

structures and stratigraphy $43-5$, $43-5,47,310$

synopsis $39-41$

Site $\mathrm{C}$, Middle Terrace, excavations 1990-4 34, 35

background $6,10,11,12,15,16,19$, 67

discussion $78-80,313,315,320,324$

environmental evidence $281-2$

finds $70-1,75-6,78$

industrial waste $269-70,271$

pottery $201,236,237,260,261-2$

stone 202, 203, 204

methodology and synopsis $67-8$

Radford's excavations $67-80,72,73$, 74,77

stratigraphy

Trench C05 68, 69, 70-1, 72

Trench C15 71-2, 73-4, 75-7

Trench C17 77, 78

Site C, Radford's excavations

archives 31

Radford 8, 16, 17, 18, 19, 20

Wright $6,7,8,10,11,11,12,15$, 16,16

location of trenches $6,6,11,18,26$, $28,28,29$

re-examination $33,34-6$

Site C, Site C Building, excavations 1991-8 35, 36, 106 background $12,16,20,40,106-7$

discussion $143-6$

Period 0309

Period I 311, 312-13

Period II $315,316,317,318,319$, 320

Period III 321

Period IV 324, 325

Period V 326

environmental evidence $286-8,312$

animal bones $290-1$

charcoal 290

plant remains 287, 288-90; Phase

T 114-18, 119; Phase W 132-3; Phase Y 142

finds

glass $223,224,225-6,229,316$

industrial waste $274-5$

inscribed slate see inscriptions, late

Roman/post-Roman

iron 268

modern 341

mortar 221

pottery $229-30,232,241,242$, $243-4,260,263-4$

stone 207, 208-11,212, 216

finds by phase

Phase S 106, 109, 112

Phase T 114-18

Phase U 121-5

Phase V 127-9

Phase W 129-32

Phase X 135, 136-7

Phase Y 139-42

Phase Z 143

methodology 107-8

Radford's excavations $106-7,110$, 134

radiocarbon dating, lack of 312,313

stratigraphy 108, 110-11

Phase S 108, 109, 112

Phase T 109, 112-14, 115-19

Phase U 119, 120-2, 123-5

Phase V 124, 125, 126-7, 128-9

Phase W 129, 130, 131-3

Phase X 133, 134, 135, 136-7

Phase Y 135-7, 138, 139-42

Phase Z 143

trench locations 107

Site C, Trench C15, excavations 1999 $34,81,82$

discussion 101-5, 309, 315-16, 318, 325

environmental evidence 283

animal bones $285-6$ plant remains and charcoal 283-5

finds

industrial waste $270-2,273-5$, 276

iron 267

pottery $229,230,231,232,236-8$, 239-40, 241, 262-3

stone $202-4,205-7,216$

finds by phase

Phase P 84

Phase R 84,86

Phase $S 86$

Phase T $86-7,88$

Phase U 87-8, 89

Phase V 91-5

Phase W 96, 97-8

Phase X 101, 102-3

Phase $Y$ 101, 103

Phase Z 101, 103

methodology 81

Radford's excavations 91, 92, 93, 96-101, 99, 100

stratigraphy

Phase P $81-2,83,84$

Phase Q 83,84

Phase R $84,85,86$

Phase S 85,86

Phase T $86,87,88$

Phase U $87,88,89$

Phase V 88-9, 90-4, 95

Phase W 90, 95-6, 97-8

Phase X 96, 99-100, 101, 102-3

Phase Y 99, 101, 103

Phase Z 101, 103

see also Site $\mathrm{C}$, Middle Terrace, excavations 1990-4

Site C, Upper Terrace, excavations 1990-4 34, 35, 60

background 57

discussion $62-6,315,324,327$

finds $61,64-5$

industrial waste $268-9$

modern 341

pottery 235-6, 259-60, 261

stone 201,202

geophysical survey $57-8$

methodology and synopsis 57-9

Radford's excavations 10, 18, 19, $57-71,60,62,63,69$

stratigraphy $59,60,61,63,64,69$

Site D, Radford's excavations

archives $7,8,11,19,31$

location of trenches $6,6,26,27,28$, 29 
Site E, Radford's excavations archives $7,8,19-21,31$

location of trenches $6,26,28,29$

Site F, Radford's excavations archives $6,6,7,8,10,11,18,21-3$, 307,308

location of trenches $6,6,28,29$, $343 n 29$

structures 324

Site $G$, Radford's excavations archives $6,6,8,11,23,34$ location of trenches 28,29 quarry, $\mathrm{N}$ of 219

structures 324

Site H, Radford's excavations archives $8,11,13,14-15,23$ location of trenches $28,29,307$

Site T, Great Ditch (T01), excavations $1999151,152,166$

archives

Radford 16, 17, 23, 25, 150

Wright 22

background 162

discussion $178-9,328,334$

Period 0309

Period I 310

Period II 314, 320

Period IV 324

Period V 326-7

environmental evidence 291

animal bones 295, 296

charcoal 293,294

molluscs 294-5, 296

plant remains 291-3

pollen 293, 294, 295

soils 295-6

environmental evidence by phase

Phase T 167

Phase U 171

Phase V 172, 173

Phase W 174, 175-6

Phase X 176

Phase Y 177

finds

iron 268

modern 341

mortar 221-2

pottery $244,245,260,264-5$

stone $212,213-19,220$

finds by phase

Phase U 171

Phase V 172, 173

Phase W 174, 175

Phase X 176-7, 177

Phase Y $176-7,178$
Phase Z 177,178

geology 162, 163, 164

location of trenches 153,166

methodology and synopsis $150-4$, $163,165-7$

Radford's excavations 8, 9, 16-17, $23-5,31-2,149-50,163-5,165$, 166,341

glass 224,225

radiocarbon dating $297-8,298$

stratigraphy and phasing 166

Phase T 167, 168-9

Phase U 167, 168-70, 171

Phase V1 166, 172

Phase V2 166, 172-3

Phase W 166, 168-9, 173-4, 175-6

Phase X 168, 170,174-6, 177

Phase $Y$ 176-7, 178

Phase Z 177, 178

Site $T$, Little Ditch (T02), excavations 1999156

background 149, 150, 155

discussion $160-1,323,326-7$

environmental evidence 156,160 , 161,291

finds

modern $160,161,341$

pottery $155,159,160,161,264,265$

stone $160,161,212$

location of trenches $153,154,183$

methodology 155

Radford's excavations 9, 11, 29, 36, $149,150,155,156,156,158,160$, 314

stratigraphy and phasing $156-60$, $156,158-9,160,183$

Site T, Lower Ward 151

CAU excavations $309,312,313,314$, 320

Site T, Lower Ward, excavations 1999 (T01 ext)

discussion $185-7,323,334$

Period 0309

Period I 310, 311-12, 313

Period II 314-15, 319, 320

environmental evidence

animal bones 299

molluses 299

plant remains and charcoal 298-9

pollen 295, 299

soils 299

environmental evidence by phase

Phase W 181, 184

Phase X 184, 185

Phase Y 185 finds

glass $226-7$

industrial waste $275,277-8,279$

iron 268

modern 341

mortar 222

pottery $230,244-5,246$

stone $212,213-15,215,216,217$

finds by phase 181,184

Phase X 184, 185

Phase Y 184-5, 186

location of trenches $6,153,154,182$

methodology and synopsis $180-1$

Radford's excavation $8,9,23-5$, $31-2,314,180-1$

radiocarbon dating $298,300,310$, 320

stratigraphy and structures

Phase V 181, 182

Phase W 181, 182, 183, 184

Phase X 181, 182-3, 184, 185

Phase Y 182, 184-5, 186

Phase Z 185

Site T, Radford's excavations

archives 5, 31-2

Radford 307

Wright $11,21,26,307$

glass 224, 225

location of trenches $21,29,32,149$, $150,153,154$

re-examination $36,149,314$

discussion 160-2

methodology and synopsis 150 , 154-5

stratigraphy and phasing $155-160$

survey 1999 149-50, 151-3

Site T, Trial Trench T03, excavations 1999

background 149, 150

discussion 160

location of trenches 153,157

methodology 154

Radford's excavations 150, 155

stratigraphy and phasing 155-6, 157

Site T, Trial Trench T04, excavations 1999

background 150

discussion 160

location of trench 153

methodology 154

Radford's excavations 150,156

stratigraphy and phasing 156

Site T, Trial Trench T05, excavations 1999

background 150 
discussion $155,160-1$

location of trench 153

methodology 155

Site Z 247, 317

slag see industrial waste

slates 219-20,318

graffiti

Site C, Radford's trenches 202, 204

Site C, Trench C15 205

Site T, Great Ditch 177, 341

grooved, Site T, Great Ditch 174, 215

incised and pictorial

parish churchyard 200

Site C, Site C Building 211, 212

Site C, Trench C15 77, 202, 205

inscribed see inscriptions, late

Roman/post-Roman

notched/structural 200-1, 315, 318

Site C, Lower Terrace 44, 56

Site C, Middle Terrace, Radford's trenches 202, 203

Site C, Site C Building: context $119,129,132,135,143$; report 207, 209-11

Site C, Trench C15: context 72, 77, 96, 101; report and discussion 104, 203, 204, 205, 206

Site C, Upper Terrace 59, 61-2, 65, 201, 202

Site T, Great Ditch: context 171, $174,176,177$; report 212,213 , $214,214,218,219$

Site T, Little Ditch 212

Site T, Lower Ward 185, 212, 215, 217

perforated/roofing 318

Site C, Lower Terrace 44, 56

Site C, Radford's trenches 68,71 , 202

Site C, Site C Building 132,207 , 210, 211-12

Site C, Trench C15: context 72,74 , $78,96,101$; report $204,205,206$

Site C, Upper Terrace 59, 62, 65, 201-2

Site T, Great Ditch $171,176,177$, $212,213,214,215$

Site T, Little Ditch 212

Site T, Lower Ward 212, 215

quarrying $330,333,334$

shaped, Site T, Great Ditch 176,212 , $214,215,216$

see also discs, slate

slaves 331

Small Ditch see Site T, Little Ditch
Smith's Cliff 220

Society of Antiquaries of London 17, 36,306

soils analysis

Site T, Great Ditch 295-6

Site T, Lower Ward 299

South Cadbury see Cadbury Castle

spindle whorls 201,319

Site C, Lower Terrace 40

Site C, Site C Building 132, 142, 207, 208,212

Site C, Trench C15 87, 91, 96, 204, 206-7

spoil-heap, Radford's 19, 20

St-Maurice-d'Agaune (Switz), dedication stone 198

stake-fragments 47

stake-holes

Burnt Area 31, 55, 315

rock ledge above Site C $31,31,314$, 315

Site C, Lower Terrace $41,43,44,45$, 56,310

Site D 31

Stanwick (N Yorks), excavations 306

status $247,321,328,334,335-6$

Steps area $21,29,33,50,235,223,226$, $246,316,317,318-19,343$ n29, $346 \mathrm{n} 111$

stone finds $200,201,202,203-11,212$, 213-16; see also architectural stone; flints; petrographic analysis

strike-a-lights 201,318

Site C, Lower Terrace 46,47

Site C, Radford's trenches 71, 202

Site C, Site C Building 209, 211

Site C, Trench C15 204

Site C, Upper Terrace 61, 62, 201

Site T, Great Ditch 214, 215

Site T, Lower Ward 184

string course fragment 217,218

structures

discussion 328

Site C, Lower Terrace

dating 55

discussion $55-6,310-11,314-16$, 324

phasing 41

stratigraphy $40-1,43-4,45,47$

Site C, Radford's trenches 72, 73-4, 77,79

Site C, Site C Building

discussion 143-6, 312-13

excavation methodology 107,108

Radford's work $12,16,20,106-7$ stratigraphy $108,110-11$; Phase S 108, 109, 112; Phase T 109, 112-14, 115-19; Phase U 119, 120-2, 123-5; Phase V 124, 125 , 126-7, 128-9; Phase W 129, 130, 131-3; Phase X 133, 134, 135, 136-7; Phase Y 135-7, 138, 139-42; Phase Z 143

Site C, Trench C15

discussion 101-5

stratigraphy $88-9,90-4,95-6$

sunken feature 68

surveys

$198529,30,34-5$

$199526-7,28,29-32$

1999 149-50, 15I-2

see also geophysical survey

Tean (Scilly), cereals 319

Tenby 198

terraces

creation $320,327,328$

location 35

Tetricus I 196

Thasos (Greece) 256

thatch weight 217

tile

modern ceramic 341

Roman 222

timber $50,285,300$

timber-slots see beam-slots

tin $247,311,328,331,334$

Tintagel Research Committee 33

Tintagel Village 4, 333, 336

Todd, Malcolm 309-10

touchstone 47,47

trade and exchange 320-1, 329-33, $334,335,336$

glass $227-8$

pottery $246-7$

Traprain Law (E Lothian), glass 226

trenches between Sites B and C 10, 11, 19

trenches between Sites B and F 8

trenches $\mathrm{S}$ of Site $\mathrm{C} 8$

trenches $\alpha$ and $\beta 10,29,29$

Trethevy, route-marker $309,329,345 \mathrm{n} 7$

Trethurgy

glass 226

ingot 331

pottery $229,230,231,311$

status 330,335

structures $56,310-11$

trial trenches $10,11,26,155-6,157$, 160

Tristan and Isolde 32 
tuff 220,221

Tunnel, excavations $8,11,26,27$

Upper Terrace

excavations see Site C, Upper Terrace location 35

Upper Ward 6, 26, 31, 151

Uther Pendragon 3

Vale, the 149,151

Valley, excavations 8

vallum monasterii 314

Vandals 332

villae regales $335-6$

Volusian $345 \mathrm{n} 7$

voussoirs $217,218,219$

Wall Walk trench, 1955 9, 24, 25, 307

wax $232,256,257$ weight, lead 47

wells $7,8,18,26,27,28,34,322$

Western Huts 27

Wheeler, Sir Mortimer 306

whetstones/hones 201, 319

Site C, Lower Terrace 40,47

Site C, Site C Building 119, 129, 207, 210,212

Site T, Lower Ward 181, 213, 215-16

Whitby Abbey (N Yorks), recording 306

Whithorn (Dum \& Gall)

cremation 312

glass 222, 225, 226-7, 321

inscription 197, 197, 198

pottery 246,317

role 330

Willapark

building stone 221 fort 309

windbreaks $41,43,56,314$

window glass 341

wine $232,233,248,256,318,321,329$, 330

wood fragments 185

Wooding, Jonathan 330

Woolgarden see Delabole

Wright, J A, archive 3, 5-7, 26, 33

drawings $9-14,16,19,21,22,23,27$, 155,308

evaluation $11-16,307$

overview 7-11

recording system $26-7,27,28,29$

summary $8-9,26,31-2$

Yassi Ada shipwreck 330, 331, 332

zoning $247,316,317,319,335$ 

